PNL-8534, Vol. 2

UC-601, 606,630

901.902

HANFORD ENVIRONMENTAL ANALYTICAL METHODS

(METHODS AS OF MARCH 1990)

APPENDIX Al-0 AND APPENDIX Al-I

S. C. Goheen

M. McCulloch

J. L. Daniel

May 1993

Prepared for

the U.S. Department of Energy

under Contract DE-AC06-76RLO 1830

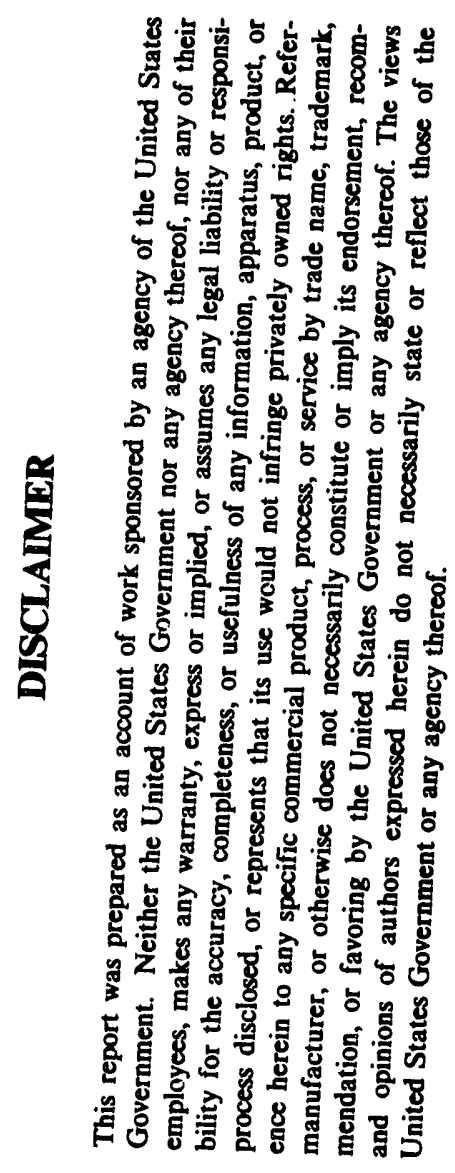

Pacific Northwest Laboratory

Richland, Washington 99352 


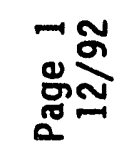

喜
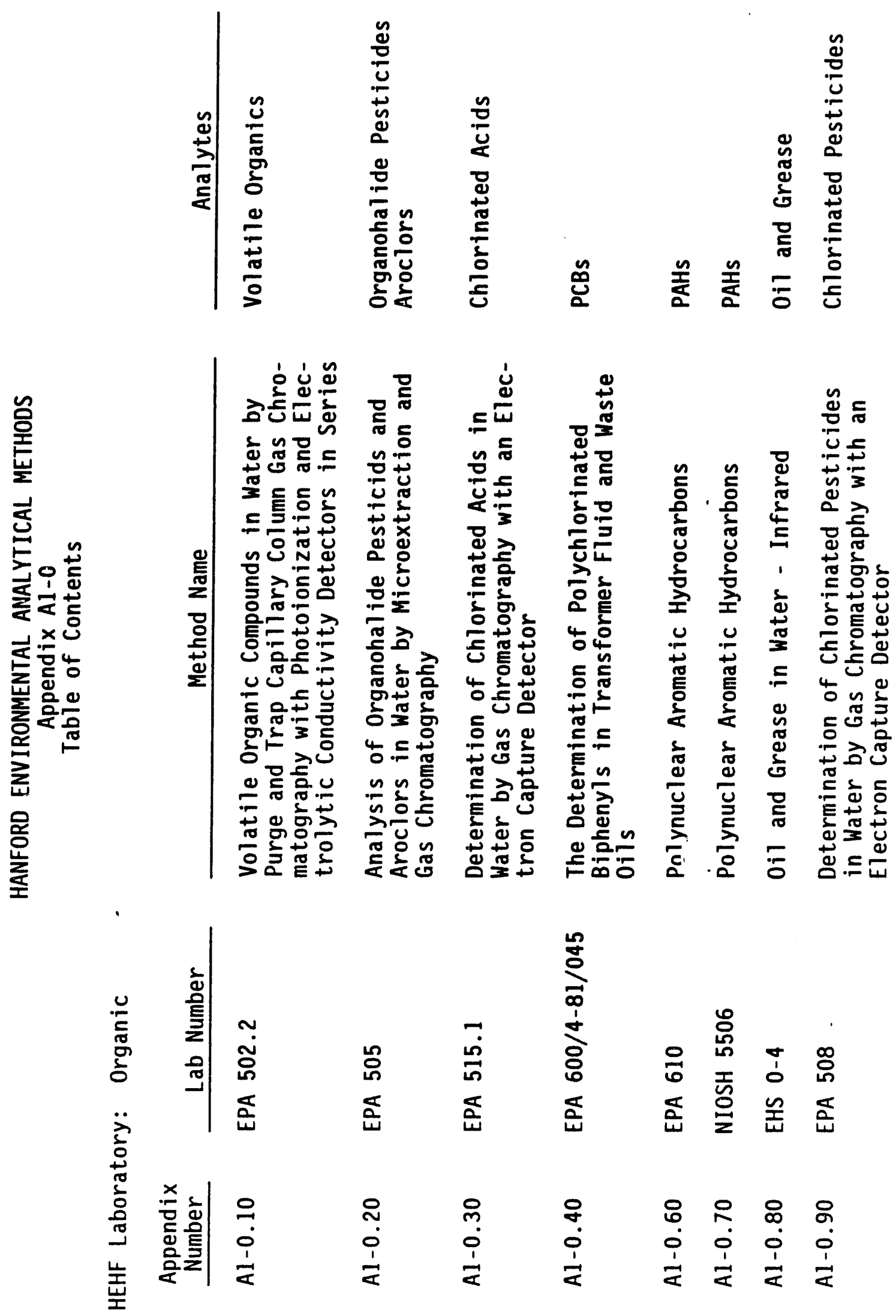
พั๊กับ

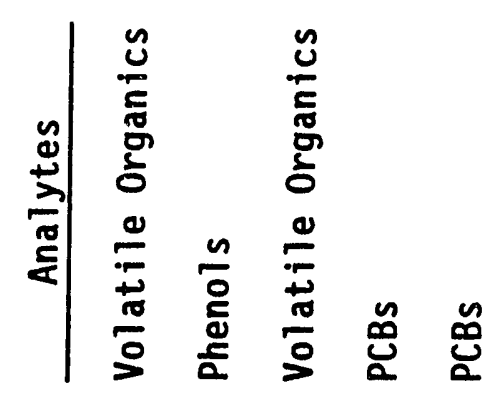

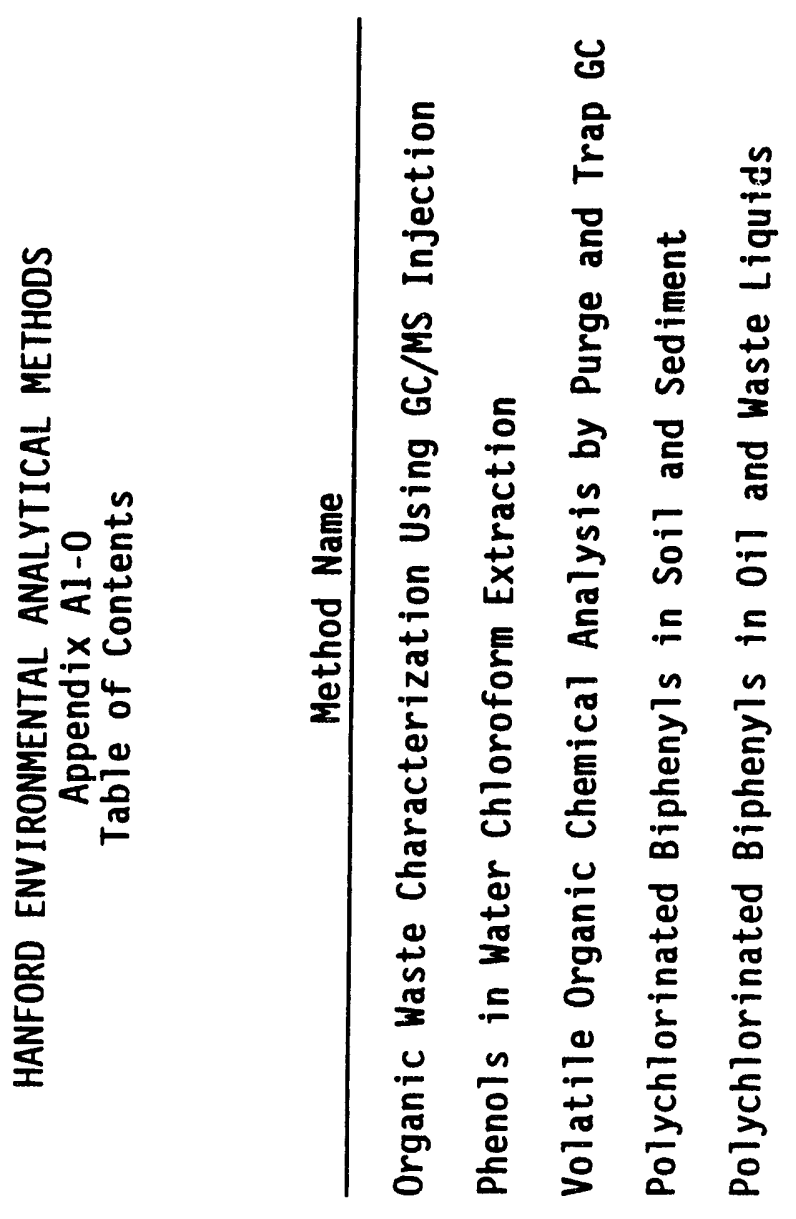

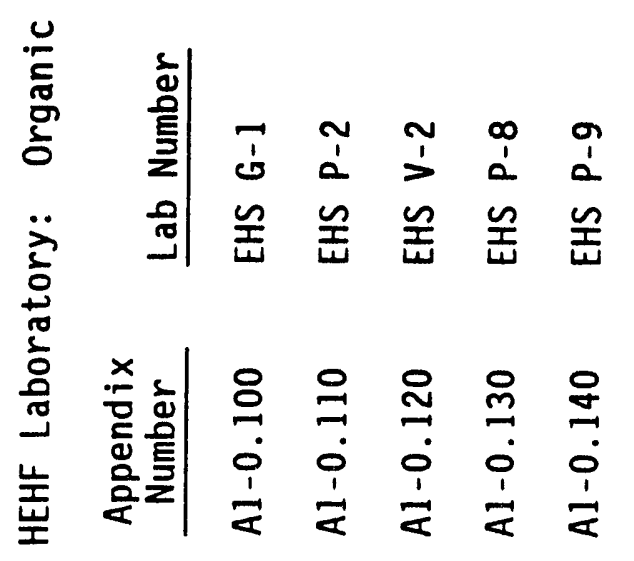


METHIOD 502.2. VOLATILE ORGANIC COMPOUNDS IN WATER BY

PURGE NI: TRAP CAPILLARY COLUMN GAS CHROMATOGRAPHY

WITH PHOTOIONIZATION ANO ELECTROLYTIC

CONDUCTIVITY DETECTORS IN SERIES

(September, 1986)

1. SCOPE AND APPLICATION

1.1 This method is applicable for the determination of various volatile organic compounds in finished drinking water, raw source water, or drinking water in any treatment stage. $(1,2)$ The following compounds can be determined by this method:

Analyte

- Benzene - -

Bromobenzene

Bromochloromethane

Bromodichloromethane

Bromoform

- Bromome thane

n-Butylbenzene

sec-Butylbenzene $*$

tert-Buty Ibenzene

Carbon tetrachloride

Chlorobenzene

Chloroethane

Chloroform

Chloromethane

2-Chiorotoluenè *

4-Chlorotoluene *

Dibromoch lorome thane

1,2-Dibromo-3-ch loropropane - extr. Hathe 50\%

1,2-Dibromoethane? - ats rethe soy.

Dibromme thane

1,2-Dich lorobenzene.

1,3-Dichlorobenzene

1,4-Dirhlorobenzene

Dich lorod if luorome thane

1,1-Dichloroethane

1,2-0ichloroe thane

1,1-Dichloroethene

-cis-1;2-Dich loroethene?
Chemical Abstract Services Registry Number

$71-43-2$

108-86-1

74-97-5

$75-27-4$

$75-25-2$

74-83-9

104-51-8

135-98-8

98-06-6

56-23-5

108-90-7

75-00-3

$67-66-3$

$74-87-3$

95-49-8

106-43-4

$124-48-1$

$96-12-8$

106-93-4

74-95-3

95-50-1

541-73-1

106-46-7

75-71-8

75-34-3

107-06-2

75-35-4

156-59-4

\footnotetext{
* Stade sperifie

....... = not on 601,602 or in stlekixes empranth on order.
} 
Analyte

trans-1,2-Dichloroethene

1,2-Dich loropropane

1,3-Dich loropropane.

2,2-0ichloropropane

1,1-Dich loropropene -

Ethylbenzene

Hexach lorobutadiene *

Isopropylbenzene

p-I sopropyltoluene *

Methylene chloride

Naphthalene *

n-Propylbenzene *

- Styrene- $*$

$1,1,1,2$-Tetrach loroethane

$1,1,2,2$-Tetrach loroethane

Tetrachloroethene

Toluene

$1 ; 2 ; 3-T r i c h l o r o b e n z e n e ~ *$

-1,2,4-Trichlorobenzene *

1,1,1-Trichloroethane

1,1,2-Trichloroethiane

Trichloroethene

Trichlorof luorome thane

$-1,2 ; 3-T r i c h l o r o p r o p a n e$ -

1,$2 ; 4-T r$ imethylbenzene *

1, 3,5-Trimethylbenzene

Vinyl chloride

$0-x y$ lene

-m-xylene

p-xylene.
Chemical Abstract Services

Registry Number

1.2 Method detection 1 imits (MOLs) (3) are compound dependent and vary with purging efficiency and concentration. The MOLs for selected analytes are presented in Table 1. The applicable concentration range of this method is compound and instrument dependent but is approximately 0.1 to $200 \mathrm{\mu g} / \mathrm{L}$. Analytes that are inefficiently purged from water will not be detected when present at low concentrations, but they can be measured with acceptable accuracy and precision when present in sufficient amounts. Determination of some structural isomers (1.e., xylenes) may be hampered by coelution. 
1.3 This method is recommended for use only by analysts experienced in the measurement of purgeable organtcs at the low $\mu \mathrm{g} / \mathrm{L}$ level or by experienced techntclans under the close supervision of a qualified analyst.

\section{SUMMARY OF METHOD}

2.1 Highly volatlle organic compounds with low water solubility are extracted (purged) from the sample matrix by bubbling an inert gas through a $5 \mathrm{~mL}$ aqueous sample. Purged sample components are trapped in a tube containing sultable sorbent materials. When purging is complete, the sorbent tube is heated and backflushed with helium to desorb trapped sample components onto a caplllary gas chromatography (GC) column. The column is temperature programmed to separate the method analytes which are then detected with a phototonization detector (PID) and a halogen specific detector placed in series.

2.2 Tentative identifications are confirmed by analyzing standards under the same conditions used for samples and comparing resultant GC retention times. Additional confirmatory information $c$ an be gained by comparing the relative response from the two detectors. Each identiffed component is measured by relating the response produced for that compound to the response produced by a compound that is used as an internal standard.

\section{INTERFERENCES}

3.1 During anaiysis, major contaminant sources are volatile materials in the laboratory and impurities in the inert purging gas and in the sorbent trap. The use of non-polytetrafluoroethylene (PTFE) plastic tubing, non-PTFE thread sealants, or flow controllers with rubber components in the purging device should be avoided since such materfals out-gas organic compounds which will be concentrated in the trap during the purge operation. Analyses of laboratory reagent blanks (Sect. 9.1.3) provide information about the presence of contaminants. When potential interfering peaks are noted in laboratory reagent blanks, the analyst should change the purge gas source and regenerate the molecular sieve purge gas filter ( $F$ ig. 1). Subtracting blank values from sample results is not permitted.

3.2 Interfering contamination may occur when a sample containing low concentrations of volatile organic compounds is analyzed imnediately after a sample containing relatively high concentrations of volatile organic compounds. A preventive technique is between-sample rinsing of the purging apparatus and sample syringes with two portions of reagent water. After analys is of a sample containing high concentrations of volatile organic compounds, one or more laboratory reagent blanks should be analyzed to check for cross contamination. For samples containing large amounts of water soluble materials, suspended solids, high boiling compounds or high levels of compounds being determined, it may be 
necessary to wash out the purging device with a soap solution, rinse $1 t$. with reagent water, and then dry it in an oven at $105^{\circ} \mathrm{C}$ between analyses.

3.3 Special precautions must be taken to analyze for methylene chloride. The analytical and sample storage area should be isolated from all atmospheric sources of methylene chloride, otherwise random background levels will result. Since methylene chloride will permeate through PTFE tubing, all gas chromatography carrier gas 1 ines and purge gas plumbing should be constructed from stainless steel or copper. tubing. Laboratory clothing worn by the analyst should be clean since clothing previously exposed to methylene chloride funes during common liquid/liquid extraction procedures can contribute to sample contamination.

\section{SAFETY}

4.1 The toxicity or carcinogenicity of chemicals used in this method has not been precisely defined; each chemical should be treated as a potential health hazard, and exposure to these chemicals should be minimized. Each laboratory is responsible for maintaining awareness of OSHA regulations regarding safe handling of chemicals used in this method. Additional references to laboratory safety are avallable (4-6) for the information of the analyst.

4.2 The following method analytes have been tentatively classiffed as known or suspected human or mammalian carcinogens: benzene, carbon tetrachloride, 1,4-dichlorobenzene, 1,2-dichlorethane, hexachlorobutadiene, 1,1,2,2-tetrachloroethane, 1,1,2-trichloroethane, chloroform, 1,2-dibromoethane, tetrachloroethene, trichloroethene, and vinyl chlorlde. Pure standard materlals and stock standard solutions of these compounds should be handled in a hood. A NIOSH/MESA approved toxic gas respirator should be worn when the analyst handles high concentrations of these toxic compounds.

\section{APPARATUS AND EQUIPMENT}

5.1 SAMPLE CONTAINERS - 40-mL to 120-mL screw cap vials (Pierce \#13075 or equivalent) each equipped with a PTFE-faced sflicone septum (Pierce \#12722 or equivalent). Prior to use, wash vials and septa with detergent and rinse with tap and distllled water. Allow the vials and septa to air dry at room temperature, place in a $105^{\circ} \mathrm{C}$ oven for one hour, then remove and allow to cool in an area known to be free of organics.

5.2 PURGE AND TRAP SYSTEM - The purge and trap system consists of three separate pieces of equipment: purging device, trap, and desorber. Systems are commerclally available from several sources that meet all of the following specifications. 
5.2.1 The all glass purging device (Fig. 1) must be designed to accept 5-mL samples with a water column at least $5 \mathrm{~cm}$ deep. Gaseous volumes above the sample must be kept to a minimum (< $15 \mathrm{~mL}$ ) to eliminate dead volume effects. A glass frit should be installed at the base of the sample chamber so that the purge gas passes through the water column as finely divided bubbles with a diameter of $<3 \mathrm{~mm}$ at the origin. Needle spargers may be used, however, the purge gas must be introduced at a point $\leq 5 \mathrm{~mm}$ from the base of the water column.

5.2.2 The trap (Fig. 2) must be at least $25 \mathrm{~cm}$ long and have an inside diameter of at least $0.105 \mathrm{in}$. Starting from the inlet, the trap should contain $1.0 \mathrm{~cm}$ of methyl sllicone coated packing and the following amounts of adsorbents: 1/3 of 2,6-diphenylene oxide polymer, $1 / 3$ of stlica gel, and $1 / 3$ of coconut charcoal. Before initial use, the trap should be conditioned overnight at $180^{\circ} \mathrm{C}$ by backflushing with an inert gas flow of at least $6 \mathrm{~mL} / \mathrm{m} / \mathrm{n}$. Vent the trap effluent to the room, not to the analytical column. Prior to use, the trap should be conditioned for 10 minutes at $180^{\circ} \mathrm{C}$ with backflushing. The trap may be vented to the analytical column during dafly conditioning; however, the column must be run through the temperature program prior to analysis of samples.

5.2.3 The use of the methyl sllicone cnated packing is recommended, but not mandatory. The packing serves a dual purpose of protecting the adsorbent from aerosols, and also of insuring that the adsorbent is fully enclosed within the heated zone of the trap thus eliminating potential cold spots. Alternatively, silanized glass wool may be used as a spacer at the trap inlet.

5.2.4 The desorber must be capable of rapidly heating the trap to $180^{\circ} \mathrm{C}$. The polymer section of the trap should not be heated higher than $200^{\circ} \mathrm{C}$ or the life expectancy of the trap will decrease. Trap fallure is characterlzed by a pressure drop in excess of 3 pounds per square inch across the trap during purging or by poor bromoform sensitivities. The desorber design illustrated in Fig. 2 meets these criteria.

5.2.5 Figures 3 and 4 show typical flow patterns for the purge-sorb and desorb modes.

\subsection{GAS CHROMATOGRAPH}

5.3.1 The GC must be capable of temperature programming and should be equipped with variable-constant differential flow controllers so that the column flow rate will remain constant throughout desorption and temperature program 
operation. The column oven must be cooled to $<10^{\circ} \mathrm{C}$ (Sect. 5.3.2), therefore, a subambient oven controller is required. The carrier gas flow is augmented with an additional $24 \mathrm{~mL}$ of helfum flow before entering the photoIonization detector. This make-up gas is necessary to ensure optimal response from both detectors. The photoionization and electroconductivity detector are connected with a short piece of uncoated capillary tubing, 0.32 $0.5 \mathrm{~mm} 1 \mathrm{D}$.

5.3.2 Gas Chromatographic Column $-60 \mathrm{~m}$ long $\times 0.75 \mathrm{~mm}$ 10 VOCOL (Supelco, Inc.) wide-bore cap 11 lary column with $1.5 \mathrm{\mu m} f \mathrm{fl} m$ thickness, or equivalent. The flow rate of hellum carrier gas is adjusted to about $6 \mathrm{~mL} / \mathrm{min}$. The column temperature is held for 8 minutes at $10^{\circ} \mathrm{C}$, then programmed to $180^{\circ} \mathrm{C}$ at $4^{\circ} \mathrm{C} / \mathrm{min}$, and held unt 11 all expected compounds have eluted. A sample chromatogram obtained with this column is presented in Fig. 5. This column was used to develop the method -performance statements in Section 12.

5.3.3 A high temperature photolonization detector equipped with a $10.2 \mathrm{eV}$ lamp is required (Tracor Model 703 or equivalent).

5.3.4 An electrolytic conductivity or microcoulometric detector is required. These halogen-specific systems eliminate misidentffications due to non-organohalides which are coextracted during the purge step. A Tracor Hall Model 700-A detector was used to gather the single laboratory accuracy and preciston data. The operating conditions used to collect these data are as follow:

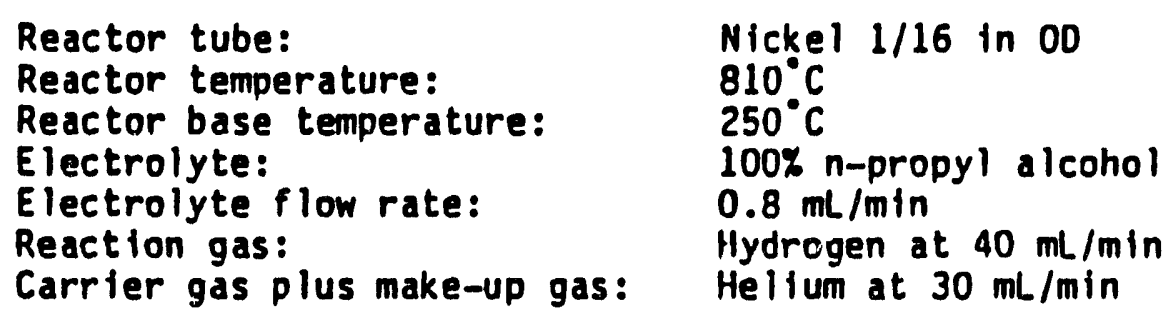
Carrier gas plus make-up gas: Hellum at $30 \mathrm{~mL} / \mathrm{min}$

Nickel $1 / 16$ in 00 $810^{\circ} \mathrm{C}$ $250^{\circ} \mathrm{C}$ $100 \%$ n-propyl alcohol $0.8 \mathrm{~mL} / \mathrm{min}$ Hydrogen at $40 \mathrm{~mL} / \mathrm{min}$

\subsection{SYRINGE AND SYRINGE VALVES}

5.4.1 Two 5-mL glass hypodermic syringes with Luer-Lok tip.

5.4.2 Three 2-way syringe valves with Luer ends.

5.4.3 One 25-uL micro syringe with a 2 in $\times 0.006$ in $10,22^{\circ}$ bevel needle (Hamiliton $\$ 702 N$ or equivalent).

5.4.4 Micro syringes - 10, $100 \mu \mathrm{L}$.

5.4.5 Syringes $-0.5,1.0$, and $5-\mathrm{mL}$, gas tight with shut-off valve. 


\subsection{MISCELLANEOUS}

5.5.1 Standard solution storage containers - $15-\mathrm{mL}$ bottles with PTFE-I Ined screw caps.

6. REAGENTS AND CONSUMABLE MATERIALS

\subsection{TRAP PACKING MATERIALS}

6.1.1 2,6-Diphenylene oxide polymer, 60/80 mesh, chromatographic grade (Tenax GC or equivalent).

6.1.2 Methyl stlicone packing (optional) - OV-1 (3\%) on Chromosorb $H, 60 / 80$ mesh, or equivalent.

6.1.3 Stlica gel - 35/60 mesh, Davison, grade 15 or equivalent.

6.1.4 Coconut charcoal - Prepare from Barnebey Cheney, CA-580-26 lot $\#$ M-2649 by crushing through 26 mesh screen.

\subsection{REAGENTS}

6.2.1 Methanol - Demonstrated to be free of analytes.

6.2.2 Reagent water - Prepare reagent water by passing tap water through a filter bed containing about $0.5 \mathrm{~kg}$ of activated carbon, by using a water purification system, or by bolling distllied water. for $15 \mathrm{~min}$ followed by a $1-\mathrm{h}$ purge with inert gas while the water temperature is held at $90^{\circ} \mathrm{C}$.

Store in clean, narrow-mouth bottles with PTFE-lined septa and screw caps.

6.2.3 Hydrochloric acid $(1+1)$ - Carefully add a measured volume of conc. $\mathrm{HCl}$ to equal volume of reagent water.

6.2.4 Vinyl chloride - 99.9\% pure vinyl chloride is avallable from Ideal Gas Products, Inc., Edison, New Jersey and from Matheson, East Rutherford, New Jersey. Certified mixtures of vinyl chloride in nitrogen at 1.0 and $10.0 \mathrm{ppm}(\mathrm{v} / \mathrm{v})$ are available from several sources.

6.3 STANOARD STOCK SOLUTIONS - These solutions may be purchased as certified solutions or prepared from pure standard materials using the following procedures:

6.3.1 Place about $9.8 \mathrm{~mL}$ of methanol into a $10-\mathrm{mL}$ ground-glass stoppered volumetric flask. Allow the flask to stand, unstoppered, for about $10 \mathrm{~min}$ or unt 11 all alcohol-wetted surfaces have dried and weigh to the nearest $0.1 \mathrm{mg}$. 
6.3.2 If the analyte is a liquid at room temperature, use a 100-uL syringe and immediately add two or more drops of re:erence standard to the flask. Be sure that the reference standard falls directly into the alcohol without contacting the neck of the flask. If the analyte is a gas at room temperature, fill a 5-mL valved gas-tight syringe with the standard to the 5.0-mL mark, lower the needle to $5 \mathrm{~mm}$ above the methanol meniscus, and slowly inject the standard into the neck area of the flask. The gas will raptdly dissolve in the methanol.

6.3.3 Reweigh, dilute to volume, stopper, then mix by inverting the flask several times. Calculate the concentration in micrograms per microliter from the net gain in weight. When compound purfty is certiffed at $96 \%$ or greater, the weight can be used without correction to calculate the concentration of the stock standard.

6.3.4 Store stock standard solutions in 15-mL bottles equipped with PTFE-l ined screw caps. Methanol solutions prepared from liquid analytes are stable for at least four weeks when stored at $4^{\circ} \mathrm{C}$. Methanol solutions prepared from gaseous analytes are not stable for more than one week when stored at $<0^{\circ} \mathrm{C}$; at room temperature, they must be discarded after one day.

6.4 SECONOARY DILUTION STANDARDS - Use standard stock solutions to prepare secondary dilution standard solutions that contain the analytes in methanol. The secondary dilution standards should be prepared at concentrations that can be easfly diluted to prepare aqueous callibration solutions (Sect. 8.1) that will bracket the work ing concentration range. Store the secondary dilution standard solutions with minimal headspace and check frequently for signs of deterioration or evaporation, especially just before preparing calibration solutions from them. Storage times described for stock standard solutions in Sect. 6.3.4 also apply to secondary dilution standard solutions.

6.5 INTERNAL STANDARD SPIKING SOLUTION - Prepare a spiking solution containing fluorobenzene, and 2-bromo-1-chloropropane in methanol using the procedures described in Sect. 6.3 and 6.4. It is recommended that the secondary dilution standard be prepared at a conceniration of $5 \mathrm{ug} / \mathrm{mL}$ of each internal standard compound. The addition of $10 \mathrm{uL}$ of such a standard to $5.0 \mathrm{~mL}$ of sample or calibration standard would be equivalent to $10 \mathrm{\mu g} / \mathrm{L}$.

6.6 LABORATORY QUALITY CONTROL CHECK STANDARD CONCENTRATE - Using standard stock solutions, prepare a solution containing each analyte of interest at a concentration of 100 times the maximum contaminant level $(M C L)$ or $1 \mu \mathrm{g} / \mathrm{mL}$, whichever is smaller, in methanol. 


\section{(1)} reported elfectiveness in the analysis of photograc industry effluents. Although the direction given hethod 272.1 oppears straightiorward, caution sirould be exercised in its use. It is Important that the snmple is besic $(\mathrm{pH}>7)$ prior to the addition of the CNI reagent to eliminate the possible formation of volatile hydrogen cyanide. Also, the CNI reagent should he added to the sample in an exhaust hood as a precautionary meosure. Once the sample or sample aliquol has been treated with the CNI reagent and diluted per instruction. the solution has a cyenide concentration of approximately $260 \mathrm{mg} / \mathrm{L}$. A solution of that cyanide concentration must be considered a potential hazardous waste and must be disposed of using an approved salety plan in accordence with local authority requirements. Until such time that a detailed disposal plan can be fully documented and approved. the use of the CNI resgent should be evolded. For the atomic absorption analysis of these semples where the "totel metal" digestion ls not adequate, the use of on aqueous bulfer of sodium thiosulfate and sodium hydroxide should be substituted for the CNI procedure. The conditions for the use of the buffer are described in footnote 28 to Table 18-List of Approved Inorganic

Test Procedures given on page 33546 of the Federal Register, Vol. 52, No. 171. September 3, 1987. For - your convenience that ontire footnote as given is restated bolow:

20Aproved methods for llin nnalysis of silver In industrial wastewaters it concentrations of $1 \mathrm{mg} / \mathrm{L}$ and above are inadequate where silver exists as an inorganic halide. Silver hallde such as the bromide and chloride are relatively insoluble in reogents such as nitric ocid but are readlly soluble in an aqueous buffer of sodium ifiosulfate and sodium hydroxide to a $\mathrm{pH}$ of 12. Therafore, lor levels of sllver above $1 \mathrm{mg} / \mathrm{L}, 20 \mathrm{~mL}$ of sample ! should be diluted to $100 \mathrm{~mL}$ by adding 40 $\mathrm{mL}$ each of $2 \mathrm{M} \mathrm{Na}_{2} \mathrm{~S}_{2} \mathrm{O}_{3}$ and $\mathrm{NaOH}$. Sland. ards should be prepered in the same manner.

$\therefore \quad$ For levels of silver below $1 \mathrm{mg} / \mathrm{L}$ the approved . method is satisfactory.

Comments concerning this recommendation are welcome.

(Theodore Martin, FTS: 684-7312: COML: 513-569-7312)

\section{Sampling and Field Measurement Section}

\section{Intergovernmental Personnel Act (IPA) Assignment}

-1. Fred Kawaliara has completed a six-month IPA nssignment wifl the National Bureau of Standards (NBS). During this period Dr. Kawahara has investigated various techniques of coating glass beads using silanes to compliment the work of NBS in developing an analytical method for aromatics with ontigens cooted on glass beads. Using C-14 assay techniques, he explored the degree of silanization of glass beads using 4-imino-butyl dimetyl ethoxy silane. Antigens are then acylated on the imino groups for activation of the analytical method.

(Joseph Roesler, FTS: 684-7286; COML: 513-569-7286)

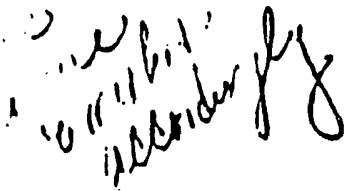

Note on Preservation of Drinking Water Samples to be Analyzed for Volatile Organic Chemicals (VOCs) and 1445 Monitoring Compounds

Necipients and users of the September 1986 "Methods lor the Determination ol Organic Compounds in Finished Drinking Water and Raw Source Water" should note that a modilication to the preservation lechnique is being made. Continuing use and ovaluation of the methods has shown that chlorinated waters inust be dechlorinated prior to acidification in order in prevent the chlorination of certain method analytes/ aromatic compounds that may be present. The Jechlorination step must be added to Methods 502.1 . 503.1. 524.1, and 524.2. The methods now being peset lor printing have been edited to read as follows:

\subsection{Sample Collection}

7.1.1 If the sample is expected to contain tree or combined chlorine, add ascorbic ocid (8) or sodium thiosulfate to the sample to arrest formation of trihalomethanes or other chlorinated artilacts. Ascorbic acid $125 \mathrm{mg} / 40 \mathrm{~mL}$ ) or sodium thiosullate 13 $\mathrm{mg} / 40 \mathrm{~mL}$ ) should be added to the empty sample bottle prior to shipping to the sampling slte.

Recent data on preservation of volatiles has shown that thiosullate cannot be used as a Iree-chlorine 
7. SAMPLE COLLECTION, PRESERVATION, AND STORAGE

\subsection{SAMPLE COLLECTION}

7.1.1 Collect all sampies in duplicate. Fill sample bottles to overflowing. No air bubbles should pass through the sample as the bottle is filled, or be trapped in the sample when the bottle is sealed.

7.1.2 When sampling from a water tap, open the tap and allow the system to flush until the water temperature has stabllized (usually about $10 \mathrm{~min}$ ). Adjust the flow to about $500 \mathrm{~mL} / \mathrm{min}$ and collect duplicate samples from the flowing stream.

7.1.3 When sampling from an open body of water, fill a 1-quart wide-mouth bottle or 1-1iter beaker with sample from a representative area, and carefully fill duplicate sample bottles from the container.

\subsection{SAMPLE PRESERYATION}

7.2.1 Adjust the $\mathrm{pH}$ of the duplicate samples to <2 by carefully adding one drop of $1: 1 \mathrm{HCl}$ for each $20 \mathrm{~mL}$ of sample volume. (7) Seal the sample bottles, PFTE-face down, and shake vigorously for one minute.

7.2.2 The semples must be chilled to $4^{\circ} \mathrm{C}$ on the day of collection and maintained at that temperature until analysis. Field samples that will not be received at the laboratory on the day of collection must be packaged for shipment with suffictent ice to ensure that they will be at $4^{\circ} \mathrm{C}$ on arrival at the laboratory.

\subsection{SAMPLE STORAGE}

7.3.1 Store samples at $4^{\circ} \mathrm{C}$ unt 11 analysis. The sample storage area must be free of organic solvent vapors.

7.3.2 Analyze all samples within 14 days of collection. Samples not analyzed within this period must be discarded and replaced.

8. CALIBRATION AND STANDARDIZATION

\subsection{PREPARATION OF CALIBRATION STANDARDS}

8.1.1 A set of at least ifive calibration standards containing the method analytes is needed. One callbration standard should contain each analyte at a concentration approaching but greater than the method detection $1 \mathrm{imit}$ (Table 1) for that compound; the other calibration standards should contain analytes at concentrations that define the range of the method or the detection ystem. 
8.1.2 To prepare a callbration standard, add an appropriate volume of a secondary dilution standard solution to an aliquot of reagent water in a volumetric flask. Use a microsyringe and rapidly inject the alcoholle standard into the expanded area of the filled volumetric flask. Remove the needle as quickly as possible after injection. Mix by inverting the flask three times only. Discard the contents contained in the neck of the flask. Aqueous standards are not stable and should be discarded after one hour unless sealed and stored as described in Sect. 7.2.

\subsection{CALIBRATION}

8.2.1 Analyze each callbration standard according to Sect. 10 , adding $10 \mathrm{uL}$ of internal standard spiking solution directly to the syringe. Tabulate area response versus the concentration for each analyte and internal standard. Calculate response factors (RF) for each analyte using Equation 1:

$$
R F=\frac{\left(A_{s}\right)\left(C_{i s}\right)}{\left(A_{i s}\right)\left(C_{s}\right)} \quad \text { Equation } 1
$$

where:

$$
\begin{aligned}
& A_{s}=\text { Area for the analyte to be measured; } \\
& \text { Ats - Area for the Internal standard; } \\
& C_{\text {is }} \text { - Concentration of the internal standard, in } \mu \mathrm{g} / \mathrm{L} \text {. } \\
& C_{S} \text { - Concentration of the analyte to be measured, in } \\
& \mu \mathrm{g} / \mathrm{L} \text {. }
\end{aligned}
$$

The choice of which internal standard to use for an analyte is left to the analyst.

8.2.2 Prepare a calibration curve for each analyte.

Alternatively, if the RF for an analyte is constant (less than $15 \%$ RSO) over the working range, the average RF can be used for that analyte.

8.2.3 The working calibration curve or average response factor must be verified on each working day by the measurement of one or more calibration standards. If the area for any analyte varies from the response determined for that standard concentration from the calibration curve or average RF established in Sect. 8.2 .2 by more than $\pm 20 \%$, repeat steps 8.2.1 and 8.2.2.

8.2.4 Calibration for vinyl chloride using a certified gaseous mixture of vinyl chloride in nitrogen can be accomplished by the following steps. The procedure requires use of a modifled purge vessel having a septum seal port in the expanded part of the device. 
8.2.4.1 Fill the purging device with $5.0 \mathrm{~mL}$ of reagent water or aqueous calibration standard, and add internal standards.

8.2.4.2 Start to purge the aqueous $m i x t u r e$. Inject a known volume (between 100 and $2000 \mu \mathrm{L}$ ) of the callbration gas (at room temperature) directly into the purging device with a gas tight syringe. Slowly inject the gaseous sample through a septum seal at the top of the purging device at $2000 \mathrm{uL} / \mathrm{min}$. Do not inject the standard through the aqueous sample inlet needle. Inject the gaseous standard before five min of the $11-m$ in purge time have elapsed.

8.2.4.3 Determine the aqueous equivalent concentration of vinyl chloride standard injected in $\mu \mathrm{g} / \mathrm{L}$, according to Equation 2:

$$
S=0.510(C)(V) \quad \text { Equation } 2
$$

where $S$ - Aqueous equivalent concentration of vinyl chloride standard in $\mu \mathrm{g} / \mathrm{L}$;

$C$ - Concentration of gaseous standard in ppm $(v / v)$;

$V$ - Volume of standard injected in milliifters.

9. QUALITY CONTROL

9.1 Each laboratory that uses this method is required to operate a formal quality control program. The minimum requirements of this program consist of an initial demonstration of laboratory capability and an ongoing analysis of spiked samples to evaluate and document data quality. The laboratory must maintain records to document the quality of data that is generated. Ongoing data quality checks are compared with established performance criteria to determine if the results of analyses meet the performance characteristics of the method. A quality control check standard must be analyzed to confirm that the measurements were performed in an in-control mode of operation.

9.1.1 The analyst must make an initial, one-time, demonstration of the ability to generate acceptable accuracy and precision with this method. This ability is established as described in Section 9.2 .

9.1.2 In recognition of advances that are occurring in chromatography, the analyst is permitted certain options (detalled in Section 10.1.1) to improve the separations or lower the cost of measurements. Each time such a modification is made to the method, the analyst is required to repeat the procedure in Section 9.2 . 
9.1.3 Each day, the analyst must analyze a reagent water blank to demonstrate that interferences from the analytical system are under control.

9.1.4 The laboratory must, on an ongoing basis, demonstrate through the analyses of quality control check standards that the operation of the measurement system is in control. This procedure is described in Section 9.3. The frequency of the check standard analyses is equivalent to $10 \%$ of all samples analyzed but at least two samples per month.

9.1.5 On a weekly basis, the laboratory must demonstrate the abllity to analyze low level samples. A procedure for low level check samples is described in Section 9.4.

9.1.6 The laboratory must maintain performance records to document the quality of data that is generated. This procedure is described in Section 9.5.

9.2 To establish the ability to generate acceptable accuracy and preciston, the analyst must perform the following operations.

9.2.1 A quality control (OC) check sample concentrate is required containing each regulated analyte, and any additional analyte which is to be reported, at a concentration of 100 times the MCL or $1 \mathrm{\mu g} / \mathrm{mL}$, whichever is smaller, in methanol. The QC check sample must be prepared by the. laboratory using stock standards prepared independently from those used for calibration.

9.2.2 Analyze seven 5-mL QC check samples at $1 / 5 \mathrm{MCL}$ or $2 \mu \mathrm{g} / \mathrm{L}$ according to the method beginning in Sect. 10. Each sample is produced by injecting $10 \mathrm{ML}$ of $\mathrm{OC}$ check sample concentrate into $5 \mathrm{~mL}$ of reagent water in a glass syringe through the syringe valve.

9.2.3 Calculate the average recovery $(\bar{X})$ in $\mu g / L$, and the standard deviation of the recovery (s) in $\mu \mathrm{g} / \mathrm{L}$ for each analyte using the seven results. Calculate the MOL for each analyte as spectfied in Ref. 2. The calculated MDL must be less than the spike level.

9.2.4 For each analyte, $(\bar{x})$ must be between $80 \%$ and $120 \%$ of the true value. Additionally, $s$ must be $<30 \%$ of $\bar{x}$. If $s$ and $\bar{x}$ for all analytes meet the criteria, the system performance is acceptable and analysis of actual samples can begin. If any $s$ exceeds the precision limit or any $\bar{X}$ falls outside the range for accuracy, the system performance is unacceptable for that analyte. 
NOTE: The large number of analytes present a substantial probability that one or more will fall at least one of the acceptance criteria when all analytes are determined.

9.2.5 When one or more of the analytes tested fall at least one of the acceptance criterla, the analyst must repeat the test according to Section $\mathbf{9 . 2 . 2}$ only for the analytes which falled the test.

9.3 The laboratory must demonstrate on a regular basis, as outlined in Sect. 9.1.4, that the measurement system is in control by analyzing a quality control sample for all analytes of interest at the MCL or $10 \mu \mathrm{g} / \mathrm{L}$, whichever is smaller.

9.3.1 Prepare a QC check standard by adding 50 uL of QC check sample concentrate to $5 \mathrm{~mL}$ of regent water in a glass syringe.

9.3.2 Analyze the QC check according to Section 10, and calculate the recovery for each analyte. The recovery must be between $60 \%$ and $140 \%$ of the expected value.

9.3.3 If the recovery for any analyte falls outside the designated range, the analyte has falled the acceptance criteria. A check standard containing each failed analyte must be re-analyzed.

9.4 On a weekly basis, the laboratory must demonstrate the ability to analyze low level samples.

9.4.1 Prepare a low level check sample by adding $10 \mathrm{uL}$ of QC check sample concentrate to $5 \mathrm{~mL}$ of reagent water in a $5 \mathrm{~mL}$ syringe. Analyze according to the method in Sect. 10.

9.4.2 For each analyte, the recovery must be between $60 \%$ and $140 \%$ of the expected value.

9.4.3 When one or more analytes fall the test, the analyst must repeat the test only for those analytes which failed to meet the criterla. Repeated fallure, however, will confirm a general problem with the measurement system. If this occurs, locate and correct the source of the problem and repeat the test for all compounds of interest beginning with 9.4.1.

9.5 It is recomnended that the laboratory adopt additional quality assurance practices for use with this method. The specific practices that are most productive depend upon the needs of the laboratory and the nature of the samples. Fleld duplicates may be analyzed to assess the precision of the environmental measurements. Whenever possible, the laboratory should analyze standard reference materials and participate in relevant performance evaluation studies. 
10. PROCEDURE

\subsection{INITIAL CONDITIONS}

10.1.1 Recommended cliromatographic conditions are summarlzed in Section 5.3.2. Estimated retention times and MULs that can be achieved under these conditions are given in Table 1. other columns or element specific detectors may be used if the requirements of Section 9.2 are met.

10.1.2 Callbrate the system dally as described in Section 8.2.

10.1.3 Adjust the purge gas (nitrogen or helfum) flow rate to about $40 \mathrm{~mL} / \mathrm{min}$. Attach the trap inlet to the purging device and open the syringe vaive on the purging device.

\subsection{SAMPLE INTRODUCTION AND PURGING}

10.2.1 Remove the plungers from two $5-m \mathrm{~L}$ syringes and attach a closed syringe valve to each. Warm the sample to room temperature, open the sample (or standard) bottle, and carefully pour the sample into one of the syringe barrels to just short of overflowing. Replace the syringe plunger, invert the syringe, and compress the sample. Open the syringe valve and vent any residual air while adjusting the

- sample volume to $5.0 \mathrm{~mL}$. Add $10 \mathrm{\mu L}$ of the internal calibration standard to the sample through the syringe valve. Close the valve. Fill the second syringe in an identical manner from the same sample bottle. Reserve this second syringe for a reanalys is if necessary.

10.2.2 Attach the sample syringe valve to the syringe valve on the purging device. Be sure that the trap is cooler than $25^{\circ} \mathrm{C}$, then open the sample syringe valve and inject the sample into the purging chamber. Close both valves and initiate purging. Purge the sample for $11.0 \neq 0.1 \mathrm{~min}$ at ambient temperature (FIgures 1 and 3 ).

10.3 SAMPLE DESORPTION - After the 11-min purge, couple the trap to the chromatograph by switching the purge and trap system to the desorb mode (Figure 4 ). Initiate the temperature program sequence of the gas chromatograph and start data acquisition. Introduce the trapped materials to the GC column by rapidly heating the trap to $180^{\circ} \mathrm{C}$ while backflushing the trap with an inert gas flow of 6 $\mathrm{mL} / \mathrm{min}$ for $4.0 \neq 0.1 \mathrm{~min}$. While the extracted sample is being introduced into the gas chromatograph, empty the purging device using the sample syringe and wash the chamber with two $5-\mathrm{mL}$ flushes of reagent water. Af.ter the purging device has been emptied, leave the syringe valve open to allow the purge gas to vent through the sample introduction needle. 
10.4 TRAP RECONOITIONING - After desorbing the sample for four min, recondition the trap by returning the purge and trap system to the purge mode. Wait $15 \mathrm{~s}$, then close the syringe valve on the purging device to begin gas flow through the trap. Maintain the trap temperature at $180^{\circ} \mathrm{C}$. After approximately seven min, turn of the trap heater and open the syringe valve to stop the gas flow through the trap. When the trap is cool, the next sample can be analyzed.

\section{CALCULATIONS}

11.1 Identify each analyte in the sample chromatogram by comparing the retention time of the suspect peak to retention times generated by the calibration standards and the laboratory quality control standard (Sect. 8.2.2) on the appropriate detector. When arplicable, determine the relative response of the alternate detector to the analyte. The relattve response should agree to within $20 \%$ of relative response determined from standards.

11.2 When both detectors respond to an analyte, quan'itation is usually performed on the detector which exhibits the greater response. However, in cases where greater speciffcity or precision would result, the analyst may choose the alternate detector.

11.3 Determine the concentration of the unknowns by using the calibration curve or by comparing the peak helght or area of the unknowns to the peak height or area of the standards as follows:

$$
C_{u}=\frac{A_{u}}{A_{15}} \times \frac{C_{15}}{R F}
$$

Equation 3

where: $C_{u}=$ Concentration of the analyte in sample, in $\mu g / L$ $C_{\text {is }}$ - Concentration of the internal standard, in $\mu \mathrm{g} / \mathrm{L}$ $A_{u}=$ Peak area of the analyte $A_{1 s}=$ Peak area of the internal standard $\mathrm{RF}$ - Relative response factor

11.4 Report the results for the unknown samples in $\mu \mathrm{g} / \mathrm{L}$. Round of the results to the nearest $0.1 \mathrm{\mu g} / \mathrm{L}$ or two significant figures.

\section{ACCURACY AND PRECISION}

12.1 This method was tested in a single laboratory using reagent water spiked at $10 \mu \mathrm{g} / \mathrm{L}(8)$. Single laboratory precision and accuracy data for each detector are presented for the method analytes in Table 2.

12.2 Method detection 1 imits for these analytes have been calculated from data collected by spiking reagent water at $0.1 \mu \mathrm{g} / \mathrm{L}$. These data are presented in Table 1. 


\section{REFERENCES}

1. "The Determination of Halogenated Chemicals in Water by the Purge and Trap Method, Method 502.1," Environmental Protection Agency, Environmental Monitoring and Support Laboratory, Cincinnat 1 , Ohio 45268, Apr11, 1981.

2. "Volatile Aromatic and Unsaturated Organic Compounds in Water by Purge and Trap Gas Chromatography, Method 503.1," Environmental Protection Agency, Environmental Monitoring and Support Laboratory, Cincinnati, Oh 10, Apr II, 1981.

3. Glaser, J.A., D.L. Foerst, G.D. McKee, S.A. Quave, and W.L. Budde, "Trace Analyses for Wastewaters," Environ. Sct. Technol., 15, 1426, 1981.

4. "Carcinogens-Working with Carcinogens," Department of Health, Education, and Welfare, Public Health Service, Center for Disease Control, National Institute for Occupational Safety and Health, Publication No. 77-206, August, 1977.

5. "OSHA Safety and Health Standards, General Industry," (29CFR1910), Occupational Safety and Health Administration, OSHA 2206, (Revised, January, 1976).

6. "Safety in Academic Chemistry Laboratories," American Chemical Society Publication,. Commlttee on Chemical Safety, 3rd Edition, 1979.

7. Bellar, T.A. and J.J. Lichtenberg, "The Determination of Synthetic Organic Compounds in Water by Purge and Sequentlal Trapping Capillary Column Gas Chromatography," U.S. Environmental Protection Agency, Environmental Monitoring and Support Laboratory, Cincinnati, Ohio, 45268.

8. Ho. J.S. Method Performance Data for Method 502.2, Unpublished Report, September, 1986. 
Table 1. CHROMATOGRAPHIC RETENTION TIMES AND

METHOD DETECTION LIMITS (MOL). FOR VOLATILE ORGANIC COMPOUNDS

ON PHOTOIONIZATION DETECTION (PID) AND

HALL ELECTROLYTIC CONDUCTIVITY DETECTOR (HECD) DETECTORS

Analyte

$$
\text { PIO }
$$

Ret. TIme, a

min.

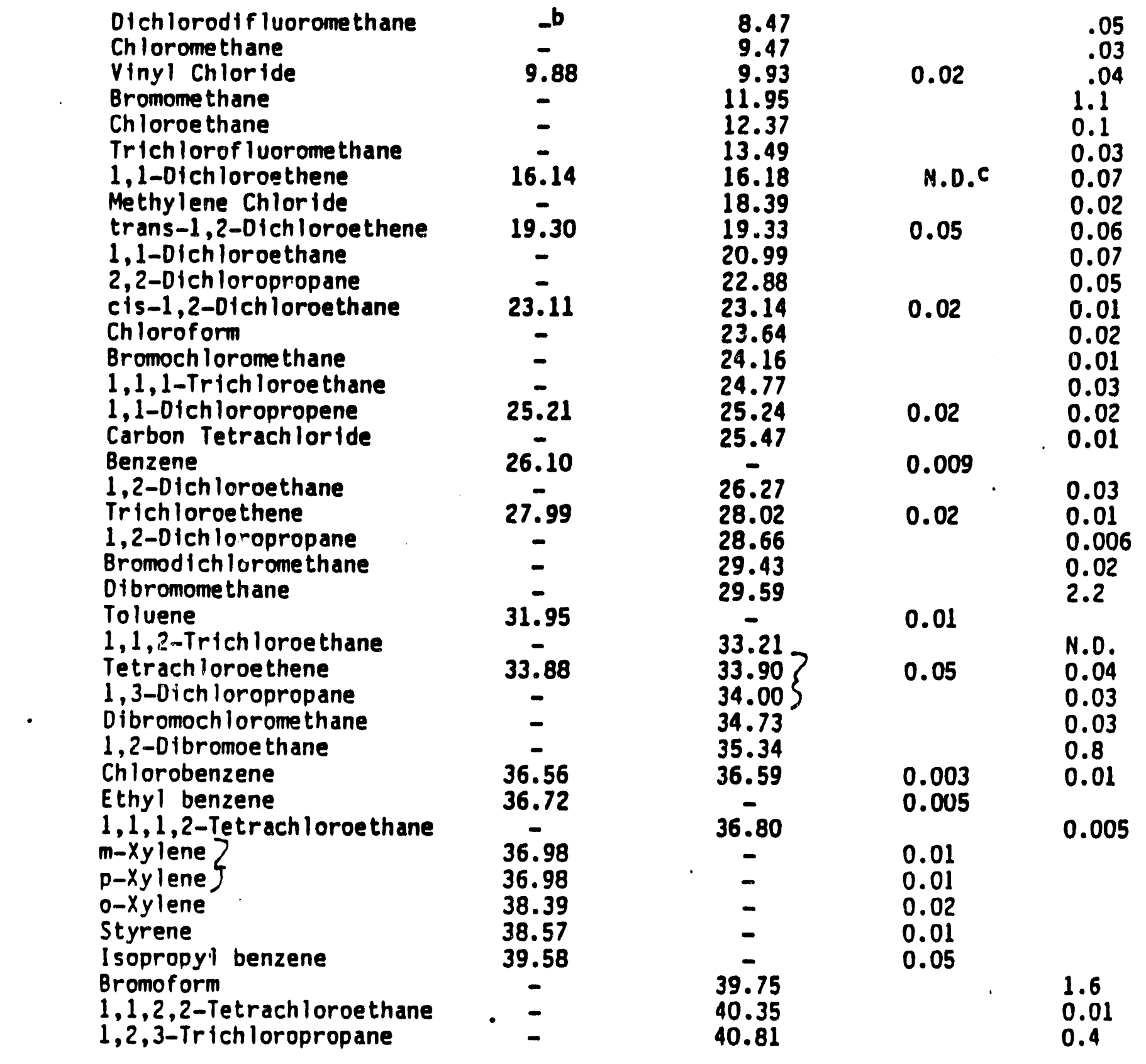

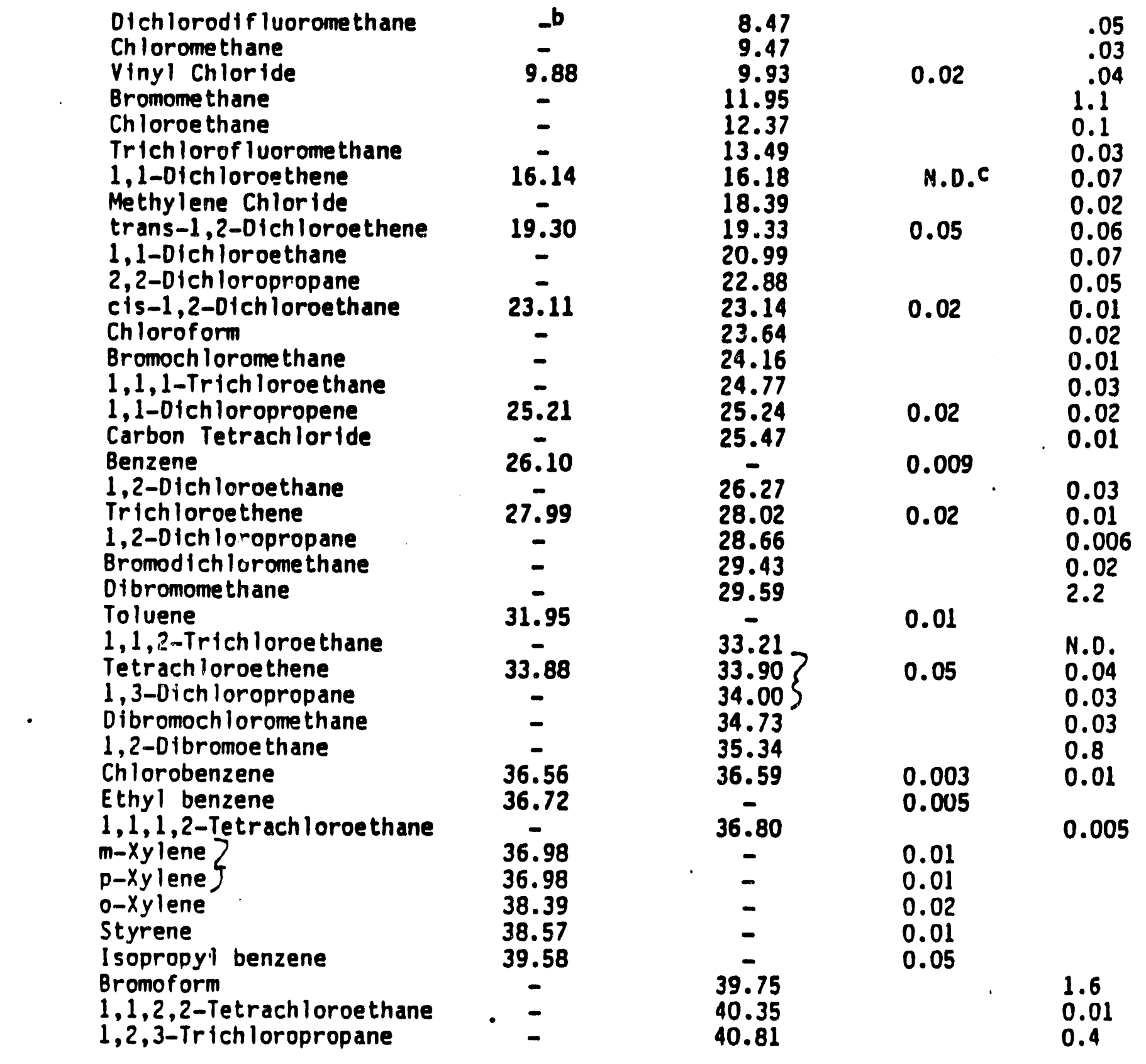

HECD

MOL $\mu g / L$ 
Table 1 (Cont Inued)

\begin{tabular}{|c|c|c|c|c|}
\hline Analyte & $\begin{array}{l}\text { PID } \\
\text { Ret. TIme, a } \\
\text { min. }\end{array}$ & $\begin{array}{l}\text { HECD } \\
\text { Ret. Time, } \\
\text { min. }\end{array}$ & $\begin{array}{l}P I D \\
M O L \\
\mu g / L\end{array}$ & $\begin{array}{l}\text { HECD } \\
M D L \\
\mu g / L\end{array}$ \\
\hline 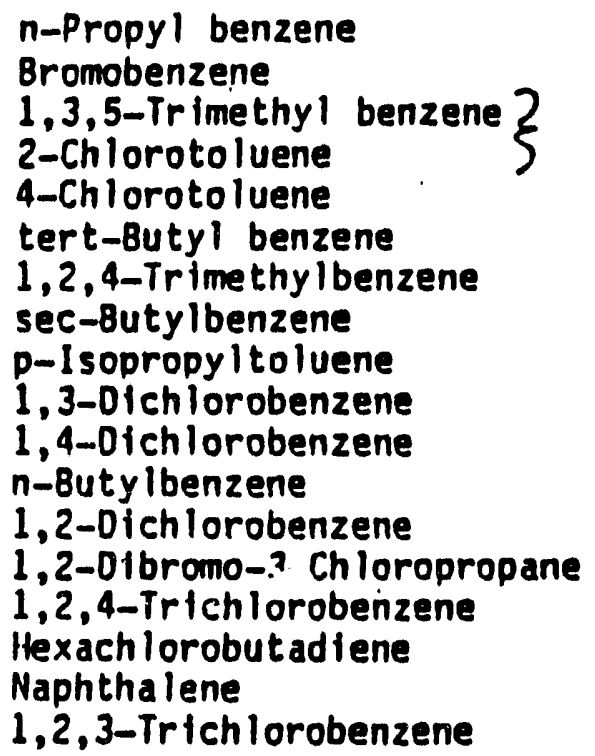 & $\begin{array}{l}40.87 \\
40.99 \\
41.41 \\
41.41 \\
41.60 \\
42.92 \\
42.71 \\
43.31 \\
43.81 \\
44.08 \\
44.43 \\
45.20 \\
45.71 \\
51.43 \\
51.92 \\
52.38 \\
53.34\end{array}$ & $\begin{array}{c}41.03 \\
- \\
41.45 \\
41.63 \\
- \\
- \\
- \\
-\overline{11} \\
44.47 \\
-\overline{45.74} \\
48.57 \\
51.46 \\
51.96 \\
53.37\end{array}$ & $\begin{array}{l}0.004 \\
0.006 \\
0.004 \\
N .0 \\
0.02 \\
0.06 \\
0.05 \\
0.02 \\
0.01 \\
0.02 \\
0.007 \\
0.02 \\
0.05 \\
0.02 \\
0.06 \\
0.06 \\
N .0\end{array}$ & $\begin{array}{l}0.02 \\
0.01 \\
0.02 \\
3.0 \\
0.03 \\
0.02 \\
0.03\end{array}$ \\
\hline
\end{tabular}

Internal Standards

Fluorobenzene

26.84

2-Bromo-1-chloropropane

$-$

33.08

a. Rentention times determined on $60 \mathrm{~m} \times 0.75 \mathrm{~mm} 10$ VOCOL capillary column. Program: Hold at $10^{\circ} \mathrm{C}$ for 8 mins, then program at $4^{\circ} \mathrm{C} / \mathrm{min}$ to $180^{\circ} \mathrm{C}$, and hold unt 11 all expected compounds have eluted.

b. - Dash indlcates detector does not respond.

C. N.D. = Not Determined 
Table 2. SINGLE LABORATORY ACCURACY AND PRECISION DATA FOR VOLATILE ORGANIC COMPOUNDS IN REAGENT WATER

\begin{tabular}{|c|c|c|c|c|}
\hline \multirow[b]{2}{*}{ Analyte } & \multicolumn{2}{|c|}{$\begin{array}{c}\text { Photoionization } \\
\text { Detector }\end{array}$} & \multicolumn{2}{|c|}{$\begin{array}{c}\text { Hall Electrolytic } \\
\text { Conduct Ivity Detector } \\
\end{array}$} \\
\hline & $\underset{x}{\operatorname{Recovery}}$ & $\begin{array}{l}\text { Standard } \\
\text { Deviation } \\
\text { of Recovery }\end{array}$ & $\underset{\%}{\operatorname{Recovery}} \mathbf{a}^{a}$ & $\begin{array}{l}\text { Standard } \\
\text { Deviation } \\
\text { of Recovery }\end{array}$ \\
\hline 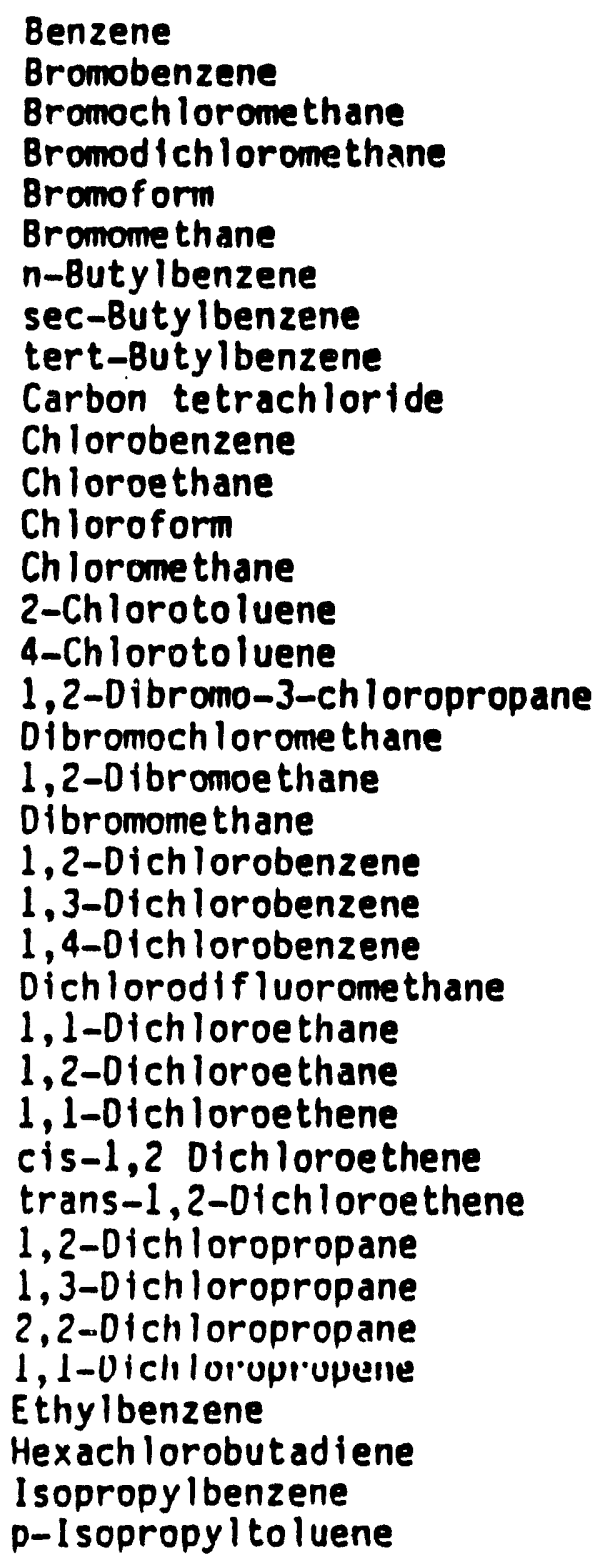 & $\begin{array}{c}99 \\
99 \\
- \\
- \\
- \\
100 \\
97 \\
98 \\
\overline{100} \\
- \\
- \\
- \\
N .0 . C \\
101 \\
- \\
- \\
- \\
- \\
102 \\
104 \\
103 \\
- \\
- \\
- \\
100 \\
N .0 \\
93 \\
- \\
- \\
103 \\
101 \\
99 \\
98 \\
98\end{array}$ & $\begin{array}{l}1.2 \\
1.7 \\
- \\
- \\
\overline{4} \\
4.4 \\
2.6 \\
2.3 \\
\overline{1} .0 \\
- \\
- \\
\overline{1} .0 . \\
1.0 \\
- \\
- \\
- \\
\overline{2} .1 \\
1.7 \\
2.2 \\
- \\
- \\
\overline{2} \\
1.4 \\
3.0 . \\
- \\
- \\
\overline{3} .6 \\
1.4 \\
9.5 \\
0.9 \\
2.4\end{array}$ & $\begin{array}{c}-b \\
97 \\
96 \\
97 \\
106 \\
97 \\
- \\
- \\
- \\
92 \\
103 \\
96 \\
98 \\
96 \\
97 \\
97 \\
86 \\
102 \\
97 \\
109 \\
100 \\
106 \\
98 \\
89 \\
100 \\
100 \\
103 \\
105 \\
99 \\
103 \\
100 \\
105 \\
10 J \\
- \\
98 \\
- \\
-\end{array}$ & $\begin{array}{l}- \\
2.7 \\
3.0 \\
2.9 \\
5.5 \\
3.7 \\
- \\
- \\
- \\
3.3 \\
3.7 \\
3.8 \\
2.5 \\
8.9 \\
2.6 \\
3.1 \\
9.9 \\
3.3 \\
2.7 \\
7.4 \\
1.5 \\
4.3 \\
2.3 \\
5.9 \\
5.7 \\
3.8 \\
2.9 \\
3.5 \\
3.7 \\
3.8 \\
3.4 \\
3.6 \\
3.1 \\
8.3 \\
- \\
-\end{array}$ \\
\hline
\end{tabular}


Table 2. (Continued)

\begin{tabular}{|c|c|c|c|c|c|}
\hline \multirow[b]{2}{*}{ Analyts } & \multicolumn{2}{|c|}{$\begin{array}{c}\text { Photolonization } \\
\text { Detector }\end{array}$} & \multicolumn{3}{|c|}{$\begin{array}{l}\text { Hall Electrolytic } \\
\text { Conductivity Detector }\end{array}$} \\
\hline & $\underset{\varnothing}{\text { Recovery, a }}$ & $\begin{array}{l}\text { Standard } \\
\text { Deviation } \\
\text { of Recovery }\end{array}$ & $\underset{x}{\operatorname{Recovery}, a}$ & $\begin{array}{l}\text { Standard } \\
\text { Deviation } \\
\text { of Recovery }\end{array}$ & \\
\hline 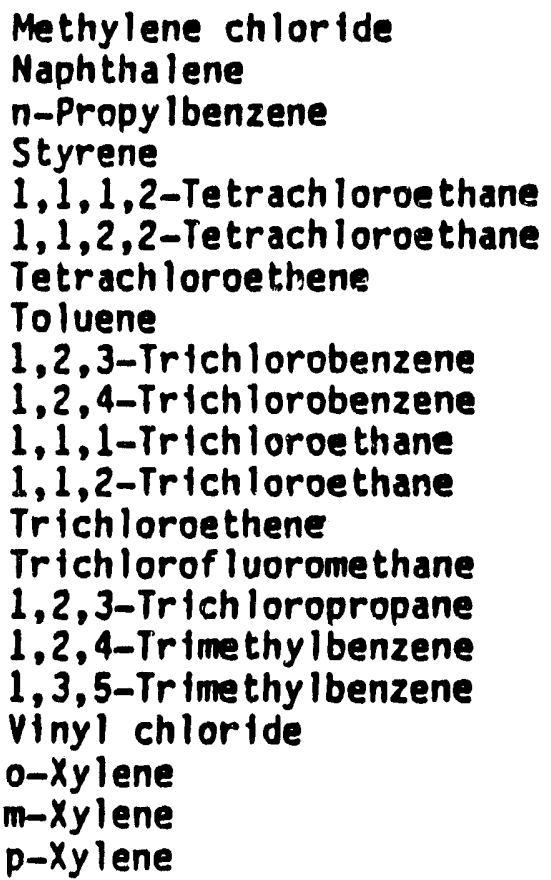 & $\begin{array}{c}102 \\
103 \\
104 \\
- \\
\overline{101} \\
99 \\
106 \\
104 \\
- \\
\overline{100} \\
- \\
\overline{99} \\
101 \\
109 \\
99 \\
100 \\
99\end{array}$ & $\begin{array}{l}\overline{6} .3 \\
2.0 \\
1.4 \\
\overline{-} \\
\overline{1} .8 \\
0.8 \\
1.9 \\
2.2 \\
\overline{-} \\
\overline{0} .78 \\
\overline{-} \\
\overline{1} .2 \\
1.4 \\
5.4 \\
0.8 \\
1.4 \\
0.9\end{array}$ & $\begin{array}{c}97 \\
- \\
- \\
\overline{99} \\
99 \\
97 \\
\overline{98} \\
102 \\
104 \\
109 \\
96 \\
96 \\
99 \\
- \\
- \\
95 \\
- \\
-\end{array}$ & $\begin{array}{l}2.8 \\
- \\
- \\
- \\
2.3 \\
6.8 \\
2.4 \\
\overline{3} .1 \\
2.1 \\
3.4 \\
6.2 \\
3.5 \\
3.4 \\
2.3 \\
- \\
- \\
5.6 \\
- \\
-\end{array}$ & \\
\hline
\end{tabular}

a. Recoveries and standard deviations were determined from seven samples spiked at $10 \mu \mathrm{g} / \mathrm{L}$ of each analyte. Recoverles were determined by internal standard method. Internal standards were: Fluorobenzene for PID, 2-Bromo-1-chloropropane for HECD.

b. Detector does not respond.

c. N.D. - not determined. 


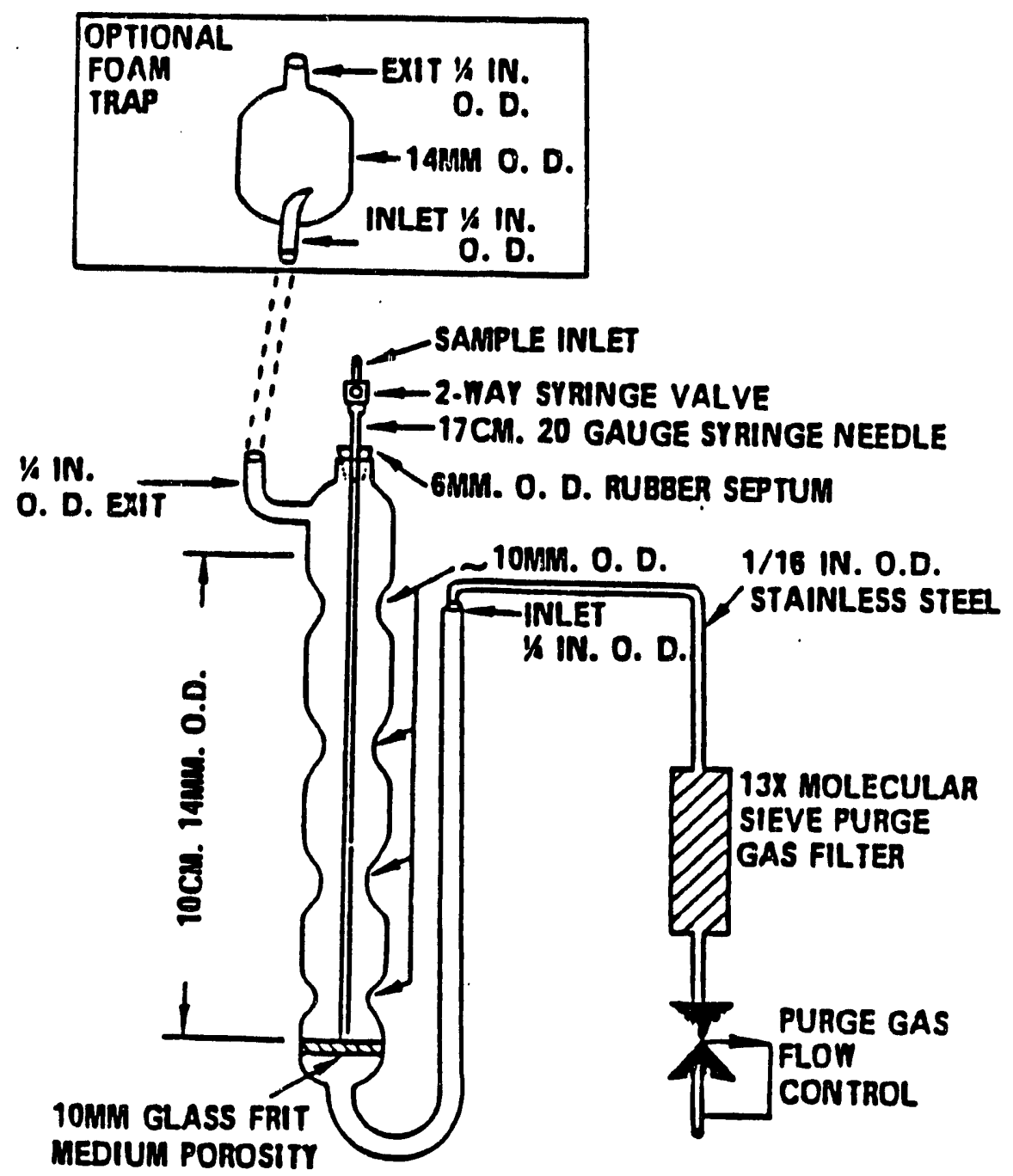

Figure 1. Purging device 


\section{$y$}

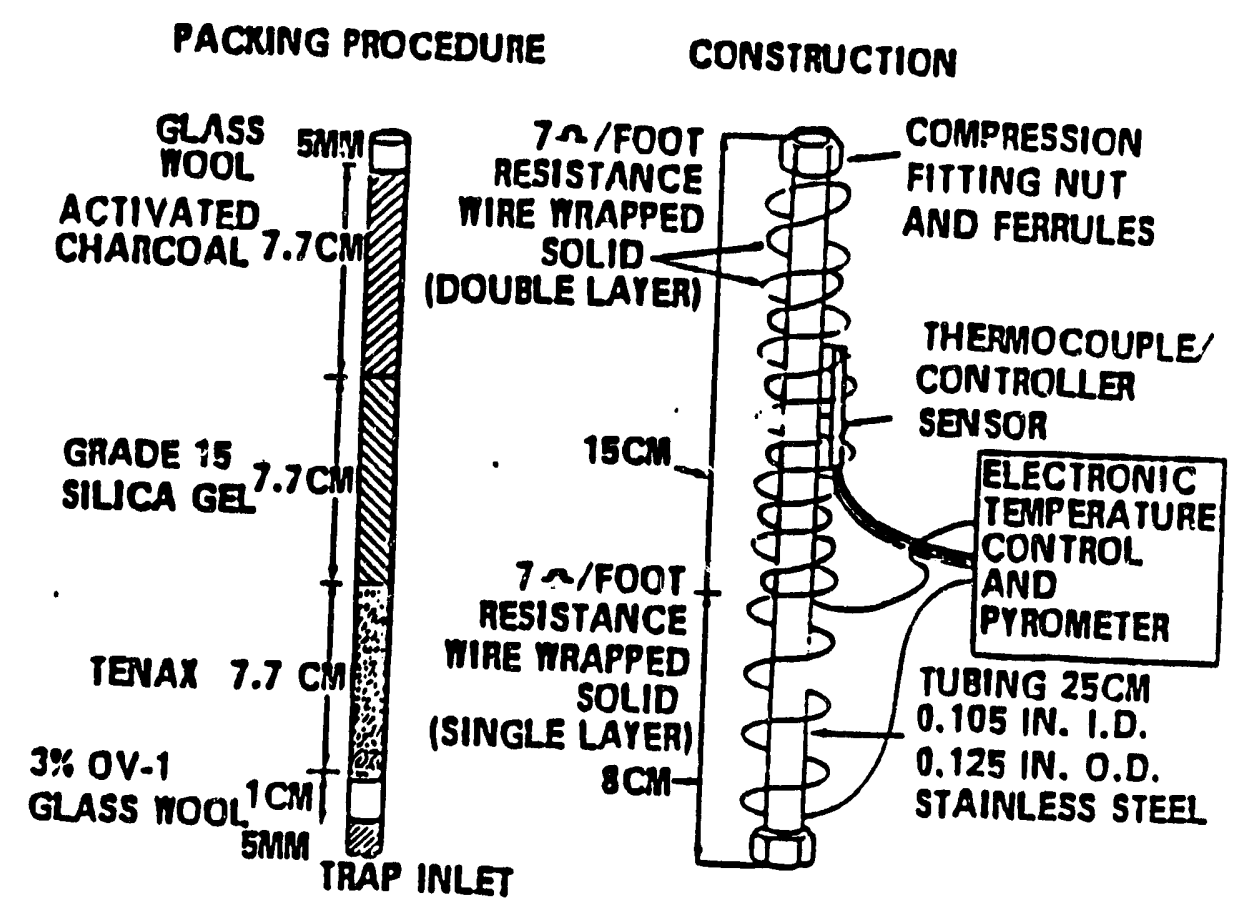

Figure 2. Trap packings and construction to include
desorb capability 


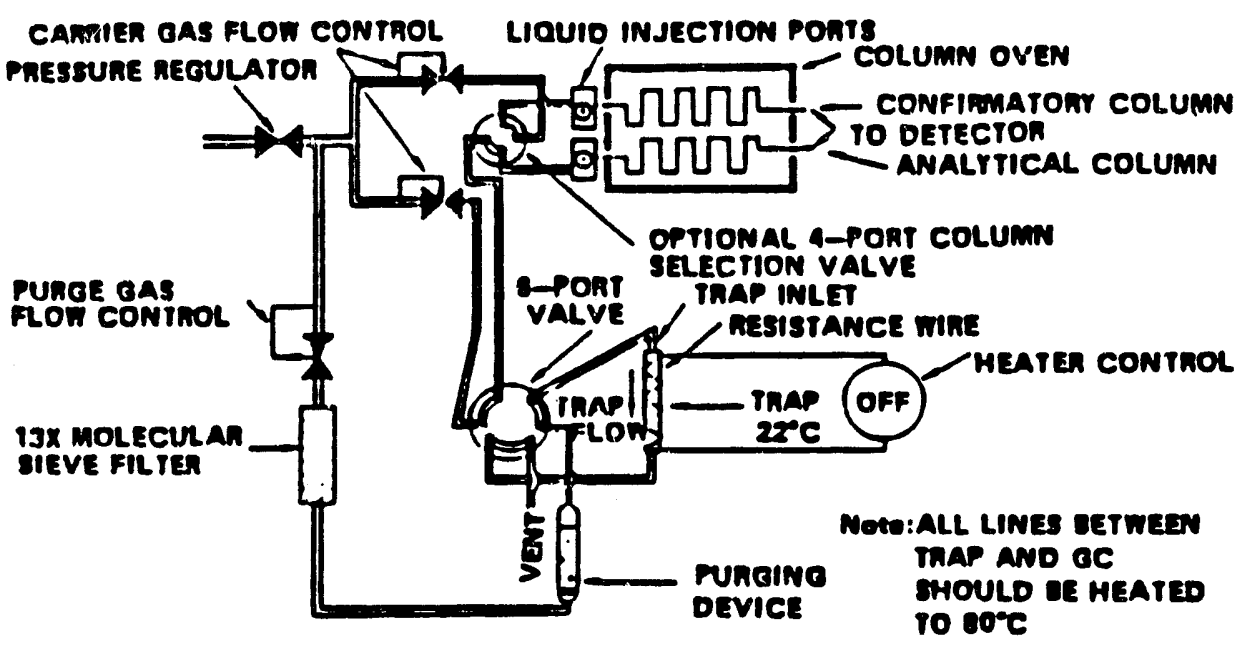

Figure 3. Purge and trap system - purge mode.

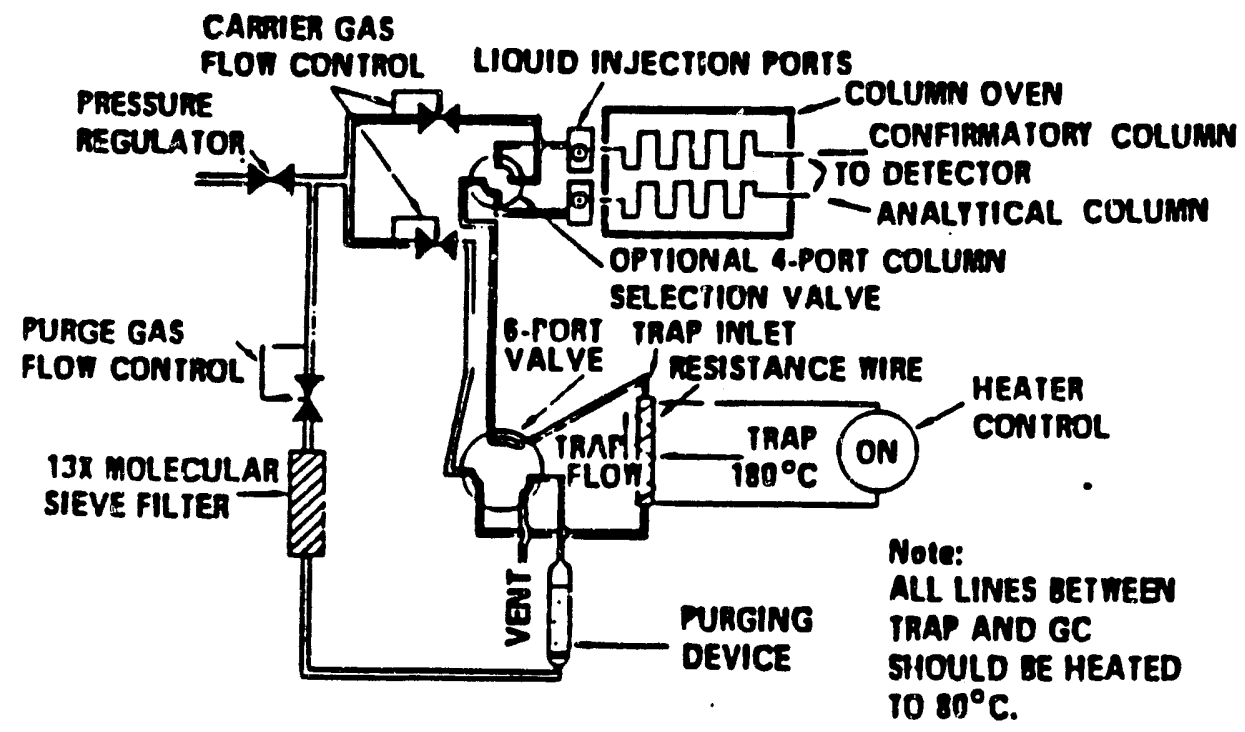

Figure 4. Schematic of purge and trap device - desorb mode 


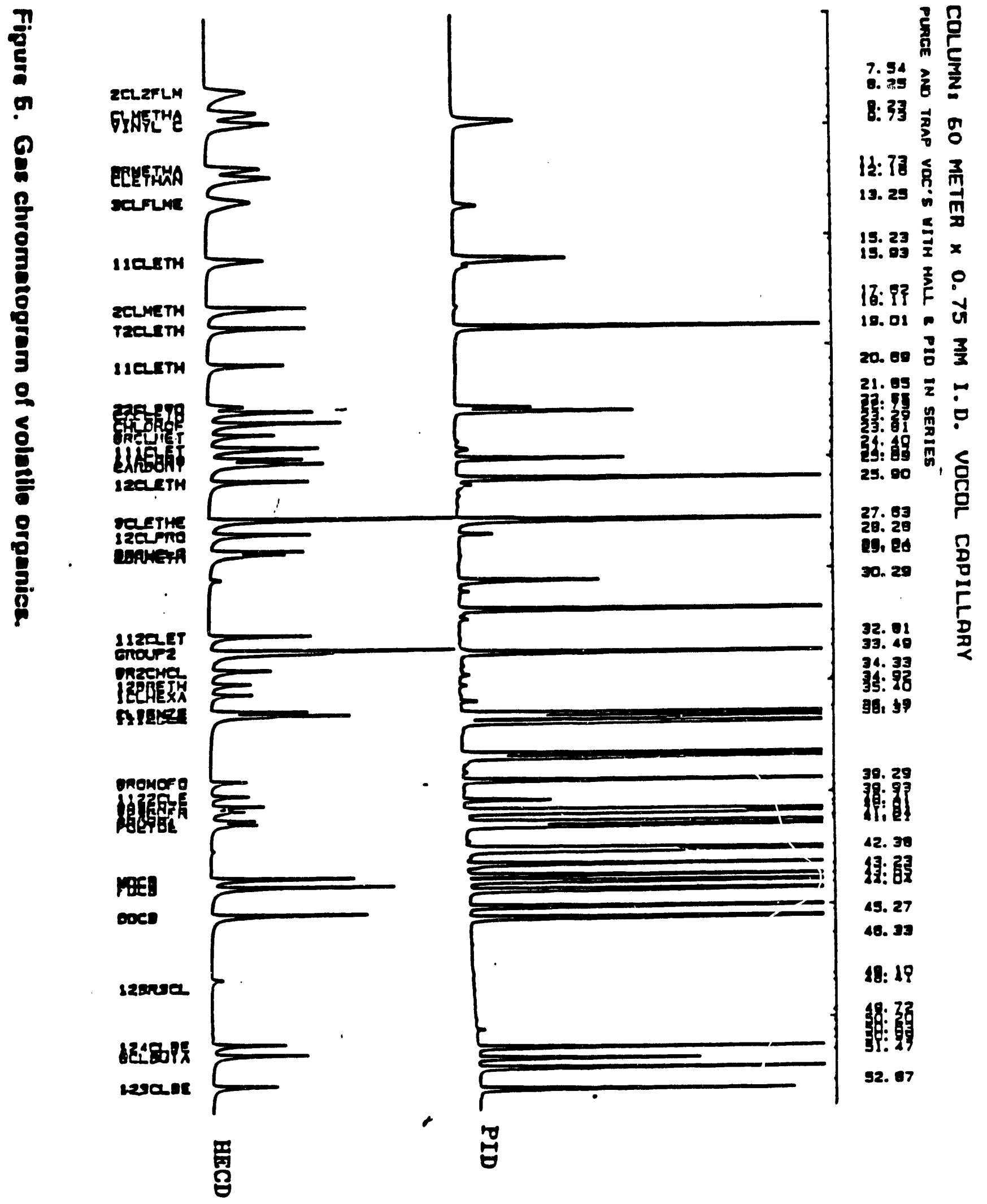




\section{Draft Method 505- For Use in WS023 Only}

\section{ANALYSIS OF ORGANOHALDEE PESTICIOES AND AROCLORS IN WATER BY MICROEXTRACTION AND GAS CHROMATOGAAPHY}

\section{SCOPE AND APPUCATION}

1.1 This method $(1,2,3)$ is applicable to the determination of the following analyes in finished drinking water, drinking water during intermedlate stages of treatment. and the raw source water.

Anary

Nection

Natrin

CAS No.

isimaten

300002

Aresine

Chiordene

$1012-240$

57.740

chone-Crivorodens"

s1007100

gemme-Cribrodene

Diddin

siost4a

0.7 .1

Endrin

$72 \cdot 2000$

Heptectiver

Hoptectiver Epouide

rentars

Hoxechloreberreme

1024573

Hoxuchlorocyelopentudiense

118.741

r.74-4

Lindene

sopes

Methoryetiloe

72-125

cientonactiver

renetrencectioer

Sinatino

Toupponens

Aroedor 1018

Arodor 1221

Aroder 1220

Nodor 1242

Noctor 1240

Arodor 1234

Aroder 1200

3iresors

122340

c001-25s

1007411.2

11104202

11141.105

5340.210

12012-206

11007 -e?

$11000-2$

1.2 PCBs are determined as Aroclors by this method.

1.3 For compounds other than the above mentioned analytes or for other sample sources, the analyst must demonstrate the appllatiblity of the muthod by collceting preciston and accuracy data on actual samples (4) and provide qualltative confirmation of results by Gas Chromatographymass Spectrometry (GCMS) (5), or by GC analysls using dissimilar columns.

1.4 Method detection IImlts (MOL) (6) for ine above organohalldes and Aroclors have been experimentalty determined (Sect.
12.1). Aclual dotectlon Ilmits are highly dependent upon the characteristics of the gas chromatographic system used (e.g. column type, age, and proper conditioning: detector condition: and injector mode and condition).

\section{SUMMLAY OF METHOD}

21 Thirty-llve $\mathrm{mL}$ of sample are extracted with $2 \mathrm{~mL}$ of hoxane. Two $\mathrm{HL}$ of the exiraci are then Injected into a gas chromatooraph equipped with a linearized electron capture detector for separation and analysia. Aqueous calibration standards are extracted and analyzed in an identical mennor in order to compensate for poselble cotraction losses.

2.2 The extractlon and analysis time is 30 to $50 \mathrm{~min}$ per sampie depending upon the andytes and the analytical conditions chosen. (Seo Sect. 5.9)

2.3 Conflimatory evidence can be obtained using a dissimilar column. When component concentrations In water samples are suiledenty high, GCMS may be employed.

\section{INTEAFEAENCES}

3.1 Impurlties contalned in the extracting solvent usually account for the majority of the analyucal problems. Solvent blanks should be andyzed on each new bottle of solvent before use. Indirect daily checks on the extracting solvent are obtalned by monltoring the laboratory reagent blanks (Sect 9.4). Whenever an interference is noted in the sample blank, the analys should andyze another sotvent blank. Low lovel Interferences generally can be removed by distilation or column chromatography (3): however, it is generally more economical to obtain a new source solvent An interference-free sotvent is a sotvent containing non-detectable peaks at the retention times of the analytes of merest

3.2 Caution must be taken in the determination of endrin since it has been reported

Method 505, Page 1, Revised 1988 
that the splitless inlector may cause endrin degradation (7). The antyct should be alerted to inis possible Interference resulting in an erratic responas for enditn.

3.3 Variable amounts of pesticides and Aroctors from aqueous solutions adhere to glass surtaces. It is recommended that sample transfers and glass surface contacts be minimized.

3.4 Ndrin and methoxychior are repldy oxidked by chlorine. Dechlorinatlon with sodium thiosuttate at itme of collection will rotard hurther exiciation of these compounds.

\section{SAFETY}

4.1 The loxiclty and careinogenicity of chemicals used in this mothod have not been proctsoly dofined: each chomical should be treated as a poteneted halth hased. and exposure to these chomiels should be minimized. Each laboratory b reaponslble for maintaining awaroness of OSHA regulatlons regarding safe handling of chemicals used in thls method. Additond references 10 laboratory eafery are evalable $(9-10)$ for the intormation of the andyat.

4.2 The following organohalldes have been tentatively classified as known or suspected human or mammalian cercinogens: aldin. Aroclors, chlordane, dloldrin, hoptachlor, hexachloroberizene, and toxaphone. Pure standard materials and stock standard solutions of these compounds should bo handled in a hood or glovebox. A NIOSHY MESA approved tode gas respirdtor should bo worn when the andyst handles high concentratlons of these toxlc. compounds.

\section{APPARATUS AND EOUIPMENT}

5.I SAMPLE CONTAINEAS - 40-mL serow cap vials (Pleree 13075 or equivalent) each equipped with a tas 24 cap with a hat disctike TFE baing backed with a polyethyien nimion exusion (Fiahw \%02-883-3F or equivalont). Prior to use, wash vials and sopen when deteroent and rinse with tap and dledilled water. Niow the vals and septa to alr on at room temperature, place the vita in a $400 \mathrm{C}$ oven for one hour, then remove and allow to cod in an area known to bo free of organios.

5.2 VIALS - auto sampler, screw cap with sepen $1.8 \mathrm{~mL}$ Vartan $196-00009900$ of coutvalent or any other autosampler vials not requiting more than $1.8 \mu \mathrm{L}$ sample volumes.

5.3 AUTO SAMPLEA - Howlett-Packard 7671A. or equivalent.

5.4 MICRO SYRINGES - 10 and $100 \mu L$

5.5 MICRO SYRINGE - $25 \mathrm{ul}$ whth a 2.inch by 0.006 -Inch needle? Hamilion $702 \mathrm{~N}$ or equivalent.

5.6 PIPETTES -2.0 and $5.0 \mathrm{~mL}$ transter.

5.7 VOLUMETRIC FLASKS - 10 and $100 \mathrm{~mL}$ olass stoppered.

5.8 STANDARD SOLUTION STORAGE CONTNNERS - 15-mL botdes with PTFE lined scrow capa.

5.9 CAS CHROMATOGRAPH - Analytiod system complete with CC suttable for use with capiliary columns and all required accessories including syinges, andytical columns, gases. detector and strpchart recorder. A data systom is recommended for measuring poak areas. Table 1 lists retention times observed for mathod analytes using the columns and andylical conditions described bolow.

5.9.1 Three gas chromatographic columns are recommended. Column I (Sece 5.9.2) should bo used as the primary analytical column uniess routinely occurring analytes are not adequately resolved. Valdation data presented in this method were obtained using this column. Columns 2 and 3 are recommended for use as confirmatory columns when GC/MS confimation is not available. Alemative columns may be used in accordance with the provisions described in Secl. 9.3.

5.9.2 Column 1 (Prtmary Column) - $0.32 \mathrm{~mm}$ ID $\times 30 \mathrm{M}$ long hused silica capillary with chomlcally bonded methyl polyslloxane phase (DB-1, $1.0 \mathrm{\mu m}$ film. or equtvalom). Hellum carrier gas how b conblished it $25 \mathrm{~cm} / \mathrm{sec}$ llnear velocty and oven tomperature is programmed from $180^{\circ} \mathrm{C} 10260^{\circ} \mathrm{C}$ at ${ }^{\circ} \mathrm{C} / \mathrm{m}$ in and hold at $260^{\circ} \mathrm{C}$ untll all uxpected compounds have oluted. A sample chomatogram for selected pesticides is presented in Figure 505-1. Chromatograms of the Aroclors. toxaphene, and technical ehlordane are presented In Flgures $\mathbf{5 0 5 - 2}$ inrough sos-10. 
DRAFT DOCUMENT - INTERNAL USE ONLY - 4/15/88

5.9.3 Column 2 (Confirmation Column) $0.32 \mathrm{~mm}$ ID $\times 30 \mathrm{M}$ long fused silica capillary with a 1:1 mixed phase of dimethyl silicone and polyethylene glyed (Durawax-DX3,0.25 $\mu \mathrm{m}$ IIIm. of equivalent). Hellum carrier gas how is extablished at $25 \mathrm{~cm} / \mathrm{sec}$ linear velocthy and oven temperature is programmed from $100^{\circ} \mathrm{C}$ to $210^{\circ} \mathrm{C}$ at $80^{\circ} \mathrm{C}$ min. and held at $210^{\circ} \mathrm{C}$ until all expected compounds have duted. Then the post cemperature is programmed to $240^{\circ} \mathrm{C}$ at $80 \mathrm{~min}$ for $5 \mathrm{~min}$.

5.9.4 Column 3 (Conflrmation Column) $0.32 \mathrm{~mm} 10 \times 25 \mathrm{M}$ long lused sillea capillary with chemically bonded 50:50 Methyl-Phenyl sillcone (OV-17, 1.5um fllm thickness. of equivalent). Hellum carriar gas flow is establistied at 40 $\mathrm{cm} / \mathrm{sec}$ llnear volocity and oven temperature is programmed from $100^{\circ} \mathrm{C}$ to $260^{\circ} \mathrm{C}$ at $4 \mathrm{C}^{\mathrm{C}} / \mathrm{min}$ and hold at $260^{\circ} \mathrm{C}$ untl all expected compounds have cluted.

Table 1. Retention Times for Method Analytes

\begin{tabular}{|c|c|c|c|}
\hline \multirow{4}{*}{ 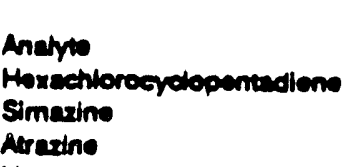 } & \multirow[b]{2}{*}{ Primery } & \multicolumn{2}{|c|}{ Artemion Timo(a). Min } \\
\hline & & Confirm. 1 & Contirm 2 \\
\hline & 3.5 & (b) & $\mid(t)$ \\
\hline & 10.9 & (0) & (ख) \\
\hline Hoxnethorobensens & 11.2 & (0) & 101 \\
\hline Unden & 123 & $\begin{array}{l}13.4 \\
18.4\end{array}$ & 156 \\
\hline Mectiler & 15.1 & 19.7 & $\begin{array}{l}18.7 \\
21,\end{array}$ \\
\hline Heptentrier & 15.9 & 17.5 & 211 \\
\hline Nodin & 17.8 & 18.4 & $\begin{array}{l}200 \\
21.4\end{array}$ \\
\hline Hoptectiver Eporide & 19.0 & 24.8 & $2+8$ \\
\hline Oernme-Criberdens. & 20.1 & (b) & (b) \\
\hline Hohe-Chlordane & $\mathbf{2 0 . 0}$ & (b) & 101 \\
\hline reme-Nonectiter & 213 & (b) & (0) \\
\hline andinn & 221 & 45.1 & 278 \\
\hline & 24.2 & 33.3 & 29.2 \\
\hline & 24.3 & (10) & (\$) \\
\hline & 300 & (0) & \\
\hline
\end{tabular}

Primary(c)

Arector 1018

Aroder 1221

Arodor $12 a 2$

Arodor 1242

Aroctor 1240

Arodor 1234

Arodor 1200

Criondune

Toxepioners

6.1.3 Sodhum chloride, NaCl - ACs Roagen Grade - For protreatmont before use, putvertze a batch of NaCl and place in a mufife humace af room temporeture. Increase the temperature to $400^{\circ} \mathrm{C}$ and hold for 30 min. Place in a bowlo and ap.

6.1.4 Sodlum thiosulfate. $\mathrm{Na}_{2} \mathrm{~S}_{2} \mathrm{O}_{3}$, ACS Reagent Grade-For preparation of solution $(0.04 \mathrm{~g} / \mathrm{mL}), \mathrm{m} \times 1 \mathrm{~g}$ of $\mathrm{Na}_{2} \mathrm{~S}_{2} \mathrm{O}_{3}$ with reagent water and bring $1025-\mathrm{mL}$ volume in a volumetric Rask.

6.2 AEAGENT WATEA - Roagont water is dofined as water froe of Interference when employed in the procadure described herein.

6.2.1 A Millpore Super-a Water System or ths equivalent may be used to generate detonized reagem water.

6.2.2 Test reagent water each day it is used by analying it according to Sect 10.

6.3 STANDARD STOCK SOLUTIONS - These

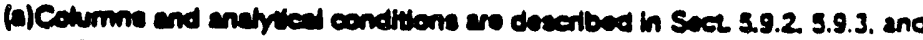
5.9.4.

(i) Not detumined.

(e)Column end condtutens deseribed in Sect 3.92 . More than one peak listec dow not lmplloses the bot mumber of poake charecteristic of the

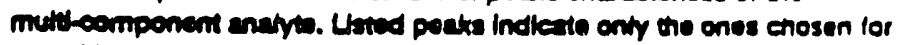
quertitileadon.

solutlons may be obtalned as certilled solutions or prepared from pure standard matertals using the following procedures:

6.3.1 Propare stock standard solutions (5000 $\mu \mathrm{o} / \mathrm{mL}$ ) by accurately welghing about $0.0500 \mathrm{~g}$ of pure matertal. Blssotve the materted in methand and dilute to volume in $10 . \mathrm{mL}$ volumotrle flask. Larger volumes can be used at the convenience of the analyse. When compound purity is assayed to be $96 \%$ or greater, the wolght can be used without correction to ealculate the concentration of the stock standard. Commerctally prepared stock standards can be used at any 


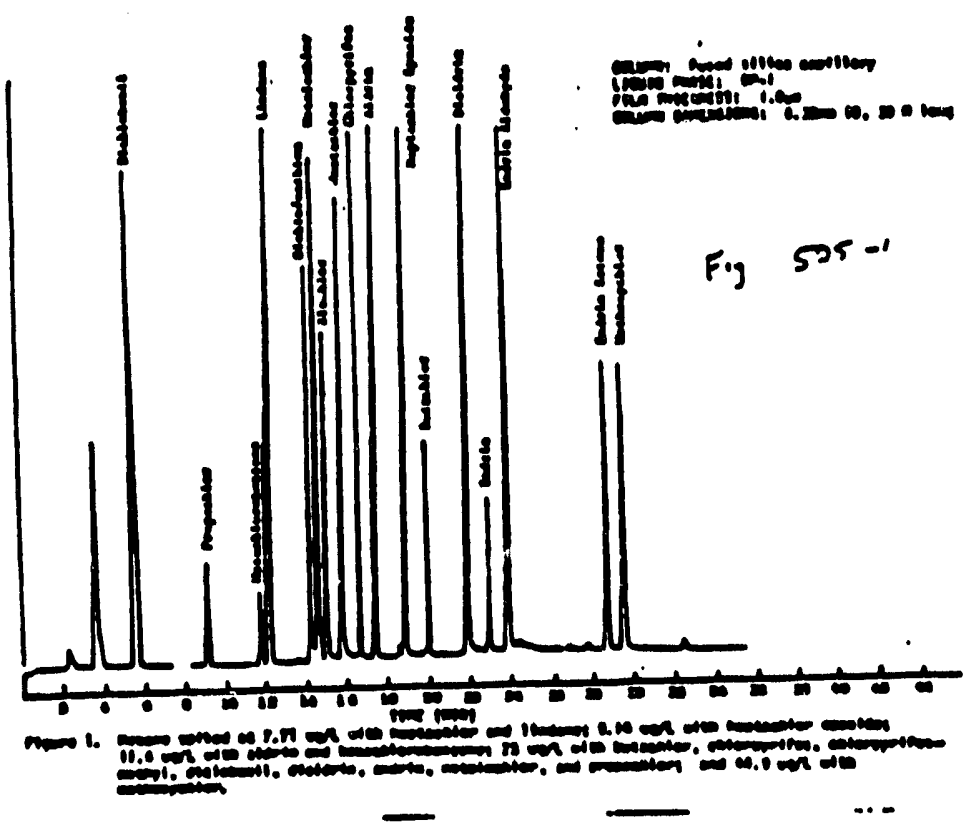

concentration 1 thoy are contuled by the manufacturep or by an Independent soures.

6.3.2 Transfor the stock standard solutions into Tollon-sealed scrow-enp bottles. Store at $4 \mathrm{C}$ and protect from light. Stock standard solutions should be checked frequently for slons of degradation or cvaporation, espectally just prtor to proparing calloratlon standards trom them.

6.3.3 Stock standard solutions must bo replaced after sbx months, or soonor 1 compartson with check standards indleates a problem.

6.4 SECONDARY DILUTION STANDARDS Use standard stock solutem to propar secondary diution standard sclutors that contain the analytes in methenol. The secondary dllution standards should be prepared at concentratlons that can be easily diluted to prepars aqueous ellioration standards (Soet. 8.1.1) that will brackot the working concentratlon range. Storo the secondary dilution standard solutlons with minimal headspece and check irequently for slons of deterloration or evaporation, espectally just betor preparting callbration standards. The storage tlme described for stock standard solvitons in Sect. 6.4.3 also applles to secondary dilution standard solutions.
7. SAMPLE COLIECTION, PAEservation, AND STORAGE

\subsection{SAMPLE COUECTION}

7.1.1 Collect all eamples in duplleate $40 . \mathrm{mL}$ bottles Into which $3 \mathrm{mg}$ of sodium inbostitate enystals have been added to the emply bottes just prtor to shipping to the eampling stro. Atermately, $75 \mathrm{~mL}$ of Ireshy prepared sodlum thiosulfate solution $(0.04 \mathrm{~g} / \mathrm{mL}$ ) may be added to empty $40-\mathrm{mL}$ botiles just prtor to sample collection. In collecting field samples, it b rucommended to add sodlum thiosuffate solviton at the sampling stie.

7.1.2 When sampling from a water tap. open the tap and allow the system to flush unt the mater temporature has stabilized (usually about $10 \mathrm{~min}$ ). Adjust the how to about $500 \mathrm{~mL} / \mathrm{min}$ and collect dupleate samples from the fowing stream.

7.1.3 When sampling from a well. IIII a wide-mouth botele or baaker with sample. and earefulty fin duplleato 40-mel sample botules.

\section{SAMPLE PRESERVATION}

72.1 The samples muse be chilled to $4^{\circ} \mathrm{C}$ at the time of collectlon and maintained at that temperature unell the analyst is prepared for the extrection process. Field 


\section{DRAT DOCUMENT - INTEANAL USE ONLY - 415/89}

samples that will not be recelved at the laboratory on the dey of callection must be peckaged for shipment with sutiletent les to Inave that they will be maintained at 4C unt antul at the laboratory.

\subsection{SAMPLE STORAGE}

7.3.1 Store samples and extracts at $4^{\circ} \mathrm{C}$ unth extraction and andycis.

7.3.2 Extract all samples as soon as possible after collection. Resutts of holding time studies seggest thet ell analytes (aidin. dleldrin, endrin, hoptachlor epoxide. hexachiorobenzene, Ilndane, and the arodors/ with the possible axception of heptachlor may be extracted within is days after collection. In general. hoptachior showed inconstetent results. If heptachlor ts to bo determined, samples must be extracted within 7 days of soltection Samples trom which analyes have not been extracted within these prescribed perlods of time must be discarded and replaced.

\section{Calubration ano standapdzation}

\subsection{CaLuBration}

Q.1.1 Al least thres callbration sandards are meeded. One should contain andyres at a concentratton noar but greater than the mothod detection limit for each compound; the other wo strould be at concentrations that bracket the range expected in samples. For example, "I the MOL is $0.01 \mu \mathrm{g} / \mathrm{L}$ and a sample expected to contain approximately 0.10 $\mu \mathrm{q}$ is to be analyzed, aqueous standards should be prepared at concentrations of $0.02 \mathrm{~kg} / 0.10 \mathrm{\mu} /$ and $0.20 \mathrm{\mu r}$

8.1.2 To prepare a callbration standard, add an approprtate volume of a secondary dilution standard to a $35-\mathrm{mL}$ allouox of reagent water in a $40-\mathrm{ml}$ bottle. Do not add less than $20 \mu \mathrm{L}$ of an alcoholle standard to the ragoent water. Uso a 25-nl micro syinge and rapidly inlect the alcoholle tandard into the middle point of the water volume. Remove the needle as quickly as possible after injection. Mbx by inverting and shaking the capped botte severd imes. Aqueous standards must be propared fresh daly.

8.1.3 Starting with the standard of lowest concentration, prepare, extract, and analyzo oach calibration standard beginning with Sect 10.2 and tabulate peak heloht of area response versus the concentratton in the standard. The results are to bo used to prepare a calibration curve for each compound by plorting the paak holght or area response versus the concentration. Alternattuely, if the ratlo of response to concentration (callbration factor) is a constant over the morking range (a relative standard devtation), linearty to the origin can be assumed and the average ratlo or callbration tactor can be used in place of a calibration curve.

8.1.4 The working callbration curve or callbratlon factor must be veritied on cach working day by the measuremerit of one or more calibration standands. II the response for an analyte varies from the predicted response by more than $=20 \%$, the lest must be repeated using a fresh ealibration standard. If the results stili do not agree. generate a new calboration curve or use a single point callbration standard as described in Sect. 8.1.5.

8.1.5 Single point callbration is an acceptable attemathe to a callbration curve. Prepare sincle point standards from the secondary dilution standard solutions. The single polnt callbratlon standard should be prepared at a concentration that produces a respones closo $( \pm 20 \%)$ to that of the unknowms. Do not use less than $20 \mu \mathrm{L}$ of the secondary dllution standard solution to produce a single point calibration standard in ragont water.

8.2 INSTRUMENT PEAFORMANCE - Check the pertormance of the entire analytical system daly using data gathered from analyses of reagent blanks, standards, duplicale samples, and the laboratory control standard (Sect 9.6).

Q.2. Slgnificant peak tailing In excess of that shown for the target compounds in the mothod chromatograms (Figures 1-10) must be corrected. Tailing problems are oeneraly traceable to active sites on the GC column, improper column installation. or the detector operation.

8.2.2 Check the precision between replicate analyses. A property operating system should perform with an average relative atandard deviation of less than 10\%. poor prectsion is generally iraceable to pnoumatic leaks, espectally at the injection port. If the GC system is apparently performing acceptably bur with decreased 
senstithity, A may be necaserery to generate a now curve or set of eallorition tactors to verthy the decreased responses.

8.2.3 Observed relattve area responses of endrin mus moet the following crtierta: endrin 50\% of rotal area.

\section{QUALITY CONTROL}

9.1 Minimum quality control (OC) requirements are Initlal demonstratton of laboratory capability, analysis of method blanks. instrumem OC solution, laboratory contro (LC) standards, OC samples, and porformance ovaluation (PE) samples.

9.2 Method Blanks. Bofore processing any samples. the analyst must demonstrate that all glaseware and reagent interferences are under control. Each tims a set of samples is extracted or rengonts are changed, mothod blank must be analyzed. If within the retention time window of any anatyte the method blank produces a peak that is 0.5 EDL for inat analyte, determine the soures of contamination and climinate the interterence betore processing semples.

9.3 Inital Demonstration of Capabiliny.

9.3.1 Solect a representallve splke concenturation (about 10 times MOL) for each analyte. Propare a LC sample concentrate (in mothand) containing each analyte at 1000 times solected concentration. Whin a syringe, add 35 $\mathrm{LL}$ of the concentrate to each of at feast four $35-\mathrm{mL}$ allquots of roagent water, and anahyes each allouot aceording 10 procedures beginning in Sect 10.

9.3.2 Calculate mean percont recovery $(x)$, and standard deviatlon of pereant recovery (S). For each anatyie, $X$ must fall in the range of 70-130\% (or whin $A+3$ ASO using the volues for $A$ and RSD for reagent water in Table 2) and $S$ must be less than $30 \%$ (or loes than $3 \times$ RSO in reagent wator in Table 2 ). If the calculated $x$ and $S$ for overy analvite meot the accoptanes erterti pertormance th accopteble and sample analysts may begin. If amy $X$ or $S$ falls outside its acceptance range, initial demonstration procedues for that compound must bo repoated.

3.4 The analys is permitued to modily GC columns, GC conditions, or detectors to improve separations or lower analytical costs. Ench tim such mithod modifications are made, the analyst must repeat the procedures in section 9.3

\subsection{Aseasing Laboratory Pertormance}

9.5.1 Intilal OC criterie are established by using the values for $X$ and $S$ generated above (Sect 9.3) to establish upper and lower control limits:

UPPER CONTROL LIMIT $=x+3 S$ LOWER CONTAOL LIMIT $=X$ - 3S

The laboratory must analyze at least one LC sample per sample sot (all samples extracted within a 24-h perlod). The epliking concentration of each analyte in the inboratory control sample should be 10 imes EDL Calculate accuracy as percem recovery (XI). If the recovery of any analyte lalls outside the control limits, that analye is judged out of control, and the source of the problem must be identified and resolved before continuing analyses. The control limits should be updated periodically. If is recomended that after each five to ten now recovery measurements that now control Ifmits be calculated using only the mox recent 20-30 data points.

9.5.2 Ench quarter the laboratory must enalyze OC check standards (if available). II erlterta provided with the OC check standard are not mot. corrective action should be baken and documented.

9.5.3 N least once a year, tho laboratory must andyze a performance cvaluation sample (if aveinble), and resutts for each analye mux be within established acceptance itrits.

9.6 Andyte Confimation - When doubt exists about Identilleation of a GC peak. confirmatory techniques such as determination with a mass spectrometer detector or a difienen GC column must be used.

\section{PROCEDURE}

\subsection{SAMPLE PAEPARATION}

10.1.1 Acmov samples from storage and allow them to equilbrate to room temperature.

10.1.2 Remove the container caps. Whthdraw and discard a $5 \cdot \mathrm{mL}$ volume using a iransfor pipot. Replace the container caps and welgh the containers with contents to the naarest $0.1 \mathrm{~g}$ and record 
these woights for subsequent sample volume deferminations (Sect 10.3).

10.1.3 Remove the contalner cap of each samplo, and add $6 \mathrm{~g}$ NaCl (Sect. 6.1.3) to the sample botte. Recap and dissotve the NaCl by inverting and shaking the botwes severd times (approx $20 \mathrm{sec}$ ).

10.2 EXTRACTION AND ANMLYSIS

10.2.1 Remove the cap, and using a transfer or auromatic dlspensing plper, add 2.0 $\mathrm{mL}$ of hexano. Recap and shake vigorousty by hand for $1 \mathrm{~min}$. Imver the botwe and allow the water and hoxame phases to separate.

10.2.2 Remove the cap and carofully transter approximately $0.5 \mathrm{~mL}$ of hoxane layer imo an autosam der vtal using a disposable glass pipol.

10.2.3 Transfer the remaining hexane phase, being carefur not to holude any of the water phase, into a second autosampler vil. Reserve this second viel at $44^{\circ} \mathrm{C}$ for an immedlate reandysis noceseary.

10.2.4 Transfer the first sample vial 10 an autosampler sot up to inject $1.2 \mathrm{~mL}$ portions into the gas chromatograph for analysts (See Sect 5.9 for GC conditons). Niemately, $1.2 \mathrm{~mL}$ portions of samples. blanks, and standards may be manually injected, although an autosampler is strongty recommended.

10.3 DETEAMINATION OF SAMPLE VOLUME IN BOTTLES NOT CALUBATED

10.3.1 Dlscard the remaining sample/hexane mbrture from the sample botte. Shake of the rermaining fow drops using short. brisk wrist movements.

10.3.2 Reweigh the empty container with original cap and calculate the not wolght of sample by difierence to the nearest 0.1 g (Sect. 10.1.2 minus Section 10.3.2). this not woight (in grams) is equivalent to the volume (in $\mathrm{mL}$ ) of water extracted (Sect 11.3).

\section{CALCULATIONS}

11.1 Identily the organohaldes in the sample chromatogram by comparing the retention lime of the suspect peak to retention ilmes generated by the callbration standards and the laboratory control standard. Identify the muticomponemt compounds using all peaks that are characteristic of the specifle compound from chromatograms generated with Indwidual standards. Select the mos senstive and reproduclble peaks for calculation. purposes.

11.2 Uso the callbratlon curve or calibration lactor (Sect. 8.1.3) to directly calculate the uncorrected concentration (C) of each analyte in the sample (e.g., callbration tactor $x$ response).

11.3 Calculate the sample volume (Vs) as equed to tho net sample weight:

$V_{9}$ - gross wolght(Sect. 10.1.2) - boltle ture (Sect. 10.3.2).

11.4 Calculate the corrected sample concentration es:

Concentration, $\mu \mathrm{O} / \mathrm{h}=35(\mathrm{C})$

(No)

11.5 Report the results for the unknown samples in $\mathrm{\mu O}$ h Round off the results to the nearest $0.1 \mu \mathrm{g} \Omega$ or two significant houres.

\section{ACCURACY AND PRECISION}

12.1 Single laboratory (EMSL-CIncinnat) accuracy and procision at several concentrations in reagent, ground, and tap water matrices are presented in Table 2.(11) These reauths were obtained from data generated with a DB-1 column.

12.2 This mathod was teated by 10 laboratories using reagent water and groundwater spiked at three concentration levels. Single operator precision, overall precision, and method accuracy were lound to be directly related to the concentration of the analyese and virtually independent of the sample matrix. Linear equations 10 descrlbe the relationships are presented in Table 3.(12)

\section{REFERENCES}

1.Glaze, W.W. Un, C.C. Optlmization of Uquid.Uquid Extraction Mothod's for Andysis of Organics in Water. EPA-600/S4-83-052, Jamuany 1984.

2.Henderson, J.E., Povion, G.P. and Glaze, W.H. (1976). In Idertification and Analysis of Organic Pollutants in Water (L.H. Keith ed.), pp. \105-111. Ann Arbor Scl Publ. Ann Arbor. Michígan. 
3.Aichard, J.J., Junk, G.A. Uquid Extraetion for Rapid Determination of Halomithanes in Wator," Jouma AWWA, 69, 62, January 1977.

4."Handbook for Andytcal Qualiy Control in Water and Wastewater Laboratories. EPA-60/4-79-019, U.S. En vironmental Protection Agency, Environmental Monitoring and Support Laboratory, Cheinnatt, Ohio. 45268, March 1979.

5.Budde, W.L. Elchelberger, J.W. Organic Analyses Using Gas Chromalography.Mass' Spectrometry," Ann Arbor Science. Ann Atoor, Michigan 1979.

6.Glaser, J.A of al. "Trace Andyeas for Wastownters." Environmental Science and Teehnology, 15, 1426 (1981).

7.Bellar, T.A. Stemmer, P. Uehtenbere, J.J., Evaluation of Capiliary Systems for the Analysis of Emvironmental Exrracts," EPA600/S4-84004, Mareh 1984.
8. Carcinogens-Working with Carchogens,"Depart. mont of Hoalth, Education, and Weltare, Publlc Heath Senvice, Conter for Disease Control, National Insthute of Oceupationd Safery and Heatth, Publleation No. 77. 206, Augue 1977.

9. OSHA Salety and Health Standands. General In. dustry (29CFR1910) Oceupational Safety and Health Adminustration, OSHA 2206. (Revised, Januar' 1976).

10. "Safoty In Academic Chemistry Laboratories." American Chernical Society Publication, Committee on Chernicel Salety, 3rd Edtion, 1979.

11. Winflevd, T. of ad "Analysts of Organohalide Pes. tcides in Dirnking Water by Mlcroaxtraction and Gas Chromatography." In preparation.

12. Muttlaboratory Method Valldatlon Siudy \#40, con. dueted by the Quallity Assurance Branch. EMSL-Cl. Report in progreses. 


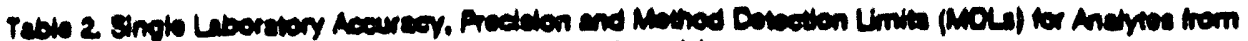

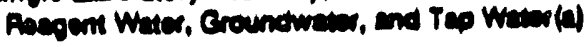

\begin{tabular}{|c|c|c|c|c|c|c|c|c|}
\hline \multirow[b]{2}{*}{ Aneme } & \multirow{2}{*}{$\begin{array}{c}\text { Motel } \\
\text { war }\end{array}$} & \multirow{2}{*}{ 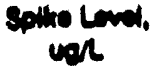 } & \multirow{2}{*}{$\underset{f(c)}{\text { nacoum }}$} & \multirow{2}{*}{$\begin{array}{l}\text { Werter } \\
\text { Rso(d) }\end{array}$} & \multirow{2}{*}{\multicolumn{2}{|c|}{$\begin{array}{c}\text { Cround Whiter } \\
9\end{array}$}} & \multicolumn{2}{|c|}{ Tep Water } \\
\hline & & & & & & & ค & ASD \\
\hline Nodrin & 0.075 & 0.18 & $\boldsymbol{\infty}$ & 11 & 100 & 11 & $\infty$ & 13 \\
\hline Areniver & 0.200 & 0.50 & 102 & 13.1 & - & - & - & - \\
\hline Mdrin & 0.007 & 0.05 & 100 & 18.8 & 8 & 120 & - & - \\
\hline Atration & 24 & $\begin{array}{r}8.0 \\
200\end{array}$ & 6 & $\begin{array}{r}19.1 \\
3.5\end{array}$ & 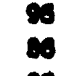 & $\begin{array}{r}7.7 \\
10.6\end{array}$ & $\begin{array}{r}100 \\
91\end{array}$ & $\begin{array}{r}10.1 \\
3.4\end{array}$ \\
\hline Nonoconiardans & 0.000 & $\begin{array}{l}0.00 \\
0.50\end{array}$ & 6 & $\begin{array}{r}2.7 \\
19.8\end{array}$ & $\infty$ & $\begin{array}{r}5.3 \\
10.8\end{array}$ & $\begin{array}{l}80 \\
91\end{array}$ & $\begin{array}{l}8.3 \\
2.8\end{array}$ \\
\hline ommme-Crierdinn & 0012 & 000 & 6 & $\begin{array}{r}0.4 \\
21.5\end{array}$ & $\begin{array}{l}\boldsymbol{c} \\
\boldsymbol{s e}\end{array}$ & $\begin{array}{r}6.2 \\
15.3\end{array}$ & 91 & $\begin{array}{r}17.7 \\
6.6\end{array}$ \\
\hline enverdene & 0.14 & $\begin{array}{l}0.17 \\
2.4\end{array}$ & $M$ & 30 & $\dot{\bullet}$ & $\dot{\bullet}$ & ${ }_{905}^{105}$ & $\begin{array}{l}11.8 \\
10.1\end{array}$ \\
\hline Dicidion & 0.012 & $\begin{array}{l}2.10 \\
2.6\end{array}$ & 114 & $\begin{array}{r}18.6 \\
20\end{array}$ & 7 & $\begin{array}{r}18.0 \\
1.1\end{array}$ & $\begin{array}{l}22 \\
11\end{array}$ & $\begin{array}{l}17.1 \\
17.3\end{array}$ \\
\hline Endin & 0.009 & $\begin{array}{l}0.10 \\
20\end{array}$ & 119 & $\begin{array}{r}240 \\
0.0\end{array}$ & 100 & $\begin{array}{l}21.5 \\
11.3\end{array}$ & $\begin{array}{r}105 \\
85\end{array}$ & $\begin{array}{l}19.2 \\
14.6\end{array}$ \\
\hline Heptectiver & $\mathbf{a . 0 0}$ & $\begin{array}{l}0.02 \\
1.2\end{array}$ & $\pi$ & $\begin{array}{r}13.3 \\
8.3\end{array}$ & $\begin{array}{l}\pi \\
71\end{array}$ & $\begin{array}{l}12.3 \\
13.8\end{array}$ & $\begin{array}{l}200 \\
100\end{array}$ & $\begin{array}{l}11.3 \\
15.8\end{array}$ \\
\hline Hoptectiver Eposides & 0.004 & $\begin{array}{l}0.04 \\
1.4\end{array}$ & $\begin{array}{l}100 \\
119\end{array}$ & $\begin{array}{r}18.6 \\
5.7\end{array}$ & $\stackrel{90}{100}$ & $\begin{array}{r}18.8 \\
6.7\end{array}$ & $\begin{array}{r}112 \\
81\end{array}$ & $\begin{array}{l}6.7 \\
\gamma .3\end{array}$ \\
\hline Hasechiverobarrems & 0.002 & 000 & 100 & $\begin{array}{r}13.0 \\
2.4\end{array}$ & $\begin{array}{r}91 \\
101\end{array}$ & $\begin{array}{r}12.0 \\
4.4\end{array}$ & $\begin{array}{r}100 \\
80\end{array}$ & $\begin{array}{r}15.8 \\
15.2 \\
9.7\end{array}$ \\
\hline Hezcectioreoydepom & no a.13. & $\begin{array}{l}0.18 \\
0.26\end{array}$ & 73 & $\begin{array}{r}7.0 \\
10.3\end{array}$ & 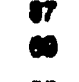 & $\begin{array}{l}5.0 \\
7.0\end{array}$ & $\begin{array}{l}191 \\
100\end{array}$ & $\begin{array}{r}9.7 \\
13.1\end{array}$ \\
\hline Unden & 2000 & Q.es & $\begin{array}{l}91 \\
111\end{array}$ & $\begin{array}{l}7.1 \\
4.3\end{array}$ & 10 & 2.0 & $\begin{array}{r}100 \\
90\end{array}$ & $\begin{array}{r}7.9 \\
19.8\end{array}$ \\
\hline Mocrangeriver & ass & $\begin{array}{l}2.10 \\
7.04\end{array}$ & $\begin{array}{r}100 \\
6\end{array}$ & $\begin{array}{l}21.0 \\
11.1\end{array}$ & : & $\dot{0}$ & : & $\dot{.}$ \\
\hline cter-ienectiver & a.er & 0.09 & $\begin{array}{r}110 \\
6\end{array}$ & $\begin{array}{l}13.0 \\
23.0\end{array}$ & $\begin{array}{r}101 \\
01\end{array}$ & $\begin{array}{r}7.1 \\
10.7\end{array}$ & $\boldsymbol{x}$ & $\begin{array}{r}15.4 \\
6.2\end{array}$ \\
\hline trane-Nonsectior & 0011 & $\begin{array}{l}003 \\
\cos \end{array}$ & 8 & $\begin{array}{l}10.1 \\
20.3\end{array}$ & 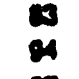 & $\begin{array}{r}2.6 \\
18.3\end{array}$ & $\begin{array}{l}73 \\
6\end{array}$ & $\begin{array}{l}3.8 \\
5.9\end{array}$ \\
\hline $\begin{array}{c}\text { Simasins } \\
.\end{array}$ & 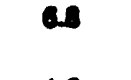 & 20 & 6 & $\begin{array}{l}2.4 \\
8.5\end{array}$ & $\boldsymbol{n}$ & $\begin{array}{r}9.5 \\
30.5\end{array}$ & $\begin{array}{r}102 \\
67\end{array}$ & $\begin{array}{r}13.1 \\
9.2\end{array}$ \\
\hline Toxaphene & 1.0 & $\begin{array}{l}10 \\
0\end{array}$ & $M$ & $\begin{array}{l}12.8 \\
15.3\end{array}$ & : & $\dot{.}$ & $\begin{array}{l}110 \\
114\end{array}$ & $\begin{array}{r}8.6 \\
11.8\end{array}$ \\
\hline Noctor 1016 & 0.00 & 1.0 & M & 8.8 & • & • & 97 & 7.7 \\
\hline Aroder 1221 & 120 & 100 & $M$ & 83 & • & • & $\boldsymbol{9 2}$ & 10.4 \\
\hline Mroctor 1223 & 0.40 & 39 & $M$ & 13.5 & • & - & 6 & Q.5 \\
\hline Nodtor 1242 & a.31 & 4.7 & $M$ & 2.0 & • & - & $\boldsymbol{\infty}$ & 7.7 \\
\hline Aroder 1240 & a.102 & $\begin{array}{l}3.6 \\
2.4\end{array}$ & $M$ & 11.8 & • & • & $\dot{n}$ & 11.8 \\
\hline Aroder l2sa & Q.10 & $\begin{array}{l}1.8 \\
1.7\end{array}$ & M & 10.4 & $\dot{\bullet}$ & $\dot{\bullet}$ & $\dot{0}$ & $13 . \dot{8}$ \\
\hline Aroder 1200 & Q.10 & $\begin{array}{l}20 \\
1.0\end{array}$ & $M$ & $\begin{array}{r}20.7 \\
-\end{array}$ & $\dot{-}$ & $\dot{-}$ & $\dot{0}$ & 18.0 \\
\hline
\end{tabular}

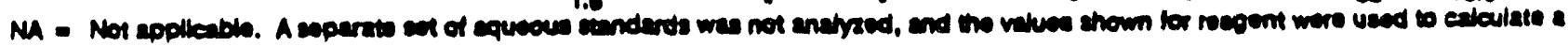
recovery for tho tho wein merte.

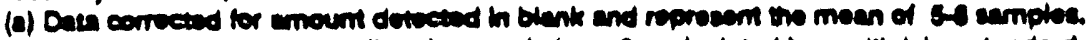

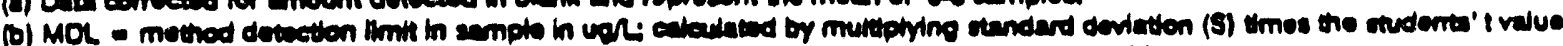

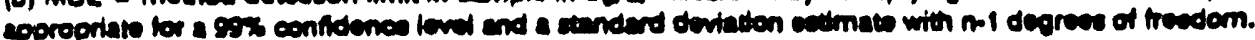

(c) $A$ - evereos pereant recovery.

(d) RSO - rellativs standard dovlation (paromil

Method 505, Page 9, Rovised 1988 
TABLE 3. Method Aceuracy and Preciaion as Functions of Concentration in Acagent Water

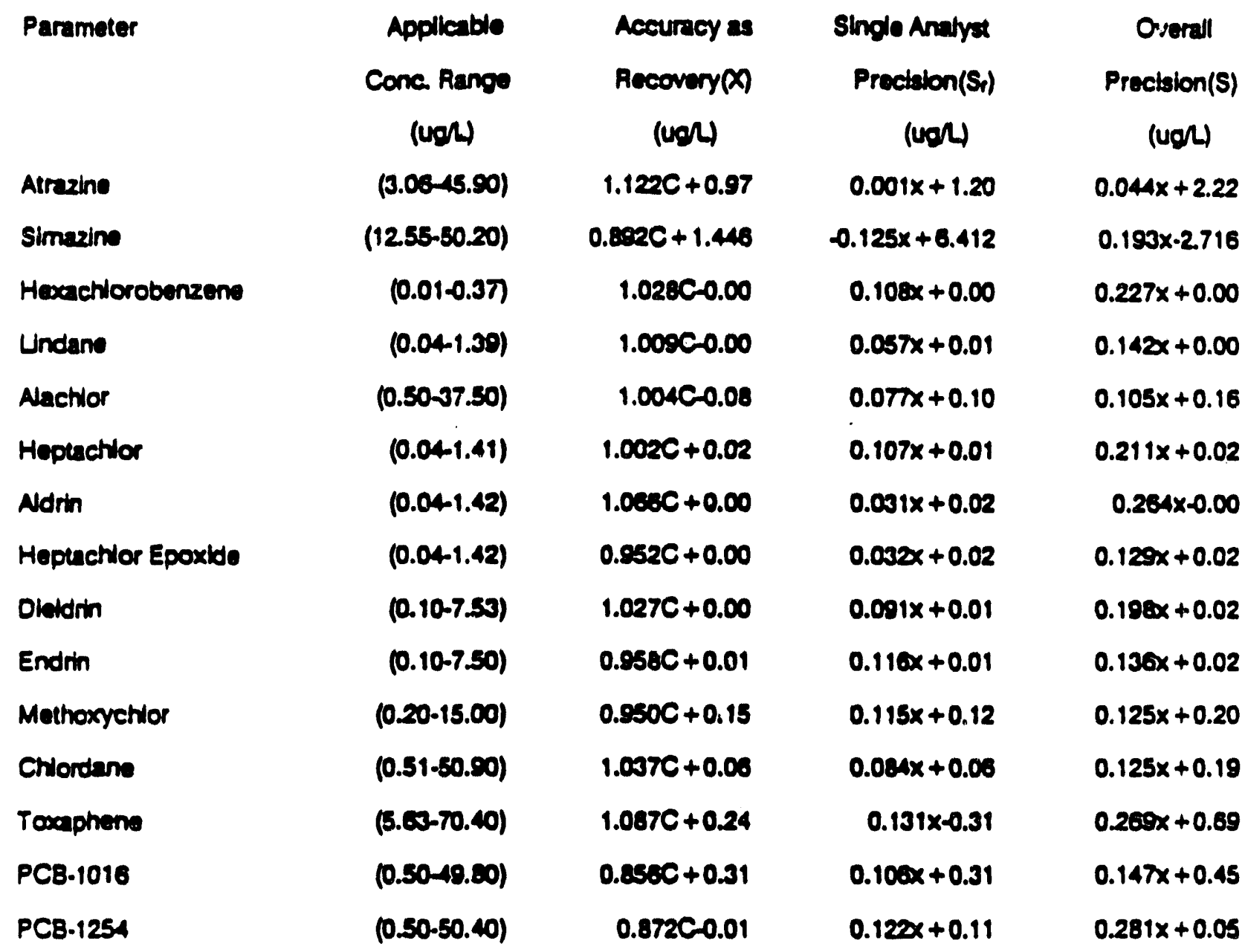



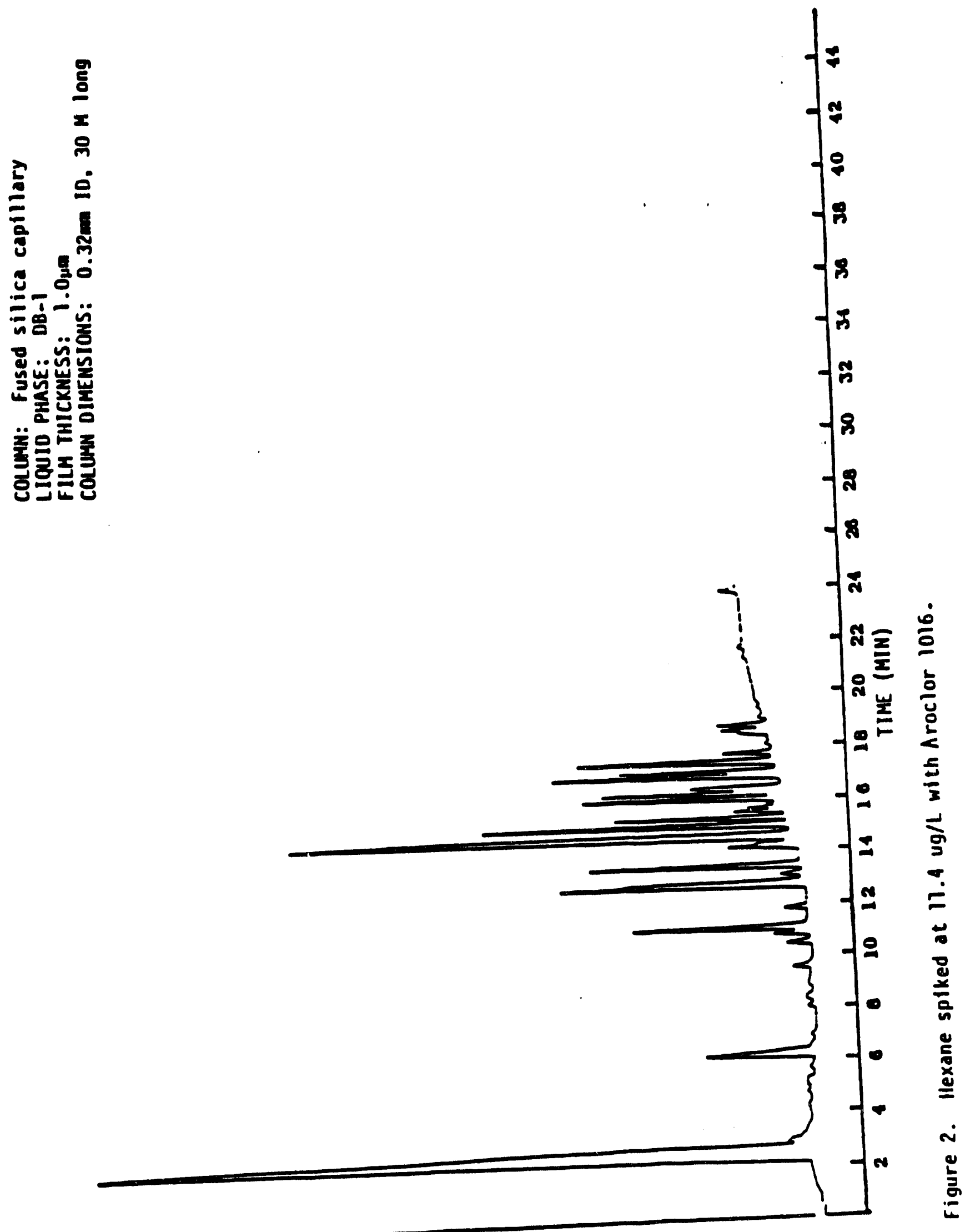


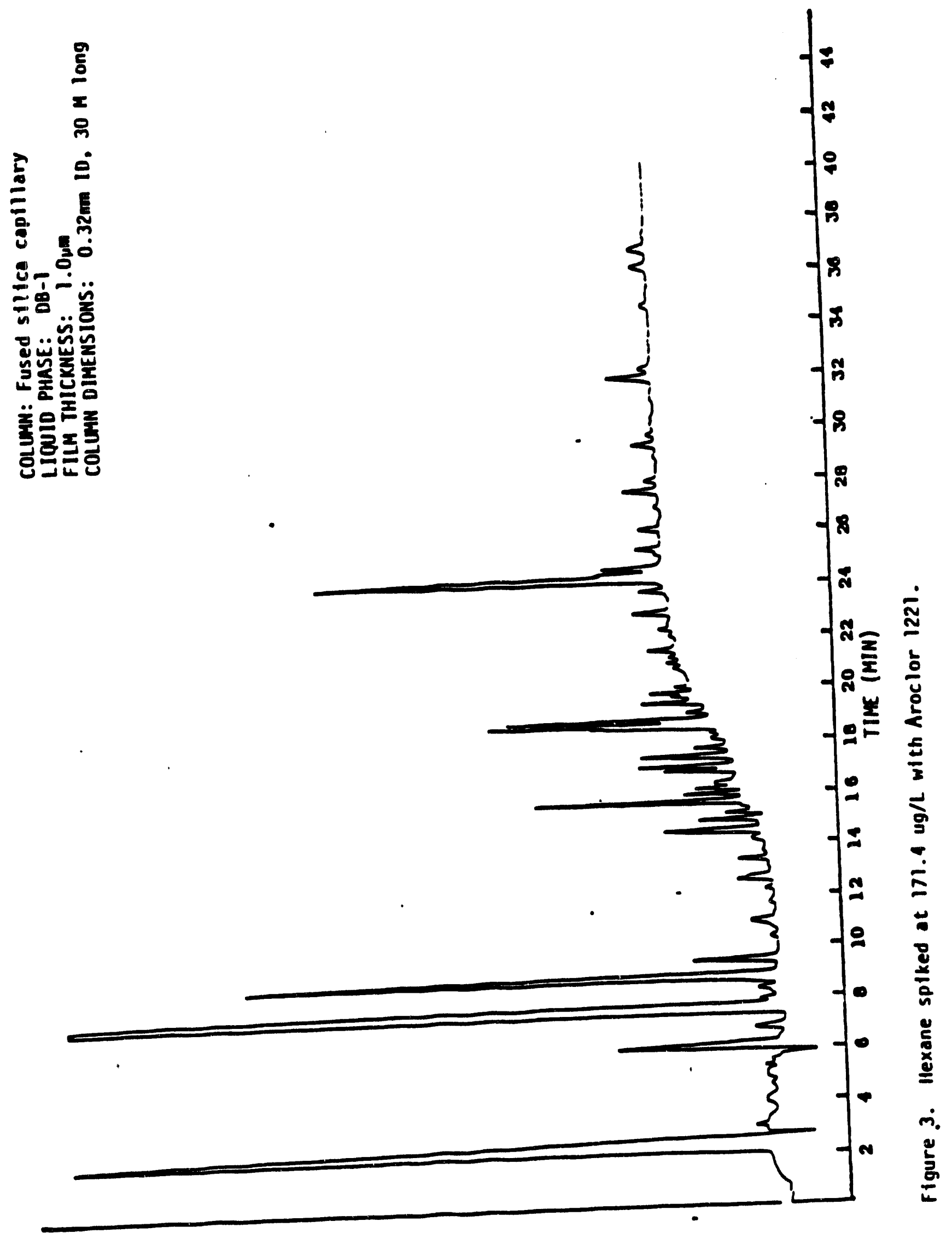



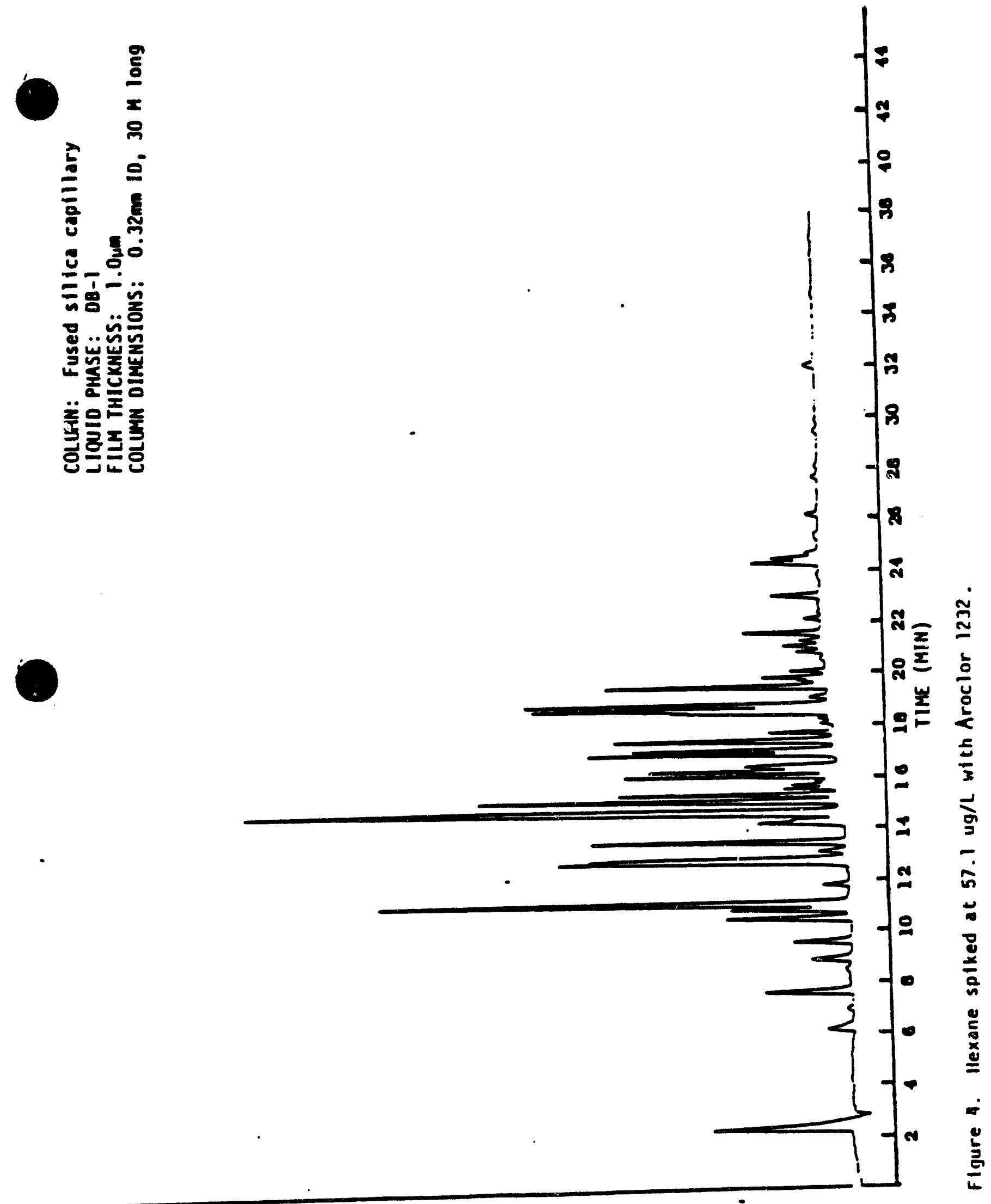

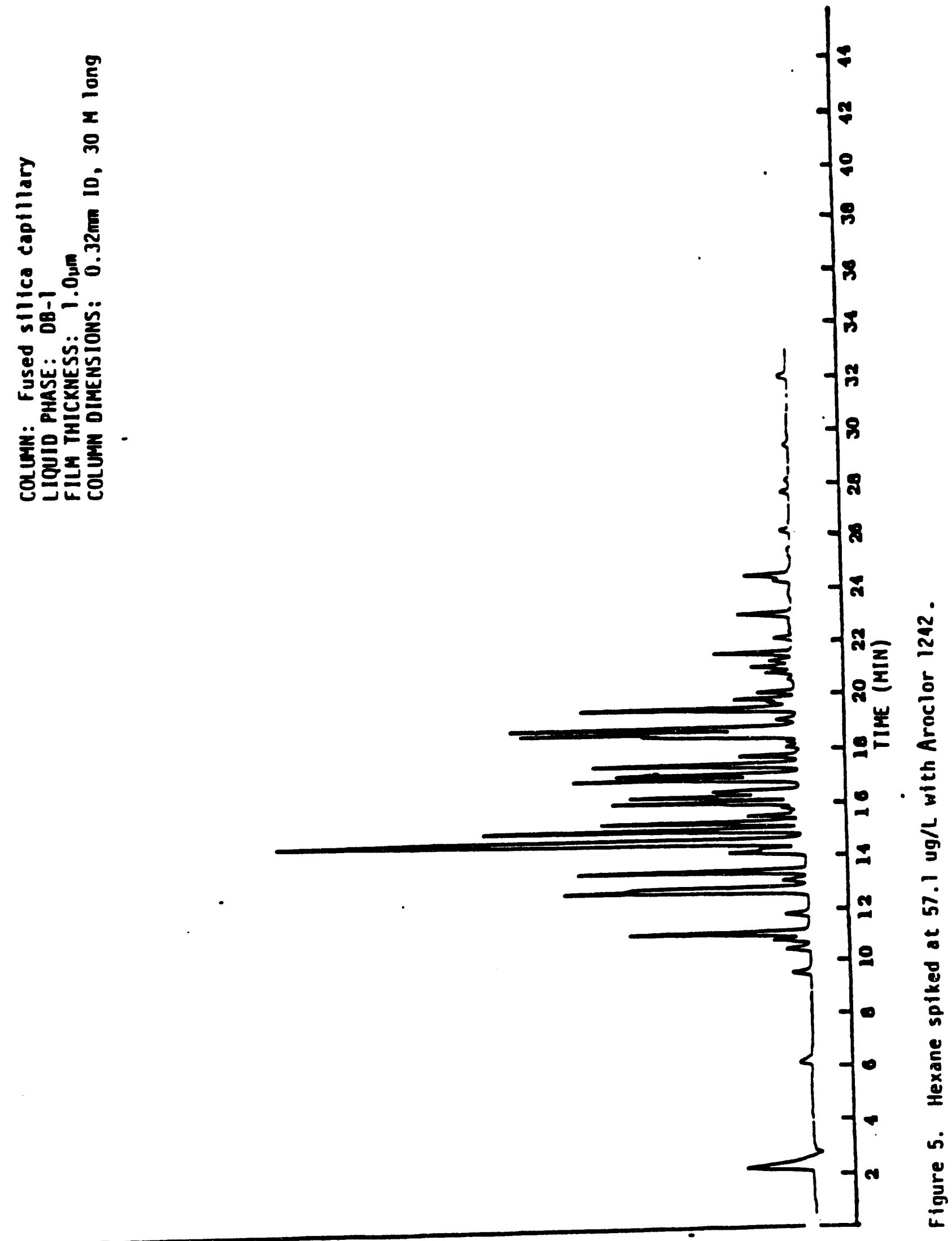

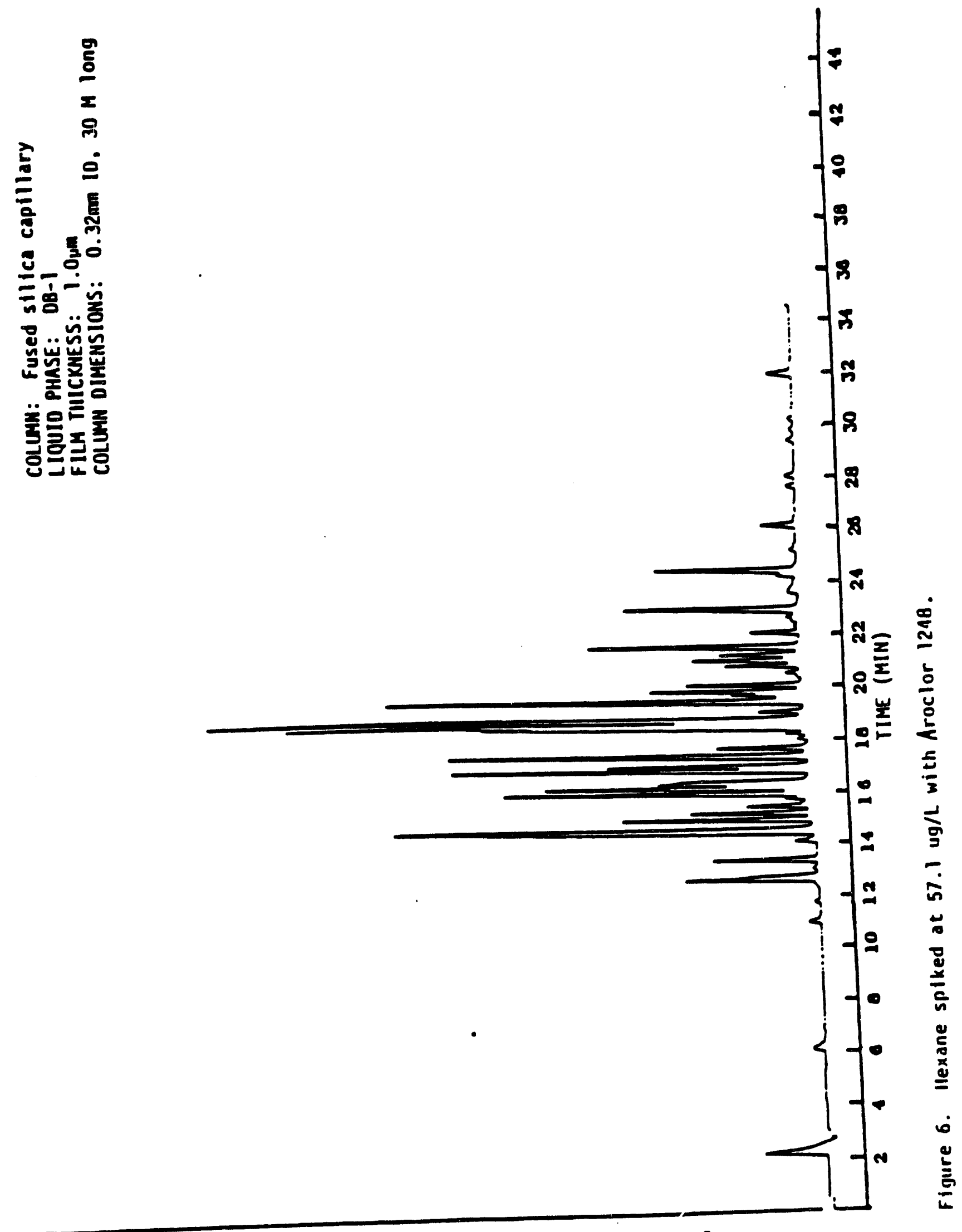

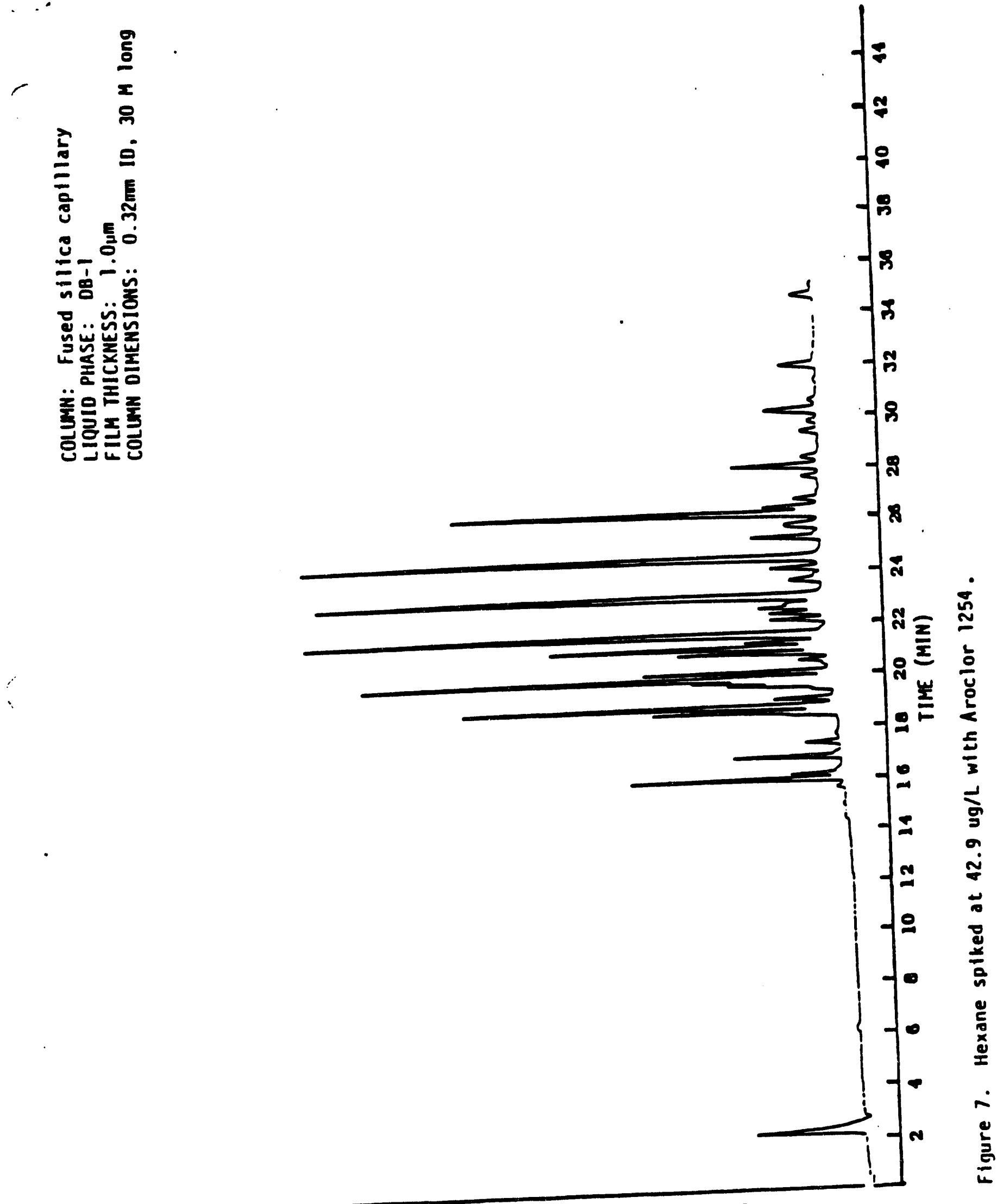


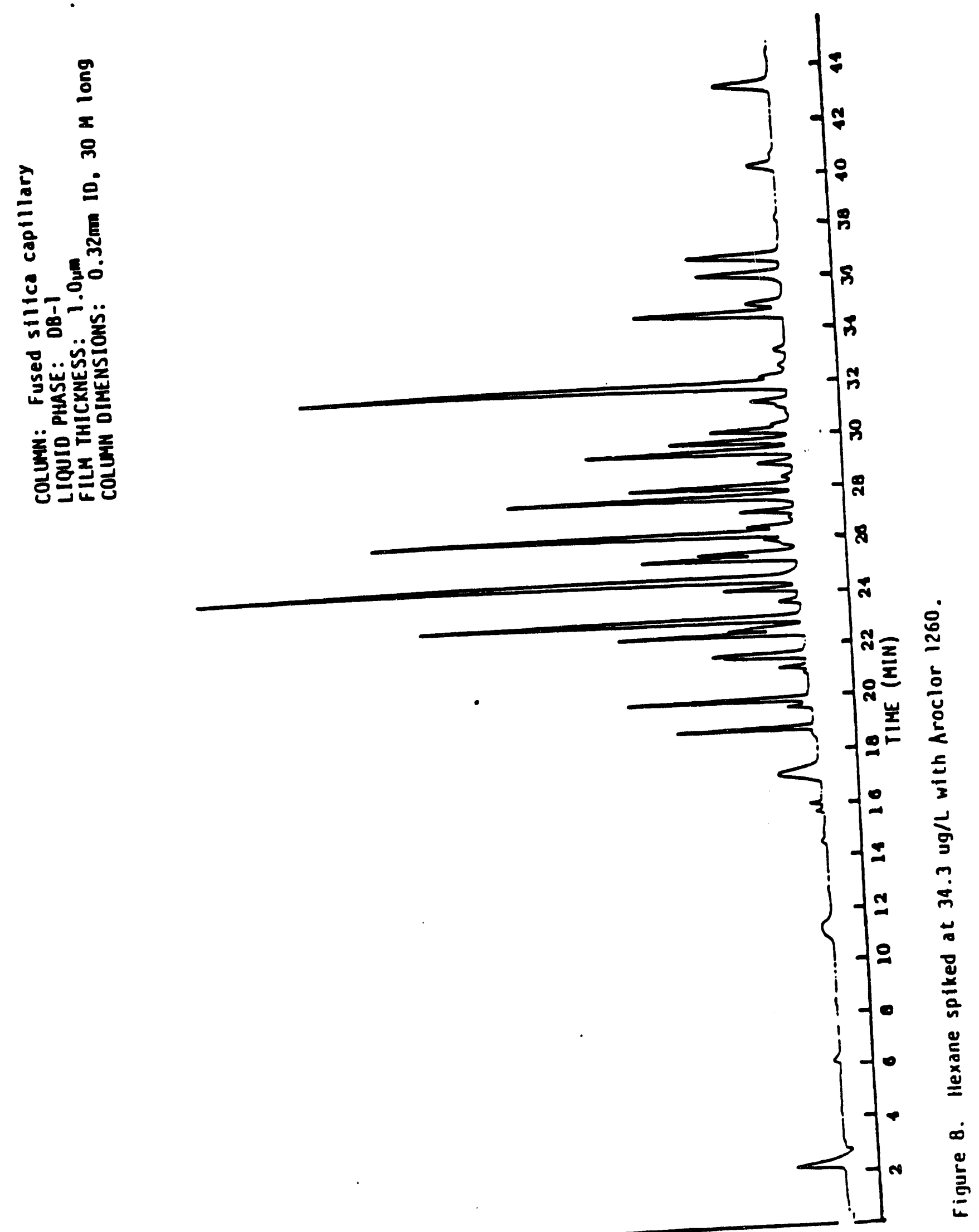



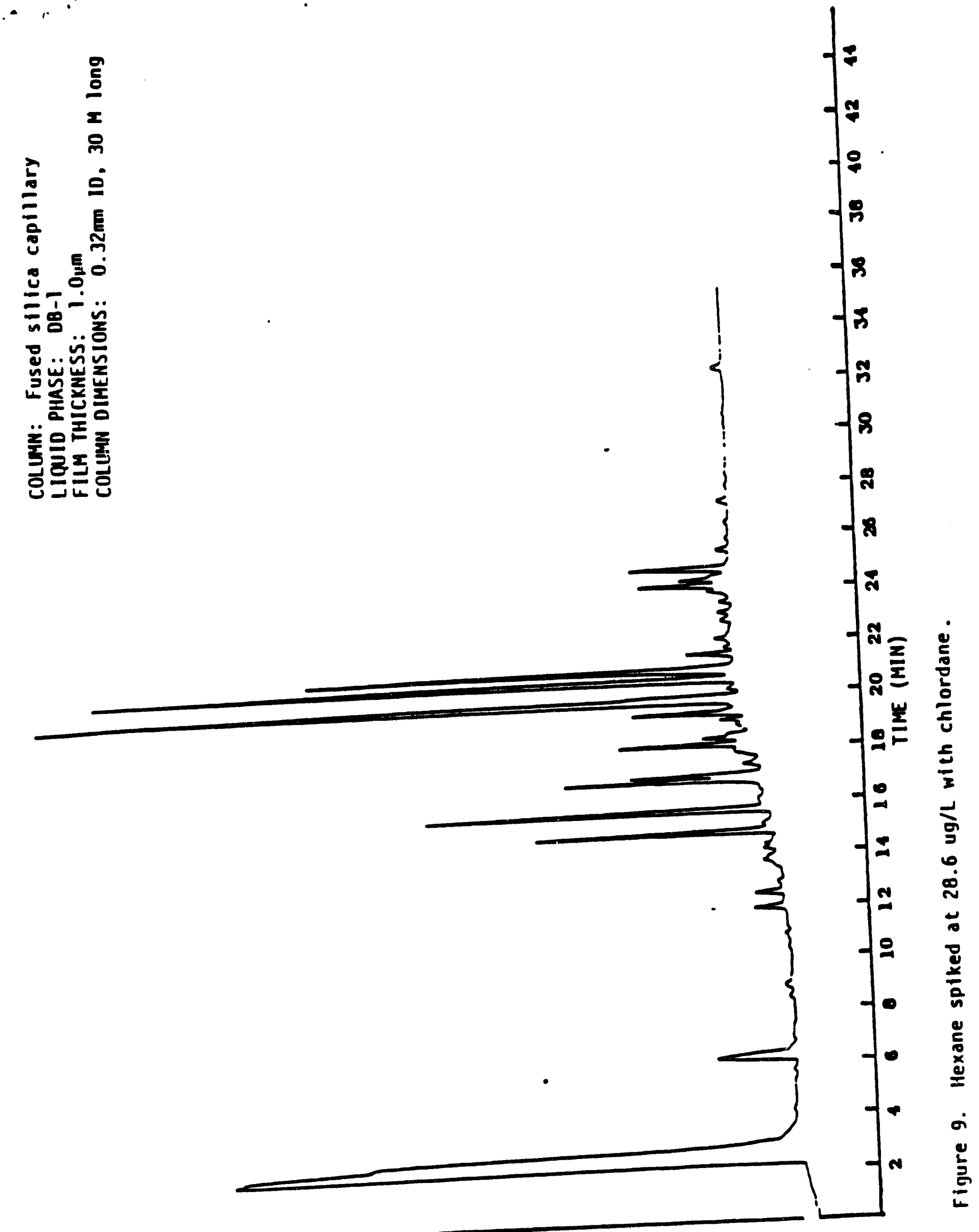

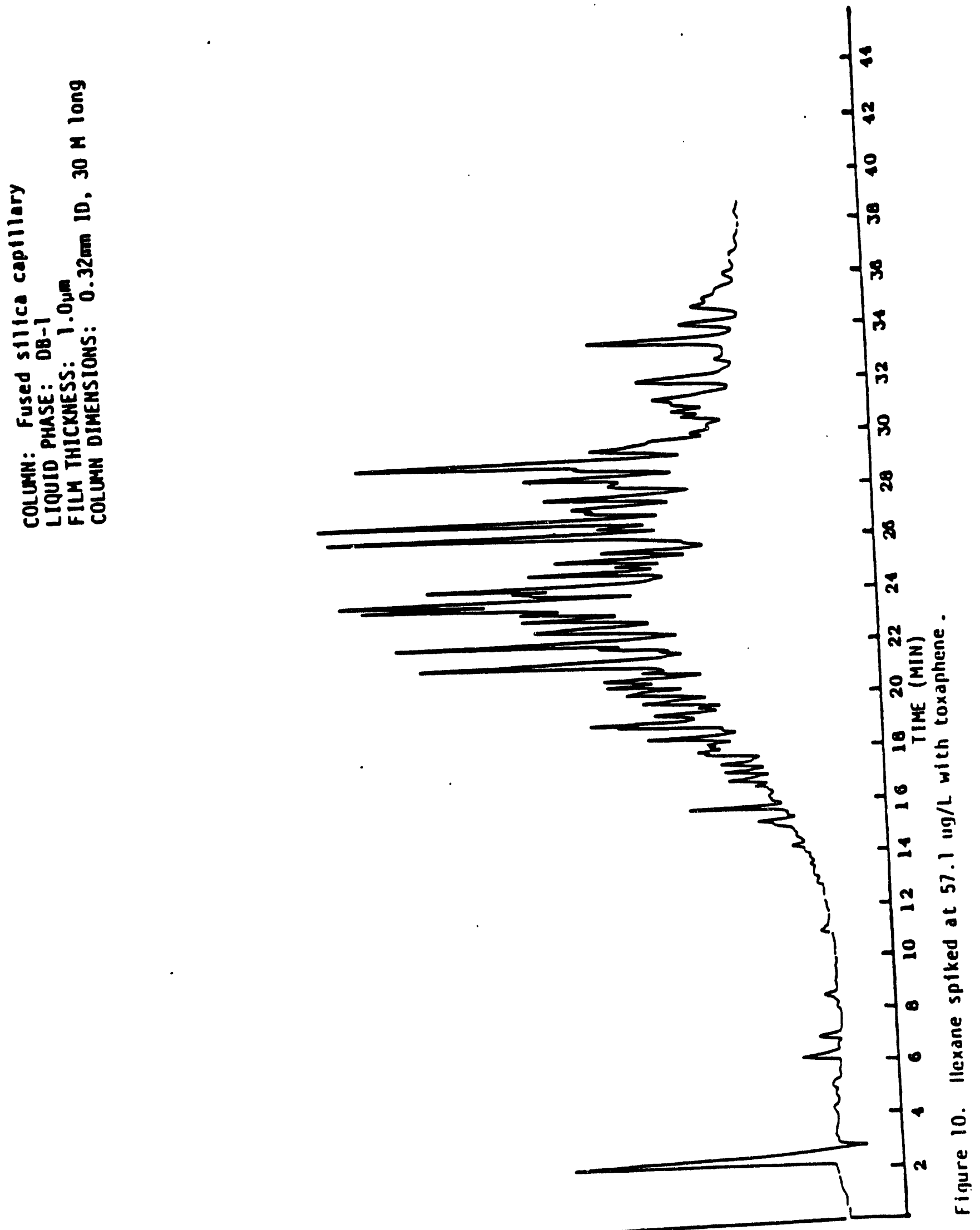


\section{Draft Method 515.1- For Use in WS023 Only}

\section{DETERMINATION OF CHLORINATED ACIDS IN WATER BY GAS CHROMATOGRAPHY WITH AN ELECTRON CAPTURE DETECTOR}

\section{SCOPE AND APPLUCATION}

1.1 This is a gas chromatographic (GC) method appilcable to the determination of certain chlorinated aclds in ground water and finished drinking water.(1) The lollowing compounds can be, detormined by this mathod:

Aneryo

CAS No.

'Meiflionten'

Bentaron."

Chioremben?

$\checkmark$ Szzo:

$\checkmark$ prapon:

12.400

, DCPA cedd motabolltes

Deamber

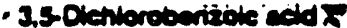

Olentorperpe

Laxioied

sthydroxydleanber??

cintreoinging

$\checkmark$ inem

Lavambe

$-2,4,54 \cdot 7=$

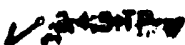
cope: DCPA disedd motnbolits used for velidation sudies.

1.2 This method may be applicable to the determination of salts and esters of analyte acids. The form of each acid is not distinguished by ihls method. Results are calculated and reported for each listed analyte as the total free acid.

1.3 Thls method has been valldated in a single laboratory and estimated detection limits (EDLs) have been determined for the analytes above (Sect.12). Observed detection llimits may vary between ground waters, depending upon the nature of Interferences In the sample matrix and the specific instrumentation used.

1.4 This method is restricted to use by or under the supervision of analysts experienced In the use of GC and in the imterpretation of gas chromatograms. Each analyst must demonstrate the abllity to generate acceptable results with this method using the procedure described in Sect. 9.3.

1.5 When this method is used 10 analyze untamillar samples for any or all of the analyes above, analyte identifications must be confimed by af least one additional qualitative technique.

\section{SUMMAAY OF NEETHOO}

2.1 A measured volume of sample of approximately $1 \mathrm{~L}$ is adjusted $10 \mathrm{pH}$ 12 with $6 \mathrm{~N}$ sodium hydroxide and shaken for 1 hour to hydrolyze derivatives. Exiraneous organic material is removed by a solvent wash. The sample is acidliled, and the chlorinated acids are extracted with ethyt ether by mechanical shaking in a separatory lunnel or mechanical lumbling in a bottle. The acids are corverted to their methyt esters using dlazomethane as the derivatizing agent. Excess derivalizing reagent is removed, and the esters are determined by GC using an electron capture detector (ECD).

2.2 The method provides a Floplsil cleanup procedure to aid in the elimination of interferences that may be encountered.

\section{INTERFERENCES}

3.1 Method Interferences may be caused by contaminamts in sotvents. reagents, glassware and other sample processing apparatus that lead to discrete antifacts or elevated basellnes in gas chromaiograms. All reagents and apparatus must be routinely demonstrated to be free from interferences under the conditions of the analysis by running laboratory mothod blanks as described in Sect. 9.2.

3.1.1 Glassware must be scrupulousty cleaned.(2) Clean all glassware as soon as possible atter use by thoroughly insing whth the last solvent used in it. Follow by washing with hot water and detergent and thorough rinsing with dilute acld. Lap and reagent water. Drain dry. 
and hat in an oven or muthe tumace af $400^{\circ} \mathrm{C}$ for 1 hour. Do not heat volumetrle ware. Thermally stable matertals such as PCBs might not be eliminated by this treatment Thorough insing with acetone may be substhuted for the heating. Aver diying and cooling. seal and store glassware in a clean environment to provent any accumulation of dust or other contaminants. Store irmerted or capped whe duminum foll.

3.1.2 The use of high purlty reagents and solvents helps to minimize interference problems. Purilleation of solvents by dtstllation in allodess systoms may bo required.

3.2 The acld forms of the analyies are strong organic acdes which renes readiy with alkailine substances and en bo lod during samplo preparallon. Gleseware and glass wool must be aeld-finsed with $(1+9)$ mydroctionic actd and the sodtum sulfate must be acldifled with sulfurle acid prior to use to evoid anatyre loseses dus to adsorption.

3.3 Organic acids and phonols, espocially chlorinated compounds. cause the most direct interterence with the determination. Akaline hydrolysts and subesusem extraction of the basle sample remove many chlorinated hydrocarbons and phthalase esters that might cothenwas interfers with the clectoron capture entyita

3.4 Interterences by phthalate ceters en pose a major problem in pesticldo analysls when using this ECO. These compounds generally appaar in the chromitogram as large peaks. Common llexible plastles contain varying amounts of phthalates, that are easlly extracted or loached during laboratory operatlons. Cross contamination of clean olaseswre routinely occurs when plastics are handled during extraction steps, espoctally when solvent-wetted surtaces are handled. Interferences from phthalates can best be minimized by avolding the use of plastles in the laboratory. Exhaustwe dearup of reaponts and glassware may bo roquired to ellminate backoround phthalate contaminaton. $(3,4)$

3.5 Imterfering contamination may cocur when a sample contalning low concentrations of analytes is anajyzed immediately following a sample containing relatively high concentrations of analyies. Between-sample pinsing of the sample syringe and assoclatod equipment with MTBE can minimize anmole cross contamination. After analysis of a sample containing high concentratlons of analytes. one or more injection of MTBE shouid be made 10 ensure that accurate values are obtained for the next sample.

3.6 Matrlx Interterences may be caused by contaminants that are cosxiracted troin the sample. The extent of matrix Interforences will vary considerably from source to source, depending upon the ground water sampled. The cleanup procedures in Sect. 10 can be used to cvercome many of these interlerences. Posthe Idemilications should be contirmed using the conflimation column specilled in sect 5.10 .2

\section{SAFETY}

4.1 The toxlelty or carcinogenicity of each reagent used In this method has nol been precisely defined; however, each chemical compound must be troated as a potentlal health hazard. From inis vlewpolnt. exposure to these chemicals must be reduced to the lowest possible level by whatever means available. The laboratory is responstble for maintaining a current awareness tile of OSHA regulations reoarding the sale handling of the chomicals specifled in this method. A reference ille of materlal safety data shoets should also bo made available to af personned imvotved in the chemical andycts. Additional references to laboratory alety are avallable and have been identified (5-7) for the Iniormation of the anatyst

4.2 Dlazomethane is a toxic carctinogen and can explode under certain conditions. The following precautions must be followed:

4.21 Use only a wall ventllated hood - do not breath vapors.

4.22 Use a satety sereen.

42.3 Use mechanical plpetting aides.

4.2.4 Do not heat above sOC - EXPLOSION may reactit.

4.2.5 Avoid grinding surfaces, ground glass joints, sleeve bearings, giass stirters DXPLOSION may result

4.2.6 Store away from alkall metals -: DXPLOSION may resute 
DRAFT DOCUMENT - INTERNAL USE ONLY - 4/1B/EO

4.2.7 Solution of dlezomethane decompose raptetly in the presences of solid matertals such as copper powder, calctum chilorida. and bolling chipe.

...

4.2.8 The dlazomethane generation apparatus used in the estorfilcation procedures (Sect. 10.4 and 10.5) produces mieromolar amounts of diazomothane 10 minimize entely havands.

4.3 Ethyl other is an extromely flammable sotvent If a mechanical devies b used for sample extraction the device should be equipped with an explosion-proof motor and placed in a hood to avoid posatble damage and injury dus to an explocion.

5. APPARATUS AND EOUIPMENT (AN spectineations ars suggosted. Catalog numbers aro included for lllustration only.)

5.1 SAMPUNG EOUIPMENT

5.1.1 Grab sample botwe - Borosilkato. 1t volume with graduatlons (Wheaton Media/Lab botile 219820), filted with serew caps lined with TFE fluorocarbon. Protect samples from lighte. The container must be washed and dried as described in Sect. 3.1.1 bolore use to minimize comamination. Cap liners are ext to it from sheets (Pleres Catalog No. 012730) and extrected when methand ovemight pror to use.

\subsection{GLASSWAFE}

5.2. Separatory lunnel $\because 2000-\mathrm{mL}$, with TFE-nuorocarbon stopcocks, ground glass or TFE-fluorocarton stoppers.

5.2 .2 Tumbler botwl - 1.74 Wheaton Roller Culture Vessel), whi TFE-fluorocarbon lined serew cap. Cap liners are cut to fit trom shoets (Plerce Cafalog No. 012736 ) and exirected with methand overnight prior to use.

5.2.3 Concentrator tube, Kudeme-Danish (K-D) - 10- or $25-\mathrm{mL}$, graduated (Kontes K-577050-2525 or Kontes K-570050-1025 of equivalent). Callbration must be checked at the volumes employed in the tase Ground glass stoppers are used to prevent evaporation of extracts.

5.2.4 Evoporatwo lask, K-O - 500-mL (Komtes K-570001-0500 or equivalent). Artach to concentrator tube with springs.

5.2.5 Smyder column, K-D - threo-ball macro (Kontes K-503000-012 or equivelent).
5.2. Snyder column, K-D - no-ball micro (Kontes K-sec00t-0219 or equivalent).

5.2.7 Fask, round-bottom - 500 mL with 24/40 ground dase joint.

5.2.8 Vals - glass, 5- to 10-mL capacity with TFE-fluorocarbon lined screw cap.

5.2.9 Dlsposable plpets .. sterlle plugged borosillcate glass, $5 \cdot \mathrm{mL}$ capacity (Coming 7078-5N or equivalent).

5.3 Separatory funnel shaker .. Capable of holdino cight $2 L$ separatory tunnels and shaking thom with rocking motion 10 achieve thorough mixing of separatory funnel contents (avallable from Eberbach Co. in Ann Artor. MiI).

5.4 Tumbler - Capable of holding 4106 tumbler botlles and tumbling them ond-ovor-end at 30 turns/min (Associated Desion and Mig. Co., Nexandria. VA).

5.5 Boilng stones - Tellon. Chernware (Norion Pertormance Plastics No. 015021).

5.6 Water bath -. Heated, capable of comporature control $\left( \pm 2{ }^{\circ}\right.$ ). The baln should be used in a hood.

5.7. Bdance - Andytical, capable of accurately woighing to the nearess $0.0001 \mathrm{~g}$.

5.8. Dlazomethans generator - Assemble from two $20 \times 150 \mathrm{~mm}$ iest tubes. iwo Neoprene rubber stoppers, and a source of nivrogen as shown in Figure 515.1.1 (avallabie from Aldrich Chomical Co.). When esterlfication is performed using dlazomothane solution, the diazomethane collector is cooled in an approximately 2-L thermos for ke bath or a cryogenically cooled vessel (Thermoelectrics Unilimited Moded SK-12 or equivalent).

5.9 Glass wool .. Acld washed (Supelco 2.0383 or equivalent) and heated at 450 C for 4 hours.

5.10 GAS CHROMATOGRAPH - Analytical system complete whth GC suitable for use with capilary columms and aff required accessories holuding syninges, analytical columns, gases. delector and stripchan recorder. A data system is recommended for measuring peak areas Table 1 llists retention times observed for method analytes using the columns and analytical condtilons described below.

5.10.1 Column 1 (Primary column) - $30 \mathrm{~m}$ long $\times 0.25 \mathrm{~mm}$ 1.D. DQ.5 bonded hused silica column, 0.25 um film thickness (available 
Tablo 1. Acteriton Timas for Method And yee

Ammientrino(4)

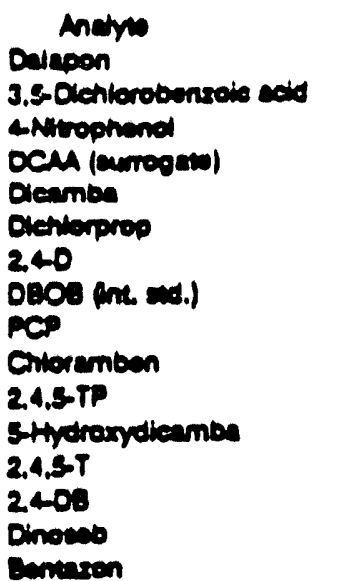

Conmin.

4.7

17.7

20.

14.8

2.

20

20

27.0

270

20

2.

30.7

30

322

34

34.6

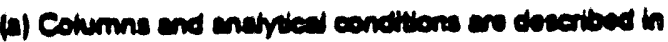
Soe 3.10 .1 and 8.102
2. RENOENTS ANO CONSUMABLE MATEALALS

6.1 Acotorie. mothanol, mothylene chloplde. MTBE - Peatledo qually or equivalem.

6.2 Elhyl other, unpreserved .. Nanograde. redtidlled in gies nocessary. Must be iroe of peroxides as Indleated by EM Ouan tose stripe (avalable from Sclentific Products Co. Cat. No. Pl126.8, and other suppllers). Procedures recommended for romoval of perexides are provided whth the lest etrips.

6.3 Sodlum sultate, granular, snhydrous. ACS grade .. Heat iroat in a shallow Iray at $450{ }^{\circ} \mathrm{C}$ for a minimum of a hours to remove interfering organic substances. Actdly by durying 100 a sodium sulfate with onough othyl other to just cover the solld. Add $0.1 \mathrm{~mL}$ concentrated sutfurte acid and $m b x$ thoroughly. Remove the other under vacuum. Mix, 0 of tho reacuting eolld with $5 \mathrm{~mL}$ of reagent water and measure the $\mathrm{pH}$ of the mberure. The PH must be below PH 4 . Store if 1300 C.

6.4 Sodlum thiosultate, granular, anhydrous. ACS grade.

Irom J8Wy. Hellum carries gas flow is established at $30 \mathrm{~cm} / \mathrm{esc}$ linar velocthy and oven temperature is programmed from $60^{\circ} \mathrm{C}$ io $300^{\circ} \mathrm{C}$ a $44^{\circ \mathrm{C}} \mathrm{mini}$. Valdation data prosented in this mothod wore obtained using this column. Nromative columns may be used in aceordance whth the provisions deacribed in Sect." 0.2

5.10.2 Column 2 (Confimation column) - 30 $\mathrm{m}$ long $\times 0.25 \mathrm{~mm}$ 1.0.08-1701 bonded hused sllea column, 0.25 um film thickness (nvilable from J\&W. Hellum carrior gas how is established at $30 \mathrm{~cm}$ sec linear velocity and oven temperature is programmed from 60"C to $300^{\circ} \mathrm{C}$ a $4 \mathrm{C} / \mathrm{min}$.

5.10.3 Dotector - Eectron capture. This detector has proven effective in the analysis of splked reagent and artinetal ground weters $A$ n ECD was ueed to gomirate the validation dat pruaented in this mothod. Niornatwo detectors. including a mass spoctrometer. may be used in accordance whith the provisions described in Sect. 9.3.
6.5 Sodium mydroxide (NaOH). Dellets - ACS

6.5.1 $\mathrm{NaOH}_{1} 6 \mathrm{~N}$ - Dissotve $216 \mathrm{~g} \mathrm{NaOH}$ in $900 \mathrm{ml}$. reagent water.

6.8 Suturite actd $\left(\mathrm{H}_{2} \mathrm{SO}_{4}\right)$, concentrated, ACS gredo - sp. or. 1.84.

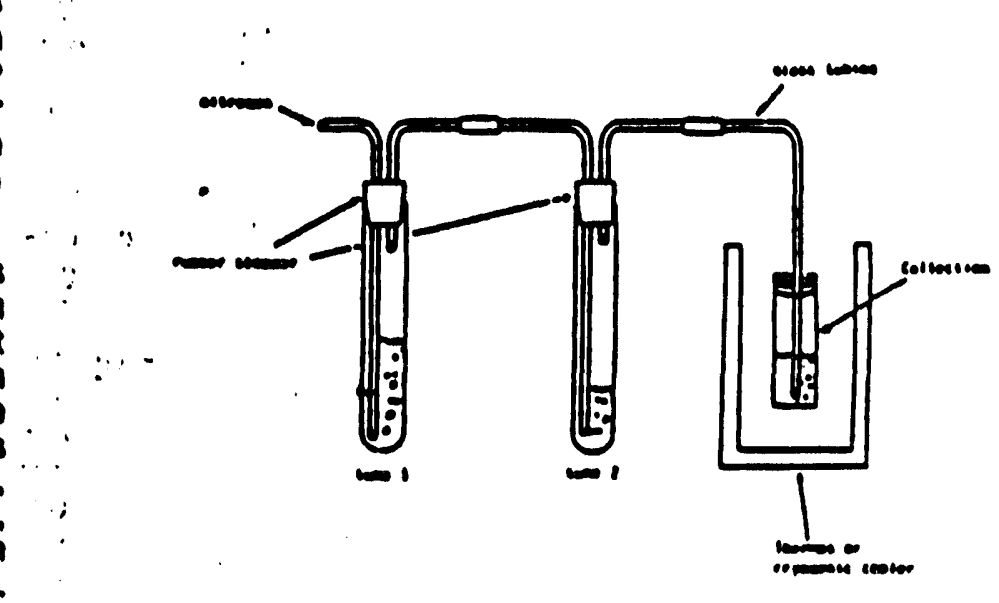




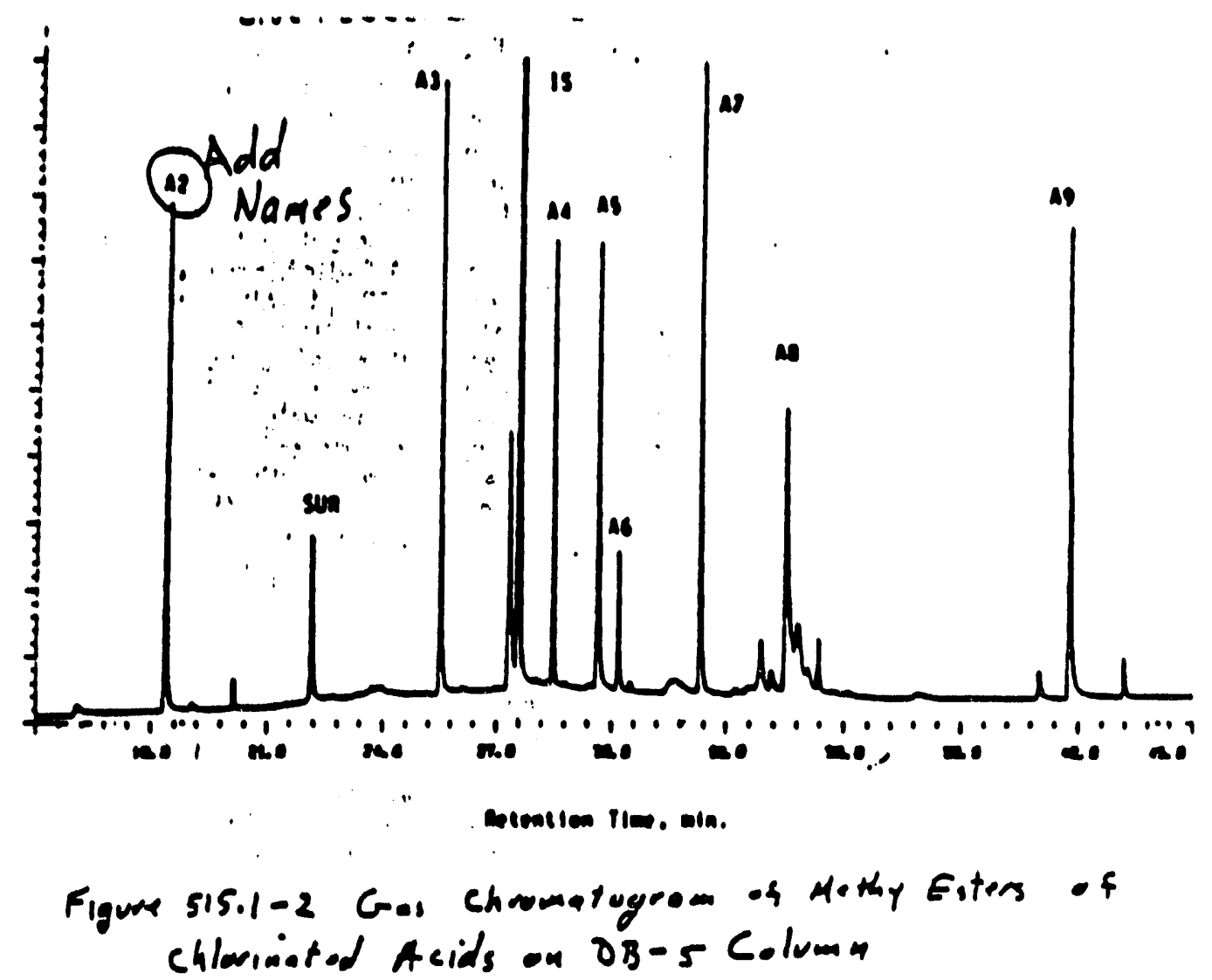

6.6.1 $\mathrm{H}_{2} \mathrm{SO}_{4}, 12 \mathrm{~N}$... Slowly add $335 \mathrm{~mL}$ concentrated $\mathrm{H}_{2} \mathrm{SO}_{4}$ to $635 \mathrm{~mL}$ of reagent water.

6.7 Potasstum hydrocide (KOH), pellets - ACS grade.

6.7.1 KOH, $37 \%(w / N)$ - Olsectve $37 \mathrm{~g} \mathrm{KOH}$ pellots in reagent water and dilute to $100 \mathrm{~mL}$

6.8 Carbitod (diethylens gtyed monoethy ether), ACS grade ... avaliable from Aldpich Chemical co.

6.9 Dlazald. ACS grade -- available from Ndrich Chemical Co.

6.10 Dlazald solutlon .- Prepare solutlon comaining 10 o Dlazald in $100 \mathrm{mk}$ of a 50:50 by volume mixture of othyl ether and carblid. This solution is stable for one month or longer when stored at $4 \mathrm{C}$ in an amber bottle with a Tellontined scrow cap.

6.11 Sodlum ctionde ( $\mathrm{NaC})$, eryeal. ACS grade

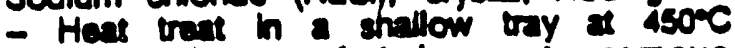
for a minimum of a hours, to remove imerterting organic substances.
$6.124,4^{\circ}$-Dlbromooctafluorobiphenyl (DBOB) .. g9\% purtisy, for use as internal standard (evallable from Adrich Chemical Co).

6.13 2,4-Dlchlorophenylacetlc acid (DCAA) .So\% purtyy. for use as surrogate standard (ivaliable from Ndrich Chemical Co).

6.14 Reagent vator - Reagent water is defined as water in which an interterent is not observed at or above the EDL of any andyte. Reagent water used to generate the valldation data in this method was distilled water obtained from the Magnetic Springs Water Co., Columbus. Ohio.

6.15 Silicic acid, ACS grade.

6.16 Florisil .- 60-100/PR mesh (Sigma No. F-9127). Actuate by heating in a shallow conteliner at 150"C for at leass 24 and not more than 40 hours.

6.17 STOCK STANOAAO SOLUTIONS (1.00 $\sigma^{\prime \mu L}$ ) .. Slock standard solutions may be purchased as certlfied solutions or prepared from pure standard materials using the lollowing procedure: 
6.17.1 Propare stock standard solutions by accurately welghing approdimately 0.0100 o of pure matertal. Diseotve the materta in MTBE and dlute to volumo th a $10 \mathrm{~mL}$ volumetrite hask Larger volumes may bo used at the comvenience of the anayse If compound purtity is certfied at $50 \%$ or groater, the wolght may be used without correction to calculate the concentration of the stock standard. Commerctally propared sock standands may bo used at any concontration if they are certifled by the manufacturer or by an independent sourea.

6.17.2 Transter the stock standard solutions into TFE-fluorocarbon-sialed serew Cap vials. Store at room temperature and protece from lighe

6.17.3 Stock standard solutions should be replaced atter two months or sooner comparison with laboratory control. candards indicates a problem.

6.18 INTEANAL STANDARD SPINNG SOLUMON -. Prepare an Internal atandard spiking solviton by aceurately woighing epprowdmately $0.0010 \mathrm{~g}$ of pure DBOB. Dissolve the DBOB in MTBE and dilute to volume in a $10-\mathrm{mL}$ volumetric lask. Trander tho internal standard splking solution to : TFE-lluorocarbon-soded scrow eap bottle and sore at room tempereture. Addation of 25 ul of the theome sandard splking solution to $10 \mathrm{~mL}$ of sample extract results in a flnal internal standard concentration of 0.25 mol Solution should be replaced when ongoing oc (sect i) Indicates a problem.

6.19. SURROGATE STANDARD SPINNG SOUTION - Prepare a surrogate standard aplking solution by accurately welghing approwematdy $0.0010 \mathrm{~g}$ of pure DCAA. Dissolve the DCAA In MTBE and dilute to volume in a $10 \mathrm{~mL}$ volumerice rask. Trander the surrogate standard splkting solution to a TFE-fluorocarbon-sealed ecrow cap bottle and store at room temperenume Addition of $50 \mathrm{\mu L}$ of the surrogate standard spiking solution to a $1 . \mathrm{L}$ sample prlor to exiraction results in surrogate standard concentrution in the sample of $5 \mu g /$ and, assuming quanthative rocovery of DCAA a surrogate standard concentration In the find octect of $0.5 \mathrm{\mu d} / \mathrm{mL}$ Solution should be replaced when ongolng OC (Sect 9) indleates a problem.

6.20 INSTAUMENT OC STANDARD - Propare a diluted dinoseb solution by adding 10 ut of the $1.0 \mathrm{\mu g} / \mathrm{\mu l}$ dinoseb stock solution to MTBE and diluting to volume in a $10-\mathrm{mL}$ volumetric lask. To prepare the inetrument OC standard. add $40 \mu \mathrm{L}$ of the diluted dinoseb solution, $16 \mu \mathrm{L}$ of the Anitrophend stock solution. 6 ML of the 3.5.dichlorobenzole acid stock colution, $50 \mathrm{\mu L}$ of the sumogate standard splking solution, $25 \mathrm{\mu L}$ of the internal standard spiking solution, and $250 \mu \mathrm{L}$ of mothand 10 a $5-\mathrm{mL}$ volumetric nask and dluse to volume with MTBE. Methylate sample as described in Sect. 10.4. Dillue the sample $1010 \mathrm{~mL} / \mathrm{m}$ MTBE. Transter the Instrument OC standard 10 a TFE-lluorocarbon-sealed scrow cap botlle and tore a rooin temperature. Solution should be replaced when ohgoing 06 (Sect 9) indloates a problem.

7. SAMPLE COLECTION, PAESERVATION, ANO STORAGE

7.1 Grab amples must be collected in glass containers. Conventional sampling practices (8) should be followed; however, the bowe mux not bo prerinsed with sample belore collection.

\subsection{SAMPLE PRESERVATION AND STORAGE}

7.21 Add morcurte chlorlde to the sample bottle in amounts 10 produce a concentration of $10 \mathrm{mg} L$ hdd $1 \mathrm{~mL}$ of a $10 \mathrm{mo} / \mathrm{mL}$ solution of mercuric chloride in water to the sample bottle at the sampling athe or in the laboratory before shipping to the sampling site. A major disedvantape of mereurle chloride is that it is a highly toxic chomical; mercuric chloride muat be handled with caution. and samples containing mercuric chloride must be disposed of property.

7.22 If reaidual chlorine is present. add 80 $\mathrm{mg}$ of sodium thiosulfate per liter of ample and mbx well.

72.3 Nhtor the sample ts collected in the botte containing preservative, sad the botte and shake vioorously for $1 \mathrm{~min}$.

724 The samplea muat bo keed or retrigerated a 40 awey from light from the time of collection untll extraction. Preservation study results Indlcate that most of the andyres (moasured as total acid) present In samples are stable for 14 days when stored under these conditions. (1) However, analyte stabilty may be affected by the matrix; therefore, the analyst 
should verify that the preservation ischnique is apolicable to the eamples under sudy.

\subsection{EXTRACT STOPACE}

7.3.1 Extracts should be stored at $4{ }^{\circ} \mathrm{C}$ eway from light. Preservation study rosults indleat that that moot andyres an stable for 28 days(1): howevor. the analyst should verify appropriate extrace holding ilmes eppleable to tho samples under study.

\section{8. calubration}

Q.1 Establish GC operating parameters equivelent to those Indleated in sect. 5.10. The GC systom may be callbratod using elther the internal standard tochnique (Sect. 8.2) or the external standard technique (sect 8.3).

8.2 INTEANAL STANOARD CALIBRATION PAOCEDUAE .. TO use this approach. the analyst must solect one or more intemal standards compatible in ancytical behavior to the compounds of interest. The andyst mus further demonatrate that the measurement of the hicemel sendard is not affected by mothod or matrix iniertorences. DEOB has been identilled as a subublo intemal standard.

2.1 Prepero callbration standards at a minimum of inve concentration lovels for cach an tyte of intereat by adding volumea of one of more stoek standands to a volumatric flask. To each calibration xandard, add a known constank amount of ons or more intemal standards and 250 it methand, and dilure to volume with MTBE. Estoplfy acids with dlazomethane as described in Sece 10.4 or 10.5. One of the calloration standards should be representative of an andyte concentration near, but above, the EDL.The other concentrations should correspond to the renge of concentrations expacted th the sample concentrates or shoudd detins the worteng renos of the derector.

8.22 Inject 2 ut of each calloration standard and tabulate the rolative response for cech andyte (RRa) to an triteme standard using the equation:

RRa - Ne/Als

where:

$A_{a}$ - the peak area of the analyte, and
Als - the peak area of the internal andard.

2.3 Cenerate a calbration curve of anajye relattve response, RRa, versus analyte concentration in the semple in $\mu /$

0.2.4 The working callbration curve must be verifled on each working shith by the measurement of one or more callbration stendards. If the response for any analye veries Irom the predlcted response by more than $+20 \%$, the lest must be repeated using a fresh callbration seandard. Atemallvely, a now callbration curve must be prepared for that anayte.

8.3 EXTERNAL STANDARD CALIBAATION PROCEDURE

Q.3.1 Prepare callbratlon standards at a minimum of five concentration levels for esch analyte of internst and surrogate compound by adding volumes of one or more stock standards and $250 \mathrm{\mu L}$ methand to a volumetrle hask. Dilute 10 volume with NTBE. Esterthy acids with disomethrne as described in Sect. 10.4 or 10.5 One of the calibration standards chould be representative of an analyie concentration near. but above, the EDL.The other concentratlons should correspond to the range of concentrations expected in the sample concentrates. or should define the working range of the detector.

0.32 Starting whth the standard of lowest concontation, antyze exch calibration standard according to Sect. 10 and tabulate peak helght or area response versers the concentration in the standard. The results can be used to prepare a calibration curve for each compound. Aremattvely, the ratlo of response to concentration (callbration factor) is a constent over the working range ( $<10 \%$ rolative standard deviation). Ilnearity through the origin can be assumed and the average ratio or callbration factor can be used in place of a calibration curve.

Q3.3 Single point callbration is viable ctemath to a callbration curve. Prepare incle point standards from the secondary dlution standards in methanol. The single point standards should be prepared at a concentration that produces a response cloes $(+20 \%)$ to that of the unknowns.

8.3.4 The working callbration curve or ealibration factor must be verified on 
cach working day by the mensumement of ons or more calibration standards. 1 the reaponse for any anatyte varies from the predicted response by more than $+20 \%$. the test must be repeated using a fresh calibration standard. If the reacits still do not agree, generate a now callibration curvo or liso a single point caltbration standard as descatbed in Sect. 8.3.3.

\section{OUAUTY control}

9.1 Minimum quality contro (OC) requirements are Initial demonstration of laboratory capabillty. determination of surrogate compound recovertes in cach sample and blank, monitoring Internal standard peak area or kelghe in each sample and blank (whon internal standard callbration procedures are being employed). enchy of method blanice metrument OC sotudon. laboratory control (LC) standards. OC samples, and pertormance overution (PE) somples.

9.2 Method Blanks. Before processing any samples, the analyat must demonstrate that ell ginserwere and reagerd interterences are under conturd. Ench tim a set of samples is extractod or reagents are changed. a mothod blank must be analyzed. If within the raterition IIme window of any anchre the mothod blank produces a peak that is 0.5 EDL for inat analyte, determine the source of contamination and ellminate the interterence betore procuesting sample.

9.3 Inital Damontuation of Capablyy.

9.3.1 Select a representative splke concentration (about 10 tmas EDL) for each analyte. Proparo a LC amplo concentrate (in mathand) contining each anatyte at 1000 imos selected concentration. Whit a sying, edd $1 \mathrm{~mL}$ of the concentrite to sach of at least four it allowots of regont wier, and analyzo each allquot according to procedurs bogining in Sucton 10

9.32 Calculate moan poreem recovery (X), and standard deviation of pereant recovory (S). For each andye, $x$ mux fall in the range of 70-130\% (or whin $A \pm 3$ ASO using the values for $A$ and ASD for ragent water in Table 2) and $S$ must bo leas than $30 \%$ (or leas than $3 \times$ ASO in rogon water in Table 2). If the calculated $x$ and $s$ for overy andive mext the acceptance criteria, performance is acceptable and sample anatysts may begin. If any $X$ or $S$ tails outside its acceptance range, Initial demonstration procedues for that compound muse be repeated.

9.4 The andya to permitued to modity GC columms, GC conditions, or detectors to Improve separatlons or lower analyelcal costs. Ench tims such mothod modifications are mode, the analyst must repeat the procedures in Section 9.3

9.5 Asesesing Surrogate Recovery.

9.5.1 When surrogare recovery from a sample or mothod blank is < $70 \%$ or $130 \%$. check (1) edculations to locate possible errors. (2) splking solutlons for degradation (3) comamination or other obvious abnormaltiles, and (4) instrument pertormance. If those steps do not reveal the euse of the problem, reanalyze the rodines

9.5 .2 If a blank extract reanalysis fails the 70-130\% recovery crterta. the problem must be identhed and corrected before condinuing.

9.5 .3 If sample extract reanalysis solves the probtom. report only data from the analysis with acceptable surrogate recovory. If sample extract reanalysis does not sotve the problem, report all dete for the enmple as suspece.

9.6 Asaceing the Interned Standard

9.2.1 For each sample and blank extract. deformins II irtemal standard peak ares or holght deviates by $30 \%$ from the average massured during analysis of cilibration sandards.

9.8.2 If 30\% deviation, optimize Instrument porformance and inject a second aliquor of thrt extrace if the retnjected allquot produces an acceptable imemal standard paak area or helght, report results for that afleuce If nol assume that an error was made during addition of internal stendard to that extrect Reextract that eample or bianik, and analyze that extract.

9.6.3 If $30 \%$ devlation continues, analyze a callbration standard (Sect 8).

9.6.3.1 If the internal standard peak area or poak halght tails to meet criteria. then recellibrate, and reanaiyze extracts that previously did not meet criterla. If ecceptable are or haight is measured.

Mothod 515.1, Page 8. Plovised 1988 
report results. If not, assume an imerierence from the matre b aflecting the internal standard and we cxemal calforation (Sect 8).

9.6.3.2 If the thternd standaro poak area or peak height moets critert thon assumb an imterference from the matrtx is affecting the internal standard in your sample extract and we external callbration.

\subsection{Assessing Laboratory Pentormance}

9.7.1 Initial OC crtteria are established by using the values for $X$ and $S$ genwrited above (Sect 9.3) to cetablish upper and lower controd limits:

UPPER CONTAOL UMIT $-x+3 S$ LOWEA CONTROL LMIT $=x$ - 35

The laboratory must andyze at lease one LC sample per sample set (all samples extracted wishin a 24-h porlod). The spiking concentration of each enchie in the laborntory control sample should be 10 itmes EDL Calculate eceuracy as percent recovery (x). If the recovery of any analyte falls outside the control IImits, that anaiyse is judged out of conterd, and the source of the problem must be identifed and resched betore continuing andyses. Thw control Itrits should bo updated periodleally. It is recommended that atter each ive to ten new recovery mansuremonts that now control limits bo clevated using only the most recent $20-30$ det pointe.

9.7.2 Each quarter the laboritory mux anatyze QC check standards (If avallablo). If criteria provided with the OC check standard are not mer correcthe acton should be taken and documented.

9.7.3 At least once a year, the laboratory must anaiyze a performance eveluatlon sample (ii avalable), and results for cach analyio must be within cotabllshed accopance limits.

9.8 Assessing Instrument Performance - The instrument OC standard (Sect 6.12) should be analyzed daily to monitor instrument performance. Inablilty to demonstrate acceptable instrument performance indicales the needs to reovaluate tho GC system. If laboratory EDLs difer from listed EDLS (Table 2). concentratlons of instrument OC standard compounds may be adjusted as needed.

9.9 Analyte Confimation - When doubl oxdsts about identllication of a GC peak. confirmatory techniques such as determination with a mass spectrometer detector or a ditierent GC column must bo used.

\section{PHOCEDUAE}

10.1 AUTOMATED HYOROLYSIS, CLEANUP. AND EXTRACTION METHOD - Validation data presented in this method were generated using the automated extraction procedure with the mechanical separatory funnel shaker.

10.1.1 Add preservative to any samples not prevbusly preserved (Sect 7.2). Mark the water meniscus on the side of the sample botte for later determination of sample volume. Spike sample with 50 $\mu \mathrm{L}$ of the surrogate standard spiking solution. If the mechanical separatory hunnd shaker is used, pour the entire sample imo a $2-L$ separatory funnet. If tho mechanical tumbler is used. pour the entire sample into a tumbler botte.

10.12 Add $250 \mathrm{~g} \mathrm{NaCl}$ to the sample, seal. and shake to dissotve salt.

10.1.3 Add $17 \mathrm{~mL}$ of $6 \mathrm{~N} \mathrm{NaOH}$ to the sample. seal. and shake. Check the pH of the sample with pH paper; If the sample does not have a pH greater than of cqual to 12. adjust the pH by adding more $6 \mathrm{~N}$ NaOH. Shake sample for 1 hour using the appropriate meshanical mbing dovice.

10.1.4 Add $300 \mathrm{~mL}$ methylene chloride to the sample botte to rinse the bottle, transter the methytene chiloride to the separatory hunnel or umbler bottle, seal, and shake for 10 s. venting periodlcally. Repeat shaking and venting untll pressure release is not observed during venting. Reseal and place sample container in appropriate mechanical mixing device. Shake or tumble the sample for 1 hour. Complete and thorough mbxing of the organic and equeous phases should be observed at ioast 2 min after starting the mixing dovice.

10.1.5 Remove the sample container from the mixing device. If the tumbler is used. pour contents of tumbler bottle into a 24 separatory funnel. Allow the organic layer to separate from the water phase lor a minimum of 10 min. If the emulsion intertace between layers is more than one third the volume of the solvent layer. 
the analyst must omploy mechanical iechniques to complete the phase separation. The optimum technique depends upon the sample, but may Include stirring. fitration itrough glass wool, centritugation, or other physica methods. Drain and dlscard the organic phase. If the tumbler $b$ used, retum the aqueous phase to the tumbler botele.

10.1.6 Add $17 \mathrm{~mL}$ of $12 \mathrm{~N} \mathrm{H2SO}$ to the sample, seal. and shake to mbe Check the pH of the sample with pH paper, the sample does not have a pH less than or equal to 2. adjust the $\mathrm{pH}$ by adding more 12 N H2SO4.

10.1.7 Add $300 \mathrm{~mL}$ ethyt ether to the semple. seal. and shake for $10 \mathrm{~s}$, venting pertodlcally. Aepeat shaking and venting untll pressure release is not observed during venting. Resed and place eample container In appropriate mochanical mbeing device. Shake or umble samplo for 1 hour. Complate and thorough mixing of the organic and aqueous phases shoutd be observed at least 2 min atter starting the mbxing device.

10.1.8 Remove the sample comtainer from the mixing device. If the tumbler is used. pour contents of tumbler botde tinto a $2-L$ separatory hunnel. Nlow the organic layer to separate from the water phase for a minimum of $10 \mathrm{~min}$. If the emulsion Intertace between layers is more than one thind the volums of the sctvent layer. the analyst must employ mechanical techniques to complote the phase separation. The optimum techntque depends upon the sample, but may Include stiring. filtration through dass wool. centrfigation, or other physical methods. Drain and discard the aqueous phase. Collect the cxtract in a $500-\mathrm{ml}$ round-bottom hask containing about 100 of acidified anhydrow sodium sulfate. Perlodlcally vigorousty shake the sample and drying agent Nlow the extract to remain In comact whth the sodium sutfate for approdmately 2 hours.

10.1.9 Determine the origind semple volume by refilling the sample bowle is the mark and transfering the water to a $1000-\mathrm{mL}$ graduated cylinder. Record the sample volume to the nearest $5 \mathrm{~mL}$

10.2 MANUAL HYDROLYSIS, CLEANUP. AND EXTRACTION METHOD - Alternative procedure.
10.2.1 Add presenvative to any samples not proviously preserved (Sect. 7.2). Mark the water meniscus on the side of the sample bottle for later determination of sample volume. Pour the entire sample into a 2L separatory tunnel. Spike sample with 50 ul of the surrogate standard spiking solution.

10.2.2 Add $250 \mathrm{gaCl}$ to the sample. seal. and shrke to dissotve salt.

10.2.3 Add $17 \mathrm{~mL}$ of $6 \mathrm{~N} \mathrm{NaOH}$ to the sample. sed, and shake. Check the pH of the sample with pH paper; if the sample does not have a $\mathrm{pH}$ greater than or equal to 12. adjust the $\mathrm{pH}$ by adding more $6 \mathrm{~N}$ NaOH. Let the sample sit at room temperature for I hour, shaking the separatory funnel and contents periodically.

10.24 Add $60 \mathrm{~mL}$ methylene chioride to the samplo botwe to rinse the bottle, transter the methyiene chioride to the separatory funnol and extract the sample by vigorously shaking the funnel for 2 min with periodic venting to release excess pressure. Allow the organic layer to separate from the water phase for a minimum of $10 \mathrm{~min}$. If the emulsion intertace between layers is more than one third the volume of the sotvent layer. the analyst must employ mechanical tochniques to complete the phase separation. The optimum technique depends upon the sample. but may include stiring. fittration through glass wool. centrtiugation, or other physical mothods. Discard the methytene chioride phasa.

10.2.5 Add a second $50-\mathrm{mL}$ volume of methylene chloride to the sample bottle and repeat the extraction procedure a second time. discarding the methylene chloride layer. Perform a third exraction in the same manner.

10.2 .6 Add $17 \mathrm{~mL}$ of $12 \mathrm{~N} \mathrm{H}_{2} \mathrm{SO}_{4}$ to the sample, seal, and shake to mbx Check the pH of the sample with pH paper, if the sample does not have a pH less than or equal to 2. adjust the $\mathrm{pH}$ by adding more $12 \mathrm{~N} \mathrm{H}_{2} \mathrm{SO}_{4}$.

1027 Add $120 \mathrm{~mL}$ ethy ether to the sample. seal, and extrect the sample by vigorously shaking the funnd for 2 min with periodic veriting to release excess pressure. Allow the organic layer to separate from the water phase for a minimum of $10 \mathrm{~min}$.

Method 515.1, Page 10, Revised 1988 
If the emilsion intertace between layers is more than one thitrd the volume of the sotvent layer, the andyse must employ mectranical technigues to complete the phase separation. The optmum technique depends upon the sample, but may include stiring. filtration through glass wool, centrffucation, or other physical mothods. Remove the aqueous phase to a 2-L Entenmoyor flask and collect the ethyl ether phase in a 500.mL round-bottom flask containing approximately $10 \mathrm{~g}$ of acidified antydrous sodium suttaie.

10.2.8 Return the aqueous phase to the separatory hunnd, add a $60-\mathrm{mL}$ volume of ethyl ether to the sample. and ropeat the extraction procedure a second tima. combining the extracts in the $500-\mathrm{mL}$ orienmeyer flask. Porform a inird extraction with $60 \mathrm{mt}$ of ethy cther in the same manner. Perlodleally vigorousty shake the sample and drying agent. Allow the extract to romain in contact with the sodlum sutate for approdmatch 2 hours.

10.2.9 Determine the original sample volum by refilling the sample botte to the mark and transtering the water to a $1000-\mathrm{mL}$. graduated eylinder. Record the samplo volume to the narrea $5 \mathrm{~mL}$

\subsection{DXTRACT CONCENTRATION :}

10.3.1 Aseamble a K-D concentrator by aftaching a concentrator tube to a $500-\mathrm{mL}$ evaporatve lask. ...!, :

10.3.2 Pour the dried extract through a funnel plugged with act washed glass wool, and collect the extract in the K-D concentrator. Use a glass rod to crush any caked sodlum sullate during the transfer. Alnse the round-bottom hask and funnel with 20 to $30 \mathrm{~mL}$ of athy ether to complete the quartitathe transfer.

10.3.3 Add 1 to 2 dean bolling stonce to the oveporative liask and attach a macro Smydercolumn. Prewe tho Smyder colum by edding about $1 \mathrm{~mL}$ ctivy other to the top. Place the K-D apparatus on hot water bath, 60 to $65^{\circ} C$, so that the concentrator tubs la partilly immersed in the hot water, and the entire lower rounded surtace of the lask is bathed with hot vapor. At the proper rate of distillation the balls of the column will actively chatter but the chambers will not lood. When the appanent volume of liquid reaches $1 \mathrm{~mL}$ remove the K-O apparatus and allow th to drain and cool for at leas $10 \mathrm{~min}$.

10.3.4 Remove the Snyder column and rinse the hask and its lower joint into the concentrator tube with 1 to $2 \mathrm{~mL}$ of othyt ether. Add $2 \mathrm{~mL}$ of MTBE and a fresh boillng stone. Attach a micro-Snyder column to the concentrator tube and prewet the column by adding about 0.5 $\mathrm{mL}$ of ethyl ether to the top. Place the micro K-D apparatus on the water bath so that the concentrator tube is partially Immersed in the hot water. Adjust the vertical position of the apparatus and the water temperature as required to complete concentration in $51010 \mathrm{~min}$. When the apparent volume of llquid reaches $0.5 \mathrm{~mL}$ remove the micro K.O from the bath and allow it to drain and cod. Aemove the micro Snyder column and add $250 \mu \mathrm{L}$ of methanol. If the aseous diazomethane procedure (Sect. 10.4) is used for esterification of pesticides. inse the walls of the concentrator tube while adjusting the volume to $5.0 \mathrm{~mL}$ with MTGE. If the pesticides will be exteriited using the dlazomethane solution (Sect. 10.5). Pinse the walls of the concentrator tube while ad usting the volum to $4.5 \mathrm{mb}$ with MTBE.

10.4 ESTEAIFICATION OF ACIDS USING GASEOUS DIAZOMETHANE .. Valldation results presented in this method were generated using tha gaseous diazomethane derivatization procedure.

10.4.1 Assemble the dlazomethane generator (Figure 515.1-1) in a hood.

10.4.2 Add $5 \mathrm{~mL}$ of ethyt ether to Tube 1. Add $1 \mathrm{~mL}$ of etmyt other, $1 \mathrm{~mL}$ of carbital. $1.5 \mathrm{~mL}$ of $37 \%$ aqueous $\mathrm{KOH}$, and 0.2 grams Dlazald to Tube 2. Immedlately place the ext tube into the concentrator tube containing the sample extract Apply nitrogen flow (10 mL/min) to bubble dlazomethan through the extract for 1 min Remove first sample. Ainse the tip of the diazomethane generator with ethyt cther atter methytation of each sample. Bubble dlazomethane through the second sample extract for 1 min. Dlazomethane reaction mixture shouid be used to esterity only two samples; prepare new reaction mixcure in Tube 2 to esterity each two additional samples. Samples should turn yellow atter addition of dlazomethane and remain yellow for at

Method 515.1, Page 11, Pevlsed 1988 
least $2 \mathrm{mtn}$. Repaat muthylation procedure necessary.

10.4.3 Seal concentrator tubes with stoppors. Store at room temperaturs in a hood for $30 \mathrm{~min}$

10.4.4 Destroy any unreacted dinzomethane by adding 0.1 to 0.2 grams silcte acid to the concentrator tubes. Nllow to stand unth the evolution of nitrogen gas has stopped (approdimately $20 \mathrm{~m} / \mathrm{n}$ ). Adlust the sample volume to $5.0 \mathrm{~mL}$ with MTBE.

10.5 ESTERIFICATION OF ACIDS USING DIAZOMETHANE SOLUTION - Alernative procedure.

10.5.1 Assemble the dizzomothane generator (Floure 515.1) in a hood. The collection vesesel th a 10. or 15-mL vial, cquipped with a Tollon-llned scrow cap and maintained a 0.5C.

10.5.2 Add a sufficient amount of othyl ther to tube 1 to cover the firse Implnger. Add $5 \mathrm{~mL}$ of MTBE to the collection vid. Set the nitrogen fiow at 5-10 mu/min. Add $2 \mathrm{~mL}$ Olazald scluilon (Sect. 6.9) and $1.5 \mathrm{~mL}$ of $37 \% \mathrm{KOH}$ solution to the second implinger. Cornect the tubing as shown and allow the nikrogen flow to purge the dlazomethane from the racetion vesed thito the collection vid for $30 \mathrm{~min}$. Cap the vit when collecton b complete and maintain at 0-5C. Whan stored at 0-5C this diazomothana solution may be used over a partod of $48 \mathrm{~h}$.".

10.5.3 To each concentrator tube containing sample or standard, add $0.5 \mathrm{~mL}$ diazomethane solution. Samples should turn yellow atter addition of the diazomethane solution and remain yellow for at least 2 min. Repeat methylation procedure nocescary.

10.5.4 Seal concentrator tubes with stoppers. Store at room temperature in a hood for $30 \mathrm{~min}$.

10.5.: Destroy any unrencted dinzomathan by adding 0.1 to 02 gram sllek actd to the concentrator tubes. Nllow to thand umil the ovolution of nitrogen gas has stopped (approdmatchy $20 \mathrm{~min}$ ). Adjust the sample volume to $5.0 \mathrm{~mL}$ with MTBE

\subsection{FLORISIL CUEANUP}

10.6.1 Place a small plug of glass wool into a 5-mL disposable olass piper Tare the pipet, and measure 1 of activated Forisl into the pipet.
10.6.2 Apply $5 \mathrm{~mL}$ of 5 percent mettand in MTBE to the Forist. Allow the llquid to fust reach the top of the Forisi. In this and subsequent steps. allow the liquid level to fust reach the top of the Forisit bofore applying the next rinse, however. do not allow the Florlsil to go dry. Dtecard eluate.

10.6.3 Apply $5 \mathrm{~mL}$ methylated sample to the Forisil leaving sillcic acid in the tube. Collecs cluate in K.D tube.

10.6.4 Add $1 \mathrm{~mL}$ of 5 percent methanol in MTEE to the sample contalner, rinsing walls. Transter the tinse to the Forisi column leaving sillicic acid in the tube. Collect eluate in a K-D tube. Repeat with $1-\mathrm{mL}$ and $3-\mathrm{mL}$ allquots of 5 percent methand in MTBE, collecting eluates in K-D tube.

10.6.5 If necessary, dilute cluate to $10 \mathrm{~mL}$ with 5 pereent methand in MTBE. Spike with $25 \mathrm{ul}$ of Internal standard solution. Thoroughty mbx sample and place aliquol in a GC vil for subsequem analysis.

10.6.6 Seal the vtal and store in a retrigerator If huther processing will not be pertormed immedlately. Andyze by GC.ECD.

\subsection{GAS CHAOMATOGRAPHY}

10.7.1 Sect 5.10 summartzes the recommended operating conditlons for the GC. Included in Table i are retention times observed using this mathod. Other GC columns. chromatographic condlitons, or detectors may be used the requirements of Sect. 9.4 an met.

10.7.2 Callbrate the system daily as described in Sect 8. The standards and extracts must be in MTBE

10.7.3 Inject $2 \mu \mathrm{L}$ of the sample extract. Record the resutting peak slze in area units.

10.7.4 The width of the retertion time window used to make Idemifications should be based upon messurements of actual retention time vartations of standards over the course of a day. Threo times the standard deviation of a retention time can be used to calculate a suggested window size for a compound. However. the expertence of the analyst should woigh heavily in the interpretation of chromatograms.

10.7.5 If the response for the peak exceeds the working range of the system, divte the wernet and reanalyze. 


\section{CALCULATIONS}

11.1 Calculate analyte concentrations in the sample from the response for the enalyte using the callbration procedure described in sect 8.

11.2 For samples processed as part of a set whers the laboratory control standard recovery falls outside of the control limits in Sect. 9, results for the affected anajyes must be labeled as suspect.

\section{PRECISION AND ACCURACY}

12.1 In a single laboratory, andyte recoverlose from reagent water were dotermined at five concentration levels. Results were used to detarmine analyte EDLs and demonstrate method range.(1) In cases where analytes cooluted using primary andivical conditions, results from confimmitory GC conditions were used. Anviye recoverles at one concentration and EDL results are given in Table 2 .

12.2 In a singte laboratory, analyte recovertes from iwo artillcial ground wators wore determined at one concentration level. Resutts were used to demonstrate applcabiliny of the method to different ground water matrices. (1) Analyte recoveries from the no articich matrices are oiven in Tablo 2.

\section{REFERENCES}

1. "Pesticide Methods Evaluatlon,"Letter Report "33 for EPA Contract No. 68-03-2097. Avaidable from U.S. Environmental Protection Agency. Environmental
Monitoring and Support Laboratory. Cincinnati. Ohio 45268.

2.ASTM Annual Book of Standards, Pan 11, Volume 11.02. D3694-82. "Standard Practice for Preparation of Sample Containers and for Preservation". American Society for Testing and Matorials, Phiedelphia. PA. $\mathrm{p}$. 86. 1986.

3.Glam C. S. Chan H. S., and Nef, G. S. "Sensitive Method for Determination of Phthalate Ester Plas. ilcizers in Open-Ocean Blota Samplos," Analvical Chemintio 172225 (1975).

4.Glam, C. S., and Chan. H. S. Control of Blanks in the Analysis of Phthatates in Alr and Ocean Blota Samples." U.S. Natlonal Bureau of Standards, Special Publication 42. Pp. 701-708, 1976.

5. Carcinogens - Working with Carcinogens." Depart. ment of Health, Education, and Welfare. Public Health Senvice, Conter for Disease Contro, National Institute for Occupational Safety and Health, Publication No. 7 . 206. Aug 1977.

6. OSHA Safery and Heatth Standards, General In. dustry." (29 CFF 1910), Occupational Safory and Health Administration, OSH '2206, (Revised, January 1976).

7. "Safety In Academle Chemistry Laboratories." American Chemical Soclery Publication, Committee on Chemical Sadety, 3nd Edition, 1979.

AASTM Annurd Book of Standards, Part 11, Volume 11.01, D3370-82, "Standard Practlce for Sampling Water. American Society for Testing and Materials. Philadelphta, PA D. 130. 1986. 
GPA

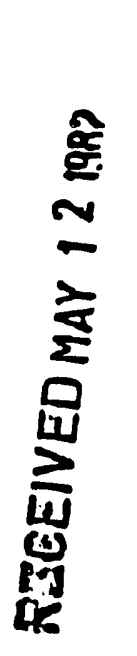

Research and

Development

The Determination of Polychlorinatad Biphenyls in Transformer Fluid and Waste Oils.

\section{Prepared for}

John P. Dekany

Deputy AssistantAdministrator for

Chemical Conitrol

Office of Toxic Substances

Prepared by

Thomes A. Bellar

James J. Lichtenberg

Physical and Chemical Methods 3ranch

Environmental Monitoring and Support Lacoratory 
THE DETERMINATION OF POLYCHLORINATED BIPHENYLS IN TRANSFORMER FLUID ANO WASTE OILS

\section{Scope}

1.1 This is the EPA preferred method for the determination of polychorinated biphenyls (PCBs) in waste oils according to PCB regulations.' This gas chromatographic (GC) procedure is applicable to the determination of commercial mixtures of PCBs in transformer fluids and certain other hydrocarbon based waste oils. The method can be used to anaiyze waste oils for individual PCB isomers or complex mixtures of chlorinated biphenyls from monochlorobiphenyl through decachlorobiphenyl only if the isomers have been previously identified by other methods ${ }^{2}$ or by knowledge of the sample history.

1.2 The detection limits are dependent upon the cormplexitg of the sample matrix and the ability of the analyst to properly maintain the analytical system. Using a carefully optimized instrument, this method has been shown to be useful for the determination of commercial PCB mixtures spiked into transformer fluid over a range of 5.0 to $500 \mathrm{mg} / \mathrm{Kg}$. Based upon a statistical calculation at 5 $\mathrm{mg} / \mathrm{Kg}$ for a simple oil matrix, the method detection limit for Arociors 1221, 1242, 1254, and 1250 is $1 \mathrm{mg} / \mathrm{Kg}$. The method detection limit (MOL) is defined as the minimum concentration of a substance that can be measured and reported with $99 \%$ confidence that the value is above zero.

1.3 This method is restricted to use by or under the supervision of analysts experienced in the use of gas chromatography and in the interpretation of gas chromatograms. Prior to sample analysis, 
each analyst must demonstrate the ability to generate acceptable results with this method by following the procedures described in Section 10.2

\section{Summary}

2.1 The sample is diluted on a weight/volume basis so that the concentrations of each PC3 isomer is within capability of the GC system $(0.01$ to $10 \mathrm{ng} / \mathrm{\mu L})$.

2.2 The diluted sample is then injected into a gas chromatograph for separation of the PCB isomers. Measurement is accomplished with a halogen specific detector which maximizes baseline stability and minimizes interferences normally encountered with other detectors. The electron capture detector (ECO) can normaliy be substituted for the halogen specific detector when samples contain dichloro through decachlorobiphenyl isomers (Aroclors 1016, 1232, 1242, 1248, 1254, $1 \overline{260}, \overline{1262}$ and 1268 ), or when the sample matrix does not interfere with the PCBs. Several cleanup techniques are provided for samples containing interferences. A mass spectrometer operating in the selected ion monitoring mode of data aquisition may also be used as the GC detector when PCB levels are sufficiently high and the PCB $m / z$ ranges are free from interference. Interferences may occur in some waste oil samples even after exhaustive cleanup.

2.3 The concentrations of the PCBs are calculated on a mg/ $\mathrm{kg}$ basis, using commercial mixtures of PCBs as standards. The analysis time, not including data reduction, is approximately $35 \mathrm{~min} / \mathrm{sample.}$

\section{Interferences}

3.1 Qualitative misidentifications are always a potential problem in GC 
analysis. The use of a halogen specific detector and the analyst's skill in recognizing chromatographic patterns of commercial PCB mixtures minimizes this possibility.

3.2 Whenever analyzed samples do not provide chromatographic patterns nearly identical to the standards prepared from commerclal PCBs, the analyst must confirm the presence of PCBs by one of three ways: by analysis after column cleanup; by analysis on dissimilar gas chromatographic columns; or, by gas chromatography/mass spectrometry (GC/MS).

3.3 During the development and testing of this method, certain analytical parameters and equipment designs were found to affect the validity of the analytical results. Proper use of the method requires that such parameters or designs are to be. used as specified. These items are identified in the text by the word "must." Anyone wishing to deviate from the method in areas so identified, must demonstrate that the deviation does not affect the validity. of the data and alternative test procedure approval must be obtained through the Environmental Monitoring and Support Laboratory, 26 West St. Clair Street, Cincinnat, Ohio 45268 Equivalency Program. ${ }^{3}$ An experienced analyst may make modifications to parameters or equipment identified by the term "recommended." Each time such modifications are made to the method, the analyst must repeat the procedure in Section 10.2. In this case, formal approval is not required, but the documented data from Section 10.2 must be on file as part of the overall quality assurance program.

3.4 Samples which are diluted at a ratio of 100:1 and are analyzed by electron capture GC, consistently produce results that are 10 to 
20\% lower than the true value (See Section 12). This is due to quenching of the detector response by high boiling hydrocarbons coeluting with the PCBs. The degree of error is matrix dependent and is not predictable for samples of unknown origin. As the PCB concentration approaches $20 \%$ of a control level, for example, $50 \mathrm{mg} / \mathrm{kg}$, the analyst must routinely reanalyze a duplicate spiked sample to determine the actual recovery. Splke the duplicate or dfluted sample at 2 times the electron capture observed value and reanalyze according to Section 10.2. Correct the results accordingly.

\section{Apparatus}

4.1 Jas Chromatograph -- The gas chromatograph should be equipped with on-column 1/4-inch injectors. The oven must be large enough to accept. a $1 / 4^{\text {n }} 002$ meter colled glass.-column.-If-halogen specific detectors are used; then the column oven should have programing capabilities.

4.2 Gas Chromatographic Detector

4.2.1 A halogen specific detector is used to eliminate interferences causing misidentifications or false-positive values due to non-organohalides which cormonly coelute with the PCBs.

a. Electrolytic conductivity detector -- the Hall electrolytic conductivity detector, Model 700-A (HED), available from Tracor, Inc. has been found to provide the sensitivity and stability needed for the current PCB Regulations.'

b. Other halogen specific detectors, including older model 
electrolytic conductivity detectors and microcoulometric titration, may be used. However, the stability, sensitivity, and response. time of these detectors may raise the method detection limit and adversely affect peak resolution. Each system must be shown to be operating within requirements of the PCB regulations by collecting single laboratory accuracy and precision data and method detection limits on simple spiked samples as described in Section 10.2

4.2.2 Semi-specific detectors, such as ECD, may be substituted wher sample chromatographic patterns closely match those of the standards. Acfd cleanup (See Section 8.1) or Florisil slurry cleanup (See Section 8.7 ) should be incorporated routinely when the ECD is used.--See Section_3 4 for additional quality control procedures for ECD.

4.2.3 Quantitative GC/MS techniques $c a n$ be used and the recommended approach is selected ion monitoring (SIM) but the GC/MS data system must have a program that supports this method of data acquisition. The program must be capable of monitoring a minimum of eight ions, and it is desirable for the system to have the ability to change the ions monitored as a function of time. For PCB measurements, several sets of ions may be used depending on the objectives of the study and the data system capabilities. The alternatives are as follows: 
Single lons for high

sensitivity

Short mass ranges which

may give enhanced sensi-

tivity, depending on the

data system capabilities

Single ions giving

decreased sensitivity

but are selective for

levels of chlorination.
$154,188,222$,

256, 292, 325,

360,394

$154-156,188-192$,

$222-226,256-260$,

290-295, 322-328,

$356-364,390-398$

$190,224,260,294$,

$330,362,394$

The data systen must have the capability of integrating an abundance of the selected ions between specified limits and relating integrated abundances to concentrations, using the calibration procedures described in this method.

\subsection{Gas Chromatographic Columns}

4.3.1 The GC columns and conditions listed below are recommended for the analysis of PCB mixtures in oil. If these columns and conditions are not adequate, the analyst may vary the column parameters to improve separations. The columns and conditions selected must be capable of adequately resolving the PCBs in the various Aroclor mixtures so that each 
Arocior is identifiable through isomer pattern recognition. (See Figures 1 through 6 to establish this.) To properly . use the calculation procedure described in Section 11.5, the analyst must use the methyl silicone liquid phase column described in Section 4.3.2. Capillary columns and their associated specialized injection techniques are acceptable alternatives; however, due to problems associated with the use of capillary columns the analyst must demonstrate that the entire systen will produce acceptable results by performing the operations described in Section 10.2 .

4.3.2 Recommended primary analytical column: Glass, I/4 in. 0.0. (2 $\mathrm{mm}$ I.0.) $6 \mathrm{ft}(180 \mathrm{~cm})$ long, packed with Gas-Chrom $Q$ $100 / 120$ mesh coated with 3\% OV-1. Carrier gas: 40 to $60 \mathrm{~mL} / \mathrm{min}$ (helfum, nitrogen or mixtures of methane in argon as recommended by the manufacturer of the detector).

Temoerature Program: $120^{\circ} \mathrm{C}$ isothermal for 2 minutes, $6^{\circ} /$ min to $220^{\circ} \mathrm{C}$ and hold until all compounds elute.

Figure 8 shows a chromatogram of the PCB locator mixture (see Section 5.8) analyzed inder these conditions. Each PCB peak has been identified by assigning the same relative retention times determined in the isothermal runs Figures 1 through 6.

Isothermal Operation: Aroclor 1221, 1232, or $\mathrm{Cl}$, through $\mathrm{Cl}_{4}$ isomers -- recommended range 140 to $150^{\circ} \mathrm{C}$ Aroclor 1016, 1242, 1254, 1260, 1262, 1268, or $\mathrm{Cl}_{3}$ through $\mathrm{Cl}_{10}$ isomers -- recommended range 170 to $200^{\circ} \mathrm{C}$ 
4.3.3 Recommended confirmatory column: Glass tubing $1 / 4$ in. 0.0., $2 \mathrm{~mm}$ I.D. a ft $(180 \mathrm{~cm})$ long, packed with Gas-Chrom $Q$ $100 / 120$ mesh coated with $1.5 \%$ oV $-17+1.95 \%$ ov -210 .

Carrier gas: 40 to $60 \mathrm{~mL} / \mathrm{min}$ (helium, nitrogen or mixtures of methane in argon as recommended by the manufacturer of the detector).

Column temperatures: Aroclor 1221, 1232, or $\mathrm{Cl}_{1}$ through $\mathrm{Cl}_{4}$ isomers recommended range -- 170 to $180^{\circ} \mathrm{C}$. Arocior $1016,1242,1248,1254,1260,1262,1268$, or $\mathrm{Cl}_{3}$ through $\mathrm{Cl}_{10}$ isomers $200^{\circ} \mathrm{C}$..

4.4 Volumetric flasks -- 10, 100, 200, and 250-mL.

4.5 Pipets $-0.10,1.0$, and $5.0 \mathrm{~mL}$ Mohr delivery (for viscous oi is cut off tip of pipet).

4.6 Micro syringes -- $10.0 \mu \mathrm{L}$.

4.7 Sample containers -- $20 \mathrm{~mL}$ or larger serew cap bottles with Tefion faced cap liners. (Aluminum foil cap liners can be used for non corrosive samples).

4.8 Chromatographic column -- Chromaflex, $400 \mathrm{~mm}$ long $\times 19 \mathrm{~mm}$ ID (Kontes $X-420540-9011$ or equivalent).

4.9 Gel Permeation Chromatograph --. GPC Autoprep 1002 or equivalent, available from Analytical Bio Chemistry Laboratories, Inc.

4.10 Balance -- Analytical, capable of weighing $99 \mathrm{grams}$ with a sensitivity of $\pm 0.0001 \mathrm{~g}$.

4.11 Kuderna-Danish (K-D) Evaporative Concentrator Apparatus

4.10.1 Concentrator tube -- 10-mL, graduated (Kontes K-570050-1025 or equivalent). Calibration must be checked. Ground glass 
stopper (size 19/22 joint) is used to prevent evaporation of solvent.

4.11.2 Evaporative flask -- 500-mL (Kontes K-57001-0500 or equivalent). Attach to concentrator tube with springs (Kontes K-662750-0012 or equivalent).

4.11.3 Snyder column -- Three ball macro (Kontes K503000-0121 or equivalent).

5. Reagents and Materials.

5.1 Reagent safety precautions

5.1.1 The toxicity or carcinogenicity of each reagent used in this method has not been precisely defined; however, each chemical compound should be treated as a potential health hazard. From this viewpoint, exposure to these chemicals must be reduced to the lowest possible level by whatever means available. The laboratory is responsible for maintaining a current awareness. file of OSHA regulations regarding the safe handling of the chemical specified in this method. A reference file of material data handling sheets shouid 2 ? so be made available to all personnel involved in the chemical analysis.

5.1.2 PCBs have been tentatively classified as known or suspected, human or mammalian carcinogens. Primary standards of these toxic compounds should be prepared in a hood.

5.1.3 Diethyl ether should be monitored regularly to determine the peroxide content. Under no circumstances should diethyl ether be used with a peroxide content in excess of $50 \mathrm{ppm}$ as 
an explosion could result. Peroxide test strips manufactured by EM Laboratories (available from Scientific Products Co. Cat. No. P1126-8 and other suppliers) are recommended for this test. Procedures for removal of peroxides from diethyl ether are included in the instructions supplied with the peroxide test kit.

5.2 Hexane (mixed hexanes), isooctane, acetonitrile, methylene chloride, cyclohexane, and diethyl ether of pesticide grade.

\subsection{Recormended Column Packings}

5.3.1 Gas Chrom Q 100/120 mesh coated with 3\% OV-1.

5.3.2 Gas Chrom Q 100/120 mesh coated with 1.5\% OV-17 + 1.95\% OV-210.

\subsection{Standards}

5.4.1 Arociors 1016, 1221, 1232, 1242, 1248, 1254, 1250, 1262, 1268. Primary dilutions of various Aroclors are available from U.S. EPA, EMSL-Cincinnati Quality Assurance Branch, 26 W. St. Clair Street, Cincinnat, Ohio 45268.

5.4.2 2-Chlorobiphenyt, 3-chlorobiphenyl, and decachlorobiphenyl 5.4.3 Pure individual PCBs as identified in the sample by mass spectrometry or indicated by retention data.

5.4.4 Alumina (Fisher A540 or equivalent).

5.4.5 Silica gel (Davison Grade 950 or equivalent).

5.4.6 Florisil (PR grade or equivalent).

5.4.7 Sulfuric acid A.C.S.

-5.4.8 Quality Control Check Sample -- Certified Samples of PCBs in oil matrices are available from U.S. EPA, E1SL-Cincinnati, 
Quality Assurance Branch, 26 W. St. Clair Street, Cincinnati, Ohio 45268.

5.5 Standard Stock Solutions -- Prepare primary dilutions of eacin of the Aroclors or individual PCBs by weighing approximately $0.01 \mathrm{~g}$ of material within $\pm 0.0001 \mathrm{~g}$. Dissolve and dilute to $10.0 \mathrm{~mL}$ with isooctane or hexane. Calculate the concentration in $\mu \mathrm{g} / \mu \mathrm{L}$. Store the primary dilutions at $4^{\circ} \mathrm{C}$ in 10 to $15-\mathrm{mL}$ narrow mouth, serew cap botties with Tefion cap liners. Primary dilutions are stable indefinitely if the seals are maintained. The validity of inhouse generated or stored primary and secondary dilutions must be verified on a quarterly basis by analyzing EMSL-CI Quality Control Check Samples or certified PCB standards.

5.6 Working Standards -- Prepare working standards similar in PCB composition and concentration to the samples by mixing and diluting the individual standard stock solutions. Dilute the mixture to volume with pesticide quality hexane. Calculate the concentration in $n g / \mu L$ as the individual Aroclors (Section 11.4) or as the individual PCBs (Section. 11.5). Store dilutions at $4^{\circ} \mathrm{C}$ in 10 to 15-mL narrow mouth, screw cap bottles with Teflon cap liners. If the seals are maintained, these secondary dilutions can be stored indefinitely. (See Section 5.5.)

5.7. Laboratory control standard (LCS) -- Prepare a LCS by spiking a PCB free oil typical of the matrix normally analyzed, such as a transformer $0 i 1$, at $50.0 \mathrm{mg} / \mathrm{Kg}$ with a PCB mixture typical of those normally found in the samples, such as Aroclor 1250 at $50.0 \mathrm{mg} / \mathrm{kg}$.

5.8 PCB Locator Mixture -- Prepare a PCB locator mixture containing 0.1 $\mathrm{ng} / \mathrm{LL}$ of 2-chlorobipheny1, $0.1 \mathrm{ng} / \mathrm{LL} 3$-chiorobipheny1, $0.5 \mathrm{ng} / \mathrm{\mu L}$ 
Aroclor 1242, $0.5 \mathrm{ng} / \mu \mathrm{L}$ Aroclor 1260, and $0.2 \mathrm{ng} / \mu \mathrm{L}$ Aroclor $1268 \mathrm{in}$ hexane $10.1 \mathrm{ng} / \mathrm{uL}$ of decachlorobiphenyl can be substituted for Aroclor 1268). Use the chromatogram generated by the PCB locator mixture to help identify the retention times of the various $P C B$ isomers commonly found in conmercial PCB mixtures.

6. Sample Collection and Handling

6.1 Sample containers should have a volume of $20 \mathrm{~mL}$ or more and have Tefion or foil lined screw caps.

\subsection{Sample Bottle Preparation}

6.2.1 Wash alt sample bottles and seals in detergent solution. Rinse first with tap water and then with distilled water. Allow the bottles and seals to drain dry in a contaminant free area. Then rinse seals with pesticide grade hexane and allow to air dry.

6.2.2 Heat sample bottles to $400^{\circ} \mathrm{C}$ for 15 to 20 minutes or rinse with pesticide grade acatone or hexane and allow to air dry.

6.2.I Store the clean bottles inverted or sealed until use.

6.2.4 Sample bottles can be reused. Prior to reuse, rinse the bottles and seais 3 times with hexane, allow to air dry, and then proceed to Section 6.2.1.

6.3 Sample Preservation -- The samples should be stored in a c001, dry, dark area until anaiysis. Storage times in excess of 4 weeks are not recommended for unknown or underined sample matrices.

6.4 Sample Collection

6.4.1 Fill a large container such as a $500-\mathrm{mL}$ beaker from a representative area of the sample source. If practical, mix the sample source prior to sampling. 
6.4.2 Fill a minimum of two $20-\mathrm{mL}$ sample bottles (Field Sample I (FS1) and Field Sample 2 (FS2)) approximately $80 \%$ full from the sampling container.

6.4.3 Repeat Sections 6.4.1 and 6.4.2 if there is a need to monitor sampiing precision as described in Section 10.6.

\section{Procedure}

7.1 The approximate PCB concentration of the sample may be determined by $x$-ray fluorescence (total halogen measurement), microcoulometry (total halogen measurement), density measurements, or by analyzing a very dilute mixture of the sample $(10,000: 1)$ according to Section 7.4.

7.2 For samples in the 0 to $100 \mathrm{mg} / \mathrm{Kg}$ range, difute at the rate of $100: 1$ in hexane.

T.2.1 Pipet $1.0 \mathrm{~mL}$ of sample into a $100-\mathrm{mL} \cdot v 0.7$ umetric flask using a $1.0-\mathrm{mL}$ Mohr pipet. For viscous samples, cut the capillary tip off the pipet. Dilute to volume with hexane. Stopper and mix.

7.2.2 Using the same pipet as in Section 7.2 .1 , deliver $1.0 \mathrm{~mL}$ of sample into a tared $10-\mathrm{mL}$ beaker weighed to $=.001 \mathrm{~g}$. Reweigh the beaker to $\pm .001 \mathrm{~g}$ to determine the weight of samp.le used in T.2.1.

7.2.3 As an alternative to Sections 7.2.1 and 7.2.2, weigh approximately $1 \mathrm{gram}$ to $\pm .001 \mathrm{~g}$ of sample in a $100-\mathrm{mL}$ volumetric flask and dilute to volume with hexane.

7.2.4 Analyze the diluted sample according to Section 7.4 or store the diluted sample in a narrow mouth bottle with a Tefion lined screw cap. 
7.3 For samples above $100 \mathrm{mg} / \mathrm{Kg}$ in concentration, dilute at a rate of $1000: 1$ in hexane.

7.3.1 Pipet $0.10 \mathrm{~mL}$ of sample into a $100-\mathrm{mL}$ volumetric flask using a. $0.10 \mathrm{~mL}$-Mohr pipet. Oilute to volume with hexane, stooper and mix.

7.3.2 Using the same pipet as in Section 7.3.1, deliver $0.10 \mathrm{~mL}$ of sample into a tared $10 \mathrm{~mL}$ beaker to $=.0001 \mathrm{~g}$. Reweigh the beaker to determine the weight of sample used in Section T.3.1.

T.3.3 As an alternative to Sections 7.3.1 and 7.3.2, weigh approximately $0 . T$ gram to $\pm .000 T \mathrm{~g}$ of sample and in a $100 \mathrm{~mL}$ volumetric flask. Dilute to volume with hexane.

7.3.4 Analyze the difuted sample according to Section 7.4 or store the diluted sample in a narrow mouth bottle with a Tefilon lined screw cap.

T.3.5. If the concentration of PCBs is still too high for the chromatographic system, prepare secondary dilutions from Sections 7.3.1 or 7.3.3, until acceptable leveis are obtained.

7.4 Analyze the sample by injecting the hexane mixture into the gas chromatograph using auto injectors or the solvent flush technique. 4

7.4.1 Recommended injection volumes: Halogen speciific detector -4 to $5 \mu \mathrm{L}$, ECD 2 to $3 \mu \mathrm{L}$. Smaller volumes may be injected when auto injectors are used if the resulting method detection limits are alsceptable.

Note: When sami-specific detectors are used, cleanup techniques (see Section 4.2.2) should be routinely incorporated into the analys is scheme prior to injection. 
7.5 If the resulting chromatogram shows evidence of column flooding or nonlinear detector responses, further dilute the sample according to Section 7.3.5.

7.6 Determine whether or not PCBs are present in the sample by comparing the sample chromatogram to that of the PCB locator mixture Section 5.8 .

7.6.1 If a saries of peaks in the sample match some of the retention times of PCBs in the PCB locater mixture, attempt to identify the source by comparing chromatograms of each standard prepared from commereial mixtures of PCBs (see Section 5.6). Proceed to Section 11.4 if the source of PCBs is identified.

7.6.2 If the sample contains a complex mixture of PCBs, proceed to Section 11.5.

T.6.3 If a dilution ratio of 1000:1 (Section 7.3) or higher was analyzed and no measurable PCB peaks were detected, analyze an aliquot of sample diluted to $100: 1$.

7.6.4 If several PCB interference problems are encountered or if PCB ratios do not match standards, proceed to Section 8 , use alternate columns, or use GC/MS to verify whether or not the nonrepresentative patterns are due to PCBs.

8. Cleanup

Several tested cleanup techniques are described. Depending upon the complexity of the sample, one or all of the techniques may be required to resolve the PCBs from interferences.

8.1 Acid Cleanup 
8.1.1 Place $5.0 \mathrm{~mL}$ of concentrated sulfuric acid into a $40-\mathrm{mL}$ narrow mouth screw cap bottle. Add $10.0 \mathrm{~mL}$ of the diluted sample. Seal the bottle with a Tefion lined screw cap and shake for 1 minute.

8.1.2 Allow the phases to separate, transfer the sample (upper phase) to a clean narrow mouth screw cap bottle. Seal with a Tefion lined cap.

8.T.3 Analyze according to Section 7.4.

8.1.4 If the sample is highty contaminated, a second or third acid cleanup may be employed.

NOTE: This cleanup technique was tested over a 6 -month period of time using both electron capture and electrolytic conductivity detectors. Care was taken to exclude any samples that formed an emulsion with the acid. The sample was withdrawn well above the sampleadid interface. Under these conditions, no adverse effects associated with column performance and detector sensitivity to PCBs were noted. This cleanup technique could adversely affect-the-chromatographic column performance for samples containing analytes other than PCBs.

\subsection{Florisil Column Cleanup}

8.2. I Variances between batches of Florisil may affect the elution volume of the various PCBs. For this reason, the volume of solvent required to completely elute all of the PCBs must be verified by the analyst. The weight of florisil can then be adjusted accordingly.

8.2.2 Place a $20.0 \mathrm{~g}$ charge of $\dot{F}$ lorisil, activated at $130^{\circ} \mathrm{C}$, into a Ghromaflex column. Settie the Florisil by tapping the column. Add about $1 \mathrm{~cm}$ of anhydrous sodium sulfate to the top of the Florisil. Pre-eiute the column with 70 to 80 $\mathrm{mL}$ of hexane. Just before the exposure of the sodium sulfate layer to air, stop the flow. Discard the eluate. 
8.2.3 Add $2.0 \mathrm{~mL}$ of the undliuted sample to the column with a 2- $\mathrm{mL}$ Mohr pipet. For viscous samples, cut the capillary tip off the pipet. Add $225 \mathrm{~mL}$ of hexane to the column. Carefully wash down the inner wall of the column with a small amount of the hexane prior to adding the total volume. Collect and discard the first $25.0 \mathrm{~mL}$.

8.2.4 Collect exactly $200 \mathrm{~mL}$ of hexane eluate in a $200-\mathrm{mL}$ volumetric flask. All the PCBs must be in this fraction.

8.2.5 Using the same pipet as in Section 8.2 .2 , deliver $2.0 \mathrm{~mL}$ of sample into a tared $10-\mathrm{mL}$ beaker weighed to $\pm 0.001 \mathrm{~g}$. Reweigh the beaker to determine the weight of the sample diluted to $200 \mathrm{~mL}$.

\subsubsection{Analyze the sample according to Section 7.4.}

\subsection{Alumina Column Cleanup}

8.3.1 Adjust the activity of the alumina by heating to $200^{\circ} \mathrm{C}$ for 2 to 4 hours. When cool, add 3\% water (weight:weight) and mix until uniform. Store in a tightly sealed bottle. Allow the alumina to equilibrate at least 30 minutes before use. Adjust activity weekly.

8.3.2 Variances between batches of alumina may affect the elution volume of the various PCBs. For this reason, the volume of solvent required to completely eiute all of the PCBs must be verified by the analyst. The weight of Alumina can then be adjusted accordingly.

8.3.3 Place a $50.0 \mathrm{~g}$ charge of alumina into a Chromaflex column. Settle the alumina by tapping. Add about $1 \mathrm{~cm}$ of anhydrous sodium sulfate to the top of the alumina. Pre-elute the 
column with 70 to $80 \mathrm{~mL}$ of hexane. Just before exposing the sodium sulfate layer to air, stop the flow. Oiscard the eluate.

8.3.4 Add $2.5 \mathrm{~mL}$ of the undfluted sample to the column with a $5-\mathrm{mL}$ Mohr pipet. For viscous samples, eut the capillary end off the pipet. Add $300 \mathrm{~mL}$ of hexane to the column. Carefully wash down the inner walls of the column with a small volume of hexane prior to adding the total volume. Collect and discard the 0 to $50 \mathrm{~mL}$ fraction.

8.3.5 Collect exactiy $250 \mathrm{~mL}$ of the hexane in a $250-\mathrm{mL}$ volumetric flask. All the PCBs must be in this fraction.

8.3.6 Using the same pipet as in 8.3.4, deliver $2.5 \mathrm{~mL}$ of sample into a tared $10-\mathrm{mL}$ beaker $\pm 0.001 \mathrm{~g}$. Reweigh the beaker to determine weight of sample diluted to $250 \mathrm{~mL}$.

\subsubsection{Analyze the sample according to Section 7.4.}

\subsection{Silica Gel Column Cleanup.}

8.4.1 Activate silica gel at $135^{\circ} \mathrm{C}$ overnight.

8.4.2 Variances between batches of silica gel may affect the elution volume of the various PCBs. For this reason, the volume of solvent required to completely elute all of the PCBs must be verified by the analyst. The weight of silica gel can then be adjusted accordingly.

8.4.3 Place a $25 \mathrm{~g}$ charge of activated silica gel into a Chromaflex column. Settle the silica gel by tapping the column. Add about $\mathrm{l} \mathrm{cm}$ of anhydrous sodium sulfate to the top of the silica gel. 
8.4.4 Preelute the column with about 70 to $80 \mathrm{~mL}$ of hexane. Just before exposing the sodium sulfate layer to air, stop the flow. Discard the eluate.

8.4.5 Add $2.0 \mathrm{~mL}$ of the undifuted sample to the column with a $2-\mathrm{mL}$ Mohr pipet. For viscous samples, cut the capillary tip off the pipet.

8.4.6 Wash down the inner wall of the column with $5 \mathrm{~mL}$ of hexane.

8.4.T Elute the PCBs with $195 \mathrm{~mL}$ of $10 \%$ diethylether in hexane volume: volume.

8.4.8 Collect exactly $200 \mathrm{~mL}$ of the eluate in a $200-\mathrm{mL}$ volumetric

- flask. All the PCBs must be in this fraction.

8.4.9 Using the same pipet as in Section 8.4.5, deliper $2.0 \mathrm{~mL}$ of sample into a tared $10-m L$ beaker $( \pm 0.001 \mathrm{~g})$. Reweigh to determine the weight of sample diluted to $200 \mathrm{~mL}$.

8.4.10 Analyze the sample according to Section 7.4.

\subsection{Gel Permeation Cleanup}

8.5.1 Set up and calibrate the gel permeation chromatograph with an 5X-3 column according to the instruction manual. Use 15\% methylene chioride in cyclohexane (volume:volume) as the mobtl phase.

8.5.2 Place $1.0 \mathrm{~mL}$ of sample into a $100-\mathrm{mL}$ volumetric flask, using a l-mL Mohr pipet. For kiscous samples, cut the capillary tip off the pipet.

8.5.3 Dilute the sample to volume, using $15 \%$ methylene chloride in cyclohexane (volume:volume).

8.5.4 Using the same pipet as in Section 8.5 .2 deliver $1.0 \mathrm{~mL}$ of sample into a tared $10-\mathrm{mL}$ beaker $=0.001 \mathrm{~g}$. Reweigh the 
beaker $\pm 0.001 \mathrm{~g}$ to determine the weight of sample used in Section 8.5.2.

8.5.5 As an alternative to Sections 8.5.2 and 8.5.3 weigh approximately 1 gram $\pm 0.001 \mathrm{~g}$ of sample and dilute to $100.0 \mathrm{~mL}$ in 15\% methylene chloride in cyclohexane (volume:volume).

8.5.6 Inject $5.0 \mathrm{~mL}$ of the diluted sample into the instrument. Collect the fraction containing the $\mathrm{Cl}_{1}$ through $\mathrm{Cl}_{10}$ PC3s (see operator's manual) in a $K-0$ flask equipped with a 10-mL ampui.

8.5.7 Concentrate the Section $\mathbf{8 . 5 . 4}$ fraction down to less than 5 $m L$, using $K-0$ evaporative concentration techniques.

8.5.8 Dilute to $5.0 \mathrm{~mL}$ with hexane, then analyze according to Section 7.4. Be sure to use $100 \mathrm{~mL}$ as the dilution volume for the final calculation.

\subsection{Acetonitrile Partition}

8.6. T Place $10.0 \mathrm{~mL}$ of the previously diluted sample into a $125 \mathrm{~mL}$ separatory funnel. Add $5.0 \mathrm{~mL}$ of hexane. Extract the sample four times by shaking vigorously for one minute with $30 \mathrm{~mL}$ portions of hexane-saturated acetonitrile.

8.6.2 Transfer and combine the acetonitrile phases to a $1-6$ separatory funnel and add $650 \mathrm{~mL}$ of distilled water and $40 \mathrm{~mL}$ of saturated sodium chloride solution. Mix thoroughly for 30 to 35 seconds. Extract with two $100 \mathrm{~mL}$ portions of hexane by vigorousiy shaking about 15 seconds.

8.6.3 Combine the hexane extracts in a $1-L$ separatory funnel and wash with two $100 \mathrm{~mL}$ portions of distilled water. Discard the water layer and pour the hexane layer through a 
column (Section 4.8) packed with 3 to 4 inches of anhydrous sodium sulfate. Drain the column into a $500-\mathrm{mL} K-0$ flask equipped with a $10-m L$ ampul. Rinse the separatory funnel and column with three $10 \mathrm{~mL}$ portions of hexane.

8.6.4 Concentrate the extracts to 6 to $10 \mathrm{~mL}$ in the $K-0$ evaporator in a hot water bath, then adjust the volume to $10.0 \mathrm{~mL}$. Be sure to use the correct dilution volume (see Section 8.6.1) for the final calculation.

8.6.5 Analyze according to Section 7.4.

\subsection{FTorisil siurry. Cleanup}

8.7.1 Place $10 \mathrm{~mL}$ of the diluted sample into a $20-\mathrm{mL}$ narrow mouth screw cap container. Add $0.25 \mathrm{~g}$ of Florisil. Seal with a Teflon lined screw cap and shake for 1 minute.

8.7.2 Allow the Florisil to settle thẹn decant the treated solution into a second container. Analyze according to Section 7.4.

9. Calibration

9.1 Single Point Calibrations -- Prepare calibration standards from

- standard stock solutions in hexane that are close to the unknown in composition and in concentration. If when using an electrolytic conductivity detector the sample response is in the low level nonlinear detection area, the ealibration point must then be within 20\% of the sample. The ECO must be operated only within its linear response range.

9.2 As an alternative to Section 9.1, prepare a calibration curve for each Aroclor or PCB detected in the sample. The standard curve must contain at least 3 points, two of which must bracket the 
sample concentration. When using an electrolytic conductivity detector, if the sample response is in a low level nonlinear area of the calibration curve, two of the calibration points must be within 20\% of the unknown. The calibration curve must be checked daily, using the Laboratory Control Standard Section 5.T. If the calibration curve is not within 15\% of the Laboratory Control Standard, recalibrate the instrument. If an electron capture detector is used then it will be necessary to correct the Laboratory Control Standard value for recovery (see Section 3.4). Use the recovery value determined the same day the calibration curve was generated. The corrected value must be within 15\% of the spike value, otherwise the instrument must be recalibrated.

10. Precision and Accuracy

10.1 Each laboratory using this method is required to operate a formal quality control program. The minimum requirements of this program consists. of an initial demonstration of laboratory capability and the analysis of spiked samples as a continuing check on performance. The laboratory is required to maintain periormance records to define the quality of data that is generated. After January 1, 1982, ongoing performance checks must be compared with established performance criteria to determine if the results of analyses are withir accuracy and precision limits expected of the method.

10.1.1 Before performing any analyses; the analyst must demonstrate the ability to generate acceptable accuracy and precision with this method. This ability is established as described in Section 10.2. 
10.1.2 In recognition of the rapid advances occurring in chromatography, the analyst is permitted certain options to improve the separations or lower the cost of measurements. Each time such modifications are made to the method, the analyst is required to repeat the procedure in Section 10.2 .

10.1.3 The laboratory must spike and analyze a minimum of $10 \%$ of all samples to monitor continuing laboratory performance. This procedure is described in Section 10.4.

10.2 To establish the ability to generate acceptabie accuracy and precision in the use of this method, the analyst must perform the following operations.

10.2.1 For each commercial PCB mixture or individual PCB isomer normally measured, select $a$ spike concentration in the range of 25 . to $75 \mathrm{mg} / \mathrm{kg}$. Using stock standards, prepare a spiking concentrate in isooctane 1000 times more concentrated than the selected concentration.

10.2.2 Using a microsyringe, add $100 \mu L$ of the $P C B$ concentrate to each of a minimum of four $100 \mathrm{~mL}$ aliquots of PCB fres oil. A representative waste $0 i 1$ may be used in place of the clean oil, but one or more additional aliquots must be analyzed to determine background levels, and the spike level must exceed twice the background level for the test to be valid. Analyze the aliquots according to the method beginning in Section 7.

10.2.3 Calculate the average percent recovery, $(R)$, and the relative standard deviation(s) of the concentration found. 
Waste ofl background corrections must be made before $R$ calculations are performed.

10.2.4 Using the appropriate data from Tables 7, 8, and 9, determine the recovery and single operator precision expected for the method and compare these results to the values calculated in Section 10.2.3. If the data are not comparable, the analyst must review and remedy potential problem areas and repeat the test.

10.2.5 After January 1,1982 , the values for $R$ and $s$ must meet method performance criteria provided by the U.S. EPA, Environmental Monitoring and Support Laboratory, Cincinnati, Ohio, before any samples may be analyzed.

10.3 The analyst must calculate method performance criteria and define the performance of the laboratory for each spike_concentration and parameter being measured.

10.3.1 Calculate upper and lower control limits for method performance:

$$
\begin{aligned}
& \text { Upper Control Limit (UCL) }=R+3 \mathrm{~s} \\
& \text { Lower Control Limit (LCL) }=R-3 \mathrm{~s}
\end{aligned}
$$

where $R$ and $S$ are calculated as in Section 10.2.3.

The UCL and LCL can be used to construct control charts ${ }^{4}$

that are useful in observing trends in performance. After January 1, 1982, the control limits above must be replaced by method performance criteria provided by the U.S. Environmental Protection Agency.

10.3.2 The laboratory must develop and maintain separate accuracy statements of laboratory performance for waste oil samples. 
An accuracy statement for the method is defined as $R \pm s$. The accuracy statement should be developed by the analys is of 4 aliquots of waste oil as described. in Section 10.2.2, followed by the calculation of $R$ and $s$. Alternately, the analyst may use four waste oil data points gathered through the requirement for continuing quality control in Section 10.4. The accuracy statements should be updated regularly.

10.4 The laboratory is required to collect a portion of their samples in duplicate to monitor spike recoveries. The frequency of spiked sample analysis must be at least $10 \%$ of all samples or one sample per month, whichever is greater. One aliquot of the sample must be spiked and analyzed as described in Section 10.2.2 at two times the background level. If the recovery for a particular parameter does not falt within the control limits for method-performance, the resuits reported for the parameter in all samples processed as part of the same set must be qualified as described in Section 11.9. The laboratory should monitoring the frequency of data so qualified to ensure that it remains at or below $5 \%$.

10.5 Before processing any samples, the analyst should demonstrate through the analysis of a PCB free oil sample, that all glassware and reagents are free of interferences. Each time a set of samples is analyzed or there is a change in reagents, a laboratory reagent blank should be processed as a safeguard against contamination.

10.6 It is recommended that the laboratory adopt additional quality assurance practices for use with this method. The most productive specific practices depend upon the needs of the laboratory and the nature of the samples. Field duplicates may be analyzed to monitor 
the precision of the sampling technique. When doubt exists ragaraing che cuencitication or a peak on the chromatogram, confirmatory techniques such as GC with a dissimilar column, specific element detector, or MS must be used. Whenever possibi 三the laboratory should perform analysis of standard reference materials and participate in relevant performance evaluation studies.

10.7 Analyze the Laboratory Control Standard Section 5.7 daily befor any samples are analyzed. Instrument status checks, calibration curve validation and long term precision are obtained from these data. In addition, response data obtained from the Laboratory Control Standard can be used to estimate the concentration of th: unknowns. From this information, the appropriate standard dilutions can be determined for single point calibrations.

10.8 Analyze on a quartarly basis an EMSL-Cincinnati Quality Control Sample (Section 5.4.8) of PCBs in oil or whenever new standard dilutions are prepared.

10.8.1 The results of the EMSL Quality Control Sample should agras within $15 \%$ of the true value. If they do not, the analys= must check each step in the standard preparation procedure to resoive the problem.

11. Calculations

11. 1 Locate each PCB in the sample chromatogram by comparing the retention time of the suspect - ak to the retention data gather $\equiv$ : from analyzing standards and intarference free Quality Control Samples. The width of the retention time window used to make 
identifications should be based upon measurements of actual retention time variations of standards over the course of a day. Three times the standard deviation of a retention time for each PCB Can be used to calculate a suggested window size; however, the experlence of the anaiyst should weigh heavily in the interpretation of chromatograms.

11.2 If the response for any PCB peak exceeds the working range of the system, dilute according to Section T.3.5.

11.3 If accurate measurment of the peaks in the PCB elution area of the chromatogram is prevented by the presence of interferences, further cleanup is required.

11.4 If the parent Aroclors or PCBs are identified in the sample, calibrate according to Section 9. The concentration of the PCBs in the sample are calculated by comparing the sum of the responses for each PCB in the standard to the sum of all of the PCBs in the sample. This is particularly important as sample concentrations approach within $20 \%$ of $50 \mathrm{mg} / \mathrm{kg}$ or any other EPA regulated concentration. If caiculations are based upon a single PCB peak or upon a small percentage of the total PCB peaks, serious errors may result. Peaks comprising less than 50\% of the total can be disregarded only if 1) interierence problems persist after cleanup; 2) the source of PCBs is obvious; or 3) the concentration of PCBs are not within $\pm 20 \%$ of an EPA controlled value such as $50 \mathrm{mg} / \mathrm{kg}$. 11.4.1 Measure the peak height or peak area of each peak identified as a PCB in Section 11.1 in both the sample and the standard. 
11.4.2 Use the following formula to calculate the concentration of PCBs in the sample:

Concentration $m g / K g=\frac{B \times V_{t}}{A \times W}$

$$
\begin{aligned}
& A=\frac{\text { Sum of standard Peak Heights (areas) }}{\mathrm{ng} \text { of standard injected }}=\mathrm{mm} / \mathrm{ng} \\
& B=\frac{\text { Sum of sample Peak Heights (areas) }}{\mu L \text { injected }}=\mathrm{mm} / \mathrm{LL} \\
& V_{t}=\text { difution volume of sample in } \mathrm{mL} \\
& W=\text { weight of the sample in grams }
\end{aligned}
$$

11.5 If the parent Aroclors or source of PCBs is not apparent, calculate the concentration according to the procedure of Webb and MeCal1. 6 The concentration of the PCBs in each peak is determined individually then added together to determine the total PCB content of the sample. Each PCB identified in the sample must-be-included in these calculations.

11.5.1 Small variations between Aroclor batches make it necessary to obtain standards prepared from a specific source of Aroclors. Primary dilutiors of these reference Aroclors will be available in 1981 from the Environmental Monitoring and Support Laboratory, Quality Assurance Branch, Cincinnati, Ohio 45268.

11.5.2 Analyze a standard mixture of Aroclors 1242, 1254 and 1260 under the conditions shown in Figures 3,5 , and 5 . Analyze the sample under the same conditions. Compare the resulting standard chromatograms to those shown in Figures 3, 5, and 6. Each PCB peak must be resolved as well or better than 
thosa shown in the figures. Determine the relative retention time (RRT) of each peak in the standards with respect to $P, p^{\prime}-D D E$ or assign the RRT shown in the figures to the corresponding peak in the standard. Identify the RRT of each PCB in the sample by comparing the sample chromatogram to the standard chromatograms.

11.5.3 Identify the most likely Aroclors present in the sample, using the Identification Flow Chart Figure 7.

11.5.4 Analyze standards according to Section 9, using the appropriate Arociors.

11.5.5 Determine the instrument response factor (A) for each individual PCB, using the following formula:

$$
\begin{aligned}
A= & \frac{\text { Peak Height (area) }}{\mathrm{Ng}_{i} \times \frac{\text { mean weight }}{100}} \\
\mathrm{Ng} i= & \begin{array}{l}
\mathrm{Ng} \text { of Aroclor standard injected } \\
\text { Obtain mean weight percent from Tables } 1 \\
\text { through } 6 .
\end{array}
\end{aligned}
$$

11.5.6 Calculate the concentration of each PCB in the sample using the following formula:

Concentration $\mathrm{mg} / \mathrm{Kg}=\frac{B \times V_{t}}{A \times W}$

$$
\begin{aligned}
& A=\text { Response factor from } 11.5 .5 \\
& B=\frac{\text { Peak Height (areas) of samole } \mathrm{mm} / \mathrm{uL}}{\mu L \text { injected }} \\
& V_{t}=\text { dilution volume of sample in } \mathrm{mL} \\
& W=\text { weight of sample in grams }
\end{aligned}
$$

The concentration of each PCB must be calculated and added together to obtain the total amount of PCBs present. 
11.6 Report all data in $\mathrm{mg} / \mathrm{Kg}$.

11.7 Round off all data to 2 significant figures.

11.8 Add all Aroclors and report what was used as the standard. For example, $57 \mathrm{mg} / \mathrm{Kg}$ measured as Arocior 1260 or $57 \mathrm{mg} / \mathrm{Kg}$ measured as Aroclors 1242 and 1260.

11.9 Data for the affected parameters of samples processed as part of a sat where the laboratory spiked sample recovery falls outside of the control limits in Section 10.4 must be labeled as suspect.

11.10 Determine the actual recovery for electron capture analyses of each sample in the uncorrected 40 to $50 \mathrm{mg} / \mathrm{kg}$ concentration range (see Section 3.4). Report the corrected value and the recovery.

12. Precision and Accuracy

12.1 The single laboratory data shown in Tables 7 through 9 were generated using the recommended procedures described in this method to analyze both spiked and nonspiked oil samples of varying degrees of complexity. Data for both the HED and ECD are present. These data were generated by the Physical and Chemical Methods Branch, Environmental Monitoring and Support Laboratory, Cincinnati, Ohio, 45268.

\section{References}

1. Federal Register, 40 CFR, Part 761.

2. Eichelberger, J. W., L.E. Harris and W. L. Budde. Anal. Chem., 46, 227 (1974).

3. Federai Register, Vol. 41, No. 232, Wednesday, December 1, 1976.

4. White, L. D., et al., AIHA Journal, 31, 225, (1970).

5. Handbook of Analytical Quality ControT in Water and Wastewater Laboratories. EPA-600/4-79-019, U.S. Environmental Monitoring and Support Laboratory, Cincinnati, Ohio 45268, March 1979.

6. Webb, R.G. and A.C. McCalT. J. Chrom. Sei., 11, 360 (1973). 
TABLE 1

Composition of Aroclor $1221^{a}$

\begin{tabular}{|c|c|c|c|}
\hline$R T^{b}$ & $\begin{array}{l}\text { Meäan } \\
\text { Weight } \\
\text { Percent }\end{array}$ & $\begin{array}{c}\text { Relative } \\
\text { Std. Dev. C }\end{array}$ & $\begin{array}{l}\text { Number of } \\
\text { Chlorines } d\end{array}$ \\
\hline
\end{tabular}

\begin{tabular}{|c|c|c|c|}
\hline $\begin{array}{l}11 \\
14 \\
16 \\
19 \\
21 \\
28\end{array}$ & $\begin{array}{r}31.8 \\
19.3 \\
10.1 \\
2.8 \\
20.8 \\
5.4\end{array}$ & $\begin{array}{r}15.8 \\
9.1 \\
9.7 \\
9.7 \\
9.3 \\
13.9\end{array}$ & $\begin{array}{ll}1 & \\
1 & \\
2 & \\
2 & \\
2 & \\
2 & 85 \%\end{array}$ \\
\hline 32 & 1.4 & 30.1 & $2 \quad 10 \%$ \\
\hline $\begin{array}{l}37 \\
40\end{array}$ & 1.7 & 48.8 & $\begin{array}{l}3 \\
3\end{array}$ \\
\hline Total & 93.3 & & \\
\hline
\end{tabular}

a Data obtained from. 6

6 Retention time relative to $p, p^{\prime}-D D E=100$. Measured from first appearance of solvent. Overlapping peaks that are quantitated as one peak are bracketed.

C Relative standard deviation of 17 analyses.

f From GC-MS data. Peaks containing mixtures of isomers of different chlorine numbers are bracketed. 
TABLE 2

Composition of Aroclor $1232^{\mathrm{a}}$

\begin{tabular}{|c|c|c|c|}
\hline$R^{T b}$ & $\begin{array}{l}\text { Mean } \\
\text { Weight } \\
\text { Percent }\end{array}$ & $\begin{array}{l}\text { Relative } \\
\text { Std. Dev. } C\end{array}$ & $\begin{array}{l}\text { Number of } \\
\text { Chlorines } d\end{array}$ \\
\hline
\end{tabular}

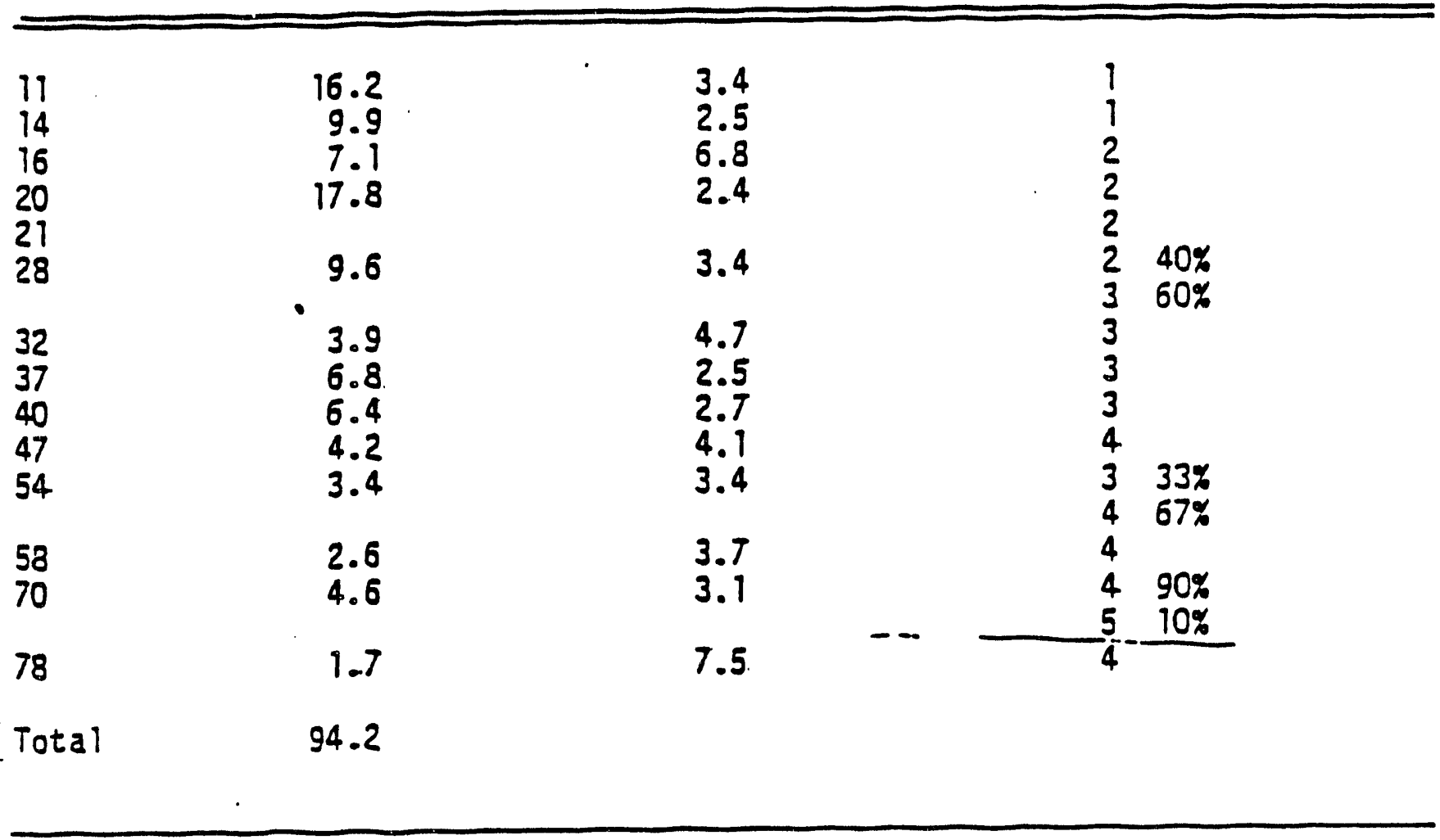

a Data obtained from. 6

$b$ Retention time relative to $p, p^{\prime}-D D E=100$. Measured from first appearance of solvent. Overlapping peaks that are quantitated as one peak are bracketed.

C Relative standard deviation of four analyses.

d From GC-MS data. Peaks containing mixtures of isomers of different chlorine numbers are bracketed. 
TABLE 3

Composition of Aroclor $1242^{\mathrm{a}}$

\begin{tabular}{|c|c|c|c|}
\hline$T^{b}$ & $\begin{array}{l}\text { Mean } \\
\text { Weight } \\
\text { Percent }\end{array}$ & $\begin{array}{r}\text { Relative } \\
\text { Std. Dev. C }\end{array}$ & $\begin{array}{l}\text { Number of } \\
\text { Chlorines } d\end{array}$ \\
\hline
\end{tabular}

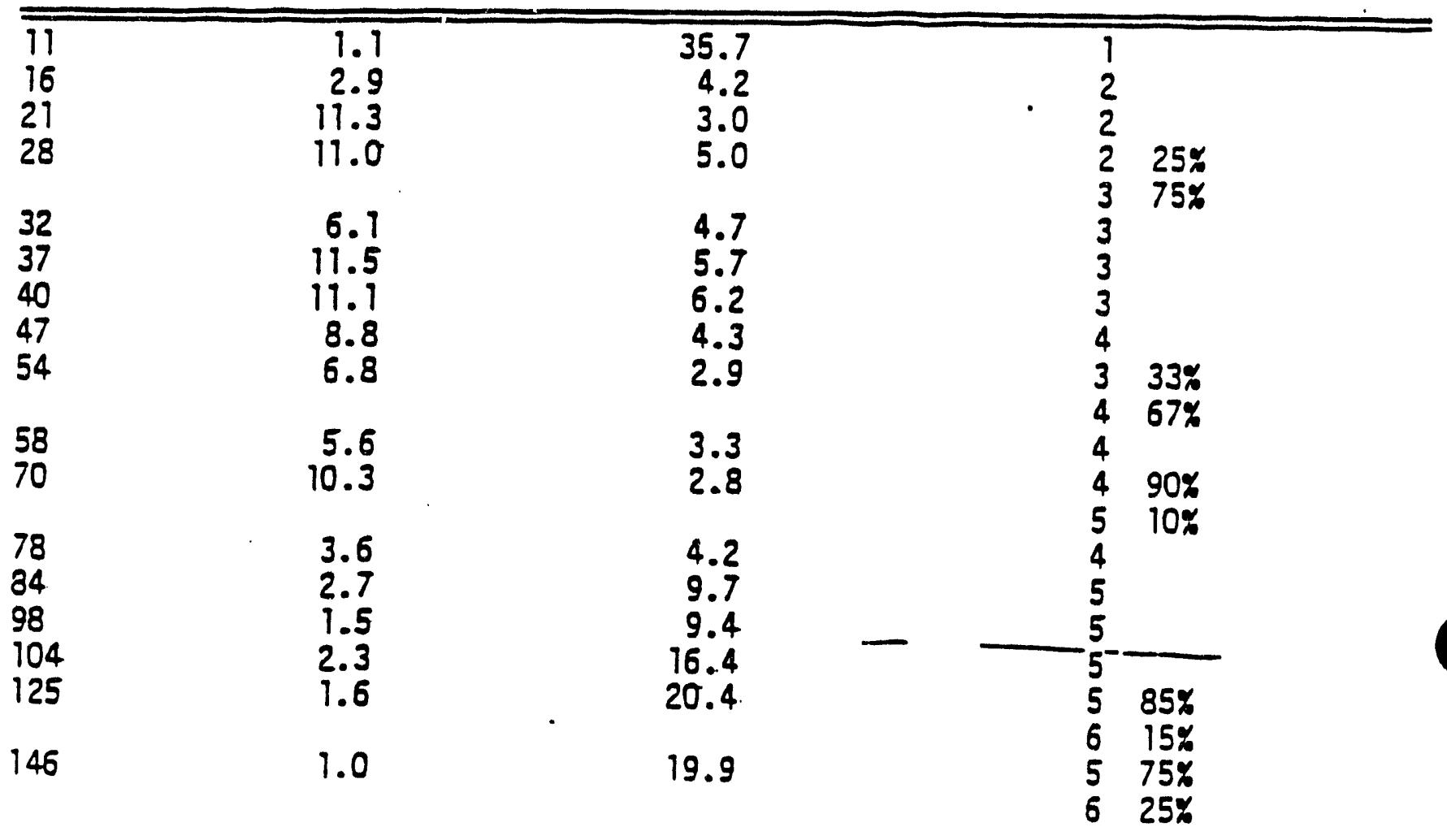

Total

98.5

a Data obtained from. 6 b Retention time relative to $p, p^{\prime}-D D E=100$. Measured from first appearance
of solvent.

C Relative standard deviation of six analyses

d From GC-MS data. Peaks containing mixtures of isomers of different chlorine numbers are bracketed. 
TABLE 4

Composition of Aroclor 1248a

Mean

$\begin{array}{cccc}\text { Weight } & \text { Relative } & \text { Number of } \\ \text { RRT } & \text { Percent } & \text { Std. Dev. } C & \text { Chlorines }\end{array}$

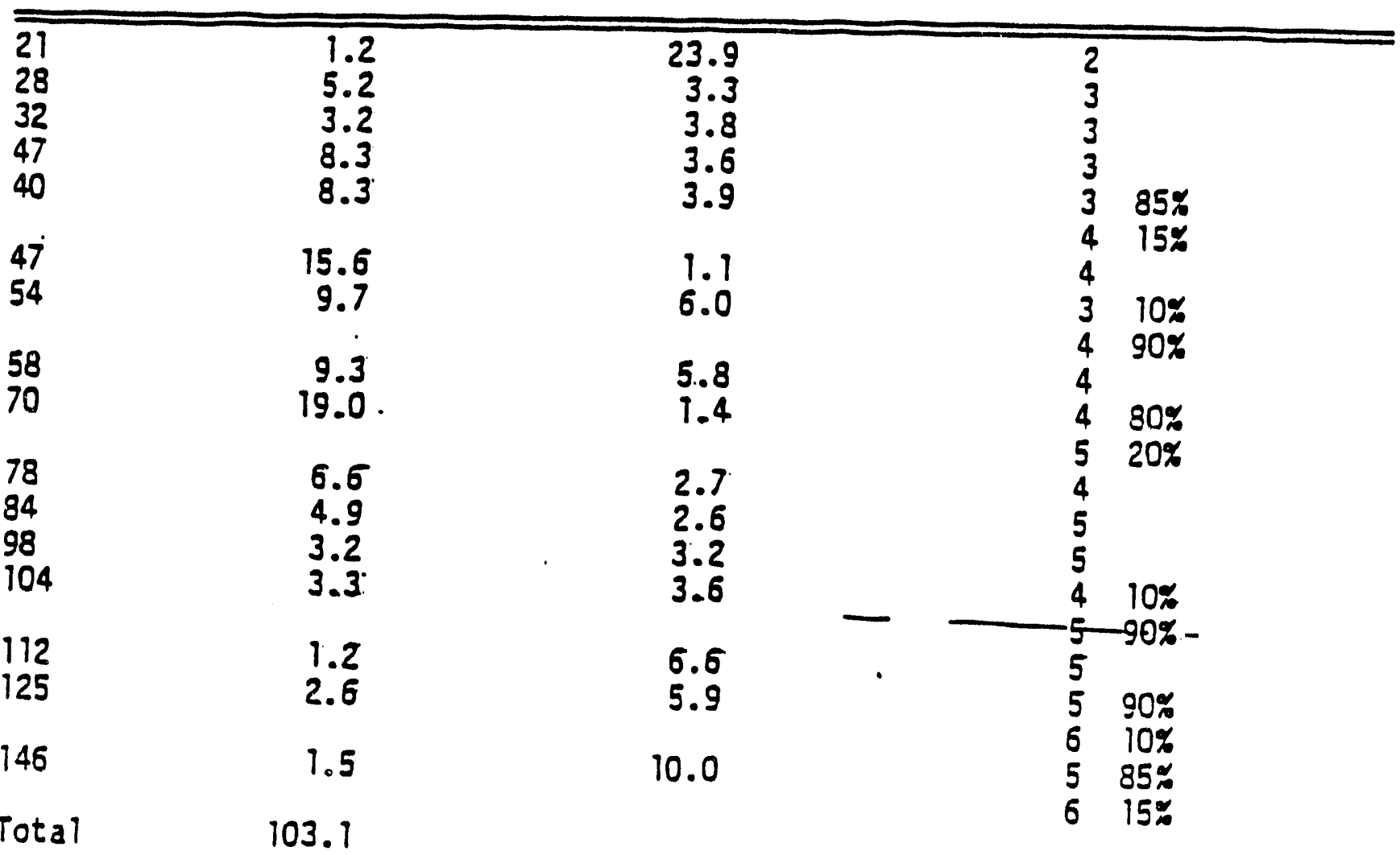

a Data obtained from. 6

betention time relative to $p, p^{\prime}-O D E=100$. Measured from first appearance
of solvent.

C Relative standard deviation of six analyses.

1 From GC-MS data. Peaks containing mixtures of isomers of different chlorine numbers are bracketed. 
TABLE 6

\section{Composition of Arocior $1260^{\circ}$}

\begin{tabular}{|c|c|c|c|}
\hline$R T^{b}$ & $\begin{array}{l}\text { Mean } \\
\text { Weight } \\
\text { Percent }\end{array}$ & $\begin{array}{l}\text { Relative } \\
\text { Std. Dev. C }\end{array}$ & $\begin{array}{l}\text { Number of } \\
\text { Chlorines } d\end{array}$ \\
\hline
\end{tabular}

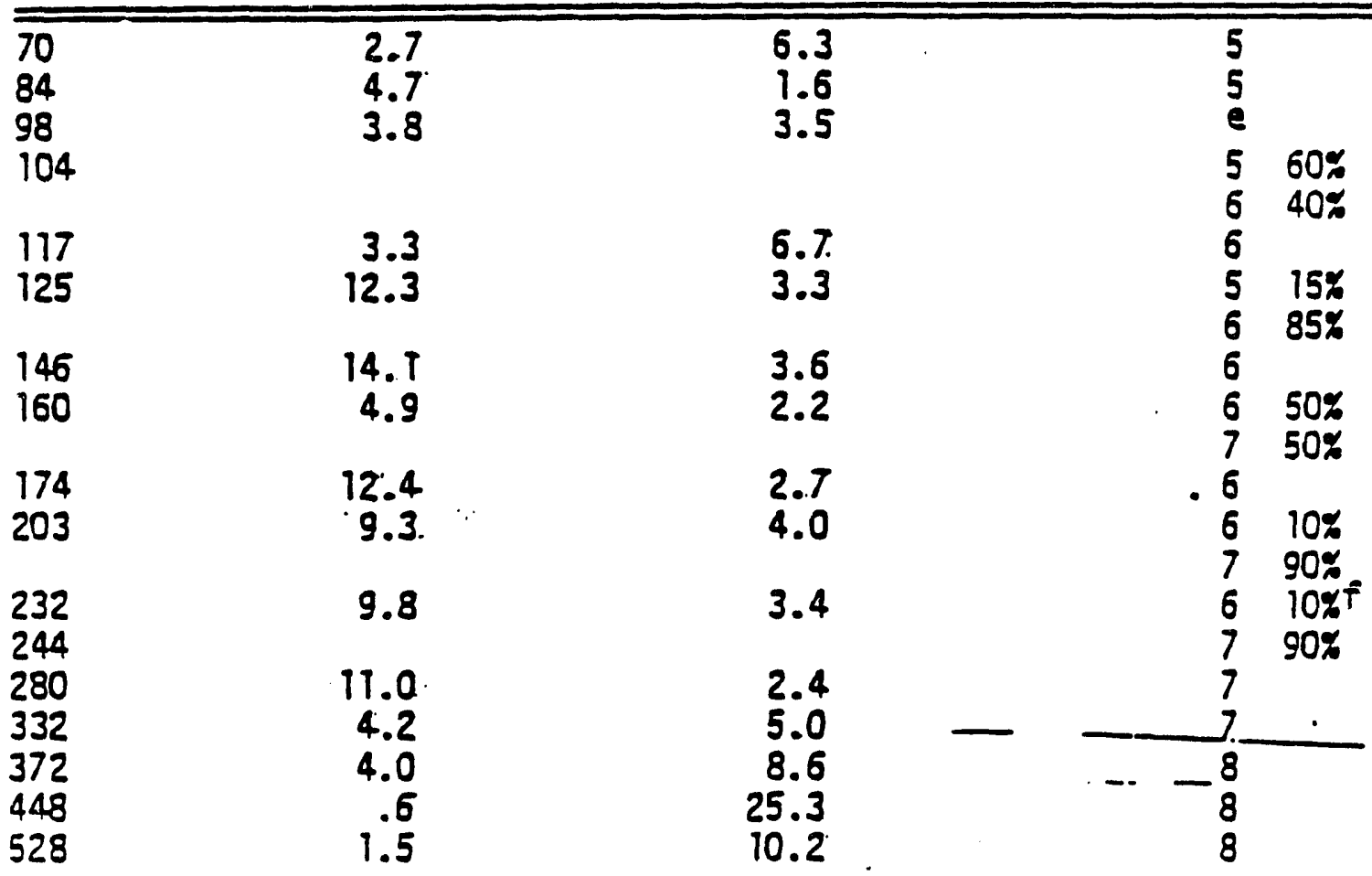

Total

98.6

a Data obtained from. 6

b Retention time relative to $p, p^{\prime}-D 0 E=100$. Measured from first appearance of solvent. Overlapping peaks that are quantitated as one peak are bracketed.

C Relative standard deviation of six analyses.

d From GC-MS data. Peaks containing mixtures of isomers of different chlorine numbers are bracketed.

e Composition determined at the center of peak 104 .

f Composition determined at the center of peak 232 . 
TABLE 7

ACCURACY AND PRECISION USING

SPIKED MOTOR OIL

\begin{tabular}{|c|c|c|c|c|c|c|c|}
\hline $\begin{array}{l}\text { Dilution } \\
\text { Ratio }\end{array}$ & Detector & $\begin{array}{l}\text { Method } \\
\text { Clean up }\end{array}$ & $\begin{array}{l}\text { Spike } \\
\mathrm{mg} / \mathrm{Kg}\end{array}$ & $\begin{array}{l}\text { Aroclor } \\
\text { Spike }\end{array}$ & $\begin{array}{l}\text { Ave. } \\
\text { Conc. } \\
\text { Found } \\
\mathrm{mg} / \mathrm{Kg}\end{array}$ & $\begin{array}{c}\text { (Precision) } \\
\text { Rel. Std. } \\
\text { Deviation } \\
\qquad\end{array}$ & $\begin{array}{l}\text { (Accuracy) } \\
\text { Percent } \\
\text { Recovered }\end{array}$ \\
\hline $\begin{array}{l}100: 1 \\
100: 1 \\
100: 1 \\
100: 1 \\
100: 1 \\
100: 1 \\
100: 1 \\
100: 1 \\
100: 1 \\
100: 1 \\
100: 1 \\
100: 1 \\
100: 1 \\
100: 1 \\
100: 1 \\
100: 1 \\
100: 1 \\
100: 1 \\
100: 1 \\
100: 1 \\
100: 1 \\
100: 1 \\
100: 1 \\
100: 1 \\
100: 1 \\
100: 1 \\
100: 1 \\
100: 1\end{array}$ & $\begin{array}{l}H E D \\
E C D \\
H E D \\
E C D \\
H E D \\
E C D \\
H E D \\
E C D \\
H E D \\
E C D \\
H E D \\
E C D \\
H E D \\
E C D \\
H E D \\
E C D \\
H E D \\
E C D \\
H E D \\
E C D \\
H E D \\
E C D \\
H E D \\
E C D \\
H E D \\
E C D \\
H E D \\
E C D\end{array}$ & $\begin{array}{r}\text { None } \\
\text { None } \\
\text { None } \\
\text { None } \\
8.1 \\
8.1 \\
8.1 \\
8.1 \\
8.2 \\
8.2 \\
8.2 \\
8.2 \\
8.3 \\
8.3 \\
8.3 \\
8.3 \\
8.4 \\
8.4 \\
8.4 \\
8.4 \\
8.5 \\
8.5 \\
8.5 \\
8.5 \\
8.6 \\
8.6 \\
8.6 \\
8.6\end{array}$ & $\begin{array}{l}30.3 \\
30.3 \\
31.1 \\
31.1 \\
30.3 \\
30.3 \\
31.1 \\
31.1 \\
30.3 \\
30.3 \\
31.1 \\
31.1 \\
30.3 \\
30.3 \\
31.1 \\
31 .-1 \\
30.3 \\
30.3 \\
31 . .1 \\
31.1 \\
30.3 \\
30.3 \\
31.1 \\
31.1 \\
30.3 \\
31.1 \\
30.3 \\
31.1\end{array}$ & $\begin{array}{r}1242 \\
1242 \\
1260 \\
1260 \\
1242 \\
1242 \\
1260 \\
1260 \\
1242 \\
1242 \\
1260 \\
1260 \\
1242 \\
1242 \\
1260 \\
1260 \\
1242 \\
-1242 \\
1260 \\
1260 \\
1242 \\
1242 \\
1260 \\
1260 \\
1242 \\
1242 \\
1260 \\
1260\end{array}$ & $\begin{array}{l}28.2 \\
26.7^{\mathrm{a}} \\
27.2 \\
23.9 \\
28.4 \\
25.4^{\mathrm{a}} \\
28.1 \\
24.3 \\
30.7 \\
27.3^{\mathrm{a}} \\
30.9 \\
31.0 \\
30.3 \\
28.9^{\mathrm{a}} \\
29.8 \\
30.8 \\
29.4 \\
26.4^{\mathrm{a}} \\
29.4 \\
23.6 \\
31.9 \\
23.4^{\mathrm{a}} \\
33.6 \\
30.9 \\
34.4^{2} \\
23.4^{\mathrm{a}} \\
29.1 \\
27.0\end{array}$ & $\begin{array}{r}4.2 \\
5.7 \\
2.0 \\
2.2 \\
11.5 \\
6.1 \\
8.0 \\
7.8 \\
2.4 \\
10.2 \\
3.6 \\
8.6 \\
8.6 \\
5.0 \\
4.7 \\
6.5 \\
-5.8 \\
5.3 \\
5.2 \\
4.5 \\
8.5 \\
3.0 \\
9.2 \\
5.5 \\
3.8 \\
4.4 \\
4.2 \\
4.6\end{array}$ & $\begin{array}{c}93.1 \\
88.1 \\
87.5 \\
76.8 \\
93.7 \\
83.8 \\
90.3 \\
78.1 \\
101 \\
90.1 \\
99.4 \\
99.7 \\
100 \\
95.4 \\
95.8 \\
99.0 \\
97.0 \\
87.1 \\
94.5 \\
75.9 \\
105 \\
77.2 \\
108 \\
99.4 \\
107 \\
77.2 \\
96.7 \\
86.7\end{array}$ \\
\hline
\end{tabular}

a Severe interference problems in elution area of 1242. Measurement based upon only 3 the 10 normally resolved major peaks. Clean up technique, Sections $8.1,8.2,8.3,8$. 8.5 , and 8.6 did not improve the quality of the 1242 chromatogram. If this were an unknown sample, it would be impossible to qualitatively identify the presenca of Aro1242 using ECD. The HED provided an interference free chromatogram. 
TABLE 8

ACCURACY AND PRECISION USING

WASTE TRANSFORMER FLUIDS

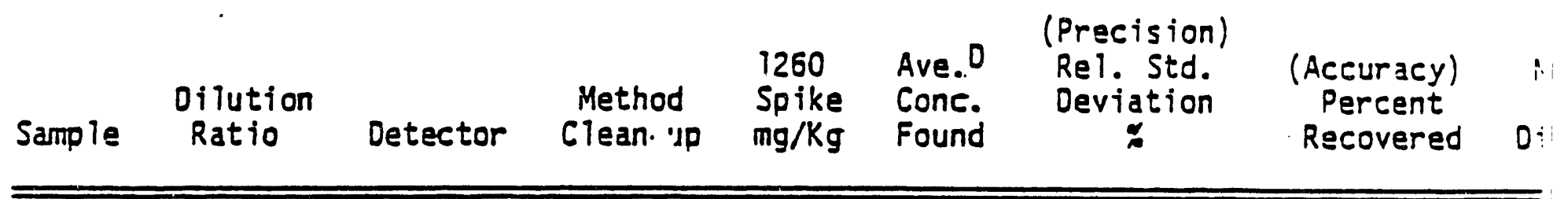

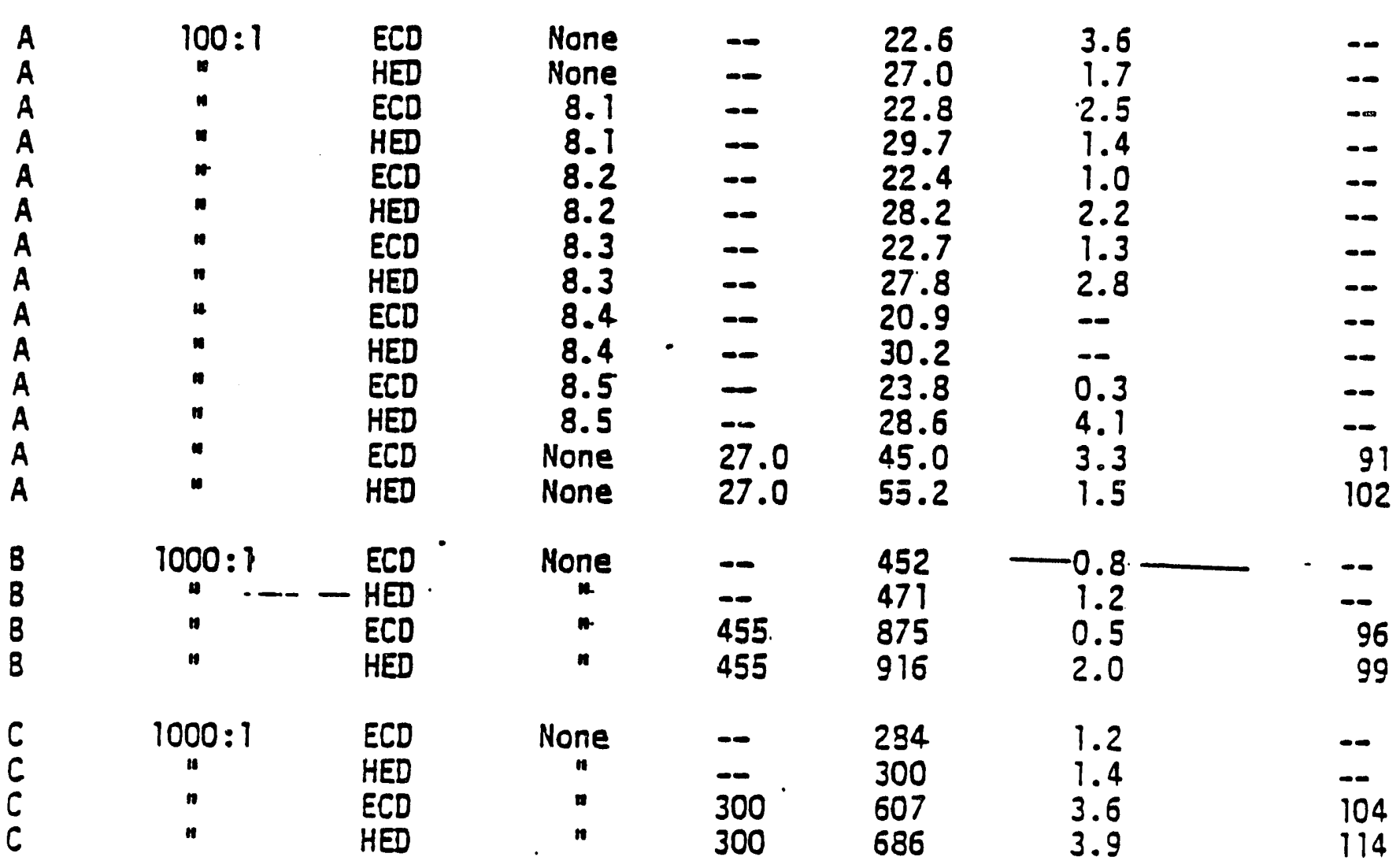

A - dark waste oil

B - black waste oil with suspended solids

$C$ - clear waste oil

D - all samples contained Aroclor 1260

e - duplicate analyses made at each dilution 
TABLE 9

Accuracy and Precision and Limit of Detection Data

Results of Analyses of Shell Transformer Fluid

Spiked with PCB̂s at 5.0 and $27 \mathrm{mg} / \mathrm{Kg}$

\begin{tabular}{|c|c|c|c|c|c|c|c|}
\hline \multirow[b]{2}{*}{ Aroclor } & \multicolumn{7}{|c|}{$\begin{array}{c}\text { Electron Capture Detector } \\
\text { (100:l Dilution) }\end{array}$} \\
\hline & $\begin{array}{c}\text { Spike } \\
\text { (mg/kg) }\end{array}$ & $\begin{array}{l}\text { Number of } \\
\text { Analyses }\end{array}$ & $\begin{array}{c}\text { Avg } \\
(\mathrm{mg} / \mathrm{kg})\end{array}$ & $\begin{array}{l}\text { Standard } \\
\text { Deviation }\end{array}$ & $x$ & Recovery & $\begin{array}{c}M O L a \\
(\mathrm{mg} / \mathrm{kg})\end{array}$ \\
\hline \multirow[t]{2}{*}{$\begin{array}{l}1221 \\
1242 \\
1254 \\
1260\end{array}$} & $\begin{array}{l}5.0 \\
5.0 \\
5.0 \\
5.0\end{array}$ & $\begin{array}{r}7 \\
14 \\
7 \\
14\end{array}$ & $\begin{array}{l}7.5 \\
3.8 \\
4.1 \\
4.7\end{array}$ & $\begin{array}{l}0.43 \\
0.18 \\
0.08 \\
0.18\end{array}$ & & $\begin{array}{r}150 \\
76 \\
82 \\
94\end{array}$ & $\begin{array}{l}1.4 \\
0.5 \\
0.2 \\
0.5\end{array}$ \\
\hline & & Electrol & $\begin{array}{l}\text { ytic Cor } \\
(100: 1\end{array}$ & $\begin{array}{l}\text { iductivity } \\
\text { Dilution) }\end{array}$ & te & tor & \\
\hline Aroclor & $\begin{array}{c}\text { Spike } \\
\text { (mg/kg) }\end{array}$ & $\begin{array}{l}\text { Number of } \\
\text { Analyses }\end{array}$ & $\begin{array}{c}\text { Avg } \\
(\mathrm{mg} / \mathrm{kg})\end{array}$ & $\begin{array}{l}\text { Standard } \\
\text { Deviation }\end{array}$ & $x$ & Recovery & $\begin{array}{c}\text { MDLa } \\
(\mathrm{mg} / \mathrm{kg})\end{array}$ \\
\hline $\begin{array}{l}1227 \\
1242 \\
1254 \\
1260\end{array}$ & $\begin{array}{l}5.0 \\
5.0 \\
5.0 \\
5.0\end{array}$ & $\begin{array}{l}6 \\
7 \\
6 \\
7\end{array}$ & $\begin{array}{l}7.5 \\
5.9 \\
5.8 \\
5.4\end{array}$ & $\begin{array}{l}0.23 \\
0.17 \\
0.16 \\
0.10\end{array}$ & & $\begin{array}{l}150 \\
118 \\
116 \\
108\end{array}$ & $\begin{array}{l}0.7 \\
0.5 \\
0.5 \\
0.3\end{array}$ \\
\hline
\end{tabular}

Shel1 Transformer $0 i 1+27$ ppm Aroclor - 1260

(100:1 Dilution) ${ }^{--}$

Detector

Spike Number of ( $\mathrm{mg} / \mathrm{kg}) \quad$ Analyses

Avg

Rel. Std.

\% Recovery

-.

ECD

HED

$27 \quad 14$

27

7

24.0

28.3

Deviation

:

CMDL $=$ Hethod Detection Limit at $39 \%$ confidence that the value is not zero. Note: At these values it would be impossible to identify Aroclor patterns with any degree of confidence. $1 \mathrm{mg} / \mathrm{Kg}$ appears to be a reasonable MDL..

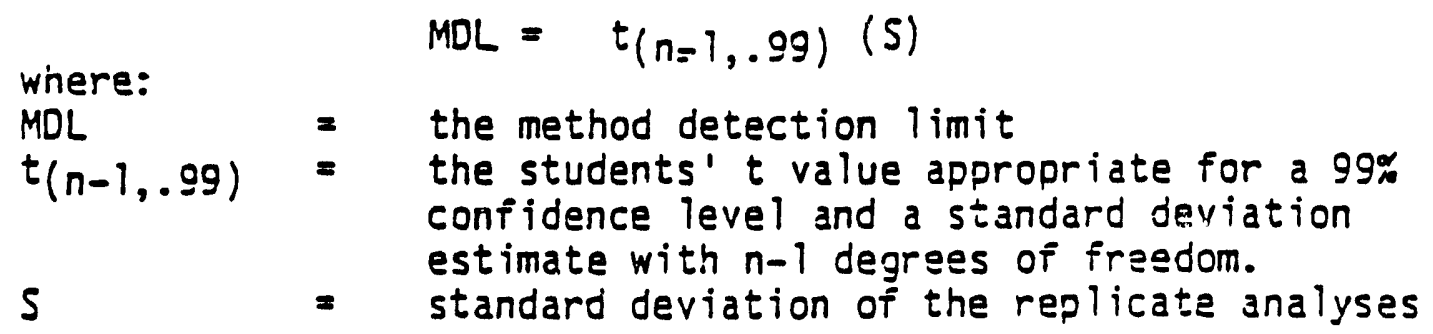




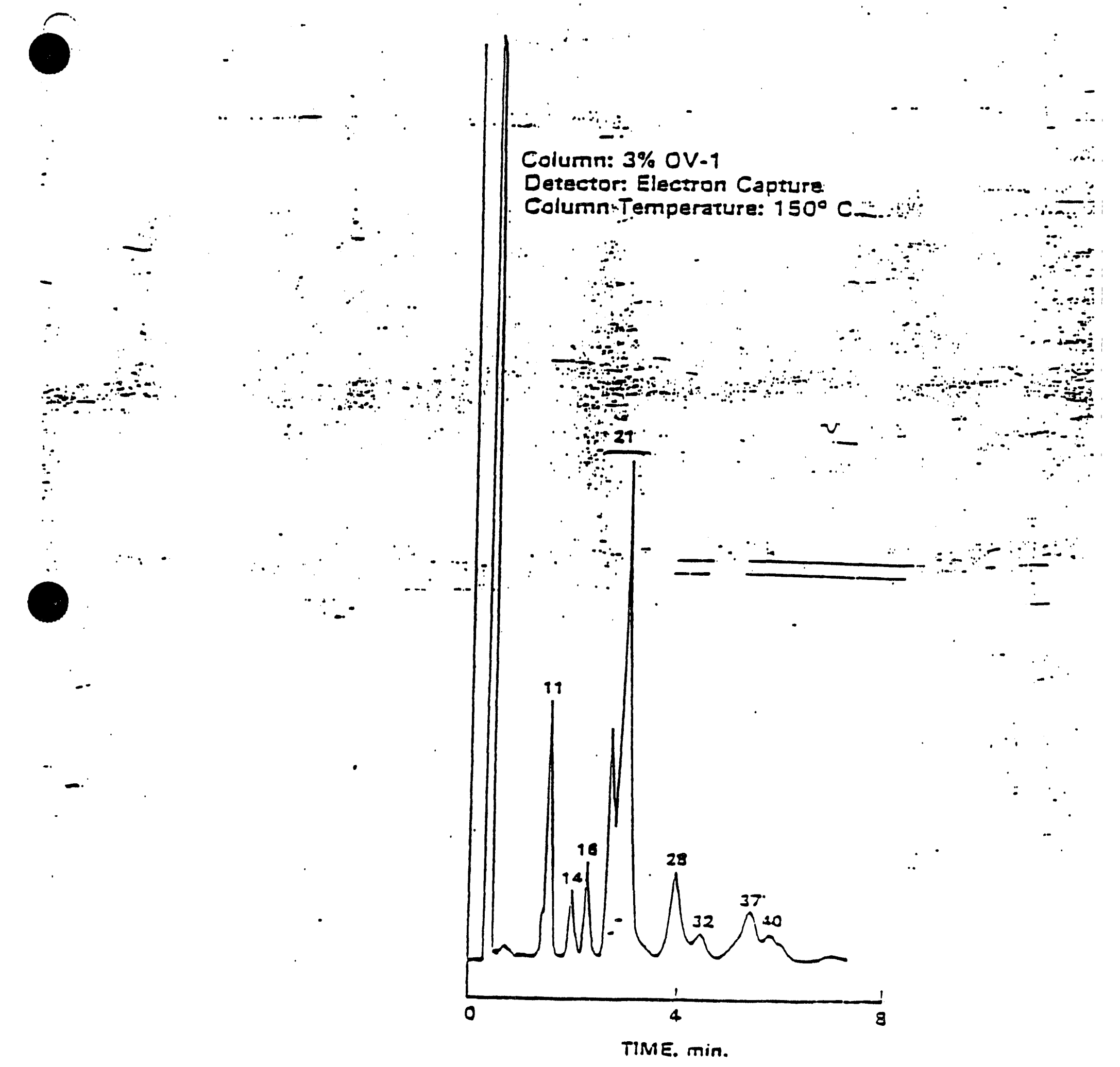

Figure 1. Gas chromatogram of Aroclor 1221. 


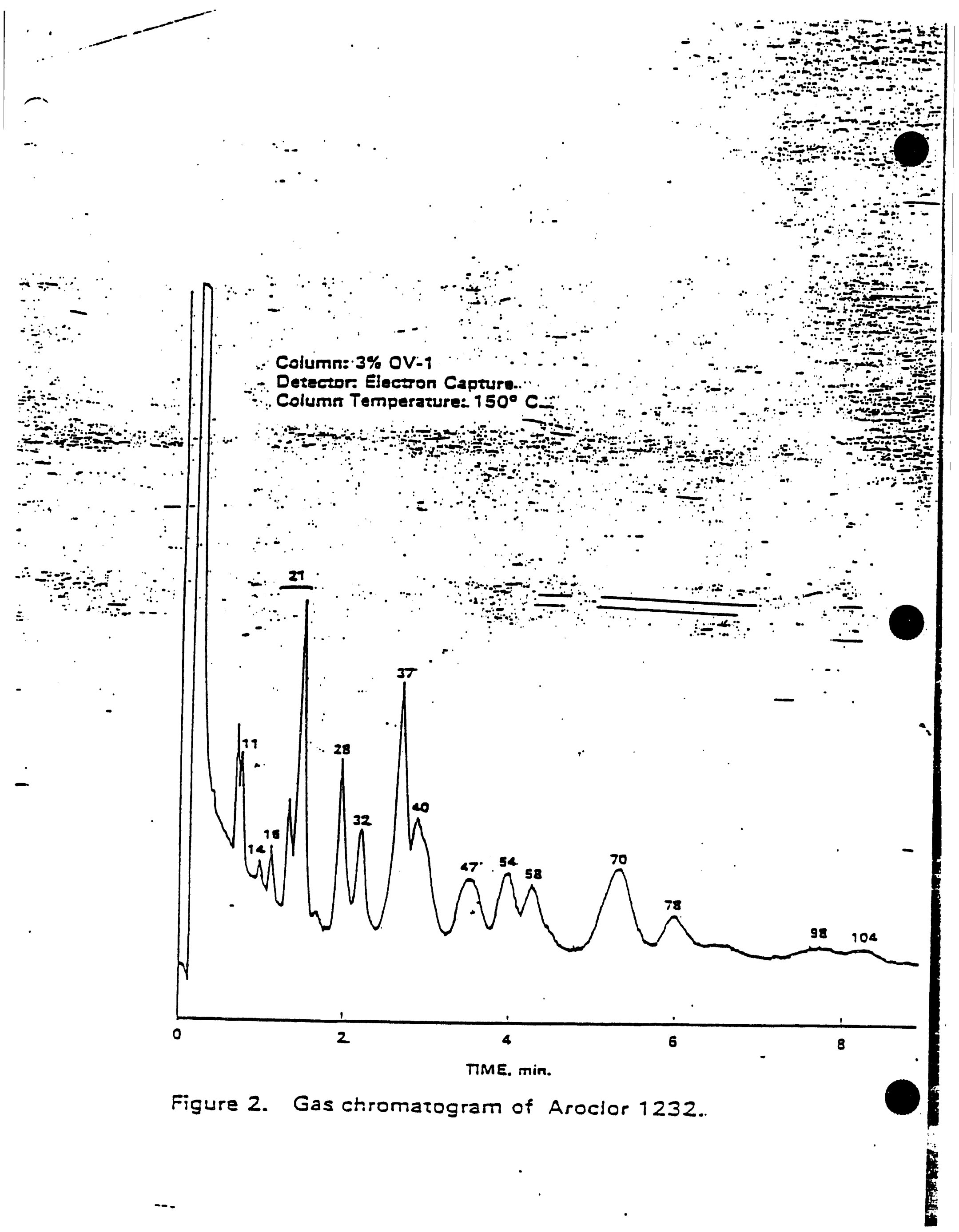




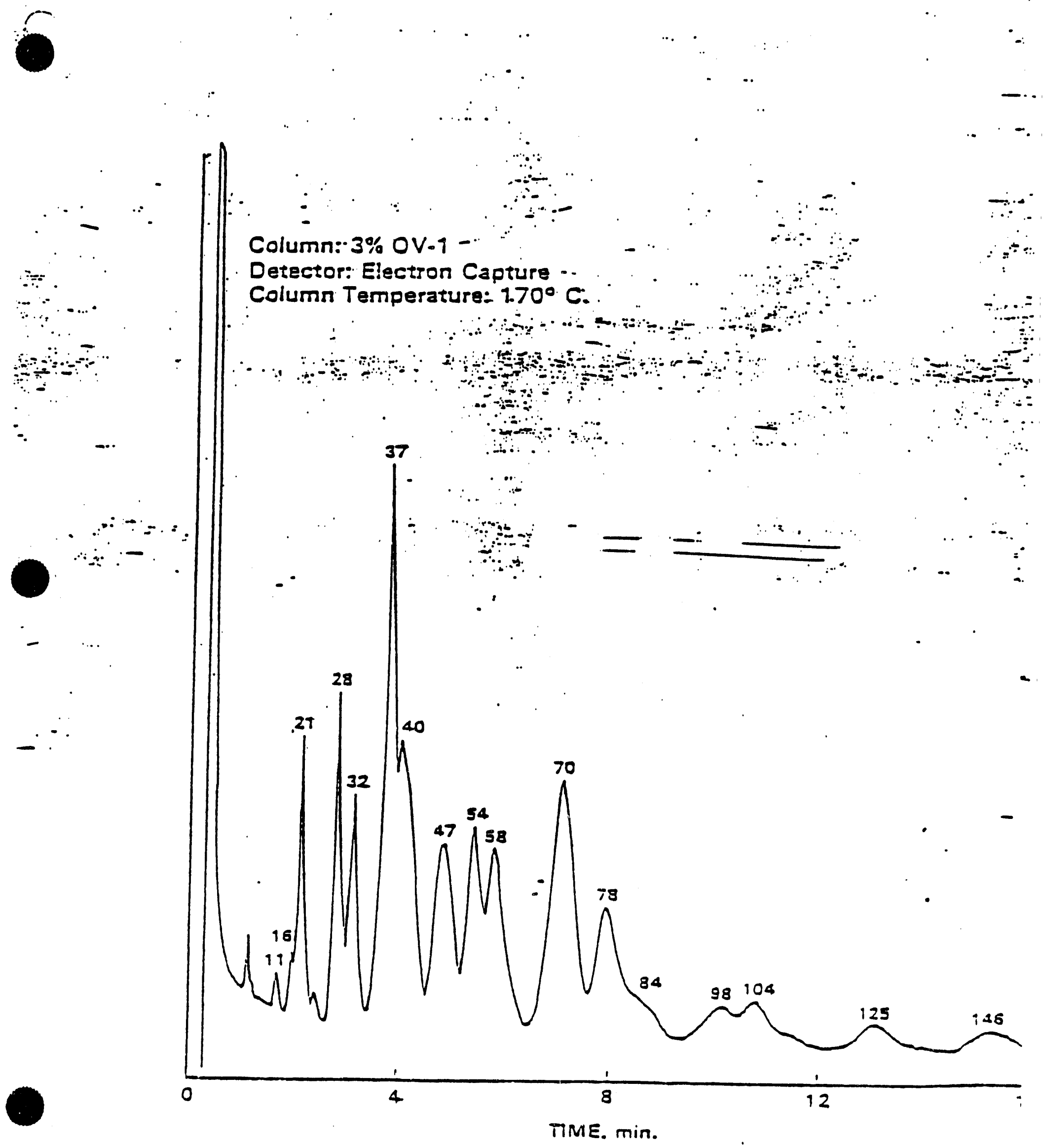

Figure 3. Gas Chromatogram of Aroclor 1242. 


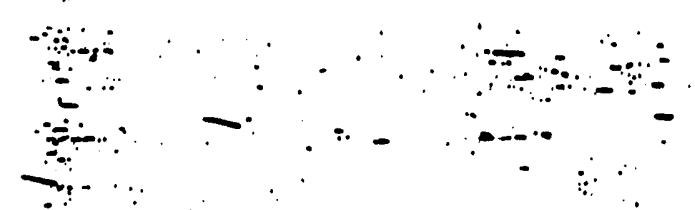

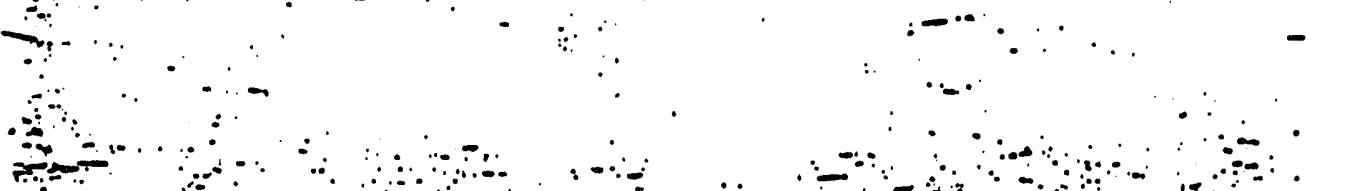

a

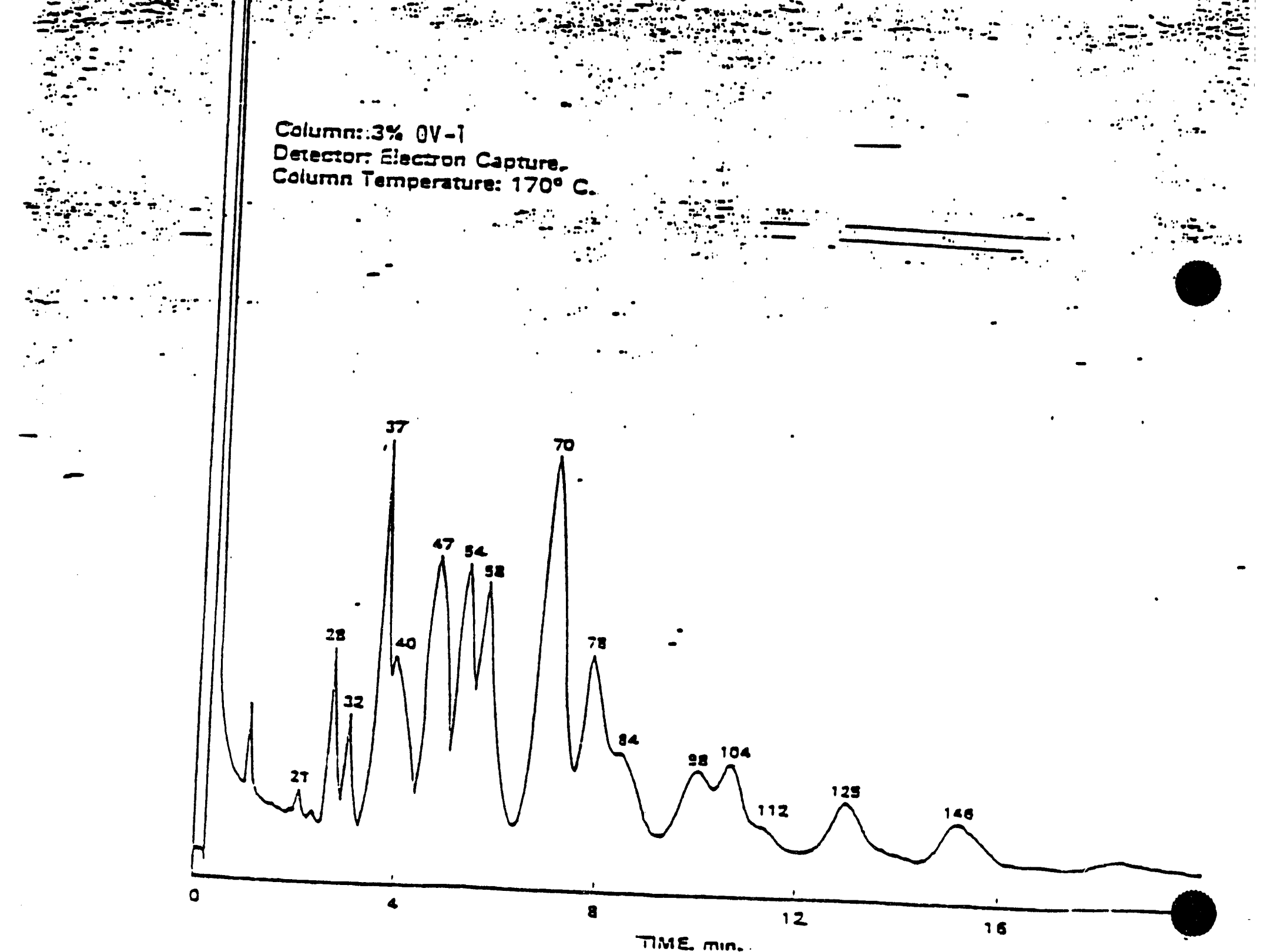

Figure 4. Gas chromatogram of Arocior 1243 . 


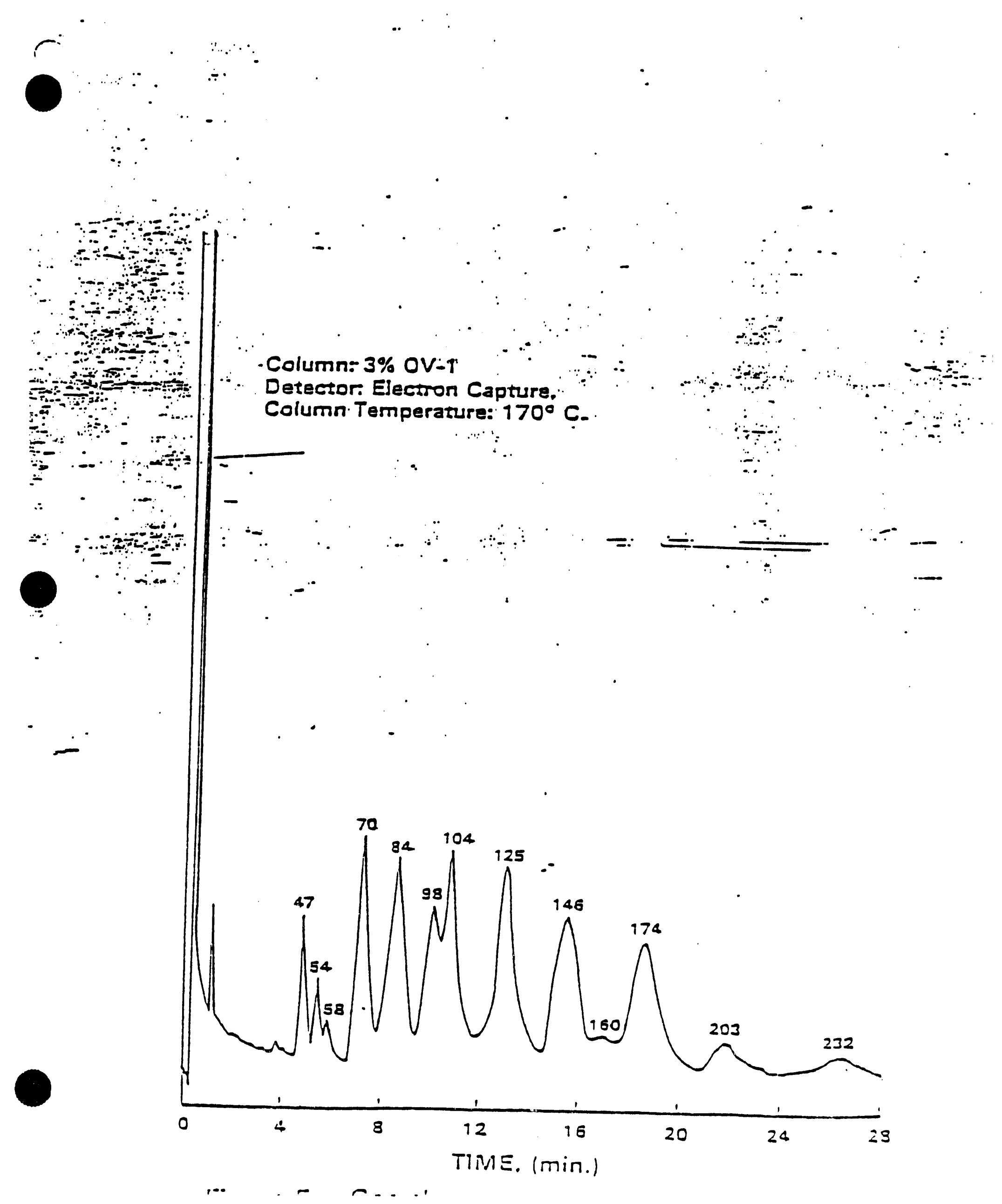




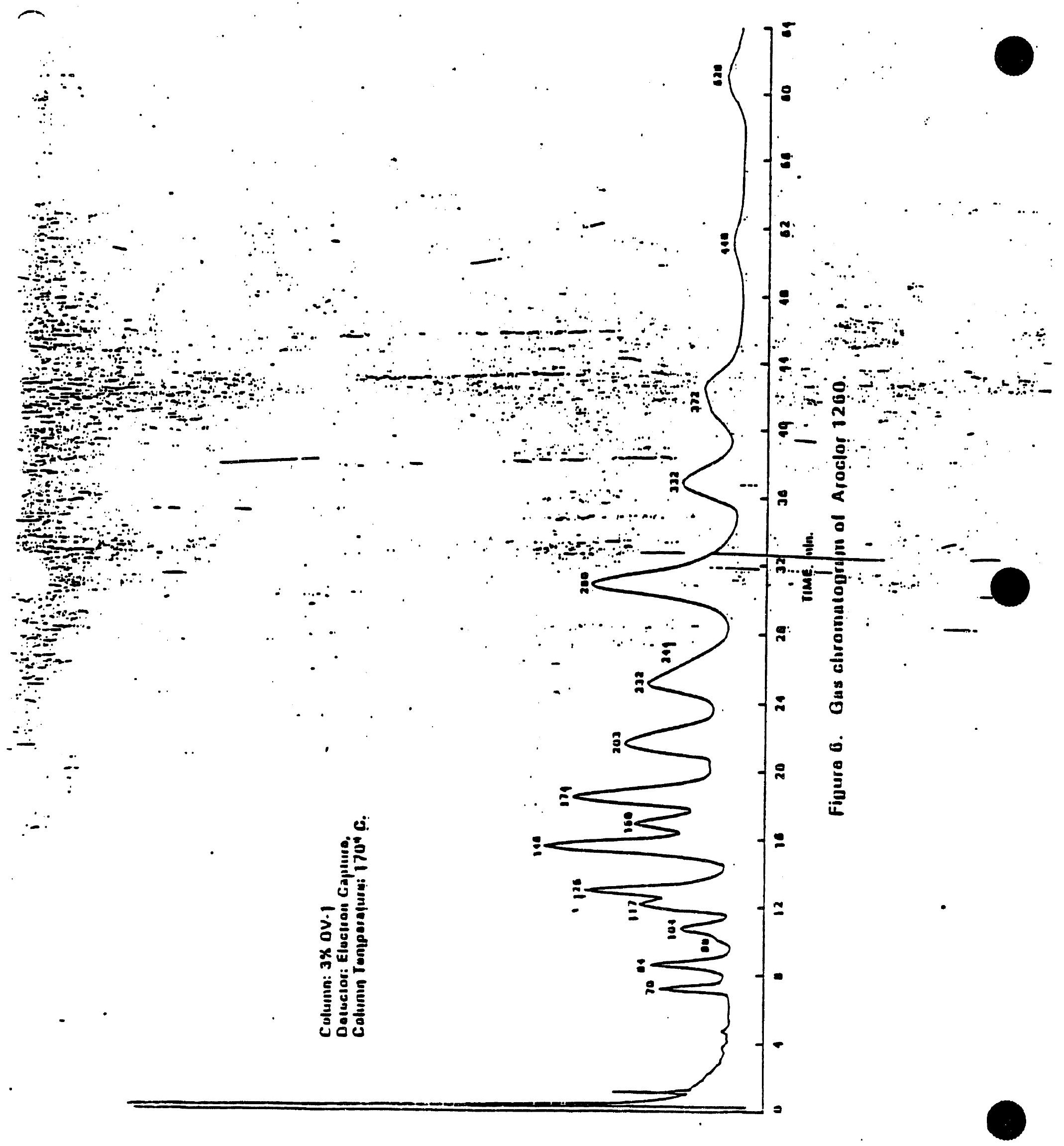




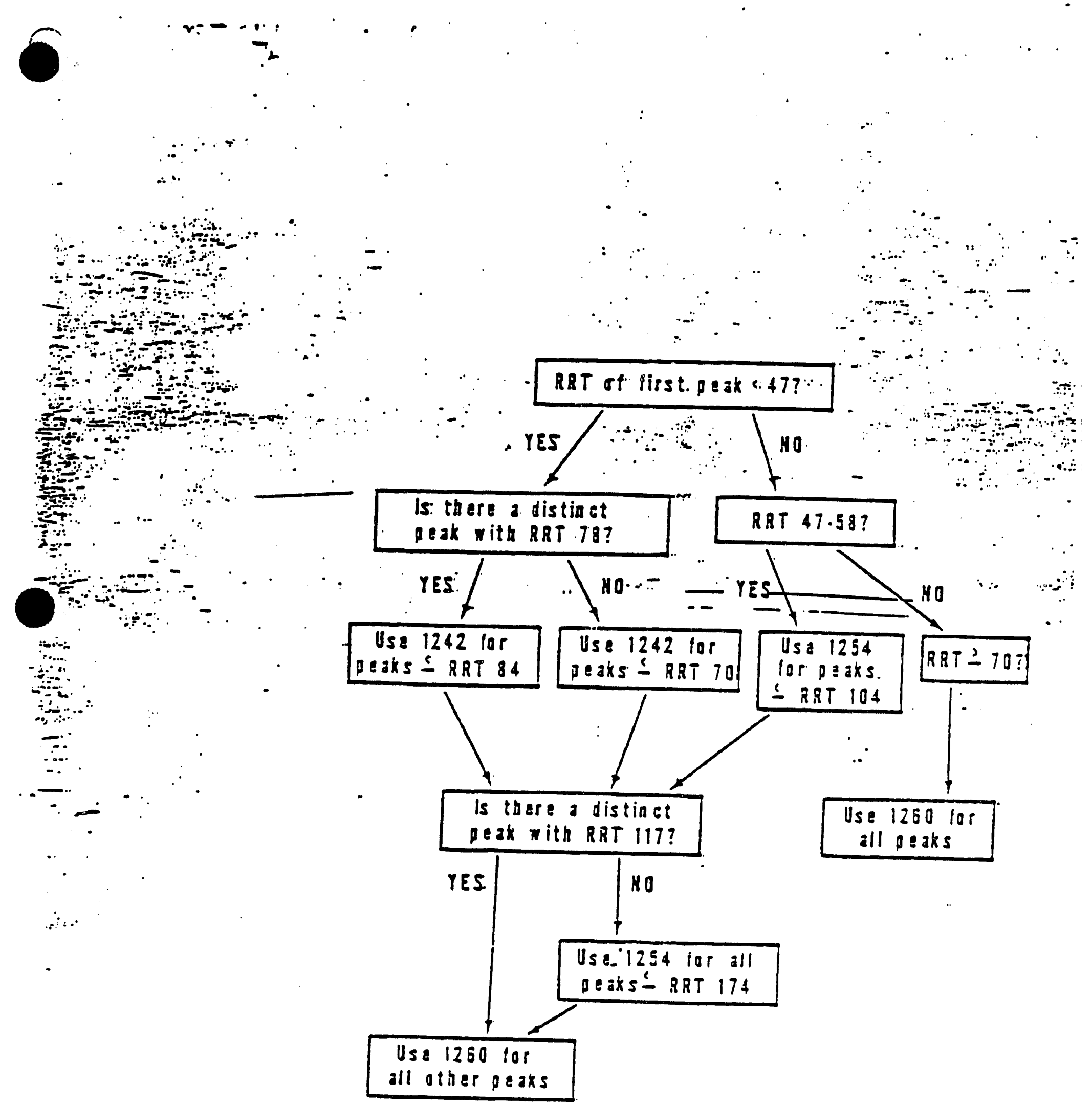

Figure 7. Chromatogram Division Flowchar 


\section{Polynuclear Aromatic Hydrocarbons - Method 610}

\section{Scope and Application}

1.1 This method covers the dotermination of certain polynuclear aromatic hydrocarbons (PAH). The following parameters may be determined by this method:

\begin{tabular}{l} 
Paramoter \\
\hline Acenaphthene \\
Acenaphthylene \\
Anthracene \\
Benzo (a) anthracene \\
Benzo (a) pyrene \\
Benzo (b) fluoranthene \\
Benzo (ghi) perylene \\
Benzo (k) fluoranthene \\
Chrysene \\
Dibenzo (a, h) anthracene \\
Fluoranthene \\
Fluorene \\
Indeno (1, 2, 3-cd) pyrene \\
Naphthalene \\
Phenanthrene \\
Pyrene
\end{tabular}

1.2 This is a chromatographic method applicable to the determination of the compounds listed above in municipal and industrial discharges as provided under 40 CFR 136.1. When this method is used to analyze unfamiliar samples for any or all of the compounds above. compound identifications should be supported by at least one additional qualitative technique. Method 625 provides gas chromatograph/mass spectrometer (GC/MS) conditions appropriate for the qualitative and quantitative confirmation of results for many of the parameters listed in Section 1.1. using the extract produced by this method.
STORET NO.

34205

34200

34220

34526

34247

34230

34521

34242

34320

34556

34376

34381

34403

34696

34461

34469
CAS No. 83-32.9

208-96-8

$120-12.7$

$56-55-3$

$50-32.8$

205-99-2

$191-24.2$

207.08-9

218.01 .9

53.70 .3

206.44-0

86-73-7

193-39.5

$91 \cdot 20-3$

85.01 .8

$129.00 \cdot 0$

1.3 This method provides for both high performance liquid chromatographic (HPLC) and gas chromatographic (GC) approaches to the determination of PAHs. The gas chromatographic procedure does not adequately resolve the following four pairs of compounds: anthracene and phenanthrene: chrysene and benzo (a) anthracene; benzo (b) fluoranthene and benzo ( $k$ ) fluoranthene; and dibenzo $(a, h)$ anthracene and indeno (1, 2, 3-cd) pyrene. Unless the purpose for the analysis can be served by reporting the sum of an unresolved pair, the liquid chromatographic approach must be used for these compounds. The liquid 
chro vatographic mathod does resolve all 16 of the PAHs listed.

1.4 The method detection limit (MDL defined in Section 15) "1" for each parameter is listed in Table 1. The MDL for a specific wastewater may differ depending upon the nature of interferences in the sample matrix.

1.5 The sample extraction and concentration steps in this method are essentially the same as in methods 606. 608, 609. 611 and 612 .

Therefore. a single sample may be extracted to measure the parameters included in the scope of each of these methods, provided the concentration is high enough to permit selecting aliquots of the extract for cleanup. when required. Selection of the aliquots must be made prior to the solvent exchange steps of this method. The analyst is allowed the latitude, under Gas Chromatcoraphy (Section 13), to select chromatographic conditions appropriate for the simultaneous measurement of combinations of these parameters.

1.6 Any modification of this method, beyond those expressly permitted. shall be considered as major modifications subject to application and approval of alternate test procedures under 40 CFR 136.4 and 136.5 .

1.7 This method is restricted to use by or under the supervision of analysts experienced in the use of HPLC and GC and in the interpretation of liquid and gas chromatograms. Each analyst must demonstrate the ability to generate acceptable results with this method using the procedure described in Section 8.2 .

\section{Summary of Method}

2.1 A messured volume of sampla. approximately one-liter, is solvent extracted with methylene chloride using a separatory funnel. The methylene chloride extract is dried and concentrated to a volume of 10 $\mathrm{mL}$ or less. The solvent is exchanged to cyciohexane prior to cleanup. Following cleanup. when using HPLC for determination of the PAHs, the solvent is exchanged to acetonitrile. Uitraviolet (UV) and fluorescence detectors are used with HPLC. When cleanup is not required and when flame ionization detector GC is used for determination, the methylene chloride extract may be analyzed directly. When cleanup is required. the cyclohexane exchange is made. Instrumental conditions are described which permit the separation and measurement of the PAH compounds ${ }^{(2) .}$

2.2 A silica gol column cleanup procedure is provided to aid in the elimination of interferences that may be encountered.

\section{Interferences}

3.1 Method interferences may be caused by contaminants in solvents. reogents, glassware, and other sample processing hardware that lead to discrete artifacts and/or elevated baselines in the chromatograms. All of these materials must be routinely demonstrated to be free from interferences under the conditions of the analysis by running laboratory reagent blanks as described in Section 8.5.

\subsubsection{Glasoware must be} scrupulously cleaned ${ }^{(3)}$. Clean all glassware as soon as possible after use by rinsing with the last solvent used in it. This should be followed by detergent washing with hot water, and rinses with tap water and distilled water. It should then be drained dry. and hested in a muffle furnace at $400^{\circ} \mathrm{C}$ for 15 to 30 minutes. Some thermally stable materials, such as PCBs, may not be eliminated by this treatment. Solvent rinses with acetone and pesticide quality hexane may be substituted for the muffle furnace heating. Volumetric ware should not be heated in a muffle furnace. After drying and cooling. glassware should be sealed and stored in a clean environment to prevent any accumulation of dust or other contaminants. Store inverted or capped with aluminum foil.

3.1.2 The use of high purity reagents and solvents helps to minimize interference problems. Purification of solvents by distiliation in all-glass systems may be required.

3.2 Matrix interferences may be caused by contaminants that are coextracted from the sample. The extent of matrix interferences will vary considerably from source to source. depending upon the nature and diversity of the industrial complex or municipality being sampled. The cleanup procedure in Section 11 can be used to overcome many of these interferences, but unique samples may require additional cleanup approaches to achieve the MDL listed in Table 1.

3.3 The extent of interferences that may be encountered using liquid chromatographic techniques has not been fully assessed. Although the HPLC conditions described allow for a unique resolution of the specific PAH compounds covered by this method. other PAH compounds may interfere.

\section{Safety}

4.1 The toxicity or carcinogenicity of each reagent used in this method has not been precisely defined: however, each chemical compound should be treated as a potential health hazard. From this viewpoint, exposure to these chemicals must be reduced to the lowest possible level by whatever means available. The laboratory is responsible for maintaining a current awareness file of OSHA regulations regarding the safe handling of the chemicals specified in this method. A reference file of material data handling sheets should also be made available to all personnel involved in the chemical analysis. Additional references to laboratory safoty are available and have been identified ${ }^{14-4}$ 'for the information of the analyst.

\subsection{The following paramenters} covered by this method have been tentatitely classified as known or suspected, humen or mammalian carcinogens; benzo (a) anthracene. benzo (a) pyrene and dibenzo (a. h) anthracene.

\section{Apparatus and Materials}

5.1 Sampling equipment, for discrete or composite sampling.

\subsubsection{Grab sample bottle - Amber} glass, one-liter or one-quart volume. fitted with screw caps lined with Teflon. Foil may be substituted for Teflon if the sample is not corrosive. If amber bottles are not available. protect samples from light. The container must be washed, rinsed with acetone or methylene chloride. and dried before use to minimize contamination.

5.1.2 Automatic sampler (optional) Must incorporate glass sample containers for the collection of a minimum of $250 \mathrm{~mL}$. Sample containers must be kept refrigerated at $4^{\circ} \mathrm{C}$ and protected from light during compositing. If the sampler uses a peristaltic pump, a minimum length of compressible silicone rubber rubing may be used. Before use, however. the compressible tubir: - ivuld be thoroughly rinsed with methanol. followed by repeated rinsings with distilled water to minimize the potential for contamination of the sample. An integrating flow meter is required to collect flow proportional composites. 
5.2 Glassware (All specifications are suggested. Catalog numbers are included for illustration only).

5.2.1 Separatory funnel $-2000-\mathrm{mL}$ with Teflon stopcock.

5.2.2 Drying column -

Chromatographic column $400 \mathrm{~mm}$ long $\times 19 \mathrm{~mm} 10$ with coarse frit.

5.2.3 Concentrator tube, KudernaDanish - 10-mL. graduated (Kontes K-570050-1025 or equivalent). Calibration must be checked at the volumes employed in the test. Ground glass stopper is used to prevent evaporation of extracts.

5.2.4 Evaporative flask, KudernaDanish - 500-mL (Kontes K-570001. 0500 or equivalent). Attach to concentrator tube with springs.

5.2.5 Snyder column, KudernaDanish - three-ball macro (Kontes K-503000-0121 or equivalent).

5.2.6 Snyder column, KudernaDanish - two-ball micro (Kontes K-569001-0219 or equivalent).

5.2.7 Vials - Amber glass, 10- to 15. $\mathrm{mL}$ capacity, with Teflon-lined scrowcap.

5.2.8 Chromatographic column $250 \mathrm{~mm}$ long $\times 10 \mathrm{~mm}$ ID with coarse fritted disc at bottom and Teflon stopcock.

5.3 Boiling chips - approximately $10 / 40$ mesh. Heat to $400^{\circ} \mathrm{C}$ for 30 minutes or Soxhlet extract with methylene chloride.

5.4 Water bath - Heated, with concentric ring cover, capable of temperature control $\left( \pm 2^{\circ} \mathrm{C}\right)$. The bath should be used in a hood.

5.5 Balance - Analytical, capable of accurately weighing $0.0001 \mathrm{~g}$.

5.6 High performance liquid chromatographic apparatus (modular):

5.6.1 Gradient pumping system, constant flow.

5.6.2 Reverse phase column, 5 micron HC-ODS Sil-X, $250 \mathrm{~mm} \times 2.6$ $\mathrm{mm}$ ID (Perkin-Elmer No. 089-0716 or equivalent).

5.6.3 Fluorescence detector, for excitation at $280 \mathrm{~nm}$ and emission greater than $389 \mathrm{~nm}$ cutoff (Corning 3-75 or equivalent). Fluorometers should have dispersive optics for excitation and can utilize either filter or dispersive optics at the emission detector.

5.6.4 UV detector, $254 \mathrm{~nm}$, coupled to fluorescence detector.
5.6.5 Strip-chant recordar compatible with detectors. Use of a data system for measuring peak areas and retention times is recommended.

6.7 Gas chromatograph - An analytical system complete with temperature programmable gas chromatograph suitable for on-column injection or splitless injection and all required accessories including syringes, analytical columns, gases. detector, and strip-chart recorder. A data system is recommended for measuring peak areas.

5.7 .1 Column - $1.8 \mathrm{~m}$ long $\times 2 \mathrm{~mm}$ ID pyrex glass packed with 3\% OV 17 on Chromosorb W-AW-DCMS (100/120 mesh) or equivalent. This column was used to develop the retention time data in Table 2. Guidelines for the use of atternate column packings are providod in Section 13.

5.7.2 Detector - Flame ionization. This detector has proven effective in the analysis of wastewaters for the compounds listed in the scope excluding the four pairs of unresolved compounds listed in Section 1.3. Guidelines for the use of alternate detectors are provided in Section 12.2 .

\section{Reagents}

6.1 Reagent water - Resgent water is defined as a water in which an interferent is not observed at the MOL of each parameter of interest.

6.2 Sodium thiosulfate - (ACS) Granular.

6.3 Cyclohexane, methanol, acetone, methylene chloride, and pentane Pesticide quality or equivalent.

6.4 Acetonitrile, high purity HPLC quality, distilled in glass.

6.5 Sodium sulfate - (ACS)

Granular, anhydrous. Purity by heating at $400^{\circ} \mathrm{C}$ for four hours in a shallow tray.

6.6 Silica gel - Grade 923 (100/200 mesh) dessicant (Davison Chemical or equivalent). Before use, activate for at least 16 hours at $130^{\circ} \mathrm{C}$ in a shallow glass tray, loosely covered with foil.

6.7 Stock standard solutions (1.00 $\mu g / \mu L)$ - Stock standard solutions can be prepared from pure standard materials or purchased as certified solutions.

6.7.1 Prepare stock standard solutions by accurately weighing about $0.0100 \mathrm{~g}$ of pure material. Dissolve the material in HPLC quality acetonitrile, dilute to volume in a 10 -
$\mathrm{mL}$ volumetric flask. Larger volumes can be used at the convenience of the analyst. If compound purity is certified at $96 \%$ or greater, the weight can be used without correction to calculate the concentration of the stock standard. Commercially prepared stock standards can be used at any concentration if they are certified by the manufacturer or by an independent source.

6.7.2 Transfer the stock standard solutions into Teflon-sealed screw-cap bottles. Store at $4^{\circ} \mathrm{C}$ and protect from light. Stock standard solutions should be checked frequently for signs of degradation or evaporation, especially just prior to preparing calibration standards from them. Quality control check standards that can be used to determine the accuracy of calibration standards will be available from the U.S. Environmental Protection Agency, Environmental Monitoring and Support Laboratory. Cincinnati. Ohio 45268

6.7.3 Stock standard solutions must be replaced after six months. or . sooner if comparison with check standards indicate a problem.

\section{Calibration}

7.1 Establish liquid or gas chromatographic operating parameters to produce resolution of the parameters equivalent to that indicated in Tables 1 or 2. The chromatographic system can be calibrated using the external standard technique (Section 7.2) or the internal standard technique (Section 7.3)

7.2 External standard calibration procedure:

7.2.1 Prepare calibration standards at a minimum of three concentration levels for each parameter of interest by adding volumes of one or more stock standards to a volumetric flask and diluting to volume with acetonitrile. One of the external standards should be at a concentration near, but above, the MDL and the other concentrations should correspond to the expected range of concentrations found in real samples or should define the working range of the detector.

7.2.2 Analyze each calibration standard 15 to $25 \mu \mathrm{L}$ for HPLC and 2 to $5 \mu \mathrm{L}$ for $\mathrm{GC}$ ), and tabulate peak height or area responses against the mass injected. The results may be used to prepare a calibration curve for each compound. Alternatively, if the ratio of response to amount injected (calibration factor) is a constant over the working range $<10 \%$ relative 
standard deviation, RSD). linearity through the origin can be assumed and the average ratio or calibration factor can be used in place of a calibration curve.

7.2.3 The working calibration curve or calibration factor must be verified on each working day by the measurement of one or more calibration standards. If the response for any parameter varies from the predicted response by more than $\pm 10 \%$. the test must be repeated using a fresh calibration standard. Alternatively, a new calibration curve or calibration factor must be prepared for that compound.

7.3 Internal standard calibration procedure. To use this approach, the analyst must select one or more internal standards that are similar in analytical behavior to the compounds of interest. The analyst must further demonstrate that the messurement of the internal standard is not affected by method or matrix interferences.

Because of these limitations, no internal standard can be suggested that is applicable to all samples.

7.3.1 Prepare calibration standards at a minimum of three concentration levels for each parameter of interest by adding volumes of one or more stock standards to a volumetric flask. To each calibration standard, add a known constant amount of one or more internal standards, and dilute to volume with acetonitrile. One of the standards should be at a concentration near, but above, the MDL and the other concentrations should correspond to the expected range of concentrations found in real samples or should define the working range of the detector.

\subsubsection{Analyze each calibration} standard 15 to $25 \mu \mathrm{L}$ for HPLC and 2 to $5 \mu \mathrm{L}$ for GC) and tabulate peak height or area responses against concentration for eech compound and internal standard, and calculate response factors (RF) for each compound using Equation 1

$$
\text { Eq. } 1 \text { RF }=\left(A_{2} C_{0}\right) /\left(A_{1}, C_{0}\right)
$$

where:

$A_{1}=$ Response for the parameter to be measured.

$A_{1 .}=$ Response for the internal standard.

$C_{n}=$ Concentration of the internal standard, $(\mu \mathrm{g} / \mathrm{L})$.

C. =Concentration of the parameter to be measured. $(\mu \mathrm{g} / \mathrm{L})$.

If the RF value over the working range is a constant $<10 \%$ RSD), the RF can be assumed to be invariant and the average RF can be used for calculations. Alternatively, the results can be used to plot a calibration curve of response ratios, AW Aw vs. RF.

7.3.3 The working calibration curve or RF must be verified on each working day by the measurement of one or more calibration standards. If the response for any parameter varies from the predicted response by more than 10\%, the test must be repeated using a fresh calibration standard. Alternativaly, a new calibration curve must be prepared for that compound.

7.4 Bofore using any cleanup procedure, the analyst must process a series of calibration standards through the procedure to validate elution patterns and the absence of interferences from the reagents.

\section{Quality Control}

8.1 Each laboratory that uses this method is required to operate a formal quality control program. The minimum requirements of this program consist of an initial demonstration of labora. tory capability and the arialysis of spiked samples as a continuing check on performance. The laboratory is required to maintain performance records to define the quality of data that is generated. Ongoing performance checks must be compared with established performance criteria to determine if the results of analyses are within accuracy and precision limits expected of the method.

\subsubsection{Before performing any} analyses, the analyst must demonstrate the ability to generate acceptable accuracy and precision with this method. This ability is established as described in Section 8.2 .

8.1.2 In recognition of the rapid advances that are occurring in chromatography, the analyst is permitted certain options to improve the separations or lower the cost of measurements. Each time such modifications are made to the method, the analyst is required to repeat the procedure in Section 8.2.

8.1.3 The laboratory must spike and analyze a minimum of $10 \%$ of all samples to monitor continuing laboratory performance. This procedure is described in Section $\mathbf{8 . 4}$

8.2 To establish the ability to generate acceptable accuracy and precision, the analyst must perform the following operations.
8.2.1 Select a representative spike concentration for each compound to be measured. Using stock standards, prepare a quality control check sample concentrate in acetronitrile 1000 times more concentrated than the selected concentrations. Quality control check sample concentrates. appropriate for use with this method, will be available from the U.S.

Environmental Protection Agency, Environmental Monitoring and Support Laboratory. Cincinnati, Ohio 45268.

8.2.2 Using a pipet, add $1.00 \mathrm{~mL}$ of the check sample concentrate to each of a minimum of four $1000-\mathrm{mL}$ aliquots of reagent water. A representative wastewater may be used in place of the reagent water. but one or more additional aliquots must be analyzed to determine background levels, and the spike level must exceed twice the background level for the test to be valid. Analyze the aliquots according to the method beginning in Section 10.

8.2.3 Colculate the average percent recovery, (R), and the standerd deviation of the percent recovery (s). for the results. Wastewater background corrections must be made before $R$ and $s$ calculations are performed.

8.2.4 Using Table' 3, note the average recovery $(X)$ and standard deviation (D) expected for each method parameter. Compare these to the calculated values for $R$ and $s$. If $s>$ $2 p$ or $|X-R|>2 p$, review potential problem areas and repeat the test.

8.2.5 The U.S. Environmental Protection Agency plans to establish performance criteria for $R$ and $s$ based upon the results of interlaboratory testing. When they become available, these criteria must be met before any samples may be analyzed.

8.3 The analyst must calculate method performance criteria and define the performance of the laboratory for each spike concentration and parameter being measured.

8.3.1 Calculate upper and lower control limits for method performance:

Upper Control Limit (UCL) $=R+3 \mathrm{~s}$ Lower Control Limit $(L C L)=R-3$

where $R$ and $s$ are calculated as in Section 8.2.3.

The UCL and LCL can be used to construct control charts ${ }^{(7)}$ that are useful in observing trends in pertor- 
mance. The control limits above must be replaced by method performance criteria as they become available from the U.S. Environmental Protection Agency.

8.3.2 The laboratory must develop and maintain separate accuracy statements of laboratory performance for wastewater samples. An accuracy statement for the method is defined as $R \pm s$. The accuracy statement should be developed by the analysis of four aliquots of wastewater as described in Section 8.2.2, followed by the calculation of $R$ and $\mathbf{s}$. Alternately, the analyst may use four wastewater data points gathered through the requirement for continuing quality control in Section 8.4. The accuracy statements should be updated regularly"

8.4 The laboratory is required to collect a portion of their samples in duplicate to monitor spike recoveries. The frequency of spiked sample analysis must be at least $10 \%$ of all samples or one sample per month. whichever is greater. One aliquot of the sample must be spiked and analyzed as described in Section

- 8.2. If the recovery for a particular parameter does not fall within the control limits for method performance, the results reported for that parameter in all samples processed as part of the same set must be qualified as adescribed in Section 14.3. The

- laboratory should monitor the frequency of data so qualified to ensure that it remains at or below 5\%.

8.5 Before processing any samples. the analyst should demonstrate through the analysis of a one-liter aliquot of reagent water, that all glassware and reagents interferences are under control. Each time a set of samples is extracted or there is a change in reagents, a laboratory reagent blank should be processed as a safeguard against laboratory contamination.

8.6 It is recommended that the laboratory adopt additional quality assurance practices for use with this method. The specific practices that are most productive depend upon the needs of the laboratory and the nature of the samples. Field duplicates may be analyzed to monitor the precision of the sampling technique. When doubt exists over the identification of a peak on the chromatogram, confirmatory techniques such as chromatography with a dissimilar column or detector must be used. This may include the use of a mass spectrometer. Whenever possible, the laboratory should perform analysis of standerd reference materials and participate in relevant performance ovaluation studies.

9. Sample Collection. Preservation, and Handling

9.1 Grab samples must be collested in glass containers. Conventional sampling practices ${ }^{\text {iol }}$ should be followed. except that the bottle must not be prewashed with sample before collection. Composite samples should be collected in refrigerated glass containers in accordance with the requirements of the program.

Automatic sampling equipment must be as free as possible of Tygon tuting and other potential sources of contamination.

9.2 The samples must be iced or refrigerated at $4^{\circ} \mathrm{C}$ from the time of collection until extraction. PAHs are known to be light sensitive, therefore, samples, extracts and standards should be stored in amber or foil wrapped bottles in order to minimize photolytic decomposition. Fill the sample bottle and, if residual chlorine is present, add $80 \mathrm{mg}$ of sodium thiosulfate per liter of sample. U.S. Environmental Protection Agency methods 330.4 and 330.5 may be used for measurement of residual chlorine" for this purpose.

9.3 All samples must be extracted within 7 days, and analysis completed within $\mathbf{4 0}$ days of extraction ${ }^{(2)}$.

\section{Sample Extraction}

10.1 Mark the water meniscus on the side of the sample bottle for later determination of sample volume. Pour the entire sample into a two-liter separatory funnel.

10.2 Add $60 \mathrm{~mL}$ methylene chloride to the sample bottle, seal, and shake 30 seconds to rinse the inner surface. Transfer the solvent to the separatory funnel and extract the sample by shaking the funnel for two minutes with periodic venting to release excess pressure. Allow the organic layer to separate from the water phase for a minimum of ten minutes. If the emulsion interface between layers is more than one-third the volume of the solvent layer, the analyst must employ mechanical techniques to complete the phase separation. The optimum technique depends upon the sample, but may include stirring, filtration of the emulsion through glass wool. centrifugation, or other physical methods. Collect the methylene chloride extract in a $250-\mathrm{mL}$

Erlenmeyer flask.

10.3 Add a second $60 \cdot \mathrm{mL}$ volume of methylene chloride to the sample bottle, rinse and repeat the extraction procedure a second time, combininn the extracts in the Erlenmeyer Hask. Perform a third extraction in the same manner.

10.4 Assemble a Kuderna-Danish (K-D) concentrator by attaching a 10 . $\mathrm{mL}$ concentrator tube to a $500-\mathrm{mL}$ evaporative flask. Other concentration devices or techniques may be used in place of the K-D if the requirements of Section 8.2 are met.

10.5 Pour the combined extract through a drying column containing about $10 \mathrm{~cm}$ of anhydrous sodium sulfate. and collect the extract in the K-D concentrator. Rinse the Erlenmeyer flask and column with 20 to $30 \mathrm{~mL}$ of methylene chloride to complete the quantitative transfer

10.6 Add one or two clean boiling chips to the evaporative flask and attach a three-ball Snyder column. Prewet the Snyder column by adding about $1 \mathrm{~mL}$ methylene chloride to the top. Place the K-D apparatus on a hot water bath $\left(60\right.$ to $65^{\circ} \mathrm{C}$ ) so that the concentrator tube is partially immersed in the hot water, and the entire lower rounded surface of the flask is bathed with hot vapor. Adjust the vertical position of the apparatus arid the water temperature as required to complete the concen. tration in 15 to 20 minutes. At the proper rate of distillation the balls of the column will actively chatter but the chambers will not flood with condensed solvent. When the apparent volume of liquid reaches 1 $\mathrm{mL}$, remove the K.D apparatus and allow it to drain and cool for at least 10 minutes. Remove the Snyder column and rinse the flask and its lower joint into the concentrator tube with 1 to $2 \mathrm{~mL}$ of methylene chloride. A $5 . \mathrm{mL}$ syringe is recommemded for this operation. Stopper the concentrator tube and store refrigerated if further processing will not be performed immediately. If the extracts wil! be stored longer than two days, they should be transferred to Teflon-sealed screw-cap bottles and protected from light.

10.7 Determine the original sample volume by refilling the sample bottle to the mark and transferring the water to a $1000-\mathrm{mL}$ graduated cylinder. Record the sample volume to the nearest $5 \mathrm{~mL}$. 


\section{Cleanup and Separation}

11.1 Cleanup procedures may not be necessary for a relatively clean sample matrix. The cleanup procedures recommended in this method have been used for the analysis of various clean waters and industrial effluents. If particular circumstances demand the use of an atternative cleanup procedure, the analyst must determine the elution profile and demonstrate that the recovery of each compound of interest is no less than $85 \%$

11.2 Before the silica gel cleanup technique can be utilized. the extract solvent must be exchanged to cyclohexane. Add a $1.1010-\mathrm{mL}$ aliquot of sample extract (in methylene chloridel and a boiling chip to a clean $K-D$ concentrator tube. Add $4 \mathrm{~mL}$ cyclohexane and attach a microSnyder column. Prewet the micro. Snyder column by adding $0.5 \mathrm{~mL}$ methylene chloride to the top. Place the micro-K-D apparatus on a boiling $\left(100^{\circ} \mathrm{C}\right)$ water bath so that the concentrator tube is partially immersed in the hot water. Adjust the vertical position of the apparatus and the water temperature as required to complete concentration in 5 to 10 minutes. At the proper rate of distillation the balls of the column will actively chatter but the chambers will not flood. When the apparent volume of the liquid reaches $0.5 \mathrm{~mL}$, remove the K.D apparatus and allow it to drain for at least 10 minutes while cooling. Remove the micro-Snyder column and rinse its lower joint into the concentrator tube with a minimum of cyclohexane. Adjust the extract volume to about $2 \mathrm{~mL}$.

11.3 Silica gel column cleanup for PAHs.

11.3.1 Prepare a slurry of $10 \mathrm{~g}$ activated silica gel in methylene chloride and place this in a 10-mm 10 chromatography column. Gently tap the column to settle the silica gel and elute the methylene chloride. Add 1 to $2 \mathrm{~cm}$ of anhydrous sodium sulfate to the top of the silica gel.

11.3.2 Preelute the column with 40 $\mathrm{mL}$ of pentane. Discard the eluate and just prior to exposure of the sodium sulfate layer to the air, transfer the 2 $\mathrm{mL}$ of cyclohexane sample extract onto the column, using an additional $2 \mathrm{~mL}$ of cyclohexane to complete the transfer

11.3.3 Just prior to exposure of the sodium sulfate layer to the air, add 25 $\mathrm{mL}$ pentane and continue elution of the column. Discard the pentane eluate.
11.3.4 Elute the column with $25 \mathrm{~mL}$ of methylene chloride/pentane $(4+6)$ (V) $)$ and collect the eluate in a 500 $\mathrm{mL}$ K-D flask equipped with a $10 \mathrm{~mL}$ concentrator tube. Elution of the column should be at a rate of about 2 $\mathrm{mL}$ min.

11.3.5 Concentrate the collected fraction to less than $10 \mathrm{~mL}$ by $K-D$ techniques as in Section 10.6, using pentane to rinse the walls of the glassware. Proceed with HPLC or GC analysis.

\section{High Performance Liquid Chromatography (HPLC)}

12.1 To the extract in the concentrator tube, add $4 \mathrm{~mL}$ of acetonitrile and a new boiling chip. then attach a micro-Snyder column. Increase the temperature of the hot water bath to 95 to $100^{\circ} \mathrm{C}$. Concentrate the solvent as in Section 10. After cooling, remove the microSmyder column and rinse its lower joint into the concentrator tube with about $0.2 \mathrm{~mL}$ acetonitrile. Adjust the extract volume to $1.0 \mathrm{~mL}$

12.2 Table 1 summarizes the recommended HPLC column materials and operating conditions for the instrument. This table includes retention times, capacity factors, and MDL that were obtained under these conditions. The UV detector is recommended for the determination of naphthalene, acenaphthylene. acenapthene, and fluorene, and the fluorescence detector is recommended for the remaining PAHs. Examples of the parameter separations achieved by this HPLC column are shown in Figures 1 and 2. Other HPLC columns, chromatrograpic conditions or detectors may be used if the requirements of Section 8.2 are mot.

12.3 Calibrate the system daily as described in Section 7.

12.4 If the internal standard approach is being used, the internal standard must be added to sample extract and mixed thoroughly. immediately, before injection into the instrument.

12.5 Inject 5 to $25 \mu \mathrm{L}$ of the sample extract using a high pressure syringe or a constant volume sample injection loop. Record the volume injected to the nearest $0.1 \mu \mathrm{L}$ and the resulting peak size in height or area units. Reequilibrate the liquid chromatographic column at the initial gradient conditions for at least 10 minutes between injections.
12.6 The width of the retention time window used to make identifications should be based upon measurements of actual retention time variations of standards over the course of a day. Three times the standard deviation of a retention time for a compound can be used to calculate a suggested window size; however, the experience of the analyst should weigh heavily in the interpretation of chromatograms.

12.7 If the peak height or area exceeds the linear range of the system, dilute the extract with acetonitrile and reanalyze.

12.8 If the peak area measurement is prevented by the presence of interferences, further cleanup is required.

\section{Gas Chromatography}

13.1 The packed column GC procedure will not resolve certain isomeric pairs as indicated in Section 1.3 and Table 2. The liquid chromatographic procedure (Section 12) must be used for these materials. Capillary (open-tubular) columns may be used if the relative standard deviations of responses for replicate injections are demonstrated to be less than $6 \%$ and the requirements of Section 8.2 are met.

13.2 To achieve maximum sensitivity with this method, the extract must be concentrated to 1.0 $\mathrm{mL}$. Add a clean boiling chip to the methylene chloride extract in the concentrator tube. Attach a two-ball micro-Snyder column. Prewet the micro-Snyder column by adding about $0.5 \mathrm{~mL}$ of methylene chloride to the top. Place the micro K-D apparatus on a hot water bath $\left(60\right.$ to $\left.65^{\circ} \mathrm{C}\right)$ so that the concentrator tube is partially immersed in the hot water. Adjust the vertical position of the apparatus and the water temperature as required to complete the concentration in 5 to 10 minutes. At the proper rate of distillation the balls will actively chatter but the chambers will not flood. When the apparent volume of liquid reaches $0.5 \mathrm{~mL}$. remove the $K-D$ apparatus. Drain and cool for at least 10 minutes. Remove the microSnyder column and rinse its lower joint into the concentrator tube with a small volume of methylene chloride. Adjust the final volume to $1.0 \mathrm{~mL}$ and stopper the concentrator tube.

13.3 Table 2 describes the recommended GC column and operating conditions for the instrument. This table includes 
retention times that were obtained under these conditions. An example of the parameter separations achieved by this column is shown in Figure 3. Other packed columns, chromatographic conditions, or detectors may be used if the requirements of Section 8.2 are met. Capillary (open-fubular) columns may also be used if the relative standard deviations of responses for replicate injections are demonstrated to be less than $6 \%$ and the requirements of Section 8.2 are met.

13.4 Calibrate the GC system daily as described in Section 7.

13.5 If the internal standard approach is being used, add the internal standard to sample extract and mix thoroughly, immediately, before injection into the instrument.

13.6 Inject 2 to $5 \mu \mathrm{L}$ of the sample extract using the solventflush technique ${ }^{(10)}$. Smaller $(1.0 \mu L)$ volumes may be injected if automatic devices are employed. Record the volume injected to the nearest $0.05 \mu L$ and the resulting peak size in area or peak height units.

13.7 The width of the retention time window used to make identifications should be based upon measurements of actual retention time variations of standards over the course of a day. Three times the standard deviation of a retention time for a compound can be used to calculate a suggested window size; however, the experience of the analyst should weigh heavily in the interpretation of chromatograms.

13.8 If the response for the peak exceeds the working range of the system, dilute the extract and reanalyze.

13.9 If the measurement of the peak response is prevented by the presence of interferences, further cleanup is required.

\section{Calculations}

14.1 Determine the concentration of individual parameters in the sample.

14.1.1 If the external standard calibration procedure is used, calculate the amount of material injected from the peak response using the calibration curve or calibration factor in Section 7.2.2. The concentration in the sample can be calculated from Equation 2:
Eq. 2. Concentration, $\mu \sigma / L=\frac{(A)\left(N_{2}\right)}{\left(V_{1}\left(V_{t}\right)\right.}$ where:

$A=$ Amount of material injected, in nanograms.

$V_{1}=$ Volume of extract injected $(\omega L)$.

$V_{1}=$ Volume of total extract $(\mu L)$.

$V_{1}=$ Volume of water extracted $(\mathrm{mL})$.

14.1.2 If the internal standard calibration procedure was used, calculate the concentration in the sample using the response factor (RF) detarmined in Section 7.3.2 and Equation 3.

Eq. 3. Concentration, $\mu g / L=\frac{\left(A_{1}\right)\left(I_{0}\right)}{\left.\left(A_{a}\right)(R F) / V_{0}\right)}$ where:

$A_{1}=$ Response for the parameter to be measured.

$A_{\omega}=$ Response for the internal standard.

1. = Amount of internal standard added to each extract (ug).

$V_{0}=$ Volume of water extracted, in liters.

14.2 Report results in micrograms per"liter without correction for recovery data. When duplicate and spiked samples are analyzed, report all data obtained with the sample results.

14.3 For samples processed as part of a set where the laboratory spiked sample recovery falls outside of the control limits established in Section 8.4, data for the affected parameters must be labeled as suspect.

\section{Method Performance}

15.1 Method detection limits The method detection limit (MDL) is defined as the minimum concentration of a substance that can be measured and reported with $9 \mathrm{~b}, \ldots$ confidence that the value is above zero"'. The MDL concentrations listed in Table 1 were obtained using reagent water'11". Similar results were achieved using representative wastewaters. MDL for the GC approach were not determined.

15.2 This method has been tested for linearity of recovery from spiked reagent water and has been demonstrated to be applicable over the concentration range from $8 \times \mathrm{MDL}$ to $800 \times \mathrm{MOL}^{(11)}$, with the following exception: benzolghilperylene recovery at $80 \times$ and $800 \times$ MDL were low ( $35 \%$ and $45 \%$ respectively).

15.3 In a single laboratory (Battelle Columbus Laboratories), using spiked wastewater samples, the average recoveries presented in Table 3 were

610.7

July 1982 obtained $^{(2)}$. Each spiked sample was analyzed in triplicate on two separate days. The stendard deviation of the precent recovery is also included in Table 3.

15.4 The U.S. Environmental Protection Agency is in the process of conducting an interlaboratory method study to fully define the performance of this method.

\section{References}

1. See Appendix A.

2. Determination of Polynuclear Aromatic Hydrocarbons in Industrial and Municipal Wastewaters." Report for EPA Contract 68-03-2624

(In preparation).

3. ASTM Annual Book of Standards, Part 31, D 3694.

"Standard Practice for Preparation of Sample Containers and for Preservation," American Society for Testing and Materials. Philadelphia, PA, p. 679, 1980.

4. "Carcinogens - Working With Carcinogens," Department of Health, Education, and Welfare, Public Health Service, Center for Disease Control, National Institute for Occupational Safely and Health, Publication No. 77-206. Aug. 1977

5. "OSHA Safety and Health Sian. dards. General Industry." (29CFR-1910). Occupational Safety and Health Adminis. tration, OSHA 2206, (Revised. January 1976).

6. "Safety in Academic Chemistry Laboratories," American Chemical Society Publication, Committee on Chemical Safety. 3rd Edition, 1979

7. "Handbook of Analytical Quality Control in Water and Waste. water Laboratories." EPA.600/ 4-79-019, U.S. Environmental Protection Agency Environmental Monitoring and Support Laboratory, Cincinnati, Ohio 45268. March 1979

8. ASTM Annual Book of Standards, Part 31, D 3370. "Standard Practice for Sampling Water," American Society for Testing and Materials. Philadelphia, PA, p. 76, 1980. 
9. "Methods 330.4 Titrimetric. DPD-FAS) and 330.5 (Spectrophotometric. DPD) for Chlorine. Total Residual," Methods for Chemical Analysis of Water and Wastes, EPA 600-4/79-020. U.S. Environmental Protection Ajency, Environmental Monitoring and Support Laboratory. Cincinnati, Ohio 45268, March 1979.

10. Burke. J. A., "Gas Chromatography for Pesticide Residue Analysis; Some Practical Aspects," Journal of the Association of Official Analytical Chemists, 48.1037 (1965).

11. Cole. T., Riggins, R., and Glaser, J., "Evaluation of Method Detec. tion Limits and Analytical Curve for EPA Method 610 - PNAs," International Symposium on Polynuclear Aromatic Hydrocarbons, 5th, Battello Columbus Laboratory. Columbus, Ohio (1980).
Table 1. High Performance Liquid Chromatography Conditions and Method Detection Limits

\begin{tabular}{|c|c|c|c|}
\hline Parameter & $\begin{array}{c}\text { Retention Time } \\
\text { (min) }\end{array}$ & $\begin{array}{c}\text { Capacity } \\
\text { Factor } \\
\left(k^{\prime}\right)\end{array}$ & $\begin{array}{c}\text { Method } \\
\text { Detection Limit } \\
(\mu g / L)^{M}\end{array}$ \\
\hline $\begin{array}{l}\text { Naphthalene } \\
\text { Acenaphthylene } \\
\text { Acenaphthene } \\
\text { Fluorene } \\
\text { Phenanthrene } \\
\text { Anthracene } \\
\text { Fluoranthene } \\
\text { Pyrene } \\
\text { Benzolatenthracene } \\
\text { Chrysene } \\
\text { Benzolb/fluoranthene } \\
\text { Benzolkflouranthene } \\
\text { Benzolpyrene } \\
\text { Dibenzola,hlanthracene } \\
\text { Benzolghilperylene } \\
\text { Indenoli,2,3-cdlpyrene }\end{array}$ & $\begin{array}{l}16.6 \\
18.5 \\
20.5 \\
21.2 \\
22.1 \\
23.4 \\
24.5 \\
25.4 \\
28.5 \\
29.3 \\
31.6 \\
32.9 \\
33.9 \\
35.7 \\
36.3 \\
37.4\end{array}$ & $\begin{array}{l}12.2 \\
13.7 \\
15.2 \\
15.8 \\
16.6 \\
17.6 \\
18.5 \\
19.1 \\
21.6 \\
22.2 \\
24.0 \\
25.1 \\
25.9 \\
27.4 \\
27.8 \\
28.7\end{array}$ & $\begin{array}{l}1.8 \\
2.3 \\
1.8 \\
0.21 \\
0.64 \\
0.66 \\
0.21 \\
0.27 \\
0.013 \\
0.15 \\
0.018 \\
0.017 \\
0.023 \\
0.030 \\
0.076 \\
0.043\end{array}$ \\
\hline
\end{tabular}

HPLC conditions: Reverse phase HC.ODS Sil-X $2.6 \mathrm{mmi} \times 250 \mathrm{~mm}$ Perkin-Elmer column; isocratic elution for 5 min using aceponitrile/water $(4+6)$. then linear gradient alution to $100 \%$ acetonitrile over 25 minutes; flow rate is $0.5 \mathrm{~mL} / \mathrm{min}$. If columns having other internal diometers are used the flow rate should be adjusted to maintein a linear velocity of $2 \mathrm{~mm} / \mathrm{sec}$.

-The mathod datection limit for naphthalene, acenaphthylene, acenaphthene. and fluorene were determined using a UV detector. All others were determined using a fluorescence detector.

Table 2. Gas Chromatographic Operating Conditions and Retention Times

\begin{tabular}{|c|c|}
\hline Parameter & $\begin{array}{c}\text { Retention Time } \\
\text { (min) }\end{array}$ \\
\hline 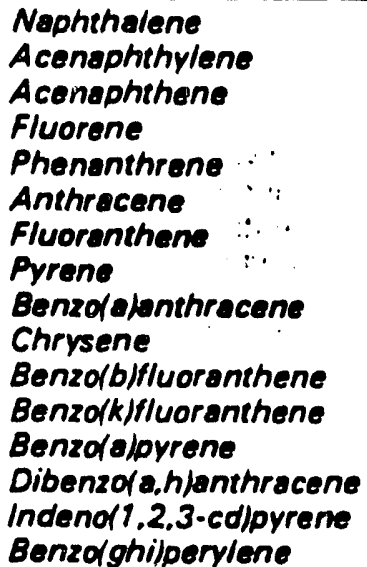 & $\begin{array}{l}4.5 \\
10.4 \\
10.8 \\
12.6 \\
15.9 \\
15.9 \\
19.8 \\
20.6 \\
20.6 \\
24.7 \\
28.0 \\
28.0 \\
29.4 \\
36.2 \\
36.2 \\
38.6\end{array}$ \\
\hline
\end{tabular}

GC conditions: Chromosorb W-AW. DCMS (100/120 mesh) coated with $3 \%$ OV -17 . packed in a $1.8 \mathrm{~m}$ long $x$ $2 \mathrm{~mm} 10$ glass column. with nitrogen carrier gas at a flow rate of $40 \mathrm{~mL} /$ min. Column temperature was held at $100^{\circ} \mathrm{C}$ for $4 \mathrm{~min}$, then pro. grammed at $8^{\circ} /$ minute 10 a final hold at $280^{\circ} \mathrm{C}$. 
Table 3 Single Operator Accuracy and Precision

\begin{tabular}{|c|c|c|c|c|c|}
\hline Paramater & $\begin{array}{l}\text { Average } \\
\text { Porcent } \\
\text { Recovery } \\
\end{array}$ & $\begin{array}{c}\text { Standard } \\
\text { Deviation } \\
\%\end{array}$ & $\begin{array}{l}\text { Spike } \\
\text { Range } \\
\text { (Mg/L) }\end{array}$ & $\begin{array}{c}\text { Number } \\
\text { of } \\
\text { Analyses }\end{array}$ & $\begin{array}{c}\text { Matrix } \\
\text { Typos } \\
\end{array}$ \\
\hline $\begin{array}{l}\text { Acenaphthene } \\
\text { Acenaphthylene } \\
\text { Anthracene } \\
\text { Benzolalanthracene } \\
\text { Benzolalpyrene } \\
\text { Benzolbfluoranthene } \\
\text { Benzolghilperylene } \\
\text { BenzodkJfluoranthene } \\
\text { Chrysene } \\
\text { Dibenzola,hlanthracene } \\
\text { Fluoranthene } \\
\text { Fluorene } \\
\text { Indenolt.2.3-cdlpyrene } \\
\text { Naphthalene } \\
\text { Phenanthrene } \\
\text { Pyrene }\end{array}$ & $\begin{array}{r}88 \\
93 \\
93 \\
89 \\
94 \\
97 \\
86 \\
94 \\
88 \\
87 \\
116 \\
90 \\
94 \\
78 \\
98 \\
96\end{array}$ & $\begin{array}{l}5.7 \\
6.4 \\
6.3 \\
6.9 \\
7.4 \\
12.9 \\
7.3 \\
9.5 \\
9.0 \\
5.8 \\
9.7 \\
7.9 \\
6.4 \\
8.3 \\
8.4 \\
8.5\end{array}$ & $\begin{array}{c}11.6 \cdot 25 \\
250-450 \\
7.9 \cdot 11.3 \\
0.64 \cdot 0.66 \\
0.21 \cdot 0.30 \\
0.24-0.30 \\
0.42-3.4 \\
0.14-6.2 \\
2.0-6.8 \\
0.4-1.7 \\
0.3-2.2 \\
6.1-23 \\
0.96-1.4 \\
20-70 \\
3.8-5.0 \\
2.3-6.9\end{array}$ & $\begin{array}{l}24 \\
24 \\
24 \\
24 \\
24 \\
24 \\
24 \\
24 \\
24 \\
24 \\
24 \\
24 \\
24 \\
24 \\
24 \\
24\end{array}$ & $\begin{array}{l}4 \\
4 \\
4 \\
4 \\
4 \\
4 \\
4 \\
4 \\
4 \\
4 \\
4 \\
4 \\
4 \\
4 \\
4 \\
4\end{array}$ \\
\hline
\end{tabular}

Column: HC.ODS SIL-X

Mobile phase: $40 \%$ to $100 \%$ Acotonitrile in water Detector: Uhre violat ot $254 \mathrm{~nm}$

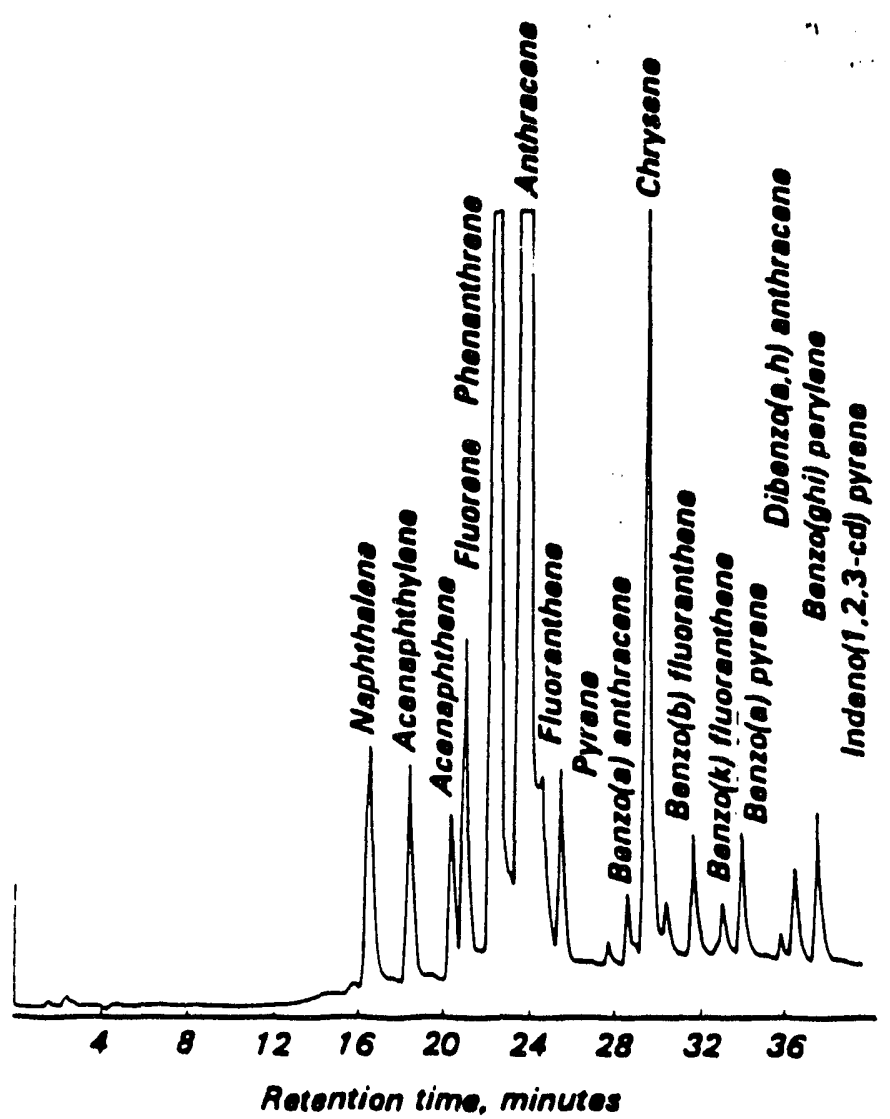

Floure 1. Liquid chromatogram of polynuclear oromatic hydrocerbons. 
Column: HC.OOS SIL.X

Mobile ohese: 40\% to 100\% Acetonitrile in woter

Detector: Fluorescence

\section{.}

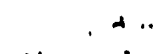

, $19.91:$

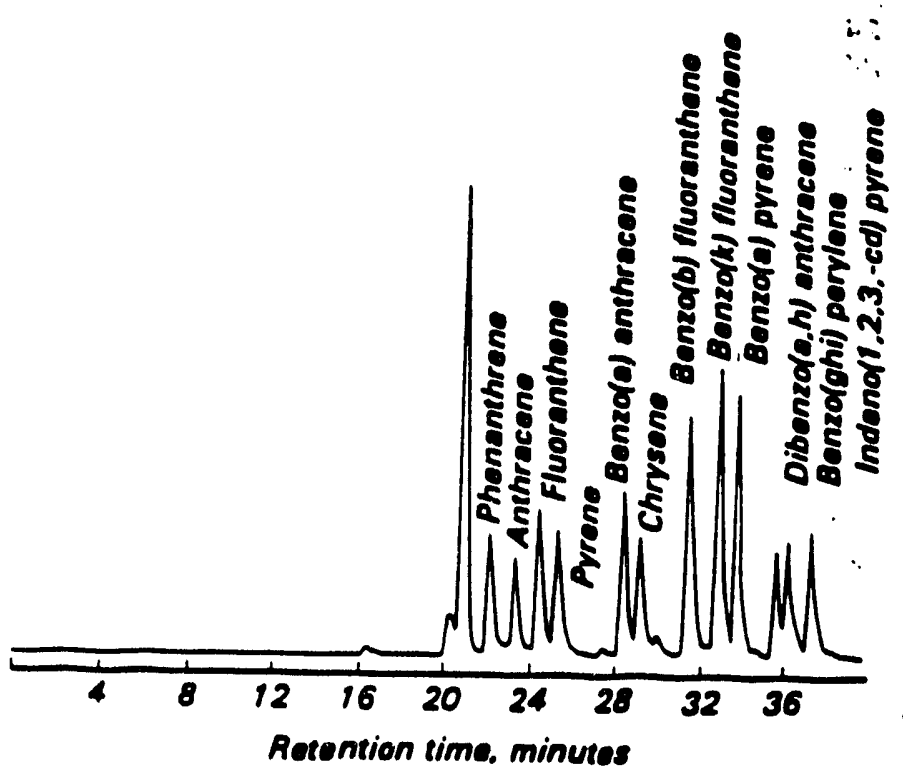

Figure 2. Liquid chromatogrom of polynuclaer eromotic hydrocarbons.

Column: $3 \%$ OV.17 on Chromosort W-AW-DCMS Program: $100^{\circ} \mathrm{C}$. 4 min.. $8^{\circ}$ por min. $10280^{\circ} \mathrm{C}$. Detector. Flame ionization

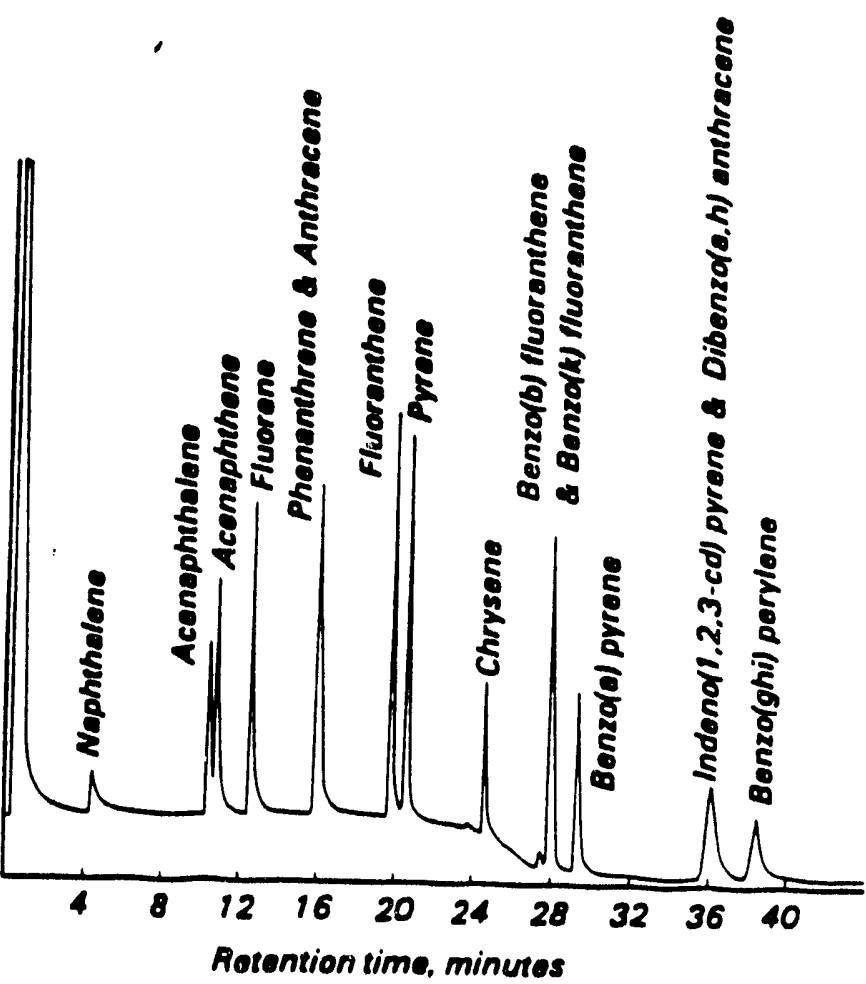

Figure 3. Gas chrometogram of polynuclear oromatic hydrocarbons. 
OSHA: proposed for B[a]P: $0.2 \mu \mathrm{g} / \mathrm{m}^{3}$ ACGIH: suspect carcinogen (B[a]P)

PropertIes: Table 1

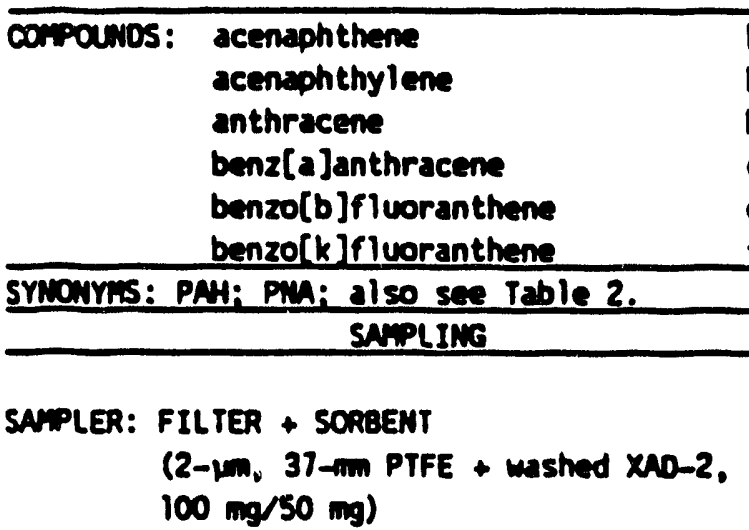

FLON RATE: 2 L/min

VOL-AIN: $200 \mathrm{~L}$

HN: $1000 \mathrm{~L}$

SHIPMENT: transfer filters to culture tubes: wrap sorbent and culture tubes in Al foil; ship $00^{\circ} \mathrm{C}$

SAMPLE STABILITY: Unknown; protect from heat and UV radiation

FIELD BLANKS: $107(\geq 3)$ of samples MEDIA BLANKS: 6 to 10

AREA SAMPLES: 8 replicates on preweighed filters for solvent selection

\section{ACQURACY}

RAMGE STUDIED, BIAS, AND OVERALL

PRECISION $\left(s_{r}\right)$ : not measured benzo[ghi ]perylene

benzo[ a ]pyrene

benzo[e ]pyrene

chrysene

dibenz $[a, h] a n t h r a c e n e$

ficaranthene fluorene

indeno $[1,2,3-c d]$ pyrene naphthalene

phenanthrene

pyrene

\section{!}

!RETHOO: HPLC, FLUORESCENCE/UV OETECTION

$!$

!AMALYTE: compounds above

!

!ExtRacison: $5 \mathrm{ml}$ organic solvent appropriate to

! sample matrix (step 1)

$!$

!coulum: $150 \mathrm{~m} \times 4.6 \mathrm{~mm}$, reverse phase, 5- $\mu \mathrm{m} \mathrm{C}_{18}$ $!$

!IMUECTION VOLURE: 10 to $50 \mu \mathrm{L}$

$!$

!rosile pHuse: $\mathrm{H}_{2} \mathrm{O} / \mathrm{CH}_{3} \mathrm{CN}$ gradient ambient

! temperature

!FLON RATE: $1.0 \cdot \mathrm{mL} / \mathrm{min}$

!DETECTORS: UN $254 \mathrm{~mm}$ fluorescence $340 \mathrm{~m}$

! (excitation), $425 \mathrm{~mm}$ (enission)

$!$

!CALIBRarion: external standards in $\mathrm{CH}_{3} \mathrm{CN}$ $!$

!RNEE, LOO ANO PRECISION (sp): EVALUATION OF $!$

METHOO

APPLICABILITY: The working range for $B[a] P$ is 1 to $50 \mu \mathrm{g} / \mathrm{m}^{3}$ for a $400-L$ dir sample. Specific sample sets may require modification in filter extraction solvent, choice of measurement method, and measurement conditions (see EVALUATIOU OF METHOO)

INTERFERENCES: Any compound which elutes at the same HPLC retention time may interfere. Heat, ozone, $\mathrm{NO}_{2}$, or UV light may cause sample degradation.

OTHER METHOOS: This revises P\&CAM 206 and 251 [1]. The spectrophotometric methods, P\&CAM 184 and 186 [1], have not been revised. Also see method 5515 (GC)

$5 / 15 / 85$

$5506-1$ 
REAEENTS:

1. Filter extraction solvent: benzene, * cyclohexane, methylene chloride, or other appropriate solvents, pesticide grade grade (step 1 ).

2. Hater, distilled, deionized, degassed.

3. Acetonitrile, MPLC grade, degassed.

4. PAH reference standards, * appropriate to the PAH-containing matrix sampled.

5. Calibration stock solution, $0.25 \mathrm{mg} / \mathrm{m}$. * Check purity of each PAY reference standard by ECAFID, HPLC/fluorescence and/or melting point. Purify, if mecessary, by recrystallization. Weigh $25 \mathrm{mg}$ of each PAH into a $100-m$ volumetric flask: dilute to volume with acetonitrile. Stable six months if refrigerated and protected from light.

* See special precuutions.

\section{EQUIPMENT:}

1. Sampler:

a. Filter. PIFE-laminated nembrane filter, 2-1m pore size, 37-min dianeter (ZEFLOUR, Menbrana, Pleasanton, CA or equivalent), backed by a gasket (37-m $00,32-m$ ID) cut from a cellulose support pad, in cassette filter holder.

NOTE 1: If sampling is to be done in bright sunlight, use cpaque or foil-wrapped cassettes to prevent sample degradation.

wore 2: Take filters to be prweighed from the filter package and allow to equilibrate 24 hrs with laboratory atmosphere before taring.

b. Sorbent tube, connected to filter with minimm length pve tubing. Plastic caps are required after supling. Hashed XaD-2 resin (front = $100 \mathrm{mg}$; back = $50 \mathrm{mg}$ ) (Scpelco Oreo 43 or equivalent). Pressure drop at 2 L/min airflow 1.6 to $2 \mathrm{kPa}$ ( 15 to $20 \mathrm{~cm} \mathrm{H}_{2} \mathrm{O}$ ).

2. Personal sapling pump capable of cperating for 8 hrs at $2 \mathrm{l} / \mathrm{min}$, with flexible connecting twing.

3. Alumimm foil.

4. Vial, scintillation, $20 \mathrm{mt}$, glass, PTfE-lined cap.

5. Refrigerant, bagged.

6. Culture tubes, PTFE-lined serew cap, 13- im $x$ 100 min.

7. Forceps.

8. Filters, 0.45-m, PTFE or nylon (for filtering sample solutions).

9. Pipet, 5-mk.

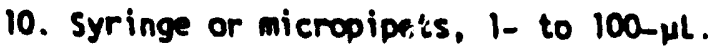

11. Ulerasonic bath.

12. HPLC, with gradient capability. fluorescence (excitation P $240 \mathrm{~mm}$, emission $425 \mathrm{~mm}$ ) and $W$ $(254 \mathrm{~mm})$ detectors in series, electronic integrator, and colum [HC-OOS-SILX (Perkin-Elmer corp.). Vydac 201Tp (The Separations Group) or equivalent; see page 5506-1].

13. Volumetric flasks, 10- and 100-m.

14. Lighting in laboratory: incandescent or W-shielded fluorescent.

15. Kuderna-Danish extractor.

SPECIAL PRECAUTIONS: Treat benzene and all polymuclear aronatic hydrocarbons as carcinogens. Neat compounds should be weighed in a glove box. Spent samples and unused standards are toxic waste. Regularly check counter tops and equipment with "black light" for fluorescence as an indicator of contanination by PAH. 


\section{SAMPLING:}

1. Calibrate each personal sampling pump with a representative sampler in line.

2. Take personal samples at $2 \mathrm{~L} / \mathrm{min}$ for a total sample size of 200 to $1000 \mathrm{~L}$. Take a concurrent set of eight replicate area samples at 2 to $4 \mathrm{~L} / \mathrm{min}$ on preweighed, 2-Im PTFE filters in an area of highest expected PAH concentration. MTE: The area samples are needed for solvent selection (step 7).

3. Inmediately after sampling, transfer the filter carefully with forceps to a scintillation vial. Hold filter at edge to avoid disturbing the deposit. Cap the scintillation vial and urap it in alumimn foil.

NOTE: This step is necessary to avoid loss of analytes due to sublimation and degradation by light.

4. Cap the sorbent tube and wrap it in aluminum foil.

5. Ship to laboratory in insulated container with bagged refrigerant.

\section{SAMPLE PREPARATION:}

MOTE: UV light may degrade PAH. Use yellow, UV-absorbing shields for flworescent lights or use incandescent lighting.

6. Refrigerate samples upon receipt at laboratory.

7. Determine optimm extraction solvent.

a. Allow the preweighed area filter samples to equilibrate 24 hrs with the laboratory atnosphere.

b. Weigh the area filters. Determine total weight collected on each.

c. Extract the first pair of area filters with acetonitrile, the second with benzene, the third with cyclohexane, and the fourth with methylene chloride, according to step 8.

nOTE: Use alternate solvents, if appropriate. PAH of intirest may be entrained within, and adsorbed by, particulate matter collected on the filter. It is necessary to datemine the solvent which maximizes recovery of the PAH fran each sample matrix. For example, methylene chloride $[2,3]$ and benzene:ethanol $(4: 1 \mathrm{v} / \mathrm{v})$ [4]

have been recommended for extraction of PAH from diesel exhaust particulate.

d. Analyze the extracts for the PAH of interest (steps 10 through 18). Normalize the total mass of PAH found to the mass of sample collected.

e. Choose the solvent which gives the highest recovery of PAH of interest. Use the solvent chosen to extract the personal filter samples.

8. Extract filters.

a. Add $5.0 \mathrm{mk}$ of the solvent chosen in step 7 to each scintillation vial containing a filter. Start media and reagent blanks at this step.

b. Cap and let sit 15 to 20 min in an ultrasonic bath.

NOTE 1: Soxhlet extraction may be required when large anounts of highly adsorptive particulate matter (e.g.. fly ash or diesel soot) are present.

MOTE 2: The sample must be dissolved in acetonitrile for chramatography. If needed, perform solvent exchange as follows:

CaUtion: To avoid loss of volatile components, do not allow the sample to go to dryness at any time.

(1) After filtration (step 10), take the sample to near dryness in a Kuderna-Danish extractor.

(2) Add ca. I $\mathrm{m}$ acetonitrile, take to near dryness, and adjust final volume to $1.0 \mathrm{~m}$ with acetonitrile and filter again.

9. Desorb PAH fram sorbent.

a. Score each sorbent tube with a file in front of the front (larger) sorbent section. Break tube at score line. 
b. Transfer glass wool plug and front sorbent section to a culture tube. Discard the foan plug. Transfer back sorbent section to a second culture tube.

c. Add $5.0 \mathrm{~m}$ acetonitrile to each culture tube. cap the culture tubes.

d. Allow samples to sit for $30 \mathrm{~min}$. Swirl occasionally.

10. Filter all sample extracts through an 0.45-nm mambrane filter.

CALIBRATION ANO QuALITY CONTROL:

11. Calibrate daily with at least five working standards.

a. Dilute aliquots of calibration stock solution with acetonitrile in $10-m$ volumetric flasks (e.g.. to 2.5, 0.5, 0.1, 0.02, and $0.002 \mu \mathrm{g} / \mathrm{m} / \mathrm{l}$ ).

b. Intersperse working standards and samples in the measurements.

c. Prepare calibration graphs (peak area vs. wg of each PAH per sample).

12. Recovery and desorption efficiency.

a. Determine recovery (R) from filters and desorption efficiency (DE) fran sorbent tubes at least once for each lot of filters and sorbent tubes used in the range of interest.

(1) Filters. Using a microliter syringe or micropipette, spike four filters at each of five concentration levels with a mixture of the andytes. Allow the filters to dry in the dark overnight. Analyze the filters (steps 8, 10, and 14 through 16. Prepare graphs of $R$ vs. anounts found.

MOTE: This step may not be used for some highly adsorptive particulate matrices for wich calibration by the method of standard additions may be more accurate.

(2) Sorbent tubes. Transfer an unused front sorbent section to a culture tube. Prepare a total of 24 culture tubes in order to masure DE at five concentration levels plus blanks in quadruplicate. Using a microliter syringe or micropipette, add calibration stock solution directly to sorbent. Cap culture tubes and allow to stand overnight. Analyze (steps 9, 10, and 14 through 16). Prepare graphs of DE vs. anounts found.

b. Check $R$ and $D E$ at two levels for each sample set, in duplicate. Repeat determination of $R$ and $D E$ graphs if checks do not agree to within \pm 52 of $D E$ graph.

13. Analyze at least three field blanks for each sample mediun.

REASUREMENT:

14. Set HPLC according to manufacturer's recommendations and to conditions on page 5506-1. Equilibrate colum at $602 \mathrm{CH}_{3} \mathrm{CN} / 4 \mathrm{OL} \mathrm{H}_{2} \mathrm{O}$ at $1.0 \mathrm{mb} / \mathrm{min}$ for $15 \mathrm{~min}$ before injecting first sample.

15. Inject sample aliquot. Start mobile phase gradient:

a. Linear gradient $602 \mathrm{CH}_{3} \mathrm{CN}$ to $1002 \mathrm{CH}_{3} \mathrm{CN}, 20 \mathrm{~min}$.

b. Hold at $1002 \mathrm{CH}_{3} \mathrm{Cr}$ for $20 \mathrm{~min}$.

MIE: Hold longer if necessary to prevent carryover of background, e.g., from cosl dust. c. Linear gradient to initial condition, 5 min.

16. Measure peak areas.

NOTE 1: Approximate retention times appear in Table 3.

NOTE 2: If peak area is above the calibration range, dilute with appropriate solvent, reanalyze, and apply dilution factor in calculations.

NOTE 3: If sample has many interferences, additional sample cleanup may be necessary. Many cleanup procedures have been published. Liquid-liquid partitioning between cyclohexane and nitromethane $[5,6]$ is widely used, but other techniques may be more appropriate for specific samples. 


\section{CaLCuLATIOHS:}

17. Read the mass, ug (corrected for $R$ or DE) of each analyte found on the filter (W) and front sorbent ( $H_{f}$ ) and back sorbent ( $\left.H_{b}\right)$ sections, and on the average madia blank filter (B) and fingt sorbent $\left(B_{f}\right)$ and back sorbent (Bb) sections from the calibration graphs. t.

18. Calculate concentration, $C\left(\mu g / m^{3}\right)$, in air as the sum of the particulate concentration and the vapor concențation using the actual air volume sampled, $V(L)$.

$$
C=\frac{\left(W-B+H_{f}+H_{b}-B_{f}-B_{p}\right) \cdot 10^{3}}{V} \cdot \mu g / m^{3} .
$$

Nore: Hf and to include analyte originally collected on the filter as particulate, then volatilized during sapling. This can be a significant fraction for many PAH (e.g., flworanthane, naphthalene, fluorene, anthracene, phenanthrene).

EVALLATION of retrod:

The fluorescence datector used in this method is both sensitive and selective. The detector can "see" as little as 50 pg of many PAy injected on the colum. LOOs for the 17 analytes range frow 50 to $350 \mathrm{ng}$ per sumple. It does not respond to non-fluorescent molecules such as aliphatics. The mathod is, therefore, most amenable to determination of trace amounts of pay in mixtures of aliphatic compounds. Successful applications include: aluminum reduction facilities, asphalt fume, coll gasification plants, call liquefaction plants, coal tar pitch, coke oven enissions, creosote treatuent facilities, diesel exhaust, graphite electrode manufacturing, petroleum pitch, and roofing tearoff oparations.

This method has been evaluated by analyzing spiked filters, spiked sorbent tubes, and complete spiked sampling trains through wich were drm $500 \mathrm{~L}$ of air [1]. Each of the three groups was spiked with each analyte at two concentration levels in sextuplicate. Particular note should be made that the effect of particulate matter has not been evaluated, and every sampling matrix is unique. The data on the following page were obtained on spiked samplers stored refrigerated in the dark for three months followed by measurewent with HPLC. 


\begin{tabular}{|c|c|c|c|c|}
\hline$\infty_{\text {npowo }}$ & $\begin{array}{l}\text { CAl IBRarion RaveE } \\
\text { (ug per saple) }\end{array}$ & $\begin{array}{c}100 \\
\text { (ug per } \\
\text { selele) }\end{array}$ & $\begin{array}{l}\text { EASUich } \\
\text { SPIKED }\end{array}$ & $\begin{array}{l}\text { PRECISION } \\
\text { SPIKED + } \\
- \text { AIRb } \\
\end{array}$ \\
\hline 1. ACEMWPHTHENE & $2.0-13$ & 0.8 & $.058 \mathrm{~s}$ & $.093(50)$ \\
\hline 2. ACEMPPHTHYLEKE & $1.0-100$ & 0.35 & $.032 \mathrm{~s}$ & $.015(100)$ \\
\hline 3. AMTHRACEME & $0.4-13$ & 0.05 & $.039 \mathrm{~s}$ & $.037(5)$ \\
\hline 4. BENZ[a JANTHRACENE & $0.4-13$ & 0.15 & $.032 \mathrm{~F}$ & $.084(5)$ \\
\hline 5. BENZO(b) JFLUORUNTHEME & $0.4-12$ & 0.1 & $.027 \mathrm{~F}$ & $.028(10)$ \\
\hline 6. BENZO[K]FLLOCANTHEME & $0.4-13$ & 0.15 & $.025 \mathrm{~F}$ & $.021(1)$ \\
\hline 7. BENZO[ ghi ]PERYLENE & $0.5-25$ & 0.2 & $.031 \mathrm{~F}$ & $.029(10)$ \\
\hline 8. BENZO[ a ]PYREME & $0.4-14$ & 0.2 & $.027 \mathrm{~F}$ & $.029(5)$ \\
\hline 9. BENZO[ ] ]PYRENE & $0.5-13$ & 0.2 & (c) & (c) \\
\hline 10. ORYSEME & $0.4-12$ & 0.15 & $.039 \mathrm{~F}$ & $.024(5)$ \\
\hline 11. DIBEnz[a,h ]ANTHPacene & $0.5-25$ & 0.2 & $.026 \mathrm{~F}$ & $.029(10)$ \\
\hline 12. FLUOPANTHEME & $0.4-13$ & 0.15 & .0265 & $.050(10)$ \\
\hline 13. FLUORERE & $0.7-13$ & 0.25 & .0315 & $.090(10)$ \\
\hline 14. INDENO $[1,2,3-c d]$ PYRENE & $0.5-12$ & 0.2 & $.044 \mathrm{~F}$ & $.032(10)$ \\
\hline 15. MPPTIHALEME & $0.6-13$ & 0.25 & .0415 & $.125(50)$ \\
\hline 16. PHEMNITREENE & $0.4-13$ & 0.1 & $.036 \mathrm{~s}$ & $.070(2)$ \\
\hline 17. PMRENE & $0.5-13$ & 0.2 & (c) & (c) \\
\hline
\end{tabular}

aRSD for filter (F) where volatilization is nil or for sorbent (S) where substantial volatilization may oceur during sapling.

bRSO determined at the ug level shown in parenthesis for a spiked filter followed by a sorbent tube. After spiking. laboratory air was dran through the sampling train at $2 \mathrm{~L} / \mathrm{min}$ for 4 hrs.

Cnot detennined.

REFEREMCES:

[1] MIOSH Manual of Aalytical methods, 2nd ed., Vol. 1, U.S. Department of Health, Education, and thelfare, PUbl. (NIOSH) 11-157-A (1977).

(2) Brever, G. M. Anal. Lett. 1I (Al1), 1293-1306 (1984).

(3) Zwidinger, R. B., S. B. Tejada, D. Oropkins, J. Huisingh, and L. Claxton. Characterization of Extractable Organics in Diesel Exhaust Particulate." paper presented at symposium on Diesel Particulate Enissions measurement Characterization. Ann Arbor. MI (1978).

[4] Swarin, S. J. and R. L. Williaus. "Liquid Chranatographic Determination of Benzo[a]pyrene in Diesel Exhaust Particulate: Yerification of the Collection and Analytical thods." Polymuclear Aromatic Hydrocarbons: Physical and Biological Effects, Bjorseth, A. and Dennis, Eds., Battelle Press, $111-790$ (1900).

[5] Hise, S. A., et al. "Analytical methods for the Detenmination of Polycyclic Aromatic Hydrocarbons on Air Particulate Matter," Polymuclear Aromatic Hydrocarbons: Physical and Biological Chenistry, Cooke, Dennis and Fisher, Eds., Battelle Press, 919-929 (1982).

[6] Movotny, M., M. L. Lee and K. D. Bartle. J. Chromatog. Sci.. 12, 606-612 (1914).

(7) Backlo Data Report for hethod 5506. Analytical Report for WIOSH Sequence 4170 (NIOSH, unpobl ished, March 16, 1984).

[8] Studt.. P.. Liebigs Ann. Chen.. 528 (1978).

[9] Clar, E. Polycyclic Hydrocartons, Acadenic Press (1964).

[10] Handook of Chemistry and Physics, 62nd ed. CRC Press (1982).

RETHOO REVISED BY: B. R. Belinky and E. J. Slick, MIOSH/DPSE. 
Method Ho.

EHS 0-4

Title:

011 and Grease In Hater - Infrared

Date Issued: $1-2-86$

Approved by: MK Hamiltortiket

Hritten by: MK Hamilton

Supersedes Method No. EHS 0-2

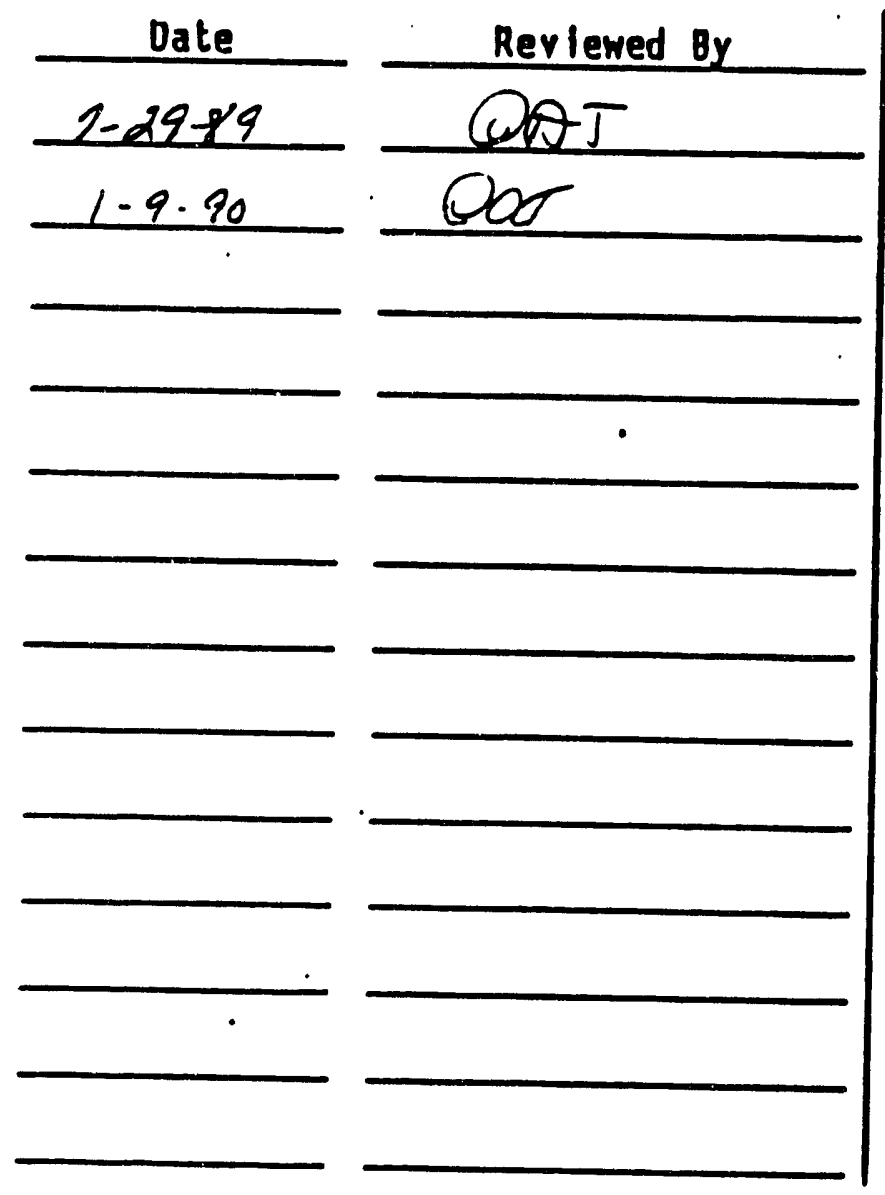

Replaced by Method ito.

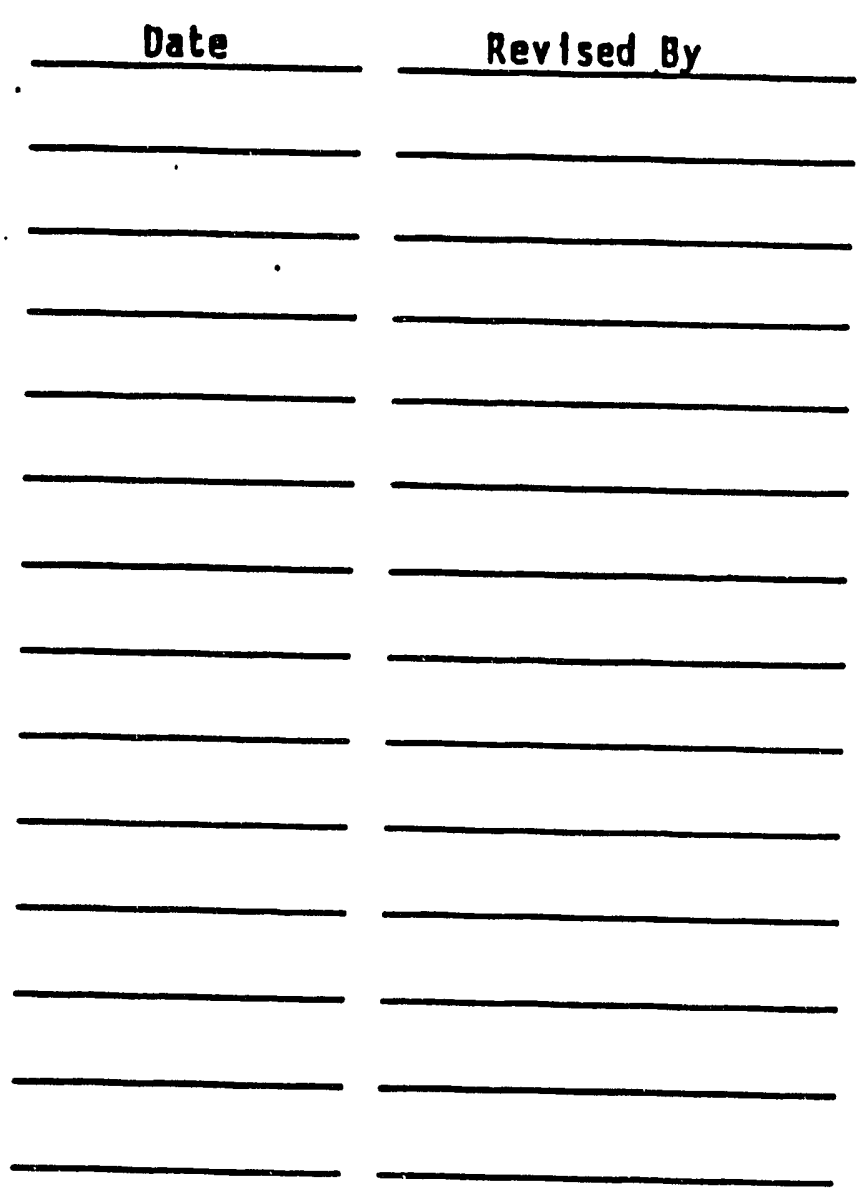

Date: 


\section{OIL AND GREASE IN HATER - INFRARED}

\section{Reference}

1. Standard Methods for the Examination of Water and Wastewater, 16th Ed., 1985, pp. 496-499.

\section{Principles}

Dissolved or emulsified ofl and grease are extracted from water using organic solvents. Since various solvents differ in their ability to extract oil and grease, it is important to be consistent in the solvents used. 1,1,2trichlorotrifluoroethane was chose to conform with the procedure used by the Environmental Protection Agency. After the oil and grease have been extracted, the amount present is quantified using infrared spectroscopy at $2930 \mathrm{~cm}^{-1}$.

\section{Limitations}

Low bolling fractions such as kerosene and gasoline can be determined reliably by this method as can other ofl and grease fractions. This must be taken into account when comparing results obtained by this method to those obtained gravimetrically as that method does not detect low bolling fractions. Since no organic solvent is known to selectively dissolve only oil and grease, other organic substances present may be dissolved as well. Only those showing infrared absorption in the $2930 \mathrm{~cm}^{-}$hydrocarbon region will cause interferences. To aid in breaking up saponified ofl and grease, samples should be acidified to about pH 1. The addition of saturated sodium chloride may also be helpful.

\section{Equipment}

1. 1-liter separatory funnels with tefion stopcocks.

2. Recprding infrared (IR) spectrophotometer for use in the 3200 to 2700 $\mathrm{cm}^{-1}$ range.

3. $1 \mathrm{~cm}$ IR cell (quartz windows).

4. $25,50 \& 100 \mathrm{~mL}$ volumetric flasks.

5. Whatman IPS phase separating paper.

\section{Reagent (Stock)}

1. 1,1,2-Trichlorotrifluorethane (TCTFE) - spec quality.

2. Sodium chloride - $\mathrm{NaCl}$.

3. Sulfuric acid conc. $-\mathrm{H}_{2} \mathrm{SO}_{4}$.

4. Isooctane

5. Hexadecane

6. Benzene - CLASS I HUMAN CARCINOGEN 


\section{Reagents (Prepared)}

1. Saturated $\mathrm{NaCl}$ - add $\mathrm{NaCl}$ to deionized $\mathrm{H} 2 \mathrm{O}$ with stirring unt $\mathrm{fl}$ no more $\mathrm{NaCl}$ will dissolve and a slight excess remains (approximately $100 \mathrm{~g} / 250 \mathrm{~mL}$ ). Prepare annually.

\section{Standards}

1. Stock Standard - Pipet $250 \mu \mathrm{L}$ benzene, $375 \mu \mathrm{L}$ isooctane and $375 \mu \mathrm{L}$ hexadecane into a tightly sealed $1 \mathrm{~mL}$ vial. This represents a reference oil of density $=0.77 \mathrm{mg} / \mu \mathrm{L}$. Refrigerate and prepare monthly.

2. Working Standards - Prepare three working standards monthly as follows:

a. Pipet $10 \mu \mathrm{L}$ of stock standard reference ofl to $50 \mathrm{~mL}$ of TCTFE. $1 \mathrm{~mL}=154 \mu \mathrm{gg} 011$ and grease. (Working standard "A")

b. Pipet $3.5 \mathrm{~mL}$ of working standard "a" $(154 \mu \mathrm{g} / \mathrm{mL})$ to a $50 \mathrm{~mL}$ volumetric and dilute to volume with TCTFE. $1 \mathrm{~mL}=10.8 \mu \mathrm{gg}$ oil and grease.

c. Pipet $10.0 \mathrm{~mL}$ of working standard "a" $(154 \mu \mathrm{g} / \mathrm{mL})$ to a $50 \mathrm{~mL}$ volumetric and dilute to volume with TCTFE. $1 \mathrm{~mL}=30.8 \mu \mathrm{g}$ ofl \& grease.

Also prepare a zero standard by filling a $25 \mathrm{~mL}$ volumetric flask with TCTFE.

\section{Procedure}

\section{A. Sample collection}

1. Preclean 1-liter glass sample bottles with $1: 1 \mathrm{HNO}_{3}$ and deionized $\mathrm{H}_{2} \mathrm{O}$.

2. Collect approximately 1 liter of sample, acidify with $2.5 \mathrm{~mL}$ conc. $\mathrm{H}_{2} \mathrm{SO}_{4}$ within 6 hours of collection and refrigerate.

3. Analyze within 24 hours of collection.

B. Analysis

1. If the sample has not been acidified, add $2.5 \mathrm{~mL}$ conc. $\mathrm{H}_{2} \mathrm{SO}_{4}$ per liter.

2. Transfer the sample to a 1-1iter separatory funnel.

3. Rinse the sample container with $15 \mathrm{~mL}$ 1,1,2-trichlorotrifluoroethane (TCTFE) and add this to the separatory funnel along with an additional $25 \mathrm{~mL}$ TCTFE.

4. Shake the separatory funnel vigorously for 2 minutes and allow the layers to separate. If an emulsion forms add $10 \mathrm{~mL}$ saturated $\mathrm{NaCl}$ solution and mix gently to break the emulsion. 
5. Draw off the lower TCTFE layer through Whatman IPS filter paper into a dry $100 \mathrm{~mL}$ volumetric flask.

6. Rinse the original sample contalner with $15 \mathrm{~mL}$ TCTFE and add this to the separatory funnel along with an additional $25 \mathrm{~mL}$ TCTFE.

7. Shake the separatory funnel vigorously for 2 minutes as before and allow the layers to separate.

8. Draw off the lower TCTFE layer and add it to the $100 \mathrm{~mL}$ volumetric containing the first TCTFE extract, again, filtering through Whatman IPS filter paper.

9. Drain the upper aqueous phase into a $1000 \mathrm{~mL}$ graduated cylinder and record the volume (v).

10. Rinse the separatory funnel with $20 \mathrm{~mL}$ TCTFE and add this washing to the $100 \mathrm{~mL}$ voiumetric, filtering as above.

11. Prepare a blank by filtering 10-20 mL TCTFE into a stoppered flask.

12. Set up the IR spectrophotometer according to the manufacturer's instructions. Zero the instrument and run a styrene spectrum to be sure the instrument is operating properly.

13. Fil] a $1 \mathrm{~cm}$ IR cell with the zero standard and scan from 3200-2700

14. Rinse the cell with each successive standard and sample and scan the same wavelength region.

15. Clean the IR cell with TCTFE and acetone, dry and return it to a desiccator for storage.

\section{Calculations}

1. Measure the absorbance of the standards and samples by constructing a straight baseline over the scan range and measuring the absorbance of the peak maximum at $2930 \mathrm{~cm}^{-1}$ and subtracting the baseline absorbance at that point.

2. Using the standards data, prepare a calibration curve by plotting $\mu \mathrm{g} / \mathrm{mL}$ 011 and grease vs absorbance.

3. Use the calibration curve to determine the oil and grease concentration of the sample TCTFE extracts.

4. Calculate the original sample oil and grease concentration as follows:

$\mathrm{mg} / \mathrm{L}$ oil and grease $=\frac{A \times 100}{v}$

$A=\mu \mathrm{g} / \mathrm{mL}$ oil and grease in TCTFE extract

$100=\mathrm{mL}$ of TCTFE

$V=m L$ of $\mathrm{H}_{2} \mathrm{O}$ extracted 


\section{Draft Method 508- For Use in WS023 Only}

\section{DETERMINATION OF CHLORINATED PESTICIDES IN WATER BY GAS CHROMATOGRAPHY WITH AN ELECTRON CAPTURE DETECTOR}

\section{SCOPE AND APPUCATION}

1.1 This is a gas chromatographic (GC) method applicable to the determination of certain chlorinated pesticides in ground water and finstied drinking water.(1) The following compounds can be determined using this method:

contreas

CASAlo.

Narin

Chlordano-ajpha

Chiordeno-gamma

Chlomet

Conlerebenzitate

Criorothalonil

DCPA

$4.4 \cdot 000$

$4.4-D O E$

$4,4.00 T$

Dioldrin

Endosultan I

Endosultan II

Endosutian suttate

Endrin

Endrin aldahyde

Etridiezole

HCHelona

HCHoot

HCHdetta

HCHogmma

Hoptechior

Heprechlor epoxide

Hoxechlorobenzeno

Mothoxyentor

cis.Pormothrin

trane-Pemethrin

Propectior

Trifturatin

$30000-2$

$5100-79.9$

5102742

$2075 \pi 78$

S01.150

$2021+0.2$

1007 ase

72-54-8

72.550

50203

0057.1

9sesed

$33213-65-9$

1001078

72.208

7421.934

$2002-15-9$

312048

$319-257$

$31986-8$

52-80

$76-40$

1024573

110741

$72+425$

s2ans-53-1

52045-53-1

$1918-16.7$

$1322-000$

1.2 This method has been valldated In a single laboratory and estlmated detection limits (EDLs) have been determined for the analytes above (Sect 12). Observed detection llmits may vary between ground waters, depending upon the nature of interferences In the sample matrix and the specific instrumentatlon used.

1.3 This method is restricted to use by or under the supervision of analysts experienced In the use of GC and in the interpretation of gas chromatograms. Each analyst must demonstrate the ability to generate acceptable resutts with this method using the procedure described in Sect. 9.3.

1.4 When ihis method is used to analyze untamillar samples for any or all of the analytes above, analyte identifications must be confirmed by at least one additional qualitative technique.

\section{SUMMARY OF METHOD}

2.1 A measured volume of sample of approximately $1 \mathrm{~L}$ is solvent extracted with methylene chlopide by mechanical shaking in a separatory funnel of mechanical tumbling in a bottle. The methylene chloride extract is isolated. dried and concentrated 10 a volume of $5 \mathrm{~mL}$ after solvent substitution with methyl tert-butyl other (MTBE). Chromatographic conditions aro described which permin the separation and measurement of the analyes in the extract by GC with an electron capture detector (ECD).

2.2 An altemative manual liquidtiquid extraction method using separatory funnels is also described.

\section{INTERFERENCES}

3.1 Method interferences may be caused by contaminants in solvents. reagents, glassware and other sample processing apparatus that lead to discrete artifacts or elevated basellnes in gas chromatograms. All reagents and apparatus must be routinely demonstrated to be froe from interferences under the conditions of the analysis by punning laboratory method blanks as described in Sect. 9.2.

3.1.1 Glassware must be scrupulously cleaned.(2) Clean all glassware as soon as possible atter use by thoroughly rinsing with the last solvent used in it. Follow by washing with hot water and detergent and thorough insing with tap 
DRAFT DOCUMENT - INTERNAL USE ONLY - 4/15/88

and reagent water. Drain dry, and heat in an oven or muffie fumace at $400^{\circ} \mathrm{C}$ for 1 hour. Do not heat volumetric ware. Thermally stable materials such as PCBs might not be eliminated by this treatment. Thorough rinsing with acetone may be substituted for the heating. After drying and cooling. seal and store glassware in a clean emvironment to prevent any accumulation of dust or other contaminants. Store inverted or capped with aluminum foil.

3.1.2 The use of high purity reagents and solvents helps to minimize imterierence problems. Purification of solvents by distillation in all-glass systems may be required.

3.2 Interferences by phthalate esters can pose a major problem in pesilcide analysis when using the electron capture detector. These compounds oenerally appear in the chromatogram as large peaks. Common flexible plastles contain varying amounts of phthalates that are easily extracted or leached Juring laboratory operatlons. Cross contamination of clean glassware poutinely occirs when plastics are handled during extraistion steps, especially when solvent-wetted surfaces are handled. Interferences from phthalates can best be minimized by avoiding the use of plastics in the laboratory. Exhausthe cleanup of reagents and glassware may be requited to eliminate background phthalato contamination. $(3,4)$

3.3 Intertering contamination may oceur when a sample containing low concentrations of analytes is analyzed Immedlately lollowing a sample containing relatively hlgh concentrations of analyies. Betwoen-sample rinsing of the sample syringe and associated equipment with MTBE can minimize sample cross contaminatlon. After analysis of a sample containing hlgh concemtrations of analytes, one or more injections of MTBE should be made 10 ensure that accurate values are obtained for the next sample.

3.4 Matrix Interferences may be caused by contaminants that are coextractod from the sample. The extent of matrlx interferences will vary considerably from source to source, depending upon the ground water sampled. Cleanup of sample exiracts may be necessary. Posltive Identifications must be conflrmed using the contimation column specified in Sect. 5.8.2.

\section{SAFETY}

4.1 The roxicity or carcinogenlcity of each reagent used In thls method has not been precisely defined; however, each chemical compound must be treated as a potentlal health hazard. From inis viewpoint, exposure to these chemicals must be reduced to the lowest possible level by whatever means avallable. The laboratory is responsible for maintaining a current awareness file of OSHA regulations regarding the safe handling of the chemicals specifled in this method. A reference flle of material safery data sheets should also be made available to all personnel involved in the chemical analysis. Addhional references to laboratory safery are available and have been identified $(5-7)$ for the information of the analyst

5. APPARATUS AND EOUIPMENT (AII specifications aro suggested. Catalog numbers are Included for illustration only.)

\subsection{SAMPUNG EOUIPMENT}

5.1.1 Grab sample bottle - Borosilicate, I.L vol-ume with graduations (Wheaton Mediallab borte \#219820), fitted with screw caps lined withTFE-huorocarbon. Protect samples from light. The container must be washed and dried as described in Sect. 3.1.1 before use to minimize contamination. Cap liners are cut to fit from sheots (Plerce $\# 012736$ ) and extracted with methand overnight prior to use.

\subsection{GLASSWARE}

5.2.1 Separatory funnel $.-2000-\mathrm{mL}$, with TFE-fluorocarton stopcock, ground glass or TFE-fluorocarbon stopper.

5.2.2 Tumbler botwe - 1.7-L Wheaton Roller Culture Vessel), with TFE-fluorocarton llned screw cap. Cap liners are cut to it from sheots (Plerce \#012736) and extracted with methanol ovemight prior 10 use.

5.2.3 Flask, Eftenmoyer - $500-\mathrm{mL}$

5.2.4. Concentrator fube, Kuderma-Danish (K-D) 10- or $25-\mathrm{mL}$, graduated (Kontes K-570050-1025 or K-570050-2525 or equivalent). Calibration must be checked at the volumes employed in the test. Ground glass stoppers are used 10 prevent evaporation of extracts. 
5.2.5 Evaporative hask, K-D 500-mL (Kontes K. 570001.0500 or equivalent). Attach to concentrator tube with springs.

5.2.6 Snyder column, K.D three-ball macro (Kontes K.503000-0121 or equivalem).

5.2.7 Snyder column, K-D iwo-ball micro (Kontes K-560001.0219 or equivalent).

5.2.8 Vials - Glass, 5. to $10 . \mathrm{mL}$ capacity with TFE-fluorocarion lined scrow cap.

5.3 Separatory funnel shaker .. Capable of holding eight 2-L. separatory funnels and shaking them with rocking motion to achieve thorough mixing of separalory funnel contents (avallable from Eberbach Co. in Ann Arbor, MI).

5.4 Tumbler .. Capable of holding four to six tumbler bottles and tumbiling them end-over-end at 30 turns/min (Associated Design and Mig. Co., Nexandrita. VA.).

5.5 Boiling stones carborundum, 12 granules (Arthur H. Thomas Co. 1590-033). Heat at $400^{\circ} \mathrm{C}$ for $30 \mathrm{~min}$ prior to use. CoOl and store in a dessicator.

5.6 Water bath .. Heated. capable of temperature control ( $\pm 2 \mathrm{C}$ ). The bath should be used in a hood.

5.7 Balance - Analytical, capable of accurately weighing to the nearest $0.0001 \mathrm{~g}$.

5.8 GAS CHROMATOGRAPH - Analytical system complete with GC suitable for use with capilary columns and all required accessories including syringes, analytical columns, gases, detector and stripchan recorder. A data system is rocommended for measuring peak areas. Table 1 llsts retention times observed for method analytes using the columns and analytical conditions described bolow.

5.8.1 Column 1 (Primary column) - $30 \mathrm{~m}$ long $\times 0.25 \mathrm{~mm}$ 1.D. DB.5 bonded fused silca column, $0.25 \mu \mathrm{m}$ film thickness (available from J\&W. Hellum carrior gas how is established at $30 \mathrm{~cm} / \mathrm{sec}$ linear velocity and oven femperature is programmed from $60^{\circ} \mathrm{C}$ to $300^{\circ} \mathrm{C}$ at $4{ }^{-C} \mathrm{C} / \mathrm{min}$. A sample chromatogram obtained with this column is presented in Fig. 508-1. Valldation data presented in this method were obtained using this column. Atternative columns may be used in accordance with the provisions described in Sect. 9.4.

5.8.2 Column 2 (Confirmation column) - 30
Table 1. Retention Times for Method Analytes

\begin{tabular}{|c|c|c|}
\hline \multirow[b]{3}{*}{ Etridiazolo } & \multicolumn{2}{|c|}{ Aotention Timo(a) } \\
\hline & Primary & Contirmatory \\
\hline & 23.40 & 22.78 \\
\hline Chlornes & 25.50 & 26.18 \\
\hline Propechior & 28.00 & 30.94 \\
\hline Trtmuralin & 31.62 & (b) \\
\hline HCHalpha & 31.62 & 32.98 \\
\hline Hexectilorobanzens & 31.98 & (b) \\
\hline HCHboen & 33.32 & 40.12 \\
\hline HCHoamme & 33.68 & 35.36 \\
\hline PCNB (intemal std.) & 34 & 34 \\
\hline HCHdent & 35.02 & 41.48 \\
\hline Chlorthalonil & 35.30 & 39.78 \\
\hline Hapesenior & 37.74 & 36.72 \\
\hline Norin & 40.12 & 38.08 \\
\hline DCPA & 41.14 & 41 is \\
\hline Heptechlor epoxide & 42.16 & 42.16 \\
\hline Chlordane-gemme & 40.52 & 43.86 \\
\hline Endosutten I & 4.20 & 1352 \\
\hline Chiordanompha & 4.54 & in sus \\
\hline $4,4^{\circ} \cdot 00 E$ & 45.90 & 488 \\
\hline Dieldrin & 45.90 & 45.90 \\
\hline Endrin adehyde & 46.92 & 4692 \\
\hline Encosutien sultate & 47.60 & 4930 \\
\hline Oniorobenzilats & 47.94 & 428 \\
\hline 4.4 .000 & 40.28 & 492 \\
\hline Endosulian $\|$ & 48.62 & 5160 \\
\hline Endrin & 49.98 & (b) \\
\hline 4,4'-00T & 50.32 & 50.32 \\
\hline Mothonyehtor & 53.38 & 53.72 \\
\hline cis-Pommethin & 59.40 & (b) \\
\hline transopermothrin & 50.82 & (D) \\
\hline
\end{tabular}

(a) Columns and anaprieal conditions ure described in Sact. 3.8 .1 and 5.8 .2

(b) Data not aveilablo.

$\mathrm{m}$ long $\times 0.25 \mathrm{~mm}$ I.D.DB-1701 bonded fused silica column, $0.25 \mu \mathrm{m}$ film thickness (available from J\&W). Helium carrier gas flow is established at $30 \mathrm{~cm} / \mathrm{sec}$ linear velocliy and oven temperature is programmed from $60^{\circ} \mathrm{C}$ io $300^{\circ} \mathrm{C}$ at $4{ }^{\circ} \mathrm{C} / \mathrm{min}$.

5.8.3 Detector - Electron capture. This detector has proven effective in the analysis of spiked reagent and artificial ground waters. An ECD was used to generate the validation data presented in this method. Aternative detectors, including a mass spectrometer, may be used in accordance with the provisions described In Sect 9.4. 


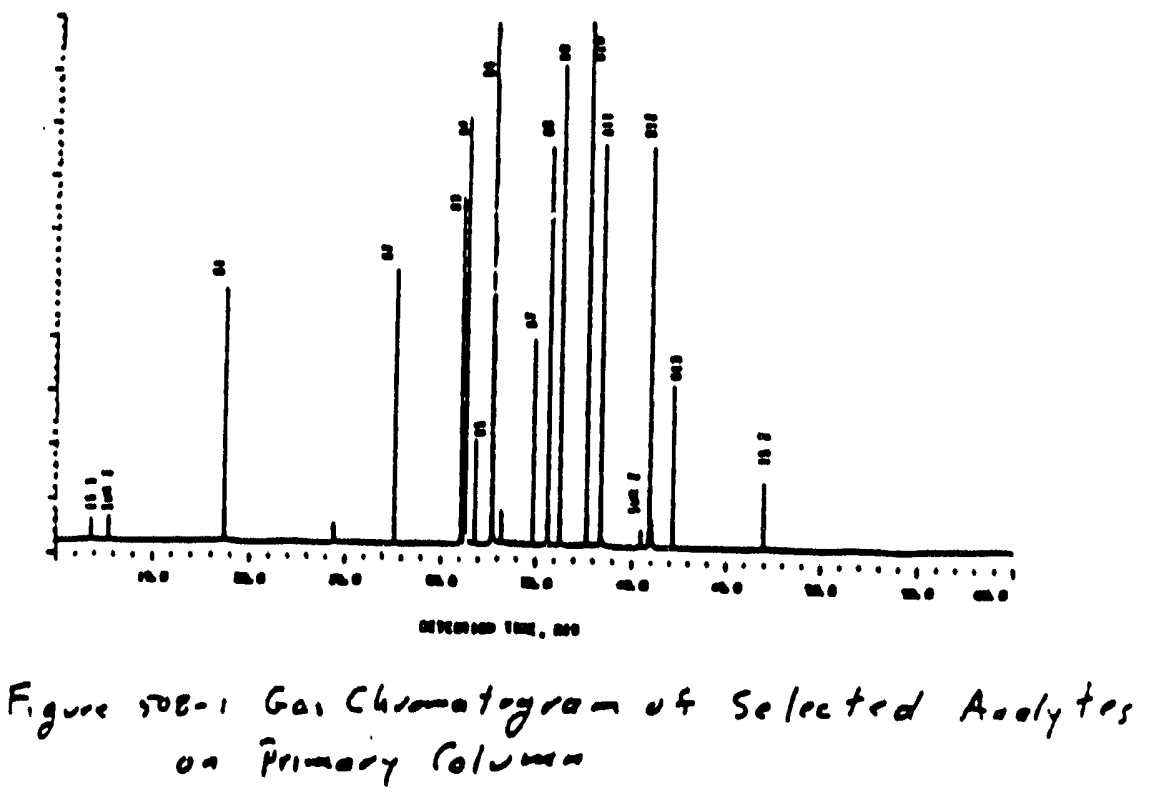

\section{REAGENTS AND CONSUMAgLE MATERIALS}

6.1 Acetone, methylene chlorlde, MTBE -. Distilled-in-glass quality or equivalent.

6.2 Phosphate bulfer, $\mathrm{pH} 7$.. Prepars by moxing $29.6 \mathrm{~mL} 0.1 \mathrm{~N} \mathrm{HC}$ and $50 \mathrm{~mL}$ 0.1 in dipotassium phosphate.

6.3 Sodium chloride, crystal, ACS grade .. Heat treat in a shallow tray at $450^{\circ} \mathrm{C}$ for a minimum of a hours to remove interiering organic substances.

6.4 Sodlum sutfate, granular, anhydrows, ACS grade .. Heal ireat in a shallow tray at 450 C for a minimum of a hours to remove interfering organic substances.

6.5 Sodlum thiosulfate, oranular, anhydrous. ACS grade.

6.6 Pentachloronitrobenzerie (PCNB) - 98\% purtty, for use as interna standard.

6.7 4.4-Dichlorobipheny (DCB) - 96\% purity, for use as surrogate standard (avallable from Chemicals Procurement Inc).

6.8 Reagent water - Reagern ' water is defined as water in which an interferemt is not observed at or above the EDL of any andyte. Reagent water used to generate the valldation data in this method was distmed water obtained from the Magnetic Springs Water Co., Columbus, Ohio.

6.9 STOCK STANDARD SOLUTIONS $(1.00$ $\mu \mathrm{g} / \mu \mathrm{L})$.. Stock standard solutions may 6e purchased as certlfled solutions or prepared from pure standard materials using the following procedure:

6.9.1 Prepare stock standard solutions by accurately woighing approximately 0.0100 g of pure material. Dissolve the material in MTBE and dilute to volume in a $10 \cdot \mathrm{mL}$ volumetric hask. Larger volumes may be used at the convenience of the analyst. If compound purtty is certified at $96 \%$ or oreater, the woight may be used without correction to calculate the concentration of the stock standard. Commerctally prepared stock standards may bo used at any concentration if they are certfled by the manutacturer or by an independent source.

6.9.2 Transter the stock standard solutions into TFE-fivorocarbon-sealed screw cap 
vials. Store at room temperature and protect from light.

6.9.3 Stock standard solutlons should be replaced after wo months or sooner comparison with laboratory control standards indleates a problem.

8.10 INTERNAL STANDARD SPIKING SOLUTION -. Prepare an Internal standard splking solution by accurately woighing approximately $0.0010 \mathrm{~g}$ of pure PCNB. Dissolve the PCNB in MTEE and dilute to volume in a $10-\mathrm{mL}$ volumetric hask. Transter the Internal standard spiking solution to a TFE.lluorocarbon-sealed screw cap bottle and store at room temperature. Addition of $5 \mathrm{\mu L}$ of the internal standard spiking solution to $5 \mathrm{~mL}$ of sample extract pesults in a IInal Internal standard concentration of $0.1 \mathrm{\mu g} / \mathrm{mL}$ Solution should be replaced when ongoing QC (Sect 9) indicates a problem.

6.11 SUAPOGATE STANDARD SPIKING SOLUTION -. Prepare a surrogate standard spiking solution by accurately weighing approximately $0.0050 \mathrm{~g}$ of pure DCE. Dissolve the DCB in MTEE and dilute to volume in a $10 . \mathrm{mL}$ volumetric flask. Transfer the surrogate standard spiking solution to a TFE-lluorocarbon-sealed screw cap bottle and store at room lemperature. Addition of $50 \mathrm{\mu L}$ of the surrogate standard spiking solution to a $1 . L$ sample prior to extraction results in a surrogate standard concentration in the sample of $25 \mu \mathrm{gl}$ and, assuming quamtiativo recovery of TDBP, a surrogate standard concentration in the final extract of $5.0 \mathrm{\mu d} / \mathrm{mL}$ Solution should be replaced when ongoing QC (Sect 9) indicates a problem.

6.12 INSTRUMENT OC STANDARD .. Proparo instrument QC standard stock solutions by accurately weighing $0.0010 \mathrm{~g}$ each of chlorothaloni, chlorpyritos, DCPA and HCH-delta. Dissolve each analyte in MTBE and dilute to volume in individual $10 \mathrm{~mL}$ volumetric hasks. Combine $2 \mu \mathrm{L}$ of the chloropyrifos siock solution, $50 \mathrm{\mu l}$ of the DCPA stock solution, $50 \mathrm{\mu L}$. of the chlorothalonll stock solution, and $40 \mu \mathrm{L}$ of the HCH-delta stock solution to a $100 . \mathrm{mL}$ volumetric flask and dilute to volume with MTBE. Transter the instrument OC standard solution to a TFE-fluorocarbon-sealed screw cap bottle and store at room temperature. Solution should be replaced when ongolng OC (Sect 9) indicates a problem.
7. SAMPLE COULETION, PAESERVATION, AND STORAGE

7.1 Grab samples must be collected in glass containers. Corventlonal sampling practices (8) should be followed; however, the bottle must not be prerinsed with sample belore collection.

\subsection{SAMPLE PAESERVATION}

7.2.1 Add mercuric chloride to the sample bottle In amounis to produce a concentration of $10 \mathrm{mg} / \mathrm{L}$ Add $1 \mathrm{~mL}$ of a $10 \mathrm{mg} / \mathrm{mL}$ solution of mercuric chloride In reagent water to the sample bottle at the sampling site or in the laboratory betore shipping to the sampling site. A major disadvaneage of mercuric chloride is that it is a highly toxic chemical: morcuric chloride must be handled with caution, and samples containing mercuric chloride muse be disposed of properly

7.2.2 If residual chlorine is present, add 80 mo of sodium thiosultate per liter of sample and mix well.

7.2.3 Atter adding the sample to the bottle containing preservatte. seal the sample botte and shake vigorously lor 1 min.

7.2.4 Samples must be lced or retrigerated at $4^{4} \mathrm{C}$ from the lime of collection until extraction. Preservation study results Indleate that most of the target analytes present in the samples are stable for 14 days when stored under these conditions. (1) However, analyte stability may be affected by the matrix; therefore. the analyst should verify that the preservation technique is applicable 10 the samples under study.

\subsection{EXTRACT STORAGE}

7.3.1 Sample extracts should be stored at $4^{\circ} \mathrm{C}$ away from light. A 14-day maximum extract storage time is recommended. However, analyte stability may be affected by the matrix: therefore the analyst should verity appropriate extract holding times applicable to the samples under sudy.

\section{8. calubration}

8.1 Establish GC operating parameters equivalent to those indicated in Sect. 5.8. The GC system may be callbrated using either the Internal standard technique (Sect. 8.2) 
or the external standard icchniqus (Sect 8.3).

8.2 INTEANAL STANDARD CALIBRATION PROCEDURE .. TO use this approach. the analyst must solect one or more internal sandards computible in analyitea behavior to the compounds of interest. The andyse must further demonstrate that the measurement of the imernal standard is not affected by mathod of matplx interferences. PCNB has been Identllied as a suttablo internd standard.

8.2.1 Propare callbration standards at a minimum of five concentration Ievels for each analyte of imerest by adding volumes of one or more stock standards to a volumotric flask. To each callbration standard, add a known constan amount of one or more internal standards, and dilute to volume with MTBE. On of the callbratlon standards should bo representative of an anatyre concentration near, but above, the EDL The other concentratlons should conespond to the range of concentrations expected in the sample concentrates, or should define the working range of the detcctor.

8.2.2 Inject $2 \mu \mathrm{L}$ of cach calibration standard and tabulate the relative response for each andyre (RRa) to an intomed standard using the equation:

RRa - AVAb

where:

A. = the peak area of the andye. and Ais - the peak area of the internal standard.

8.2.3 Generate a calibration curve of analye relative response, RAa, versus analyte concentration in the sample in $\mu \Omega$. Data presented in Sect. 12.2 were generated using TPP for quantilication calculations.

8.2.4 The working callbretlon curve must be verifled on each working shith by the measurement of one or more calibration standarda. If the response for amy analye varies from the predleted response by more than $+20 \%$. the test must be ropeated using a frosh callbration standard. Atematwely, a now calibration curve must be prepared for that analyte.

\subsection{EXTERNAL STANDARD CALIBRATION PROCEDURE}

8.3.1 Prepare callbration standards at a minimum of five concentration levels for oach analyte of interest and surrogate compound by adding volumes of one or more stock standards to a volumetric hask. Dlute to volume whi MTBE. One of the calbratlon standards should be representatve of an analye concentration near, but above. the EDL. The other concentrations should correspond to the range of concentrations expected in the ande concentrates, or should define the working range of the detector.

8.3.2 Staring with the standard of lowest conceniration, analyze esch calibration standard according to Sect. 10 and inbulate pask haight or area response versus the concentration in the standard. The results can be used to prepare a calloration curve for each compound. Ntematively, Ithe ratio of response to concentration (callbratlon factor) is a constant ovor the working range ( $<10 \%$ rolatlve standard deviation), linearify inrough the origin can be assumed and the average ralio or calibration factor can be used in place of a calibration curve.

8.3.3 Single point calibration is a viable attemathe to a callbration curve. Prepare singlo point standards from the secondary dilution standards in methand. The single point sandards should be prepared at a concemtration inat produces a response close $( \pm 20 \%)$ to that of the unknowns.

8.3.4 The working calibration curve or callbration factor must be verilled on each working day by the measurement of one or more calibration standards. II the response for any analyte varies from the predleted response by more than $\pm 20 \%$, the test must be repeated using a fresh calibration standard. If the results stili do not agree. oenerate a new calibration curve of use a single point callbration standard as described in Sect. 8.3.3.

\section{QUALTY CONTROL}

9.1 Minimum quality control $(\mathrm{OC})$ requirements are Initlal demonstration of laboratory capability, dotermination of surrogale compound recoveries in each sample and blank, monitoring Internal standard peak area or height in each sample and blank (when internal standard calibration procedures are being employed), analysis of method blanks. Instrument OC solution. laboratory control (LC) standards, QC 
samples, and pertormance cveluation (PE) samples.

9.2 Method Blanks. Botore processing any samples, the analyst must demonstrate that all daseware and reagent interferences are under contrd. Each time set of samples is extractod of reagents aro changed. a mothod blank must be analyzed. If within the retention time window of any analye the method blank produces a peak inat is 0.5 EDL for that analyte, determine the source of contamination and eliminate the interference belore processing semples.

9.3 Initial Demonstration of Capability.

9.3.1 Solect a representatlve spike concentration (about 10 umes EDL) for each analyio. Proparo a LC sample concentrate (In mothanol) containing each analyte at 1000 times selceted concemtration. What a syinge, add $1 \mathrm{~mL}$ of the concentrate to each of at least four id allouots of reagent water, and analyzo ocen allquol according to procedures beginning in Section 10.

9.3.2 Calculate mean percent recovery $(X)$. and standard deviatlon of pereant recovery (S). For onch andyro. $X$ must fall in the range of $70.130 \%$ for within $A+3$ ASO using the vilues for $A$ and ASD for rengem water in Table 2) and $S$ must bo leas than 30\% (or lose than $3 \times$ ASO in reagent wates in Table 2). If the calculated $x$ and $s$ for every analyte meet the acceptance criteria. performance is aceoptable and samplo analysis may begin. If any $X$ or $S$ talls outside lts acceptance range, initial demonstration procedues for that compound must be repeased.

9.4 The analyst is permitted to modify GC columns. GC conditions, or detectors to improve separations or lower analytlcal costs. Each time such method modifications are made, the analys must repeat the prucedures in Section 9.3

\subsection{Ascessing Surrogate Recovery.}

9.5.1 When surrogate recovery from a sample or mothod blank is < $70 \%$ or $130 \%$. check (t) calcutations to locate possible errors. (2) splking solutions for degradation. (3) contemination or other obvious abnomalkies, and (4) instrument performance. If those steps do not reveal the cause of the problem, reanalyze the extract.
9.5.2 If a blank extract reanalysis tails ine 70-130\% recovery criteria, the problem mus be identified and corrected before continuing

9.5.3 If sample extract reanalysis solves the problem, report only data trom the analysls with acceptable surrogate recovery. If sample extract reanalysis does not solve the problem, repor all data for that sample as suspect.

9.6 Assessing the Intermal Standard

9.6.1 For each sample and blank exiract. dotermine it internal standard peak area of hoight deviates by 30\% from the average measured during analysis of calibration standards.

9.6.2 If 30\% devlation, optimize instrument performance and inject a second aliquot of that extract. If the reinjected aliquot produces an acceptable internal standard peak area or hoight, report results for that aliquot. If not, assume that an error was made during addition of internal standard to that extract. Feextract that sample or blank, and analyze that extract.

9.6.3 If 30\% devlation continues, analyze a calibration standand (Sect. 8).

9.6.3.1 If the Intemal standard peak area or peak hoight talls to meet criteria. then recalibrate, and reanalyze extracts that proviously did not meet criteria. If accaptable area or height is measured. peport results. If not, assume an interference from the matro is affecting the internal standard and use external calibration (Sect. 8).

9.6.3.2 If the Intemal standard peak area or peak height meets criteria then assume an interference from the matrix is affecting the Internal standard in your sample extract and use external calibration.

\subsection{Assessing Laboratory Pertomance}

9.7.1 Initlal CC criteria are established by using the values for $X$ and $S$ generated above (Sect. 9.3) to establish upper and lower control limits:

UPPEA CONTAOL LIMIT $=x+3 S$ LOWEA CONTROL LIMIT $=x$ - 3S

The laboratory must analyze at least one LC sample per sample sel (all samples extracted within a $24-h$ period). The spiking concentration of each analyte in the laboratory control sample should be 
10 ilmos EDL. Calculate securacy as percent recovery (X). If the recovery of any analvie lalls outside the control limits, that analyte is judged out of contrd, and the source of the problem must be identiled and resolved belore cominuing analyses. The comrol limtis should be updated periodically. If is recommended that ather ach twe to ten now recovery measurements that now control limits be calculated using only the most recent $20-30$ data points.

9.7.2 Each quarter the laboratory must analyze OC check standards (If available). If criteria provided with the OC check standard are not met. correctve action should be taken and documented.

9.7.3 At least once a year, the bobratory must analyze a pertormance evaluation sample (II avallable), and resutts for cach analye must be within established aceeptance limits.

9.8 Assessing Instrument Performance - The instrument OC standard (Sect 6.12) should be analyzed daily to monitor instrument performance. Inabillty to demonstrate acceptable instrument performance indicates the needs to reevaluate the GC.NPD systom. If laboratory EDLs diffor from listed EDLs (Table 2). concentrations of instrument oC standard compounds may be adjusted is needed.

9.9 Analyte Confirmation - When doubt exists about Identlfication of a GC peak. contirmatory techniques such as determination with a mass spectrometor detector or a different GC column murt bo used.

\section{PROCEDURE}

10.1 AUTOMATED EXTRACTION METHOD Validation data presented in this method were generated using the automated extraction procedure with the mechanicy separatory funnel shaker.

10.1.1 Add preservattve to any sampies not provlously preaerved (Sect 72). Mark the water mentecus on the side of the sample bode for later determination of sample volumo. Spike sample with $\mathbf{5 0}$ $\mu \mathrm{L}$ of the surrogate standard spiking solution. If the mechanical separatory funnel shaker is used. pour the entire sample Into a $2-L$ separatory hunnel. If the mechanical tumbler is used. pour the enture sample into a tumbler botte.
10.1.2 Adjust sample to pH 7 by adding 50 $\mathrm{ml}$ of phosphate butfer.

10.1.3 Add $100 g^{\circ} \mathrm{NaCl}$ to the sample. seal. and shake to dissotve satt.

10.1.4 Add $300 \mathrm{~mL}$ methylene chloride to the sample bottle, seal, and shake $30 ; 10$ inse the Inner walls. Transfer the solvent to the sample contained in the separatory hunnel or tumbler bottle, seal, and shake for $10 \mathrm{~s}$, vening periodlcally. Repeat shaking and venting untll pressure release ts not observed during venting. Reseal and place sample container in appropriate mechanical mixing device (separatory funnel shaker or tumbler). Shake or tumble the sample for 1 hour. Complete and thorough moxing of the organic and aqueous phases should be observed at least 2 min atter starting the mixing device.

10.1.5 Remove the sample container from the mixing device. If the tumbler is used. pour contents of tumbler botte into a $2-L$ separatory tunnel. Alow the organic layer to separate from the water phase for a minimum of 10 min. If the emulsion Intertace between layers is more than one third the volume of the solvent layer. the analyst must employ mechanical techniques to complete the phase separation. The optimum technique depends upon the sample. but may include stiring. filtration through glass wool, centrtigation, or other physical methods. Collect the methylene chioride extract in a 500-mL Erlenmeyer llask containing approximately $5 \mathrm{~g}$ anhydrous sodium sutfate. Swit hask to dry extract; allow hask to sit for $15 \mathrm{~min}$.

10.1.6 Determine the original sample volume by refilling the sample bottle to the mark and transterring the water to a $1000 . \mathrm{mL}$ graduated oylinder. Record the sample volume to the nearest $5 \mathrm{~mL}$

10.2 MANUAL EXTRACTION METHOD Alemative procedure.

10.2.1 Add preservative to any samples not proviously preserved (Sect. 7.2). Mark the water meniscus on the side of the sample botte for later determination of sample volume. Spike the sample with $50 \mathrm{\mu L}$ of the surrogate standard spiking solutton. Pour the entire sample into a 2.L soparatory hinnes.

10.2.2 Adjust sample to pH 7 by adding 50 $\mathrm{mL}$ of phosphate butter. 
10.2.3 Add $100 \mathrm{~g} \mathrm{NaCl}$ to the sample, seal, and shake to dissolve salt.

10.2.4 Add $60 \mathrm{~mL}$ mothylene chloride to the samplo bottle, seal, and shake 30 s to inse the inner walls. Transter the sotvent to the separatory funnel and extract the sample by vigorously shaking the funnd for $2 \mathrm{~min}$ with periodle venting to release excess pressure. Allow the organic layer to separate trom the water phase for a minimum of $10 \mathrm{~min}$. If the emulsion intertace between layors is more than one third the volume of the sotvent layer. the analyst must employ mechanical rechniques to complete the phase separation. The optimum technique depends upon the sample, but may include stirring. Pltration through glass wool. centrifugation, or other physical methods. Collect the mettryiens choride extract in a $500-\mathrm{mL}$ Entonmoyer flask containing approxlmately 59 antydrous sodium sulfate.

10.2.5 Add a second $60-\mathrm{mL}$ volume of methytene chioride to the sample bottle and repeat the extraction procedure a second time. combining the extracts in the Entenmeyer hask. Pertorm a third oxtraction in the same manner. Switt hask to dry caract: allow hask to sit for $15 \mathrm{~min}$.

10.2.6 Dotormine the origind sample volume by refilling the sample boted to the mark and transtering the water to a $1000-\mathrm{mL}$ graduated oylinder. Acecord the samplo volume to the neareat $5 \mathrm{~mL}$

\subsection{EXTRACT CONCENTRATION}

10.3.1 Assomble a K-D concentrator by attaching a $25 . \mathrm{mL}$ concentrator tube 10 a $500-\mathrm{mL}$ ovaporative flask. Decant methylene chlorlde extract imto K-D concentrator. Alnso remaining sodlum sultate whth wo $25-\mathrm{mL}$ portions of methylene chlorlde and decant rinses into the K-O concentrator.

10.3.2 Add 1 to 2 dean boling stones to the ovaporattvo hask and attach a macro Smyder column. Prowet tho Smyder column by adding about $1 \mathrm{~mL}$ methylono chioride to the top. Place the K-D apparaius on a hot water bath, 65 to $70^{\circ} \mathrm{C}$. so that the concentrator tube is partially immersed in the hot water, and the entire lower rounded surtace of the hask is bathed with hot vapor. Adjust the vertical position of the apparatus and the water temperature as requlred to complete the concentration in 15 to $20 \mathrm{~min}$. At the proper rate of distillation the balis of the column will actlvoly chatser. but the chambers will not llood. When the apparent volume of liquid reaches $2 \mathrm{~mL}$. remove the K.D apparatus and allow it to drain and cool for at least $10 \mathrm{~min}$.

10.3.3 Remove the Snyder column and inse the flask and lis lower joint into the concentrator tube with i $102 \mathrm{~mL}$ of MTBE. Add $10 \mathrm{~mL}$ of MTBE and a Iresh boiling stone. Altach a micro-Snyder column to the concentrator lube and prewer the column by adding about 0.5 $\mathrm{mL}$ of MTBE to the lop. Place the micro K.D apparatus on the water bath so that the concentrator tubo is partially immersed in the hot water. Adjust the vertical position of the apparatus and the water temperature as required to complete concentration in $51010 \mathrm{~min}$. When the apparent volume of liquid reaches $2 \mathrm{~mL}$ remove the micro K.D from the bath and allow it to drain and cool. Add 10 $\mathrm{mL}$ MTBE and a boiling stone to the micro $K-D$ and reconcentrate to $2 \mathrm{~mL}$ Aemove the micro K.D from the bath and allow it to drain and cool. Remove the micro Snyder column, and rinse the walls of the concentrator tube while adjusting the volume to $5.0 \mathrm{~mL}$ with MTBE.

10.3.4 Add $5 \mu \mathrm{L}$ of Intemal standard spiking solution to the sample extract. seal. and shake to dlstribute the internal standard. Transter extract to an appropriate sized TFE-fluorocarbon-sealed screw-cap vial and store, refrigerated at $4^{\circ} \mathrm{C}$, until analysis by GC-ECD.

\subsection{GAS CHROMATOGRAPHY}

10.4.1 Sect 5.8 summarizes the recommended operating conditions for the gas chromatograph. Included in Table 1 are retention times observed using this method. Other GC columns. chromatographic condtitons, or detectors may be used if the requirements of Sect. 9.4 are met.

10.4.2 Calibrate the system daily as described in Sect. 8. The standards and extracts must be in MTBE.

10.4.3 Inject $2 \mu \mathrm{L}$ of the sample extract. Record the resulting peak sizes in area units.

10.4.4 The width of the retention time window used to make Identifications should be based upon measurements of actual

Method 508, Page 9, Revised 1988 
DRAFT DOCUMENT - INTERNAL USE ONLY • 4/15/88

retention time vartations of standards over the course of a day. Three thes the standard deviation of a retention time can be used to calculate a suggested window size for a compound. However. the experience of the analyst should weigh heavily in the intorprotation of chromatograms.

10.4.5 If the response for a peak exceeds the working range of the system. diuse the coxtract anc reanalyze.

\section{CalCULATIONS}

19.1 Calculate analyte concentrations in the sample from the response for the andyic using the calibration procedure described in sect 8.

11.2 For samples processed as part of a set whore laboratory control standard measurements thly outside of the control limits in Sect. 9, dat for the affected anaives must be labeled as suspect.

\section{PRECISION AND ACCURACY}

12.1 In a single Iaboratory, andye recoveries from reagent water were determined at five concentration levels. Results were used to determine analyte EDLs and demonstrate method range.(1) Analytes mero dhided into two spiling groups for recovery studies. Analyte recoverles at ono concentration and EDL data aro given in Table 2.

12.2 In a single laboratory, andyte recoveries from iwo artiflcial ground waters were determined at one concentration level. Resutts were used to demonstrate applicability of the method to different oround water matrices. (1) Analyte recoverles from the no arificta matrices are oiven in Table
2.

\section{AEFERENCES}

\section{Banelle/NPS Mothod 2}

2.ASTM Annual Book of Slandards. Pan 11. Volume 11.02. D3604-82. "Standard Practice for Preparation of Sample Containers and for Preservation". American Socloty for Teasing and Materials. Philadelphia. PA, D. 86. 1966 .

3.Glam, C. S. Chan H. S., and Nof, G. S. "Sensitive Method for Dotermination of Phthalato Ester Plas. tcizers in Open-Ocean Blota Samples." Analyical Chomistry, 112225 (1975)

4.Givm. C. S.. and Chan. H. S. "Control of Blanks in the And ysts of Phithlates in Air and Ocean Biota Samples." U.S. National Bureau of Standards, Special Publication 42. pa. 701-708. 1976.

5. Carcinogens - Working with Carcinogens." Depan. ment of Heakth, Education, and Welfare, Public Health Service, Cemter for Disenso Control. National Instinute for Oceupational Safety and Heath. Publication No. 77 . 206. Aug. 1977.

6. OSHA Saloty and Heath Standards, General in. dustry." (29 CFF 1910). Oceupational Safery and Health Administration, OSHL 2205, (Revised, January 1976).

7."Safoty In Acadomic Chomistry Laboratories." American Chomical Soctery Publication, Committee on Chemied Safoy. Ind Edidon, 1979.

8.ASTM Annual Book of Standards. Part 11, Volume 11.01. D3370-82. "Standard Practice for Sampling Water." American Soclety lor Testing and Materials. Philadelphta, PA p. 130, 1986. 
DRAFT DOCUMENT - INTERNAL USE ONLY - W15/88

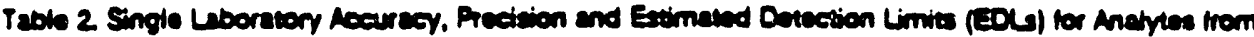
Asegert Water and Symmete Groundwears(a)

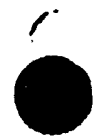

Anarve Adrin

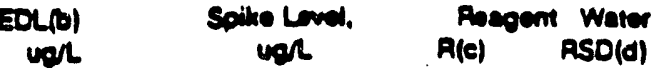

$\begin{array}{ccc}\text { Symenece Water 1 } & \text { Smonotic Water } 2 \\ \text { A RSO } & \text { R } & \text { RSO }\end{array}$

Chlordene-alohe

$0.075 \quad 0.15$

0.0015

Q.15

Chlornes

0.0015

Chlorobenzilate

0.5

Cniormalonil

ocpa

4.4.000

4.4.00E

4.4.00r

Dictarin

Endosutten I

0.15

3

0.005

0.025

o.00es

0.01

0.05

0.02

Endosutian sultate

Endrin

0.015

0.015

0.015

Endrin aldemydo

0.025

0.024

Eutotingele

HCHelping

a.ers

0.005

HCHoon

MCHden

HCHgamma

Hoptachler

0.01

0.01

0.015

0.01

Heptachler eporide

0.015

Moxachiorobenzeno

0.0077

Mathoryenior

o.0s

eis-Permethrin

trans-Permotrin

Propechios

Trifiuralin

0.5

0.5

0.5

0.003

$\begin{array}{rr}80 & 11 \\ 99 & 12 \\ 99 & 12 \\ 97 & 12 \\ 109 & 5 \\ 91 & 9 \\ 109 & 12 \\ 107 & 8 \\ 99 & 12 \\ 112 & 15 \\ 87 & 10 \\ 87 & 10 \\ 102 & 15 \\ 89 & 10 \\ 89 & 9 \\ 92 & 11 \\ 103 & 8 \\ 92 & 11 \\ 95 & 7 \\ 102 & 11 \\ 99 & 11 \\ 99 & 12 \\ 87 & 10 \\ 99 & 22 \\ 105 & 13 \\ 91 & 10 \\ 111 & 6 \\ 103 & 9 \\ 103 & 5\end{array}$

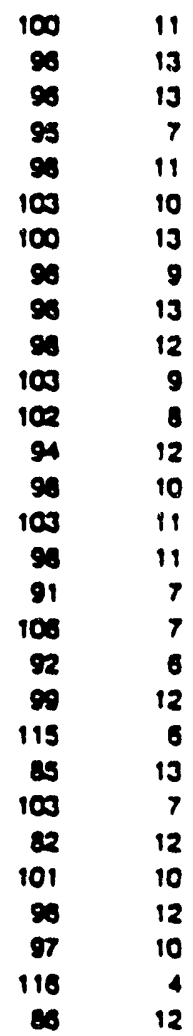

$\begin{array}{rr}69 & 13 \\ 99 & 8 \\ 99 & 7 \\ 75 & 11 \\ 102 & 9 \\ 71 & 13 \\ 101 & 6 \\ 101 & 7 \\ 99 & 7 \\ 84 & 10 \\ 82 & 9 \\ 84 & 10 \\ 72 & 17 \\ 104 & 9 \\ 84 & 11 \\ 75 & 9 \\ 98 & 4 \\ 86 & 9 \\ 100 & 6 \\ 103 & 6 \\ 85 & 9 \\ 85 & 9 \\ 82 & 12 \\ 68 & 9 \\ 104 & 6 \\ 86 & 11 \\ 102 & 7 \\ 95 & 8 \\ 87 & 11 \\ & \end{array}$

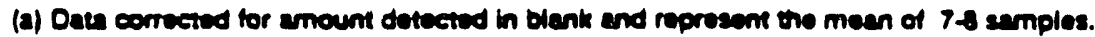

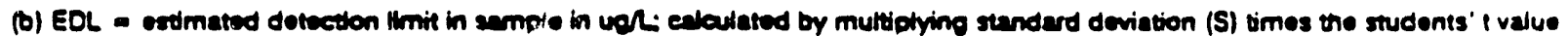

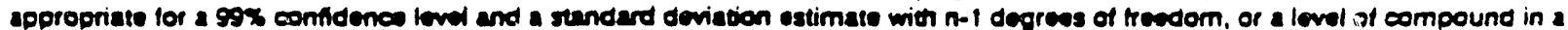
sample vielding a pack in the find exurect with signd-toncies rado of approximatefy 5. whichever value is higher.

(c) $A$ - everage pereant recovery.

(d) ASO = rolative standard deviation (porean)

Mothod 508, Page 11. Revised 1988 
Method No. EHS G-1

Title: ORGANIC WASTE CHARACTERIZATION USING DIRECT GC/MS INJECTION

Date Issued: $1-9-90$

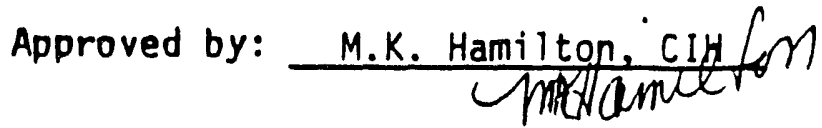
Written by: M. K. Hamilton, CIH

Supersedes Method No. New

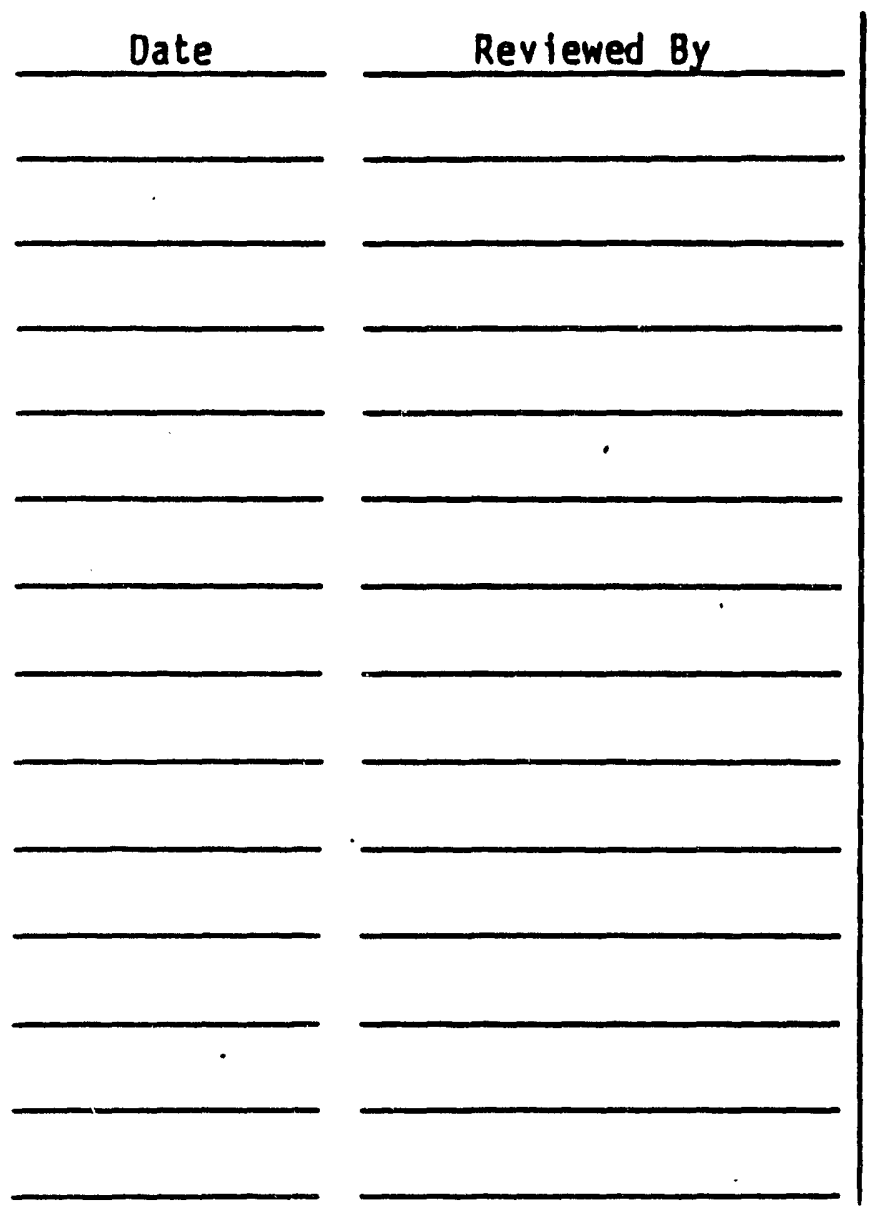

Replaced by Method No.

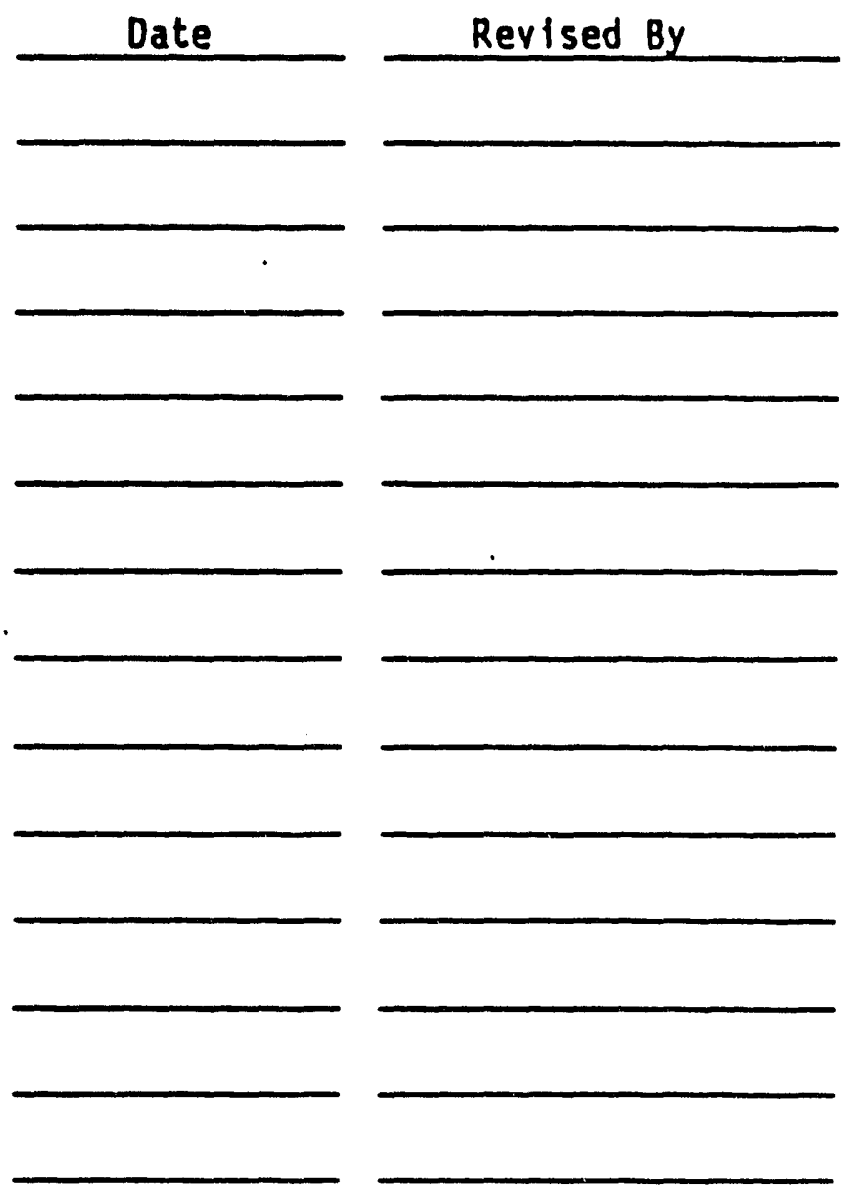

Date: 


\section{ORGANIC WASTE CHARACTERIZATION USING DIRECT GC/MS INJECTION}

\section{References}

Method developed by HEHF's Environmental Health Sciences Laboratory.

\section{Principles}

Identification and semi-quantitative analysis of major components of organic liquid waste samples is possible by direct injection of the sample into a gas chromatograph/mass spectrometer (GC/MS) equipped with a capillary column and split injection system. GC conditions and column of choice are determined by the type of sample being characterized. In general, components present at concentrations above $0.5-1 \%$ and chromatographable at column temperatures below $250^{\circ} \mathrm{C}$ can be detected. Halogenated hydrocarbons can be detected at concentrations as 1 ow as $1000 \mathrm{mg} / \mathrm{Kg}(\mathrm{ppm})$. Semi-quantitative concentration values are determined using relative component abundances.

This technique, when combined with sample density information, can also be used for the determination of percent levels of giycols in aqueous solutions.

\section{Limitations}

Not all GC/MS instruments are compatible with this technique. Suitable instruments must be capable of producing a large split ratio (up to $-200: 1$ ) when the sample is injected to avoid ion source contamination and column overloading problems. When use of this technique on a new instrument is being considered, it should be tried cautiously to avoid damage to or contamination of the instrument.

Complete resolution or identification of all components in samples consisting of complex mixtures may not always be possible and concentrations determined are quite approximate. For many waste samples, however, this is all the information that is necessary for adequate characterization for disposal purposes. This is a good screening tool which should be supplemented by additional analyses as needed.

\section{Equipment}

1. GC/MS equipped with capillary column and split injection system. Instruments known to be compatible with this method include:

a. Hewlett Packard 5992A bench top GC/MS

b. Hewlett Packard 5890 GC with 5970 B mass selective detector

2. DB-5 $0.25 \mu$ film, $0.25 \mathrm{~mm} \times 30 \mathrm{~m}$ capillary column or equivalent

3. 1 LL syringe for manual injections or autosampler

4. Mass spectral library \& softiware to perform "reverse" library searches 
Page 2

\section{Reagents}

Isooctane, acetone and deionized water or other appropriate solvents for syringe rinsing.

\section{Procedure}

1. Autotune the $\mathrm{GC} / \mathrm{MS}$ and make sure the instrument is functioning properly.

2. Select an appropriate temperature program. The following programs have been found satisfactory when using the DB-5 capillary column:

a. HP5992A- $-30^{\circ} \mathrm{C}$ initial, $10^{\circ} \mathrm{C} / \mathrm{min}$. ramp, $250^{\circ} \mathrm{C}$ final, run time 45 minutes

b. HP5890/5970B- $-30^{\circ} \mathrm{C}$ initial, $10^{\circ} \mathrm{C} / \mathrm{min}$. ramp, $300^{\circ} \mathrm{C}$ final, run time 35 minutes

3. Establish the appropriate split ratio of $-15: 1$ for the HP5992A or $-150: 1$ for the HP5890/5970B.

4. Inject the sample and collect the chromatographic and mass spectral data. Data collection parameters should be set to yield a Total Ion Chromatogram containing approximately 100 peaks in a complex oil sample.
a. HP5992A - manually inject $0.1 \mu \mathrm{L}$ using a $1 \mu \mathrm{L}$ syringe.
b. HP5890/5970B - manually or with an autosampler inject $1 \mu L$ using a $10 \mu \mathrm{L}$ syringe (viscous samples must be injected manual1y).

5. Produce a printout of the sample chromatogram and the mass spectra for each chromatographic peak.

6. Identify the sample constituents by comparing sample spectra to mass spectra of known compounds. The following mass spectral data bases are available:

a. NIH/EPA Mass Spectral Data Base, NSRDS-NBS 63, 1983, 6 volumes hard copy.

b. Chemical Information Systems, Inc. Mass Spectral Search System for searching the NIH/EPA/MSOC Mass Spectral Data Base and Wiley Mass Spectral Search System for searching the 1982 Registry of Mass Spectral Data from John Wiley \& Sons, Inc. (See Lab Operating Procedure L-8.10 for accessing these computer data bases.)

c. NBS-Rev.F Mass Spectral Library, resident on the HP5890/5970B GC/MS. (Instrument has capability of automatically searching all spectra in a sample against this library.) 


\section{Calculations}

Approximate concentrations of sample components are determined by summing the abundances of all components and dividing that sum into the abundance of the component of interest. This assumes equivalent responses for all compounds, which is not true; however, the information obtained is adequate for the gross characterizations provided by this method.

The following guidelines are used when characterizing organic liquids, especially oil matrices:

1. Aliphatic hydrocarbons are grouped as to those with molecular weights less than or equal to 10 and those greater than 10. (Decane has a flash point of $-60^{\circ} \mathrm{C}$, the critical temperature for flammable or nonflammable waste designation.)

2. Low molecular weight solvents (ketones, alcohols, benzene, toluene, xylene, etc.) are characterized and reported individually when possible.

3. Halogenated solvents and other halogenated materials are identified and reported separately as much as possible.

4. Aromatic compounds heavier than xylene are grouped as substituted benzenes, subs. naphthalenes, subs. phenols, etc. If polynuclear aromatics with three or more rings are found, they are identified separately as much as possible. At a minimum they are grouped by the number of rings present.

The following procedure is used to determine ethylene and propylene glycols in water when no other major components are present:

1. Identify the glycol or glycols present.

2. Determine the sample density.

3. Using charts of density versus percent glycol or solution of two equations with two unknowns, determine the amount of glycol present.

Example: Sample identified as ethylene glycol and water. density $=1.065$

$$
\begin{aligned}
& A+B=1 \\
& A=\% \text { water } / 100 \\
& B=\% \text { ethylene glycol } / 100 \\
& 1.000 A+1.113 B=1.065 \\
& 1.000=\text { approximate density of water } \\
& 1.113=\text { density of ethylene glycol } \\
& 1.065=\text { measured density of the sample } \\
& \text { solution: } A=0.42=42 \% \text { water } \\
& B=0.58=58 \% \text { ethylene glycol }
\end{aligned}
$$

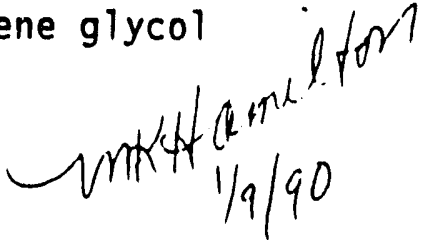


Method Ho. EHS P-2

THtle: PHENOLS IN HATER - CHLOROFORM EXTRACTION

Date 1ssued: Before 12/82

Approved by: $\frac{M K \text { Hamllton }}{P^{4}}$

Written by: $M K$ Hamilton

Supersedes Method No.
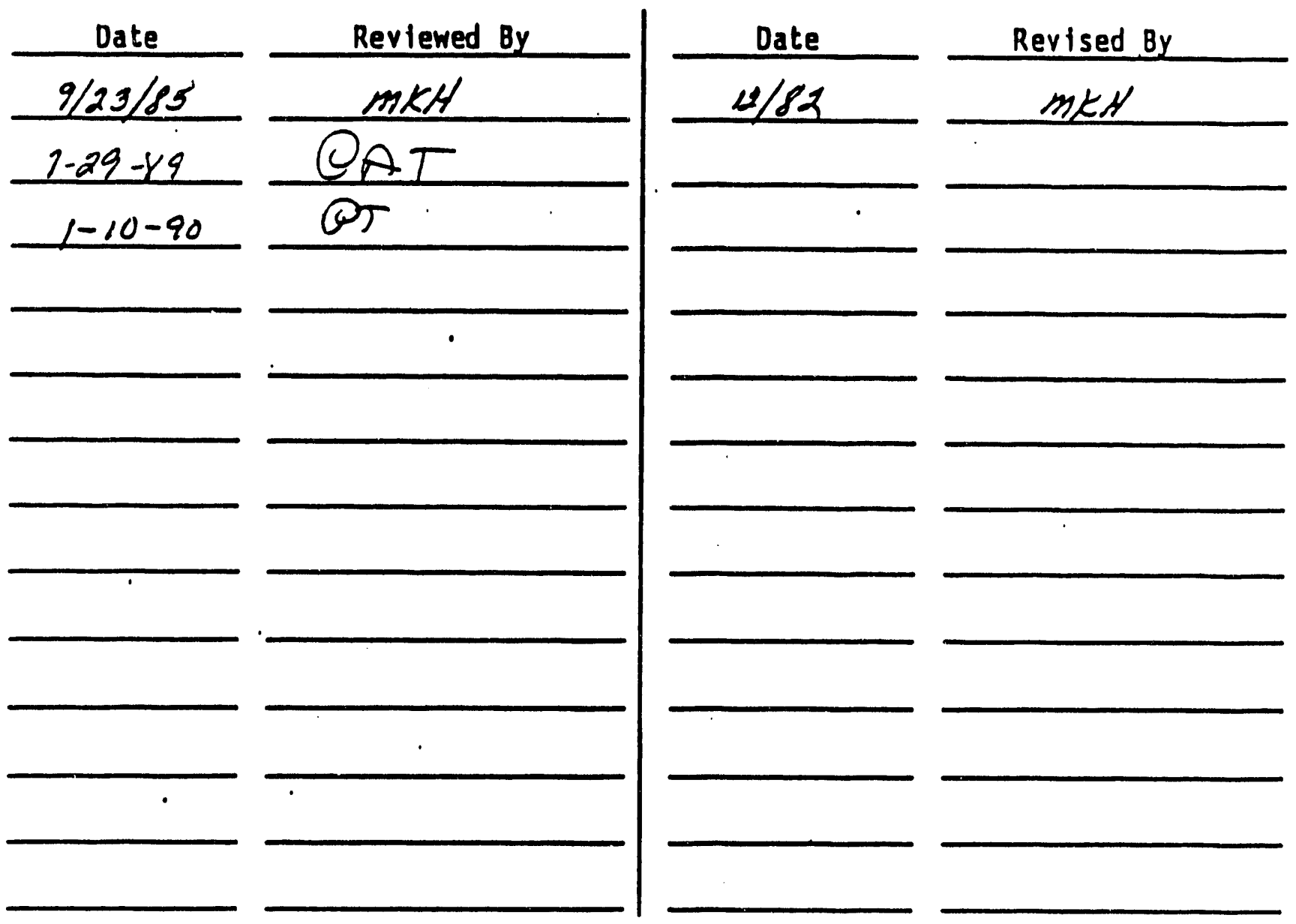

Replaced by Method No.

Date: 
PHENOLS IN WATER - CHLOROFORM EXTRACTION

Reference

Standard Methods for the Examination of Water and Wastewater, 16th Ed., 1985 , pp. 556-560.

Principle

After a preliminary distfllation, the steam-distilled phenols in alkaline solution are reacted with 4-aminoantipyrine in the presence of potassium ferricyanide to form a colored antipyrine dye. The dye is then extracted into chloroform and the absorbance is measured at $460 \mathrm{~nm}$.

\section{Limitations}

Some interferences must be removed before the phenols may be determined. $\mathrm{H}_{2} \mathrm{~S}$ and $\mathrm{SO}_{2}$ interference is eliminated by acidifying the sample to $\mathrm{pH} 4$ or less with $1.5 \mathrm{~mL}$ conc. $\mathrm{H}_{3} \mathrm{PO}_{4}$ per 1 tter and aerating immediately after collection. To inhibit biochemical oxidation, $1.0 \mathrm{~g} \mathrm{CuSO}_{4} \cdot 5 \mathrm{H}_{2} \mathrm{O}$ is added per liter and the sample is stored at $4^{\circ} \mathrm{C}$ until analysis (no more than 24 hours). A preliminary distillation is performed to separate the phenols from any non-volatile impurities. Many different phenolic compounds may be present in the sample, all of which produce the colored antipyrine dye. To achieve uniformity, all results are reported in terms of $\mathrm{mg} / \mathrm{L}$ phenol which gives the minimum concentration of phenolic compounds present.

Equipment

1. All glass distillation apparatus as shown or equivalent.

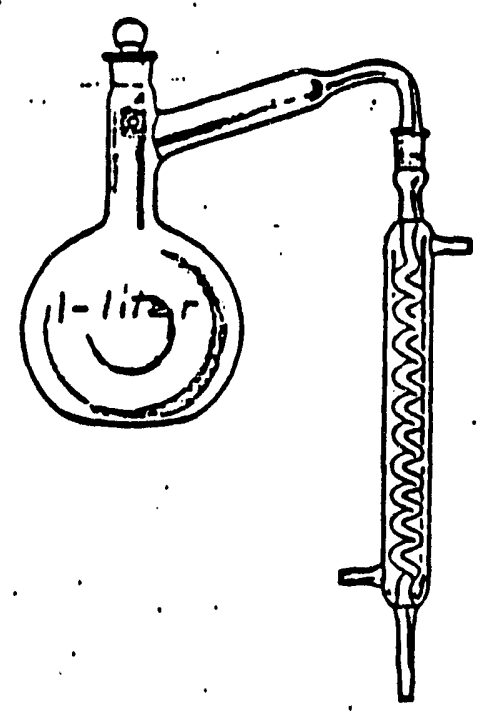


2. $500 \mathrm{~mL}$ graduated cylinders

3. Spectrophotometer for use at $460 \mathrm{~nm}$ with $1.0 \mathrm{~cm}$ cells

4. Whatman 41 f flter paper - $11 \mathrm{~cm}$

5. Long-stermed glass funnels

6. $\mathrm{pH}$ meter

7. 1-11ter separatory funnels

Reagents (Stock).

1. Phosphoric acid - conc. $85 \% \mathrm{H}_{3} \mathrm{PO}_{4}$

2. Cupric sulfate pentahydrate - $\mathrm{CuSO}_{4} \cdot 5 \mathrm{H}_{2} \mathrm{O}$

3. Reagent grade phenol

4. Armonium chloride $-\mathrm{NH}_{4} \mathrm{Cl}$

5. Ammonium hydroxide - conc. $\mathrm{NH}_{4} \mathrm{OH}$

6. 4-amino ant ipyrine

7. Potassium ferricyanide $-\mathrm{K}_{3} \mathrm{Fe}(\mathrm{CN})_{6}$

8. Chloroform - $\mathrm{CHCl}_{3}$ - CLASS 2 SUSPECT HUMAN CARCINOGEN

Reagents (Prepared)

1. Ammonium chloride solution - Dissolve $25 \mathrm{~g} \mathrm{NH}_{4} \mathrm{Cl}$ in deionized $\mathrm{H}_{2} \mathrm{O}$ and dilute to $500 \mathrm{~mL}$. Prepare annually.

2. Aminoantipyrine solution - Dissolve $2.0 \mathrm{~g}$ of 4-aminoantipyrine in deionized $\mathrm{H}_{2} \mathrm{O}$ and dilute to $100 \mathrm{~mL}$. Prepare fresh daily.

3. Potassium ferricyanide solution - Oissolve $8.0 \mathrm{~g} \mathrm{~K}_{3} \mathrm{Fe}(\mathrm{CN})_{6}$ in deionized $\mathrm{H}_{2} \mathrm{O}$ and dilute to $100 \mathrm{~mL}$. Filter if necessary. Prepare fresh weekly.

Standards

1. Stock phenol solution - Dissolve $1.00 \mathrm{~g}$ reagent grade phenol in freshly boiled and cooled deionized $\mathrm{H}_{2} \mathrm{O}$ and dilute to l-liter. (If extreme accuracy is desired, see Standard Methods, page 559, for standardization.) $1 \mathrm{~mL}=1.0 \mathrm{mg}$ phenol. Prepare weekly.

2. Standard phenol solution - Dilute $1.0 \mathrm{~mL}$ of the stock phenol to $100 \mathrm{~mL}$ with freshly delonized $\mathrm{H}_{2} 0$. Prepare fresh daily. $1 \mathrm{~mL}=10.0 \mathrm{~kg}$ phenol. 


\section{Procedure}

1. Transfer a $500 \mathrm{~mL}$ allquot of sample that has been actdified and treated with $\mathrm{CuSO}_{4} \cdot 5 \mathrm{H}_{2} \mathrm{O}$ to the distfllation flask and begin distlliing into a $500 \mathrm{~mL}$ graduated cylinder. (Also carry a standard containing $10 \mathrm{\mu g}$ phenol/500 $\mathrm{mL}$ and a reagent blank through the distillation.)

2. When about $450 \mathrm{~mL}$ has been distilled, stop the distillation. After boiling ceases, add $50 \mathrm{~mL}$ of deionized $\mathrm{H}_{2} \mathrm{O}$ to the distillation flask and continue distilling until $500 \mathrm{~mL}$ has been collected. Transfer the distillate to a l-Liter separatory funnel.

3. In 1-1iter separatory funnels, prepare a $500 \mathrm{~mL}$ defonized $\mathrm{H}_{2} \mathrm{O}$ blank and a sertes of standards containing $1,5,10$, and $20 \mu \mathrm{g}$ phenol in $500 \mathrm{~mL}$. $(0.1,0.5,1.0$ and $2.0 \mathrm{~mL}$ of $10 \mathrm{~kg} / \mathrm{mL}$ phenol standard.) Carry all 5 amples and standards through the remainder of the procedure.

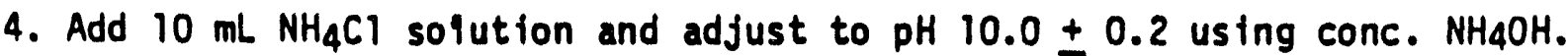

5. Add $3.0 \mathrm{~mL}$ of aminoantipyrine solution and mix well.

6. Add $3.0 \mathrm{~mL}$ of $\mathrm{K}_{3} \mathrm{Fe}(\mathrm{CN})_{6}$ solution, $\mathrm{mix}$ well and allow pale yellow color to develop for three minute.

7. Extract Immediately with $25 \mathrm{~mL}$ of $\mathrm{CHCl}_{3}$. Shake separatory funnel at least 10 times, let phases separate and shake again. NOTE: ALL WORK WITH CHLOROFORM SHOULD BE DONE WITH GLOVES IN A HOOD:

8. After the phases separate, filter the $\mathrm{CHCl}_{3}$ extract through IPS filter paper to remove any $\mathrm{H}_{2} \mathrm{O}$.

9. Measure absorbance of samples and standards at $460 \mathrm{~nm}$, using chloroform as a reference.

10. Discard $\mathrm{CHCl}_{3}$ solutions in waste can marked for organic carcinogens.

Calculation

1. Plot $\mu \mathrm{g}$ phenol in $500 \mathrm{~mL}$ vs. absorbance.

2. Determine $\mu \mathrm{g}$ phenol in the samples from the curve.

$\mathrm{mg} / \mathrm{L}$ phenol $=\frac{\text { allquot } \mu \mathrm{g} \text { phenol }}{500 \mathrm{~mL} \text { sample }}$

Use the standard carried through the distillation to determine $\%$ recovery. Make necessary correction in results if recovery is less than $100 \%$. 
Method No. EHS V-2

Title: Volatile Organic Chemical Analys is by Purge \& Trap GC

Date issued: 8-15-88

Approved by: M.K. Hamilton

Written by: T.J. G11foil

Supersedes Method No.

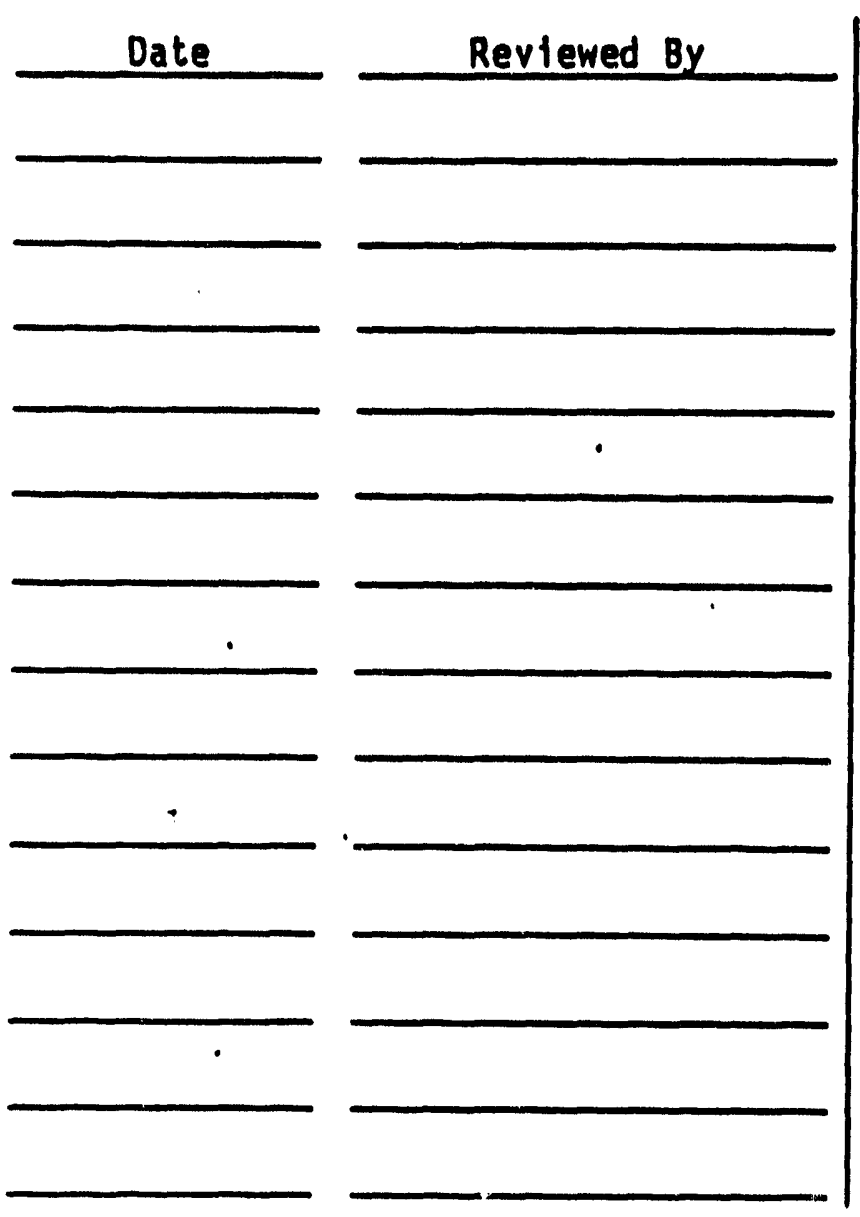

Replaced by Method No.

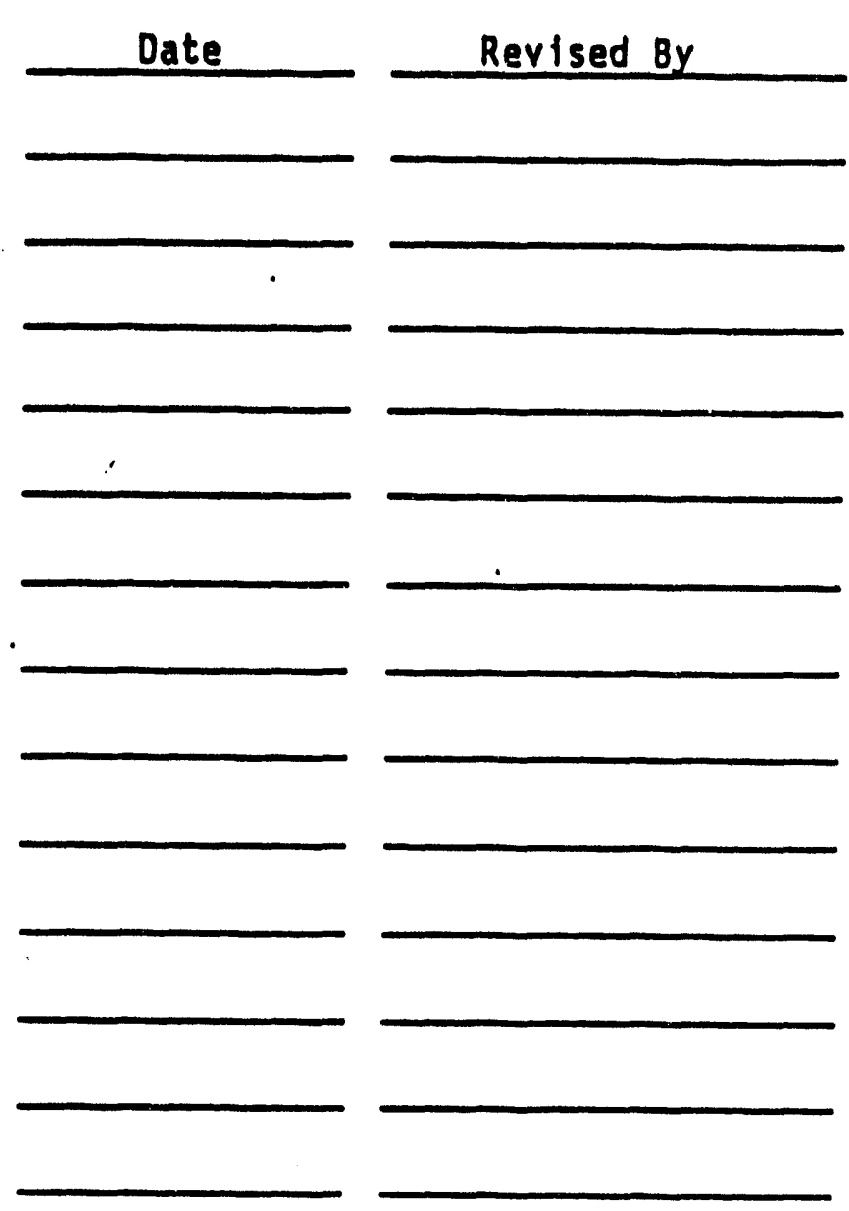

Date: 


\section{VOLATILE ORGANIC CHEMICAL (VOC) ANALYSIS \\ BY PURGE AND TRAP GC WITH \\ PHOTOIONIZATION AND ELECTROLYTIC CONDUCIIVITY DETECTORS IN SERIES}

\subsection{SCOPE AND APPLICATION}

1.1 This method is applicable to the determination of at least 58 VOC's in finished drinking water, raw source water, or drinking water in any treatment stage. A list of the determinable compounds is given in Reference 1 and show in Attachment $A$.

1.2 Method detection 1 imits are very compound dependent and are variable. Each analyst as part of the quality control associated with this method must determine the precision of his or her own technique and thereby a personalized set of detection 1 imits.

The analytical range of this method is currently defined by the equipment we are using to perform it. The span of the data processing equipment and the spans of the two detectors used combine to effectively limit the working range to approximately 0.2 to $20 \mu \mathrm{g} / \mathrm{L}$.

Co-elution of some compounds effectively prohibits their direct determination by this method; meta and para xylene, 1,2,3trichloropropane and 1,1,2,2-tetrachloroethane are the two problem pairs on the column system used in this method. The identities of all other co-eluting compounds can be distinguished by the particular detector responding to them; 1.e., in all other cases each of the co-eluting compounds only responds on one detector.

1.3 It is highly recommended that this method only be used by analysts experienced in the measurement of purgeable organics at low $\mu \mathrm{g} / \mathrm{L}$ concentrations. As mentioned above, part of the quality control for this method includes a demonstration of analyst performance. Before proceeding further it is mandatory that the analyst read Reference 1 thoroughly.

\section{METHOD PRINCIPLES}

2.1 Volatile organic compounds with low water solublitty are removed (purged) from a $5 \mathrm{ml}$ volume of the aqueous sample contained in a sparging cell by passing helfum through the sample. The purged compounds are carried with the gas through a stainless steel tube packed with several adsorbent materials, on which the compounds are trapped. After completion of sample purging the sorbent tube is heated and backflushed with helium. The trapped compounds are carried onto a megabore fused silica capillary column which ts held at subambient temperatures. The column is then temperature programmed to separate the method analytes which are then detected by the photoionization detector (PID) and the electrolytic conductivity detector (ELCD) in series. 
2.2 Tentative identifications are based on retention time comparison betweep sample peaks and standard peaks as well as a compartson of response fro each detector if the compound responds on both. Internal standarc calibration is used to enhance the precision of the technique and to provide "reference" peaks which can then be used to more positively identify the analyte peaks by adjusting the identification windows to account for minor fluctuations in predicted retention times.

\section{INTERFERENCES}

3.1 The primary interferences for this method are common laboratory solvents such as methylene chloride and freon 113 which are used in our facility. Isolating, as much as possible, the area in which any work related to VOC analysis is to be performed is the uitimate solution.

3.2 There are several compounds which are known to be chromatographic interferences. Those which are known at this time are: 1-chlorohexane and chlorobenzene, Freon 113 and 1,1-dichloroethylene, trfchlorobromomethane and one of the middle eluting chlorinated compounds, and a dichlorotoluene coelutes with one of the later eluting aromatics. As can be seen, Identification is far from foolproof so great care needs to be exercised.

3.3 Carryover from a high to a low sample may also be a source of contamination, but with the use of the ALS-10 it is more important that the sparging cells be thoroughly cleaned after each use to prevent any carryover problems.

\section{METHOD PITFALLS}

4.1 Analyte volatility represents the major source of both sample and calibration standard instability.

As regards samples, any air space above aqueous samples renders them invalid. Samples must also be kept cold (ca. $4^{\circ} \mathrm{C}$ ) from the time of collection to the time of analys is and they must be analyzed within 14 days of collection to avold losses of volatile components.

Calibration standards also suffer from stability problems. Methanolic working standard solutions last about 1 week during normal usage; a drop in response, espectally in the gaseous compounds indicates standard decomposition. Working standards must be replaced when the response observed differs from that of the initial calibration curve by $20 \%$ or more (see Section 11., Quality Control). It is highly recommended that stock and working standard solutions be stored after preparation in a number of small autosampler vials to maximize the amount of time that a batch of standards will last. Minimizing the amount of time a standard spends at room temperature is also highly advised. Stock standard solutions last approximately one month if stored in a freezer.

A final problem arising from analyte volatility involves sample and standard storage. Samples should be stored refrigerated, with a holding blank, in a refrigerator free of volatlle contaminants. Standards should be stored in a freezer. This will minimize the amount of cross 
contamination that will occur. An additional precaution that can be taken to prevent contamination is storage of standards and/or samples in closed containers with activated carbon to adsorb any atmospheric contaminants.

\section{SAFETY}

5.1 A number of the analytes dealt with in this method have toxic and/or carcinogenic properties which mandates that all standards be prepared in a fume hood and that proper protective equipment be utflized. For further information the analyst is referred to the safety references cited in Reference 1. Also refer to EHS Lab Operating Procedure L-4.10, "Laboratory Policy Guide - Use of Carcinogens."

\section{APPARATUS AND EQUIPMENT}

6.1 SAMPLE CONTAINERS-- $40 \mathrm{ml}$ glass screw cap vials equipped with PTFE-faced sillcone septa: (I-Chem $S-3360040$ or equivalent). If 1 -Chem pre-cleaned bottles will not be used, wash vials and septa with detergent and rinse with tap and defontzed water.

Allow vials and septa to air dry at room temperature, place in a GC oven at $105^{\circ} \mathrm{C}$ for one hour, allow to cool in the GC $1 \mathrm{ab}$ and replace caps and septa. Vials should be prepared as close to their usage as possible to prevent any contamination during storage.

6.2 PURGE AND TRAP SYSTEM-- The basic operating principles of the Tekmar LSC 2 and the ALS-10 units, utilized by EHS, are covered in their respective operating manuals (Reference 2 \&. It is highly recomended that these be read thoroughly before beginning any work with this equipment. of special concern are the flow patterns utilized in the system. This equipment satisfies the criteria of EPA method 502.2 and other EPA methods involving purge and trap equipment.

There are minimal problems with this equipment, and routine maintenance consists of cleaning the sparging cells and periodically (perhaps monthly) pressure checking the ALS-10 sparging positions for leaks, as is detailed in the Tekmar manual for the ALS-10. Sparging cells are cleaned after each use by sucking a weak detergent solution through the cells in a reverse direction to the normal flow, followed by a thorough rinsing with deionized water and baking at $110^{\circ} \mathrm{C}$ in a GC oven until dry. Periodic flow checks are also required and flows must be verified whenever a new trap is installed. Appropriate flows are a purge flow of $40 \mathrm{cc} / \mathrm{min}$. (at the sparge cell inlet), and a desorb (column carrier gas) flow rate of approximately $6 \mathrm{cc} / \mathrm{min}$. Helium is the gas utflized.

The trap utilized for this method is the one specified in Section 5.2 .2 of EPA method 502.2 (Tekmar 142366-003 or equivalent). The trap cycle 1 isted below is a modification of the EPA recommended purge cycle. It is one recommended by Lowell Wright of 01 corporation as one which will minimize ELCD signal suppression and premature catalytic tube faflure due to desorbed water. 
Purge time is $11 \mathrm{~min}$., purge temperature is $30^{\circ} \mathrm{C}$ or less (in deference to the room temperature). Desorb preheat temperature is ${ }^{\circ} \mathrm{C}$, desorb time and temperature are $2 \mathrm{~min}$. and $180^{\circ} \mathrm{C}$ respectively (to minimize water deposition onto the column). Bake time and temperatures are $11 \mathrm{~min}$. and $180^{\circ} \mathrm{C}$. Prior to using a new trap or using one which has been idle for an extended period, it should be conditioned by subjecting it to at least one bake cycle and more if necessary. The traps are susceptible to premature failure if any sample foams and is carried into the tubing beyond the sparge cell. It is also advisable not to bake the trap unless it is being sparged with helium (with the ALS-10 this means a sparge cell must be in place) since this does seem to shorten the life of the trap.

Trap life is highly variable; some indicators of a failing trap are an increased number of artifact peaks in the PID chromatogram, perhaps a decrease in bromoform sensitivity (but there are many causes for this phenomena), an increase in back pressure required to maintain flow across the trap, and perhaps also problems with sensitivity of the gaseous compounds espectally vinyl chloride since this compound is barely retained on the trap.

6.3 GAS CHROMATOGRAPHIC SYSTEM -- The basic requirements of the gas chromatographic system are detalled sufficiently in Reference 4 so no further discussion will be made here of general requirements. Rather, the specific conditions under which our particular system has been found to operate best are given.

Gas Chromatograph: HP 5880

Column: $J \& W$ Scientific DB-624, $0.53 \mathrm{~mm}$ 1.d.

Column Length: $30 \mathrm{~m}$.

Film Thickness: Approx. $3 \mathrm{\mu m}$.

Start Temp-Time: $-15^{\circ} \mathrm{C}, 1 \mathrm{~min}$.

Program Rate: $3^{\circ} \mathrm{C} /$ min.

End Temp-Time: $140^{\circ} \mathrm{C}, 5 \mathrm{~min}$.

Post Temp-Time: $175^{\circ} \mathrm{C}, 2$ min.

Det 1-Type \& Temp: PIO, $180^{\circ} \mathrm{C}$, Range $=100$.

Det 2-Type \& Temp: ELCO, $180^{\circ} \mathrm{C}$, " $\mathrm{S}^{\mathrm{N}}$ Mode.

PID Lamp: $10.2 \mathrm{ev}$.

ELCD Tube Temp \& $\mathrm{H} 2$ Flow: $900{ }^{\circ} \mathrm{C}, 100 \mathrm{t} /-10 \mathrm{cc} / \mathrm{min}$.

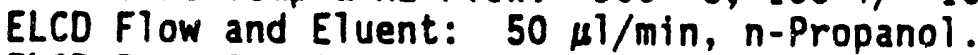

ELCO Pump Setting: $3-4$ turns (10 turn pot.)

Carrier Flow \& Gas: $6 \mathrm{cc} / \mathrm{min}$ He $140 \mathrm{C}$.

Make-Up Gas-Flow: He, $24 \mathrm{cc} / \mathrm{min}$.

\section{Special Notes}

PID Intensity should be set at $30 \%$. The two detectors are connected in series with a short piece of deactivated, uncoated, $0.53 \mathrm{~mm} i . d$. fused silica tube.

A copy of a correct printout of the various conditions, run tables, and the short keystroke program which needs to be entered in order to operate the instrument from the $\mathbf{5 8 8 0}$ terminals is contained in Attachment B. A current copy of this is also kept in the GC laboratory. Understanding this information is critical to successful operation of this instrument. 
A listing of each of the methods used on the Hewlett-Packard (HP) di system are also contained in Attachment B. The analyst is referred L. Reference 7 for detailed instructions on the use of the data system.

The instrument utilizes liquid nitrogen (LN2) cryogenics as the means to lower the column oven temperature to $-15^{\circ} \mathrm{C}$. Two $25^{\circ} \mathrm{L}$ dewar flasks of LN2 are used to fill the instrument dewar, which is then pressurized to 20 psi with nitrogen. It is important to remember when using the ALS-10 to make a clock table entry such that after the last run of a series the oven temperature is ralsed above $50^{\circ} \mathrm{C}$ so that the cryogenic cooling is not activated unnecessarily for an extended period.

A troubleshooting guide which has more specific information about what to do when things go wrong is kept in the Laboratory Operating Procedures Manual (see Proc. (L-8.11).

6.4 MISCELLANEOUS EQUIPMENT-- A number of small items will be required to perform this method; a variety of microliter syringes for dilutions etc., as well as a $5 \mathrm{ml}$ gas tight syringe with a luer lock valve for loading of standards and samples into the $5 \mathrm{ml}$ sparging cells.

\section{REAGENTS}

7.1 METHANOL -. Methanol which is free from any analyte contaminants must be used to prepare standard solutions. Burdick and Jackson Purge and Trap grade methanol (product 1232 ) is highly recommended.

7.2 n-Propanol--The n-propanol used as eluent in the ELCD cell must be a high purity glass distilled type (Burdick and Jackson product 322 or equivalent).

7.3 Gases--Three gases are used to perform this analysis; helium, hydrogen, and LN2. Uitra high purity helium and hydrogen are required for the proper operation of the ELCD. The LN2 used for the cryogenic system is obtained from Battelle's tank outside the whole body counter. Its purity is really an unknown but it also has no bearing on the performance of the method.

7.4 REAGENT HATER-- Analyte-free reagent water is prepared by passing deionized water through two Millipore activated carbon organic removal cartridges (Millipore \#CC1512000) using a vacuum flask apparatus (Rainin \$38-181). This water is then sparged in a large impinger with high purity nitrogen for $1 / 2 \mathrm{hr}$ and stored in a closed container in the GC laboratory.

7.5 SAMPLE PRESERVATIVE-- Hydrochloric acid $(1+1)$ is prepared using ACS reagent grade $\mathrm{HCL}$ and the reagent water prepared above.

7.6 STANDARD STOCK SOLUTIONS-- These solutions are prepared from commercially avallable stock solutions (Supelco) or from ampulated stock solutions provided by the EPA Quality Assurance Materials Bank (QAMB). The stor solutions can also be prepared from neat materials following $t_{1}$. directions in Sections 6.3.1-6.3.4 in Reference 1. Typically stock solutions are at concentrations of 1000 to $10,000 \mathrm{ug} / \mathrm{mL}$. Refer to 
Section 4.1 for storage conditions and shelf 1 ife of these solutions.

7.7 WORKING STANDARD SOLUTION-- The working standard solution is prepared from the commercial stock solutions by additions of appropriate microliter volumes of the stock solutions to methanol. The working solution concentration is $5 \mathrm{ug} / \mathrm{mL}$ of each analyte. Additions of $1 \mu \mathrm{L}$ to $20 \mu \mathrm{L}$ of this solution to $5 \mathrm{ml}$ of reagent water in a $5 \mathrm{ml}$ glass syringe yield calibration standard concentrations of $1-20 \mu \mathrm{g} / \mathrm{L}$ in the aqueous solution. Refer to Section 4.1 for storage conditions and standard shelf Iife.

7.8 INTERNAL STANDARD WORKING SOLUTION--The internal standard working solution is prepared from EPA stock solutions by dilution into methanol. The two internal standards are fluorobenzene (PID) and 1,4-Dichlorobutane (ELCD). 2-Bromo-1-chloropropane is not used because it cannot be separated from another analyte on the DB-624 column or on the VOCOL column recommended in Reference 1. The internal standard in EPA method 502.1 is 1,4-dichlorobutane and this compound was adopted for this methodology. The internal standard working solution is prepared at a concentration of $10 \mu \mathrm{g} / \mathrm{mL}$ of each standard compound by dilution of the stock solutions. Addition of $5 \mu \mathrm{L}$ of this solution to $5 \mathrm{~mL}$ of aqueous sample or reagent water in a $5 \mathrm{~mL}$ glass syringe to yields a final aqueous concentration of $10 \mu \mathrm{g} / \mathrm{L}$.

7.9 SURROGATE WORKING SOLUTION-- Surrogate compounds are added to each sample to yield recovery information on each sample. The two surrogates use (one for each detector) are 2-chlorobutane and p-difluorobenzene. Stock surrogate spiking solutions are prepared from either neat material as per Sections 6.3.1-6.3.4 of EPA method 502.2 (2-chlorobutane) or from available EPA standard solutions ( $p$-difluorobenzene). The surrogate working solution is prepared at a concentration of $10 \mu \mathrm{g} / \mathrm{mL}$. This solution is used for calibration and for sample spiking. Calibration standards are prepared by addition of $1,2,5,10$ and $20 \mu \mathrm{L}$ of this working solution to $5 \mathrm{~mL}$ of reagent water in a glass syringe to which the internal standard and calibration standard solutions have already been added. This results in aqueous concentration levels of $2,4,10,20$, and $40 \mu \mathrm{g} / \mathrm{L}$. A $5 \mu \mathrm{LL}$ allquot of the surrogate working solution is used to spike the samples at a $10 \mu \mathrm{g} / \mathrm{L}$ level.

7.10 LABORATORY QC CHECK SOLUTIONS-- Two different kinds of QC check solutions are prepared in our laboratory. A check solution is currently being made from EPA standard solution mixes to check the comparability of our standards to those of the EPA. This EPA QC Check solution does not contain all of the analytes covered by method 502.2 but it does contain a substantial number of them. EPA currently does not have a standard solution mix or even several standard solution mixtures which have all of the analytes covered under method 502.2. Currently we are using this EPA solution to function as the "Laboratory quality Control Check Standard" referred to in method 502.2 .

A source of standard solution mixes different from that used to prepare the calibration standards has been found (U1tra Scientific) from which second $Q C$ check solution will be prepared to cover all of the analytes. The EPA QC check solution will continue to be analyzed in addition to the 
normal QC check solution in order to validate comparability with EPA standards. More will be sald on this subject later in Section 11.

8. SAMPLE COLLECTION, PRESERVATION, STORAGE

8.1 SAMPLE COLLECTION--The analyst is referred to Reference 1 for adequate details concerning sample collection. All samples are collected in duplicate. If samples are to be composited it must be done according to the guidelines contained in Reference 8.

8.2 SAMPLE PRESERVATION--Samples are held at $4^{\circ} \mathrm{C}$ from the time of collection to receipt at the laboratory by the use of biomailers and cold packs. Upon receipt at the laboratory lower the sample $\mathrm{pH}$ to $<2$ by addition of $200 \mu \mathrm{L}$ of $1: 1 \mathrm{HCl}$ (see Section 7.3) to the sample through the septum using a syringe equipped with a narrow gauge needle.

8.3 SAMPLE STORAGE--Store samples in a refrigerator free of organic solvent vapors (see Section 4.1) at $4^{\circ} \mathrm{C}$ until analysis. All samples must be analyzed within 14 days of collection. Samples not analyzed within this time period must be discarded and replaced.

\section{CALIBRATION AND STANDARDIZATION}

9.1 CALIBRATION STANDARD PREPARATION--Calibration standards are prepared by adding $5 \mathrm{~mL}$ of reagent water to a $5 \mathrm{~mL}$ glass gas-tight syringe. Five microliters of internal standard working solution are then added quickly through the luer valve to the syringe. Then the appropriate volumes of surrogate working solution and the calibration standard working solution are added in the same fashion. The contents of the syringe are then loaded into a sparge cell and analyzed according to Section 12.

Calibration standards are prepared at concentrations of $1,2,5,10$, and $20 \mu \mathrm{g} / \mathrm{L}$ by addition of $1,2,5,10$, and $20 \mu \mathrm{L}$ of the $5 \mathrm{ug} / \mathrm{ml}$ standard working solution. Surrogate levels are twice this concentration because the same volumes are added but the concentration of the surrogate working solution is $10 \mu \mathrm{g} / \mathrm{mL}$.

9.2 INTERNAL STANDARD INSTRUMENT CALIBRATION--The internal standard method of calibration is used. Response factors are calculated and a calibration curve generated using the Extrachrom II Data system. For a discussion of how this is performed and the pertinent equations used the analyst is referred to Reference 7. A first order (1 inear) or second order (quadratic) fit must be used to generate the calibration curve, the one yielding the highest correlation coefficient should normally be chosen. The \% RSD of the response factors must be less than $20 \%$ for all of the analytes or another calibration curve must be prepared.

\section{METHOD PERFORMANCE DEMONSTRATION}

10.1 METHOD PERFORMANCE AND MDL DETERMINATION--In order to demonstrate acceptable method performance and to determine the method detection limits (MDL) each analyst is required to analyze seven samples at a concentration of $0.5 \mu \mathrm{g} / \mathrm{L}$. These samples are prepared using the 
laboratory QC check solution.

For each analyte the mean recovery must be between $80 \%$ and $120 \%$ of the true value and the relative standard deviation of the values must be $<30 \%$. If either of these tests fail, system performance is unacceptable and corrective action must be taken. Corrective action can be a repeat of the test, preparation of fresh QC check solution, recalibration of the instrument or other means. The method detection limit at the 99\% confidence level is determined as $3.143 \times s$ where $s$ is the standard deviation of the concentrations observed above.

\section{QUALITY CONTROL.}

11.1 DAILY METHOD BLANKS--Each day before any standards or samples are analyzed a method blank consisting of $5 \mathrm{~mL}$ of reagent water containing $5 \mu \mathrm{L}$ of internal standard working solution, and $5 \mu \mathrm{L}$ of surrogate working solution must be analyzed and found to contain less than the MDL of any of the 502.2 analytes. If any compounds are found above the MDL corrective action must be taken. Corrective action could include preparation of fresh reagent water, re-cleaning of the sparging cells, replacement of the trap, and replacement of the purge gas hydrocarbon traps, or all of the above.

11.2 DAILY STANDARD VALIDATION--Each day after analysis of the method blank two standard check solutions must be analyzed. First, a calibration standard solution must be analyzed and the concentrations obtained mug be within $20 \%$ of their true values. Standard concentration levels us should alternate to cover all standard levels over a period of several days. Standards should be run at the end of each sample batch as well, if possible. Second, a solution prepared to be $5 \mu \mathrm{g} / \mathrm{L}$ using the Laboratory $Q C$ Check Solution must be analyzed and the recoveries obtained must be within $40 \%$ of their expected values. If either of these solutions fails the test for no obvious reason, then corrective action must be taken in the form of fresh standards or a recalibration of the instrument.

1:.3 DAILY EPA QC STANDARD CHECK--Each day of analysis a solution prepared to be 5 to $20 \mu \mathrm{g} / \mathrm{L}$ using the EPA QC check solution must be analyzed and the recovery must be within $40 \%$ of the expected value. Corrective action for a fallure of this test must be taken in the form of fresh standards or a recalibration of the instrument.

11.4 SURROGATE RECOVERY CHECK--Surrogates are added to each sample and blank to yield a concentration of $10 \mu \mathrm{g} / \mathrm{L}$. Surrogate recovery must be within $80-120 \%$.

11.5 INTERNAL STANDARD AREA CHECK--Internal standard areas must be recorded and each day must be within $50 \%$ of the areas observed for the daily calibration standards and within $50 \%$ of the prior day's daily calibration standard values. Failure of this test invalidates all samples it affects. Corrective action may include replacement of internal standap solution, a repair of a particular detector, or a recalibration of th instrument. 
11.6 WEEKLY LOW LEVEL STANDARD CHECK--At least once each week a calibration. standard at the $0.5 \mu \mathrm{g} / \mathrm{L}$ must be analyzed and the analyt recovery must be within $40 \%$ of the expected value. If this test is falled, corrective action must be taken. Corrective measures might include a simple repetition of the test, preparation of fresh standards, instrument repair, or recalibration of the instrument.

11.7 WEEKLY EPA PE SAMPLE ANALYSIS--Performance Evaluation (PE) samples are available from EPA EMSL-Cincinnati and one of these must be analyzed at least once each week at a concentration that is within the range of the calibration curve. The analyte concentration values must be within $20 \%$ of those provided by EPA EMSL-Cincinnati or within the acceptance 1 imits provided, whichever is applitcable.

11.8 SAMPLE DUPLICATE ANALYSIS--Any samples in which a positive result is obtained for any analytes other than trihalomethanes must be analyzed in duplicate, duplicate analyses should agree to within $40 \%$.

11.9 RESPONSE FACTOR CHECK--When analytes are found in the samples for which responses are observed on both detectors the analyte concentrations obtained on both detectors should be within $40 \%$ of each other.

\section{SAMPLE ANALYSIS}

12.1 INSTRUMENTAL CONDITIONS--The instrumental conditions to be used al described fully in Sections 6.2 and 6.3. Approximate retention times anc example chromatograms are contained in Attachment $B$.

12.2 QUANTITATION--The analyte concentrations are calculated by the internal standard method by comparison of the response factors observed in the samples with those of the calibration standards. More information on the calculation methods used is contained in Reference 7 . Results are reported in $\mu \mathrm{g} / \mathrm{L}$ and rounded off to two significant figures or $0.1 \mu \mathrm{g} / \mathrm{L}$.

13. DOCUMENTATION

13.1 QUALITY CONTROL--Quality control results are recorded to verify acceptable method performance on a series of forms prepared for this purpose, copies of these forms are contained in Attachment $C$.

13.2 QUANTITATION-- The analytical quantitative results obtained from analysis of the samples are recorded on a form established for this purpose, a copy of this form is contained in Attachment $C$.

\section{REFERENCES}

1. Volatile Organic Compounds in Water by Purge and Trap Capillary Column Gas Chromatography with Photoionization and Electrolytic Conductivity Detectors in Series, Method 502.2, EPA, as shown in 52 CFR 12879 (Apri) 17,1987 ). 
2. Tekmar Company Liquid Sample Concentrator Model LSC-2 operating. manual.

3. Tekmar Company Automatic Liquid Sampler Model ALS-10 operating manual.

4. Hewlett-Packard Gas Chromatograph Model 5880 operating manual.

5. HNU Photoionization Detector (PID) Model PI-52 operating manual.

6. OI Corporation Electrolytic Conductivity Detector (ELCD) Model 4420 operating manual.

7. Extrachrom II Data System Operators manual.

8. Federal Register, Vo1. 52, No. 130, Wednesday July 8, 1987. 


\section{ATTACHMENT A}

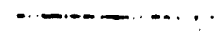




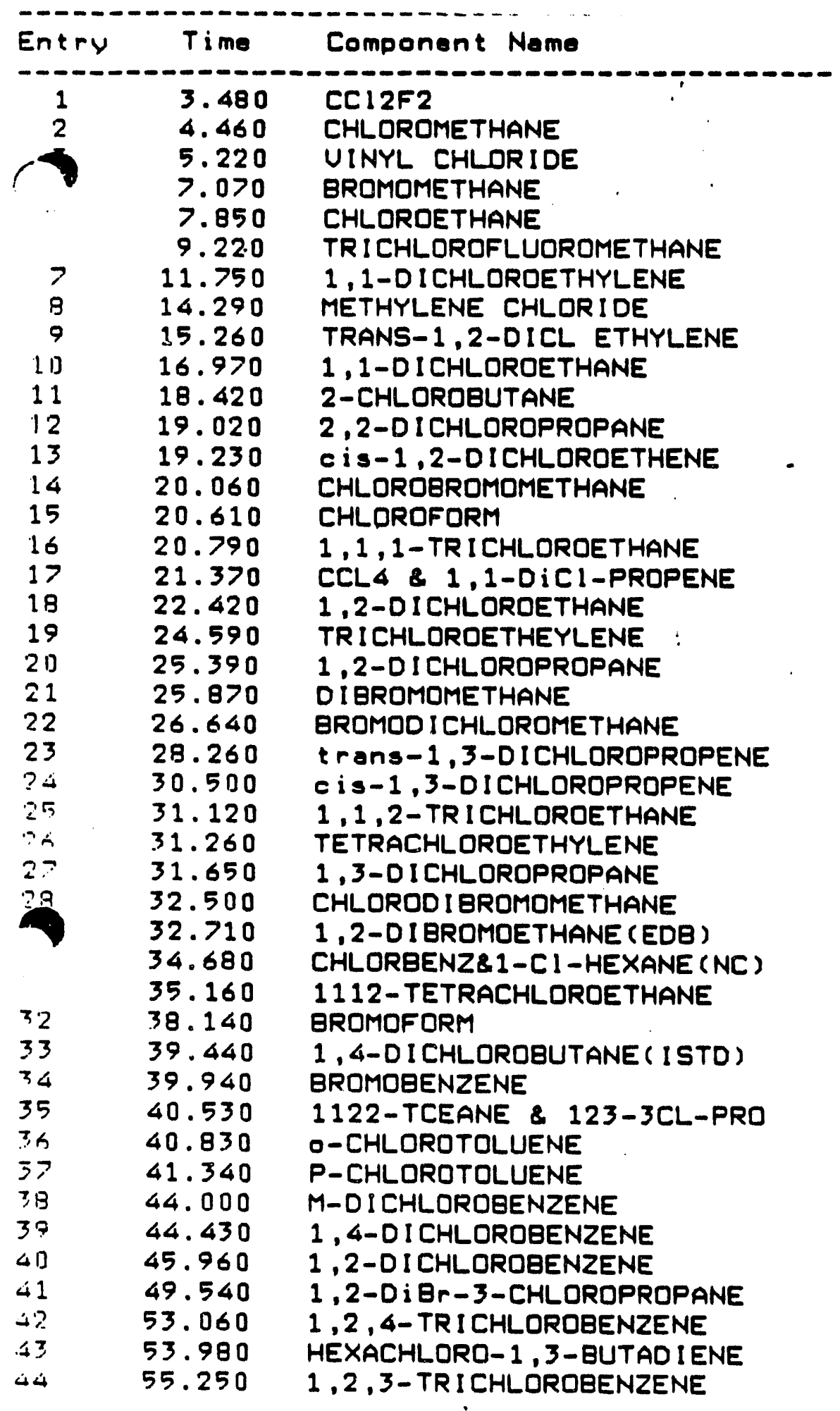




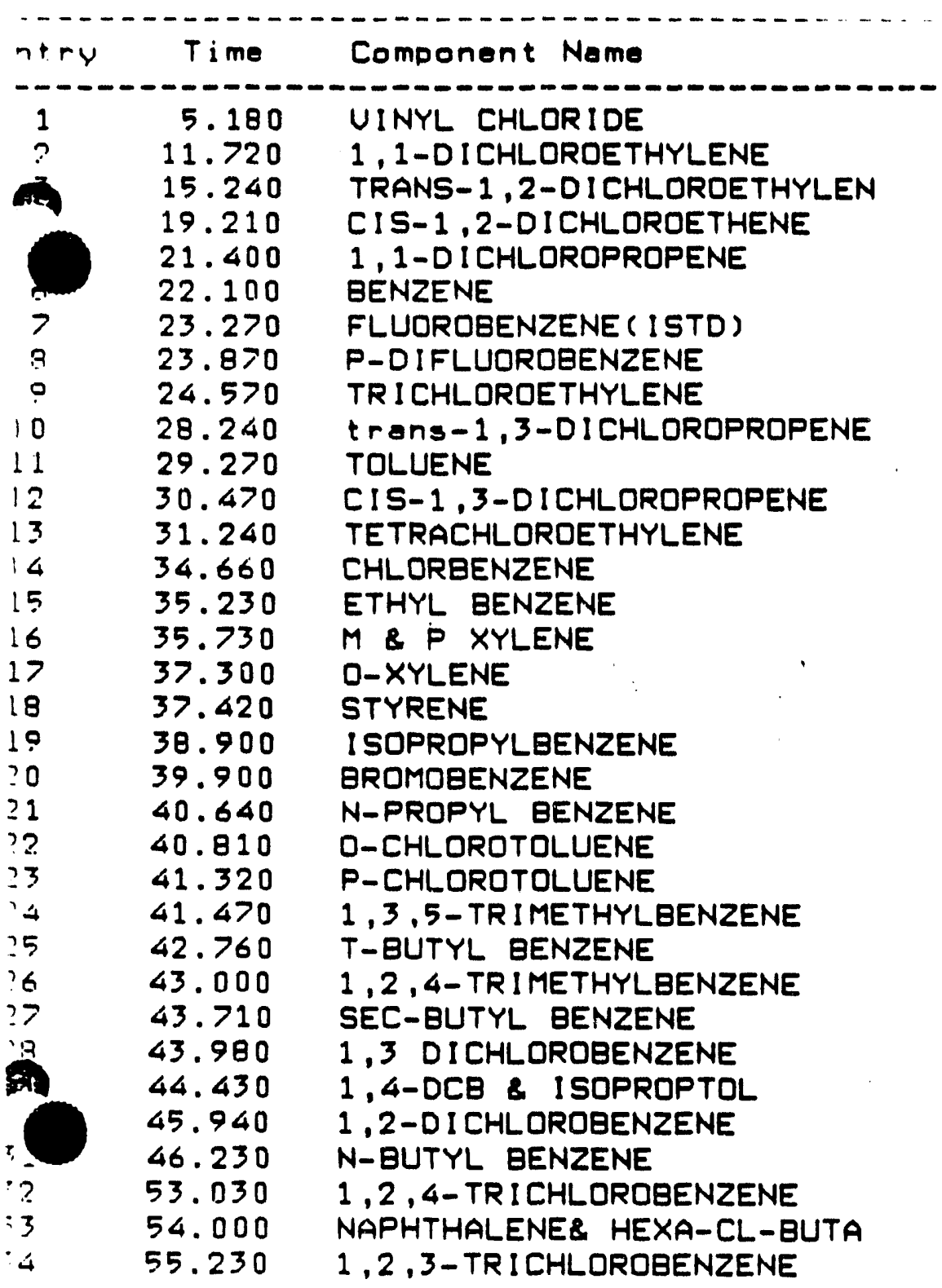


Method No. EHS P. 8

Title:

Polychlorinated Biphenyls in Soll and Sediment

Date 1ssued: $9-23-85$

Approved by:

H. K. Hamiliton

Written by: H. L. Boorse

Supersedes Method No.

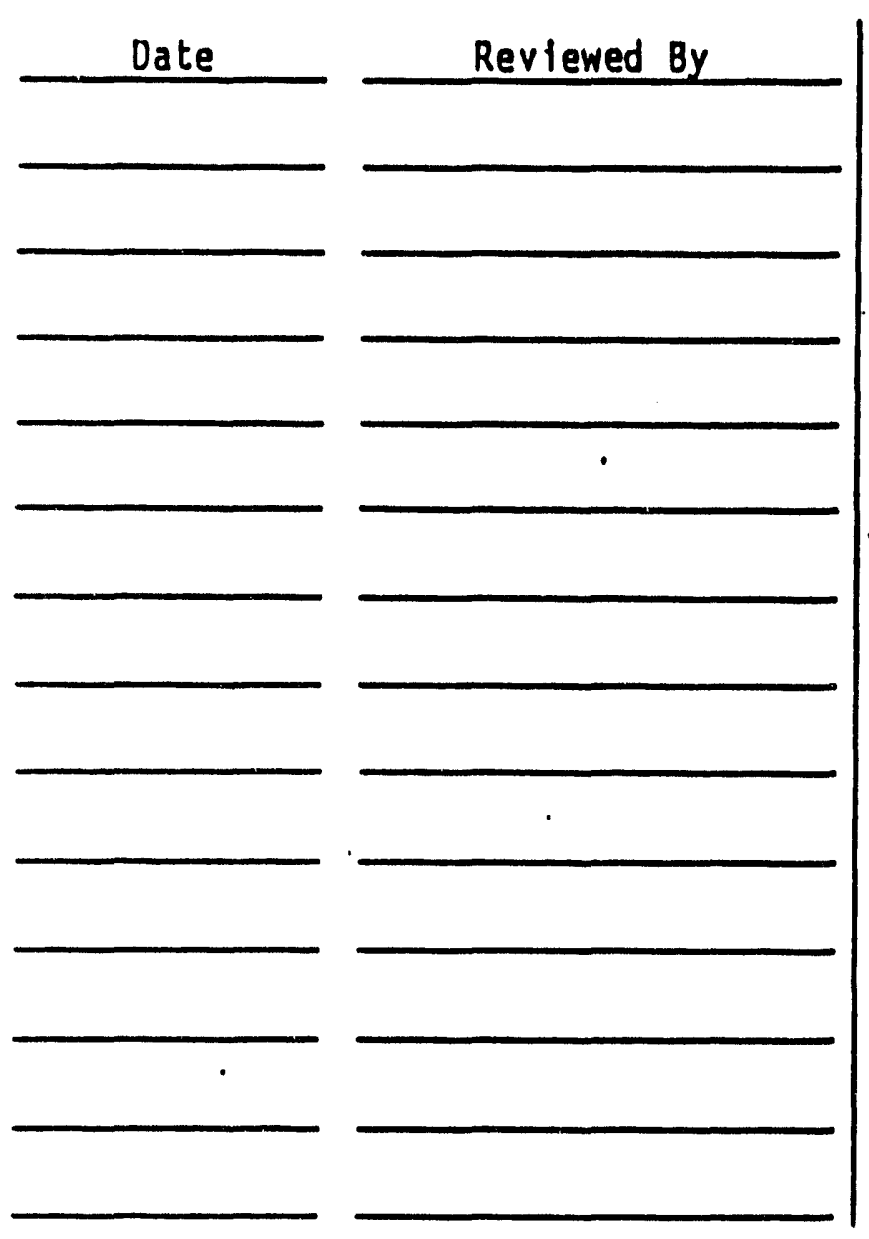

Replaced by Method No.

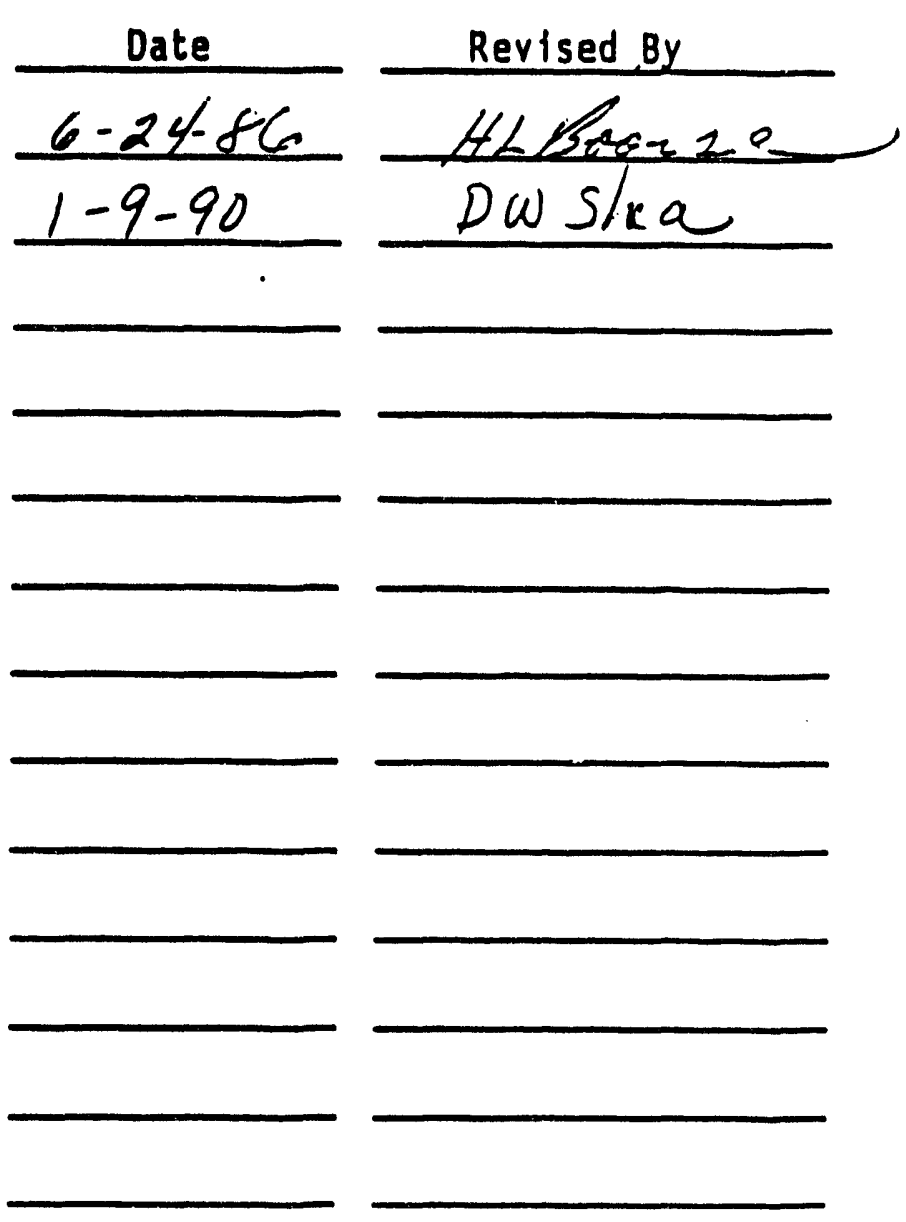

Date: 
EHS P-8-1

$01-09-90$

\section{POLYCHLORINATED BIPHENYLS IN SOIL AND SEDIMENT}

\section{References}

A. "Test Methods for Evaluating Solid Waste," EPA SW 846 Methods 3540, 3660 , and 8080 .

B. "Determination of Pesticides and PCB's in Sediments (Gas Chromatographic Method)," Region 10 Laboratory Surveillance and Analys is Division U.S. Environmental Protection Agency, Seattle, Washington.

C. The analytical chemistry of PCBs, M. D. Erickson, Butterworth Publishers, Boston, 1986.

\section{Princioles and Limitations}

The dried soll is extracted with acetone/hexane in a Soxhlet extractor. The extract is evaporated to a low volume and then solvent exchanged into isooctane. The resulting solution is treated by a cleanup procedure (routinely: acid wash/florisil slurry) to remove interfering substances. Analysis is by capillary gas chromatography using an electron capture (EC) detector. The method is made qualitative and quantitative by comparing peak patterns, area counts, and retention times of the sample chromatogram with chromatograms of known quantity and type of aroclor standards, obtained under the same conditions. Results can be confirmed by running the samples and standards using a second dissimilar column.

Occasionally, sample chromatograms indicate the presence of PCBs; however, no aroclor or mixture of aroclors are indicated by the pattern. This is often the case with weathered or otherwise degraded aroclor mixtures or when a non-aroclor material is the PCB source. In these cases the Dry Color Manufactures Associations' (DCMA) method for PCB identification is employed, (see Section IV.F "Non-aroclor and partial aroclor PCB mixture").

Electron capture detectors respond to chlorine containing compounds other than PCBs and to certain other electrophilic materials containing other halogens, nitrogen, oxygen, and sulfur. Most common interferences can be removed by sulfuric acid washing. The chromatogram of each analyzed sample should be carefully compared with those of the standards. The response of an EC detector to PCBS is reduced by high boiling hydrocarbons that co-elute with the PCBS. This suppression can be compensated for by running spiked samples to determine the actual recovery.

Residual oxygen in carrier and makeup gas can react with components of samples to give oxidation products to which EC detectors will respond. Purity of these gases should be assured. 


\section{Materials}

A. Equipment:

1. Extraction apparatus, Soxhlet, Allihn Condenser ( $250 \mathrm{~mL}$ flask, $40 \mathrm{~mm}$ I.D. ext. tube, $73 \mathrm{~mm}$ Ht siphon tube)

2. Controlled heating mantle

3. Extraction thimbles (Whatman cellulose $35 \mathrm{~mm} \times 80 \mathrm{~mm}$ )

4. $1 \times 12 \mathrm{~cm}$ screw cap tubes

5. Tefion 1 ined caps

6. $10 \mathrm{~mL}$ repipetors for solvent and acid measurement and transfer

7. $0.5 \mathrm{~mL}, 1 \mathrm{~mL}$, and $2 \mathrm{~mL} \mathrm{Class} A$ or better glass pipets

8. Volumetric flasks, isooctane washed

9. Analytical balance with $0.1 \mathrm{mg}$ sensitivity

10. Analytical balance with $0.1 \mathrm{~g}$ sensitivity

11. SE-54 or DB-5 fused silica capillary column 30 meter length, $0.250 \mathrm{~mm}$ I.D., $0.25 \mathrm{\mu m}$ film thickness

12. DB1-30m megabore column 30 meter length, $0.53 \mathrm{~mm} 1.0 ., 1.5 \mu \mathrm{m}$ film thickness

13. Gas chromatograph fitted for capillary column and equipped with electron capture detector and auto sampler

14. Vortex

15. Centrifuge

16. Pasteur Pipets

17. Autosampler vials with teflon caps

18. Mechanical rotary extractor

19. Three ball Snyder Column .

20. Oven capable of maintaining temperature of $50-55^{\circ} \mathrm{C}$

21. Carborundum boiling chips, soxhlet extracted

22. Aluminum foil 
23. Lambda pipets

B. Reagents :

1. Pesticide grade 2,2,4-trimethylpentane (isooctane)

2. Pesticide grade hexane

3. Pesticide grade acetone

4. Reagent grade (conc.) Sulfuric Acid

5. Activated Florisil, 60/100 mesh, reagent grade, suitable for pesticide-residue analysis. Availabie from Floridin Company and treated per AOAC (1980) 29.002 before use

6. EPA standards (1000 to $5000 \mathrm{ppm})$ of aroclors $1016,1221,1232$, $1242,1248,1254,1260,1262,1268$

7. Hexabromobenzene (PCB surrogate)

8. Ultra high purity helium

9. 90 percent argon--10 percent methane (P10) or 95 percent argon--5 percent methane (P5)

10. Tetrabutylammonium hydrogen sulfate, reagent grade

11. Sodium sulfite, reagent grade

12. Ethanol, USP $95 \%$

13. Potassium hydroxide, anhydrous pellets

14. Dry Color Manufactures Association mixture of PCB isomers in hexane. Available from Uitra scientific.

15. Sodium sulfate, anhydrous, certified A.C.S.

16. 2-propanol, reagent grade

C. Standards \& Prepared Reagents:

Note: All glassware should be dedicated for the preparation of aroclor standards.

1. Stock Aroclor solutions. EPA Aroclor standards range from $5000 \mu \mathrm{g} / \mathrm{mL}$ to $1000 \mu \mathrm{g} / \mathrm{mL}$ and are received in $1 \mathrm{~mL}$ glass ampules. The appropriate amount of standard is volumetrically transferred to a 25 or $50 \mathrm{~mL}$ volumetric flask and diluted in isooctane so that a 10 to $20 \mu \mathrm{g} / \mathrm{mL}$ solution is produced. 
Transfer the stock solution to a brown glass bottle fitted with a teflon lined cap. Transfer remaining EPA standard material to a $1 \mathrm{~mL}$ auto sampler vial. The stock solution and the EPA standard are stable indefinitely if their seals are maintained and they are stored at or below $0^{\circ} \mathrm{C}$.

2. Working standards - $(0.5,0.1,0.05,0.01 \mu \mathrm{g} / \mathrm{mL})$. Add appropriate amount of stock standard (depending on stock standard concentration) to screw cap test tubes and make up with isooctane so that a $0.5 \mu \mathrm{g} / \mathrm{mL}$ solution results. Serially dilute the $0.5 \mu \mathrm{g} / \mathrm{mL}$ to make up the remaining standards 10.01 , 0.05 , and $0.1 \mu \mathrm{g} / \mathrm{mL}$ ). Total volume of each working standard should be approximately $10 \mathrm{~mL}$. Prepare monthly or as needed.

3. DCMA mixture, stock and serial dilutions. The DCMA mixture ampule is opened and an aliquot diluted 100 fold. Serial dilutions of 2, 10, and 20 fold are made up of this solution. The remaining original DCMA mixture is transferred to an auto sampler vial, sealed with a teflon backed cap and stored at or below $0^{\circ} \mathrm{C}$.

4. Hexabromobenzene (HBB) surrogate-working standard. The neat HBB standard is removed from the freezer and a $10 \mathrm{mg}$ al iquot volumetrically made up into $10 \mathrm{C} \mathrm{mL}$ of isooctane. The resulting $100 \mu \mathrm{g} / \mathrm{mL}$ solution, the $\mathrm{HBB}$ working standard, is subdivided into $10 \mathrm{~mL}$ vials, secured with a tefion lined screw cap. These materials are stable indefinitely if their seals are maintained and they are stored at or below $0^{\circ} \mathrm{C}$.

5. $1: 1$ acetone/hexane extraction solution-mix equal volumes of hexane and acetone. Use the same "batch" of extraction solvent for a given set of samples, spikes and controls.

\section{Methods}

Note: This procedure is intended to qualitatively and quantitatively analyze samples for the nine specific aroclors listed on page 3. This method is not adequate for qualitative and/or quantitative analysis of partial aroclors or individual congeners which may resuit from aroclor degradation or by products of chemical reactions. For non-aroclor samples see Section IV.F for the analysis of these partial or non-aroclor containing samples.

A. Extraction: (Soxhlet extraction, based on: "Test Methods for Evaluating Solid Waste," EPA SW 846 Method 3540.

1. Empty the majority of the sample from its container on to a sheet of aluminum foil. Pick through the sample and remove larger stones, roots and other non-homogeneous material. Place $10 \mathrm{~g}$ of cleaned, homogeneous material into a cellulose thimble. Add $10 \mathrm{~g}$ of sodium sulfate and mix. 
EHS P-8-5

$01-09-90$

Alternately, place approximately $100 \mathrm{~g}$ of soil sample in a 250 $\mathrm{mL}$ beaker and place in an oven to dry at $50-55^{\circ} \mathrm{C}$ for $6-8$ hours. Cool to room temperature. Sieve soil through 20 mesh, Standard Sieve (A.S.T.M. Designation Ell). Weigh $10 \mathrm{~g}$ of sieved sample into a cellulose extraction thimble. Do not add sodium sulfate. This is the preferred method when working with exceptionally wet materials (i.e. sludges with standing liquid phase).

2. Prepare blank, spike and other QC samples in accordance with Section IV.C.

3. Spike every sample, sample duplicate, sample spike, EPA QC, and blank with $100 \mu \mathrm{L}$ of the HBB surrogate.

4. Place $150 \mathrm{~mL}$ of $1: 1$ acetone/hexane solution into the $250 \mathrm{~mL}$ round-bottom flask containing several carborundum boiling chips. Attach the flask to the soxhlet extractor, and extract the sample for 18 hours.

5. Allow the extract to cool after the extraction is completed. Rinse the condenser with the extraction solvent and drain the Soxhlet apparatus into the collecting round-bottom flask.

6. Attach three-ball Snyder column to the flask and reduce solvent to a volume of approximately $25 \mathrm{~mL}$.

7. Rinse down Synder column with isooctane and add an additional $25 \mathrm{~mL}$ isooctane to sample flask. Add a new boiling chip and reduce solution volume to approximately $10 \mathrm{~mL}$. It may be necessary to wrap the Snyder column in aluminum foil to speed evaporation.

8. Allow the extract to cool. Rinse down the Snyder column with isooctane and quantitatively transfer extract to a $50 \mathrm{~mL}$ volumetric flask and adjust to volume with isooctane.

9. Transfer $10 \mathrm{~nL}$ of the extract to a screw cap tube.

B. Cleanup techniques

1. Acid wash/florisil cleanup (Primary procedure)

a. Add $3 \mathrm{~mL}$ concentrated sulfuric acid to each of the $10 \mathrm{~mL}$ sample aliquots, including blanks, QC samples, etc.

b. Shake by hand for 30 seconds and Vortex for 30 seconds.

c. Transfer all test tubes containing samples, blanks, quality control and spiked samples to the rotary extractor. Run extractor for 1 hour.

d. Label test tubes for each sample, blank, quality control and spiked sample being run. Add $-0.2 \mathrm{~g}$ florisil to each empty test tube. 
e. Remove sample test tubes from the extractor and centrifuge for approximately 5 minutes at $3000 \mathrm{rpm}$. Transfer each isooctane layer to its corresponding florisil-containing test tube.

f. Place sample test tubes in extractor for 1 hour.

g. If the isooctane extract appears colored or cloudy additional/alternative cleanup procedures may be necessary, ntherwise the extract is ready for analysis (Section IV.D.).

\section{Sulfur removal (Based on EPA SW 846 Method 3660)}

This procedure is used routinely with sediment and sludge samples or when suifur interference is indicated on the chromatogram.

a. Prepare TBA-sulfite reagent: Dissolve $3.39 \mathrm{~g}$ tetrabutylammonium hydrogen sulfate in $100 \mathrm{~mL}$ of deionized water. Extract 3 times with $20 \mathrm{~mL}$ portions of isooctane. Discard the isooctane extracts and add $25 \mathrm{~g}$ of sodium sulfite to the water solution. Resulting solution is saturated with respect to sodium sulfite and is stable for 1 month at room temperature.

b. Transfer $2 \mathrm{~mL}$ of extract from Section IV.B.I.g (Acid wash/florisil cleanup) to a new test tube.

c. Add $1 \mathrm{~mL}$ of TBA-sulfite reagent and $1 \mathrm{~mL} 2$-propanol to the test tube. Shake test tube for at least 1 minute and look for clear crystals from precipitation of sodium sulfite. If crystals are not present, add crystalline sodium sulfite in $100 \mathrm{mg}$ portions until solid material remains (one portion is usually enough).

d. Add $5 \mathrm{~mL}$ of deionized water and shake for at least 1 minute. Let stand for 5 minutes for phase separation. Collect top, isooctane, layer in an auto sampler vial. The extract is ready for analysis (Section IV.D.).

3. Ethanol/potassium hydroxide cleanup

This procedure is used when hydroxyl containing species such as pentachlorophenol and glycols are present. Additionaliy, fats are made more water soluble through saponification. Certain chlorinated pesticides undergo dehydrochlorination.

a. Prepare $2 \%$ potassium hydroxide/ethanol solution: Dissolve $2 \mathrm{~g} \mathrm{KOH}$ into $100 \mathrm{~mL}$ of $95 \%$ ethanol.

b. Prepare $50 \%$ ethanol/water solution: add equal volumes of ethanol and deionized water. 
c. Pipet up to $4 \mathrm{~mL}$ of extract from Section IV.B.1.g. (Acid wash/florisil cleanup) into a pyrex test tube and reduce to dryness under $\mathrm{N}_{2}$.

d. Add $2 \mathrm{~mL}$ of ethanol/KOH reagent and 1 boiling chip.

e. Reflux test tube contents over boiling water bath for 20 minutes. During first 5 minutes the test tube should be immersed only in the steam of the water bath. This gentle refluxing is to prevent the loss of analytes along with the solvent stream. The steam refluxing should reduce the sample to near dryness. Continue refluxing with the tube immersed in the water bath for the remaining 15 minutes.

f. Remove test tube from water bath. Following cooling add $2 \mathrm{~mL}$ of ethanol/water solution. Note: if a precipitate forms during the refluxing step it should be dissolved before adding the ethanol/water solution. To dissolve the precipitate, reheat the test tube and add a few drops of the ethanol/KOH reagent. Swirl, to dissolve the precipitate and then add the $2 \mathrm{~mL}$ of ethanol/water.

g. Add isooctane in a 1 to 1 ratio of the amount of extract used in step " $c$ " above and shake for 1 minute.

h. If a clear separation of isooctane from the ethanol/water phase is achieved, the extract is ready for analysis, otherwise a second iteration of the acid wash/florisil slurry cleanup is recommended.

\section{Analyte Recovery and quality control}

\section{Preparation of spiked samples}

a. In order to determine the effect of matrix suppression on the electron capture detector every 10th sample is spiked with aroclor material. If a given sample set contains a variety of widely different matrixes, each type should be spiked.

b. Samples to be spiked are cut in duplicate. A small amount ( 1.0 to $0.5 \mathrm{~mL}$ ) of aroclor stock solution (10 to $20 \mu \mathrm{g} / \mathrm{mL})$ is added to the sample in the extraction thimble. The resulting concentration of the added spiked sample after extraction is in the range of 0.1 to 0.5 $\mu \mathrm{g} / \mathrm{mL}$.

c. The sample spike is handled as any other sample beginning with Step 4 of the extraction procedure, IV.A. 
EHS P-8-8

$01-09-90$

a. There are currently no PCB containing sediments or soi available from the EPA.

3. Preparation of blank sample

a. Place $10 \mathrm{~g}$ of sodium sulfate in a cellulose extraction thimble and handle as any other sample beginning with Step 4 of the extraction procedure, IV.A.

D. Gas chromatography analysis (splitiess mode)

1. Instrument parameters:

$\begin{array}{cll}\text { H.P. 5880A } & \begin{array}{l}\text { Initial Oven Temperature } \\ \text { Initial Time }\end{array} & 150^{\circ} \mathrm{C} \\ \text { Temperature Profile: } & 0.5 \mathrm{minute} \\ \text { Rate } & 10^{\circ} \mathrm{C} / \text { minute } \\ \text { Final Temperature } & 225^{\circ} \mathrm{C} \\ \text { Final Time 1 } & 0 \mathrm{minutes}^{2} & 8^{\circ} \mathrm{C} \\ \text { Rate 2 } & 260^{\circ} \mathrm{C} \\ \text { Final temperature 2 } & 15 \mathrm{minutes} \\ \text { Final time 2 } & 300^{\circ} \mathrm{C} \\ \text { Post temperature } & 1 \mathrm{minute} \\ \text { Post time } & 250^{\circ} \mathrm{C} \\ & 300^{\circ} \mathrm{C} \\ \text { Injector Temperature } & \text { Electron Capture } \\ \text { Detector Temperature } & 1 \mathrm{~cm} / \mathrm{minute} \\ \text { Detector } & 3 \\ \text { Chart Speed } & 2 \\ \text { Attenuation } & 0.04 \\ \text { Threshold } & 1 \mathrm{~mL} / \mathrm{minute} \\ \text { Peak Width } & 2 \mathrm{~mL} / \mathrm{minute} \\ \text { Flows: } & 65-70 \mathrm{~mL} / \mathrm{minute} \\ \text { Capillary Column (He) } & 30-40 \mathrm{~mL} / \mathrm{minute} \\ \text { Septum Purge } & \\ \text { Split Vent } & 0.5 \mathrm{~min}\end{array}$

2. Operation

a. Transfer aliquots of samples to auto sampler vials and load them into $7672 \mathrm{~A}$ auto sampler tray while entering autosampler vial data into "sample table."

b. Run interspersed sets of standards and controls with samples. Also include isooctane washes on a regular basis. Average set of runs should contain 40 percent analytical standards, controls, spikes, and blanks to 60 percent samples.

c. Start resident program: "PCBs". This program provides for summing of peak areas occurring between discrete time windows. These windows correspond to the major peaks of specific aroclors. Program also provides for selecting individual vials for double injection. See Appendix 1 for 
d. Double inject all quality control samples, ail spikes, at least one analytical standard from each set of a given aroclor, and isooctane washes that follow a high concentration injection.

e. Inspect the results of the initial run of samples and assess the following:

1. the need for further dilutions and or clsaning,

2. the identity of the aroclor contaminant(s), (if present at a11), and

3. the correct selection of aroclor standards to run along with the samples. (Standards must be of the same aroclor type as the samples and the standards' area counts must bracket the samples' area counts).

f. If there is doubt as to the aroclor identity or there are other reasons for needing confirmation of the results, the analysis can be repeated using the DB1-30m megabore column, or other dissimilar columns.

g. When necessary, dilute samples, perform any additional cleanup, or reselect appropriate aroclor formulations for standards. Then return to Section IV.D.2.a. for reanalysis. When a sample is subjected to additional cleanup, a spiked sample must also be similarly treated.

E. Calculations

1. Single Aroclor Samples

PCB concentrations in single aroclor samples are calculated by summing the total area of all the peaks due to that aroclor and comparing to the total area of those same peaks found in the standards.

a. Dete nine which aroclor is present in the sample by comparing retention times and peak patterns of the sample to those of the standards.

b. Plot concentration versus area count for the aroclor standards. Using the method of least squares, calculate the regression equation for the best line, using the analytical standards data. Calculate the correlation coefficient (must be 0.999 or better). Regression analysis may be done using a hand calculator such as the HP1lC or a computer program such as LOTUS 123.

c. Determine the concentration of aroclor present in the sample from the calibration curves. 
EHS P-8 -10

$01-09-90$

d. Use the spiked sample(s) to determine percent recovery of PCB material in the sample(s). If a sample set is large, and of similar matrix, then the recovery data can be averaged. Check the quality control charts to confirm that this level of recovery is within the acceptable range. (See Section $V$ on quality control.)

e. Use the EPA control sample(s) to confirm that the method is under control. Use the area counts of the analytical standards to confirm that the instrument is operating correctly.

f. Use the HBB surrogate data to determine percent recovery on all non aroclor spiked samples.

g. Calculation: $\quad$ Ppm PCB in $011=\frac{C \times D}{R \times W}$ where:

C the observed PBC concentration in $\mu \mathrm{g} / \mathrm{mL}$

$D$ the dilution ratio of the sample

$R$ the recovery correction factor as determined by spikes or surrogates

$W$ the weight of the sample aliquot in $\mathrm{g}$

h. Round off all data to 2 significant figures and report all data in $\mathrm{ppm}$ on a $\mu \mathrm{g} / \mathrm{g}$ ratio in the soil/sediment.

2. Mixed aroclor samples

PCB concentrations in mixed aroclor samples are calculated from individual congener peak areas or peak grouping sums. These peaks are chosen from non-overlapping regions of the chromatogram. These areas are compared with the same areas on the chromatograms of the analytical standards. A concentration is determined for each aroclor present and a total concentration calculated.

a. Look at the sample's chromatogram and also at those of aroclor standards to determine which aroclors comprise the mixture. Determine which peaks from each aroclor have the least contribution from the other aroclors present.

b. Using the area of the selected non-overlapping peaks determine the concentration of each aroclor by standard ratios:

Calculation: $\quad X=(A \times c) / a$

where:

$\begin{array}{ll}X & \text { concentration of aroclor " } X " \\ A & \text { area of selected peaks in sample } \\ \text { a area of selected peaks in standard } \\ \text { C concentration of standard in } \mu \mathrm{g} / \mathrm{mL}\end{array}$ 
EHS P-8-11

$01-09-90$

c. The total PCB concentration is determined by the summation of each of the individual aroclor concentrations. This value is substituted into "the observed PCB concentration in $\mu \mathrm{g} / \mathrm{mL}$ " in step " $\mathrm{g}$ " of the above section.

d. See Appendix 2 for an example of a calculation for determining total PCB concentration in a mixed aroclor sample.

F. Analysis of non-aroclor and partial aroclor PCB mixtures

Samples that contain PCBs from non-aroclor formulations or from aroclors that have been altered through chemical or biological action are best analyzed using the Dry Color Manufacturers Association (DCMA) method.

Essentially, this method divides the distribution of PCB congener peaks into 10 regions. Each region is centered around the retention time of each PCB homologous series (i.e. pentachlorobiphenyl, hexachlorobiphenyl, etc.). In each homologous series one congener has been selected that has an average response factor for that series. These 10 congeners are prepared at different concentrations and run on the GC as outlined above in

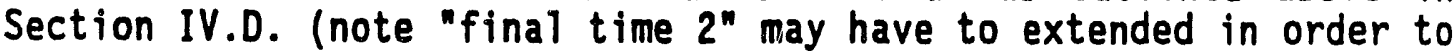
see decachlorobipheny 1). Regression equations are calculated for each of the 10 congeners as described in Section IV.E.1.B. Samples are cleaned up as needed and run as described in sections IV.A through IV.D. Sample peaks are summed for each PCB congener region. Sample data for each region is compared against the appropriate DCMA regional standards to determine individual congener concentrations.

Total PCB concentration in a given sample is determined by summing the individual regional/congener concentrations.

\section{Quality Control}

Quality control data relating to PCBs are kept on the following matrix types: aqueous, solid, surface, air, and non-aqueous fluids. Quality control data relating to samples analyzed using this method are recorded under the category "Wastes" in our QC records. Since there are no PCB containing soils or sediments available from the EPA, quality control data for this matrix consists of spike and surrogate recovery data. Results of the analyses of the quantitation standards are also maintained. See the record categories "Environmental" and "Industrial Hygiene" for other PCB QC records. 
A. The following data are recorded for each sample set:

1. The spiking aroclor, its concentration, the amount spiked, and the dilution factor.

2. The date of analysis and run number.

3. The calculated true value of the spiked sample and the observed value(s).

4. The percent recovery of the observed value as compared to the calculated true value. This is plotted for an estimate of method accuracy.

5. The percent difference between the low and high observed values. This is plotted for an estimate of instrument precision.

- Currently, this data is entered into a LOTUS 123 spreadsheet which determines means and standard deviations and plots results against these descriptive statistics.

B. The area counts of the aroclor standards are monitored as an estimate of detector sensitivity. Likewise the HBB peak is used to determine theoretical plate height as an indicator of degradation in chromatography.<smiles>[191In]</smiles> 
EHS $P-\varepsilon-13$

Appendix 1. PCB progran for HP 5880 gas chromatograply

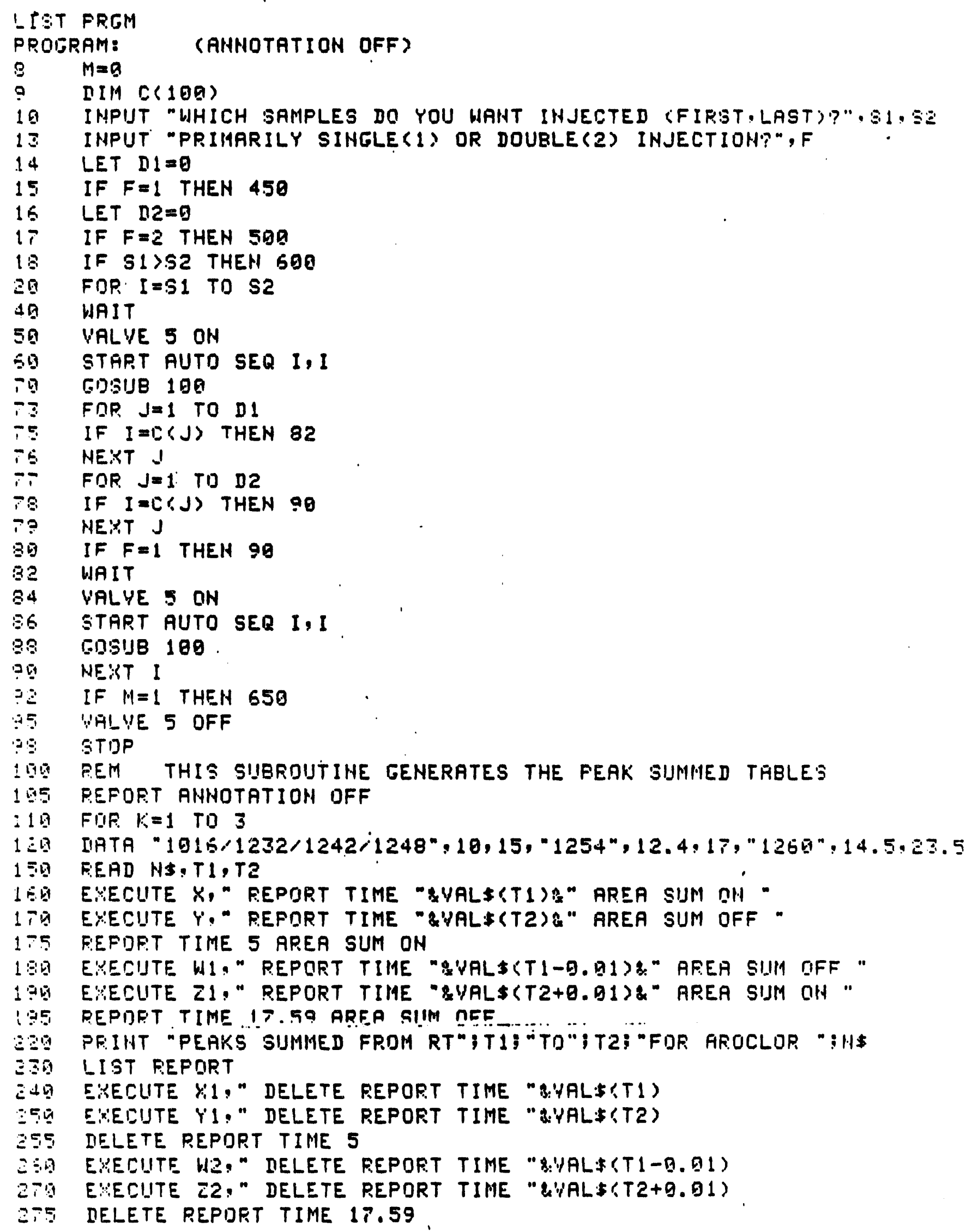




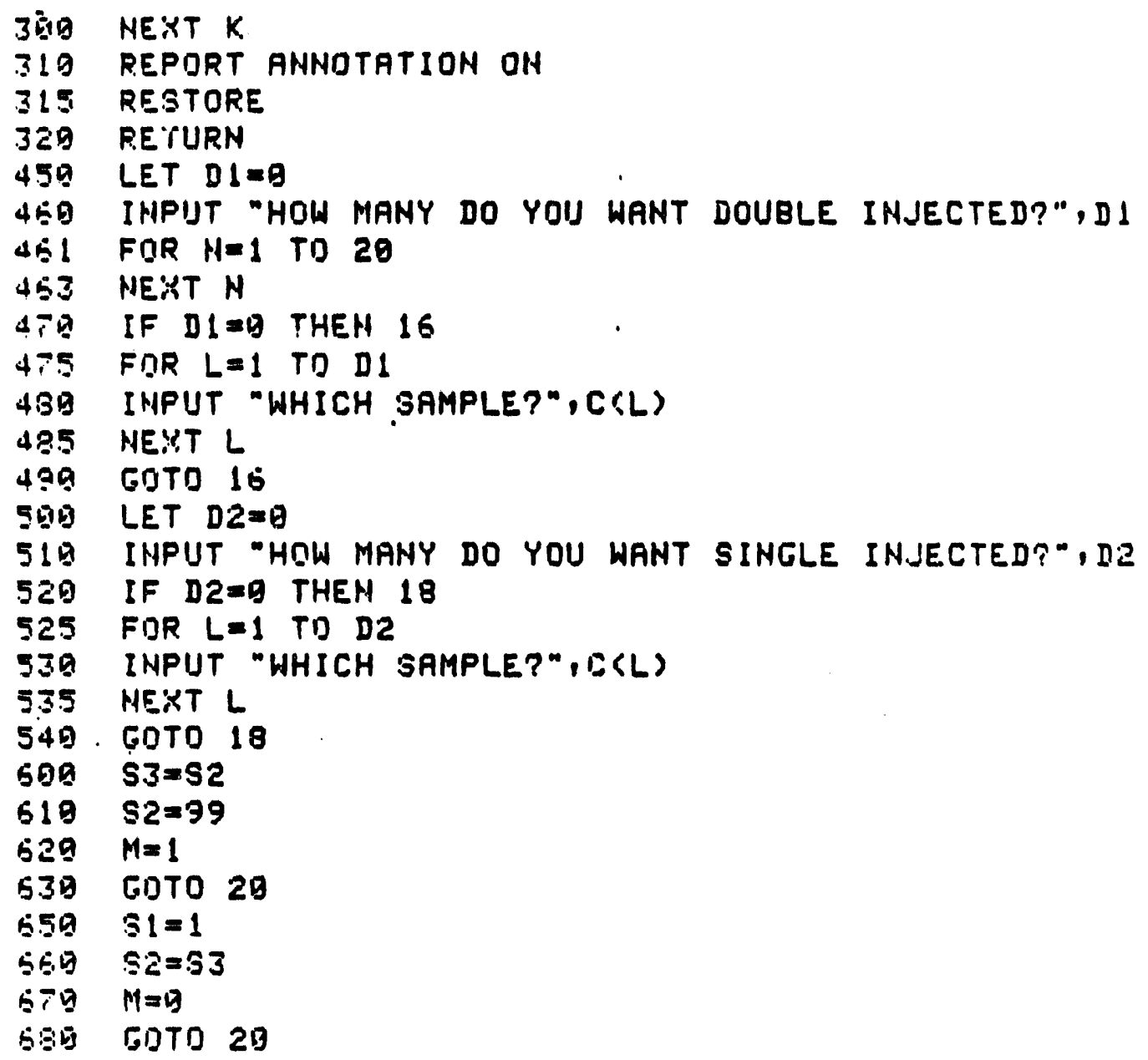


Appendix 2. Determination of PCBs in mixed aroclor samples

The attached figure includes three chromatograms: A) a mixed aroclor waste sample containing arociors $1242 / 1248$ and $1260 ;$ B) a $0.1 \mu \mathrm{g} / \mathrm{mL}$ aroclor 1242 standard; C) a $0.01 \mu \mathrm{g} / \mathrm{mL} 1260$ standard.

Some of the peaks from the $1242 / 1248$ region that are not overlapped by 1260 peaks occur at retention times (RT): $7.73,8.61,9.01,9.56$, and 9.78 minutes. Similarly, non-overlapped peaks for the 1260 region occur at retention times: 18.58, 1897, and 19.24 minutes. The area counts for these peaks are as follows:

\begin{tabular}{lccc} 
R.T. & Region & Area from standards & Area from sample \\
\hline 7.73 & 1242 & 159.0 & 93.11 \\
8.61 & 1242 & 302.8 & 261.83 \\
9.01 & 1242 & 155.6 & 129.8 \\
9.56 & 1242 & 408.13 & 325.8 \\
9.78 & 1242 & $\frac{204.2}{1229.7}$ & $\frac{165.8}{976.34}$
\end{tabular}

$\begin{array}{llll}18.58 & 1260 & 43.63 & 74.76 \\ 18.97 & 1260 & 18.74 & 31.10 \\ 19.24 & 1260 & 24.70 & \frac{39.94}{145.80}\end{array}$

Calculation:

The concentration of each aroclor is determined from the ratio of peak areas in the sample to that of the standard. The 1260 contribution is therefore:

$$
(0.01 \times 145.8) / 87.07=0.0167 \mu \mathrm{g} / \mathrm{mL}
$$

and the 1242 contribution is:

$$
(0.1 \times 976.34) / 1229.7=0.0794 \mu \mathrm{g} / \mathrm{mL}
$$

The total concentration of PCBs in the sample extract is $0.096 \mu \mathrm{g} / \mathrm{ml}$. This value is then substituted for "the observed PCB concentration in $\mu \mathrm{g} / \mathrm{mL} "$ in the equation for calculating Ppm PCB in oil found in Section IV.E.1.g. 


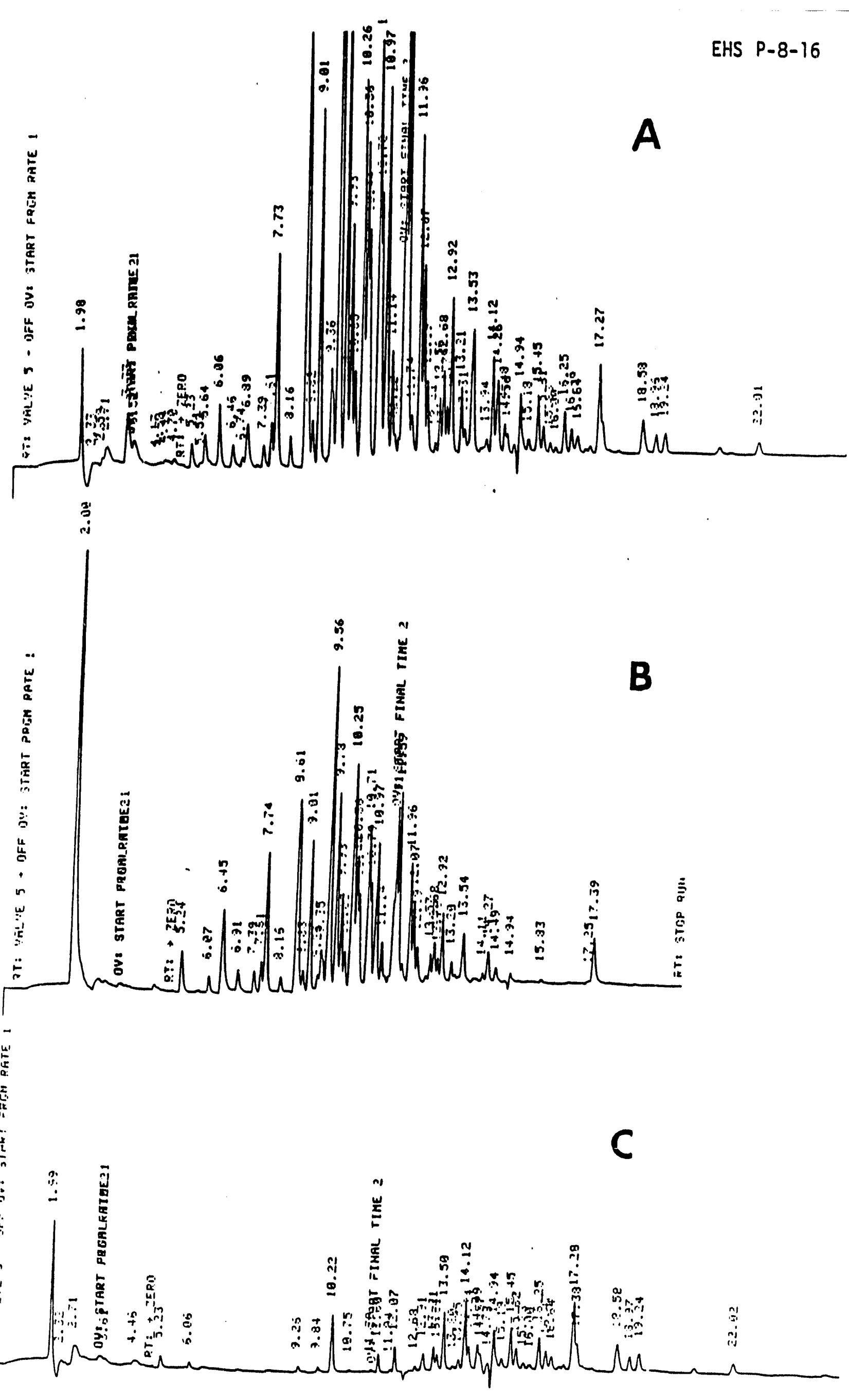


Method No. EHS P-9

Title: Polychlorinated Biphenyls in 011 and Waste Liauids

Date Issued: 9-23-85

Approved by: $\frac{\text { M. K. Hamilton }}{\text { hell }}$

Written by: H. L. Boorse

Supersedes Method No.

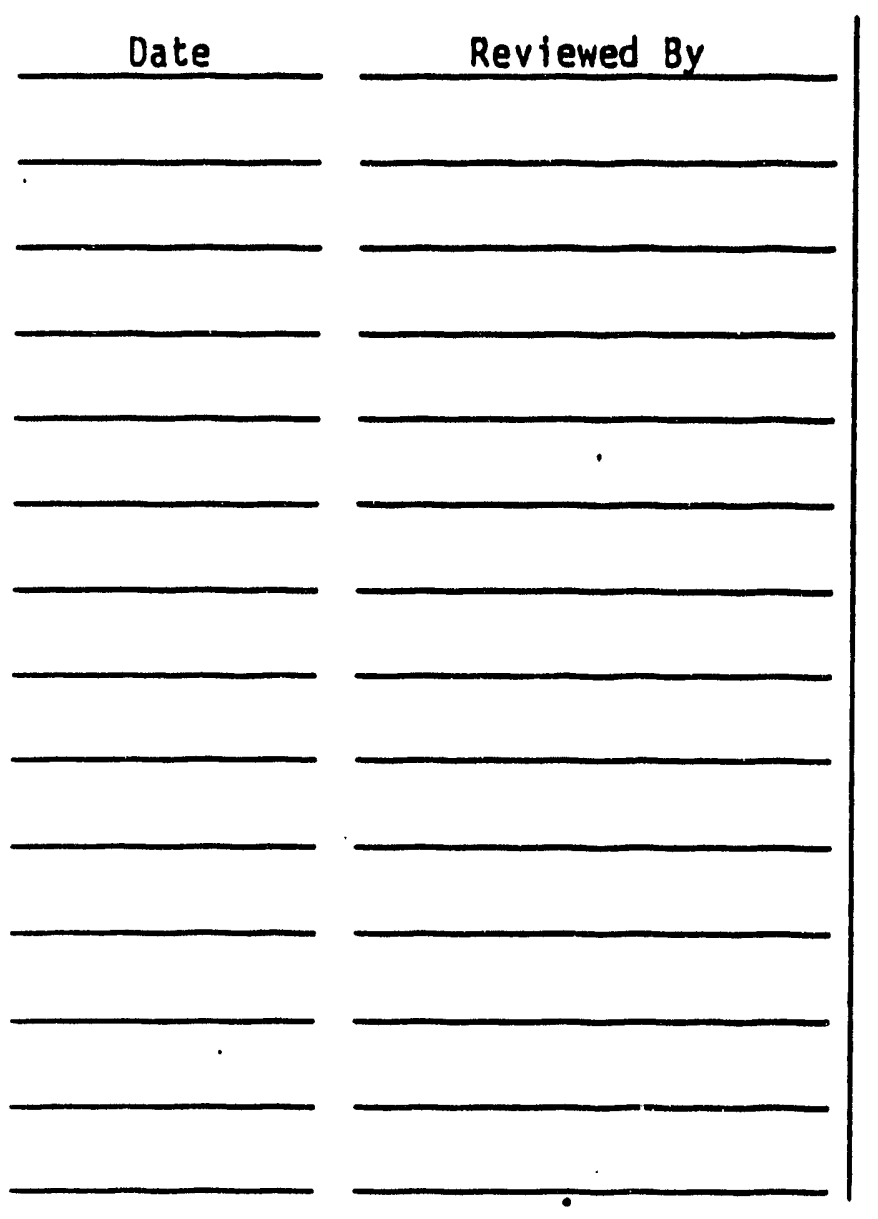

Replaced by Method No. $\frac{\text { Date }}{6.19-86} \frac{\text { Revised By }}{1-9-90}-\frac{\text { HL Beriza }}{\text { D W S/10a }}$

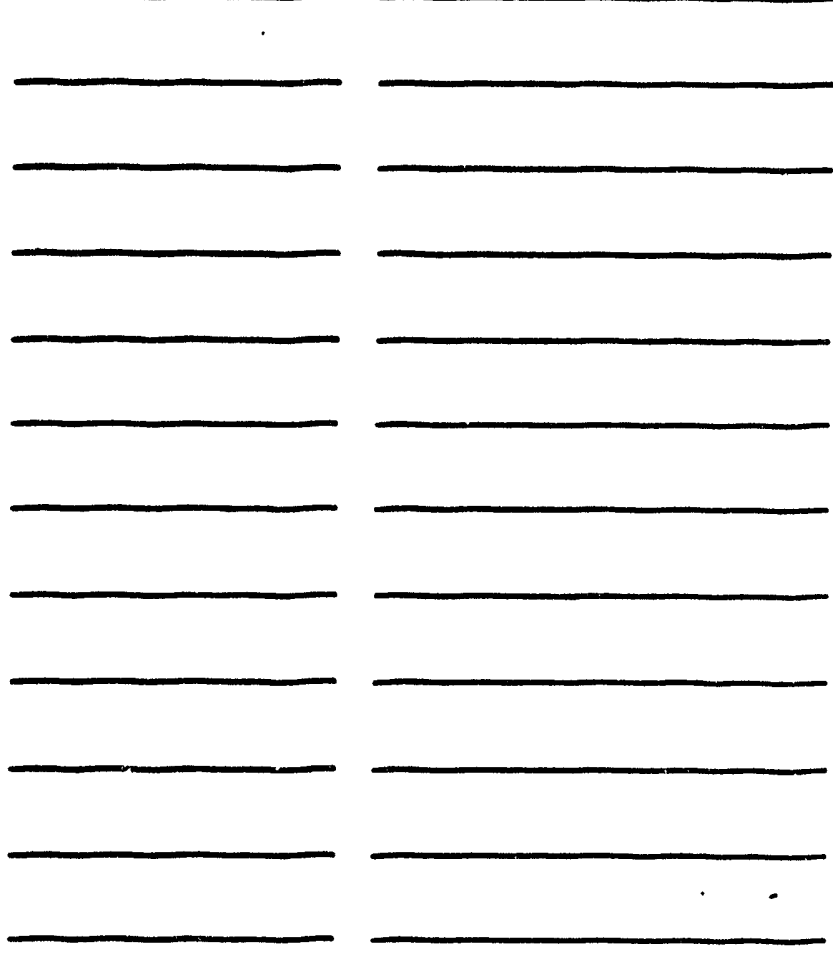
Date: 
EHS $P-9-1$

$01-09-90$

\section{POLYCHLORINATED BIPHENYLS IN OIL AND MASTE LIQUIDS}

\section{References}

A. "EPA (Environmental Protection Agency) Method Study 28, PCB's (Polychlorinated Biphenyls) in 0i1," Versar, Inc., Springfield, VA. Prepared for Environmental Monitoring and Support Lab.Cincinnati, OH October 1984.

B. "Analysis of Polychlorinated Biphenyls in Mineral Insulating 0ils by Gas Chromatography," ASTM D4059-83. Vol. 10.03 Electrical Insulation Liquids, Gases, Protective Equipment.

C. "The Determination of Polychlorinated Biphenyls in Transformer Fluid and Waste 0ils", EPA-60014-81-045, T. A. Bellar and J. J. Lichtenberg. Environmental Monitoring and Support Laboratory.

D. The analytical chemistry of PCBs, M. D. Erickson, Butterworth Publishers, Boston, 1986.

E. "Test Methods for Evaluating Solid Waste," EPA SW 846, Methods 3660 \& 8080 .

\section{Principles and Limitations}

The sample is diluted with isooctane and the resulting solution is treated by a cleanup procedure (routinely: acid wash/florisil slurry) to remove interfering substances. Analysis is by capillary gas chromatography using an electron capture (EC) detector. The method is made qualitative and quantitative by comparing peak patterns, area counts, and retention times of the sample chromatogram with chromatograms of known quantity and type of aroclor standards, obtained under the same conditions. Results can be confirmed by running the samples and standards using a second dissimilar column.

Occasionally, sample chromatograms indicate the presence of PCBS; however, no aroclor or mixture of aroclors are indicated by the pattern. This is often the case with weathered or otherwise degraded aroclor mixtures or when a non-aroclor material is the PCB source. In these cases the Dry Color Manufactures Associations' (DCMA) method for PCB identification is employed. (See Section IV.F "Non-aroclor and partial aroclor PCB mixture.")

Electron capture detectors respond to chlorine-containing compounds other than PCBs and to certain other electrophilic materials containing other halogens, nitrogen, oxygen, and sulfur. Most common interferences can ve removed by sulfuric acid washing. The chromatogram of each analyzed sample should be carefully compared with those of the standards. The response of an EC detector to PCBs is reduced by high boiling hydrocarbons that co-elute with the PCBS. This suppression can be compensated for by running spiked samples to determine the actual recovery. 
Residual oxygen in carrier and makeup gas can react with components of samples to give oxidation products to which EC detectors will respond. Purity of these gases should be assured.

\section{Materials}

A. Equipment:

1. $1 \times 12 \mathrm{~cm}$ screw cap tubes

2. Tefion lined caps

3. $10 \mathrm{~mL}$ repipetors for solvent and acid measurement and transfer

4. $0.5 \mathrm{~mL}, 1 \mathrm{~mL}$, and $2 \mathrm{~mL}$ Class $A$ or better glass pipets

5. Volumetric flasks, isooctane washed

6. Analytical balance with $0.1 \mathrm{mg}$ sensitivity

7. SE-54 or DB-5 fused silica capillary column 30 meter length, $0.250 \mathrm{~mm}$ I.D., $0.25 \mathrm{\mu m}$ film thickness

8. DB1-30m megabore column 30 meter length, $0.53 \mathrm{~mm} 1.0 ., 1.5 \mu \mathrm{m}$ film thickness

9. Gas chromatograph fitted for capillary column and equipped with an electron capture detector and auto sampler

10. Vortex

11. Centrifuge

12. Pasteur Pipets

13. Autosampler vials with teflon caps

14. Mechanical rotary extractor

15. Lambda pipets as needed

16. Carborundum boiler chips

B. Reagents:

1. Pesticide grade 2,2,4-trimethylpent ne (isooctane)

2. Reagent grade (conc.) Sulfuric Acid 
3. Activated Florisil, $60 / 100$ mesh, reagent grade, suitable for pesticide-residue analysis. Available from Floridin Company and treated per AOAC (1980) 29.002 before use.

4. EPA standards (1000 to $5000 \mathrm{ppm}$ ) of aroclors 1016, 1221, 1232, $1242,1248,1254,1260,1262,1258$

5. EPA controls of aroclors in oils (transformer, hydraulic, and capacitor)

6. Hexabromobenzene (PCB surrogate standard)

7. Ultra high purity helium

8. 90 percent argon--10 percent methane (P10) or 95 percent argon- 5 percent methane $(P-5)$

9. Tetrabutylammonium hydrogen sulfate, reagent grade

10. Sodium sulfite, reagent grade

11. Ethanol, USP $95 \%$

12. Potassium hydroxide, anhydrous pellets

13. Dry Color Manufactures Association mixture of PCB isomers in hexane. Available from Ultra scientific.

14. 2-propanol, reagent grade

C. Standards \& Prepared Reagents:

Note: All glassware should be dedicated for the preparation of aroclor standards.

1. Stock Aroclor solutions. EPA Aroclor standards range from 1000 to $5000 \mu \mathrm{g} / \mathrm{mL}$ and are received in $1 \mathrm{~mL}$ glass ampules. The appropriate amount of standard is volumetrically transferred to a 25 or $50 \mathrm{~mL}$ volumetric flask and diluted in isooctane so that a 10 to $20 \mu \mathrm{g} / \mathrm{mL}$ solution is produced. Transfer the stock solution to a brown glass bottle fitted with a tefion lined cap. Transfer remaining EPA standard material to a $1 \mathrm{~mL}$ auto sampler vial. The stock solution and the EPA standards are stable indefinitely if their seals are maintained and they are stored at or below $0^{\circ} \mathrm{C}$.

2. Working standards-- $(0.5,0.1,0.05,0.01 \mu \mathrm{g} / \mathrm{mL})$. Add appropriate amount of stock stanciard (depending on stock standard concentration) to screw cap test tubes and make up with isooctane so that a $0.5 \mu \mathrm{g} / \mathrm{mL}$ solution results. Serially dilute the $0.5 \mu \mathrm{g} / \mathrm{mL}$ to make up the remaining standards 10.01 , 0.05 , and $0.1 \mu \mathrm{g} / \mathrm{mL}$ ). Total volume of each working standard should be approximately $10 \mathrm{~mL}$. Prepare monthly or as needed. 
3. DCMA mixture, stock and serial dilutions. The DCMA mixture ampule is opened and an aliquot diluted 100 fold. Serial dilutions of 2, 10, and 20 fold are made up of this solution. The remaining original DCMA mixture is transferred to an auto sampler vial, sealed with a teflon backed cap and stored at or below $0^{\circ} \mathrm{C}$.

4. Hexabromobenzene (HBB) surrogate-working standard. The neat HBB standard is removed from the freezer and a $10 \mathrm{mg}$ al iquot volumetrically made up into $100 \mathrm{~mL}$ of isooctane. The resulting solution, the $A B B$ working standard, is subdivided into $10 \mathrm{~mL}$ vials, secured with a teflon lined screw cap. These materials are stable indefinitely if their seals are maintained and they are stored at or below $0^{\circ} \mathrm{C}$.

IV. Methods

Note: This procedure is intended to qualitatively and quantitatively analyze samples for the nine specific aroclors listed on Page 3 . This method is not adequate for qualitative and/or quantitative analys is of partial aroclors or individual congeners which may result from aroclor degradation or by products of chemical reactions. For non-aroclor samples see Section IV.F for the analysis of these partial or nonaroclor containing samples.

A. Dilution:

1. Pipet approximately $0.10 \mathrm{~g}$ sample using a pasteur pipet into a tared screw top test tube.

2. Reweigh the test tube to $\pm 0.0001 \mathrm{~g}$ and record the weight of the sample.

3. Prepare blank, spike, and other QC samples in accordance with Section IV.C.

4. Dilute to $10 \mathrm{~mL}$ with isooctane and mix well.

5. Spike every sample, sample duplicate, sample spike, EPA QC, and blank with $2 \mu \mathrm{L}$ of the HBB surrogate.

B. Cleanup techniques

1. Acid wash/florisil cleanup (Primary procedure)

This procedure is used for all samples received at the laboratory.

a. Add $3 \mathrm{~mL}$ concentrated sulfuric acid to each of the samples, including blanks, QC samples, etc.

b. Shake by hand for 30 seconds and Vortex for 30 seconds. 
c. Transfer all test tubes containing samples, duplicate samples, blanks, quality controls and spiked samples to the rotary extractor. Run extractor for 1 hour.

d. Label test tubes for each sample, blank, quality control and spiked sample being run. Add $-0.2 \mathrm{~g}$ florisil to each empty test tube.

e. Remove sample test tubes from the extractor and centrifuge for approximately 5 minutes at $3000 \mathrm{rpm}$. Transfer each isooctane layer to its corresponding florisil-containing test tube.

f. Place sample test tubes in extractor for 1 hour.

g. If the isooctane extract appears colored or cloudy, additional/alternative cleanup procedures may be necessary; otherwise the extract is ready for analysis. (Section IV.D.)

2. Sulfur removal (Based on EPA S10846 Method 3660)

This procedure is used routinely with sediment and sludge samples or when sulfur interference is indicated on the chromatogram.

a. Prepare TBA-sulfite reagent: Dissolve $3.39 \mathrm{~g}$ tetrabutylammonium hydrogen sulfate in $100 \mathrm{~mL}$ of deionized water. Extract 3 times with $20 \mathrm{~mL}$ portions of isooctane. Discard the isooctane extracts and add $25 \mathrm{~g}$ of sodium sulfite to the water solution. Solution is saturated with respect to sodium sulfite and is stable 1 month at room temperature.

b. Transfer $2 \mathrm{~mL}$ of extract from Section IV.B.1.g. ("Acid wash/florisil cleanup") to a new test tube.

c. Add $1 \mathrm{~mL}$ of TBA-sulfite reagent and $1 \mathrm{~mL}$ 2-propanol to the test tube. Shake test tube for at least 1 minute and look for clear crystals from precipitation of sodium sulfite. If crystals are not present, add crystalline sodium sulfite in $100 \mathrm{mg}$ portions until solid material remains (one portion is usually enough).

d. Add $5 \mathrm{~mL}$ of deionized water and shake for at least 1 minute. Let stand for 5 inutes for phase separation. Collect top, isooctane, luser in an auto sampler vial. The extract is ready for analys is (Section IV.D). 
3. Ethanol/potassium hydroxide cleanup

This procedure is used when hydroxyl-containing species such as pentachlorophenol and glycols are present. Additionally, fats are made more water soluble through saponification. Certain chlorinated pesticides undergo dehydrochlorination.

a. Prepare $2 \%$ potassium hydroxide/ethanol solution: Dissolve $2 \mathrm{~g} \mathrm{KOH}$ into $100 \mathrm{~mL}$ of $95 \%$ ethanol.

b. Prepare 50\% ethanol/water solution: add equal volumes of ethanol and deionized water.

c. Pipet up to $4 \mathrm{~mL}$ of extract from Section IV.B.1.g ("Acid wash/florisil cleanup") into a pyrex test tube and reduce to dryness under $\mathrm{N}_{2}$.

d. Add $2 \mathrm{~mL}$ of ethanol/ $\mathrm{KOH}$ reagent and 1 boiling chip.

e. Reflux test tube contents over boiling water bath for 20 minutes. During first 5 minutes the test tube should be immersed only in the steam of the water bath. This gentle refluxing is to prevent the loss of analytes along with the solvent stream. The steam refluxing should reduce the sample to near dryness. Continue refluxing with the tube immersed in the water bath for the remaining 15 minutes.

f. Remove test tube from water bath, cool and add $2 \mathrm{~mL}$ of ethanol/water solution. Note: if a precipitate forms during the refluxing step it should be dissolved before adding the ethanol/water solution. To dissolve the precipitate, reheat the test tube and add a few drops of the ethanol/KOH reagent. Swirl, to dissolve the precipitate and then add the $2 \mathrm{~mL}$ of ethanol/water.

9. Add isooctane in a 1 to 1 ratio of the amount of extract used in Step " $c$ " above and shake for 1 minute.

h. If a clear separation of isooctane from the ethanol/water phase is achieved, the extract is ready for analysis, otherwise a second iteration of the acid wash/florisit slurry cleanup is recommended.

C. Analyte Recovery and quality control

1. Preparation of spiked samples

a. In order to determine the effect of matrix suppression on the electron capture detector, every loth sample is spiked with aroclor material. If a given sample set contains a variety of widely different matrixes, each type should be spiked. 
EHS $P-9-7$

$01-09-90$

b. Samples to be spiked are cut in duplicate. A small amount ( 0.1 to $0.2 \mathrm{~mL}$ ) of aroclor stock solution (10 to $20 \mu \mathrm{g} / \mathrm{mL}$ ) is added to one of the sample aliquots. The sample aliquot with added aroclor material is made up to $10 \mathrm{~mL}$ in isooctane and shaken. The resulting concentration of the added spiked sample is in the range of 0.1 to $0.5 \mu \mathrm{g} / \mathrm{mL}$.

c. The sample spike is handled as any other sample beginning with the acid wash/fiorisil slurry cleanup.

2. Preparation of quality control samples

a. Available from the EPA are PCBs in transformer, hydraulic, and capacitor oils. They are available at approximately 10, 50, and 500 ppm concentrations. A typical oil would be identified as: "Aroclor 1260 transformer oil, concentration 1, WP\# 683." Starting with an approximately $0.1 \mathrm{~g}$ aliquot, quality control oils are treated as any sample.

3. Preparation of blank sample

a. Dispense $10 \mathrm{~mL}$ of isooctane into a screw top test tube and treat as any sample extract.

D. Gas chromatography analysis (splitless mode)

1. Instrument parameters:

\begin{tabular}{|c|c|c|}
\hline P. $5880 \mathrm{~A}$ & $\begin{array}{l}\text { Initial Oven Temperature } \\
\text { Initial Time } \\
\text { Temperature Profile: } \\
\text { Rate } \\
\text { Final Temperature } \\
\text { Final Time } 1 \\
\text { Rate } 2 \\
\text { Final temperature } 2 \\
\text { Final time } 2 \\
\text { Post temperature } \\
\text { Post time } \\
\text { Injector Temperature } \\
\text { Detector Temperature } \\
\text { Detector } \\
\text { Chart Speed } \\
\text { Attenuation } \\
\text { Threshold } \\
\text { Peak Width } \\
\text { Flows: } \\
\text { Capillary Column (He) } \\
\text { Septum Purge } \\
\text { Split Vent } \\
\text { Make Up Gas } \\
\text { (90\% Argon 10\% Methane }\end{array}$ & $\begin{array}{l}150^{\circ} \mathrm{C} \\
0.5 \mathrm{minute} \\
10^{\circ} \mathrm{C} / \text { minute } \\
225^{\circ} \mathrm{C} \\
0 \mathrm{minutes} \\
8{ }^{\circ} \mathrm{C} \\
260^{\circ} \mathrm{C} \\
15 \mathrm{minutes} \\
300^{\circ} \mathrm{C} \\
1 \mathrm{minute} \\
250^{\circ} \mathrm{C} \\
300^{\circ} \mathrm{C} \\
\text { Electron Capture } \\
1 \mathrm{Cm} / \text { minute } \\
3 \\
2 \\
0.4\end{array}$ \\
\hline
\end{tabular}


2. Operation

a. Transfer aliquots of sample extracts to autosampler vials and load them into $7672 \mathrm{~A}$ auto sampler tray while entering auto sampler vial data into "run table."

b. Run interspersed sets of standards and controls with samples. Also include isooctane washes on a regular basis. Average set of runs should contain 40 fercent analytical standards, controls, spikes, and blanks to 60 percent samples.

c. Start resident program "PCBs." This program provides for summing of peak areas occurring between discrete time windows. These windows correspond to the major peaks of specific aroclors. Program also provides for selecting individual vials for double injection. See Appendix 1 for listing of program.

d. Double inject all quality control samples, all spikes, at least one analytical standard from each set of a given aroclor, and isooctane washes that follow a high concentration injection.

e. Inspect the results of the initial run of samples and assess the following: (1) the need for further dilutions and or cleaning, (2) the identity of the aroclor contaminant(s), (if present at all), and (3) the correct selection of aroclor standards to run along with the samples. (Standards must be of the same arocior-type as the samples and the standards' area counts must bracket the samples' area counts.)

f. If there is doubt as to the aroclor identity or there are other reasons for needing confirmation of the results, the analysis can be repeated using the DBI-30m megabore column, or other dissimilar columns.

g. When necessary, dilute samples, perform any additional cleanup, or reinject with appropriate aroclor formulations for standards. Then return to Part "a" above for reanalysis. When a sample is subjected to additional cleanup, a spiked sample must also be similarly treated.

E. Calculations

1. Single Aroclor Samples

PCB concentrations in single aroclor samples are calculated by summing the total area of all the peaks due to that aroclor and comparing to the total area of those same peaks found in the standards. 
a. Determine which aroclor is present in the sample by comparing retention times and peak patterns of the sample to those of the standards.

b. Plot concentration versus area count for the aroclor standards. Using the method of least squares, calculate the regression equation for the best line using the analytical standards data. Calculate the correlation coefficient (must be 0.999 or better). Regression analysis may be done using a hand calculator such as the HPIIC or a computer program such as LOTUS 123.

c. Determine the concentration of the aroclor present in the sample from the calibration curves.

d. Use the spiked sample(s) to determine percent recovery of PCB material in the sample(s). If an sample set is large, and of similar matrix, then the recovery data can be averaged. Check the quality control charts to confirm that this level of recovery is within the acceptable range. (See Section $V$ on quality control.)

e. Use the EPA control sample(s) to confirm that the method is under control. Use the area counts of the analytical standards to confirm that the instrument is operating correctly.

f. Use the HBB surrogate data to determine percent recovery on all non-aroclor spiked samples.

g. Calculation:

where:

$$
\text { Ppm PCB in } 0 \text { i1 }=\frac{C \times D}{R \times W}
$$

\footnotetext{
C the observed PBC concentration in $\mu \mathrm{g} / \mathrm{mL}$

$D$ the dilution ratio of the sample

$R$ the recovery correction factor as determined by spikes or surrogates

$W$ the weight of the sample aliquot in $\mathrm{g}$
}

h. Round off all data to 2 significant figures and report all data in $\mathrm{ppm}$ on a $\mu \mathrm{g} / \mathrm{g}$ ratio in the 0 il.

2. Mixed aroclor samples

PCB concentrations in mixe-t aroclor samples are calculated from individual congener peak areas or peak grouping sums. These peaks are chosen from non-overlapping regions of the chromatogram. These areas are compared with the same areas on the chromatograms of the analytical standards. A concentration is determined for each aroclor present and a total concentration calculated. 
a. Look at the sample's chromatogram and also at those of aroclor standards to determine which aroclors comprise the mixture. Determine which peaks from each aroclor have the least contribution from the other aroclors present.

b. Using the area of the selected non-overlapping peaks determine the concentration of each aroclor by standard ratios:

Calculation: $\quad X=(A \times C) / a$

where:

$$
\begin{aligned}
& X \text { concentration of aroclor " } X " \\
& A \text { area of selected peaks in sample } \\
& \text { a area of selected peaks in standard } \\
& \text { C concentration of standard in } \mu \mathrm{g} / \mathrm{mL}
\end{aligned}
$$

c. The total PCB concentration is determined by the summation of each of the individual aroclor concentrations. This value is substituted into "the observed PCB concentration in $\mu \mathrm{g} / \mathrm{mL}$ " in Step " $g$ " of the above section.

d. See Appendix 2 for an example of a calculation for determining total PCB concentration in a mixed aroclor sample.

F. Analysis of non-aroclor and partial aroclor PCB mixtures

Samples that contain PCBs from non-aroclor formulations or from aroclors that have been altered through chemical or biological action are analyzed using the Dry Color Manufacturers Association (DCMA) method.

Essentially this method divides the distribution of PCB congener peaks into 10 regions. Each region is centered around the retention time of each PCB homologous series (e.g. pentachlorobiphenyl, hexachlorobiphenyl, etc.). In each homologous series one congener has been selected that has an average response factor for that series. These 10 congeners are prepared at different concentrations and run on the GC as outlined above in

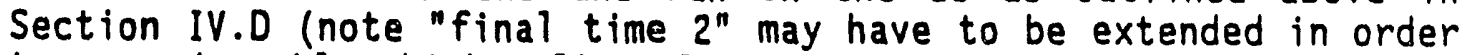
to see decachlorobiphenyl). Regression equations are calculated for each of the 10 congeners as described in Section IV.E.1.b. Samples are cleaned up as needed and run as described in Sections IV.A through IV.D. Sample peaks are summed for each PCB congener region. Sample data for each region is compared against the appropriate DCMA regional standards to determine individual congener concentrations.

Total PCB concentration in a given sample is determined by summing the individual regional/congener concentration. 
V. Quality Control

Quality control data relating to PCBs are kept on the following matrix types: aqueous, solid, surface, air, and non-aqueous fluids. Quality control data relating to samples analyzed using this method are recorded under the category "Wastes" in our QC records. Results of the arialyses of the EPA oils, surrogate data, and the quantitation standards are maintained. See the record categories "Environmental" and "Industrial Hygiene" for other PCB QC records.

A. The following data are recorded for each sample set:

1. The EPA QC oil's type, concentration and WP number, amount weighed, and dilution factor.

2. The date of analysis and run number.

3. The calculated true value of the QC sample and the observed value(s).

4. The percent recovery of the observed value as compared to the calculated true value. This is plotted for an estimate of instrument precision.

Currently, this data is entered into a LOTUS 123 spreadsheet which determines means, standard deviations, and plots results against these descriptive statistics.

B. The area counts of the aroclor standards are monitored as an estimate of detector sensitivity. Likewise the HBB peak is used to determine theoretical plate height as an indicator of degradation in chromatography.

Dos 
Appendix 1. PCB progran for HP 5880 gas chromatograph

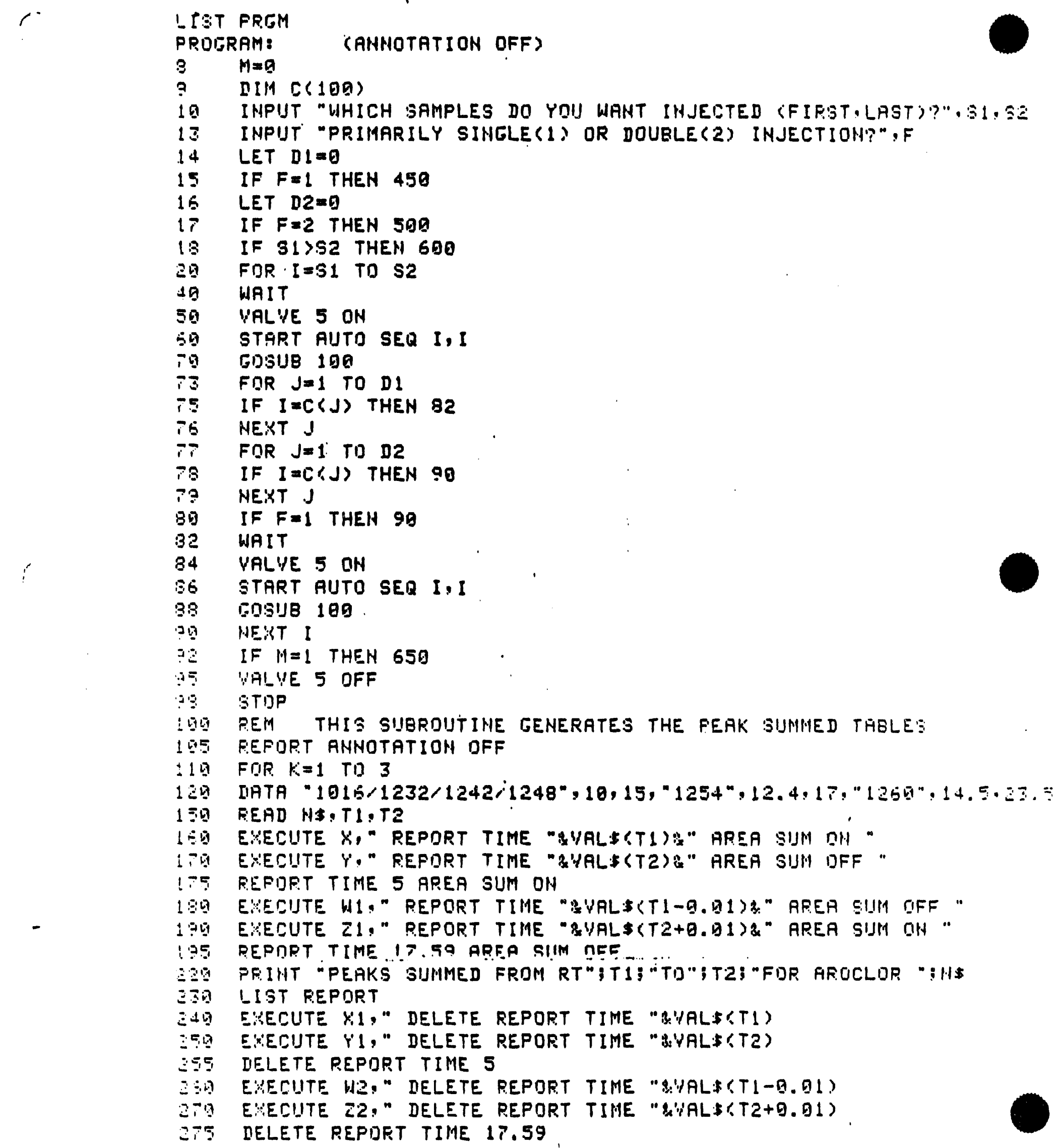




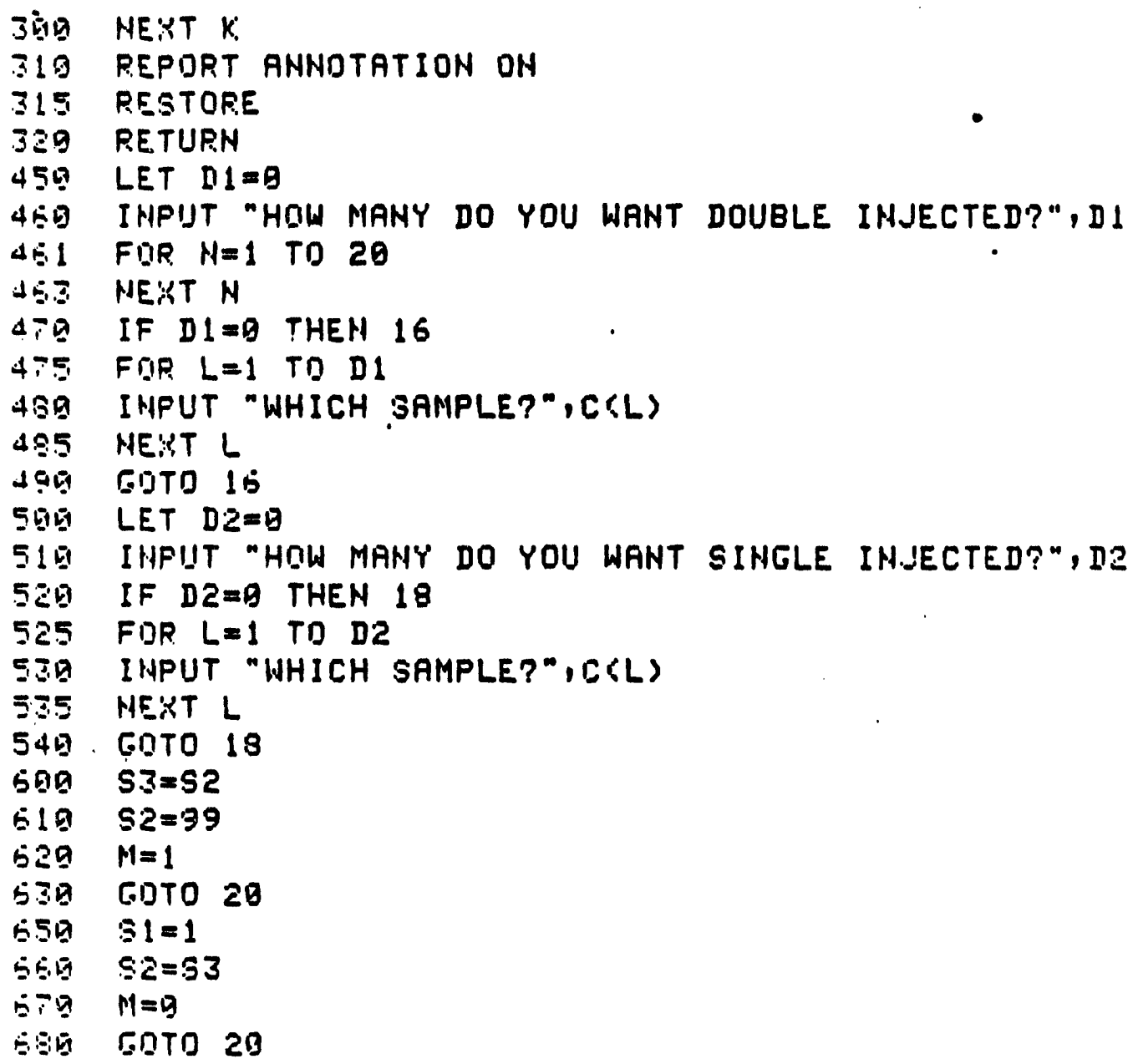


Appendix 2. Determination of PCBs in Mixed Aroclor Samples

The attached figure includes three chromatograms: (A) a mixed aroclor waste sample containing aroclors $1242 / 1248$ and 1250 ; (B) a $0.1 \mu \mathrm{g} / \mathrm{mL}$ aroclor 1242 standard; (C) a $0.01 \mu \mathrm{g} / \mathrm{mL} 1260$ standard.

Some of the peaks from the $1242 / 1248$ region that are not overlapped by 1260 peaks occur at retention times (RT): 7.73, 8.61, 9.01, 9.56, and 9.78 minutes. Similarly, non-overlapped peaks for the 1260 region occur at retention times: 18.58, 1897, and 19.24 minutes. The area counts for these peaks are as follows:

\begin{tabular}{lcc} 
R.T. & Region & Area from standards \\
\hline 7.73 & 1242 & 159.0 \\
8.61 & 1242 & 302.8 \\
9.01 & 1242 & 155.6 \\
9.56 & 1242 & 408.13 \\
9.78 & 1242 & $\frac{204.2}{1229.7}$
\end{tabular}

$\begin{array}{ll}18.58 & 1260 \\ 18.97 & 1260 \\ 19.24 & 1260\end{array}$

$\begin{array}{r}43.63 \\ 18.74 \\ 24.70 \\ \hline 87.07\end{array}$

43.63

$\frac{24.70}{87.07}$

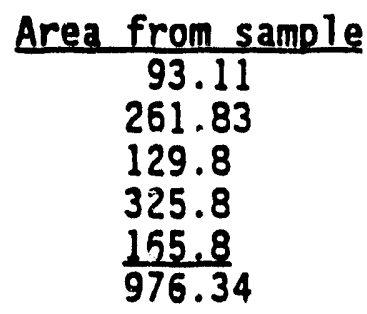

74.76

31.10

$\frac{39.94}{145.80}$

Calculation:

The concentration of each aroclor is determined from the ratio of peak areas in the sample to that of the standard. The 1260 contribution is therefore:

$$
(0.01 \times 145.8) / 87.07=0.0167 \mu / \mathrm{mL}
$$

and the 1242 contribution is:

$$
(0.1 \times 976.34) / 1229.7=0.0794 \mu / \mathrm{mL}
$$

The total concentration of PCBs in the sample extract is $0.096 \mu / \mathrm{mL}$. This value is then substituted for "the observed PCB concentration in $\mu \mathrm{g} / \mathrm{mL}$ " in the equation for calculating Ppm PCB in oil found in Section IV.E.1.g. 
จูำ

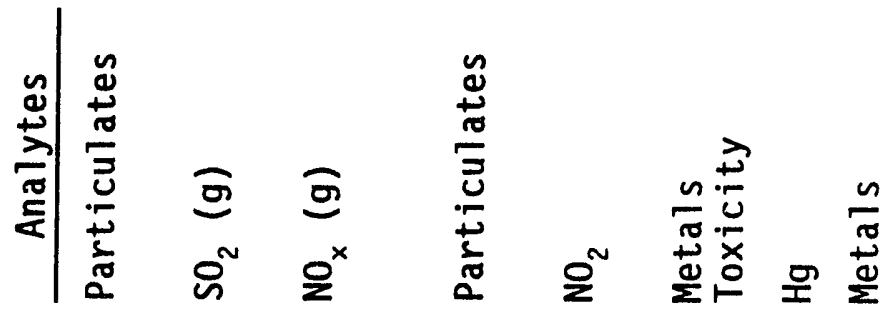

음

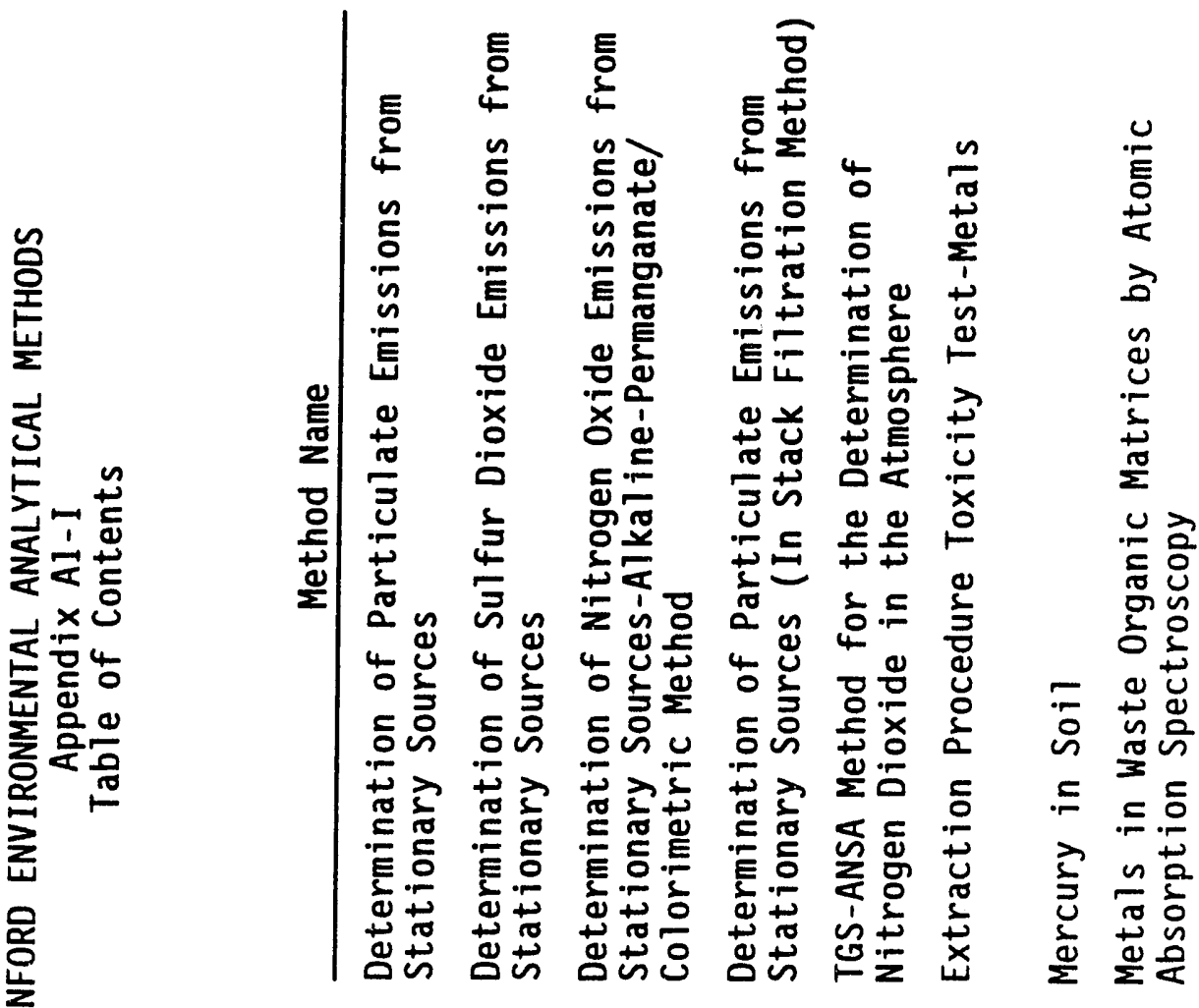

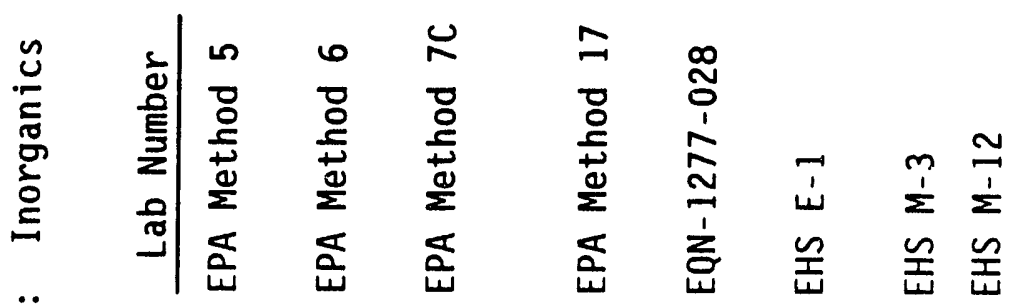

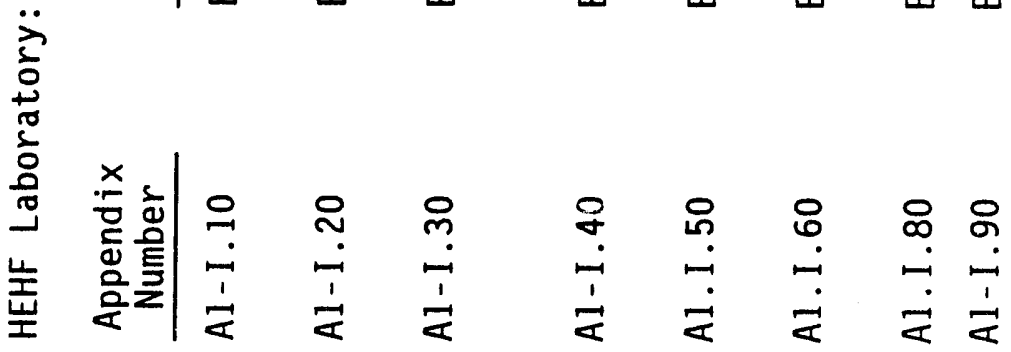




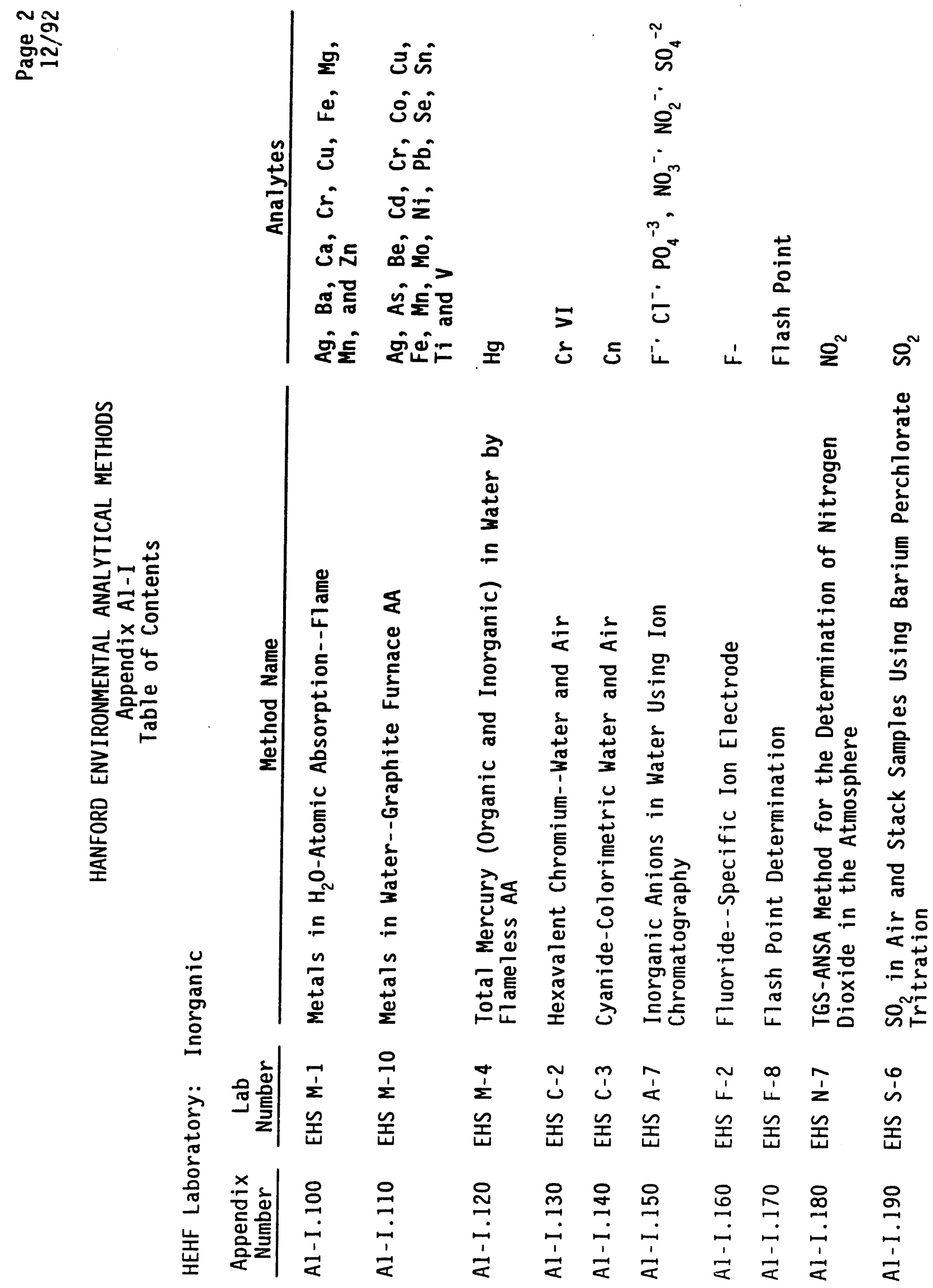




\section{- ฐू̃}

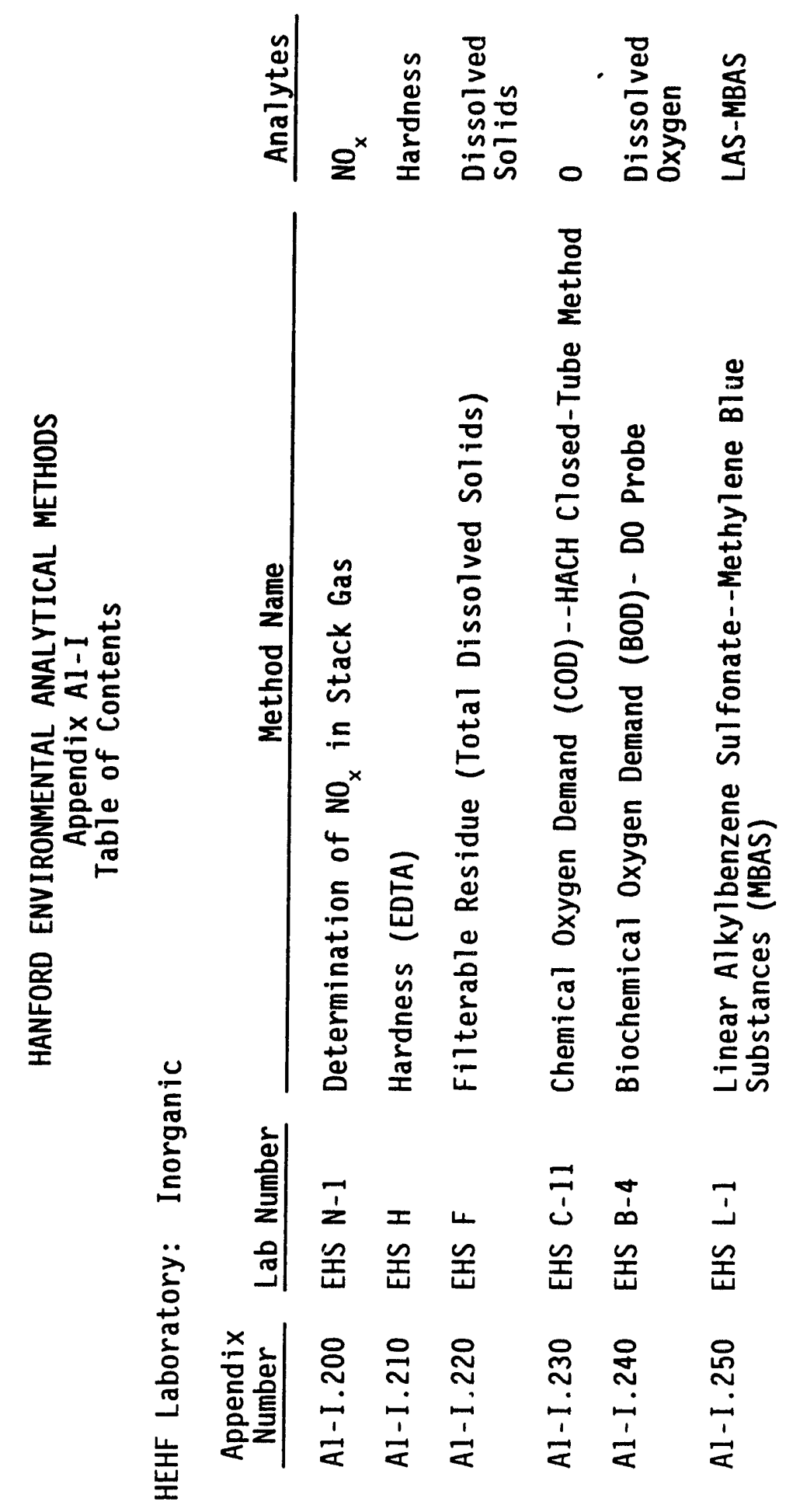


3.22 Connect the proben buert it inte the tact. and sample of a cocutent rite of 8

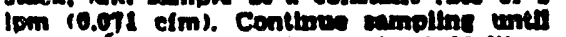
the dir cen milop rezletern about 30 lllew (1.1 It' or unul vadble llapuld dropiete are carried over irmm the flrst bapinger to the meond. Record tempernturs. prevern, and dis ine meler readime is rwoutred bs Meure 4-8.

3.2.3 Aler collesing the sumple ero bine the contevts of the two lonbengers and menture the "oliume to the mearess o.s mi.

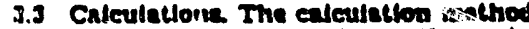
presented is dealened to eatumate the mole ture in the staek gers therefore, other duth

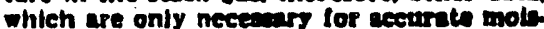
ture dateminntion are not collected The collowite equation edequately extlunte the moisture eontenl. for the pupoes of deter.

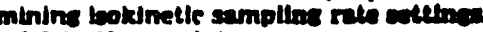

3.3.1 Nomervelature.

De-Approximate proportlon bs voluine

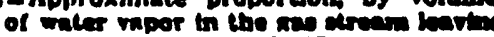
the seend imolnowe. 0.020.

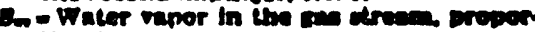
tion by volume.

Mom Moleculer welcht of mates. $180 \mathrm{~V}$ mole (11.0 16/16-mole).

Po-Abolute presure llor the mathed inme an baromotite on sex meter.

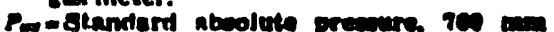
ne (2).02 in. Ite).

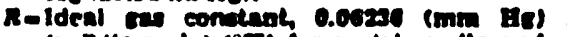

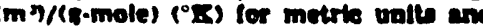
21.06 (m. Ae) (1t) Itsh unite.

T. - Absolute tempernture af meter. 25 (TR)

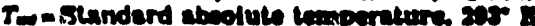
(8220. R).

$V$ - Mnal volume of trapincer conlente, mal

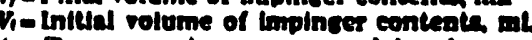

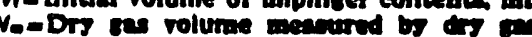
meter. den (daf).

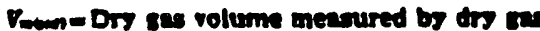

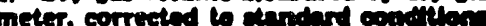
(cinel)

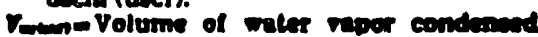

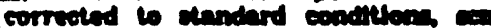
(cof).

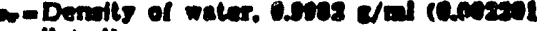
$10 / \mathrm{ml})$.

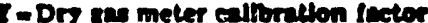

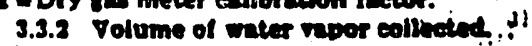
where:

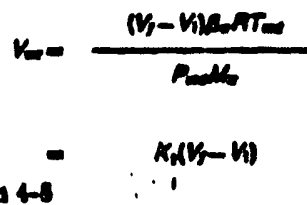

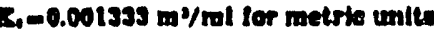

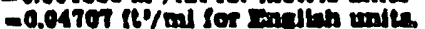
eng 0 roni

$$
\begin{aligned}
& \text { : }
\end{aligned}
$$

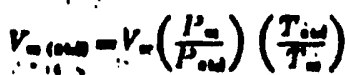

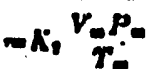

where?

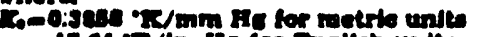

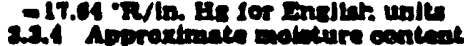

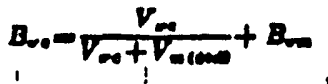

$$
\begin{aligned}
& -\frac{V_{\infty}}{V_{n}+V_{\text {men }}}+
\end{aligned}
$$

\section{Carlonaten}

4.1 For the reterence mothod eallbrate coutpracint as opetfled in the following ese How of Method to Eection 8.3 inatering

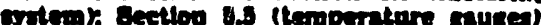

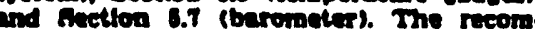
monded leak ebeek of the metertin asster (Beetion 8.0 of Method 8 ) bto applles to the reterince method. For the epproximatlon method ve the procothrea outitined in Bes. Uon Bl.l of Method to ellibrite the mo

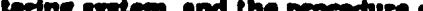

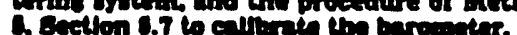

\section{a. sexionaty}

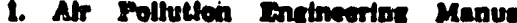
(Eecond Dditton). Denieleon J. A (cid). O. A mnitrommental Protection Agenes. Otiles of Alr Quallsy Phonter and Blandarda. Re. coreh Trtando Parts M.C. Prablieallon No. AP-10. INTs.
2. Devortin, Howard et al. Ar Pollution cource Tedins Manual. Alr Pollution Con trol Dirtrieh Lo Anceler Call. Norember. 100.

3. Methods for Determinatlon of Velorits: Volume Durt and Mist Content of Cinses. Teatern Prectpltalion Diriston of Joy Man. uferturing Co. Las Anceled. Call. Bulletln W.

Mrnos \&-Derenminasion or Pastrcolate Imiceione Fhou Brationant Sooxce

1. Prinetple and Applicebiltey

l.1 Principle. Particulate malter is with tram boldnetleally from the source and collected on a sine flber fllter malntalned at anperature in the rance of $120 \pm 14^{\circ} \mathrm{C}$ (240 $+29^{\circ}$. F) or weh other temperature as acted by apllesble subpert of the tandurd of aporoved by Adrolnitetrator. Dach or approved os Administrator. 0.2. Inviroumental Protectson Aceney. for - parteviar application. The partletilate ares when inciudes any materis that con denese of obove the flltration tempers. cure, in determined travimetrieally ster re. movl of uncombined water.

12 Applleabllits. This method is sppllen. be for the determinselon of pertleutate

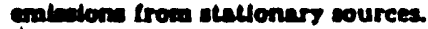

\section{Apperatus}

21 Eampline Trala. A sechematle of the ampling train used in this method is stinxin in sicure 8-1. Complete const ruction det.atts re tiven in AP1O-0581 (Clintion 2 in Bibl crover commercial model of this bra oset and lor allowable modillentions of the train ahom in Mrare \&-1, wee the following arlocetlotit.

The operntine and maintenence proce. dure for the enmpline tratn are deserlbed in Aryo-ase (c)tenton 3 in Bibllogrnphy. Eince correct uense is bre relld revilte all users should tead APro-0075 and idopt the operating and malntenance procedures outlined in If. unles otherwlse peeflled hereln. The sim plins train consints of the following compo nenter 


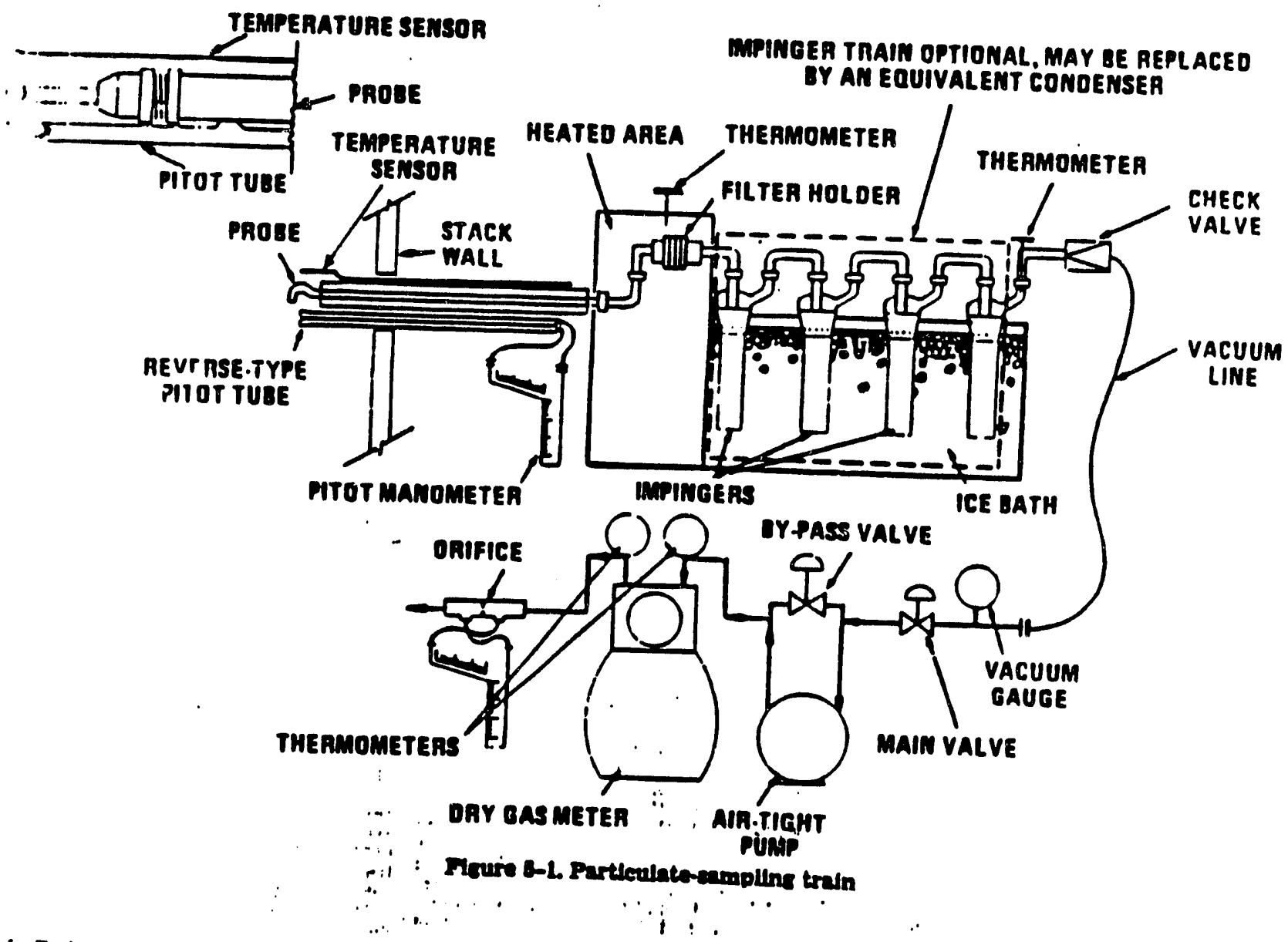

2.1.1 Frobe Norate Btalnlem ated (s20)

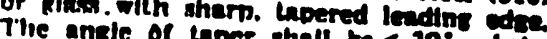
Inper shall be on the outeld $\leq 30^{\circ}$ and the rnopt shall be on the outelds to prentre rnnstant Internal diameter. The probs

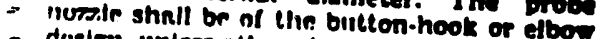
- Hovim, unless otherwise spociffed by the Ad. - Iilinistrator. If made of stalndes steed. the initir sinail be constricted from seemise lillihrs: ollier mnterials of conntruetion I:, "ssiet, subject to the approval of the Ad iniiriatrator.

it ranke of nmade stzes sullable for bothin i'r. "itinnltur should be avallable. 1.. $1.27 \mathrm{~cm}$ (\% to $x$ in.) avalable. e. 0.38 1. limme mampling irains nre ureer if hisher

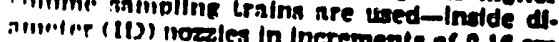

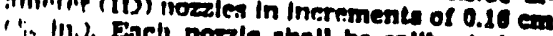
iin III.). Ench nozale shall be ellibried so linen 5 .

|2.1.1 amended by S2 FR 34639, Septem bir 14, 19871
21.2 Prote Inser. Doroullevete or quarts

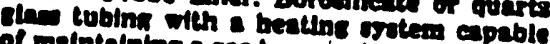
of radntalntne a cas tempernture at the exil and during anaplins of $120 \pm 14^{\circ} \mathrm{C}\left(24^{\circ} \pm 20^{\circ}\right.$

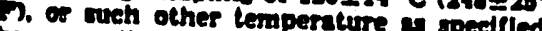

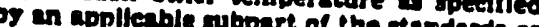
aporoved by the Admintetentor lor s and or ufer applteation. (The tester mas opt to opthe the equipment at a temperature lower whin that peeflled.) Sloce the cetual tem. perature at the outlet of the probe is not avelly monltered durtm compline is not comatructed eceording to Appos otllteing the cullbrition

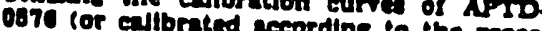

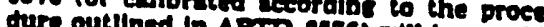
cure outsined in APro-0376) will be condd red ecceptable.

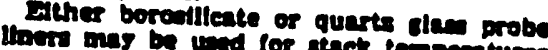

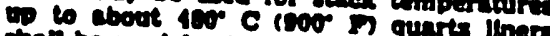

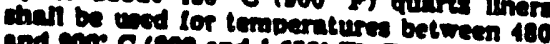

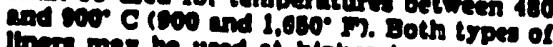
lines was be und of hloher temperture then epeefled for ahort periods of time, sub. lect to the approval of the Adminiets sut

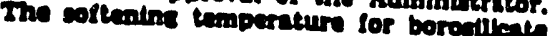

b. $820^{\circ} \mathrm{C}(1,800 \mathrm{~F})$, and for querts it in $1.800^{\circ}$ C(2,735 7$)$

Whenever prectled, every effort hould be minde to use borcillicate or quartz aless probe Inera. Altermalively. metal liners

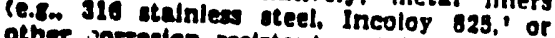
other sorrosion reatstant metals) mnde of ceanlea tubins may be used, oubject to the upproval of the Administrator.

2.1.3 Pitot Tube. Type 8 , described in acetion 2.1 of Method 2, or other device in. proved by the Administrator. The nice nD. abll be attreched to the probe is stoow tube inure s-1) to vllo the probe (as stiown in the rtack ras veloctty. The imnnct inten preavere) opentng plane of the pll hish hall be even blane cone nozle entry

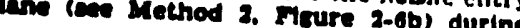

'Mention of trade names or speclfle prod. vet does not constllute endorsement prod. environmental Protection Acency. 


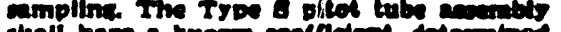

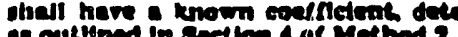
a cutbinad in sectlos 4 of Methined 2.

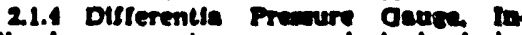

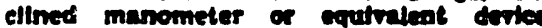

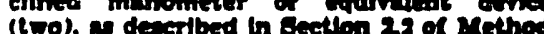
2 One manometer andl be und of modt

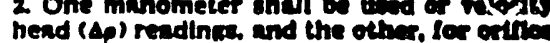

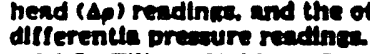

2.2.5 Filler Holdor. Borvolllente dem

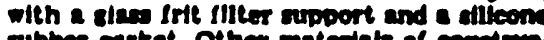
rubber reaket. Other maleriats of corvetrue Uon (e.s., stalniew eteel. Teflon viton) mas be ined rublect to aporonl of the Adrilat. trator. Ihe holder deatse shall provids poatlive sad araint leatsege from the out olde or around the mier. The holder uhil be altached Immediately at the ondlet of th probe (or cyelone. if uned).

21.0 Filter Heallan sytem Ans healtur. orvtern eapeble of mintulnto tempers ture around the mier holde dertin

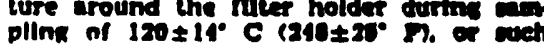
other temperature es peedfled of an epplt enble subpert of the etendard of aperove bs" the Adminiatrator lor a partioular apoll. calion. Allarmalivefy, the tever mas opt to

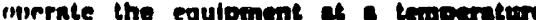

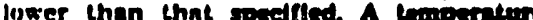

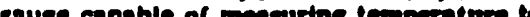

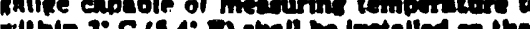
inglied of the the temperature cround the meer holde. mil be reculated and monltored durtins wem illine. Henting systeme other then the car sherin in A Pro.nsel mas be und

9.7 Condenrer. The following outer. shall be used lil determing tha eted on molature concent: Fout imptingers conneter

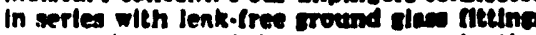
or ans etmilar leak-free noosentenlmader IItilnce. The linst third and fourts bo plnmere shall be of the Ormenburs bunlth dmitn, modifled by replecting the wp with

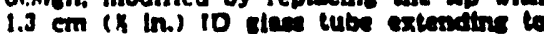
bout $1.3 \mathrm{~cm}$ (s in.) from the botlow of the

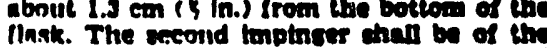
Creenburn.8mith deiten with the tender

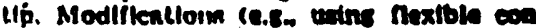

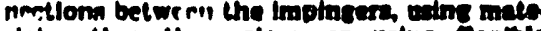

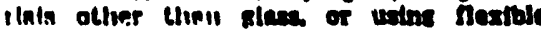
ramium lines In ronnect the fuler holder to (he condenime) ines bo und rubject to the npproval of thr Adminlotortor. The flrit end smond imoliseris shell contain known quen. illim of waler (a) be rmoty, and the (purth shall contaln known welsht of stlles cel, or equivalent desiresnt. A tirermometer, expebie of mea upins lemperture to within $t^{\circ} C(x)$ shell be placed at the outlet of the fourth th. plnener for monitorins purponet.

Aiternativels, any syntem that coots the oninple ses strenm and allowe measuremen. of the water condensed and molsture leat. Ing the conderser.r. each to within $1 \mathrm{ml}$ or 18 mas be used. subjeet to the approvel of the Admintatralor. Aceeptable mear are to mensure the conderwed weter efther mnt metrically or volumetrically and 10 mexerise lif molsture Irnvine the coodenser by (I) muniloring thr lemperatiure and preatire at the extl of the condenter and uing Detton's las of vartal propires or (2) Dawine the canple hes etrrean through o tared aflue gel

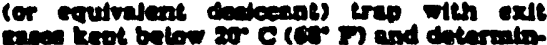
tor the wethe reits

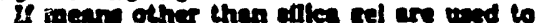

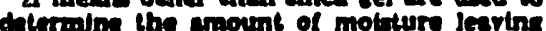
the conden in te

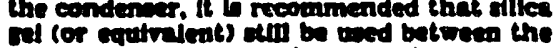
condeners anters and pump to provent undetern condenianter in the pumo and me. cerine deritees and to avold the newd to matre correction for moleturs to the metered volume.

Nose II a determination of the partleu. into matter collected in the lonpincere is do atred in eddition to motrture content. the

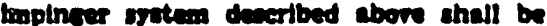
wod plesout modiflestlon. Individuel

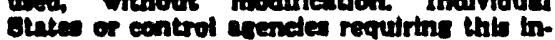
formation chall be contected is to the cample recovers and contrity of the lin. placer eoplente

2.1. Metertas Oscterm Vecuum ganne.

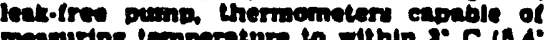

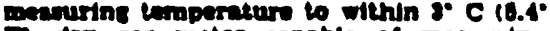
I). as the meter espeble of menourtas roivon is within a pereent and rinted

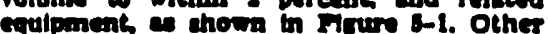

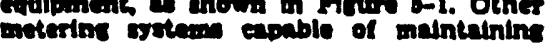

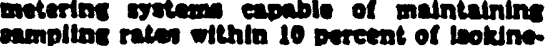

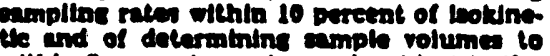
wenth 2 pereent mag be used, rubject to the upprovel of the Administrator. When the

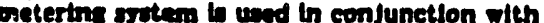
- pltot tubs, the osstem thall ensble encete of boldinctle nete.

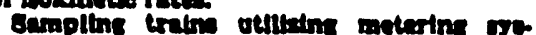

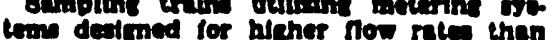

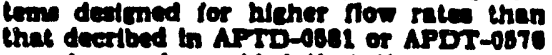
mas be ued provlded that the cocelfles low of this method are met.

2.1.9 Barometer, Mercary, aneroid, of other barometer enpble of measuring atmoopherie presoure to within $2.5 \mathrm{~mm}$ Hs (0.1 is. HB). In many esees, the berome irie reading mey be chininod from a nearby nallowal weather cervice station, In which ease the station value (which is

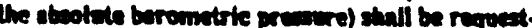

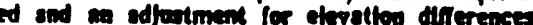
between the reather statton and sampling point shall be applied at a rate of mines $2.5 \mathrm{~mm}$ he $(0.1$

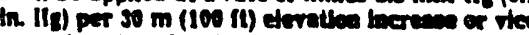
rersi for elevation decreace

2.1.10 Ov Denaity Determinatlon Dquipment Temperature cancor and prevuro mevike, in descorlbed in Bertlori 2.5 ind 2.4 of Method 2, and ras analyzer. If necesivary, of deactibed in Method 3. The temperntur oensor shall. preferably. be permaneplly al. tached to the pltot tube or sampling probe In a Ilxed conilicuration. sueh that the Ulp of the sensor extendn beyond the leadine edre of the probe thealh and doew not touch an metal. Alternaltvels. the senoor may be at tached junt prior to use in the field. Note nowever. that $\mathbf{I}$ the lemperature encor is stenched in the fletd, the enneor must be

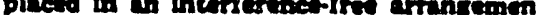

With rapeet to the Irpe 8 pltol tube open. ince ine Method 2. Mrure 2-7). An a serond ateinetre, if alleference of not more thisn 1 purest in the sverase veloctty menvire ment $t$ to be latroduced, the temperaliure to to the prober or ollot tube. (Init alternative la sublect to the pllot tube. (This alternative is sut

28 Banole Recovery. The following Items are neteded.

221 Probe-Lner and Probe-Noczle Bruaher. Nylon bristle brushes with staln lea steel wire handlea The probe brush chall have extenslons (at least as lone as the probe) of atainlew steel. Nylon. Tellon, nr imilerly Inert material. The brushes shall be properly staed and shnoed to brush out the probe liner and nowle.

2.2 .2 Wenh Botlle- Two. Olan wash cottle tre recommended: polyethylene wash bottle may be uned at the option of the leater. It is recommended that ncetnne not be rtored in polrethylene botties for longer than a month.

2.2.3 Oless Sample Stornne Contalinits. Cheraleally reatstant, borosillcale eloss hol. Her for acetone washes. $500 \mathrm{ml}$ or $1000 \mathrm{ml}$. Berew ea llner shall elther be rilbber. bected Tenon or sliall be conntrueted sn 25 to be leak-iree and resistant to ehemienl attack by actone. (Nerrow mnuth slake tont. lles have been lound to be less prour in leatage.) Alternallvely, polyethylene bot.llio nas be used.

2.2.4 Petry Dishes. For (IIter snmuiles. ine or polyethylene. imles otherwise suke. illed by the Adminietrator.

2.2.8 Oraduated Cyllnder and/or I3nI. ince. To meavure condensed water to within 1 il of 1 Gradurled erllnders shnll liacr cubdivistom no ereater than $2 \mathrm{ml}$. Most 1 nh. orvtory balances are capable of weipliling in the beareat 0.9 or less. Any of these hal. ances in sutuble or une here and in seetlon 2.3.4.

22. Pastle atorase Contalnera AIr. Unht contalners to store silicn sel.

2.2 .7 Funnel and Rubbrr Pollecman. To add In trengfer of sllie cel to contniner not mecesiang If sllice sel to relclied In the fjeld.

2.2.8 Punnel. Glass or polyethylene. to add in ample recovery.

2.3 Analysts. For analyals, the followine cqutpment is needed.

2.3.1 Olass Welshine DLshes.

2.3.2 Destecator.

2.3.3 Analytioal Balance. To measure to wthin $0.1 \mathrm{me}$.

2.3.1 Bajance. Tn messure to wilhin $0.5 \mathrm{R}$. 2.3.5 Beskers. $250 \cdot \mathrm{ml}$.

2.3.8 Hyzrometer. To mrasure the rela. tive humidity of the laboralory environ. ment.

2.3.7 Temperature Oalize. To mrnsitre the temperature of the laboralory enriron. rant.

3. Reacones

3.2 Semplins. The reacents used in sam. plins are an followe. 


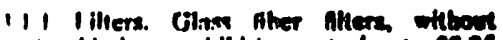
uranic himker. exhibitims at lesa Mass in'recnt eflictency (<0.05 percent pouetrs.

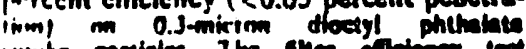

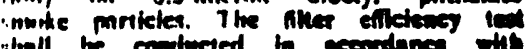

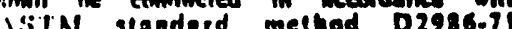
Hil stanninid method D 2986.7 cence - ee (fin.17). Tex date from the

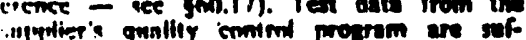

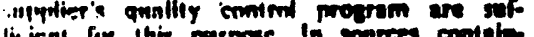
in iont fin this mipres. In soarces contab inp S(O), as SO, the Blier material mest be at is isfe lhat is unreactive to $\mathrm{SO}_{2}$ or SOy. 1 irsinin 10 in Secting 7 Blblogrephy. nis be used to select the apporopinite lilicr.

Ii i.l amended by 48 FR 3735, Jabuary 27. ingil

3.1.2 Silken Gel. Indientine 6ros, is 10 mesh. If previously uned on at $170^{\circ} \mathrm{C}\left(360^{\circ}\right.$ pi for 2 hours. New sllle bel was be und a rmerirned Alternatlvaly. other typee of dede enints (mulvalmne or betlers whe be uech

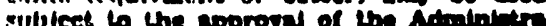
int

7.1.I Wacer. When enclyate of the mate inl enuelit in the Impincers bo requited, dlo lilimi waler shall be uad. Reun blantes prier

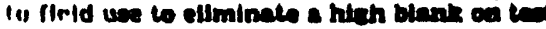
sonmples.

3.1.1 Crushed lee.

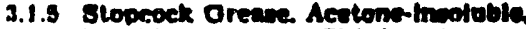

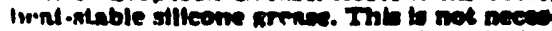

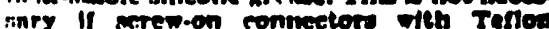

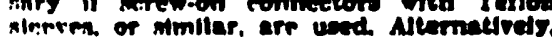

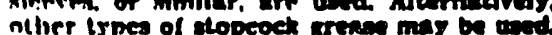
nlire trpes of stopecex arease may be wish sil

3.2 sample Recovery. Acatomereager

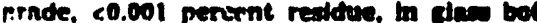

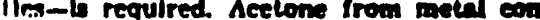

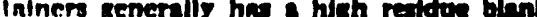
ind should not be uned. Somethme cupot rm Iranafer scotone to glas bottles fros

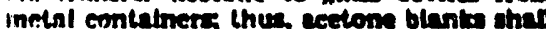
in rin prlor to fleld un and only covton with low blank valives (30.001 percent) ehell is thed. In no ense shell blank vise erenter than 0.001 percent of the melobs of arntone lued be mbtricted from the math ectehe.

3.3 Anniysts. Two reacents ere repotnd for the annissin

1.3.1 Acelone. Bame as 3.2

3.1.2 Drsiccanl. Anhydroun calctum gat.

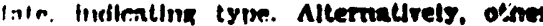

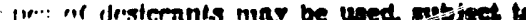

"inien at of the Admintetrator.

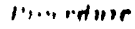

11 snmuline The complextly of the

llinl is sticli that, in order to obenin rell.

renilles. Inaters slimild be tralned and

i..lle if rilli llir imt procedurea.

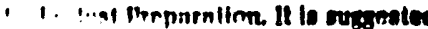

"1....e reperipment len meintalned

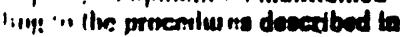

$$
\text { IIn;il }
$$

i I I ankemled by s0 I.K I165, Jamars 9. 1 1k8
Wetish emerls 200 to 200 portlow of

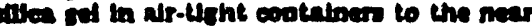
- 0.8 \& Record the lotal vetotht of the

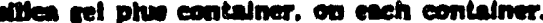

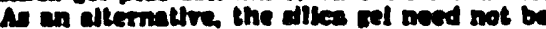

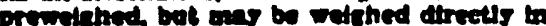

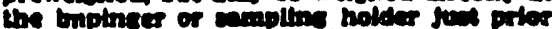

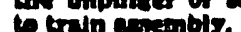

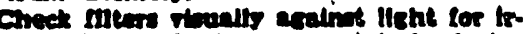
reculartese eod naw or pluthole leatse Label filter of the proper dinneter on the back olde near the edce cuine numbertne machine Inth in an aternedre, Iabal the

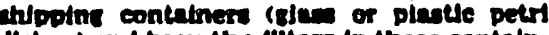
dincel and kew the ulter in thes contaln

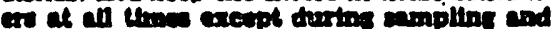
wiontis.

Dedeente the mitters at $20 \pm 80^{\circ} \mathrm{C}(0) \pm 10^{\circ}$ $\rightarrow$ and cublent premin for at least 2 boum and woth es laternaly of at leant hours to a content wethen Le. o.s as

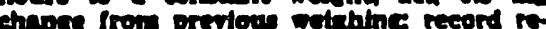
anle to the pinviou of rains Durtes each alle to the nearnt o.l mac. Durthe each Fileting the mler mut not be expond to

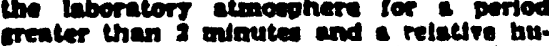
midity above so perceent Aleernaturely

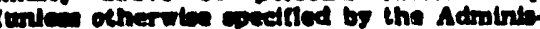
traters. the fitter way be oven dirled at $105^{\circ}$ C (Eor In for 2 to 3 bour dembented for 2

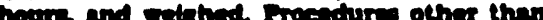
thare derd whin

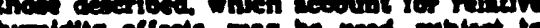

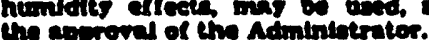

4les Prollwainery Determinatione Beleet be enpline ate ad the mintonum number

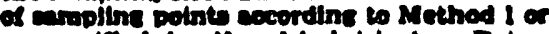

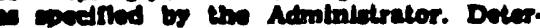

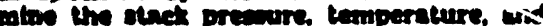
the rnne of retodts beed uning Method 25

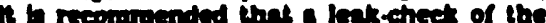

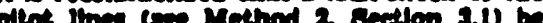

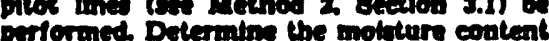
performed. Determin the motetere content mine Approzimatten Method 4 or tis clles.

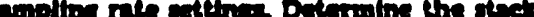

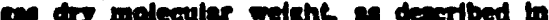
Method 2 getten 3. 11 intermated Method

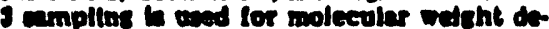
eirminallon. the beternted bes eample

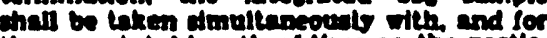

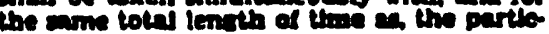
ulate nuple rum.

Gelect nocle sto based on the rance of reloelty hende rueh that it ta not necedaing to ehnnge the nocite sto in. order to maln. tiln tootinets molne tain bokinede surplini rated buring the rin, the not change the norade stce. Erwure that the prover differental prevure gauce countered (or the mance of voloetty head

belect a molleble probs liner and orobe lencth such that all traverce polnts can be ampled. For larke stacter, consider ampilin: frow oponte stdes of the stinct to reduce from opponite sides

Ealect e loty ampling the menter than or equal to the minimum tolal camplins the epedifled in the teat procedures for the

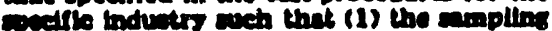

Limes ver potht I not lea than 2 min for com spencer tlone incervel as speetfled by the Adrintatralor), and (2) the sample roluras taken (eorrected to standard concil. lone) will exceed the requiter minimum lotal an anple volume. The Intler la based on an aoprosimale sverase samplini rale.

If th recommended that the number of Denten sampled at each point be in Interer on integer ples ine hals minute in order to avold umekeeplng errors. The samplin line at ench polnt shul be the snme.

In eoone elrumbtances. e.s.. batch eycles, It may be necesanery to sample for shorter limes at the traverse polnts and to obtain mollet on somple volumen. In these cases. the Aduintiturtor's approvel must flrst be obtaloed.

4.1.3 Preparation of Collection Tratn. Durthe meparation and asiembly of the amplins triln. keep all opentner wlicse con inmination ear occur covered unul Just prior to enembly or unctl eampitne b about to betin.

Fince $100 \mathrm{ml}$ of water in ench of the lirst two implngers, leave the third impinne ompty, and hranster approximately Imately 200 to 300 of arewetshed sille sel irom its cont. inine to the courth Impinger. More sille cel mes be ued bee eare should be taken to invere thet it is not entrelned and cartlod out from the implnier durtns sumnilnk. Fiece the contalner in a clean pince lor inter un to he enmple reovery. Allernnlively. the welcht of the stlice rel plus imninzer ous be determined to the neareat 0.3 and reverded.

Uath a treener or elean disponnble surst. al clone ples inbeled (idenifledt) and rel hed tilter in the illte holdne. Be nire that the inler bo property centered and the avet property placed so is to prevrnl the anvole ges etream trom circumventine the mier. Chect the iller for tean atter sueem. uly 41 completed

wine flac linere are ued, Install the se

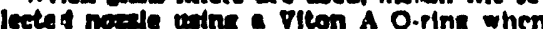
stads iemperatures are less than $260^{\circ} \mathrm{C}$ $\left(800^{\circ}\right)$ and en esbestos atrine Rasket whel ceopernture are hicher. See AMTD-0570 for detalls. Other connectlme systems usine ether 310 stainien steet or Tellon (errules mat when metel linem are used. Intell the nocele $n$ above of by a lenk-lrce direet mechanical connectlon. Mark the probe with heat resiatant tane or by sminc other method to denote the prnimer dist ninrn into the tack or duct for esech simmiline Doint.

Set us the train as in Frure $3-1$, isine 11 necesiant a vers llaht cont ni slllente grease on all mound elass Jolnts. Rrcasing only the outer portion (see APID-0376) 10 avoid poesiblitty of contaminallinn by llin atleone erense. Subject to the sinprovial ni the Administrator. alese creleme may be the between the probe ind fllecr loolder when the told partleulate entch is experted to exened 100 min or when water droplets are Dreant in the stect ger. 


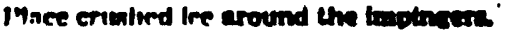
1 1 i Leah.C:Inreth Procedure

$\$ .1$ 1.1 Itreteat Leat-Cheets A pretex Irat. l loort is monmmended but not ro.

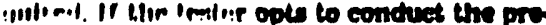

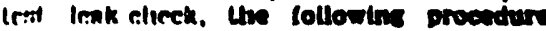
shall be ined.

After the semelline trats has been exper blont. Ium on and set the fllter ind probe honting syminm at the dedired overatine inmmaratures. Nllow time lor the tempere. ilirm to atiblitre. If a vicon A O-rtm or

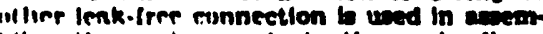
loflite lise probe norcle to the probe liner. Imak rhmek llin irnin at the samplint stle by

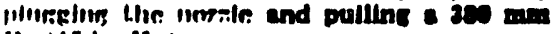
IIr IIs In. II / vnrinmm.

Mirre A Imxer rncuram may be ned por likent thint It ta imol exceeded durtin the leat

Il an nabrstion ntrim is und do not cop imet tise probe 10 the tratn durthe the leat chert Intenul. Irnk-cheet the triln by Ire: illingina thr intel to the miles holde

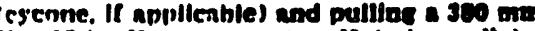

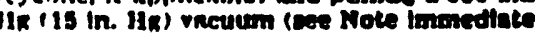
iy aboves. Then conneet the prots to the traln and teak-cheets at about 25 mon Bic (1) In. Ite) vecuumi elletnallvaly. the brobe mar he leak-chected with the rate of the

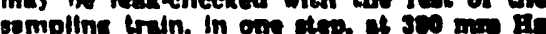

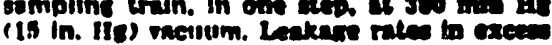
of 1 pereent il the sverage simplins rete of $0.00057 \mathrm{~m} / \mathrm{min} 10.02 \mathrm{efm})$. whichene th the ore unnecemplinble.

The followine lestz-cheet In trustlons for the sampling inin derertbod in A pro-ont and AFTh-oset mas be helplul. start the mimn with bsmase valve fully open and llally open the coorse adfut valre and slowly alowe thr bypass valve unets the dy sirred metuum ta renched Do not rovern 4. rection of bypans vilue: this will eares weter to back in into the tiles holdet. If the de

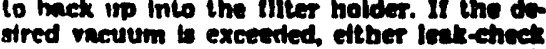

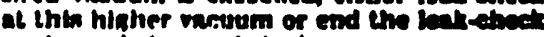
a shown below and atart over.

When the leak-cheet b eompleted first slmily minove the ples from the talet to the probe. illter holder, or evelon ilf spolles. bie) and hwactiately tum ofl the vacuum pinme. Thit prevents the water in the Im. pincers irow batoe forced badsward inco the

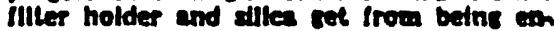
indred burtward into the chind Impinger.

4.1.4.3 Lenk-Chects Dorlns Bumple Rm. 11. durins the anplins ron, component (e.e. fitet enombly or impinger) change bo comes uncevenry, a lack-eheet shall be con. diveted immediately before the chance b made. The leak-eneet ahall be done aceord. Ins lo the orocedure outlined in section 4.1.4.1 above, except that it shall be done at - veculim equel to or treater then the mext. mum value recorded up to inat polnt in the tesh If the icarere nte in found to be no crmater than $0.00087 \mathrm{~m} / \mathrm{mm}(0.02 \mathrm{~cm})$ or 4 pereent of the averne sumpline rale (whichever is les), the reville are nceepte able, and no correctlon will need lo be ep. plled to the tolal rolume of dis ass metereds

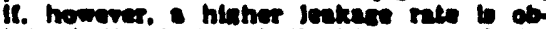
lalned the enter shell etther record the

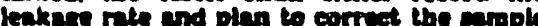
volume shom in gectos as of the method, of shall rold the enmpline res.

Immedistely after counoonent chance leak-chcetes are optlonil: If wets leate-cheet.

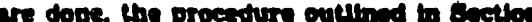
41.4.1 cbove chall be tow

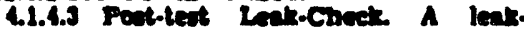
cheet is mundators of the condenden of each umplist rus. The leakeheck thall be done in accordance vilh the procedures out Ined in Beetlon 4.1.4.1. exeept that it ind be conducted at a recurim earnl to or rroat er than the mextmum vioe resched durthe

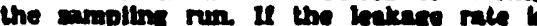
found to be no rencer than $0.00007 \mathrm{~m} / \mathrm{min}$ (0.02 efm) or 1 pereant of the evernge arr. pline rale (whicherver b lew), the reaule or exeeplable, and no correction besd bo ap plled to the extal voluine of dis sen metered. II. howere. \& hicher leakege rele is ob. cained, the teoter shin elther reserd the leatrage rele end comet the ennole volum shom in section 4.3 of this method of chall roid the eamolting ran.

4.1.5 partloulate Trath Operatlos. Durtns the ampline run. mintale an too

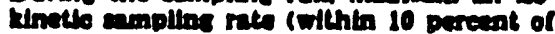

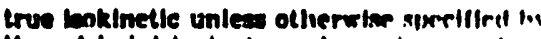
the Administralor) and $A$ Iemmentill, around the inter of $120+14^{\circ} \mathrm{C}\left(21 \mathrm{~A}^{2} .25\right.$ । or weh other temperature as sporfllinl l. an appllesble subpart of the stendarts iI approved by the Administrator.

For esch run, record the dnin requilrril m - date steet mich 0 lic me shown In Mrure 8-2. Be sure to reenrd llin InItial diry tes meter reading. Reeord tlie dry ens minirr readine at the bestnnine nind end of enrti ampling ume incremenle. whon cliause's it now rates ure made, before and n/trir cnrli leak-chect, and when sampling is linileil. Take other readinge requitrd by Fipiti s?

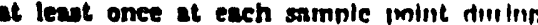
ench the Incement and nddltlouni rracl. Then sicnlfleant etraters $12 n$ percent veriation In veloctly haad rendlines i neressi. tace eddilional adfustmenta in llow ralr. Level and zero the manometer. Brealisr thir manometer level and zero may trift dur to tbratsone and tempernture chantes. make pertodle chected durthe the traverse.

Clean the portholes prine to the test run to minimtee the chance of sainpline dronslf. ed matertal. To beeln sampiling. remove lic no:ale eap, verlfy that the lilter and probc healdn spatems are up to temperalure, and that the pllot tube and probe are proprefly oottloned Poottion the nmate al flir IIrst treverse Doint with the tlo pointine ilirertly. Into the ens stream. Immerllntely stant thr pump and adjust the flow to Innklinelle cnil. ditsone Nomocraph are nunilable. Nilirh ald in the rapld adfuatment of the Isoklinclir cappling rale vilhoul excesalve coninvilin. Hore Thene nomorraplas nre drsinued for

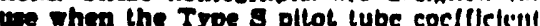
to $0.89 \pm 0.02$. and the slaek mas enulsuinint dendly (dry molecular veleht) is crimi to 2014. APTO-0578 detalls the prncedirr lirr uilog the nomorraphs. II C. Meld Afa nre nut. dde the above stated rances do not usp thic nomorraph inles eppropriate shos lsee Citation 7 in Bibliographyl are taken to compensente for the devintions.

[4.1.5 amended by 48 FR 39011. August 26. 1983]

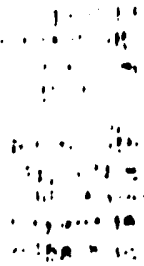

CAppendix A, Mothod 31 
nans

tocarrem

enenaron

eare

nem no.

semer cos m.

mieren eex no.

meren abs

cracton

mror ruot cosfricient,

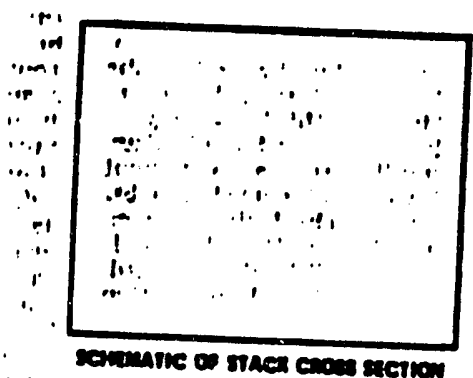

$\cdot$.

\section{mencers renanarem.}

cancmerewe pretcione

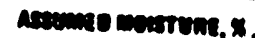

choce semorn, on

cerese contrication wo

Arenace enticiares worese oumeren, edial

mose mearen sermu

Leak nare. miminaletad

mose timen marewiat

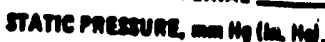

mren wa.

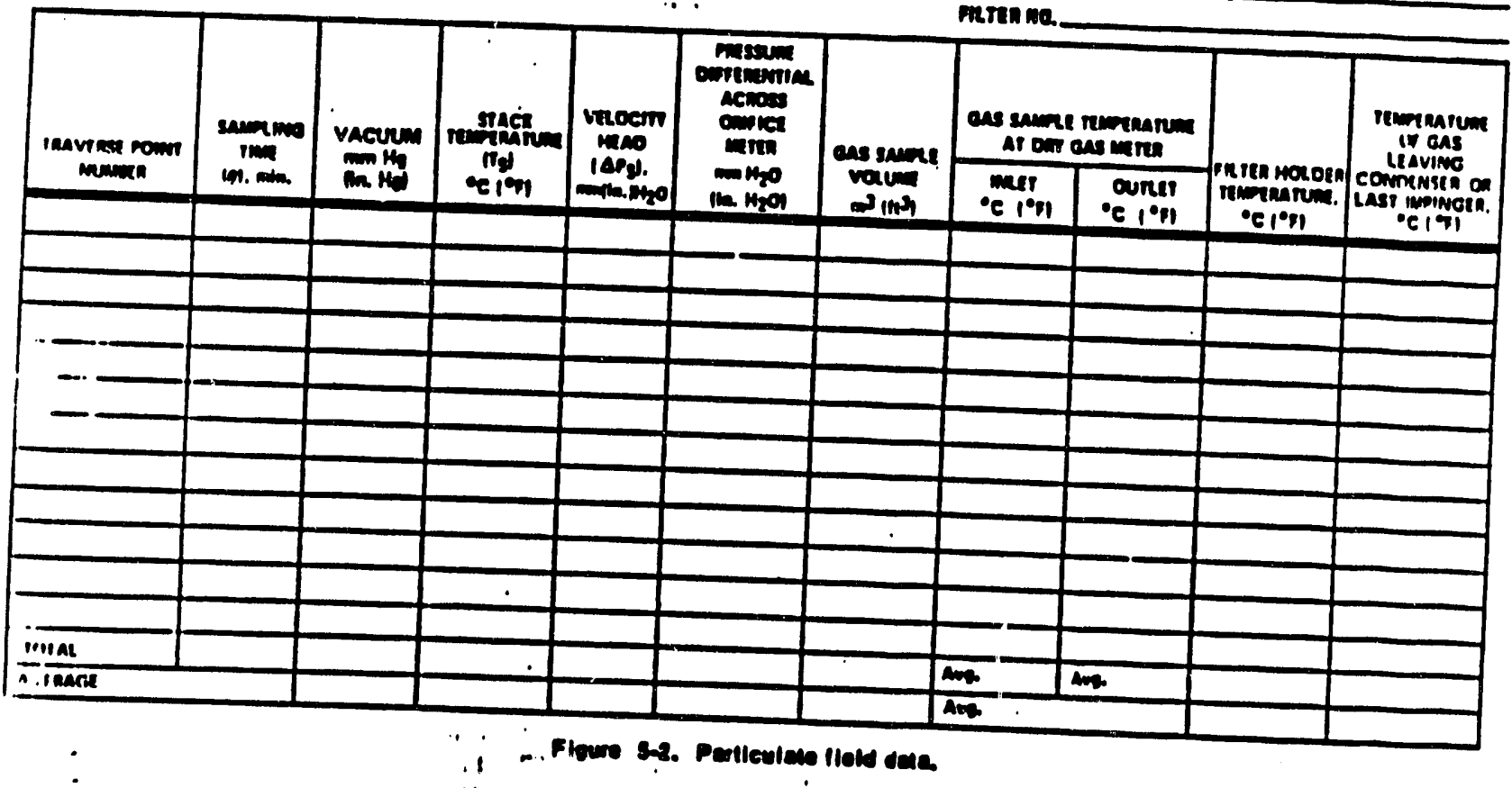

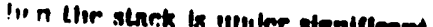

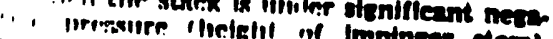
w.'." Mrossiler 'lielehil of Impinner steml. in "ire in elowe tlir ronrse adfite vilve In len. lissertling the pioive Into the stact to

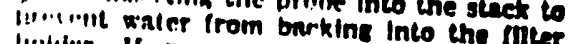

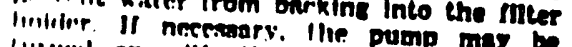

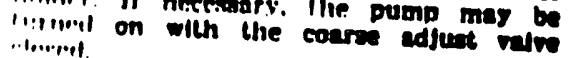

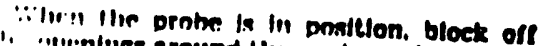
1. "I"renlines arning llie: probe and porthole in..'ant inrepresentsitive diluken of the a. : illenm.

linurpar the sturk cross-gectlon. 'jilirel hy Metliod I or 25 spection, is rel. inilitist rntor, belne enreful il.. prnber nosile into eareful not to bump "1willine near the the stect mall wher

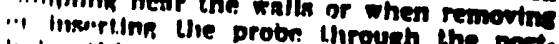

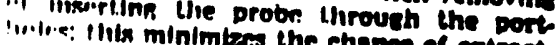
.11. irisealted maters the chares of extret

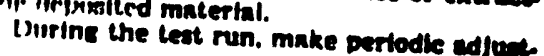

mente to kees the temperature around the filcer holder at the proper levef: add more loe and, II neee-ary, all to malnitaln a tem. Dernture of lee than $20^{\circ} \mathrm{C}\left(60^{\circ} \mathrm{P}\right)$ et the

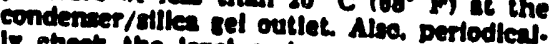
If eheet the level end son af pertodien. preter.

If the preasure drop sarom the piter bo

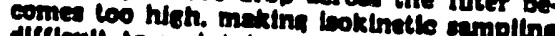

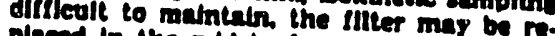
pleced in the roldet of achole man if recoumanded that another complete int is recombly be uned thother complete fllter chembly be uned ruther than attempedng to chance the mer linell. Befor a bev thice

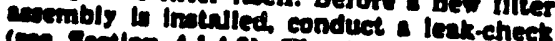
(wo Eetson 1.1.2.2). The lotal purtenlate wethe ond belude the cotal partenlate olter ond belude th

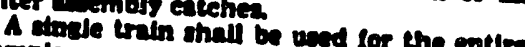

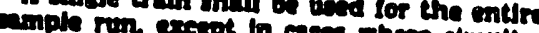

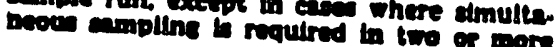

coparate dects or at lwo or more different locelion wlthin the snme duch or, In cases where equipment Idlure neeessilates chenge of trains. In all other situntlons, the une of two or more trilns will be sublect to the approvel of the trilns will be sublect to Noterol of the Administrator.

uoce that when two or more trains nre uned. ceparate analgses of the front-half and (If applleable) impincer entricen trom each trala shall be performed, unless identl ed nocile thes were used on unless Identl. which ere, the were used on all tralna. In Inditere, the Iront-helf calches from the individual trains may be comblned (ns may the Implacer eatches) and one analygis of iront-hull evedh and one enalgats of $\mathrm{Im}$. pinger eaces may be performed. Consult wh hdininiatrator for detalls concerm. more the elculation of revile when two or wore tratio are uaed.

At the end of the asmple run, turn off the coarca adjut vive. remeve the probe and 
nosale from the stack torn ofl the punse record the flinal dry pan moter readtong and

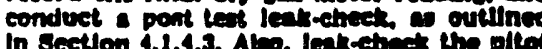
IInen an denribed in Method 2. Section 3.18

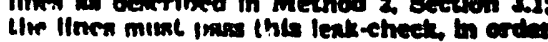

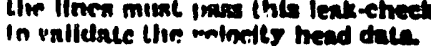

4.1.8 Calenisiliom of Pereent Icotinetse

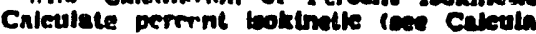
tions. Beetion of lo determine whether the nin was valld or another teat rum should bo made. If there was difflewlty in malontelning trokinalle rales dive to soures condillon corvatile with the Adminivatralor tor poedsite variance on the boletnetie rater

1.2 Sumple Reeovers. Proper cleanup procedure bratinn an coon as the probe to ro moved from line stack at the end of the ener. olling perlod. Allow the probe to cool.

When the probs an be ealels handled. - Whe off all external particulate malter near the thp of the probe nowile and plece a cap over if 10 prevent lowins or salntme purtlew. lete matles. Do not cap off the probe to Wehtly while the amoline trin in eodine

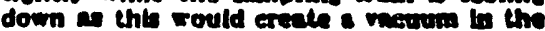
iliter holder, thus drewting weter trow the implinsers into the inter holdut.

Bejore moolng the oample trale to the eleanime alle. remove the prote from the eample traln. Wipe off the dilleone mence. and eno the open outlat of the probs. Be careful not to low ans condeneate had mient be present. wipe ofl the milleone creace from the criter tintet where the probs was fartened and an Ih. Remove the unblif eal cord fiom the last hoptinger and ene the Impinfer. If a nexblele line th und between the nirst impincer of condener and the

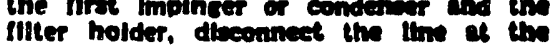
iliter holder and let ans condenend water or itquild draln into the truplinetre of conderiv. er. Alter wiplins off the aflleom trease, eap off the illter holder oullet and bmpinger Inlet. Exther mround-glan stoppers placte capa, or emrmm

Tranafer the probe and inter-truptonser a. sminhly in the cleanup ares Thl are shnuld bre clean and protected from the x. Init so thint the chances of contaminatine or losine llir snmple will be mintentead.
Eave a portion of the septone mad for deanup as a blant Take $200 \mathrm{onl}$ of this etone diroethy from the man bothle betos

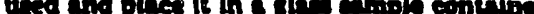
inbeled "reatone blank."

inepeet the traln prtor to and durtne dis. anembly and note any abnormal condition. Treat the stanples es followe

Concalner Na 2. Carafults remove the inter from the filler holder and place it in 1is Identuried petrt dish contalmer. Une a pal of iweceer and/or eteen dipoomble oursical slove to handle the filler. II Il I necessary to fold the filter. do 20 mech that the partle. wlate cake is inoide the fold Carefully tran fer to the petrt dish ans partsculate mallet end/or niler mbere which adbere to the miter holder renceth by wins a dry Mylon briatle brush and/or a aharpodeed blede. Eeal tha contaliner.

Conlatner $\mathrm{Na} 2$ Tatdme cire to see the duet on the outedde of the probe or other ox. terior surfeces does not get inlo the sample, guantulatively reover particulate matten of ans condeniente trou the probe notate probe metune. probe itser, and front half of

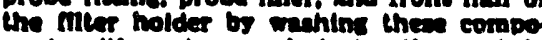
nents with seetone and plecting the wash in

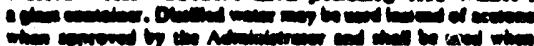

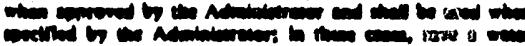

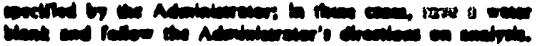

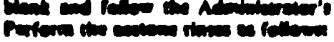

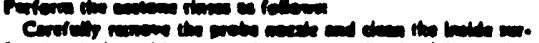

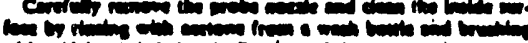

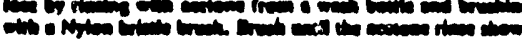

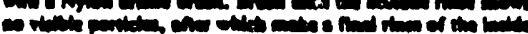

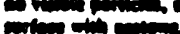

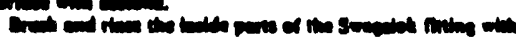

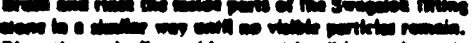

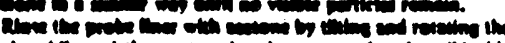
a

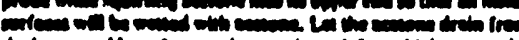

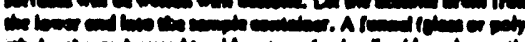

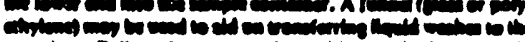

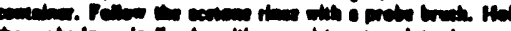

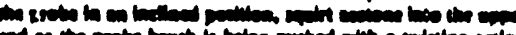

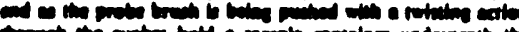

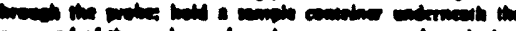

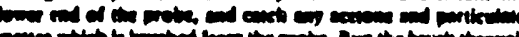

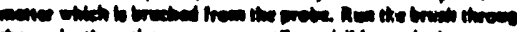

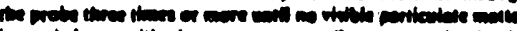

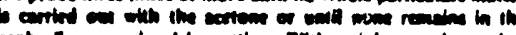

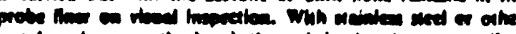

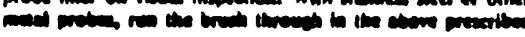

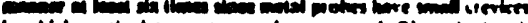

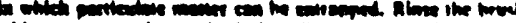

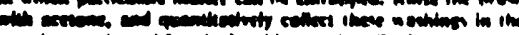

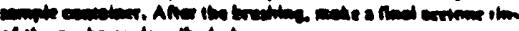

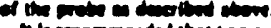

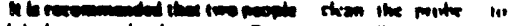

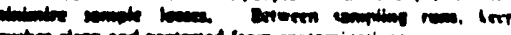

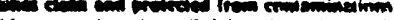

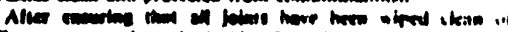

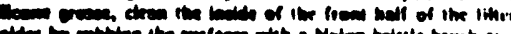

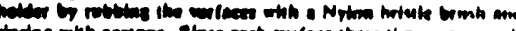

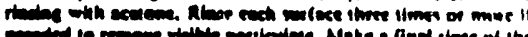

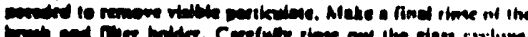

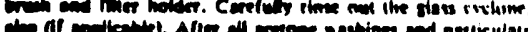

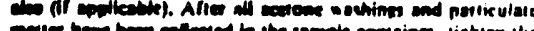

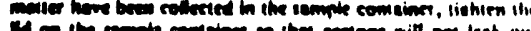

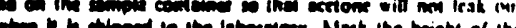

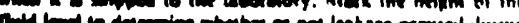

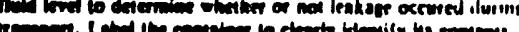

14.2 Container No. 2 amended by 52 FR 34639, September 14, 19871

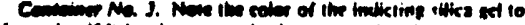

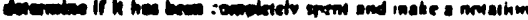

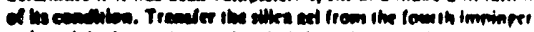

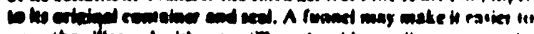

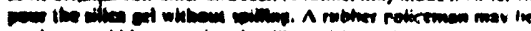

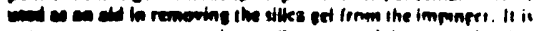

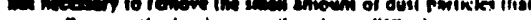

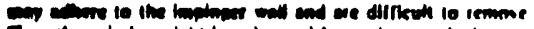

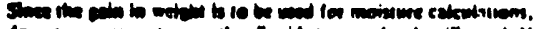

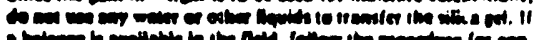

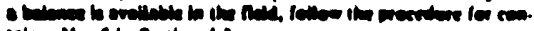

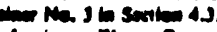

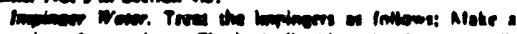

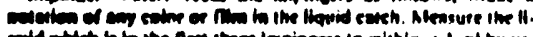

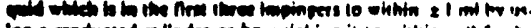

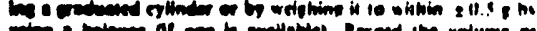

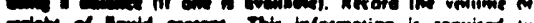

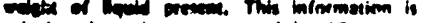

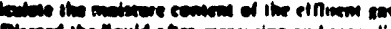

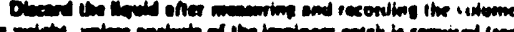

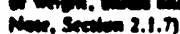

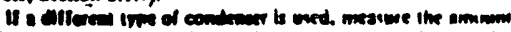

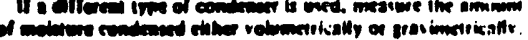

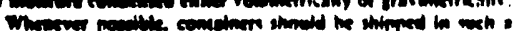

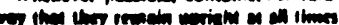

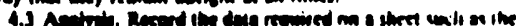

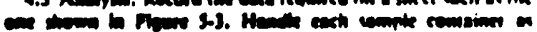
(a)

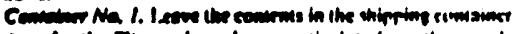

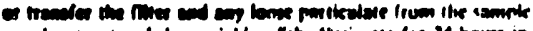

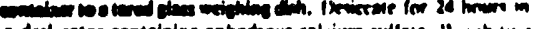

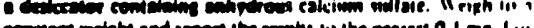

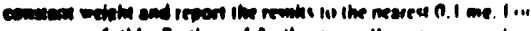

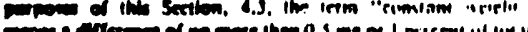

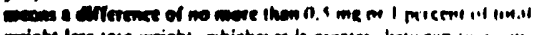

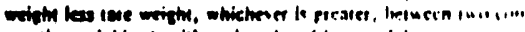

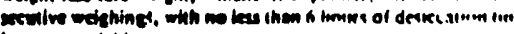

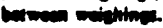


Plome

Minle.

limn Ne.

Filter No.

Amoune liquid lost dering trangent

Acrtone blank volume, int

Aestone wash volume, $\mathrm{ml}$

Aretone blank concentration, mg/my (cenation 5-4)

Aratone wash blanh, mg lequation 5.51

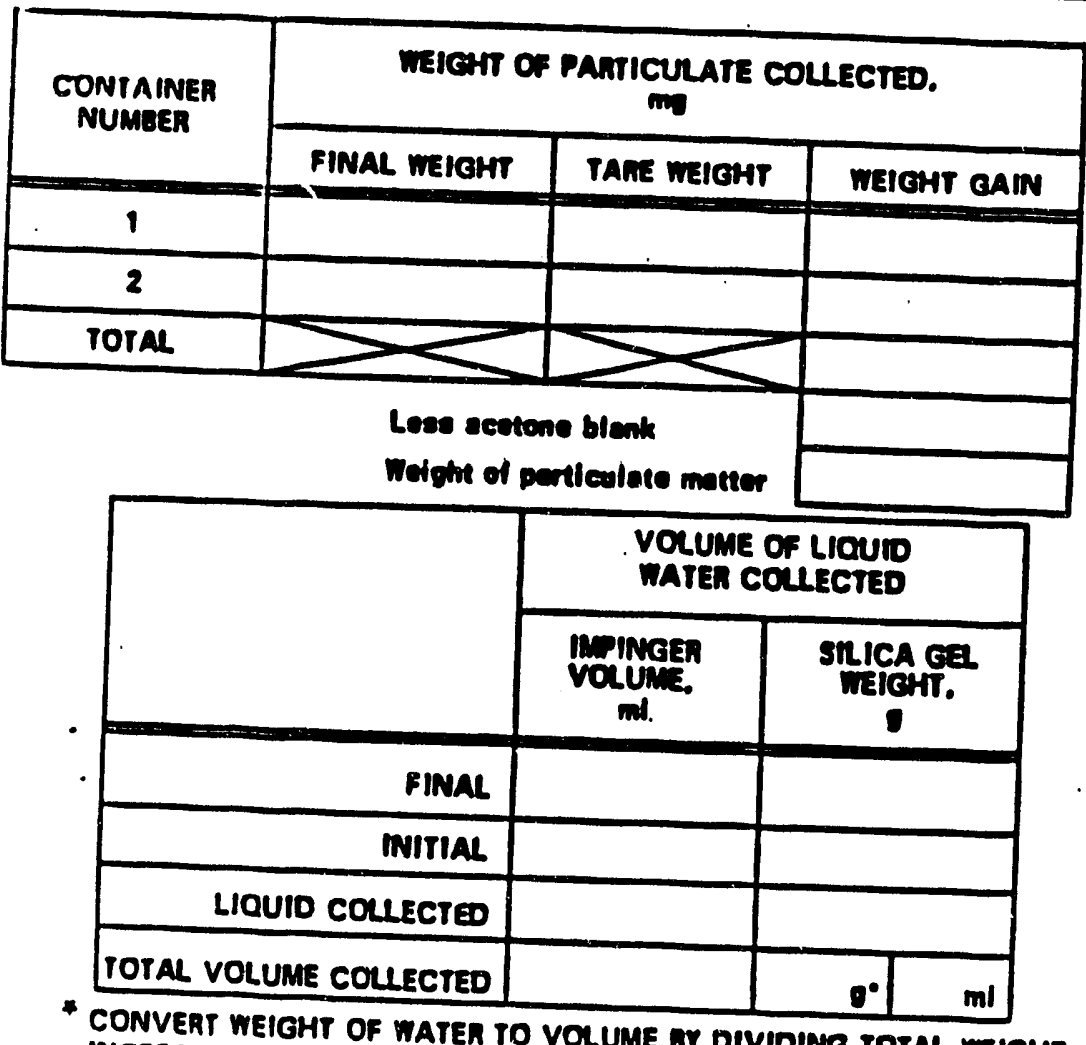
INCREASE BY DENSITY OF MATE $(1 \mathrm{e} / \mathrm{ml})$.

Figure 5-3. Analylleal dala.

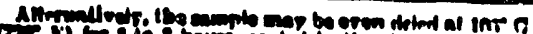

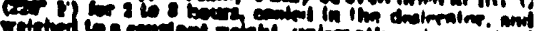

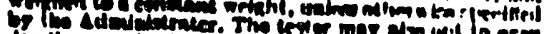

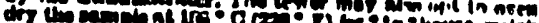

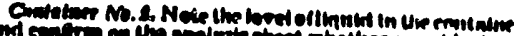

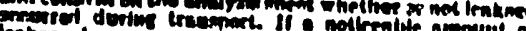

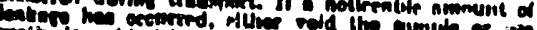

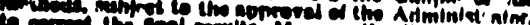

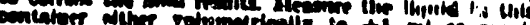

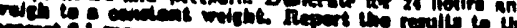

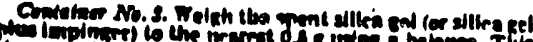

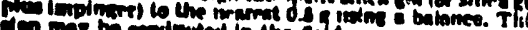

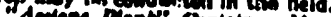

烈

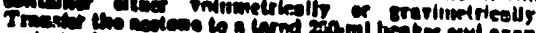

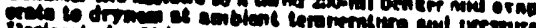

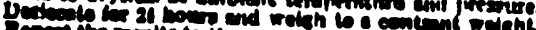

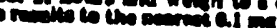

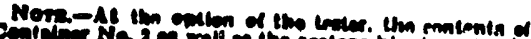

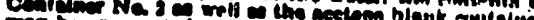

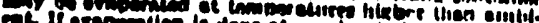
The lon

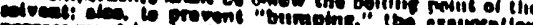

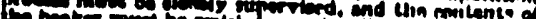

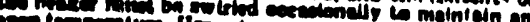

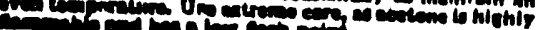

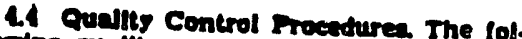
bowing rallie control proviuren the fol. ceeted to ehed control procedures are sue. ceibd checs the volume melerting syolem cilibrition vilues at the fleld text site prlor 6. enple colicetion. Thew procedure are cotoad for the lerter.

4.4.1 Netes Orifles Cheat Odne the call. brellon dale obcalined during the ene call. women data obcaloed durlos the evflorallon orocedurs decertbed in Bectlon 5.3, deler. mine the Afic for the zeterths system ort.

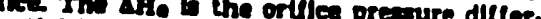
culd in wite of In 8.0 that correlates to

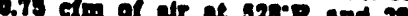

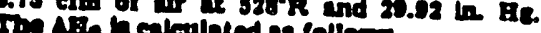
th $\Delta$ in beloulated as follow 


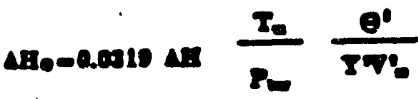

In

Where:

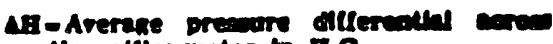
the ortice moter, th $\mathrm{B}, \mathrm{O}$.

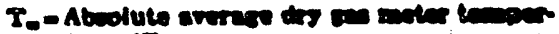
oture. ' $R$.

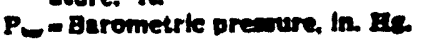

Q-Total samplins time. min.

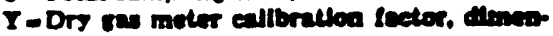
stonlez.

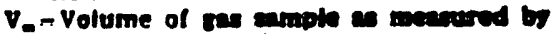
dry gav meter, del.

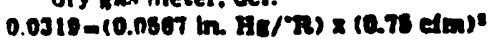

Before bontnning the fleld tent is at of

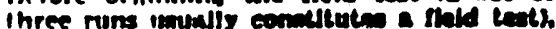

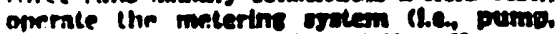
volume meter, and orfles at the chic pres. oure differenciai for 10 mbinetes Recurd the

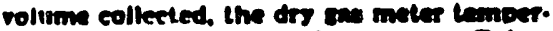

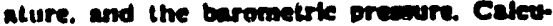

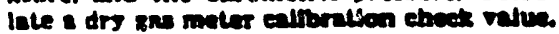
$X_{n}$ a follow.

$$
Y_{.}-\sum_{-}^{10}\left[\frac{0.0010 \mathrm{I}_{0}}{V_{-}}\right] v=0
$$

Where:

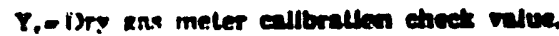
dimensimilex.

10 - 10 minites of ron thrme.

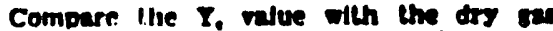

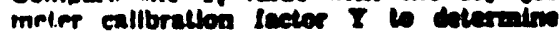
llial:

$0.97 Y<Y_{1}<1.00 Y$

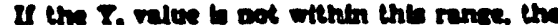

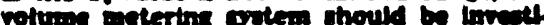
onted bolore bedninter the ted.

4.4.2. Cellibrition Critleal Orifies. A

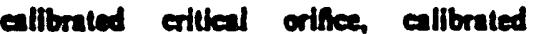
egaind 2 wet teet meter or spirometer and deaigned to be inverted at the inlet of tho nimpitme meter box, may be ead on a quality control etrect by following the procediere of Sectlon 7.2

[4.4.2 Amended by 52 FR 9658. Mareh 26. 19871

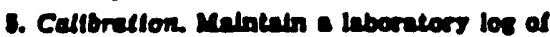
all enliontlon.

9.1 Probe Nowde. Prote nowles shall be -illenied bien thet inifin ine in the

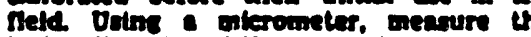

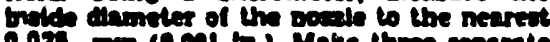
0.024 and (0.001 in). Make thres epparale

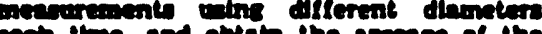
each thes asd obtuth the spriage of the

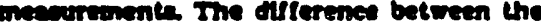
hich and low muspbers shall not exeend 0.1 min (0.004 lon). When pozles beeone nileted dealed of corroded. thes shall be rechaped sharemed, and reallorated

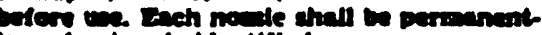

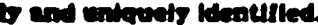

[S.1 amended by 52 FR 34639, September [4. 1987]

9.2 Filed Tube The Troe 8 pllot tube en combly shall be ellibrated secording to the

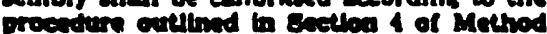
(2)

as Metates oroten

[5.3 noviaed by SO FR 1165, January isis]
8.3.1 Calinelion Frtor to Une. Before its intund in the fledd. the meterins gratim thall be eillorated 20 followr. Connect the actertan esstem inlet to the outipt of $n$ ret lest roter that b ecourate in oithin I per. cent Reder to Fure 5.s. The wel lest metrs chould have a encetly of 30 Ilters/rev (1 (t)/rus). A mirometer of 400 Illers (14 If?) or more capedty. or equivalent mas be teml of thi cilbrition. Jthoush wet test mete is yully more practical. The tert text moter should be perfodteally callbreted with a mirometer or a llauld disnincemnnt meter to envure the eceurses of the wet frst meter. Splrowelers or wet lest mnters in other atres may be used. Drovided that llin rectiled sccurectes of the proceture "1." intedned Run the meterine srstam pini!!.

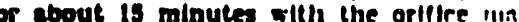
cometer Indlecline a mmilian rendine as $1 .:$ peted in field use to allow llie pismn 10 arm up and to permil the intertor surince of the wet leat meter to be thorouslity etted. Then. al each of a minimurs if Chres ortiles manometer seltings, pass an exact quentity of san throush the wet I rat coter and nole the ras volume indiented in the dry res meter. Nien note the barnmetrle recure. and the temperalures of llie w.r.t eat motes. the inlet of the dry ans metar and the outlet of the dry ens maln: .s.l... the hisheat and lowrst orlfler smillinp. '..

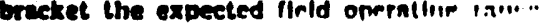

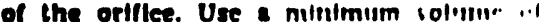

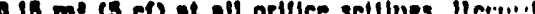

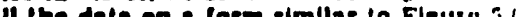
and ealeulate $Y$. the dry ans metre callin' ton inctor, and $\Delta H A$. the oriflire eallbentlon fector. at esch orfllee salline as slior.ll ill Moure 9.6. Nlowable toterances Inr Indilili

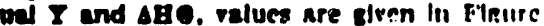
3. Use the erenge of the $\bar{y}$ values in thir enteriatlon in Bection 6.

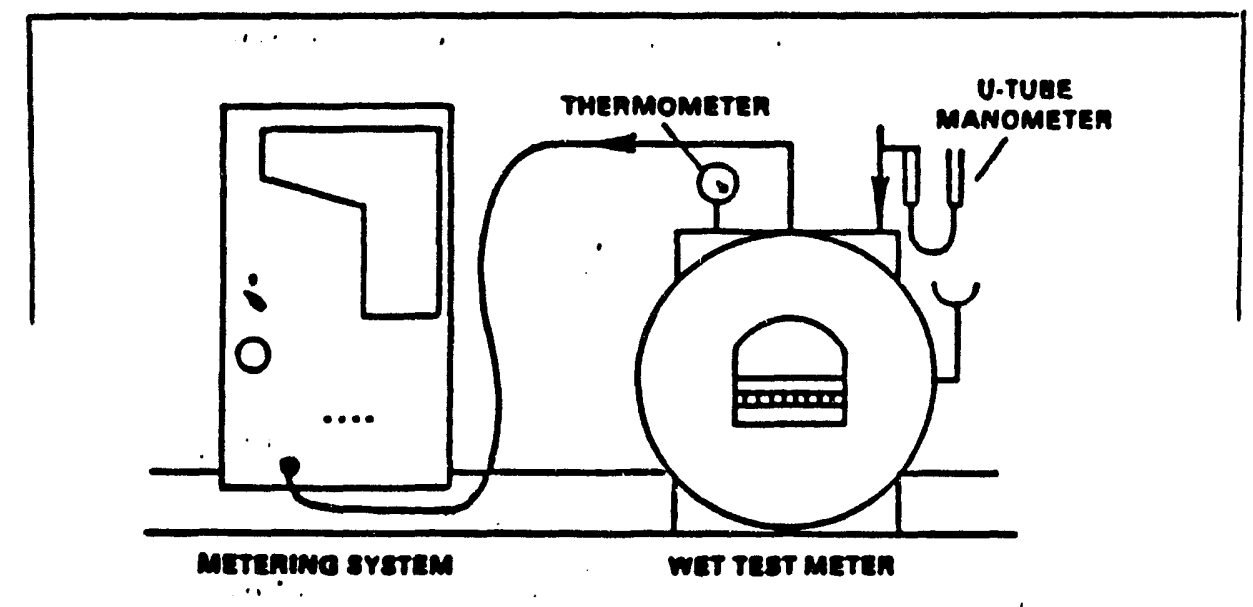

Foure 8.8 Equipment inrangement lor motering cretain callbretion. 


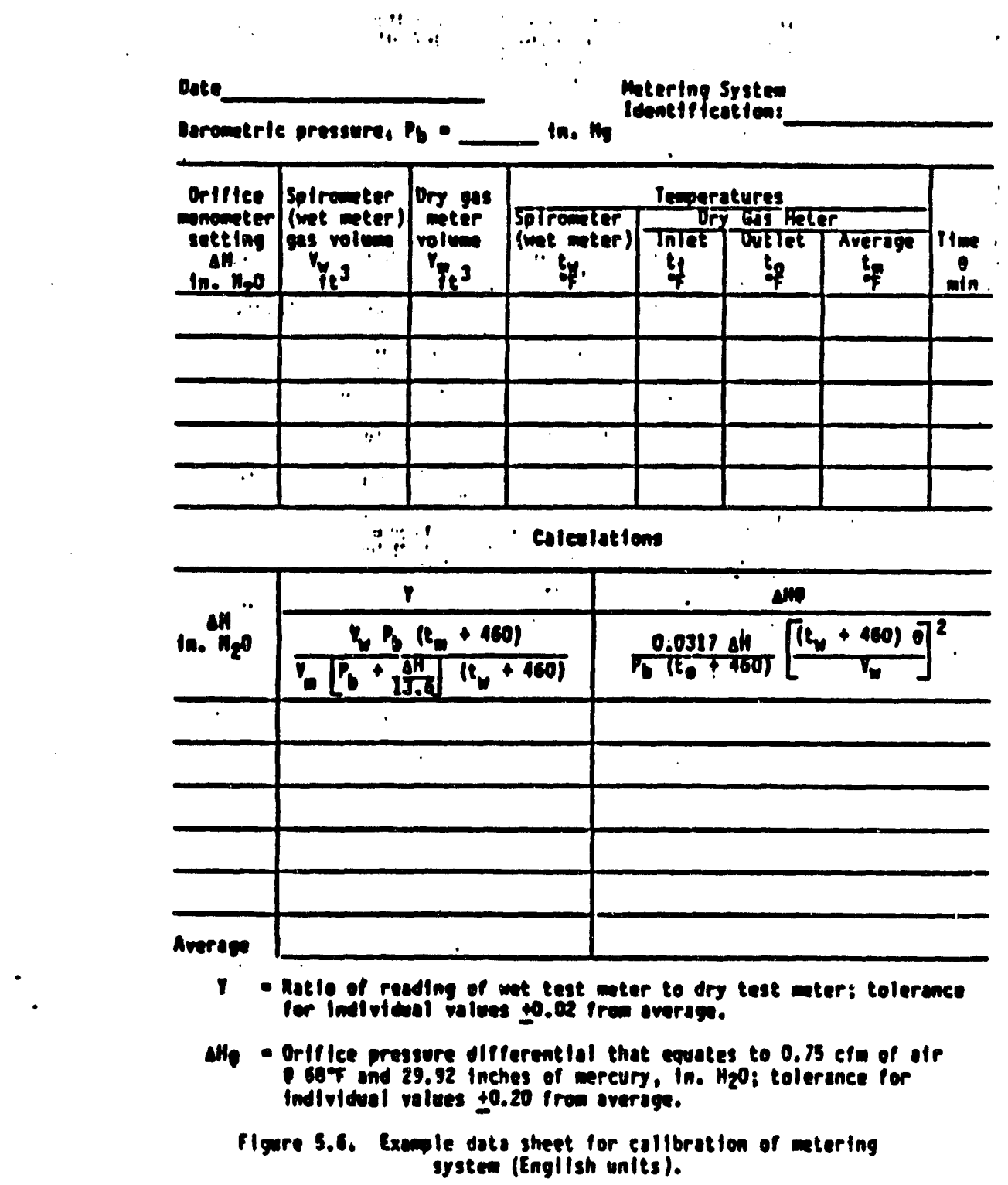

[Figure 3.6 revised by 52 FR 34639, Seplember 14, 1987]

IInfurn enlihraling the meterina motem, it Is silnkmied that $a$ Irati-check be eonducted For meterins system havine diaphrar. pump. the normal leak-cheet procesum will not detect leakeges whiln the punse

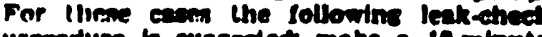

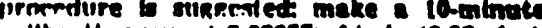
rallbention nin at $0.00037 \mathrm{~m}^{\circ} / \mathrm{min}(0.02 \mathrm{etm})$ ni lie end of the ping take the dirlerines ad the meavured wet teat meter and dry ons ate ortllce setting bosed on thr previnus meter volumex diflded the differteet by 10, fleld teat), with the vecuum set at the maxl.

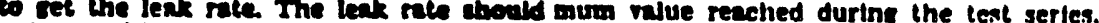

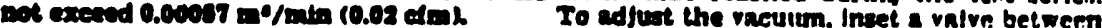
the wet tert meter and the inlat of the me.

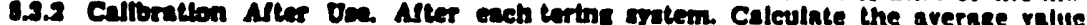

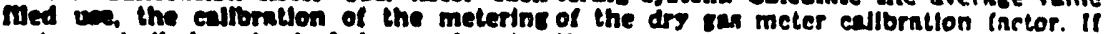
gratem shall be checked by performing the value has changed by more than 5 pirt.

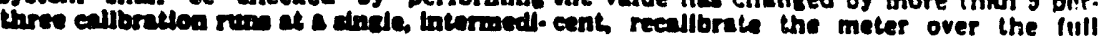




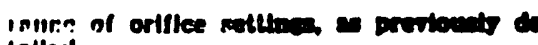
inlled.

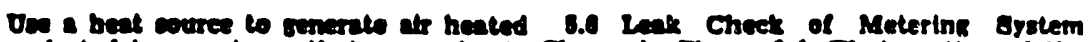

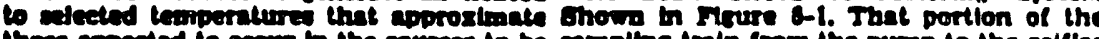

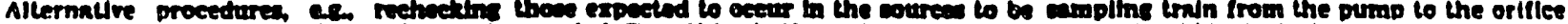

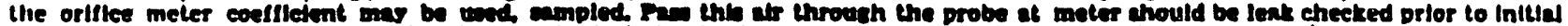

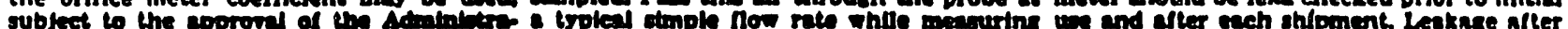

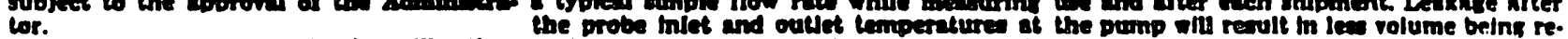

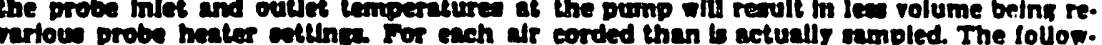

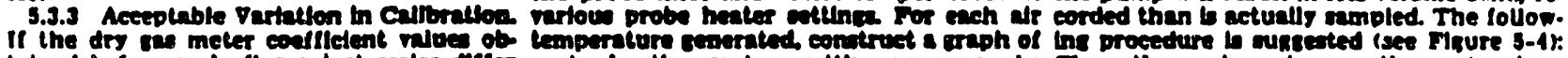

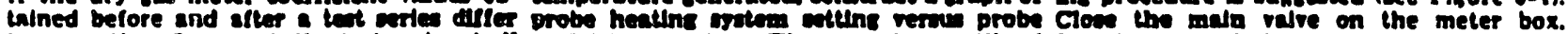

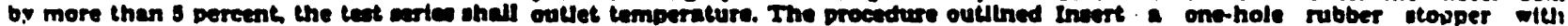

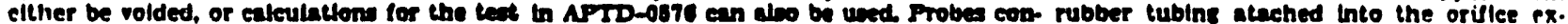

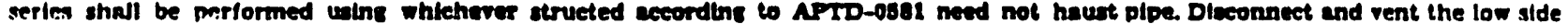

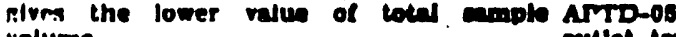
volime. outlel tempernture moniterting eapabulite to $18 \mathrm{~cm}(\mathrm{~s}$ to $7 \mathrm{ln}$ ) valer column by blow. S.4 Probe IImi er Callbrallon. The prote do not require eallbratlon. the into the rubber tublng. Pinch oll the

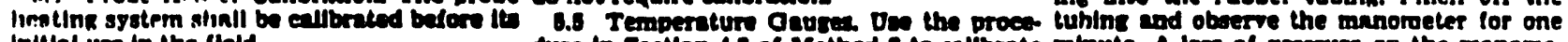
Inithal use in the flatd.

15.4 revised by 50 FR 1163, Jancery 9, dure in Bection 43 of Method 8 to ellibruts mbnate. A low of presure ot the manome.

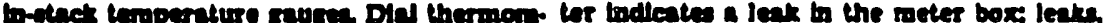
1985

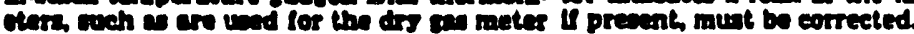

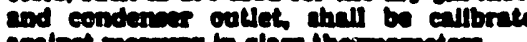

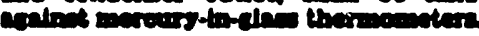

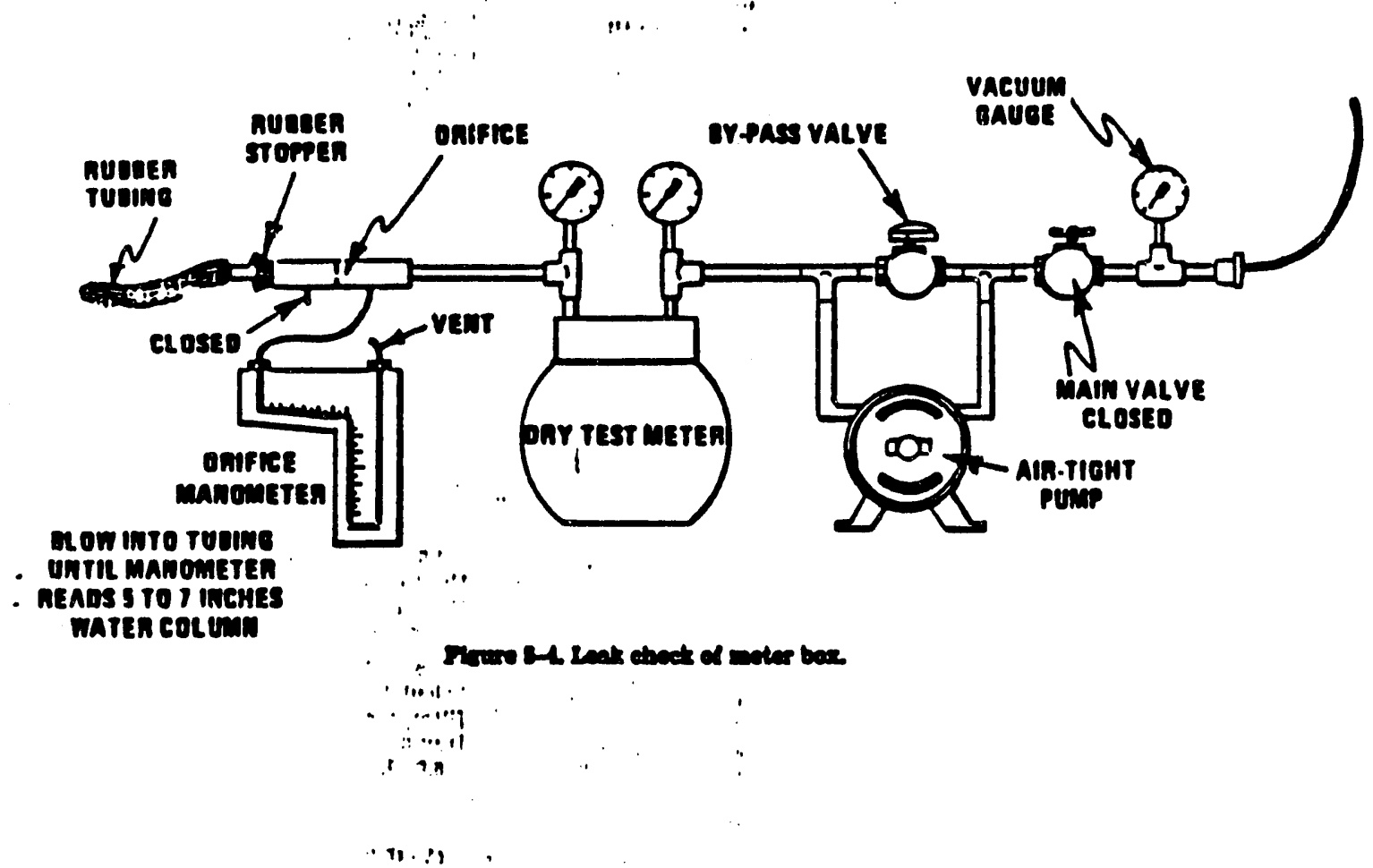

[Appendix A, Mothod 5] 


\section{Caleulations}

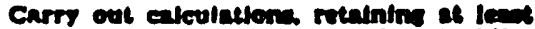
one extre dectmal flgure bejond that of the ecculred data. Round off flewre ales the IInal eateulatton. Other form of the cate.

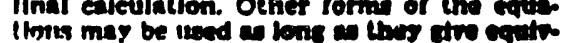
limes may be

6.1 Nommentalure

A. Crnastometlonal aren of nocile. me ift?.

B.. - Wnter vnpor in the ene etreas. bropor unn by volume.

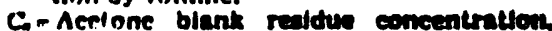
meime.

c-Concentration of partleutate matter in stack om, dry basta, corrected to atench ard conditions, n/dien (s/dxef).

1. Pereent of boktinetle sampline.

L. - Maxtminm aceepleble leakare ris for elther a "reteot lest chect of for a lats

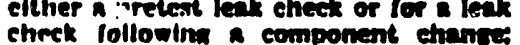
chrek followin a component ofranes permml of the scernese expolting nits - hikelierer la lems.

L. Individiunl lenknge rate obcerved durtne Ilire Imak rlierk combtueted prior to the - po.: menimient chance $(1-1,2,3-\infty)$.

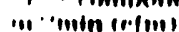

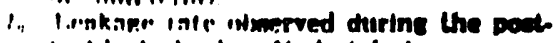

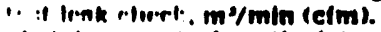

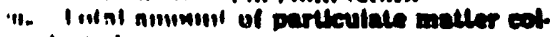
lertmi, me.

M. Mnimular wright of waler. 140 e/o molr (1A.nib/lib-mole).

m. Masis of reaktue of seteon arter eveos rallon. me.

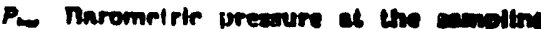
sile. mm IIR (In. He).

- im an

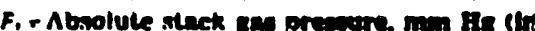
IIR.

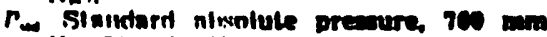
lle 120.82 in. IIp!.

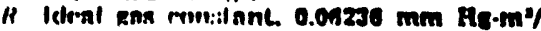

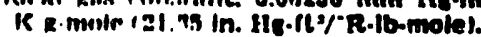

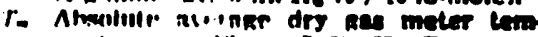

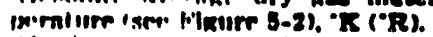

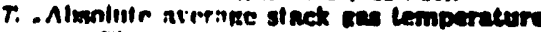

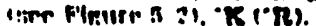

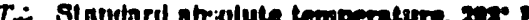
(32n (R).

li. Volume ol acr.tone blank. $m$ l.

i. Vnliuma of arrtone used in wesh, $\mathrm{m}$.

$V_{w}$. Thtal voliunr of llauld collected in in

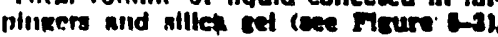
inl.

V. Volumn of ank sample a measurnd by Ary Ras mu:trr. Hem (docel).

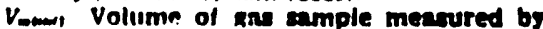
lile ifry ens mrler. corrected to standind condllions, deem (dect).

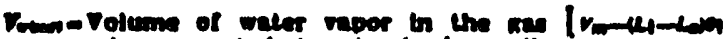

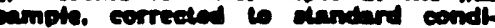
llone con (eat).

- Blact res veloetes. enleulated by Method

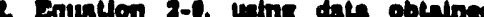

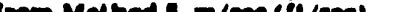

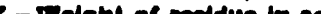

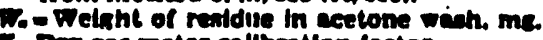

Tin Dirs tas meter editirition inctor.

A-Avernge premurs differentld seros the offlee meter (eve Morore \&-2). $\mathrm{mm}$ H.O (In B.O).

n- Desalts ol cercome, me/ml twe label on botlles.

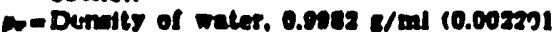
(b/mi).

- Total sampilm Ume. min.

cosamollas lime interval. Irom the betin. nins of a run unth the flrut eomponent change min.

h-8umpline Uime Interval, batween two meceedve component changer bein. nind with the Intervil between the firet and second chences $\mathrm{m} / \mathrm{n}$.

o ormpiling time interval. Irom the Inn (nim) component chande untll the and of the anmollns ron, min.

13.8 - Speelfle ernvily of mercurs.

0. Sec/min.

100-Comveriton to porcent.

|6. I amended by 52 FR 34639, September [4. 1987]

0.2 Averece dry cas meler temperalure and averase oftile preme drop. see dat hese (Mgure 8-2).

6.3 Drs Oen Volume. Correct the enmple volume metweured by the din ter meter to

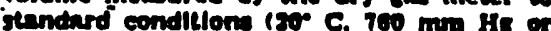

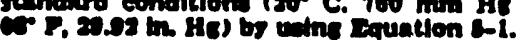

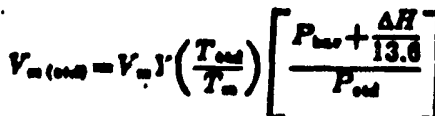

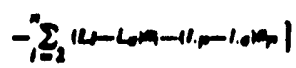

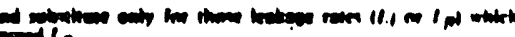

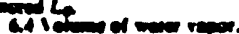

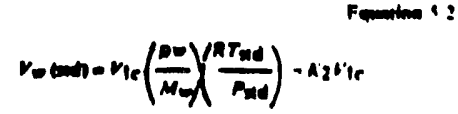

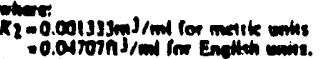

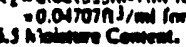

$$
\ln \frac{r_{\infty}(n d)}{\left.r_{m} \ln (\ln )+v_{\infty} \ln d\right)}
$$

T:manion 9.1

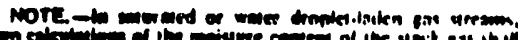

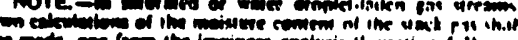

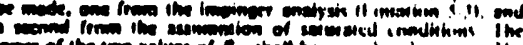

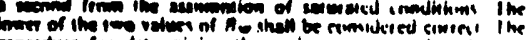

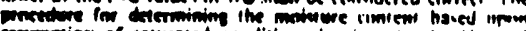

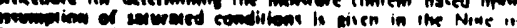

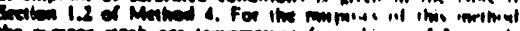

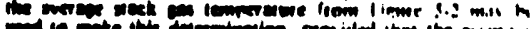

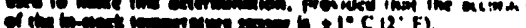

1. Acatone Blant Concentration.

$$
c=\frac{m}{v_{\infty}}
$$

zauation a-1

\subsection{Acutow Weah Blank.}

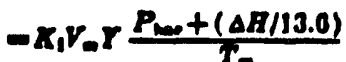

$$
\text { Wo-cinen }
$$

Pquatlon a-s

6.8 Total Pertleulate Welchit. Determine the lotel particulate extch from the sum ni the welchte obtalned from eontalners $I$ and a lew the calone blank (cee Mrure s-3).

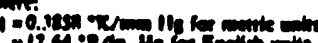

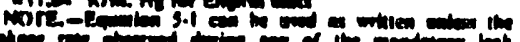

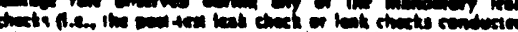

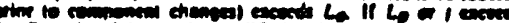

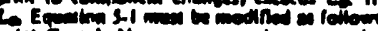

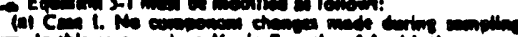
tim.

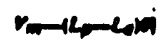

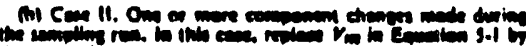
tim
Norr Refer to section 4.1.5 to sasist in calculation of results involvine two or more futer seamblles or two or more sampline triver

a.) Partleulate Concentration.

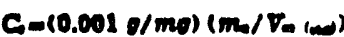

rquation 8-6 
ade Converten Paters

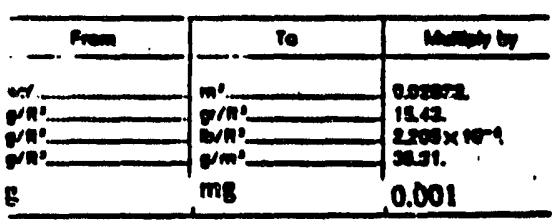

|6.10 labie amended by S2 FR 34639, September 14, 1987]

0.11 isokinetle Vartlion.

9.11.1 Caleviluton From Rar Date .

$1=$

$\left.100 r_{0} U_{1} \nabla_{w}+V_{1} Y / / T_{n} \times P_{n}+A B / 120\right)$ cons is

vhere:

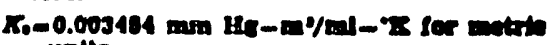
imite.

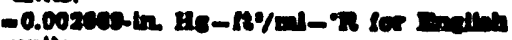
unita.

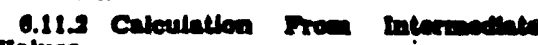
velies

$$
\begin{aligned}
& I=\frac{T_{0} V_{\operatorname{men}} P_{001} 100}{T_{\min 0,0} \lambda_{0} P_{0} 00\left(1-L_{06}\right)} \\
& =x_{1} T_{0} P_{0} T_{0} V_{0}=\frac{\operatorname{com}}{\left(1-\delta_{0 n}\right)}
\end{aligned}
$$

Inanim the

wher:

Lis $=4.320$ for metrite andts -0.00480 for Endling weile.

e.12 Acceptable Rewilts il 0 percent I

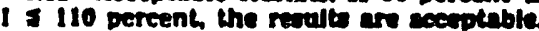
If the partleulate rejulte ar for th covapart son to the standard, and I t over 110 per. cent or leve than 90 percent the Adminiter. in may nceept the resulte cineten 4 in the or mas aceepl the resulk claselon 4 in the inte nes "pII nlolll.y Jindementes. II I is Judeed to be ".on... illinhle. rrbent the parteulate ravelle led o.peral the lemt

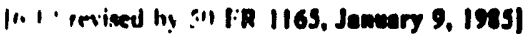

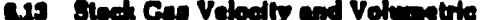

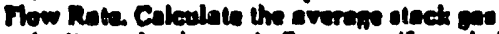
veloetly and votumente how rale. If meeded. catme date oblatined In iblo method and the carallem in 8oction 2 and as of Mothed 2

16.13 added by 52 FR 34639, September [4, 1987]

\section{Allemative Procodured}

17. aded by 49 FR 39011, Avgene 26. 1983)

7.1 Drs on Meter a a Callbratlon Otandnrd A dry gas moter may be uned as a - Alloritton standard for volume messure ments In plese of the net leat meter meet. thed in Eection B.3, provided that it is call. crated indthilf and reallireted periodlealls e follown

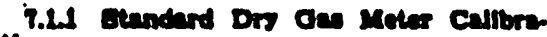
thon.

T.L.1.2 The tor ens meter to the evflurated and und is a encondars reference meter chould be of hich quallty and have in ap. proprtately of acd eapolty. e. 3 ilters/ret

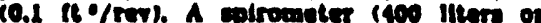

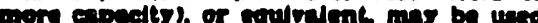
ic

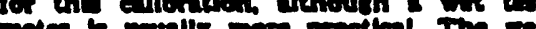

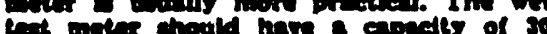
then/res (1 $\mathrm{n} \% / \mathrm{rm}$ ) and eapuble of

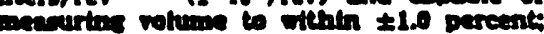

wet lent meterr chould be ehecked natingt optroneler or a llquild dipplinesment meter to moure the sceuracs of the wet lest meter. optrometers or wel teat nieters of other abce mas be uaed provided that the soret Iled eccurnetes of the procedure are maln. inined.

7.1.1.2 Det us the components is shove in Iroure 5.7. A mplromeler. or equlunlent. may be used in place of the wel lest metrs minutee at a flow rate of about $10111 \mathrm{crm} / \mathrm{m} / \mathrm{n}$

$(0.38 \mathrm{~cm}$ lo condilion the Intertor surfince of the wet test meter. The pressure drop In dlated by the manometer at lise inict slde of the dry an meter should be m/nimired Ino revter then $100 \mathrm{~mm}$ 11, O (4 In. 11,0$)$ at - Dow rate of 30 llters/min (1 cfm)!. Thits on be secomplinhed by using larpe illame. ter tublese connectlom and straicht pipe IIt An.

7.1.1.3 Colleet the date as ahown in the crample dals sheet (see Figure S-R). Mfake intolleate mon at each of the how rates and at wo lea than five difreremt how rates. The range of flow rate should be between 10 and 34 Aters/min $(0.35$ and $1.2 \mathrm{fm})$ or over the $e x$. peted operatins rance.

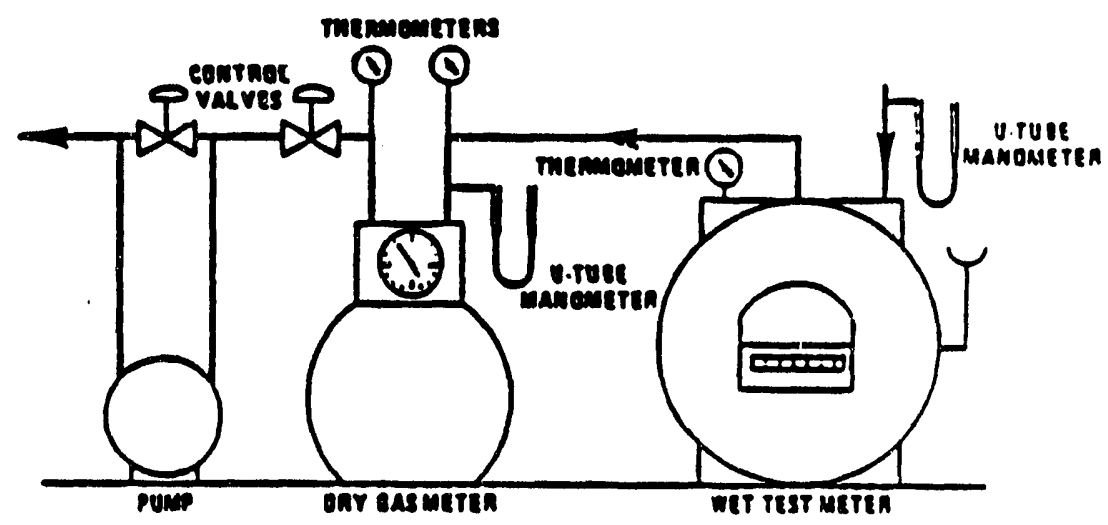

Pigun 2.7, Equibment arrangement for dry-ges moter ealibersion. 
care:-

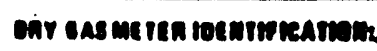

canoute tanc paterone orts inm

\begin{tabular}{|c|c|c|c|c|c|c|c|c|c|c|c|}
\hline \multirow[b]{3}{*}{$\begin{array}{c}\text { Arpnoxmare } \\
\text { Plownaie } \\
|a| \\
0\end{array}$} & \multirow{3}{*}{ 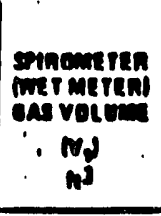 } & \multirow{3}{*}{ 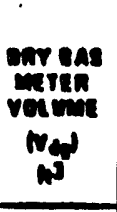 } & \multicolumn{4}{|c|}{ remerantunes } & \multirow{3}{*}{ 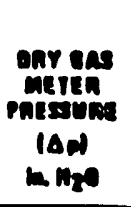 } & \multirow[b]{3}{*}{$\begin{array}{l}\operatorname{Tim} \\
101 \\
\text { ate. }\end{array}$} & \multirow[b]{3}{*}{$\begin{array}{c}\text { Plgy } \\
\text { ante } \\
\text { vel } \\
\text { ind }\end{array}$} & \multirow[b]{3}{*}{$\begin{array}{c}\text { meren } \\
\text { merten } \\
\text { coefrienent } \\
\text { (rod }\end{array}$} & \multirow[b]{3}{*}{$\begin{array}{c}\text { avenpos } \\
\text { meten } \\
\text { coespieient } \\
\left|\gamma_{a}\right| \\
\end{array}$} \\
\hline & & & \multirow[b]{2}{*}{ 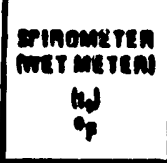 } & \multicolumn{3}{|c|}{ ear eas citren } & & & & & \\
\hline & & & & $\begin{array}{c}m i 1 \\
4\end{array}$ & ource & $\begin{array}{c}\text { Avenace } \\
\text { fis } \\
4\end{array}$ & & & & & \\
\hline \multicolumn{12}{|l|}{0.40} \\
\hline & & & & & & & $\cdot$ & & & & \\
\hline \multirow{2}{*}{\multicolumn{12}{|c|}{0.0}} \\
\hline & & & & & & & & & & & \\
\hline & & & & & & & & & & & \\
\hline \multicolumn{12}{|l|}{0.60} \\
\hline & & & & & & & & & & & \\
\hline \multirow{2}{*}{\multicolumn{12}{|c|}{ ist }} \\
\hline & & & & & & & & & & & \\
\hline & & & & & & & & & & & \\
\hline \multicolumn{12}{|l|}{1.20} \\
\hline
\end{tabular}

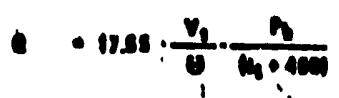

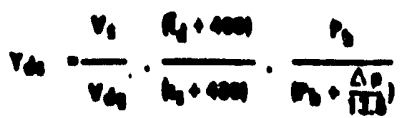

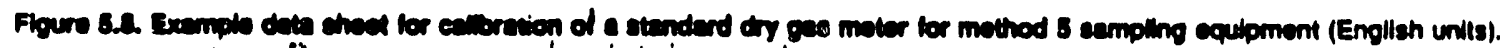

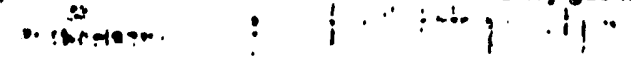

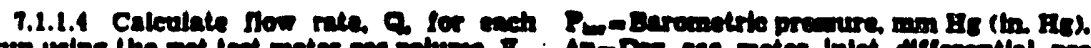

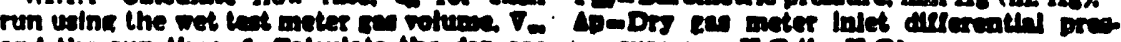
and the min time. e. Caleulate the dis to.

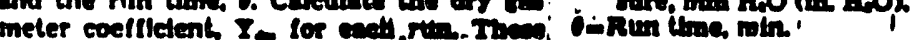

7.1.LS Compart the throe I. value at chet of the Dow ratea and determing the

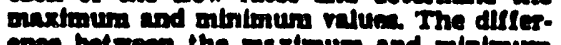
ence between the maxtruum and rolntmum ralues at each Doo rate should be no meat F thas 0.030. Extro ceth of triplleate rum mas be made in order to complete this ro gulrement in addillua the meter coelo.

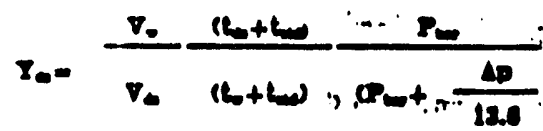

Where:

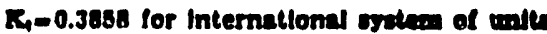
(ais: 17.04 for Enslloh mite.

V.- Wet leat metes volume thens (R).

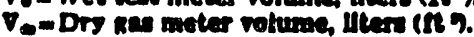

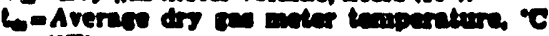
(')

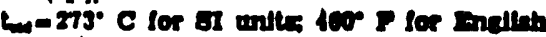
untle.

h-Avernose wot lest moter tempernture, "C ('P).

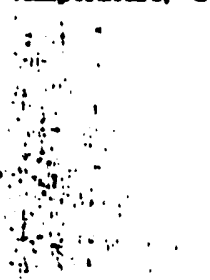

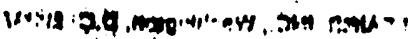<smiles>[C]1C23C=CC12C=C3</smiles>

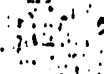

$\therefore$

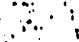

\section{Whother recillbritlon is requiled.}

Ho.
7.1.2.1 Recallbrate the standard dry 202 meter aralunt a wet test meter or apiromelner annually or aller every 200 hours of clion. whichever comes firet. Thls re ment is volld provided the standard dr meler in kept in a laboratory and. If Lrans ported eared for a eny other laboralory In. otrument Abure to the standard meter may caube a change in the callbration and wili require more frequent recallibrations.

7.1.22 A an elternative to fult rmcalibra. Hon. - two-point elltbrallon chect mny be made. Foltor the same procedure and equipment arrantement a for a full rrenll. bration but run the meter al only two llnw

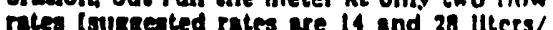
inles $(0.5$ and $10 \mathrm{c}(\mathrm{m}) 1)$ Calculate the mrict coeffledents for these two points, and rnin. pare the valuea with the meler calloralinn curve. If the two coeffleients are vithilin t1. percent of the calibration cirre velums the thene nor ratee the meter need nol be recallbrated untll the next dale for a re. ealloration ehcet.

7.2 Critleal OAfiess A. Callhralinn Slondurta. Critleal orfilees may he used ng

\section{eallbrallos atandard in plices of the mal leel}


mpice rpeatiod in section as provided the thim on colveted ealltenlat and end followe

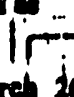

17.2 added by 52 FR 9658. Marel to [987]

9.24 Destlon of Crtteal Othase

7.21.1 The proesdre that followe

descertbes the wes of hypodernte neadics

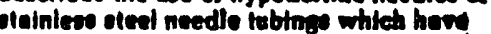
bern found ewileble fon wes atteal

orifles. O1her moteriationd erflienl orther

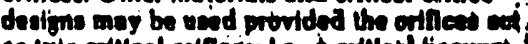

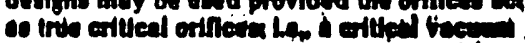

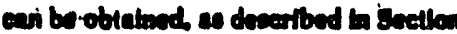

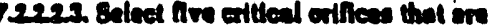
oppropulatel efaed lo cover the remen of tov. vies betwein 20 and s4 Htem/ inta of the

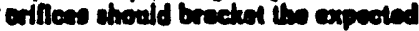

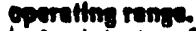

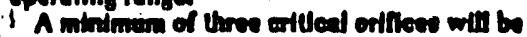

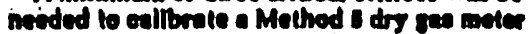

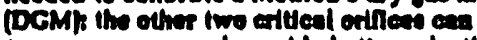

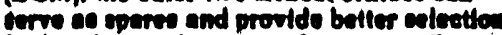
for breseteting the rans of opereting flow rater. The needle abses and lublng lemethe chom balow to be fellowith eponotinate thow balow

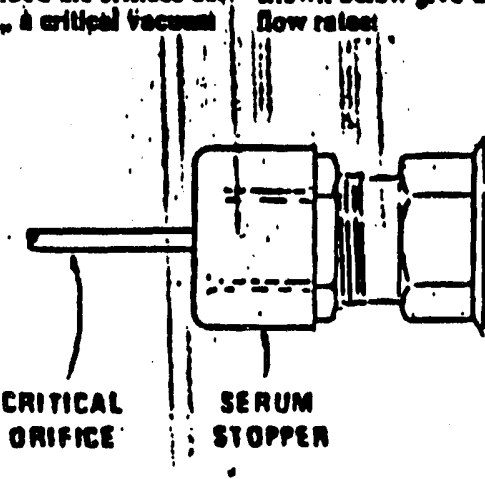

.

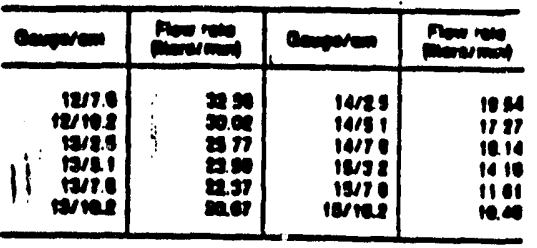

7212 Thoes needien can be edepted to Mothod type anpling train os followe: insert a cerrem bollle stopper, 13. by $20 . \mathrm{mm}$ aleeve type. Into a 4 -inch Swegelok quick conneet. Insert the nowdle into the olopper as chown to frowe gat

Figure 5-9. Critical orifice adaptation to Method 5 metering system.

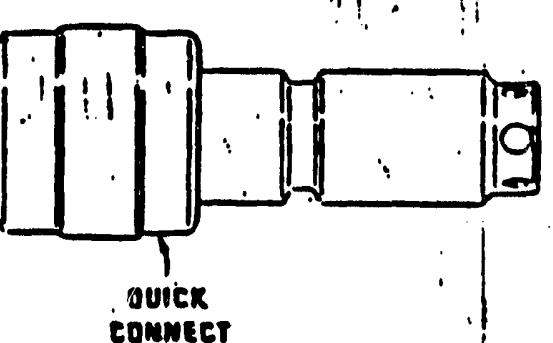

CONWET

$$
\therefore \text { " } \because \text { i i : }
$$

922 Critieal orthes Callbollon The

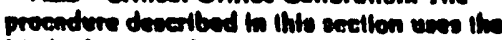

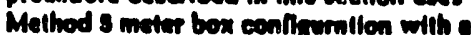
DCM es dewatbed in section 2.1.0 10

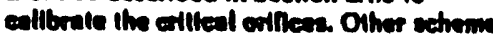
nasy be ened moject is the apprevel of the Adenimitetretes.

7221 Callbretion of Meret Bor The

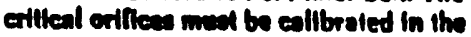
come conflyorallow as thes will be read lo there should be no cosinections to the inlet of the oritien.

7.221.1 Before eallbrating the meter box. leak ehreek the oyalem at lollowe fully open the course adfet valve, and complately clowe the by-pees valve. Plos the inlat. Then iru on the panpe and dotemaine whether there is

$$
\begin{aligned}
& \text { I inim! ist } \\
& \text { be anes } \\
& \text { n., - in ments. }
\end{aligned}
$$

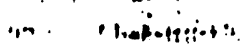

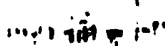

Le. no delecteble movement of the DCM diol hall be coren for 1 minute.

72212 Chect also for bakeres in inet portion of the eampling train belween the

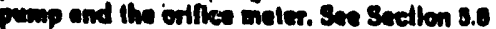

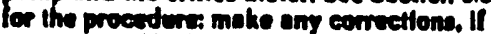
moceseary. If lapkoge is dolected cheek for arecked geokete, loow Hillnge, worn Oringer

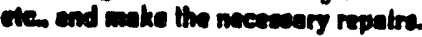

7221.5 Alter deleminimg that the mater box is leaklese. ciblibrale the meter box eccording to the procedure trom in section si. Moke sure that the wel lest meter meets the requiremente stoled in Section 7.1.1.1. Check the water level in the wel leat mater. Reeond the DCM eallbrallow fecter. $Y$.

7222 Callbratlon of Crilleal Ortliree. s-

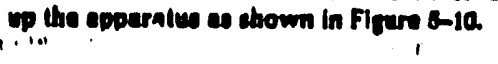




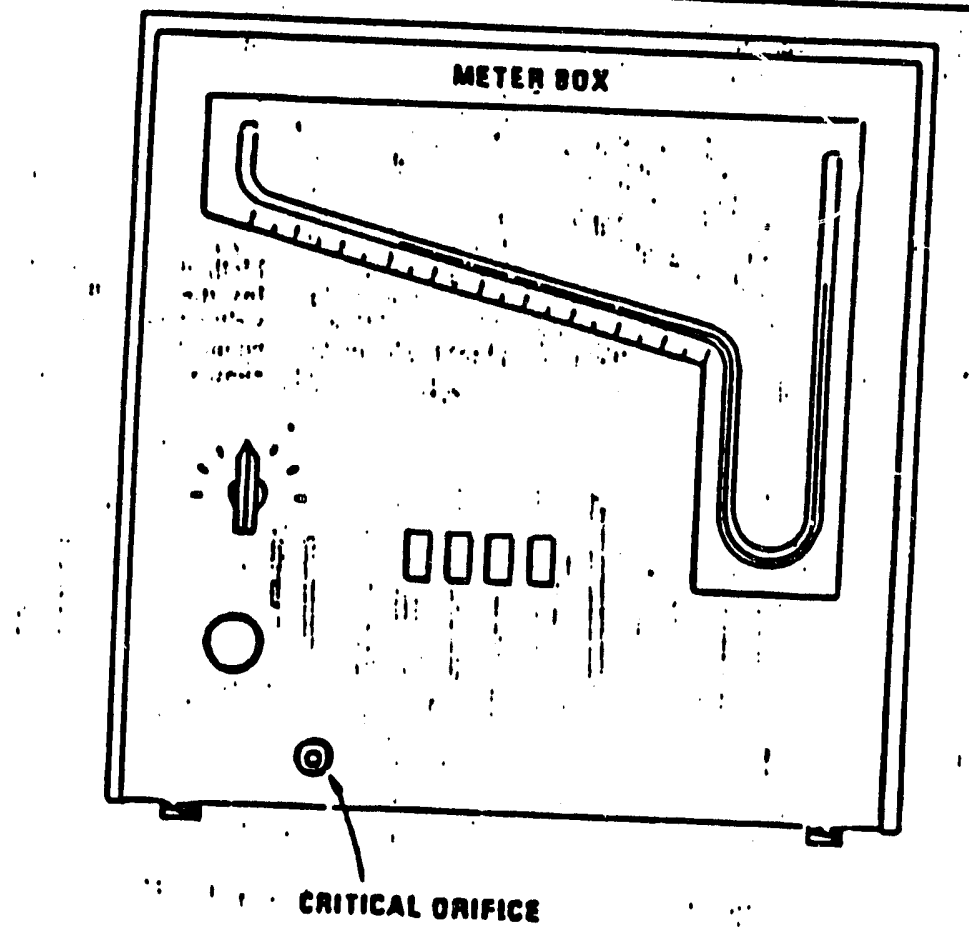

\section{Flqure 5-10. Apparatus setup.}

7.22.2.1 Allow a warm-up lime of 89 minmim. This olep is importent lo equillonste the lamperature conditions throwh the bey 7.22 .22 . lanok check the gytem os in

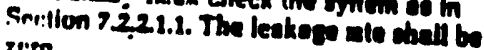
ring.

?:...9 Drfiom ralilirniling the crilleal

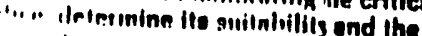

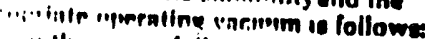

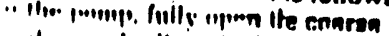
11. . onel nellinst llee hypase volve to

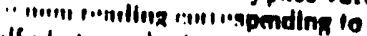

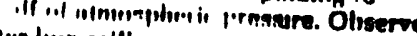

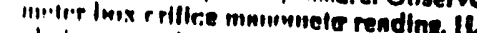
l., lils Incisnan the var:uum meding ungil

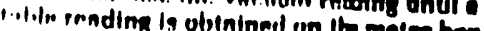
wilier minnnmeter. Recoed the otllest bed

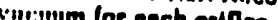

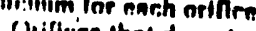

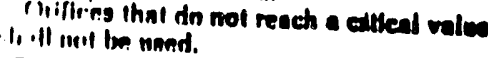

7.2.2.1 Oblatn the harmmente preserm

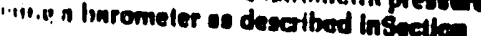

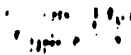

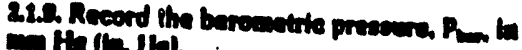
… He the Ihe

$$
\text { 7222: }
$$

72225 Conduat dupleale rom at rewon of 23 to $80 \mathrm{~mm}$ Holt lo $2 \mathrm{~L}$. II) obowe the cotileal vecuma. The rwe shall to at least 8 minilles ench. The DCM volume

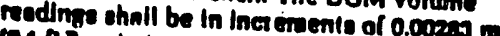
(0.1 17 os in inerements of complete nuolutions of the DCM. As a guideltan, the

$$
\text { of the DCM. As a guidelian, the }
$$$$
\text { K' - Critieal orthee contmelom }
$$

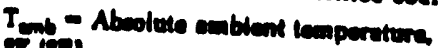
Trions

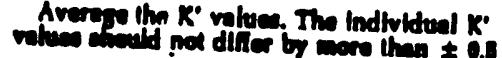

Himes ahould not differ by more than 9.0 cecondo feht Includes allownnea lor chningme

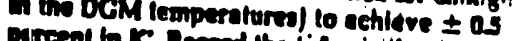
pircent in K. Recend the fif forvisitha llated in

7222.5 comected by 82 FR 22000. lune 16

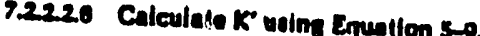

where:

$K=\frac{K_{1} V_{-} Y\left(P_{-}+\Delta H / 13.0\right) V_{T}}{P_{-} T_{-} \theta} E_{q . ~ s-0}$

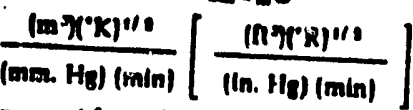

perome the the averose

T.22.20 cometed by 12 FR 22000, jone 10.

7.25 Uatm the Crilleal Oriflean as Callbrattea standarda.

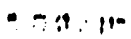

$\therefore 11$ Entronment pepertion
} 
7.2.3.1 Recurd the burometric preasure.

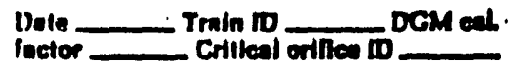

\begin{tabular}{|c|c|c|c|}
\hline \multirow{2}{*}{ Ory gas moler } & & \multicolumn{2}{|c|}{ Aun No. } \\
\hline & & 1 & 2 \\
\hline 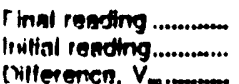 & $\begin{array}{l}m^{3}(n) .- \\
m^{\prime}(i n j)-\infty\end{array}$ & & \\
\hline 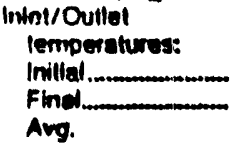 & 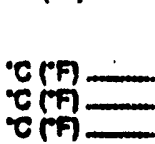 & 1 & $!$ \\
\hline Thme. & $\min / 2 x$ & 1 & 1 \\
\hline 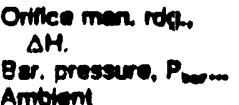 & 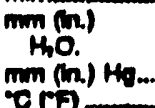 & & \\
\hline Pump vecum & 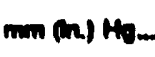 & & \\
\hline Averegen... & & & \\
\hline
\end{tabular}

Figure s-11. Dala sheet for doterndutag $K$ Puctor.

7.25.2 Collibrute the motering ayalem errording to tha pmendore netlined th Sneltona 7.222.1 10 7.222.6. Recond the Informalion lialed in Figure 3.12

7.2.3.3 Calculnte the sitind ind volumes of air pasand throught the DCM and the eritteal orifices, and esiletiale the DCM callbentlon lector, Y, vaing the oquatione below"

$$
\begin{aligned}
& V_{m} \text { (sid) }=K_{1} V_{\infty} \frac{P_{m}+(\Delta H / 2300)}{T_{0}}
\end{aligned}
$$

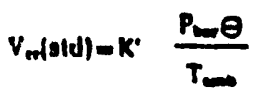

$$
\begin{aligned}
& Y=\frac{v_{\text {mate }}}{v_{\text {max }}}
\end{aligned}
$$

where:

$V_{\text {morw }}=$ Volume of gne semple panaed through the erflical orfiles, corrected to oundurd condilliona, dom' (deet)

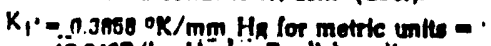
$17.54^{\circ} \mathrm{R} / \mathrm{ln}$. $\mathrm{H}_{\mathrm{B}}$ lor Engltah unith

I.

72.74 Avernger the DGM eallbratlow valines ine narsh no line How ralee. The

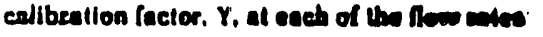

ghoold not difler by move.lbea \pm 2 persend tow the everese.

123.8 To determine the need lor recallbratting the critieal orliteas. compare the DGM Y foetors oblalned frem two adjacem orfilees ench lime $\triangle$ DCM lo ealibraledi for oxumpla. whon eheching 13/2s, use orifieter 12/10.2 and 15/8.2. If any crllical ortiles yloids $n$ DCM Y foetor difinertin by more that 2 pereent from the olhere, recallbrate the entical artilea according to section 7222
Dale Train 10 CHillenl ortilie to _ Critical ortice $X$ faetor

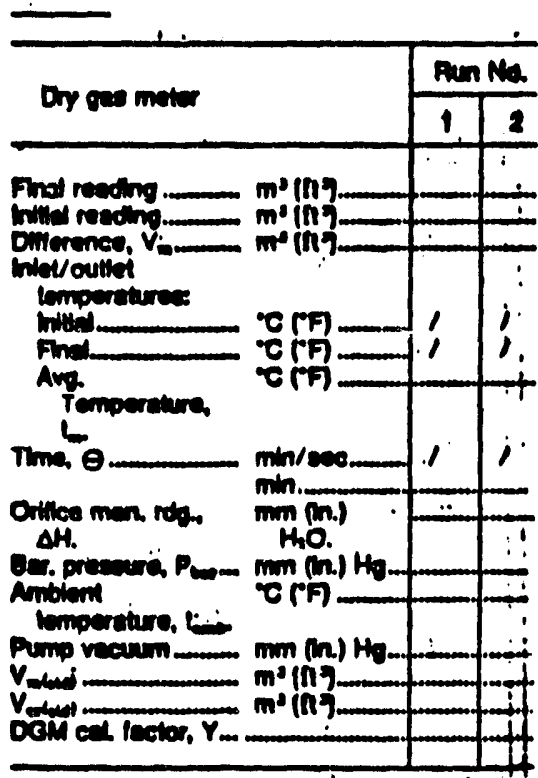

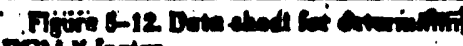
DGM Y lector.

\section{Q Diblowashis}

1. Addendur to Apeedificationa for Inetiner. ctor Tenting at rederal preilister Ptr. ICAPC. Dec. 8. 1907.

2. Martin. Robert M. Conotruction Detall of isotinetse Bource.sconpling Environmental Protection A cency. Recearch Triande Purte N.C. APTD-0Bot. April imi.

3. Rom, Jerome J. Malntenance, Callbra. tom and Operation of Lotinetle source Eumplint Equipment. Imvironmental Pro. ceetion Asency. Research Trtancle Park. N.C. APTD-0675. Mesech, 1072.

4. Smith, W. B. R. T. Bhicehire and W. F. Todd. A method of Interpreting stack Bampline Dath Paper Presented at the 63d Annual Menting of the Alr Pollution Con. trol Aricetation, BL Loule Ma. Jun 14-10. 1970.

B. Emith. W. B. of at steck Oan Bampling improved and simplified with Ner Equib. menh APCA Paper No. 07-111. 1007.
- Speedneatsons tor Inetneralor Trating at Foderd Fellltee PHS. MCAPC. 1967.

7. Bbizehara R. T. Adfustments in the ma Nomostept for Different Pitot Tibe Coetriejents and Drs Molecular Welehis. stact Samplline Newe 2:4-11, October, 1974 .

1. Vollaro, R. F. A Survey of Commerelnlly Arallable tratrumentation For the Mresure. ment of LoT.Ranse ONe Velocttles. U.S. In. rironmental Protection Asencs. Emissinn Mescurement Branch Research Trianfile Part. N.C. November, 1970 (unpubllshed paper).

1. Annual Book of ASTM Standards. Part 20. Onreoue prets: Coal and Coke; Atmos. pherte Analysta Amertean Society lor Teat. ine and Matertale Philedelphita, P2. 1074. pp. 017-622

10. Pells, L. O. O. 1. Clinurd. O. 2. Leces. and J. D. MeCaln. Inertlal Carcade Impac. tor Subatrate Medis tor Fue Ons Sampline. Os. Environgrenlal Protegtion Arency. Re.

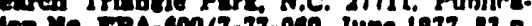

11. Teetlin, P. $R$ und $R$. T. Bhlgeharn. procedure for cilloreting end Usine Dry procedure for Calbrating and Using Dry and Voume Meters a calbratlon stand.

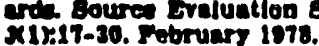

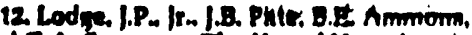
and G.A. 8 waneon. The Uee of Ilyportermic Needles as Crifical Orinees in Air Snmpling. 1. Alr Pollutlon Control Aecoctallon. 10:1972002 1 rea

112. added by 32 FR 9698, March 26. ianti

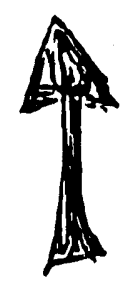

mamarion or Panticolate

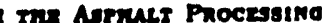
oprwa Imoverser

ided and corrected by 52 nber |4, 1987| 2d prineiple.

by. This method apslles to I of partleulate emicolons ine induatry process salu. dils. and other cources as rulationa.

?ertleulate malter is with conmentelly frow the source and atemperature of $4 r^{\circ} \pm 10^{\circ} \mathrm{C}\left(108^{\circ} \pm 18^{\circ} \mathrm{F}\right)$. Theteriar ration temperature. Is dectermined gravi. metrically alter removel of uncombined rater.

2.1 Bamollng Traln. The eampline traln conilmuration in the same as shown in Mrure s-1 of Method s. The anmplins train consiate of the following components:

21.1 Probe Norete, Pilot Tube, Differen. tal Presoure Qause, Intiter Holder. Condens. er, Metertins System. Barometer, and cies Denatts Determination Equipment. Snme ns Mathod 5, Betlon 2.1.1, 2.1.J to 2.1.5, ind 21.7 w 2.1 .10 , respectively.

21.2 Probe Liner. 8ame as In Methor 9. Sectlon 2.1.2. With the note thint at high itack on lemperatures (treater then $250^{\circ} \mathrm{C}$ 
Revision No. 0

Date May 1, 1979

Page 1 of 3

\subsection{REFERENCE METHOD *}

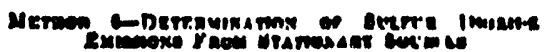

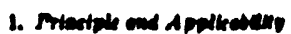

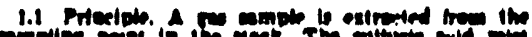

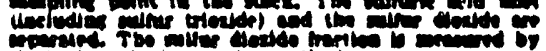

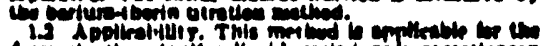

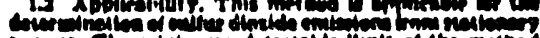

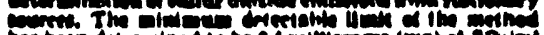

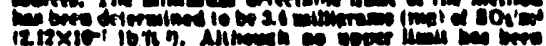

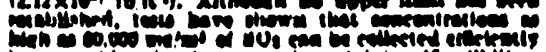

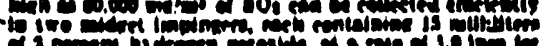

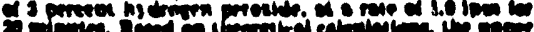

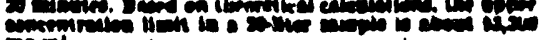

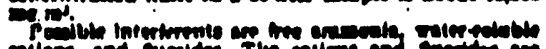

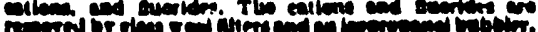

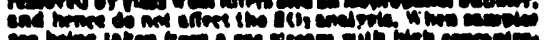

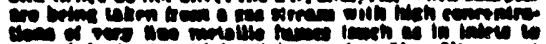

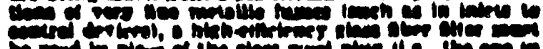

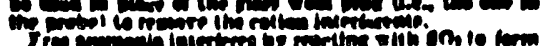

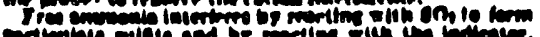

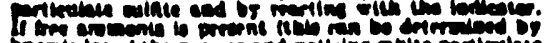

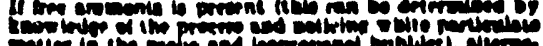

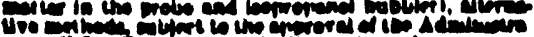

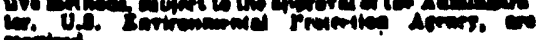
2. Apencise

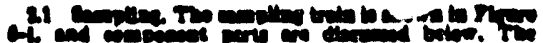

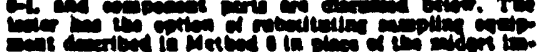

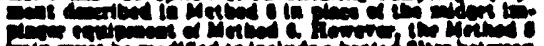

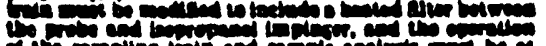

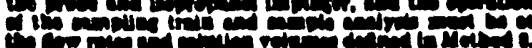
on som

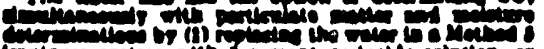

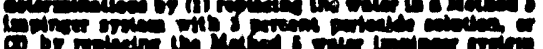
Cif thach

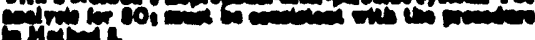

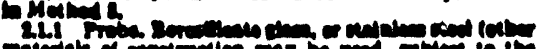

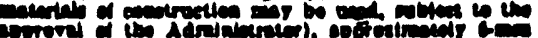

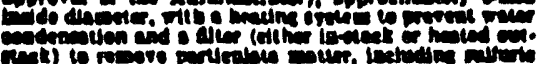

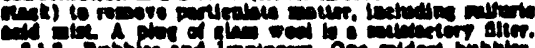

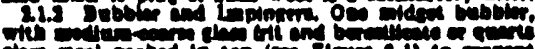

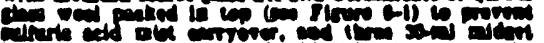

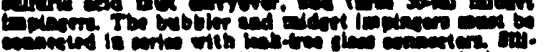

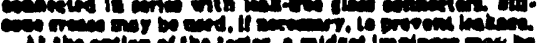

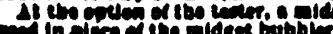

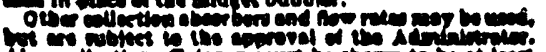

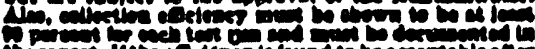

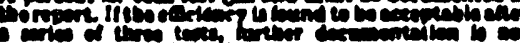
conter os to

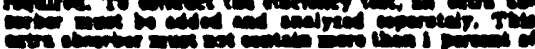

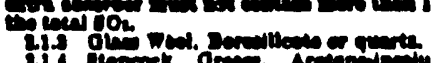

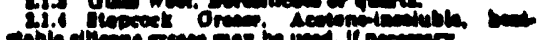

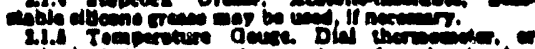

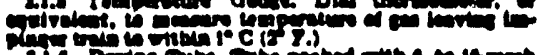

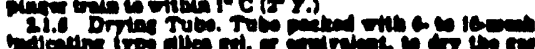

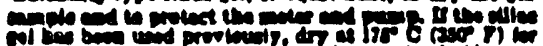

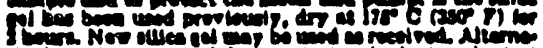

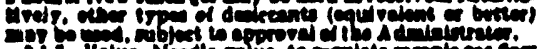

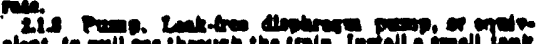

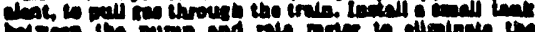

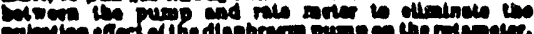

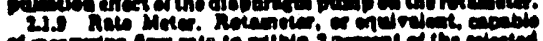

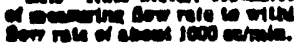

*40 CFr 60, July 1, 1978

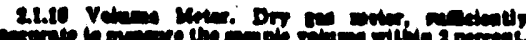

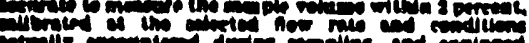

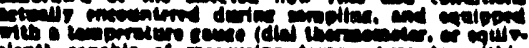
C(s,p).

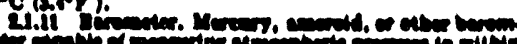

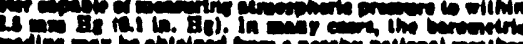

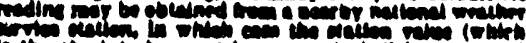

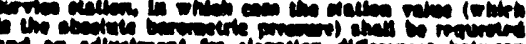

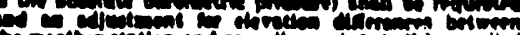

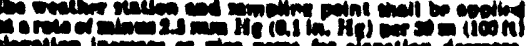

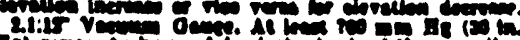

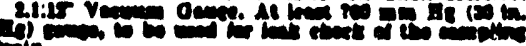

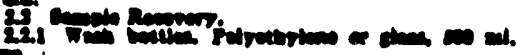

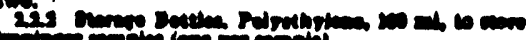

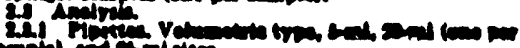

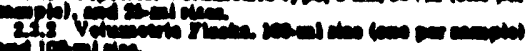

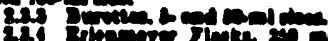

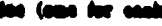

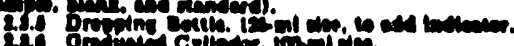

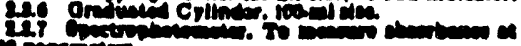
10

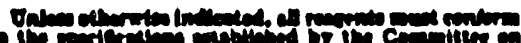

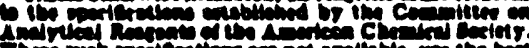

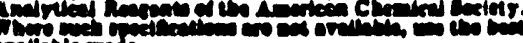

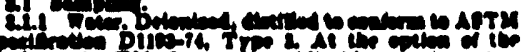

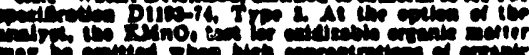

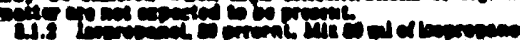

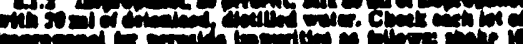

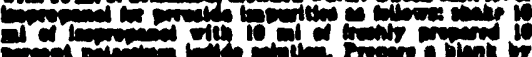

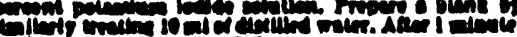

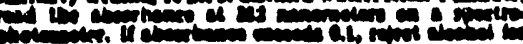

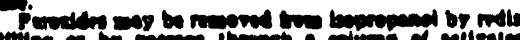

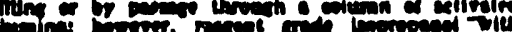

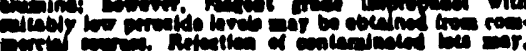

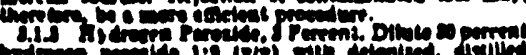

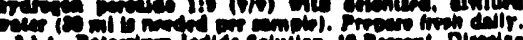

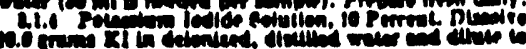

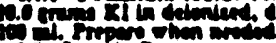

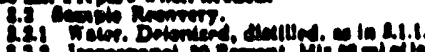
21.2

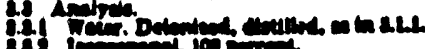

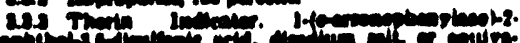

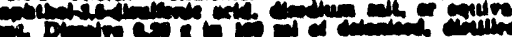

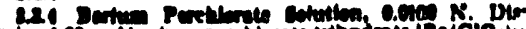

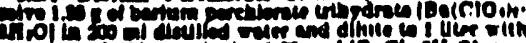

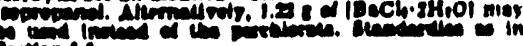

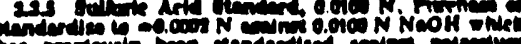

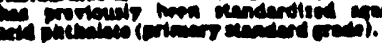

4 mondencen.

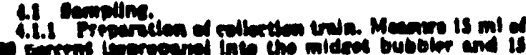

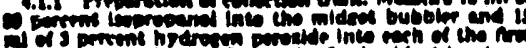

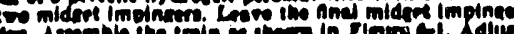

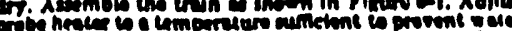

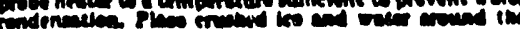
Extrome

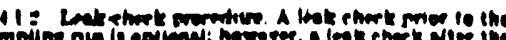

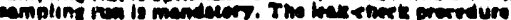

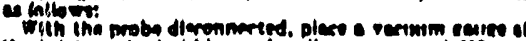

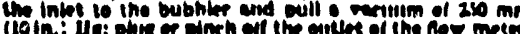
Hi. Lt: Din ff

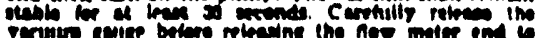

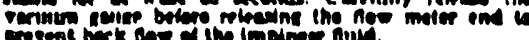

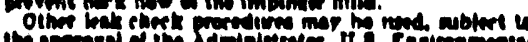

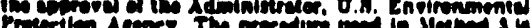

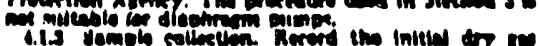

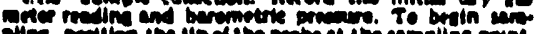

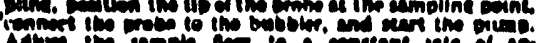

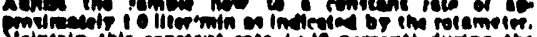

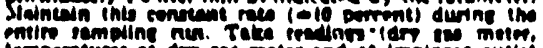

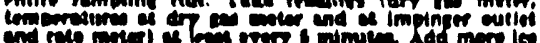

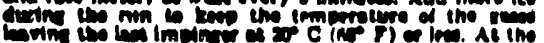

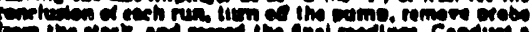

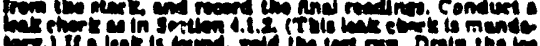

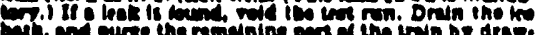

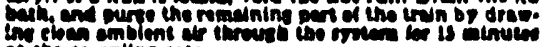
give sempling nelc

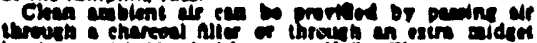

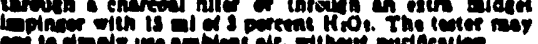

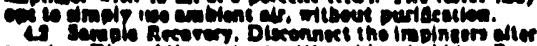

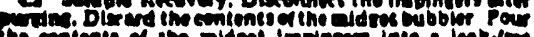

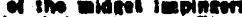

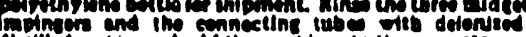

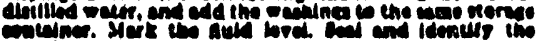

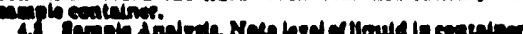

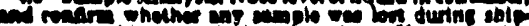

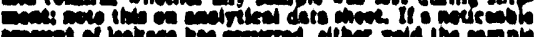

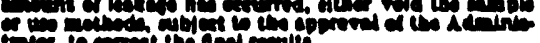

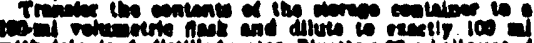

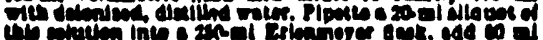

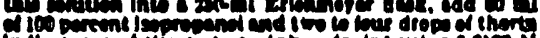

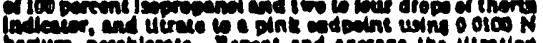

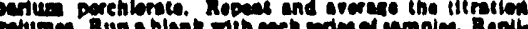

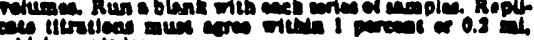
whebove to ines.

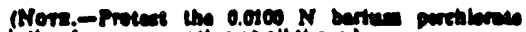

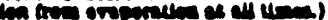

a. combresion

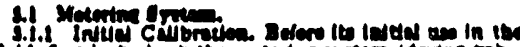

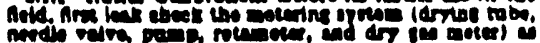

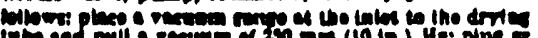

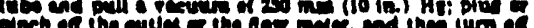

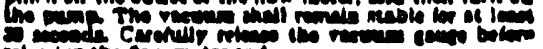

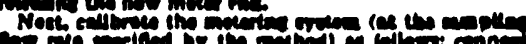

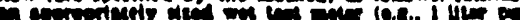

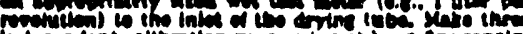

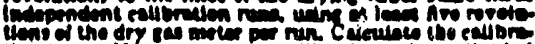

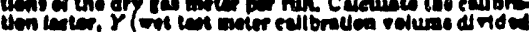

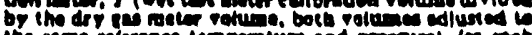

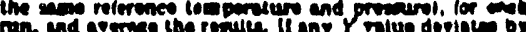

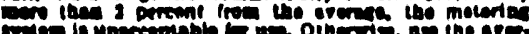

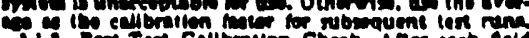

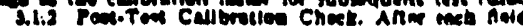

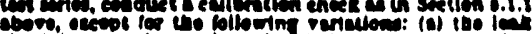

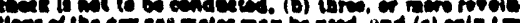

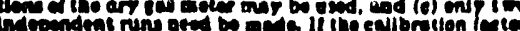

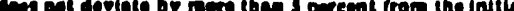

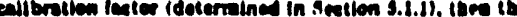

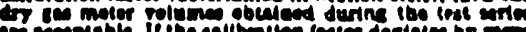
rescen

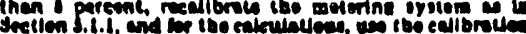

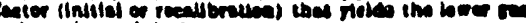

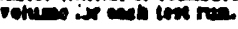


Revision No. 0

Date May 1, 1979

Page 2 of 3

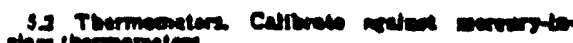

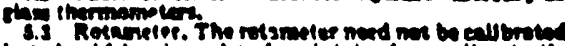

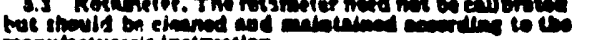

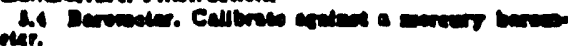

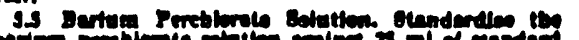

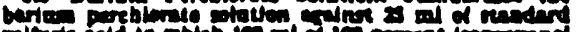

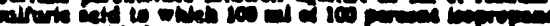

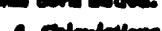

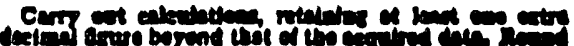

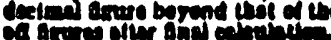

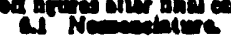

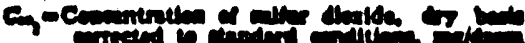
fotheris.

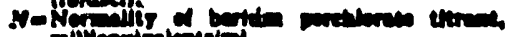

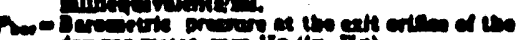

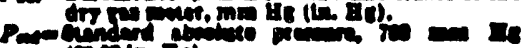

Pom trition.

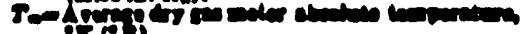

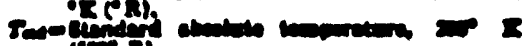

(4) 3 .

Y.0. in

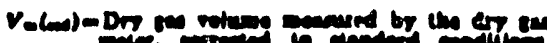
pervent

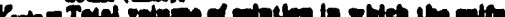

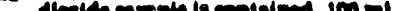

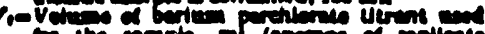

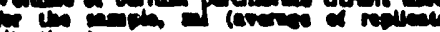
(toritina)

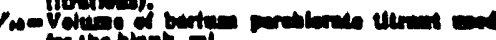

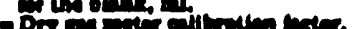

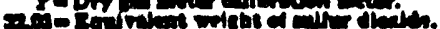

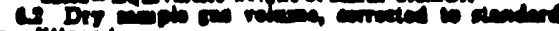

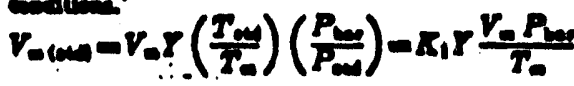

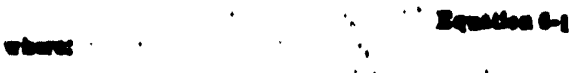

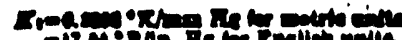

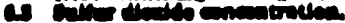

$$
C_{\infty}=\alpha_{1} \frac{\left(V_{1}-V_{\omega}\right) N\left(\frac{V_{\infty}}{V_{0}}\right)}{V_{\text {and }}}
$$

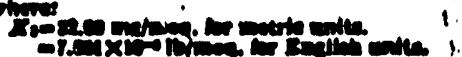

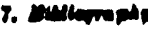

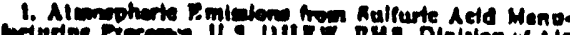

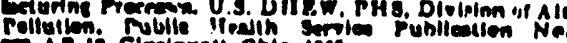
m-A P-12 Clmednrall, Onle. ins.

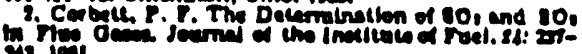

2. Maily. R. Z. and Z. E. Dlohl. Mmantine Flue Oes

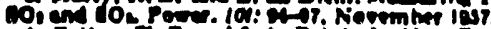

4 Taten W. F. and J. A. Brint. Jo No Enulrme

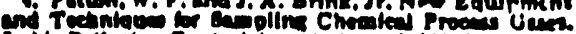
J. At Pelutien Centrel Amestation. 19: 12. 1 ais.

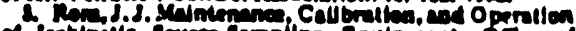

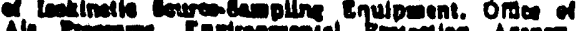

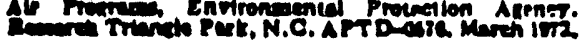
Q. Befll. R. P. and D. B. Comann. Cellabomire

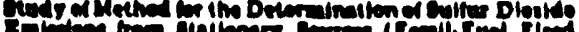

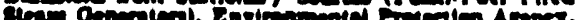
Anem Tranti Pot. N.C. BPA Deconser ifre

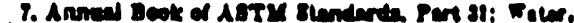

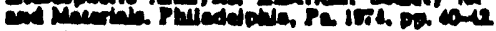

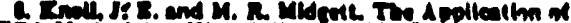

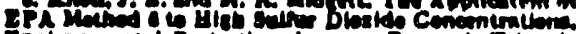

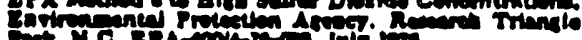

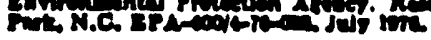

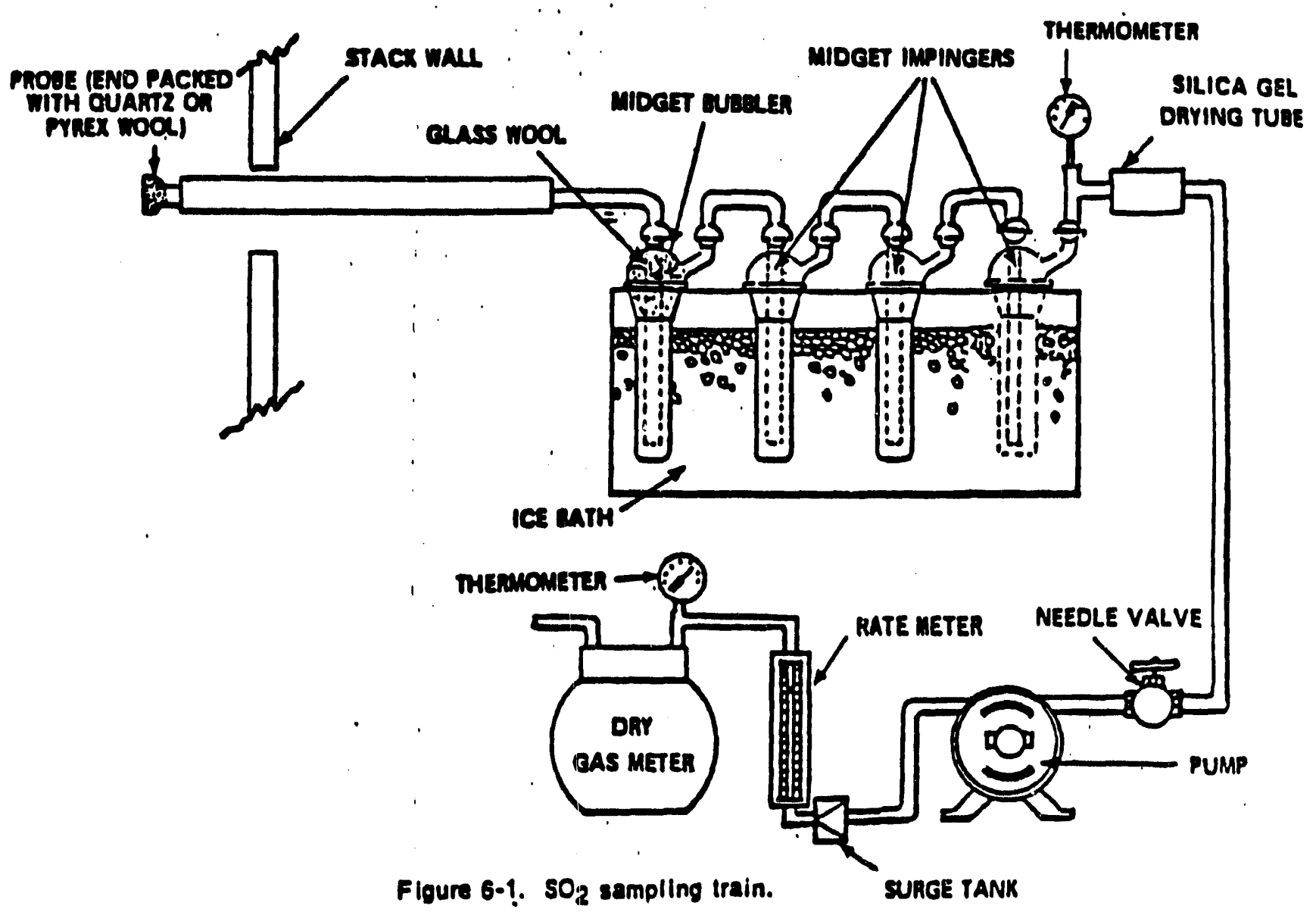


In Method of Appondls A. Bectlon 21. 21.0, 21.7, 214 2.1 .11 2.12.

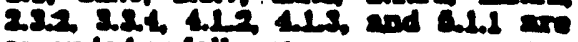
ancendad an follow

1. In Eection 2.1, the word opertos: Ido" in the iourth line of the second

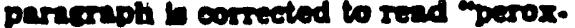
Ide."

2 In sectlon 2.1.6, the word "ulliecen in the thind lins in corrected to read "allien"

3. In Eection 21.7, the word nviun". which appensi trites is corrected to rend "vielve"

4 in Bection 210, the word wdiph. remo" is correeted to read "dile

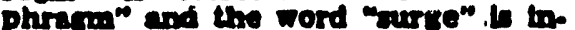

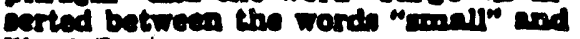
mente- :

B. In Bection 2.1.11, the word "amen. old" is corrected to read " vaerold"

6. In Eeetjon 21.12, the phrise "and Fotinnter" in ineted after the Phres "Vecuum Oauge" and the phries "and 0-10 co/mts rotanetere" of inerited between the wordy " and " to."

7. If Eection 232, the phrase "and

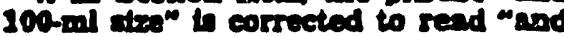
I0000mi gten

A in eection 3.3.4 the word isopro. parol" in the lourth ilse is corrertad co read "ivoprosanol

2. In Geetlon 41.2. delete the int

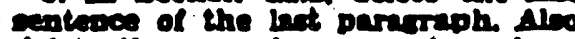

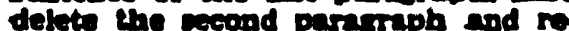
Dince fit with the following paramphe

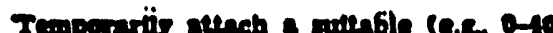
cefminl rotameter to the outset of the as res meter and plecs a nourm rauge ot 0

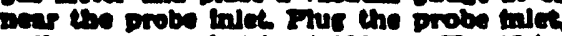

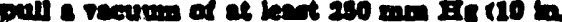

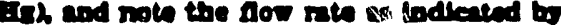

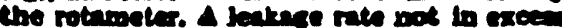
of a percent of the everace earolling ste in cocoplable.

Mose Carefully release the probe tinfet plus bulere turning off the purme.

If 1 magsented (not mandators) that the pump be leat-ebected sepantely, efthes prtor to of after the ampling ron If dowe priter to the sampling run, the purop leakcheet shat precode the leak eheet of the

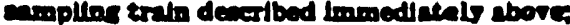
to dove efter the empling rom the porom Ion' eheet indil follow the tring leat-ehect

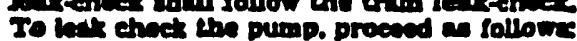

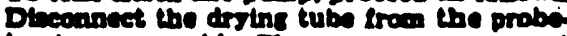

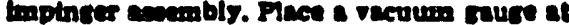

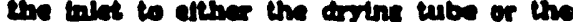
IFump, pull a vecurim of $230 \mathrm{~mm}(10 \mathrm{th}$ ) Be plus or pinch off the outlet of the now acter and then turn ofl the pump. The vecuun abould remals atable for as leat 20 acosed

10. In section 4.1.3, the seatence "If - leat is lound vold the lest run" on the elsteenth line is corrected to read

orf i leat b found rold the teat rum ar un

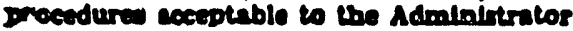
to adjot the amplo volume for chic leats cos."

11. In Bectlon 8.1.1, the word "or" on the alxth ine is corrected to read "ol."

-Federal Register, Vol. 43, No. 57-March 23, 1978 


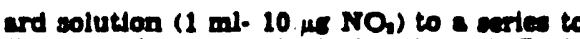

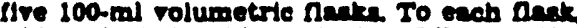
ard $5 \mathrm{ml} \mathrm{of}$ abeorting solution. Dllute to the mart with water. The reoulting colutiom contaln 0.0. 50, 100, 150, and $200 \mu \mathrm{NO}$. $\mathrm{ro}$ ppectively. Mearure the abeorbence by UIreviolet spectrophotometry at $210 \mathrm{~nm}$ unins the blant as a zero reference. Prepare standard curve plottins absorbence in me NO.

Nors If other than a 20-ml sllquot of sumple is uned for anclyale then the amount of abeorbtens solution th the blant and standurct must be adfunted such the the same amount of aboorbtans solution in in the blank and standard as is in the allquot of sample used. Culoulate the spectrophoto meter calibration factor $K$ is follows:

$$
K_{c}=\frac{{ }^{N} M_{1} A_{1}}{N} \begin{aligned}
& A_{1}^{2} \\
& 1=1
\end{aligned}
$$

Where:

M- Man of MO, in rtandard Lo me. A - Abeorbance of NO, standird $L$ N - Total number of callbration standardh

For the set of callibretion standard mpect. fled hero, Dquation 7-1 ctmolleles to the fol lowing:

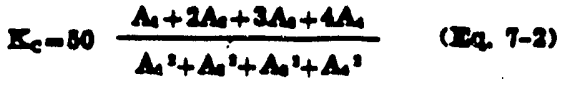

[5.1 Note corrected by 52 FR 34639 , September 14, 1987]

\section{Celculatione}

Same a Method 7. Sectlons 0.1. 6.2, and 6.4 with the addition of the lollowine

6.1 Totel ma NO, Per sample: $M-8 E, A P$

(20. $7-3)$

Where:

$5-100 / 20$, the ellquot factor.

Nore If other than a zo-inl allouot in uned for enengale, the fector 8 must be ropleced by a correapondins fector.

0.2 Relative Ifrror (REE) for Quallty As surance Audits.

$$
R=\frac{C_{0}-C_{0}}{C_{0}} \times 100
$$

Where:

C. - Determined sudit concentration. C. - Actual sudit concentration.

\section{Blaklooruphy}

1. National Instltute for Ocoupationa Burets and Bealth Recommendation for Oceupationd Inpontre to NItrite Aeld. in Oceupational safety and Bealth Reporter. Warington D.C. Bureas of Nationd $A$. faire, ine 1076. p. 140

2 Reanie. P.J. AM. Sumner, and F $B$ Barizetter. "Determination of Nitrate in Raw. Potable, and Warte Waters by Uitra. Violet Spectrophotometrs." "Anelyst" Vol. 104. Beptember 1079. p. 037.

Mrmod TC-Dirmamatron of Nmoon

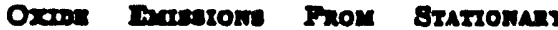

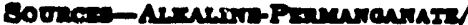
Cosonininic Mmos

[Method 7C amended and corrected by 52 FR 34639, September 14, 1987]

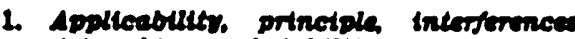
onctition blas and stablitis.

1.1 Applleablilts. The mothod to sppllear bis to the determination of NO, emitedion from forell-fuel fired steam renerntors, electric utillty plantes nitric ectd plantes of other cources as spectifled in the reculations. The lower detectable limit is $13 \mathrm{~ms} \mathrm{NO} / \mathrm{m}^{\prime}$ es NO (7 ppon NO) when ampling at 500 ce/min for I hour. No upper limit hes beet challined: howerer when urine the recom mended ampllns condition the method hes been found to collect NO, unitedon qunntitativels up to $1.782 \mathrm{~ms} \mathrm{NO} / \mathrm{m}$ : a NO (032 ppos NO, ).

12 Prinetple. An interrnted ras sample th cxtrected from the stack and collected in al. Filine-potandum parmanranate colution NO (NO+NO) coniming are oxddtead to NOr and NOn The NOr it reduced to

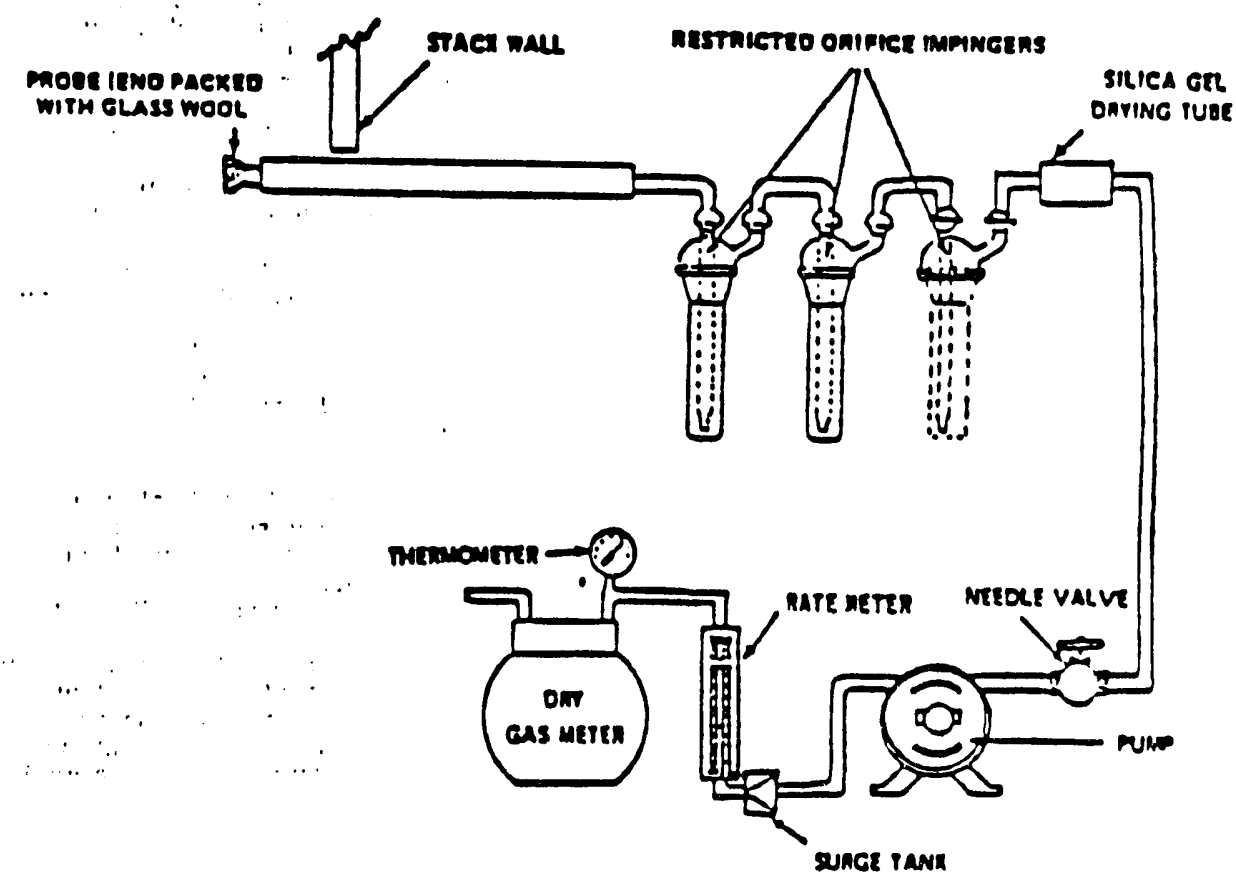

Pigure 76-1. 110 sampling train
NOr with cadmium and the NOr is ans. d colortmetricalls.

1.3 Interferences Poendble Interferences are $8 O_{1}$ and $\mathrm{NE}_{2}$. Alyh concentrations of 8O, could Interfere because SO, consumes MOL- (as does NO, and, therefore, could reduce the NO, collection elflciency. Howev. er. When sumplins emisstons from con. flred electrte utillty plant buming 2.1-per. cent rulfur cos with no control of so, emis. slone, collection elficlency was not reduced. in frect calculations show that samplins $3000 \mathrm{ppm}$ 80, will reduce the MnO.- con. centration by only 5 percent if all the SO, to conrumed in the flist impinger.

NE is slowly oxidtred to NOy- by the abcorbing solution. At $100 \mathrm{ppm}$ NE, in the sas stream, an interference ol $6 \mathrm{pDm}$ NO, (11 mis NO/ms was obarved when the sumple we anvised 10 dase after collection Therefore, the method may not be eppllen. ble to plents uotas NE, injection to control NO enlowion unles means are taken to correct the reculte An equation has been developed to sllow quintitation of the inter ference and is discueved in Cltation 5 of the Hbllocraphy.

1.4 Prectsion and Bias. The method does not exhibit any bla relative to Method 7 .

The within-iaborators relative stindard deviation for a sinmle measurement is 2.8 and 2.0 percent at 201 and $208 \mathrm{ppm}$ NO. respec. trels.

1.5 Stabllity. Collected samples are stable lor at least 4 weeks.

2. Apparatue

21 Sampline and Sample Recovers. The Sampline train is shom in Fyrure $7 \mathrm{C}-1$, and component parts are discused below. Aiter. mative apparatus and procedures are 1 . lowed provided aceeptable sccuracy and pre drion can be demonrtinted. 


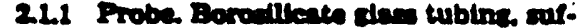
Felentls beated to provent water coodencer tha and equfoped with an in-atect or out atect ollei to remove particulate matter (a phus of cine rool th atratectors for thin

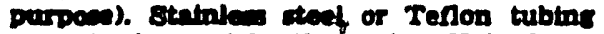
mas atoo be und for the oroba. (Noter Men. ton of trade name or speetifle producta doe not constitute eodorsement by the $0 \Omega$ inavironmental Protection Arencs.)
2.2 Impinger Three reatrictèd-oriflce clan Impincers having the spectification ctven in Frrure 7C-2, are required for each ampline triln. The Implncers must be con. Dected in serice with leak-iree slaes connec.

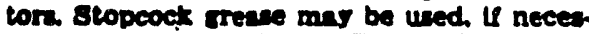
arrs, to provent leakage. (The impingers can be fabricated by slass blower untll they become avallable commereivlly.)

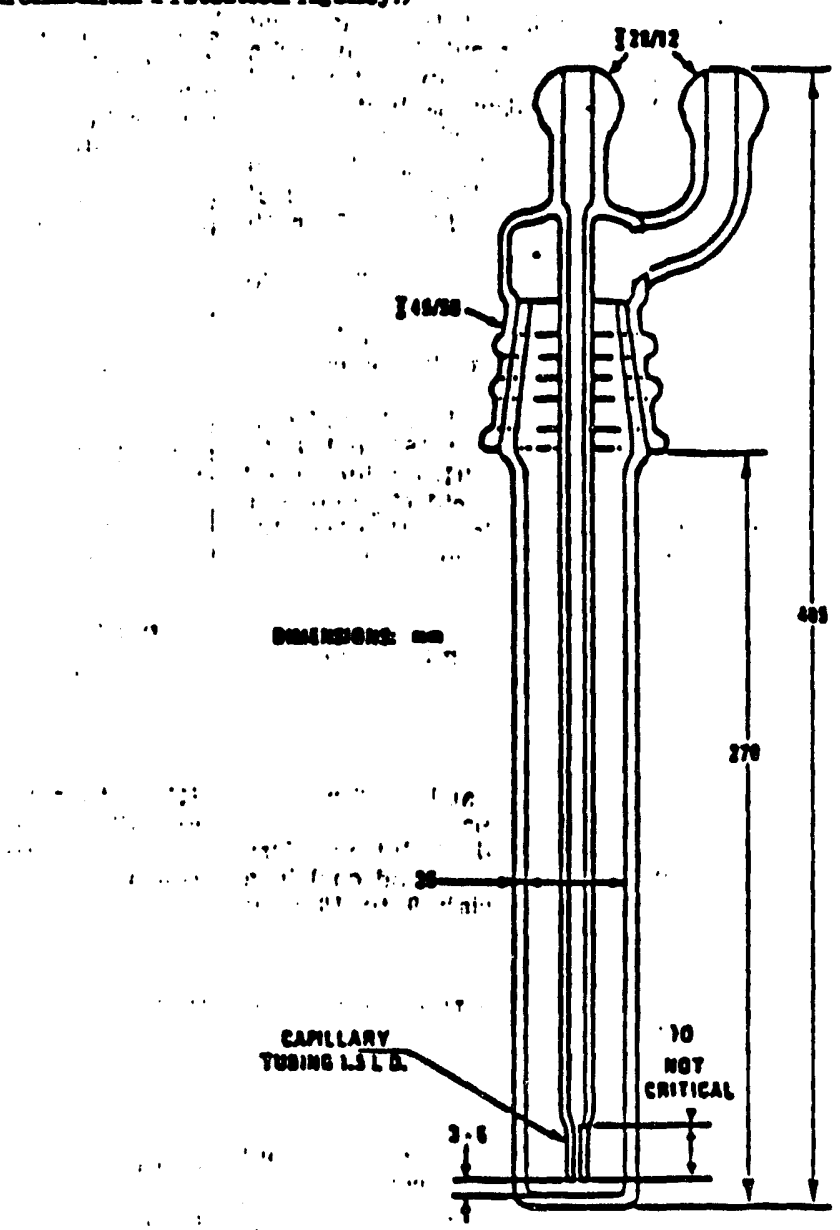

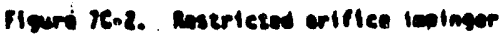

21.3 Glie Wool stopecote Oreace. Drsins Tube, Valve, Pump, Barometer, and Vrevum Gauce and Rotameter. Bame 20 in Nethod o. Scetion 21.3. 21.4 21.6. 21.7. 214 21.11, and 21.12, recoectively.

2.1.4 Rate Meter. Rotameter, or equive. lent sccurate to within 2 percent at the selected now rate between 400 and $300 \mathrm{ce} /$

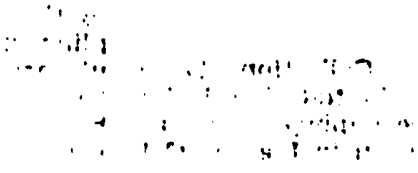

min. Por rotameters a range of 0 to 1 llter/ min in recommended.

2.1.5 Volume Meter. Dry gus meter capable of meanurins the sample volume, under the samplins conditions of 400 to $500 \mathrm{ce} /$ win for 60 minutes within an sccuracy of 2 pereent. 
2.6 Fiter. To renowe NO, trom min ent afr, prepared by adding 20 c of a sens. etrom molecular steve to a cyllindtel tubs. e. E. a polyethylene drying tubs.

21.7 Polsethslem Bottien 1-114x, fo emple recovery.

2.1.8 Frinol and stirtion Rods jor anple recovers.

22 Snmole Preperntion and Analyd

2.2 .1 Bot Finte. Stiring troe with so by 10-mim Tehon-couted stirring bar.

2.22 Betters 400 , c00, and 1000-m an pectiter

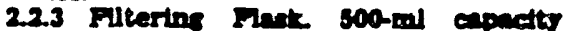
with ste arm.

224 Buchner Junnel $75-\mathrm{mm}$ D. with

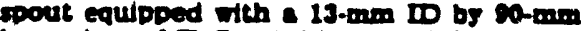
lone plece of Teflon tubtos to mintontes po.

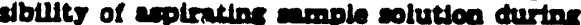
interneton.

2.2 .5 Fuler Peos. Whateng GP/C. 7.0 cin dinmeter.

22.0 Stirtins Rode

227 Volumetrite Finito 100, 204 or 28.

soo-, and 1000-ol enreates.

2.2 Weteb olner io cover can and 1,000-nil beatere.

228 Graduned Cylloder so and ras al expedter

2.210 Pipette- Clne A

2.211 DE Meter. To meanre DE trom 0.5 1012.0

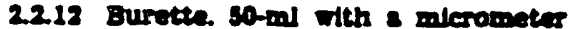

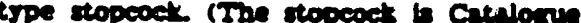

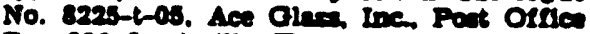
Box No, Louirville. Eentuct's sozol.) Pince - elas wool plus is botton of buretie Cut off burette at a helicht of $43 \mathrm{~cm}$ trom the

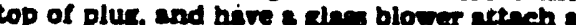
dive funnel to top of burette ach that the dinmeter of the burette roming ementivill unchanged Other weng of esenchton the cuniel are scoeterbie.

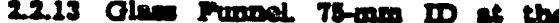
wo.

2211 spectrophotometer. Capable of

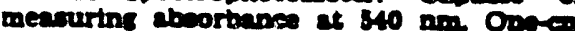
cells are edeque: 2

22.15 Metal Thermometer Blmetnilk thermometers, minge 0 to $150^{\circ} \mathrm{C}$

2.2 .16 Culture Tubes 20 by $190 \mathrm{~mm}$ Bimnx No. 45048.

22.17 Paratlim "M" Obtained trom American Can Compens. Greentats Con necticut 0.830.

$2.18 \mathrm{CO}$ Mesturement raufonent Sine on in Method 3.

3. Reagents

Unles othermive Indicated ill rearent should conlorm to the spectifiction exth lished by the Committee on Andrtion Re renes of the Amertern Chembel Sodters. where such spedilestlon are spillate os.

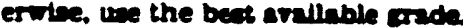

3.1 Snmplins.

3.1.1 Wrter. Delonted distilled to con form to ASTM specification D 1193-74. Type 3 (Incorported by relerenco-iee (60.17).

3.1 .3 Potnalum Permangennte, 40 par cent $(\sigma / \sigma)$. Sodium Brdroxide, 2.0 percent ( $/$ / $)$. Dimolve 40.0 of EQMnO. and 20.0 of NeOE ta $940 \mathrm{ml}$ of witer.

32 Eample Properation and Anilyath

3.21 Tater. Same an in Bection 3.1.1.

8.22 Bulfurte Add Coscentrated E,SO.

3.23 Oxalle seld Solution. Diwoive 48 of oxalle sedd [(COOE)r.2R,O] in water, and dilute to $800 \mathrm{~mL}$ Do not heat the colution.

3.24 Sodium Erdraxide, $0.5 \mathrm{~N}$. Dtwolve 20 s of NaOB in weter, and dilute to t llter.

32.5 Sodium Ejdroxde. 10 N. Dimolve $40 \mathrm{~s}$ of NaOE in water and dilute to $100 \mathrm{ml}$ 32.0 Nhblenedinmibe Tetrencetic Actd (IDIA) Bolution, 6.5 Percent Dirolve 6.5 of imors (dinodium eilt) in weter. and dilnte to $100 \mathrm{~mL}$ solution b bent cocom plinhed by uting a menetie otirner.

327 Column Rtries Eoluttor. Add $20 \mathrm{~m}$ of as percent Fots solution to $800 \mathrm{bl}$ of wete. and adfut the pE to 11.7 to 12.0 with os IN NeOE:

228 Eydrochlorte Aald (ECI), 2 N. Add $8 \mathrm{ml}$ of concentreed ECI to a s00-mil volu metaric and contentoting weter, dllute to volume, and mix wil. stom in s cheren pared botele.

320 Sulfaningide solution Add $20 \mathrm{~g}$ of

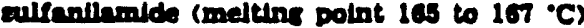
to $709 \mathrm{mi}$ of wier. Add Fith mirting $50 \mathrm{mi}$ concemtrinted phophorte celd (86 percent). and dilute to $1000 \mathrm{mil}$. Ints solution in atable for at least 1 month, if refrtsernted.

$$
\begin{aligned}
& \vdots ., \cdots \\
& \vdots i, !)
\end{aligned}
$$

This colution is atrble for at least 6 month inder inboretors condition

3213 LVO Btandind solution DT wio a $110^{\circ} \mathrm{C}$ for 2 bours and cool in devicenter. Accuritely weteh 9 to 10 of

$$
\text { MS NO, } / \mathrm{ml}=5 \text { of KNO } \times 10^{\prime} \times \frac{62.01}{101.10}
$$

Thls solution is stable for 2 monthe without preservative under Inboratory conditjon.

3.2.14 Spling Solution. Plpette $7 \mathrm{ml}$ of the $\mathrm{KaNO}$ standard into a $100 \mathrm{ml}$ rolumetric Anat and dilute to volume.

3.2.15 Blunt 8olution. Diseolve 2.4 I of ENinO, and 1.28 of NeOE in $90 \mathrm{ml}$ of ater. Altementrely. dllute $00 \mathrm{ml}$ 0.MO./NaOE solution to $100 \mathrm{ml}$

32.10 Qullty Amurnee Audit samples. sene is in Method 7. Section 3.3.9. When requetion sudit enopies, apeelfy thet thes be in the epproprinte concentrution ringe for Method 7C.

4. Procedure

4.1 Snmollns.

4.1.1 Preparation of Collection Trin. Add $200 \mathrm{~m}$ of EMPO./NaOE solution (3.12) to each of three impingers and is cemble the trin an shom in Firure 7C-1. Ulonblp: 4.1 .2
2210 N-11-Naphthsl-Sthylenedinmine (N) Solution. Drasolve 0.8 of $\mathrm{NHOA}$ in $800 \mathrm{ml}$ of water. An sque ou colution should have one absorption gin woy more then one aborp tion peats over thin runce, is impure and should not be used. This solution is stuble

3.2.11 Cadmium Obtained from Mathewa Colemen and Bell. 2900 Bighland Avenue, Norwood, Ohlo 46212. a MM Lab Catulorue No. 2001. Prepare by

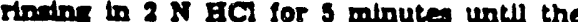
color to allver-tres. Ithen rinse the cadmium wth wher uncll the rinsing are neutral when teated with $\mathrm{DE}$ paper. CAUITON: $\mathbf{E}$ G Ubanted durting prepartion. Prepare in on erhurt hood awey from any name.

3.2.12 NanO standard Solution. Nomb. Concentrution, $1000 \mu \mathrm{g} \mathrm{NO}_{\mathrm{r}} / \mathrm{ml}$. Desic cate'NeNO oremight Aceuntely wetes 1.4 to 1.8 of NaNO (anesy of of percent Nush or rreter). disolve in water. and colo 1 liter. Calculate the exact NO concentartion from the folloming reintionanip:

[3.2.12 corrected by 52 FR 34639. September 14, 1987]

ENo to wthin $0.1 \mathrm{mg}$. disoolve in water. and dllute to 1 liter. Calculate the exact ar concentrution from the following rele

Adjust probe heater to a temperature sulfl. dent to prevent water condensation.

4.1.2 Leal-Check Procedure. A leak. check prtor to the sampling run should be earried out: a leak-check after the sampling run In mandatory. Carry out the leak. chects(s) sccording to Method 6. Section

41.3 Chect of Rotameter Callbration Ac. curney (Optlond). Disconnect the probe rom the firct impinzer, and connect the futer (2.1.6). Start the pump, and adjust the rotameter to read between 400 and $500 \mathrm{cc} /$ min. After the How rate has stabllired start mersuring the volume sampled, as recorded by the dry ins meter (DGM), and the sam. pline time. Collect enough volume to messure accurately the now rate, and calculate the now rate. This sverage now rate must be les than $500 \mathrm{cc} / \mathrm{min}$ for the sample to be valld therefore. It is recommended that the 
Now rate be chected as above prlor to each teot

L.1.4 Sample Collection. Record the ind tial DCM readins and barometric prearure. Determine the sampline polnt or point 16 cordins to the approperinte resulatione ex Section 60.46(c) of 40 CIR Part 60. Poultion the tho of the probe at the amplins polat conneet the probe to the ftrat imptneer, and start the pump. Adfunt the sample now to s value between 400 and $300 \mathrm{ce} / \mathrm{min}$ CAO. TION: HIGEIMR FLOW RATES WWI PRODUCE LOW RJSULTS. Once sdjurted maintain a constant Now rate durins the entire sampline run Sample for 60 minute. For relative sceuracy (RA) teating of contho. uous emiedion monitorm the minimum anm. pline time is 1 hour. sampling 20 minute at each traverse polnt. DNors-When the SO concentration is reater than $1200 \mathrm{ppom}$, the amplins time may have to be reduced to 30 minutes to ellminate plustins of the im. pincer ortifice with MnO. For RA teats with SO. Treater then $1200 \mathrm{ppm}$ sample for 30 minutes (10 minutes at each polat)]. Record the DOM temperature, and cheets the now rate at leant evers 3 minuter At the cosclu. aton of each run turn off the pump, remone probe from the stack, and rocord the fine readings. Divide the sumple volume by the samplins time to determine the sversere now rate. Conduct a leak-ebeck an in Seo ton 1.1.2. If a leat is found vold the tert run. or use procedures scceptable to the Adininistrator to adjurt the sample volume for the learage.

4.1.5 CO, Mearurement: Durtng amplinf. mearure the CO, content of the stect ons near the samplins point uins Method 3. The singlo-point trab simplins procedure it adequate, provided the meacurements are made at leart thries times-Dear the etart midway, and belore the end of a run and

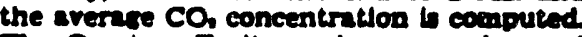
The Orate or Fyrite saviszer mny be und for this andyols

4.2 Sample Recovery. Disconnect the the pinsers. Pour the contents of the tmpinsers into - 1-liter polyethylene bottle uing funnel and a stirring rod (or other means) to prevent splilinge. Complete the quantite Wve tranafer by tinaing the tompingers and connectins tubes with water untw the rtas. Incs that are clear to Usht pint, and add the rinsines to the bottle. Max the momple, and mark the solution level. Seal and Identify the sample container.

L.3 Sample Preparation for Analyale. Prepare a cadmium reduction column as fol. lowe Fill the burette $(2.2 .12)$ with weter. Add freahly prepared cadmium slowls with tappine until no further settllns oecurs. The helstit of the exdminm column should be 30 cor. When not in use, store the column under rinse solution (3.2.7). (Nom-The column should not contain any bands of cadmium fines. This may occur if resenerac. ed column is used and will creatly reduce the column llfetime.)

Note the level of llquid to the sumple container. and determine whether any ample was lont durins shipment. If a notleesble amount of leakse bas occurred, the volume lost an be determined from the difference betreen Initid and final colution levele, and this value an then be aned to correct the andirtieal revult Quantitativels tranafer the contents to a 1.llter volumetric hack and dillute to volume

Take a 100-ol allquot of the sample and blank (unexpoesed KNenO./NaOB) solutlone. and trancifer to $400-\mathrm{ml}$ - beakers contalning mapretle stiritns bars. Oaine a $\mathrm{DB}$ meter. add concentrated B-30, with stirring until a DE of 0.7 in obtrined Allow the solutions to stand for 15 minutea. Cover the beakers

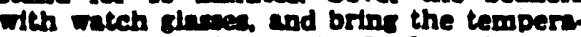
ture of the solucton to $50{ }^{\circ} \mathrm{C}$. Beep the tem. perneture below $60^{\circ} \mathrm{C}$ Disolve 48 ef ox alle acld to a mintmum volume of Deter, ap. proxtmintely $50 \mathrm{ml}$ at room cemperature. Do not beat the solution. Add this colution clowly, in lnaremente untel the EMMO, so Iution becomen colorlen. If the color is not completely removed prepare some more of the above oxalle acid colutton, and add untll - colorice solution b obtained Add an excees of oxalle seld by dimolving $1.6 \mathrm{~g}$ of oralle ectd in $80 \mathrm{ml}$ of moter, and add $6 \mathrm{ml}$ of thit solution to the colorien solution if rumpended matter th prewent add concemtrated ESO, untul s clear colution to obtalned.

Allow the ample to cool to near room cemperature, belns sure that the ample ere atil clear. Adjurt the pB to 11.7 to 12,0 with 10 N NaOE Qunotitatirels tranifer the misture to a Buchner funnel contalning CF/C Olter paper, and filter the prectpltate. mear the misture into $\$ 500-\mathrm{mil}$ futerins gink weeh the colld matertal four time with water. When tutration is complete, Wan the Teflon tubine. qunntutatively trenafer the filtrate to a soo-ill volumetric anit, and dilute to volume. The samples are now reads for cedonium reductlon. Pipette a so-mi ellauot of the ample Into a 130-mi bearex, and add s manetic stirring bar. P1pette in $1.0 \mathrm{ml}$ of 4.5 percent IHDTA solu. toon and onle

Determine the correct stopeock setting to eatablian a nor rate of 7 to $9 \mathrm{ml} / \mathrm{min}$ of column thes solution throung the cadnlum reduction column. Use a sa-mi sradunted ejllnder to collect and mesure the solution volume. After the last of the rinse solution has pared from the funnel into the burette. but before alr entrapment can occur. start adding the sample, and collect it in a 250-m craduated cyllinder. Complete the quantita. Uve tranufer of the sample to the column a the sample parces throush the column. After the lart of the sample has paraed from the funnel into the burette. start adding 60 inl of column rince solution, and collect the trase colution until the colution juat disaspears from the funnel. Quantitatively trane fer the ample to $\& 200-\mathrm{ml}$ volumetric hack $(230-\mathrm{m} / \mathrm{mas}$ be required), and dilute to volume. The samples are now ready for NOn- andreth CNore-Both the sample and blent should so throush this proce dure. Additionnlly, two splked samplea chould be run with evers croup of samplea paraed throuch the column. To do this, pre pare two additional 50-mil allauots of the sample aupected to have the highest NOconcentration, and add $1 \mathrm{ml}$ of the spikdn solution to these allauota. If the spike recorers or column elficiency (see 0.2 .1 ) is below 96 percenh prepare a new column. and repeat the cadmium reduction].

4.4 Semple Analyals. Pipetie $10 \mathrm{~m}$ ample into culture tube. (Norz-Som teast tubes give a high blant NO, value but culture tubes do not.) Pipette in $10 \mathrm{ml}$ of culfanilamide solution and $14 \mathrm{ml}$ of NTDA solution. Cover the culture tube with parn. flim. and mix the solution. Prepare a blank to the same manner using the sumple from treatment of the unexposed EMnO. NaOH solution (3.1.2). Also, prepare a callbration standard to check the slope of the callbre. tion curve. Aster a 10-minute color development Interval, mearure the aboorbance at $340 \mathrm{~nm}$ soulnt water. Read $\mu \mathrm{s}$ NOr/mi from the callbration curve. If the absorbance is greater than that of the hichest callbration standard, pipette less than $10 \mathrm{mi}$ of sumple and enourh water to make the total sample volume $10 \mathrm{ml}$ and repeat the andyale Determine the Nor concentration ualns the calibration curve oblained in sec. tion 5.3 .

4.5 Audit Analyats. This is the same an in Method 7. Section 4.4.

8. Caltoration

\subsection{Dry Gas Metertng System (DGM).}

5.1.1 Initial Callbration. Same as in Method 6. Section 5.1.1. For detalled in. structions on carrying out this callbration. it is sursested that Section 3.5.2 of Citation 4 in the blbiorrephy be consulted.

3.1.2 Post-Test Calibration Check Same $a$ in Method 6. Section 5.1.2.

5.2 Thermometers for DGM and Baromever. Same a in Method 6, Sections 3.2 and 8.4. rempectuvely.

3.3 Callbration Curve for Spectrophot meter. Dilute $5.0 \mathrm{ml}$ of the NaNO, standar colution to $200 \mathrm{~m}$ with water. This solution nominally contalns $25 \mu \mathrm{NOr} / \mathrm{ml}$. Use this solution to prepare callbration standards to cover the range of 0.25 to $3.00 \mu \mathrm{NO}-/ \mathrm{mL}$. Prepare a minimum of three standards each for the linear and slightly nonlinear (de seribed below) runre of the curve. Ose plpettes for all additions.

Run standards and a water blank as in. structed in Section 4.4. Plot the net absor. bance ve ugNOr/ml. Draw a smooth curve through the points. The curve should be linear up to an abeorbance of approximately 1.2 with a slope of approximately 0.33 absor. bance units/us NO-/mil. The curve should pare throush the ortein The curve is slight. 15 noalloear irom an abeorbance of 1.2 to 1.6.

\section{Calculations}

Carry out calculations, retaining at least one extre decimal firure beyond that of the scquired data Round off firures after final calculation.

0.1 Semple volume, dry baris, corrected to standerd conditions. 


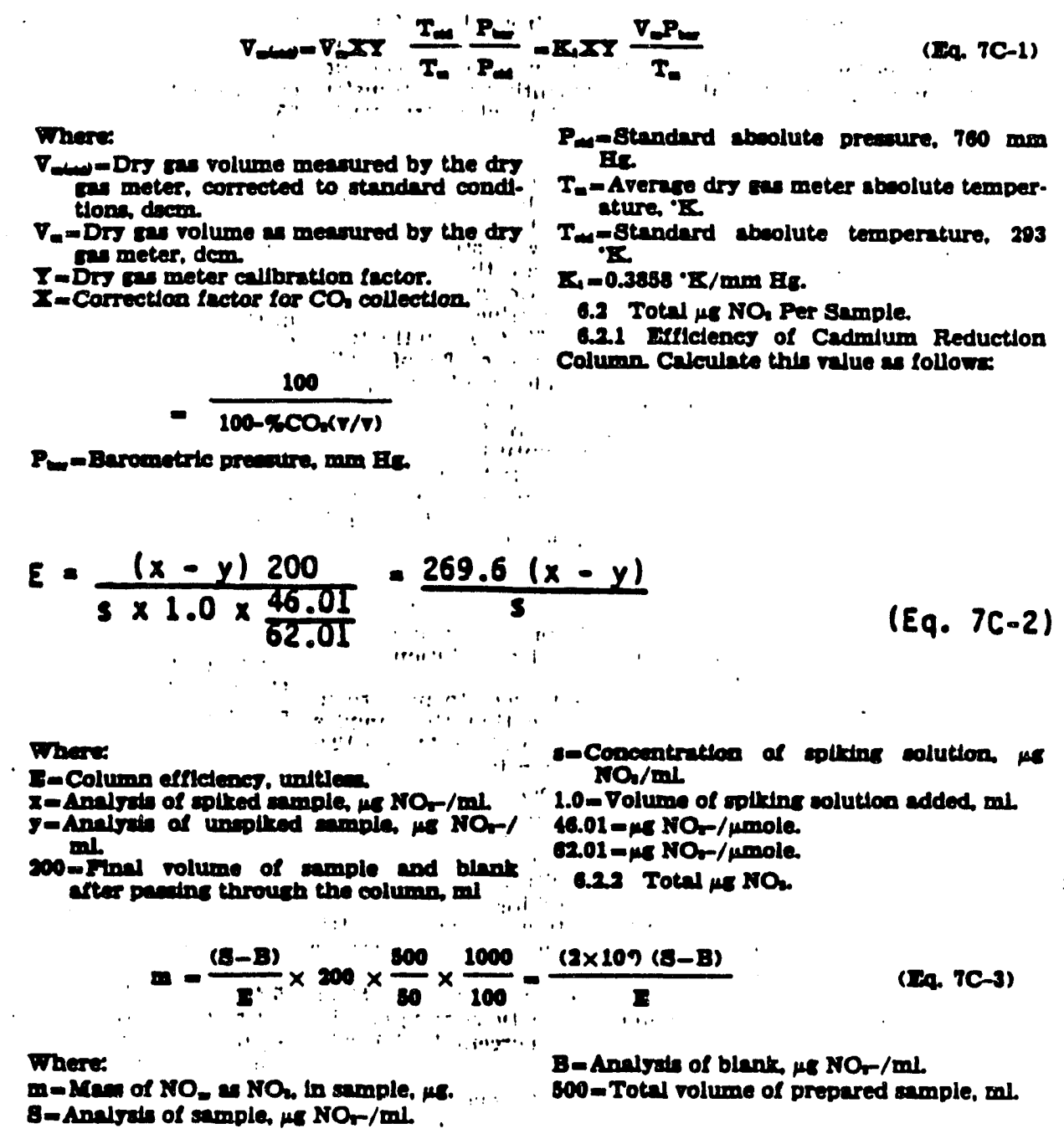

50-Allquot of prepared sample proceseed throush cadmium column ml 100 - Allquot of EMMO./NaOB solution, mi 1000 -Totel volume of EMMO,/NaOB colu. tlon mi.

\subsection{Sample Concentration.}

$$
C=R_{0} \frac{m}{\nabla+m}
$$

Where:

C-Concentration of NO, 2 NO, dry bedis, $\mathrm{me} / \mathrm{dsem}$

$\mathrm{B}_{1}=10^{-} \mathrm{img} / \mu \mathrm{se}$.

6.4 Converion Fetors

$1.0 \mathrm{ppm} \mathrm{NO}=1.247 \mathrm{~ms} \mathrm{NO} / \mathrm{m}^{2}$ at STP.

$1.0 \mathrm{ppm} N \mathrm{~N}_{1}=1.012 \mathrm{~ms} \mathrm{NO} / \mathrm{m}^{2}$ at STP.

$\mathrm{It}^{\mathrm{s}}=2.832 \times 10^{-2} \mathrm{~m} \mathrm{~m}^{2}$.

$1000 \mathrm{mg}=1 \mathrm{~g}$

[6.4 amended by 52 FR 34639, September 14. 1987]

\section{T. Quality control}

Quality control procedures are spectrled in Sections 4.1.3 (nov nte sceuracy); 4.3 (cedmium column efficiency) 4.4 (callbration curve cocuracy); and 4.5 (audit anelyols accuracy).

Q. Btotlography

1. Margewon, J.R. W.J. Matchell. J.C. sursen and MR. Mdrett internted sim. pling and Anal rais Methody for Determin.

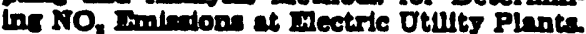
O.S. Invironmental Protection Agency, Researeh Triancle Part. N.C. Journal of the Air Pollution Control Armodetion 321210 1215. 1982.

2. Memorandum and attachment from J.H. Margeson. Source Branch. Quallty Assurance Diviaton. Envtronmentil Monitor. Ins Sprtem Inbortory to The Record IFPA. March 30, 1983. NE. Interference in Methods 7C and 70 .

3. Marceson, J.H. J.C. Suges, and M.R. [Method 7D amended by 52 FR 34639. Midgett Roduction of Nitrate to Nitrite September 14, 1987]
Wth Cadmium. Anal. Chem. 52:1955-57. 4 Qunlity Amurance Bandbook lor Alr Pollution Measurement Systems. Volume inI-Stationary Source Spectilc Methods. Aurunt 1977. O.S. Envtronmental Protection Arency. Research Triangle Park, N.C. Publlcation No. EPA-600/4-77-027b. Aurust 1877.

5. Marteson. J.H. et al. An Interrated Method for Determinine No, Imisalons at Nitric Acld Plents. Manusertpt submitted to Anvigtical Chemistry. April 1984.

Mrtiod TD-Ditramenation or Nitrogen OXdos Eucussions Fron Stational

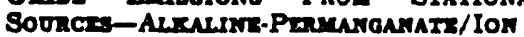

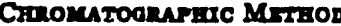


1. Margeson. J.H. je Knoll. and "iR. Midgell. A Manual Method for TRS

Determination. Draft availe ble from the outhors. Source Branch, Qualliy Acsurance Division. U.S. Environmental Prolection Agency, Research Triangle Parth North Garolian 20711.

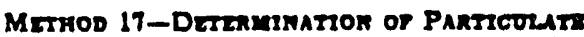
Emissions Frou Statronary Sooncen (Im. stact Pretrution M(trmod)

(Method 17 corrected by 52 FR 34039, Septem. ber 14. 1987)

\section{Introduction}

Partleulate malter is not an aboolute quantity; rather, it is a function of tempers. ture and pressure. Therelore. to prevent vartability in particulate matter emigoton resulations and/or-aseoctated test method. the temperature and presoure at which par. Heulate matter is to be meerured muat be carefully defined. Of the two vartablea (L.en temperature and presoure), tempernture has the rreater effect upon the smount of par. lleulate matter in an effuent sas streami in most atatlonary source catecories, the effeet of prearure sppeare to be neellatble.

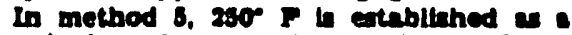
nominal reference temperature. Thum where Method o is rpecefled in an appllicable mubpart of the standard partleulate matter beflined with respect to temperature in order to malntata s collection temperature of $200^{\circ}$. Method is emploss heated filc This equipment is comewhat cumbernome and require care in its operation. Thers

core. Where partloulate matter concentro tlons (over the normal range of temperature acoctited with a specifled source catesors! are known to be independent of lempera. ture. It it destrable to eliminace the stace probe and beating asutemes and anople as teck temperature.

This method describea an in-steck sam. pline aratem and ampline procedure for une In wich cases it lo intended to be unod only when apeeffled by an apolleable mub part of the standarde, and onls within the apolleable temperature limits (il specifled). of when otherwise approved by the Admio. Ietrator.

\section{Princtple and Applicabultry.}

1.1 Principle. Purticulate matter is when drawn teotinetically from the cource and collected on a claen fiber filter malntained at atact temperature. The partleulate mes a determined rrerlmetrically alter removel of uncombined weter.

1.2 Applicability. This method coplles to the determinetion of partleulate emissione trom stultonary sourees for determining compluance with new source performance standarda, only when spectlically provlded for In an applleable subpart of the stand. arda. This method is not spollcable to stacks that contain llquld droplets or are saturated with water vapor. In addition. this method ahall not be used as written If the projected cross-sectlonal aree of the probe extension. fllter holder assembly covers more than s percent of the ateck croas-sectlonal area (see section 4.1.2).

\section{Apparatue}

21 Sampllns Train. A schemallc of the sampline train uned in this method is shown in Frure 17-1. Construetion detalls lor mans. but not al. of the traln components are stren in APTD-0881 (Cltation 2 in See. Uon 7): tor chanses from the APTD-0581 document and for sllowable modiflentlons to Froure 17-1, consult with the Administre. lor. 

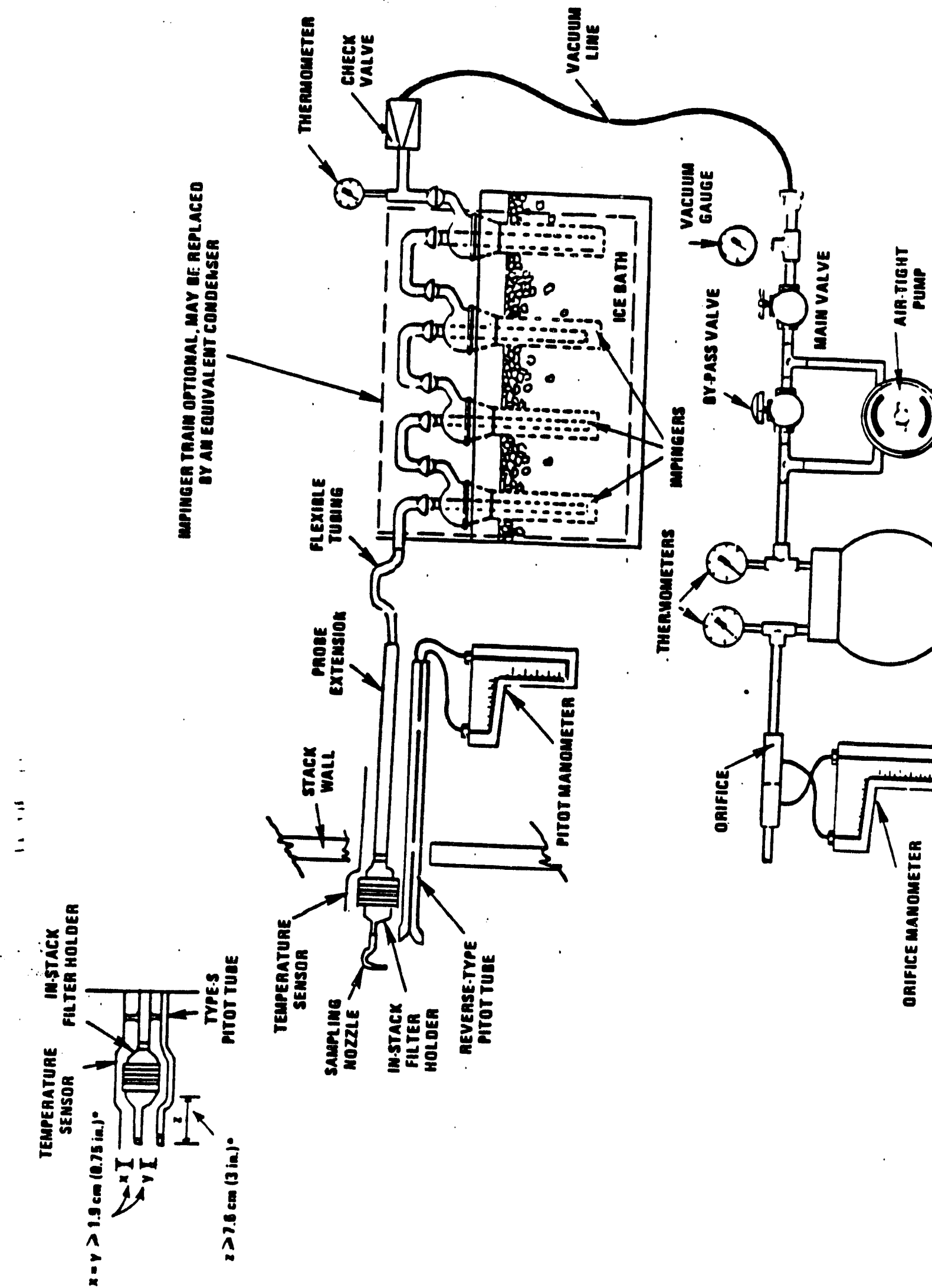

[Appendix A, Mothod 17] 
The operallne and malntenunce proce. dures for many of the samplins traln comDonents are descrlbed tn APTD-0576 (CIte. on 3 in Section 7 ). Since correct usase is Dortant in obtainilos valld reoultar all I should read the APTD-0876 document adopt the operating and mainternance sdures outlined in It. untea otherwise speeifled lioreln. The sampling traln cos. sists of the following componente

2.1.1 Probe Norale. Stalnless steel (310) or elass, with sharp. tapered leadine edse. The ancle of taper shall be $30^{\circ}$ and the taper shall be on the outside to preserve. constant Internal dismeter. The probe nowde shall be of the button-hook or elbow desisn, unless otherwlese speetfled by the Ad. ministrator. If made of stalnies steel, the nozale shall be constructed from seamien tubins. Other materials of construction may be used subject to the approvel of the Administrator.

A rence of stzes sultable for boktnetlo inmolins should be evallable, e.s. 0.32 to $1.27 \mathrm{~cm}$ ( $k$ to $h$ in)-or larter if hicher volume sampling trains are uned-Inotde dfemeter (ID) nocales in inerements of $0.10 \mathrm{~cm}$ $\left(k_{1} \cdot \ln \right)$. Each nozale shall be callbrated we cordine to the procedure outilined in Beo tion 5.1 .

2.1.2 Filter Holder. The In-atieck futer holder shall be constructed of borosilleate or quartz zlass. or stainless steel: If a rasket is used. It shall be mede of sllicone rubber. Tellon, or stalniess steel. Other holder and sasket materials mny be uset subject to the approval of the Administrator. The fllter holder shall be desimed to provide a poedtive seal acalnst leatage from the outalde or sround the fllter.

2.1.3 Probe Extension. Anj sultable ritd probe extension may be ueed after the filter holder.

2.1.4 Pitot Tube. Type 8, as deacribed in iectlon 2.1 of Method 2, or other device ap'ved by the Administrator, the pitot tube be attuched to the probe extension to constant monitorins of the stack sas veloctty (see Mrure 17-1). The Impact (hich mressure) opening plane of the pltot tube shall be even with or above the nozale entry plane durtns sampltins (see Method 2. Figure 2-6b). It is recommended: (1) that the pltot tube have a known baseline coersl. clent. determined as outlined in Section 4 of Method 2: and (2) that this known coelfl. clent be preserved by plecins the pltot tube In an Interference-free srrangement with re spect to the sampling nozde. fllter holder. and temperature sensor (see Fisure 17-1). Note that the $1.9 \mathrm{~cm}(0.75 \mathrm{ln})$ iree-space be toeen the norele and pltot tube shown in Figure 17-1, is besed on a $1.3 \mathrm{~cm}(0.8 \mathrm{ln})$ id nozzle. If the samplins train to dealoned for sampling at hicher flow rates than that described in APTD-0581, thus necessitatins the use of larrer sized nozales. the free. space shall be $1.9 \mathrm{~cm}(0.75 \mathrm{ln})$ with the lare. est sized nozzle in place.

Source-sampling assemblles that do not meet the minimum spacing requirements of Figure 17-1 (or the equitralent of these requirements, e.c. Firure 2-7 of Method 2) mas bo uned howerer, the pltot tube coeln clents of ruch awemblles shall be deter. mined by calloration, usins methods subject to the approval of the Adminintrator.

2.1.5 Dufferentlal Presoure Geuse. inallned manometer or equivalent devter (two), 2 dewaribed in Bectlon 2.2 of Method 2. One manometer shall be ueed for reloctty need $(\Delta p)$ reading and the other, for or flee differentill presoure reading.

21.0 Condeneer. It is recommended that the impinger aystem described in Method be uned to determine the moloture content of the stact sal Nternativels. any system that allow measurement of both the water condensed and the molsture leaving the condenier, each to withtn $1 \mathrm{mi}$ or $1 \mathrm{~m}$ m be uned The molnture leaving the condenser ean be mearured elther br: (1) monitortin the temperature and presururs at the exit of the condencer and uring Delton's lar of partial preanures of (2) penaing the eample res atrean through a allea sel trap with exit races kept below $20^{\circ} \mathrm{C}\left(60^{\circ} \mathrm{s}\right)$ and de torminine the weteht salo.

stexible tubins mas be uned botween the probs extenviton and cosdenser. If mean other ghina willea rel are used to determine the mount of molature leaving the condeneer, it is recommended that stlice sel atjul be used between the condenser system and pump to prevent molature condensation in the pump and metering devices and to svold the need to make correctlons for molnture In the metered volume.

2.1.7 Meterine Syatem. Vscuum sauce. leak.lree pump, thermometers cupabie of mesouring tempernture to wthin $3^{\circ} \mathrm{C}$ (5.4 7 . drs gas meter capable of mensurin volume to wthin 2 percent, and related equipment $2 x$ shown in Ficure 17-1. Other meterins sratems capable of malntalnin amplins retes within 10 percent of botzineWe and of determining ample volumes to within 2 percent may be used. subject to the epproval of the Administrator. When the metering system is uned in conjunction with pltot tube, the asntem anvil enable chectes of lsokinetle rates.

samplins trains utlliztng metertne sys tem dealoned tor hicher now rates than that described in APTD-0881 or APTD-0578 mas be used provided that the apeelflos Hons of this method are met.

2.1.8 Barometer. Mereury, inerold, or other barometer capable of meamurine at moapherte preanure to oithin $2.5 \mathrm{~mm}$ Hs (0.1 in. Be). In many eases, the barometric readine may he obtained from a nearby na. tlonal wewther service station. in which case the rtation value (which is the aboolute bar. ometrte premure) shall be requeated and an edjuntment for elevalton differences between the weather atation and amplin point shall be epplled at a rate of minus 2.5 mom 8 e.1 in. Hs) Der $30 \mathrm{~m}$ (100 (t) eleva. thon tnerease or vice veria for elevation de crease.

2.1.9 Ges Density Determinatjon Equipment. Temperature eensor and pressure saure, an descrtbed in Sections 2.3 and 2.4 of Method 2. and gav analyzer, If neceatary, a decaribed In Method 3.

The temperature sensor shall be altached to elther the pltot tube or to the probe ex. tenstor. in a fixed confliruration. If the tem. peralure senwor is attached in the lleld; the censor shall be pleced in an interference. tree arrangement with respect to the Type 8 pltot tube odenines (es shown in Fisure 17-1 or in Firure 2-7 of Method 2). Alterna. thely, the temperature sensor need not be attached to either the probe extension or pltot tube durtne sampline, provided that : difference of not more than I percent in the averase veloclty measurement is introduced. Thin alernative is subject to the approval of the Adminlstrator.

2.2 Sumple Recovers.

2.21 Probe Norde Brush. Nylon bristle brush with atalniesa steel wire handle. The brush shall be properly alzed and shaped to orush out the probe nowale.

2.2.2 Wash Bottlea-Two. Glass wash bottles are recommended: polyethylene wah bottle may be used at the option of the tester. It is recommended that acetone not be atored in polyethylene bottles for lonser than a month.

2.2.3 Olace Sumple Storece Contalners. Chemleally resistant, borosilleate inss bot. thes, for acetone washes, $500 \mathrm{ml}$ or $1000 \mathrm{ml}$. Screw eap liners shall elther be rubber. backed Tenon or shall be constructed so as to be leak-Iree and resistant to chemical atteck by scetone. (Nerrow mouth slass bot. Hes have been found to be less prone to leakace.) Alternatively, polyethylene bottles mas be used.

2.2.4 Petrt Dishes. For IIlter samples: dess or polyethylene, unless otherwise spec. Ifled by the Administrator.

2.2.8 Oraduated Cyllnder and/or Bal ance. To measure condensed water to within $1 \mathrm{ml}$ or $1 \mathrm{~g}$. Oraduated cylinders shall have subdivisions no rreater than $2 \mathrm{ml}$ Most lab. oratory balences are capable of velehing to the nearest 0.5 or less. Any of these bal. ances is rultable for use here and in Section 2.3.4.

2.2.6 Plastic Storage Containers. Alr Weht containers to store slllea gel.

2.2.7 Punnel and Rubber Pollcemen. To ald in transfer of sillica sel to contalner, not necessary if silliea gel is welched in the lieid.

2.2.8 Punnel. Glass or polyethylene, to ald In sumple recovery.

2.3 Analysis.

2.3.1 Glass Weighing Dlohes.

2.3.2 Deslcestor.

2.3.J Analytical Balence. To messure to thin $0.1 \mathrm{~ms}$.

2.3.4 Balance. To meanure to within 0.5 6.

2.3.3 Beakers. $250 \mathrm{ml}$

2.3.6 Bysrometer. To messure the rels. lve humidity of the Isboratory environ. ment.

2.3.7 Temperature Gauge. To messure the temperature of the laboratory enviton. ment.

3. Reagente.

3.1 sampline. 
3.1.1 Futern. The th-ated miers thall bo

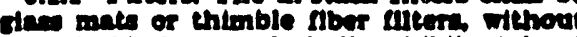
orranic binders, and ahall exhlbte at least 00.08 perreent effleterses 10.08 peroent perw tration) on 0.3 mieron dioctyl phthalnet cinoke particlea The tuler ofridenes tent ahill be conducted to mecordagen wilh ASTM Standard Method D2000-71 (Retp proved 1070) (ineorpdrated by relereneswe (60.17). Teat date frotn the muppllerts qualits control procrum aro eurfiedent lor this purpoese.

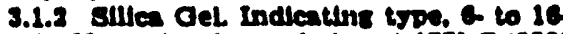
meah. If prevtously uned din at 17.' C (360 F) for 2 bourn. New alles rel mes be uned a recelved Aleernatdvels, other tspes of dedecants (equivalent or better) mos be ued, rubject to the epprovel of the Adminintar cor.

3.1.3 Crunhed Ioe.

3.1.4 Btopeock Oreace. Acetons-incoluble, heat-rtable alleone rreace. Thin is not nee exwers If ecrew-on connectors with Teflot cleever, or idonllar, are ued. Allermatively. olher tspee of etopeoct roves may be uned. cubject to the approvel of the Adintinintr. tor.

32 Sample Recovery. Acatons, reacent Inde 0.001 percent redidue. In clace bottle reato. from metel containers senerally Acetone from metal contalners ald not be has a hich residue blank and inould not be to vin bottie from metel contalpers. Thur scetons blan's chell be rus prior to field we and onls scetons with lon biant values ( 0.001 pereent) shall te ued in 80 care shall a blank vilue of creater then 0.001 percent of the velght of seetores und be mubtracted from the momple weicht. 3.3 Analyola

3.3.1 Acotone. Bame a 3.2.
3.32 Dedcoant Anhydrover Elelum nulfate indicating tipe Alernatively, oche: troes of dedecants may be uned, nubfeet to the approvel of the Adminintanter.

4 Proesdere

4. Sampling. The complextls of thit mothed is euch thats in order to obtain rell. able resulte teaters anould be trained and experieneed with the lext procedurea.

4.1.1 Preteat Propartion. All compo pents ohall be maintalned and callbrated so. cordine to the procedure deweribed in APID-0076, unles otherwive upeotried herela.

Welch exveral 200 to 300 a portlons of

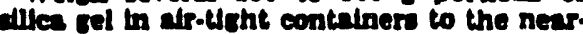
ent 0.5 . Record the lotal weicht of the Allies rel plus contalner. on exch contalner. As an ellermative, the allien rel nead not be prewelched, but mas be welehed directly to ite impinger or exmpline holder junt prtor to traln accembly.

Cheat flitere vrually aseinst lisht for It. reculartile and naw or pinhole lentes Label mters of the proper the on the bect alde near the edes uaine numbering me. chine Int. As an allersative, label the shippine contalners (elan or plantle petrl dishes) and keep the riltern in these contalners at all times except duriss amplins and weich. ine.

Dealceate the futers at $20 \pm 8.6^{\circ} \mathrm{C}\left(68 \pm 10^{\circ}\right.$ $P$ and amblent premere for at leant 24 hours and welch at intervals of at leart 6 hours to a content welcht. Len $0.8 \mathrm{~ms}$ chance from prevtous wetchlng: record re. riles to the netrot $0.1 \mathrm{~ms}$. Durins ench relebing the fliter munt not be exposed to the Inborntors atmoenhere for pertod creater thas o minutes and in relative hy (unlew otherwles apedfled by the Admints trator), the fluter mas be oven dried at 108 $C\left(220^{\circ}\right.$ I) for 2 to 3 hours, destecaled for 2 hours and weiched. Procedures other thrn thowe described, which eccount for $\mathrm{re}$ humidity effects, may be used. sub.l the approval of the Adminimetrator.

4.1.2 Preliminary Determinatlons. Select the campllne alte and the minimum number of sampline points sceordine to Melhod 1 or as spectfled by the Administrator. Make projected-ares model of the probe exten son-fllter holder assembly, with the pitot tube fece openin as posttioned slons the cen cerline of the steck. as shown in Firure 17-2. Calculate the eatlmated crose-section block. are, as shown in Firure 17-2. Il the blockate exceeds s percent of the duct croes sectional ree the leater ha the following options: (1) a sultable out-of-stack filtrallon method may be used Instend of In-stuck IIItratlon: of (2) a special in-stack arrangement, In which the sampling and veloctey messurement dien are ceparate may be used; for detall concernins this spprosch, consult with the Adminiatrator ree aloo Citution 10 in see. don 7). Determine the stack pressure, tem. peralure, and the rance of veloclty head uning Method 2: it is recommended that leak-check of the pllot lines (see Method 2 Bection 3.1) be performed. Determine the molsture content using Approximation Method 4 or lts slternatives for the purpose of making lsoktnetlc,sampling rate settings. Determine the stack ras dry molecular weleht. a described In Method 2. Section 3.6: If Interrated Method 3 samplins is used or molecular wetsht determination, the in terraced bat ample shall be taken simulta. neouly with, and for the same cotal lencth

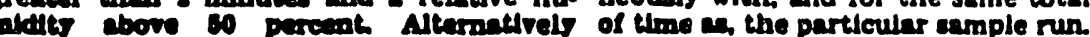




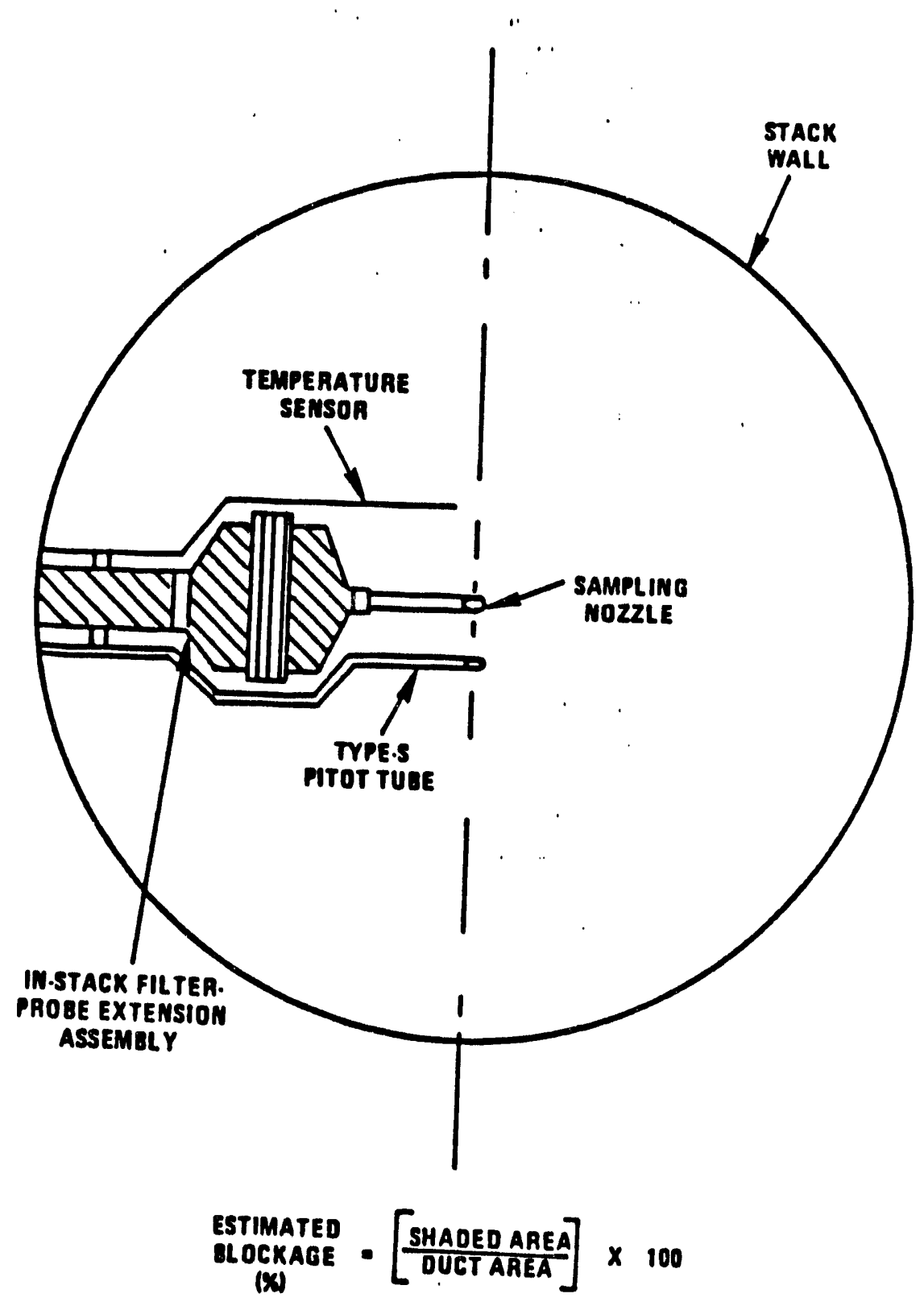

Figure 17.2. Projected-area model of cross-section blockage (approximate average for a sample traversel caused by an in-stack filter holder.probe extension assembly. 
Select a nowio sto based on the range of voloetty heade weh thre it in not noce to chance the nocile ates in order to malo tatn boldinette amplins reter Durles the run do not chenes the nowile the. Invire that the proper differential prescure gause b chowen for the ranse of veloetty heads en. countered (see Bectlon 2.2 of Mothod 2).

Beleet a probe extension lenrth euch that al traverse potnts can be sampled. For lare otactes, constder amplins from opponte otdes of the rtact to rotues the lenth of probea.

Beleet a told campling the rrenter thas or equal to the mintmum total amplins thre spectifled in the lest procedure for the speedfle Industry weh that (1) the sampline tirne per point is not lea than 2 minutes (or come rreater ulone interval if pectried by the Adminiatrator), and (2) the ample volume taken coorreted to itenderd condl. tlonu) will exceed the required mintmuse lotal tos sumple volume. The latter is besed on an approximate averase pumplins rate.

It is recommended that the number of minuter sampled at eech potnt be an tateger or an triever plum one-half vilnuta in orde. to avold tlmekeeplos errors

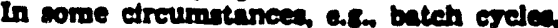
It may be necesians to emple for thorter times at the traverne polnts and to obtein

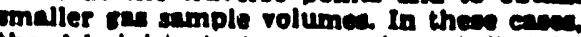
the Adminintrator's approvil muth nit be obtalned.

4.1.3 Preparation of Collection Train Durting preparation and coembly of the ampline trala, keep all openinge where contamination on oceur covered until fint

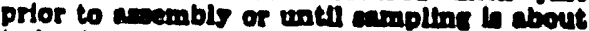
to beeth.

I Impingess are uned to condense atact res moleture. propare them is followr plece $100 \mathrm{ml}$ of weter in each of the firt tivo im. plncerch leave the third impincer empty. and transfer approximately 200 to 300 of prewelehed sllien sel trom its coatalner to the lourth impinzer. More sllte rel may bo used. but care should be taken to envure that it ts not entralned and carried out from the impincer durting sampling. Plece the container in a clean place for later uve in the sample recovers. Atternatively, the welght of the sllie cel plus Implncer may be determined to the nearent 0.5 and re corded.

Il some means other than Implnzen in used to condense molsture, prepare the con denser (and, if appropriate, allic sel for condenser outlet) (or use.

Usins a itweezer of clein disposable rury. al slovea, place a labeled (Identifled) and welched micer in the meer holder. Be vure that the miter is properls entered and the gaket property placed so an not to allow the ample se etream to etreumirent the filter. Cheat miler for tenr ster anembly is com. pleted Mark the probe extendion wteh hent redrtent tape or by come other mothod to denote the proper dintance into the stacts of duet for each romplins polnt.

Acemble the traln of in IIrure 17-1, unin - vers Ulabt cont of alleone rrease on all Fround dien Jolnts and rreasing only the outer portion (Eee APID-0370) to avold por Ablilty of contamination of the sllicone prease. Place aruibed tes around the im. Dlagerer.

4.1.1 Leak Chect Proceduren

4.1.4.1 Frotent Leat-Ched. A pretent leak-chect of recommended, but not ro quired If the teeter opte to conduet the pro teat lear-ahcest the following procedure chall be uned.

Aler the sampiling traln hes been waem. bled plus the Inlet to the probe nosele with - materta that will be able to vlehntend the ctact tempernture. Invert the Illter holder toto the rtack and walt approxtmately s minuted (or longer. If necevars) to allow the esstem to come to equilibrium with the comperature of the rteck on stream. Tum op the pump aod draw a vecuum of at least $360 \mathrm{~mm}$ Bi (16 in Bes; note that is lower recuum ons be ued, provided that it to not exceseded durtn the tart. Determine the leateces rate A leatrape rate in exces of percent of the sverne ampling rate of $0.00087 \mathrm{~m} / \mathrm{min}(0.02 \mathrm{~cm} / \mathrm{m})$, whlchever is lem in unecoceptable.

The following leak-chect Inotruntlons for the amoling tratn dewerlbed in APTD-0870 and APLD-0831 man be helplul start the powp with by-pen vire fully open and coure edjust velve completely elowed Par. thills open the cours adfut vilve and clowly clow the by-pen vive unth the de dred veuum is resched Do not reverse di. rection of by-paces vilve. If the desired recuum is exceeded, elther leak-chect this hlgher vecuum or end the leats-chects a chows below and start over.

When the leak-cheet is completed, first slowly remove the plue from the Inlet to the probe nowale and immediately turn off the vecuum pump. This prevents water irom beins forced backward and keepe alliea sel trom belne entralned beckward.

41.4.2 Leak-Chects Durine Sample Run IS. during the aumpling run, a component (e.c. Illter enembls or Impinger) chance be

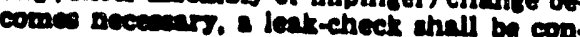

duoted lmmediately before the chanse is mede. The leak-eheck shall be done eceord. ins to the procedure outlined in sectlon 4.1.4.1 above, except that it shall be done - vecuum equal to or sreater than the m mum velue recorded up to that point in teath II the leakerse rate is found to be nit Treatst than $0.00057 \mathrm{~m} / \mathrm{m} / \mathrm{n}(0.02 \mathrm{ctm})$ or percent of the average sampling rate (whichever is less), the results are eccepta. ble, and no correction will need to be $\mathrm{ap}$ plled to the lotal volume of dry sas metered. II. however, higher leakage rale ts ob tained. the lester shall elther record the leakage rate and plan to correct the sample volume a shown in Section 6.3 of this method, or shall vold the sampllne run.

Immediately after component changes, leak-cheeles are optlonal: II such leak-checks ire done, the procedure outlined in section 41.4.1 above ahall be used.

4.1.4.3 Post-Test Leak.Check. A leak. check to mundatory at the conclusion of ach ampling run The leak-check shall be done in sceordance otth the procedures out. lined in Bection 4.1.4.1. except that it shall be conducted at a recuum equal to or srent. or than the maximum value resched during the sampling run. If the leaksge rate is lound to be no sreater than $0.00057 \mathrm{~m} / \mathrm{min}$ $(0.02 \mathrm{cfm})$ or 1 percent of the everage sam. pline rate (whichever is lesa), the resulks are acceptuble, and no correction need be olled to the total volume of dry res metered. if. howerer, a hicher leakace rate is obtained. the tester shall elther record the leakere rate and correct the sample volume Thown in section 6.3 of this method. or chall vold the samplins run.

4.1.5 Partleulace. Train Operation. Durtne the sampling run, malneain sam. pling rate such that sampline is within 10 percent of true bokinetle. unles otherwl ipeetfled bs the Administrator.

por each rum. record the date required on the example data sheet shown In Firure 17. 3. Be sure to record the Initial dry ras meter reading. Record the dry gus meter readines at the berinnins and end of each samplins time increment, when chances in now rates are made, before and after each leak check. and when sampling is halted. Take other readinge requtred by Firure 17-3 at least once at each sample point during each time increment and additional readints when sis. ndfleant changes $(20$ percent variatlon in ve. loclty head readin(s) necessitale additlonal adjuntments in hor rate. Level and zero th manometer. Because the manometer level and zero may drilt due to vibrallons and temperature chenges mate periodle chects durtas the traverse. 


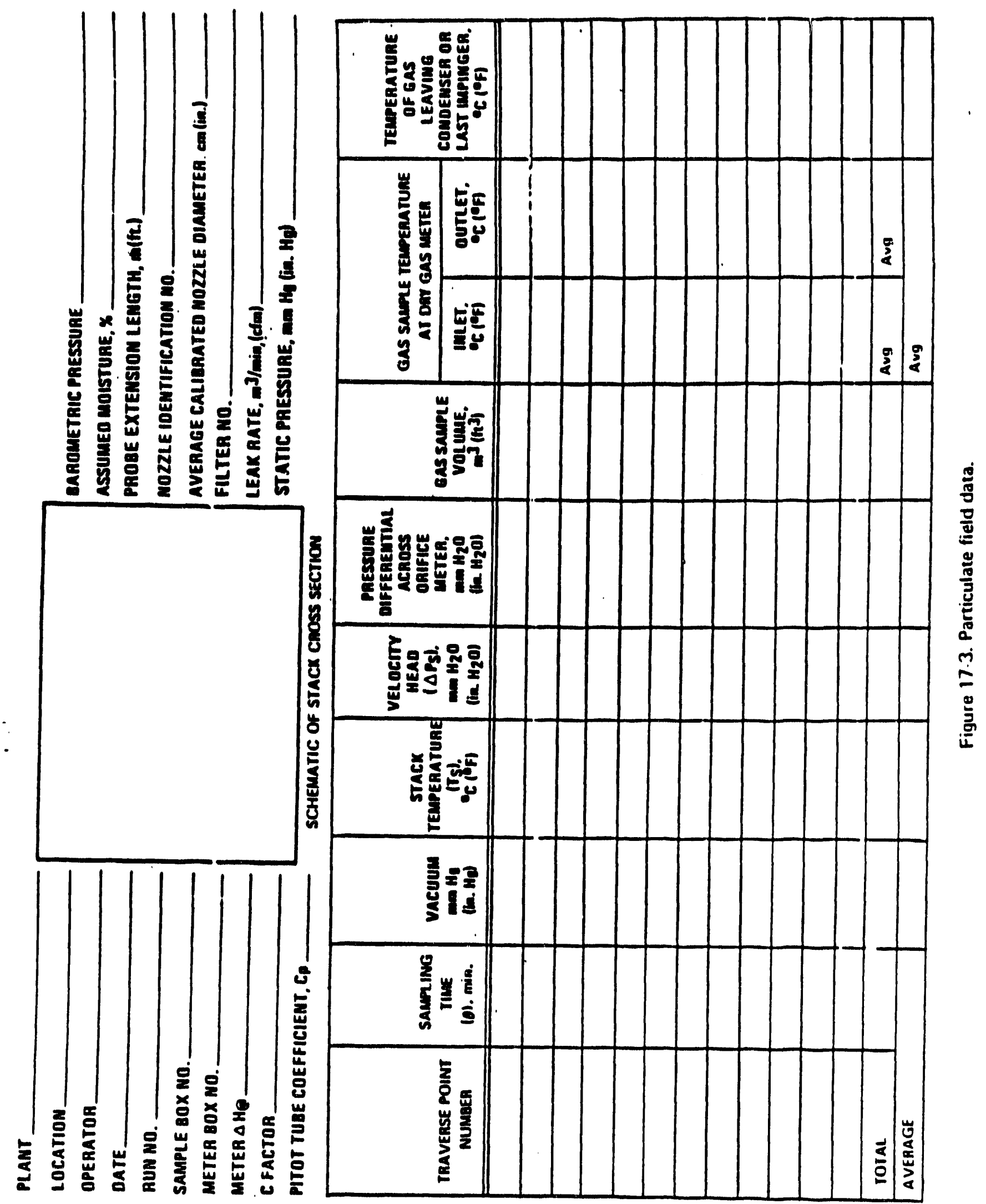


Cletn the porthole prior to the teet ru to minimien the ahno of enplin the de poulted matertel. To beth sampline, rewow the nowde eap and vertif thet the pleot tut and probs extenvion are oroperly poed. Uoned Posteton the nocile et the ntret the veres polnt wth the t/p polntins directs Into the of stream. Inmediacely otart the pump and edfunt the now to tookinetle cor

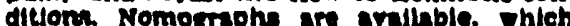
ald in the rapid adjustment to tho tsoternotle eampline rite without exceuive compule tlons. Theas nomonraphs are dealoned for use when the Trre 8 pleot tubs coerfletent b $0.08 \pm 0.02$ and the ot ack ser oquivelent density (drs asolecular veleht) is caud to 29 \pm 4. APID-0870 detalis the procedurs for using the nomomphe if $C_{\text {a }}$ and $M$ ars out Ide the above tated rancer, do not ue the

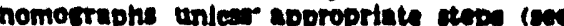

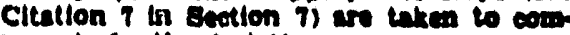
Druate for the deviation.

When the eted in under alonifleans new.

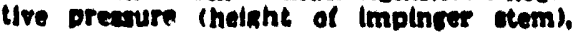

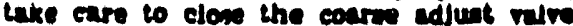
befors Innerting the prob exteridon smen. bly into the otack to prevent weter ifrom beling forend backward if nocensy. the oumb mas be turned on with the conse edfurt velve elooed.

When the prots is in pontelon. bloek ofl the openines around the probe and porthole to prevent inneprementefve divution of the to provens

Travers the stack aros costlon of ro quired by Methad 1 or en rechlled by the Admintatintor. belne carvivi not to burn. the probe notive into the etacts will whes exmollne net the welb or when removing or Inserting the probe extenston throuph the portholen to minimite ehanes of ex. irmotine depodted materith

Durlns the text run take aporopetate

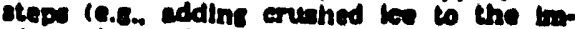

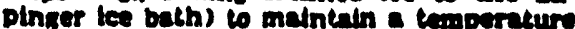
of lew then $20^{\circ} \mathrm{C}\left(90^{\circ} \mathrm{P}\right)$ at the condenem outlet: this in provent exeendre mothturs

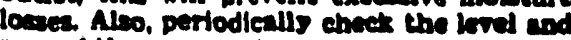
eero of the manometer.

If the presure drop saros the filter bo comes 100 hich, makln, bokinelle sumplins diffleult to muintaln. the fllter mas be ${ }^{\circ}$ - placed in the midat of a ample run it' is recominended that another complete fular holder asiembly be used rather than at templine to chenge the fllter Itedf. Before new illter holder is installed, conduet a leas check, is outlined in sectlon 4.1.4.2 The total particulate weirht shal include the summalion of all illter saembly extches.

A sincle tretn shall be uned for the entirs sample run. exeept in cares where otruulte. neous sempline te requitred la two or moro separate ducts or at two of more dirferme locations withth the enme ducth or, in eases share equipment fellure necontenter change of trutns. In all other altustlons, the use of two or more indna will be subject to the approval of the Adminlatrator. Note llist when two or more tralns are used. senarate enalyst of the collected partleu. late trom each trin shell be pertormed. unlese Identicel nozle glaes vere ured on II truins, in which case the partloulate entehes from the Individual trains may be comblined and a sincle analssis performed.

At the end of the sample run, tum oft the pump, remove the probe extenston sembly Irom the stack. and reeord the final dry ths meter rradins. Perform a leak-check, a out. Iined in Bection 4.1.4.3. Also, leat.check the pltot lines as described in Sectlon 3.1 of lilethod 2: the lines munt pars this leat. ancete in onder to ralldate the veloedts bead date.

4.1.9 Caledation of Provet Iookinetie.

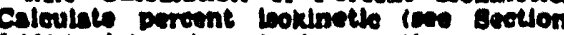
c.11) 6 doceminte whother unother levt run chould be tunde. Is them is difficulis in

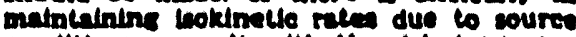
condlelow: conrule with the Adminterster tor pomible vinnes on the leopinctio rete 4.2 Sumple Recovers. Proper deanup procedure betins es coon an the probe ex. cerifion seembly is remored from the stuct. at the and of the cumpling perted Allow the entembly to cool.

When the remembly an be sulels handled. the off all extemil pertloulate meter non the tip of the probe nonle and pleces oup

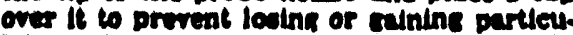
late matter. Do not cis off the orobe us Unhtly whlle the earopitis traln in coollne down os this would ereate a recuum is the

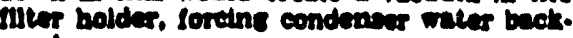
werd

Before movins the anple traln to the decinum alle disonnet the thees holder. prote nacle encmbly trom the probs ex. indent eap the open inlet of the probe ex. canton so eareful not to low eny conden. ente, if powme Rewowe the umbilleal cord irom the condenver outlet and eap the outlet If a nexible line b uned between the ort tmplnger (er coodenest) and the probe

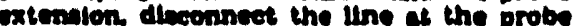
extendea end ith any condenend vater or levild dinin theo the implacers or condene. - Direvancet the probe exennion from the condenver oos the probe exteridon outlet.

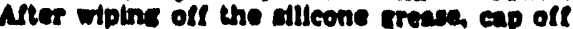

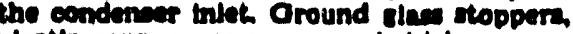

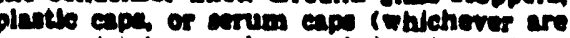
apropitates mey be uned to close theme coentin.

Trunifer both the mier holder-probe

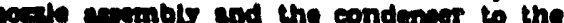
dranup ere- Int eren should be dean and protected froen the ofind os that the ennnes of contaninating of loding the cample will - minlonited

Qnve portion of the scetone uned for cleanus a a blent. Tate $\mathbf{2 0 0} \mathrm{mi}$ of this ac. etone directly from the weh bothe beine aned and place it in a slan expole container ibeled "ncetone blene"

Inpect the trath prior to and during dis. entubly and note any sbnormel condluton Treat the camples of follows:

Concalner Na. L. Carefully remove the miter from the miter holder and olece it in It Identifled petrt dish contather. Uee a pais of tweetern and/or clean dispoenble aursten doves to hendle the filter. If it is ncevasurs to lold the fllter. do so weh thas the partleulate eate is tride the fold. Carefully tran fer to the pert dinh ans perticulate metter and/or miter nbers anloh adhere to the fliter holder mekeh by uine a dry Nylon bristle brunh and/or \& sharp-edsed biede. Seal the contelner.

Conlatner $\mathrm{Na} 2$ Takine care to see the dust on the outalde of the probe nocale or other extertor surisces doen not ret into the armple, quantletivels recover particulste mntier or ens condenate from the probe nozde. Ilting. and front half of the fllter holder by weshing these components with ceetone and plactns the wesh in s clase con tajner. Dintlled water may be uned Inatead of scetone when approved by the Adminis. trator and shall be used when spectled by the Administrator. In these eased. save water blank and follow Adminiatrator's df rections on andyals. Pertorm the scetone rinces a tollows.
Carefully remove the probe norsle and dean the instde ourfane by rinalne with ac. erone from whin botle and bruining with - Nyton brtatle briah. Bruah until ceptone rines shows no vislble parlleles. allep why mite a find rines of the inaide surface seetone.

Bruih and rines with ncetore the Inslde parts of the flttene in a almilar wny unell no viatble partleles romain. A funnel inlass or polyethylenel may be used to ald in trans. terrtns llquid weshes to the container. Rinse the bruth with scetone and quantitatlvely collect three weining in the sample con. ulner. Between cumpline runs. keep bruine olcan and protected from contamj. nattor.

Nerer mourtne that all Jolnts are vibed ctean of allicone stence (If applicable), clenn the instde of the front half of the fliter holder by rubbins the surfaces with a Nylon brtate bruli and finsine with acetone Alnse each surfece three limes or more if necded to remove vinble partlculate. Make IInd rine of the bruin and fliter holder. Alter all scelone weshinge and purtleulate ancter are rollnetod in the anmple contain. er. Whiten the lld on the sample container w thet cetone will not leak out when it is chlpoed to the Inborntory. Mark the helcht of the nuld level to determine whether or not leakece ceeurred durins transport Iabel the concliner to dearly Identily its contente

Contatner Na 3. If oflles rel to used in the conden sytem for mositure content de. chrmination, note the color of the cel to de. cerming if it he been completely spent: make noteclon of lts condition. Transipr the altion gel back to lts orininal container and cel $A$ funnal may make it exsler to pour the allie cel withoul spliting. and rubber pollemin may be uned as an ald in removtno the sllies sel. It is not neceasury to remove the imall amount of dust particts that way sdhere to the walls and are difl cult to remove. Slnce the gain in weirht is to be uned for mobture caleillatlons, do not use any weer or other llquids to transter the allica sel. If $n$ balance is avallable in the fleld follow the procedure for Contalner No. 3 under "Analysta."

Condenser Water. Treat the condenser or Impinger water as follows: inake notolion of eny color or fllm in the llauid eateh. Men. vure the llquid volume to wlthin $\pm 1 \mathrm{ml}$ by uains araduated cylinder or, If a balance is avaliable, determine the llauld wetpht to within \pm 0.58 . Record the tolal volume or releht of llauid present. This information is requited to edculste the molsture content of the efnuent as. Dtscard the llauld after uearuring and recordins the volume or weleht.

43 Analysta. Record the data required on the example shrel shown in Firure 17-4. Bandle each sumple container is follows:

Container No. 2. Leave the contents in the shipplne contalner or transfer the fllter and any loose particulate frnm the snmple contalner to a tared glese velating dish. Destc. ate for 24 hour in a destecator enntainin anhydrous calclum sullace. Wetsh to a constant welcht and report the results to the nearest $0.1 \mathrm{me}$. For purposes of this sertlon. 1.3. the term "constant weidit" means a dif. ference of no more than $0.5 \mathrm{mg}$ or 1 percent of lotal weleht ims tare weleht. whicherer in realer, between iwo consecullve welshings. with no less than 6 hours of desiccntion tIme betweell weighings.

Alternatluely, the samnle may he ounn drted at the sverase stack temperatiare or 


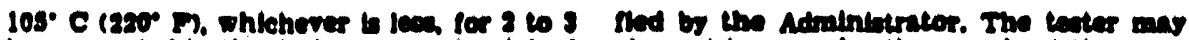

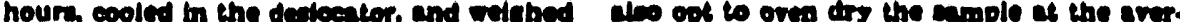

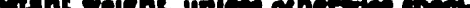

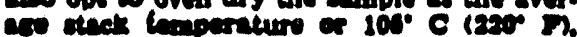

whelumes b lem for 2 to 1 hours, weth the

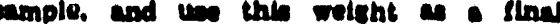
weinter

Pient

Dato

Ren No.

Fitin No.

Amount liquid lase during transport

Acetone blenk rolume, $\mathrm{ml}$

Aeatem wach volume, $\mathrm{ml}$

Acotono bleck eencentrotion, ma/mg (equation 174)

Aeatone mash Wank, my lequation 17.5)

\begin{tabular}{|c|c|c|c|}
\hline \multirow{2}{*}{$\begin{array}{c}\text { CONTAWER } \\
\text { NUMAEA }\end{array}$} & \multicolumn{3}{|c|}{ WEIGHT OF PATTICULATE COLLECTED. } \\
\cline { 2 - 5 } & FINAL WEICHT & TARE WEIGHT & WEIGHT GAIN \\
\hline 1 & & & \\
\hline 2 & & & \\
\hline TOTAL & & & \\
\hline
\end{tabular}

\begin{tabular}{|c|c|c|}
\hline & \multicolumn{2}{|c|}{$\begin{array}{l}\text { VOLUME OF LIOUIO } \\
\text { WATER COULETED }\end{array}$} \\
\hline & $\begin{array}{c}\text { IMPINGER } \\
\text { VOLUME. } \\
\text { ml }\end{array}$ & $\begin{array}{c}\text { SILICA GEL } \\
\text { WEIGHT. } \\
0\end{array}$ \\
\hline Final & & \\
\hline INITIAL & & \\
\hline LIQUID COLECTED & & \\
\hline TOTAL VOLUME COLLECTED & & $g^{\circ}$ \\
\hline
\end{tabular}

* convert meight of water to volume by divioing total weight INCREASE BY DENSITY OF WATER $(1 \mathrm{~g} / \mathrm{ml})$.

$$
\frac{\text { INCREASE. } \mathrm{g}}{1 \mathrm{~g} / \mathrm{ml}} \text { : VOLUME WATER, } \mathrm{ml}
$$

Figure 17.4. Analytical data. 
Conlatrer Na 2 Note the level of Hauld is the contalner and consirm on the enalyet. ancet whother of not leateape cecurree durins tranport if a noticatble amount of leakese has oecurred, ether pold the monplo or aw methods, nubject to the approval of the Adminiatralor, to correet the final re pulte Mensurs the llquild in this contalnes elther volumetrieally to $\pm 1 \mathrm{ml}$ or mavimo trtealiy to \pm 0.8 s. Transfer the contents to tared 280.mI beaker and emapornte to dry nees at amblent temperature and presoure. Destecate for 24 houre and weich to otant weleht Report the rewelte to the wears. ent 0.1 wis.

Container $\mathrm{Na}$ i Thle stop may be con dueted in the efold. Weloh the spent alle

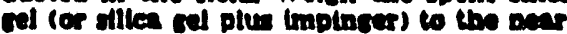
cot 0.8 s uilns a balance.

"Acelone Dlenk" Conlatner. Mearure no tome in this contalnes etcher volumetrically or errinimetrically. Tranater the ceetone to lared 250-ail beater and eveoorale to dry.

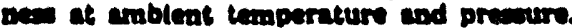
Dentecate for 24 bours and welch to a con

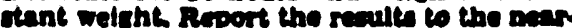
ext $0.1 \mathrm{me}$

Nore-At the option of the teater, the content of Contaluer No. a wa well an the ceetome blents container mas be mporten at temperatures bigher then amblent. If mporntion b done at an elevated tempere. ture the tempereture munt be belor the bolline polat of the solvent: alvo, to prevent "bumptins." the ereporatios proces mut be elowily rupervited and the coatents of the benker muxt be misted cecadenally to contintan an even teraperature. Des extreme care, ot ceetone is hichls anmonable and twe a low Rash potne.

b. Celtbration Matneala a Leborators los of all calloricton.

o.1 Probe Norite. Probe nociles shall bo elibented betore thetr initual use in the Neld Uains a mierometer, measure the tridde diameter of the nocde to the neareat
$0.093 \mathrm{~mm}(0.001 \mathrm{In})$. Make three separate measurementu uaine different diamelon ach time, and obtain the eversere of the mearurements The differemes between the bich and 10\% numbers ahall not exeeed 0.1 mm $(0.004 \mathrm{tn}$ ). When noeder becotme nicted dented or corroded they shull bo reahaped oharpened and recallbrated belore we. Ifech noede shull be permanent is and uniquels Identifled.

8.2 Pitot Tube. II the pitot tube in pleced in an interterences iree smantement with re coet to the other probe saembly compo nenth its baceline (lvolated tube) coeffietent andil be determined a outlined in Beetion of Yethod 2 If the probe anembly ts not interterences free the pltot tube seembly coeffletent shall be determined by edibration wine method sublect to the approvel of the Adralniatrator.

B.3 Yetering sytem Bofore it Initie wes in the fleld the metertne aratem shal bo eillbrated eceording to the procedure outllined in APSD-0676. Intead of phrnicul. if alfunting the dry an meter divl rendino to comeroond to the wet tent moter read.

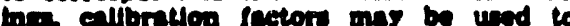
mathrematteally correet the tas meter dil rendingo to the proper valuea.

Bafore culibrating the metering system, it - mergented that a leak-ehect be conducted For actertes asntean harting dlaphracm pumber the normal leat-cheet procedur will not datert leatrases withis the pump. For them ares the following leak-cheet proconture In miscented make $10 . \mathrm{minute}$ callbration run at $0.00007 \mathrm{~m} / \mathrm{mm} / \mathrm{n} 10.02$ efmis at the end of the run take the differ wee of the mearured wet lent meter and ins en meter volumes dulde the difference

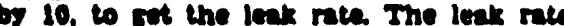
chould bot excosd $0.00007 \mathrm{me} / \mathrm{min} 10.02$ (m).

After ach fleld use the callbration of the metering artem shall be chreted by pet. formine three callbration rune at a eincle.

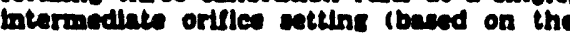

provious fleld leat), with the racuum set at the maximum value reached during thent certea To adjust the vecuum. Insert

between the wet teat meter and the I

the metering aratem. Caleulate the arein

value of the ealibration tactor. If the ealli. bratlon has ehanged by more than 5 per. eenh realibrate the meter over the full rance of orifle setungs, a ouldined in APTD-0876.

Aternative procedures, e.s. using the orl. tlee meter coulfletents may be used, mubject to the approval of the Admintatrator.

Wore-Il the dry an meter coeffletent values obtalned belore and alter a test certes differ by more than s pereent. the teat eertes shall elther be volded, or calcula. How for the teat sertes ahall be performed Haing hicherer meter coeffletent value (Le. before or after) stven the lower value of total aumple volume.

s.4 Temperature Gauses. Use the proce. dure in Section 4.3 of Method 2 to calibrate in-etect temperature saures. Dial thermom. etern, wuch as are used for the dry gas meter and condenser outlet, shall be callbrated chalnat mereury-in-elect thermometers.

b.3 Leak Check of Metering system Shom in Mrure 17-1. Thet portion of the ampling train from the pump to the ortfice meter should be leak checked prior to Initial uea and after each shipment. Leakage alter the pump will result in less volume being re. corded then th setually sampled. The tollow. ing procedure is sugzented (see Mroure 17-5). Close the maln valve on the meter box. incert a onehole rubber stopper with rubber tubling attached tnto the ortflee ex. hauat ploe. Dineonnect and vent the low side of the orflice menometer. Close off the $10 \%$ alde ortilen tap. Preasurtze the system to $18 \mathrm{~cm}(5$ to $7 \mathrm{ln}$ ) waler column by ing into the rubber tubling. Pinch of

cubins and obeerve the manometer for or minuce. A low of presaure on the mano meter indlcates a leak in the meter box: leaks, is present, must be corrected. 


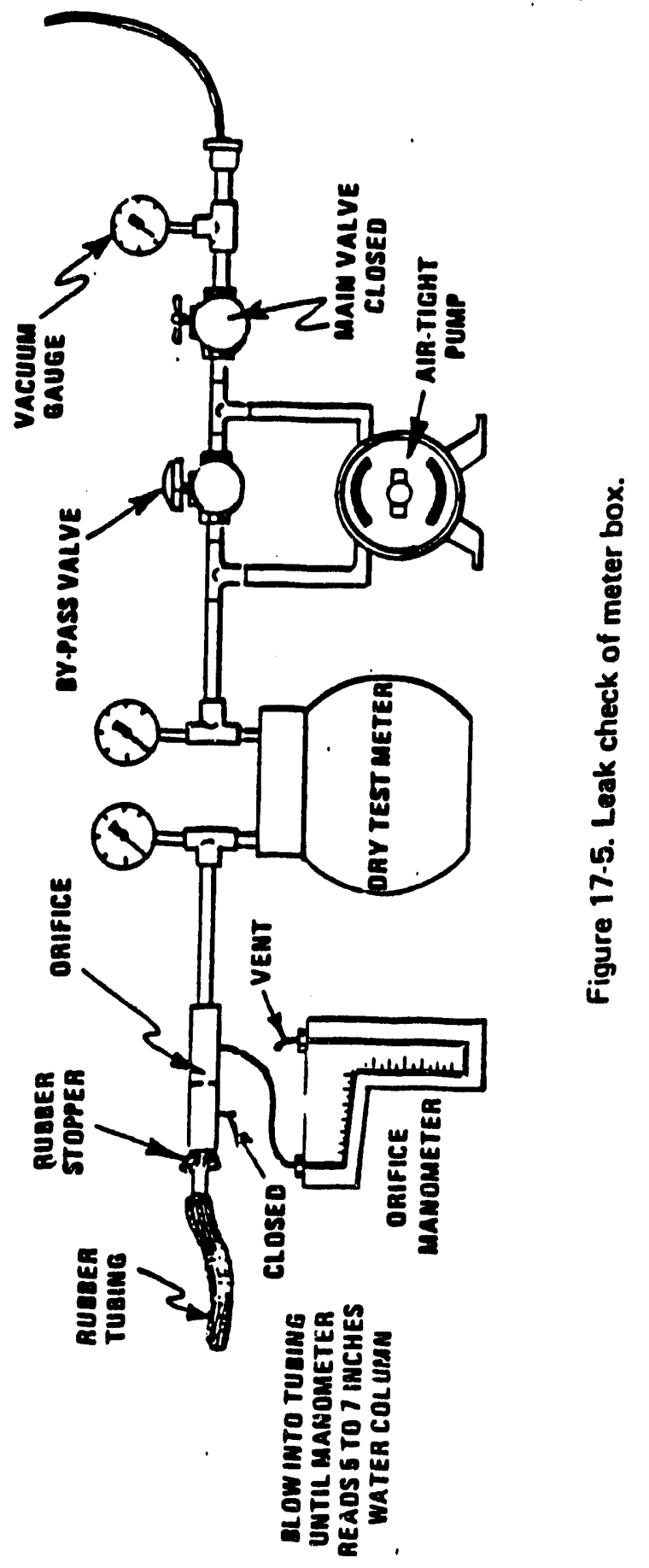

[Appendix A, Mothod 17] 
8.6 Bamoter. Callorata epint a mar. curs becometer.

6. Calculations Carn out caleulaclone re taining at leat one extre dectrind ilsure begond that of the sequired dale Round off lisures afler the Iinal ealeulation. Other forms of the equation may be uned a loos - they give equiralent remult

0.1 Nomenclalure.

16.1 corrected by 32 FR 34639. September 14,

1987: S2 FR 42061. November 2. 19871

A-Crom-sectlenal ares of nomile. m' (ft').

B- Water vapor th the sal stream propor. tlon by volume.

C. $=$ Acetons blank reiddus concentration, $\mathrm{mg} / \mathrm{mg}$.

c-Concenisution of particulate matler in stack par dey basth, corrected to eteng. dard ronditione s/decm ( $\mathrm{e} / \mathrm{dec}$ ).

l- Fercent of tookinette semplins.

In - Maximum ecceptable leakase race for ether a pretest leak ehect or for a leal: check folloring a component chanser equal to $0.00057 \mathrm{~m} / \mathrm{min}(0.02 \mathrm{ctm})$ or percent of the everace samplins rate. rhicherer b lea.

L-Indtritual leatence race observed durtne the leak theet conducted prior to the momponent chance $(1-1,2,3 \ldots$ n). mi/min (cim).

4.-Leakare rate observed durting the poattest leak check, $\mathrm{m} \cdot / \mathrm{min}$ (cfm).

$m_{n}=$ Tolal amount of partloulate matler col lected. ms.

M-Molecular velent of maler. $18.0 \mathrm{~s} / \mathrm{s}$. mole (18.0 tb/1b-roole).

mo-Mess of readdue of ectone ster eveov. rellon ms.

Pu-Barometrte preasure of the ampline die. orm IIn (In: Bns).

$P_{1}=$ Abeolute ettect on presiure. $\mathrm{mm}$ Bn (in Aiz).

Po-standard aboolute presure. $700 \mathrm{mo}$ Hin (20.92 in F(n).

$R$-Ideal tas constant $0.00236 \mathrm{~mm}$ Hermo/

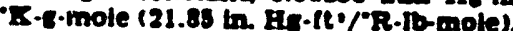

To-Absolute averase dry mo meter lew perature (ace Frrure $17-3)^{2}$, '. ( $(-R)$.

$T_{1}$-Absolute armprare rtant mi temperature (see Mrine 17-3), $\cdot \mathbf{R}(\cdot R)$.

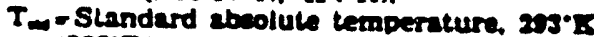
(528'R).

$V_{\text {. }}$ - Volume of ncelone blank. $\mathrm{ml}$

$\nabla_{\text {.. }}$ - Volume of metone uned in wash, mL.

V. - Tolal volume of llquid collected in $\mathrm{tm}$. pingers and allica rel (see Fisure 17-4). mi.

$V_{-}=$Volume of ras sample as searured by dry gas meter, dem (def)

$v_{\text {man }}=$ Volume of ans ample mearured by the dry ras meter. corrected to itandiry condlitiona decm (dact).

V - Volurne of water vapor in the mas sumple. corrected to etandard condl. tlons. $\mathrm{scm}$ (sct).

$r$ - - Slack ran veloctty, calculated by Method 2. Equation 2-0, using dets obtalned from Method $17 . \mathrm{m} / \mathrm{sec}$ ( $(\mathrm{t} / \mathrm{sec})$.

W. - Wetight of residue in acetone wash. me.

$Y$ - Dis kas meter callbration coefficient.

AA-Arerage presoure differential cerom the ortflce meter (ese Firure 17-3), $\mathrm{mm}$ H.O ('n. H.O).

D, -Densily of acelone. $\mathrm{ms} / \mathrm{ml}$ (see label on botile).

1. - Denstry of water, $0.0902 \mathrm{~g} / \mathrm{ml} 10.002201$ $|b / m| \mid$

- - Total saropling Ume. min

$0,-8$ ampilin tirae interval. from the bexin nink of a run untll the first component chance. min.

0-Bampline lime interval. between two ruccesalve component chances besin. ains wth the interval between the fint and secood chares onin.

0.-8umpling time interval from the fina (a) component chance untll the end of the samplins run min.

13.6-8peetfle crevits of mercurs.

$6-8 \mathrm{ec} / \mathrm{min}$.

100 -Conversion to percent.

8.1 Averace dry tas meler temperature and everace ortilce preanure drop. See dals aheet (Mrure 17-3).

6.3 Dis Gas Volume. Correct the sample colume meanured by the dry meter to standard condillons $\left(20^{\circ}\right.$ C. $760 \mathrm{~mm}$ He or Cr F, 20,92 in $\mathrm{BS}$ ) by untere Equation 17-L.

$$
\begin{aligned}
& V_{m(\text { std })} \cdot V_{m} r\left(\frac{T_{\text {std }}}{T}\right)\left[\frac{P_{\text {bar }}+\frac{a H}{\Gamma_{3.6}}}{P_{\text {std }}}\right] \\
& -R_{1} r_{a} r \frac{P_{\text {bar }}+(\Delta H / 13.6)}{T_{a}}
\end{aligned}
$$

Equation 17-1

where:

E $=0.3868^{\circ} \mathrm{K} / \mathrm{mm}$ Hs for metsle units $17.44^{\circ} \mathrm{R} / \mathrm{kn}$. Bis for Insilien unile

Norr-Equation 17-1 aa be ured as writ. ten unies the leaknge rate observed durtns any of the mandators leak checta (le the post-lest lonts cheet or leak chectes conduct. ed prior to component chancel exceeda is If If or 4 exceeds is Equatsoa 17-1 must be modifled a followe

(a) Case I. No component chanres made durtine ampllne rum In thit ease. replece

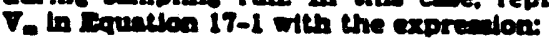

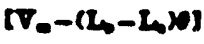

(b) Case II. One or more component changes mede durting the mamplins run. In this case. replece $\nabla$. In Equation $17-1$ by the expreaton:

$$
\begin{array}{r}
\left(V_{0}-\left(L_{1}-L_{a}\right) \theta_{1}-\sum_{i=2}^{n}\left(L_{1}-L_{a}\right) O_{1}\right. \\
\left.-\left(L_{p}-L_{2}\right) O_{p}\right)
\end{array}
$$

and substitute only for those leakage rates (I) of L) whteh exceed Lh.

C.1 Volume of mater repor.

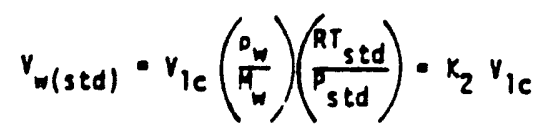

where:

Equation 17-2

Bn $=0.001333 \mathrm{me} / \mathrm{ml}$ tor metric unita: 0.04707 $1 t 1 / \mathrm{ml}$ lor Enelleh unite.

0.8 Molnture Content.

$$
B_{w s}=\frac{V_{w(s t d)}}{\frac{m(s t d)}{+V_{w}(s t d)}}
$$

Equation $17-3$ a. Acetone Blant Concentration.

$$
c_{2}=\frac{m_{a}}{\frac{a}{s_{a}}}
$$

6.7 Acetone Wash Blenk.

$$
W_{0}=C_{0} V_{0.0 p}
$$

Equation 17-5

6.8 Total Partleulate Weight. Determine the total particulate catch from the sum of the wetrhts obtalned from containers 1 and 2 leas the acelone blank (sce Figure 17-4).

Norz-Refer to Section 4.1.3 to essist in calculation of results involving two or more guter seeemblies or two or more sampiline trains.

6.9 Partleulate Concentration.

$$
c_{c}=(0.001 \mathrm{~s} / \mathrm{ms})\left(\mathrm{m}_{\mathrm{m}} / \mathrm{V}_{\mathrm{m}}\right)
$$

Q.10 Converston Fectors

Squation 17-6

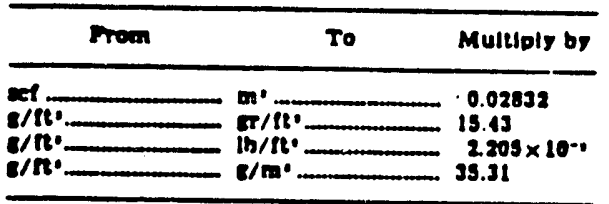

6.11 Leoklnetle Variation.

6.11.1 Caleulacion from Ran Data.

$1 \cdot \frac{100 r_{s}\left(K_{3} Y_{1 c}+\left(V_{m} Y / T_{a}\right)\left(P_{\text {ber }}+\Delta H / 13.6\right)\right]}{600 V_{s} r_{s} A_{n}}$

where:

Equation $17-7$

$\mathrm{K}_{0}=0.003454 \mathrm{~mm} \mathrm{~Hz}-\mathrm{m}^{\prime} / \mathrm{ml} \cdot{ }^{-} \mathrm{K}$ lor metric units; 0.002869 in. He.ft $/ \mathrm{ml}-{ }^{-} \mathrm{R}$ lor Eng lith units.

0.11.2 Calculation from Intermediate Valuea

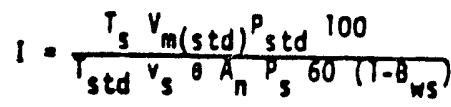

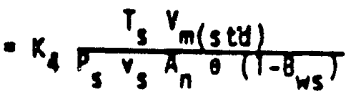

where:

Equation 17-8

8. -4.320 for metric units: 0.09450 for EneItsh unite.

6.12 Acceptable Results. Il 90 percent 010110 percent. the results are ncceptable. If the resulta cre low in comparison to the standard and : is beyond the acceptable rangc, or, If I ls less than 90 percent. the Ad. ministrintor may opt to sccept the results. Ose Citation 4 in Section 7 to make Juds. ments. Otherwise, reject the results and repeat the test.

7. Bibllogrephy.

\section{[Appendix A, Method 17]}


1. Addendum to Spectileations for Incinerator Testing at Federal Fretlities PHB. NCAPC. December 6. 1907.

2. Martin. Robert M. Construction Detal of Isokinetle Source-Snmpling Equipment. Environmental Prolection Arency. R search Triandle Park. N.C. APTD-0sat. Aprtl, 1971.

3. Rom, Jerome J., Malntenance, Callbra ton. and Operation of IsokInetle Source Sampilne Equipment. Environmental Protection Asency. Research Triancle Park. N.C. APTD-0576. Merch. 1072

4. Smith. W. S.. R. T. Shigehara and $W$ F. Todd. A Method of Inlerpreting Stack Sampllng Data Paper Presented at the 63rd Annusl Meeting of the Alr Pollution Con trol Assoctation. SL Louls, Mo. June 14-19, 1970.

5. Smith. W. S., et w. Stack Oes Sampline Improved and Simpllfled with New Equip ment. APCA Paper No. 67-119. 1907.

6. Speclflestlons for Incinerator Testins at Federal Facllitles. PBS, NCAPC. 1907.

7. Shirehara $\boldsymbol{R}$. $T$.. Adjustments in the EPA Nomograph for Different Pilot Tube Coeffleients and Drs Molecular Welehts. Stuck Sampline News $24-11$. October. 1974. 8. Volle.ro, R. F.. A Surves of Commercta I Avallable instrumentation for the Meas urement of Low.Rante Gas Velocitles. U.S. Environmental Protectlon Acency. Emission Measurement Branch. Research Trtande Park. N.C. November. 1976 (unpublished paper).

9. Annual Book of ASTM Standards. Part 26. Gaseous Puels; Coal and Coke: Atmoe pheric Analysts. American Soctety for Test. ine and Matertals. Philadelphis, P2 1974 pp. 617-822.

10. Vollaro. R. F.. Recommended Proce dure for Sample Traverses in Ducts Sm than 12 Inches in Diameter. U.S. Inviron. mental Protection Acency. Smisoion Mess urement Branch. Research Triangle Part N.C. November, 1076.

\section{IETIIOD 18 - MEASUREMENT OF} GASEOUS ORGANIC COMPOUND ENILSSIONS BY GAS CHROMATO GRAPIIY

(Method 18 added by 48 FR 48335, October 18. 1983: amended by 49 FR 22606. Nay 30, 1984; 52 FR 5106. February 19. 1987]

Introduction (This method should not be stempled by persons uniamiliar with the performance characteristles of gas chroma. tography. nor by those persons who are unlamillar with source simpling. Pertlcular care should be exercised in the aree of safety concernins cholce of equipment and operation in potentidly explodive atmon pheres.]

1. Applicablltly and Princtple

1.1 App!lcabillty. This method applles to the analysis of approximately 90 percent of the total gaseous organics emitted from an industrial source. It does not Include lech. niques to Identliy and messure trace emounts of organic compounds, such those found in bullding air and fudtive emboton sources.

This method will not determine compound that (1) are polymerte (hish molecu. lar welght), (2) ean polymerize before analy. of or (3) have very low rapor preseures at Esect or instrument conditions.

1.2 Principle. The major organic components of a gas mixture are separated by ges chromatography (GC) and individually quantified by fiame ionization, photoionization, electron capture, or other ap propriate detection principles.

[1.2 revised by 52 FR 5106, February 19, [987]

The retention umes of each separated component are compared with those of knom compounds under Identleal condltlons. Therelore. the analyst conflrms the Identity and approximate concentratlons of the ortanlc emission components before hend. With this informstlon the ansiyst then prepares or purchases commerctally svallable standard mixtures to callbrate the GC under condlutom Identical to those of the simplea. The envlyat alo determine the need tor sample dilution to avold detec. tor saturation. ges stream flitration to ellmt. nate partlculate matler, and prevention of molsture condensation.

\section{Ranoe and Sentllobly}

2.1 Ranze. The range of this method th from about 1 part per million (Dpm) to the upper Ilmit soverned by OC detector satur. ulon or column overlondins. The upper IImil ean be extended by dllutloc the stact geses with in thert on or by uning andler sen ampline loopa

2.2 sendivity. The semitivity limit for compound is deflned so the minimum de tectable concentration of that compound, or the concentration that produces a simal-to nolse ratlo of three to one. The minimum datectable conce:itration is determined durtne the presirves callbration for each compound.

\section{Prectston and Accuracy}

Gas chromstoeraphic techniques typically provide a precision of 5 to 10 percent rela. Ure standard deviation (RSD), but an experienced OC operator with a rellable instru. ment can readlly echleve 5 percent RSD. For this method, the following combined OC/operator values are required.

(a) Preciston. Dupllate andyses are within 5 percent of their mean value.

(b) Aceurnes. Andysis results of prepared eudit samples are within 10 pereent of prep aration veluea.

4. Interferences

Resolution Interferences that msy occur cen be ellminated by sppropriate GC column and detector cholce or by shifting the retention times through changes in the column now rate and the use of tempern. lure prosramming.

The analytical aystem is demonstrated to be exentidly free from conteminnits by pe- riodleally enslyzine blanks that consist of hydrocarbon-Iree alr or nilrogen.

Sumple cross-contamination that oceurs when hich-level and low-level samples or atendardis are analyzed alternately, is best dealt ith by thorourh pirgins of the GC anmole loop between samples.

To assure consistent detector response. calibration gases are contained in dry xir. To adjust gaseous organic concentrations when water vapor is present in the sample. water vapor concentrations are determined for those samples, and a correction factor is applied.

14. amended by 52 FR 5106, February 19. 1987]

5. Presurvey and Presurvey Samplin:

Perform a presurvey for each source to be tested. Refer to Figure 18-1. Some of the information can be collected from lit. erature surveys and source personnel. Collect gas samples that can be analyzed 10 confirm the identities and approximate concentrations of the organic emissions.

15. revised by S2 FR 5106, February 19. [987]

5.1 Apparatus. This apparatus list also applies to Sections 6 and 7 .

[5.1 revised by 52 FR 5106. February 19 , [987]

s.1.1 Teflon Tublng. (Mention of trade names or spectlic products does not consts. tute endorsement by the U.S. Environmen. tal Protection Asency.) Diameter and lensth determined by connectlon require. ments of cyllnder resulators and the GC. Additional tubins is necessary to connect the GC sample loop to the sample.

5.1.2 Oss Chromatorraph. GC with sult. able detector, columns, temperature.con. trolled sample loop and valve assembly. and temperature programable oven. If neccssary. The GC shall achieve sensitivity require. ments for the compounds under study.

5.1.3 Pump. Capable of pumping $100 \mathrm{ml} /$ min. For flushing sample loop.

5.1.4 Flowmeters. To measure now rates.

[5.1.4 revised by 52 FR 5106, February 19. 1987 ]

5.1.5 Regulators. Used on gas cyllnders for OC and for cyllnder standards.

5.1.6 Recorder. Recorder with linenr strip chart is minimum acceplable. Intearator (optional) is recommended.

5.1.7 Syringes. $0.5 \mathrm{ml}, 1.0-$ and $10-$ microliter sizes, calibrated, maximum accuracy (gas tight), for preparing calibration standards. Other appropriate sizes can be used.

5.1.7 revised by 52 FR. 5106, February 19. 19871 
TGS-ANSA METHOD FOR THE
DETERMINATION OF NITROGEN
DIOXIDE IN THE ATMOSPHERE

EPA Designated Equivalent Method No. EQN-1277-028

U. S. Environmental Protection Agency Environmental Monitoring and Support Laboratory Research Triangle Park, North Carolina 27711 December 1977 


\section{$T$ Guaiacol. \\ TGS-ANSA METHOD FOR THE DETERMINATION \\ OF NITROGEN DIOXIDE IN THE ATMOSPHERE}

EPA Designated Equivalent Method No. EQN-1277-028

\section{Principle and Applicability}

1.1 Ambient nitrogen dioxide $\left(\mathrm{NO}_{2}\right)$ is collected by bubbling air through a solution of triethanolamine, 0-methoxyphenol, and sodium metabisulfite. $(1,2)$ The concentration of nitrite ion $\left(\mathrm{NO}_{2}^{-}\right)$produced during sampling is determined colorimetrically by reacting the nitrite ion with sulfanilamide and 8-anilino-l-naphthalenesulfonic acid ammonium salt and measuring the absorbance of the highly colored azo dye at 550 1 m.

1.2 The method is applicable to 24-hour integrated sampling of $\mathrm{NO}_{2}$ in ambient air. Collected samples are transferred to a laboratory for manual analysis., ! ,

1.3 Agencies desiring to use this method in a network operation may find it necessary to dévelop and use additional operation and quality assurance procedures not provided in the method description. Information regarding quality assurance procedures can be found in reference 3 .

2. Range and Lower Detectable Limit

2.1 The nominal range of the method is 15 to $750 \mu \mathrm{g} \mathrm{NO} / 2 / \mathrm{m}^{3} \quad(0.008$ to $0.4 \mathrm{ppm}) .{ }^{\text {(2) The range of the analysis is } 0.025 \text { to } 4.0 \mathrm{\mu g} \mathrm{NO}}-2 / \mathrm{ml}$, following Beer's law throughout this range ( 0 to 2.0 absorbance units). 
Uider the specified conditions of $50 \mathrm{ml}$ of absorbing reagent, a sampling rate of $200 \mathrm{~cm}^{3} / \mathrm{min}$ for 24 hours, and a sampling efficiency of 0.93 , the runge of the method is therefore 5 to $750 \mathrm{\mu g} \mathrm{NO}{ }_{2} / \mathrm{m}^{3}(0.003$ to $0.4 \mathrm{ppm})$.

2.2 Based on results from a collaborative study, the lower detectable 1 imit of the method is estimated to be $15 \mu \mathrm{gNO} / \mathrm{m}^{3}(0.008 \mathrm{ppm})$. (4)

\section{Interferences}

3.1 At a $\mathrm{NO}_{2}$ concentration of $100 \mathrm{\mu g} / \mathrm{m}^{3}$ the following pollutants, at the levels indicated, do not interfere: ammonia, $205 \mu \mathrm{g} / \mathrm{m}^{3} 10.29$ ppm); carbon monoxide, $154,000 \mu \mathrm{g} / \mathrm{m}^{3}$ (134 ppm); formaldehyde, $750 \mu \mathrm{g} / \mathrm{m}^{3}$ $(0.61 \mathrm{ppm})$; nitric oxide. $734 \mathrm{\mu g} / \mathrm{m}^{3}(0.60 \mathrm{ppm})$; phenol, $150 \mathrm{\mu g} / \mathrm{m}^{3}(0.04$ $\mathrm{ppm})$; ozone, $400 \mu \mathrm{g} / \mathrm{m}^{3}(0.20 \mathrm{ppm})$; and sulfur dioxide, $439 \mu \mathrm{g} / \mathrm{m}^{3}(0.17$ ppn). (1)

\section{Precision, Accuracy, and Stability}

4.1 Based on results from a collaborative study, the within laboratory standard deviation is $7 \mathrm{\mu g} / \mathrm{m}^{3}(0.004 \mathrm{ppm})$ and the between laboratory standard deviation is $12 \mathrm{\mu g} / \mathrm{m}^{3}(0.006 \mathrm{ppm})$ over the range of 50 to 300 i $\mathrm{NO}_{2} / \mathrm{m}^{3}(0.027$ to $0.16 \mathrm{ppm})$. (4) Based on results from the Subpart $\mathrm{C}$ consistent relationship test (see Appendix), the within laboratory standard deviation is $9 \mathrm{\mu g} / \mathrm{m}^{3}(0.005 \mathrm{ppm})$ over the range of 120 to 540 l.g $\mathrm{NO}_{2} / \mathrm{m}^{3}$ (0.062 to $\left.0.29 \mathrm{ppm}\right)$.

4.2 Based on results from a collaborative study, the method has an average bias of $-5 \%$ over the range of 50 to $300 \mu \mathrm{g} \mathrm{NO}{ }_{2} / \mathrm{sm}^{3}(0.027$ to 
ن. $16 \mathrm{ppm})$. (4) Based on results from the Subpart $C$ consistent relationship iest (see Appendix), the method has an average bias of $+2 \%$ over the range of 120 to $540 \mathrm{\mu g} \mathrm{NO} / \mathrm{m}^{3}$ (0.062 to $\left.0.29 \mathrm{ppm}\right)$.

4.3 Collected samples are stable for at least 3 weeks at room emperature. Stored samples should be tightly sealed to prevent absorption of $\mathrm{NO}_{2}$ from the atmosphere.

\section{Apparatus}

5.1 Sampling. A diagram of a suggested sampling system is shown in Figure 1.

5.1.1 Sample Inlet. Teflon ${ }^{\circ}$ or glass tube with an inverted Teflon or glass funnel at the sampling point to prevent entrance of precipitation.

5.1.2 Absorber. Polypropylene tube, $164 \mathrm{~mm}$ long $\times 32 \mathrm{~mm}$ diameter, equipped with a polypropylene two-port closure (see figure 1). (Rubber stoppers cause high and variable blank values and should not be used.) The closure must be fitted with an $8 \mathrm{~mm}$ 0.D., $6 \mathrm{~mm}$ I.D. glass tube approximately $152 \mathrm{~mm}$ ' long having the end drawn out to form an orifice with an I.D. of 0.3-0.6 $\mathrm{mm}$. This tube must be positioned to allow a clearance of $6 \mathrm{~mm}$ from the orifice to the bottom of the absorber. The closure and ports must be free of leaks.

5.1.3 Moisture Trap. Polypropylene tube similar to absorber. The entrance port of the closure is fitted with tubing that extends to the bottom of the trap. The unit is loosely packed with glass wool or silica gel to trap moisture to protect the flow control device. The tlap nust be repacked with fresh glass wool or silica gel before the start of each sampling period. 
5.1.4 Membrane Filter. Of 0.8 to 2.0 micron porosity and $3 \mathrm{~cm}$ diameter. Be sure the filter does not leak. The filter must be replaced after collecting 10 samples.

5.1.5 Flow Control Device. Any device capable of maintaining $\mathrm{J}$ constant flow through the sampling solution between 180 and 220 $\mathrm{cm}^{3} / \mathrm{min}$. A convenient flow control device is a 27 gauge hypodermic needle, ${ }^{(5)} 10 \mathrm{~mm}$ (3/8 inch) long, used as a critical orifice. (Most 27 gauge needles will give. flow rates in this range.)

5.1.6 Air Pump. Capable of maintaining a vacuum of at lesst 0.6 atmosphere (450 torr) across the flow control device. [This value is based on the critical pressure differential, 0.53 atmosphere

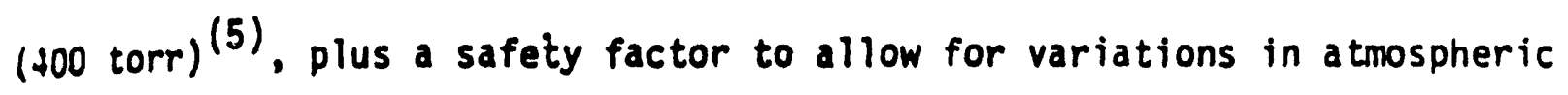
pressure and minor variations in pump performance.]

5.1.7 Flowneter. Properly calibrated flowmeter for measuring air flow rates in the range of $150-250 \mathrm{~cm}^{3} / \mathrm{min}$. The use of a mass flowmeter is particularly convenient since no corrections are required when used under temperature and pressure conditions that differ from the conditions under which tt is calibrated (see 10.1).

5.1.8 Flow Measurement Standard. Precision wet test meter (1 liter/revolution), bubble flowmeter, or other reliable standard.

\subsection{Analysts}

5.2.1 Volumetric Flasks. 100, 200, 250, 1,000-m1.

5.2.2 Pipets. $1,2,5,10,15,20,50-\mathrm{ml}$ volumetric; 1 , 3-ml, graduated in $1 / 10-m l$ intervals.

5.2.3 Test Tubes. Approximately $150 \mathrm{~mm}$ long $\times 20 \mathrm{~mm}$ diameter.

5.2.4 Spectrophotometer. Capable of measuring absorbance at $550 \mathrm{~nm}$; equipped with $1 \mathrm{~cm}$ optical path length cells. 
6. Rejgents All reagents should conform to ACS specifications for resiunt grade materials unless otherwise specified.

\subsection{Sampling}

6.1.1 Distilled Water. Must be reagent water as defined by istM procedure 1193-66 part 6.3 (Consumption of potassium permanganate tesi). (6)

6.1.2 Triethanolamine.

6.1.3 0-Methoxypheno1. Also known by its trivial name, gudiacol. Melting point, $27-28^{\circ} \mathrm{C}$. CAUTION: Technical grade material will not meet this specification and should not be used.

6.1.4 Sodium Metabisulfite.

6.1.5 Absorbing Reagent: Dissolve $20 \mathrm{~g}$ of triethanolamine, $0.5 \mathrm{~g}$ of 0 -methoxyphenol, and $0.250 \mathrm{~g}$ of sodium metabisulfite consecutively in $500 \mathrm{ml}$ of distilled water. Dilute to $1000 \mathrm{ml}$ with distilled water. lix thoroughly. The solution should be colorless. This solution is ituble for 3 weeks if protected from light.

\subsection{Analys is}

6.2.1 Sulfantlamide, melting point $165-167^{\circ} \mathrm{C}$.

6.2.2 8-Anilino-l-naphthalenesulfonic Acid Ammonium Salt (ANSA). Molecular weight $=316.33$. The ANSA must have a molar absorptivity (i) of 19,000 to 19,300 liter/mole-cm as given by:

$$
\varepsilon=\frac{A}{b \times C}
$$

Mere: $A=$ Absorbance measured at a wavelength of $264 \mathrm{~nm}$

b = Cell length, cm

$c=$ Concentration, mole/liter on a dry basis, in water at $\mathrm{pH} 7.0 \pm 0.2$ 
iole: ANSA usually has a moisture content of 2 to $3 \%$.

fives: Eastman Chemical Co. ANSA, minimum analysis 98\%, has been found to met the above specifications. (a)

6.2.3 Hydrogen Peroxide, 30\%.

6.2.4 Methanol, absolute.

6.2.5 Hydrochloric Acid, concentrated.

6.2.6 Sulfanilamide Solution: Add $2.0 \mathrm{~g}$ of sulfanilamide iu a 100-ml volumetric flask containing approximately $50 \mathrm{ml}$ of distilled wdter. Then slowly add $33 \mathrm{ml}$ of concentrated $\mathrm{HCl}$ and dilute to $100 \mathrm{ml}$ with distllled water. Mix thoroughly. This solution can be used for 4 weeks when stored under normal laboratory conditions.

6.2.7 ANSA Solution: Dissolve 0.1. g of ANSA in $50 \mathrm{ml}$ of ausolute methanol. Dilute to $100 \mathrm{ml}$ with absolute methanol in a volumetric flusk. Mix thoroughly. Keep stoppered, when not in use, to minimize eyaporative losses. This solution can be used for 3 weeks when stored under normal laboratory conditions. The solution will develop some color under these conditions, but this color does not affect subsequent andlyses. (If this color formation is objectionable to the analyst, tive sulution can be stored in the dark to minimize color formation.) Exposure to elevated temperature should be avoided. Solutions exposed to temperatures of $30^{\circ} \mathrm{C}$ or higher for 8 hours or more should be discarded.

\subsubsection{Hydrogen Peroxide Solution: Dilute $0.2 \mathrm{ml}$ of $30 \%$} hydrogen peroxide to $250 \mathrm{ml}$ with distilled water. This solution may be used for one month, if refrigerated and protected from light.

ailention of commercial products does not constitute endorsement of the product by the U.S. Government. 


\subsection{Calibration}

6.3.1 Sodium Nitrite, assay of $97 \% \mathrm{NaNO}_{2}$ or greater.

6.3.2 Sodium Nitrite Stock Solution ( $500 \mathrm{ug} \mathrm{NO}_{2}^{-} / \mathrm{ml}$ ):

ilssolve an accurately weighed (to nearest $0.1 \mathrm{mg}$ ) amount of desiccated sudium nitrite in distilled water and dilute to $1,000 \mathrm{ml}$ such that a sulution containing $500 \mathrm{\mu g} \mathrm{NO}_{2}^{-} / \mathrm{ml}$ is obtained. The amount of $\mathrm{NaNO}_{2}$ to wse is calculated as follows:

$$
G=\frac{1.500}{A} \times 50
$$

where: $G$ = Amount of $\mathrm{NaNO}_{2}$, grams

1.500 - Gravimetric conversion factor

A = Assay, percent (should be 97 or greater)

Tris stock solution can be stored for 6 weeks, if refrigerated:

6.3.3 Sodium Nitrite Working Standard $(10 \mu \mathrm{g} \mathrm{NO}$ Pipet $5 \mathrm{ml}$ of the stock solution into a $250-\mathrm{ml}$ volumetric flask and silute to volume with absorbing reagent. Prepare fresh daily.

\section{' Calibration}

7.1 Flowmeter. Calibrate the flowmeter against a calibrated flow easurement standard, such as a wet test meter, bubble flowmeter, or ther reliable volume measurement standard. Calibrate in units of tandard $\mathrm{cm}^{3} / \mathrm{min}$ (i.e., corrected to $25^{\circ} \mathrm{C}$ and 760 torr).

7.2 Absorber. Caltbrate the polypropylene absorber (see 5.1.2) by peting $50 \mathrm{ml}$ of water or absorbing reagent into the absorber. Scribe 
the level of the meniscus with a sharp object, mark over the area with a folt-tip marking pen, and rub off the excess.

\subsection{Spectrophotometer}

\subsubsection{Prepare calibration standards by dilution of the} susium nitrite working standard (see 6.3.3) as indicated below. Use atsurbing reagent for all dilutions.

\begin{tabular}{|c|c|c|c|}
\hline , & $\begin{array}{l}\text { Volume of working } \\
\text { standard, } \mathrm{ml}\end{array}$ & $\begin{array}{c}\text { Final } \\
\text { volume, } \mathrm{ml} \\
\end{array}$ & 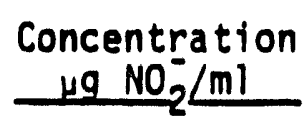 \\
\hline $\begin{array}{l}(0 ;) \text { tiona } 1) \\
(\text { Ortiona } 1) \\
\text { (Or tional) }\end{array}$ & $\begin{array}{r}0.0 \\
1.0 \\
2.0 \\
5.0 \\
10.0 \\
15.0 \\
20.0 \\
25.0 \\
30.0 \\
40.0\end{array}$ & $\begin{array}{l}100 \\
100 \\
100 \\
100 \\
100 \\
100 \\
100 \\
100 \\
100 \\
100\end{array}$ & $\begin{array}{l}0.0 \\
0.1 \\
0.2 \\
0.5 \\
1.0 \\
1.5 \\
2.0 \\
2.5 \\
3.0 \\
4.0\end{array}$ \\
\hline
\end{tabular}

7.3.2 In accordance with the analytical procedure given in 8.2 , nessure and record the absorbance for each callbration standard $(0.1$, $0.2,0.5,1.0,1.5$, and $2.0 \mu \mathrm{g} \mathrm{NO} / \mathrm{ml})$.

\subsubsection{Plot absorbance (y-axis) versus the corresponding} :oncentration in $\mathrm{\mu g} \mathrm{NO}_{2}^{-} / \mathrm{ml}$ (x-axis). Draw or compute the straight line sest fitting the data to obtain the calibration curve. A straight line vith a slope of $0.50 \pm 0.02$ absorbance unfts/ug $\mathrm{NO}_{2}^{-} / \mathrm{ml}$ and a $y$-intercept If approxinately 0.01 absorbance units should be obtained. The absorbance 5 linear up to a concentration of $4.0 \mu \mathrm{g} \mathrm{NO} 2 / \mathrm{ml}$. Therefore, if samples :xceed the absorbance of the highest calibration standard and the above bsorbance is within the range of the spectrophotometer, the calibration urve can be extended by, including the higher concentration standards. $f$ a higher absorbance range is not available, samples must be diluted itn unexposed absorbing reagent until the absorbance is within the ange of the highes't standard. 


\section{Procedure}

\subsection{Sample Collection}

8.1.1 Assemble the sampling apparatus (Figure 1) at the sa.i.ipling site. Components upstream from the absorber may be connected, where required, with Teflon "tubing; glass tubing with dry ball joints; or ylass tubing with butt-to-butt joints with Tygon ${ }^{\star}$, Teflon ${ }^{\infty}$, or polyprojylene.

8.1.2 Add' exactly $50 \mathrm{ml}$ of absorbing reagent to the calibrated ausurber.

8.1.3 Disconnect the funnel, connect the calibrated flowmeter, messure the flow rate before sampling and record as $F_{f}$. If the flow rase before sampling is not between 180 and $220 \mathrm{~cm}^{3} / \mathrm{min}$, replace the fluw control device and/or check the system for leaks. Start sampling only after obtaining an initial flow rate in this range.

8.1.4 Sample for 24 hours. Record the exact sampling time in minutes as $t_{s}$.

8.1.5 Measure the flow rate after the sampling period and reiord as $F_{f}$.

8.1.6 Seal the collected samples and transport to the lacuratory for analysis.'

\subsection{Analysis}

8.2.1 Replace any water lost by evaporation during sampling iy adding distilled water up to the calibration mark on the absorber. li. thoroughly.

8.2.2 Pipet $5 \mathrm{ml}$ of the collected sample into a test tube. lijet in $0.5 \mathrm{ml}$ of hydrogen peroxide solution and mix vigorously for puroxinately 15 seconds. Add $2.7 \mathrm{ml}$ of sulfanilamide solution and mix 
vilurously for about 30 seconds. Then pipet $3 \mathrm{ml}$ of the ANSA solution did mix vigorously for about 30 seconds. CAUTION: The ANSA must be dused within 6 minutes after adding the sulfanilamide solution. Longer line intervals will result in lower absorbance values.

8.2.3 Prepare a blank in the same manner using $5 \mathrm{ml}$ of uriesposed absorbing reagent.

8.2.4 Measure and record the absorbance of each sample and the blank at $550 \mathrm{~nm}$ against distilled water. The absorbance measurement can be made anytime from 1 to 40 minutes after addition of the ANSA. The sosorbance of the blank should be approximately the same as the $y$ incercept in the calibration curve (see 7.3.3).

8.2.5 Determine $\mu \mathrm{g} \mathrm{NO}_{2}^{-} / \mathrm{ml}$ from the calibration curve (see 7.3.3)

8.2.6 When using a spectrophotometer with an absorbance ranye of 0 to 1 , samples' with an absorbance greater than 1.0 must be resildyzed after diluting an allquot of the collected sample with unexpused absorbing reagent.

8.2.7 A randomly selected 5-10\% of the samples should be redinalyzed as part of an tnternal quality assurance program.

8.2.8 After use, the spectrophotometer cells must be rinsed thoroughly with distllled water and acetone, and dried; otherwise d filin will build up on the cell walls.

3. Sampling Efficiency. The overall average efficiency is $93 \%$ from 20 so $750 \mathrm{\mu g} \mathrm{NO} / \mathrm{m}^{3}(0.01$ to $0.4 \mathrm{ppm})$. 
10. islculations

10.1 Air Volume. Calculate the volume of air sampled as follows:

$$
y=\frac{F_{i}+F_{f}}{2} \times t_{s} \times 10^{-6}
$$

while: $V=$ Volume of air sample, $m^{3}$

$F_{i}=$ Air flow rate before sampling, $\mathrm{cm}^{3} / \mathrm{min}$

$F_{f}=$ Air flow rate after sampling, $\mathrm{cm}^{3} / \mathrm{min}$

$t_{s}=$ Sampling time, min

$10^{-6}=$ Conversion of $\mathrm{cm}^{3}$ to. $\mathrm{m}^{3}$

If the temperature and pressure conditions at the time of the initial ins inal air flow rate measurements are substantially different from the cunditions under which the flowneter was callbrated, appropriate :orrections to the flow rate measurements may be made to improve the IC: :orm of these corrections depends on the type of flowmeter used: consult in sppropriate reference for gutdance.

$10.2 \mathrm{NO}_{2}^{-}$Concentration in Analyzed Sample. Determine $\mu \mathrm{g} \mathrm{NO}_{2}^{-} / \mathrm{ml}$ irapnically from the calibration curve or compute from the slope and intercept values (see 7.3.3).

$10.3 \mathrm{NO}_{2}$ Concentration in Air Sample. Calculate as $\mu \mathrm{g}$ of $\mathrm{NO}_{2}$ per . eanuard cubic meter of air as follows:

$$
. \mathrm{NO}_{2} / \mathrm{m}^{3}=\frac{\mu g \mathrm{NO}_{2}^{-} / \mathrm{ml} \times 50}{V \times 0.93} \times D
$$


wiere: $\mathrm{kM}_{2}^{-j} / \mathrm{ml}=\mathrm{NO}_{2}^{-}$concentration in analyzed sample

50 - Volume of absorbing reagent used in sampling, $\mathrm{ml}$

$V=$ Volume of air sample, $\mathrm{m}^{3}$

$0.93=$ Sampling efficiency

$D=$ Dilution factor $(D=1$ for no dilution; $D=2$ for $1: 1$ dilution; etc.)

10.4 The $\mathrm{NO}_{2}$ concentration may be calculated as ppm using:

$$
p \mathrm{pm} \mathrm{NO} 2=\left(\mu \mathrm{g} \mathrm{NO}{ }_{2} / \mathrm{m}^{3}\right) \times 5.32 \times 10^{-4}
$$


ii. ieferences

1. Ujlih, J. D. et al. "Development and Optimization of 24-Hour Munual Methods for the Collection and Colorimetric Analys is of iti:uspheric $\mathrm{NO}_{2}$ " International Journal of Environmental Analytical inemistry. 3. 333-348 (1974).

2. Hurst, R. G. and Margeson, J. H. "An Evaluation of the TGS-ANSA rrocedure for Determination of Nitrogen Dioxide in Ambient Air." iid Report Ho. 650/4-74-047, November 1974.

3. "Qudity Assurance Handbook for Air Pollution Measurement Systems." EPA 'rublication No. EPA-600/9-76-005, January 1976.

\&. Constant, P. C., Jr. et al. "A Collaborative Test of the TGS-ANSA Methud for Determination of Nitrogen Dioxide in Ambient Air." EPA Contract No. 68-02-1363. EPA Report No. 650/4-74-046, September $197 \$$.

j. Ludue, J. P., Jr., et al. "The Use of Hypodermic Needles as Critical Urifices in Air SampTing." J.A.P.C.A., 16, 197-200 (1966).

6. ASTM Standards (Water: Atmospheric Analysis), Part 23. October lycig. (p. 225). 


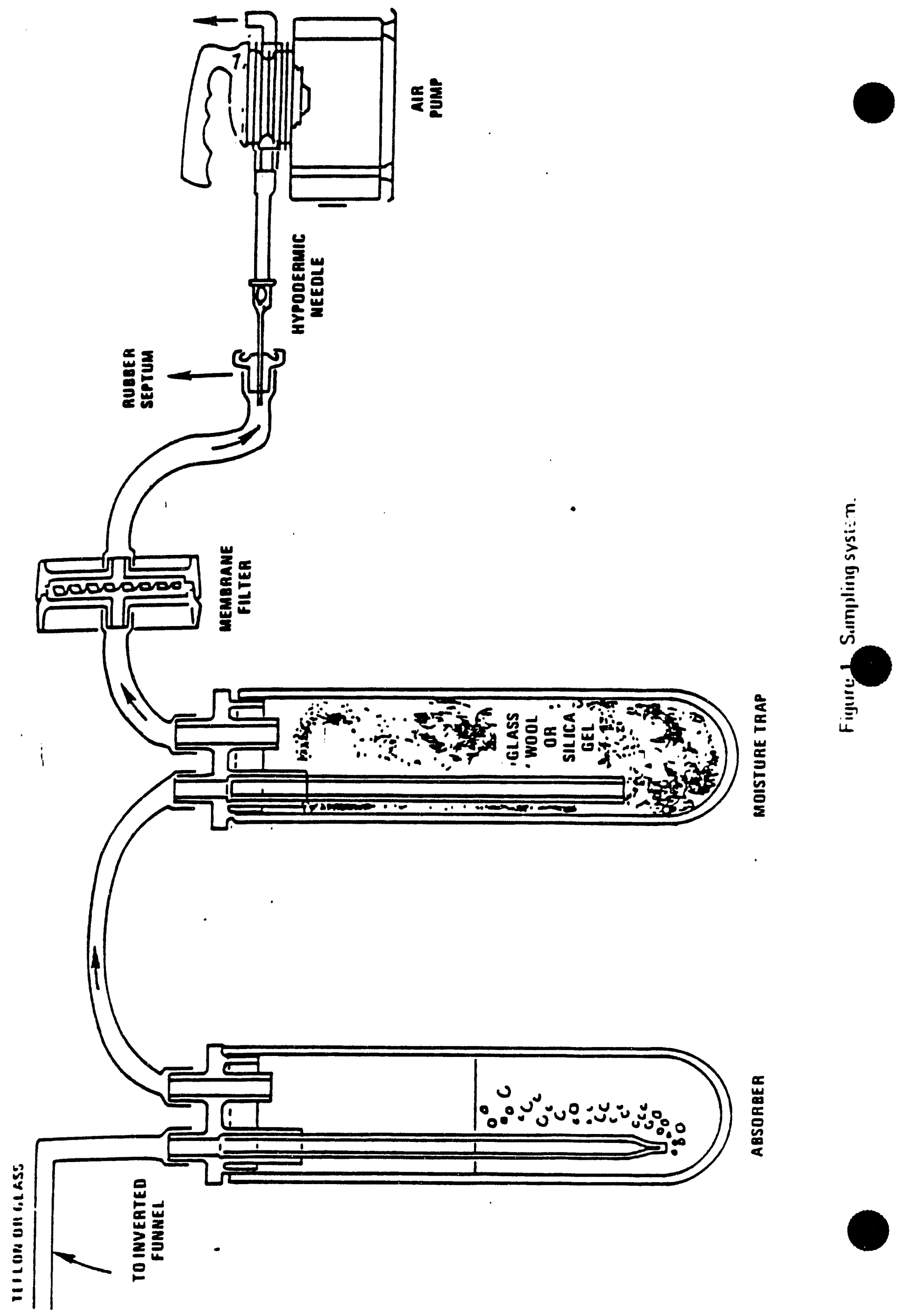


APPENDIX

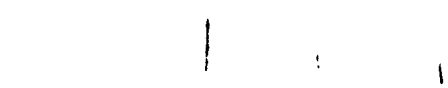


Nat:: :

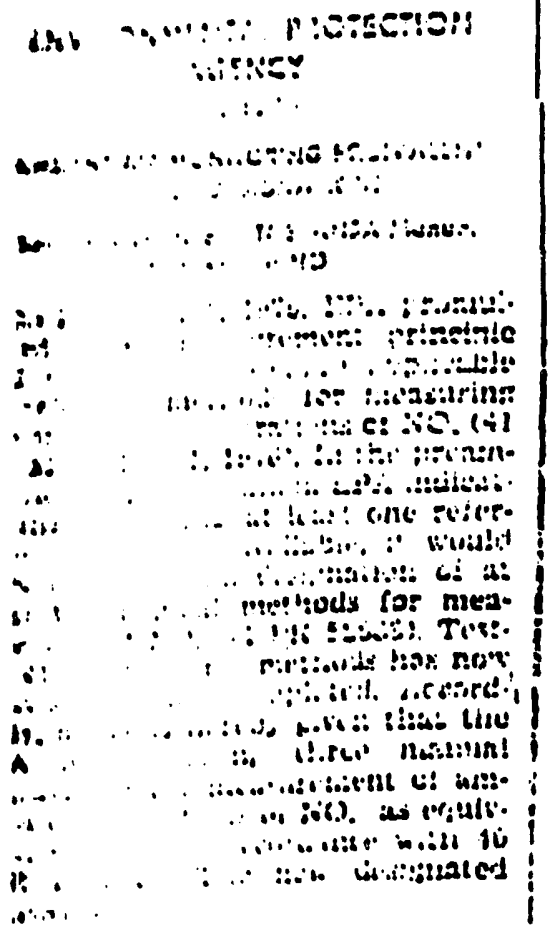

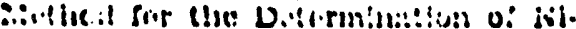
Irousten Dioxide In the Alminsi)linre."

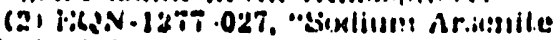

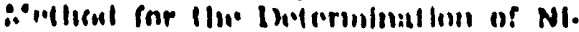

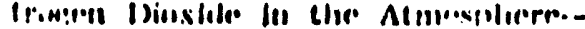

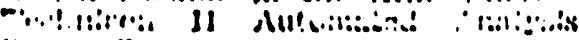
Sivil:?!11."

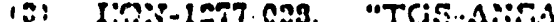

ac:iansi fur the Delertninalton of NI-

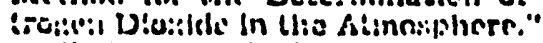

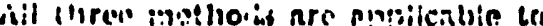
2.1-!dever Int:ngraleed meanuraments of

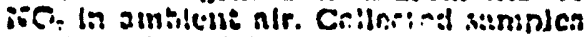

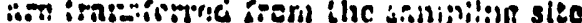

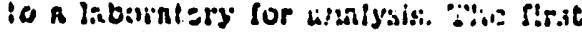
li:o m.tliets arn rery si:n!isr, and l:are Iden(!on) manip!Ins procedures. In

t:a securad metliod, an sutoriated n:Malyyis porscadure molesess He

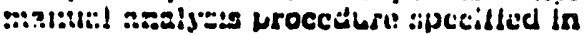
the flrst ri:oil l:od.

ivit! bolls sodlum arsenil " me:linnts.

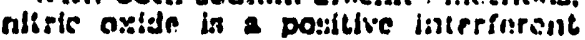
nnei carbonn e:ioxide is a nrt:aile: $\ln 1$ cr. tortint. Biceditid these Interficrunts existblt rosugarakatling offects, the resulle-

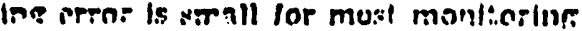

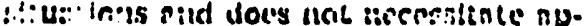

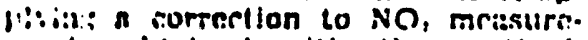
ni..: oblalmerl withe lise nintheol.

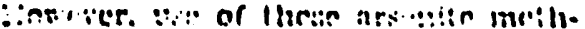

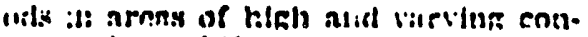

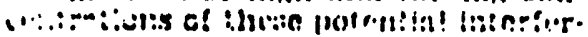
(rit.i busch as acar rondiditl's ur vilier

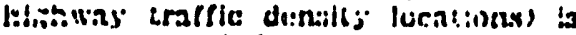
an: iores:inninited.

Eit:al of these meihois wits tested. ar:e ..:forms:i!e: nins co:nisiled. b: Eil'a

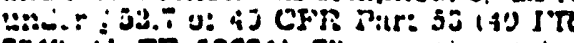

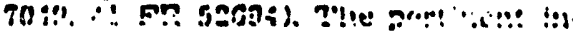
turm!at!on n:ll be kept on f!le by De.

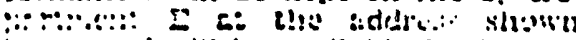

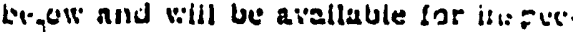

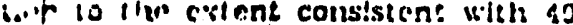

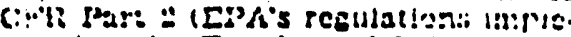
reentric the Ercedein of In! irnia!ton Air:l.

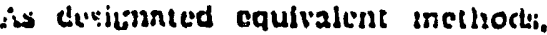
niten of these: methods is arientinble gor une bj Sintrs rind uther can:rol ser:nrin:: for purposen ef \$ 51.172 of 40

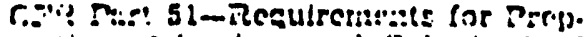
ne.t!!r:i, dsuation. and Suij.ritut!l of

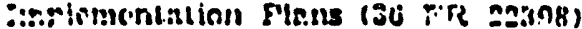
as ansinded Dreember 1, 1976 (4) I'R s.602). For these puryo:er. tronst:re. inents made by any of ilicse :acthuds

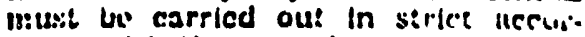

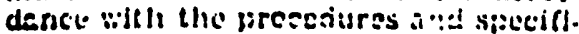
caltons provided in the rome!tfe al:.!

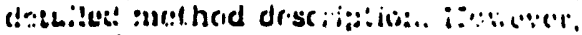
wet:y of ally of thest ini:t!not:i stinuld be nwore tisn! nromulräliun of a strurt ta:era (1 to 3 howr) standard for Nit). Is lli:cly unsler the larti amendrnuetis to thr Cican fir Act. and tlial aciirl of

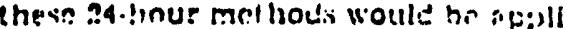
cible to such a short term stind tru.

Copjics of the method desceintinn for ece!l of these inethods, or flitither infurmallon, miny be ubtalned from nny

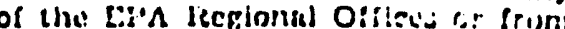
the Ënvironnmental Moniluti::s and

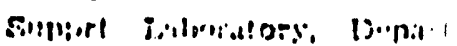
(AIt).7C), U.S. Eliblicint:icisto

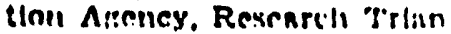
N.C. 2'itill.

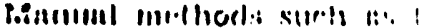

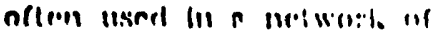

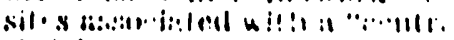

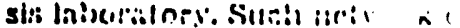

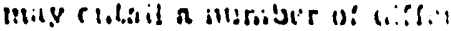
tecluliclons and Inbura! (")" n! varialy ol simmpl!ne allil minly. merit, silil vinguti mn:les 12! t Ine or sh!pisinf sample's to th tars. It is Fil'n's oluecri:al

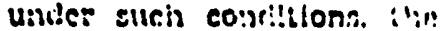
and preriston of the nit: ins:l

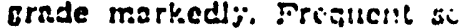
error Include ITproperts o flow masurument devise:s, ait

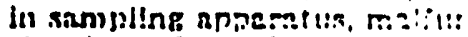
clocfias of :Ni !lc:: cint:-u! lcakcae of ebuortst:ä solt: semble during to:sdiciso:t or: fenpure reskunls or wilil'., sitid

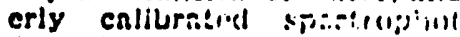
Ageneles desirtrez to use olli metlods in a nei:i:o-t: o;inn!! derelso and ure ade:!

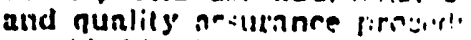

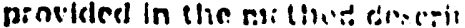

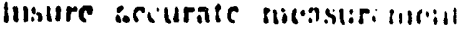

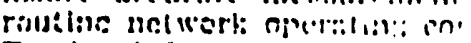

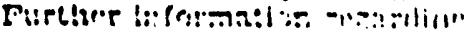

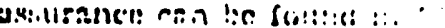

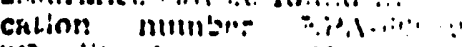

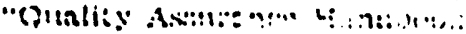

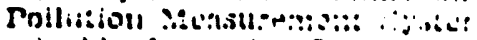

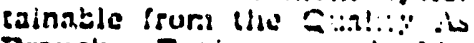

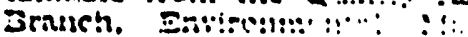

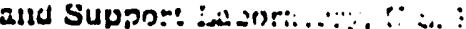

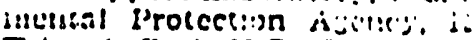

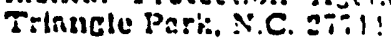

Eatred: Decumber 6. 107.

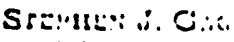

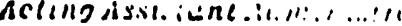

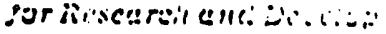

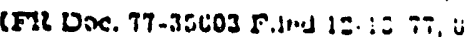




\section{S.GPART C CONSISTENT RELATIONSHIP TEST SUMMARY}

I: $\therefore$ of of 1977, the TGS-ANSA method for the determination of A1... $n$ jiocide in the atmosphere was tested and information was ca. lics o: LPA under $\$ 53.7$ of 40 CFR Part 53 (40 FR 7049, 41 FR 52694). itu. : : : : irucudures given in Subpart $C$ of Part 53 were used to determine If: : isl.slidste method has a consistent relationship to a reference

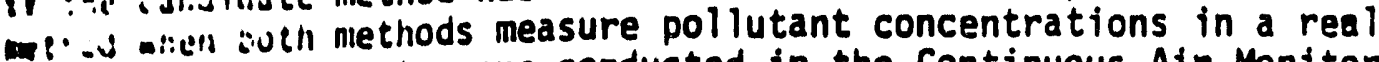
Ler : r.re.c. Pric tests were conducted in the Continuous Air Monitoring irt rs. istion located at $427 \mathrm{~N}$. New Jersey Avenue in Washington, D. C.

$\because$. susignated reference method analyzers were used during the :0. .. : if the tests: (1) RFNA-0677-021, Monitor Labs Model 8440E "1!. . . W. Ans Analyzer; (2) RFNA-0777-022, Bendix Model 8101-C Oxides

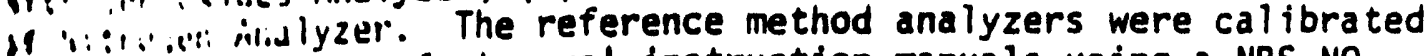
15. ..": (") ene manufacturers' instruction manuals using a ${ }^{\prime} B S \mathrm{NO}_{2}$ itu ispi interence Material (SRM 1629) as the reference standard. The is : :...: i.:enod was calibrated according to the procedure specified in inc ?".s hescription.

$\because$ siver to generate a conclusive set of consistent relationship Wi. sil: $t u$ ubtuin an estimate of the precision of the candidate method, 1 s. $\therefore$. nere obtained each test day for 8 days for a total of 32 Le its. Fullowing collection, the samples were transported to RTP, 1.6. is. sudlysis. From the time of collection to the time of analysis, se s.;iles were kept at a temperature of $20^{\circ}$ to $25^{\circ} \mathrm{C}$.

is fiom the two reference method analyzers were reduced by taking 3-:ir.uis averages throughout the 24-hour sampling period. The 15ir...: Jreldges for each analyzer were used to calculate a 24-hour ve: $:$.:.

r.d difference (discrepancy) between the candidate method measurement n :1.c 'sverage of the two reference method measurements was calculated no $\therefore$...isidu to the maximum discrepancy specifications given in Table - $\because \because$ sosurt $C$ of Part 53. The candidate method met all requirements or i innsistent relationship. Accordingly, on December 6, 1977, EPA es $1: \cdots$ is the TGS-ANSA method as an equivalent method for the measurement inliroyen dioxide in the atmosphere.

$\therefore$ subpart $C$ consistent relationship test data is tabulated below lor.. will a statistical evaluation of the test results. 


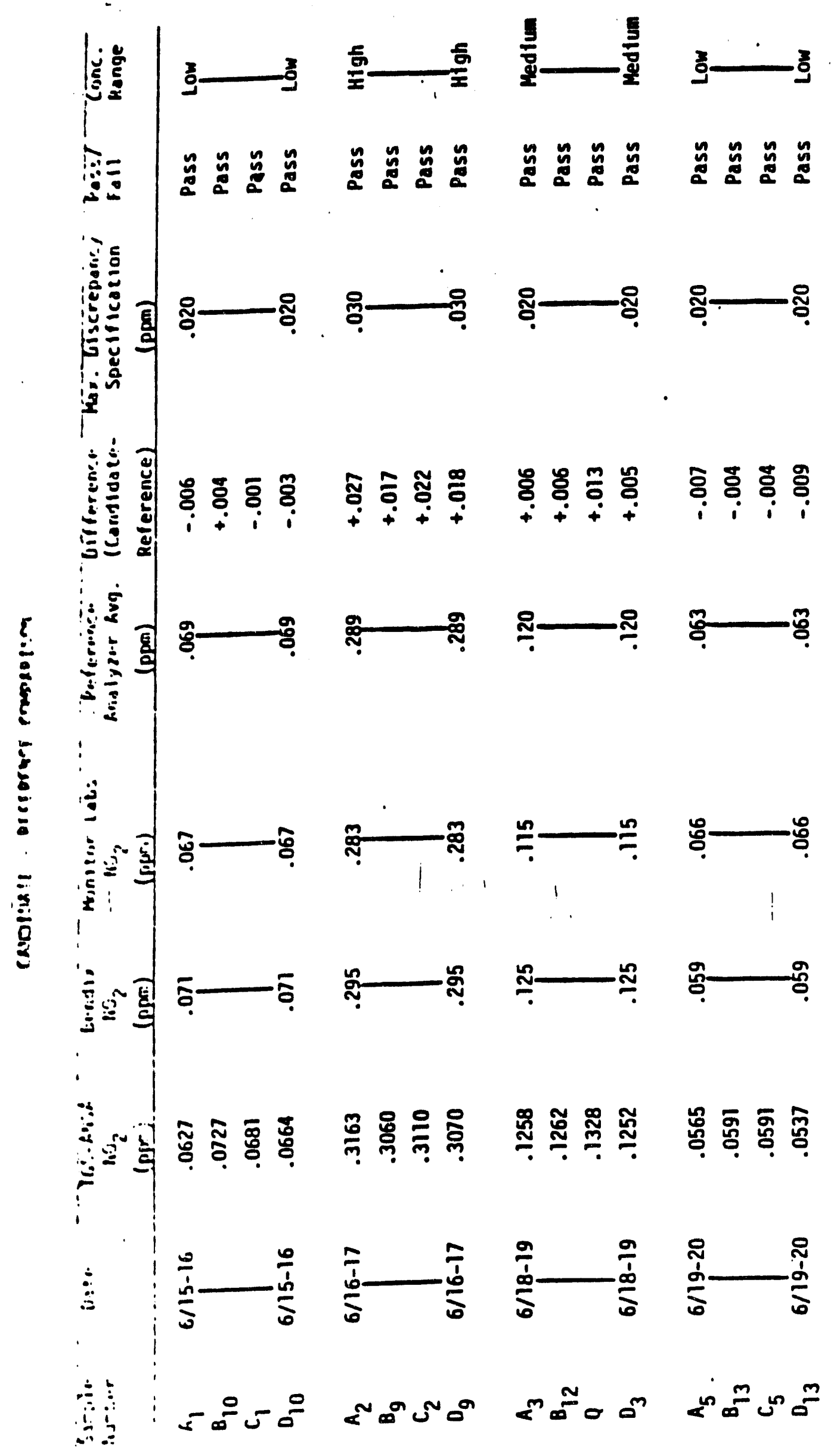




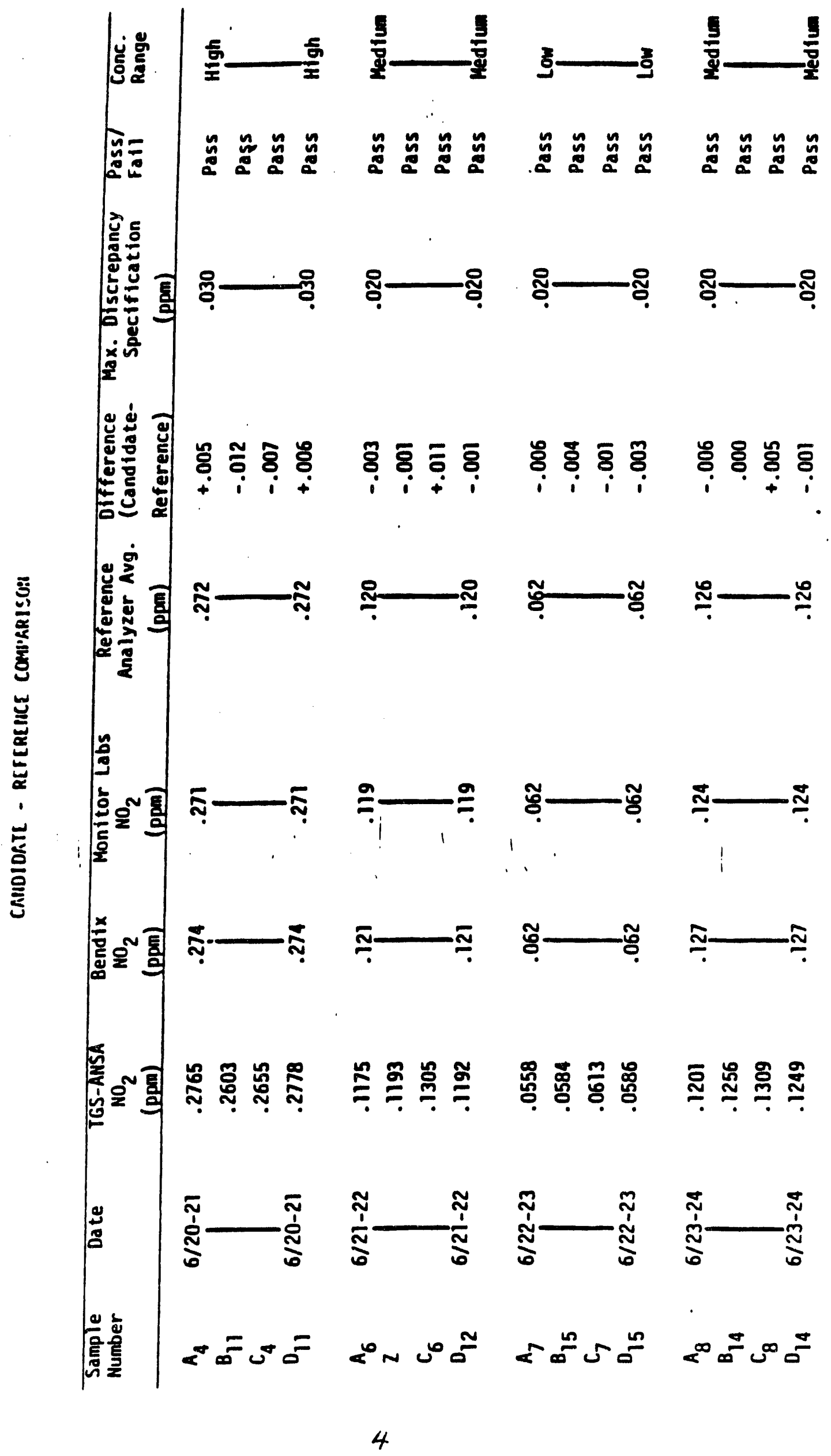




\section{S: $2: 13: 1$ isd Evaluation of Subpart C Consistent Relationship \\ Test Results (TGS-ANSA Method)}

$\therefore \therefore$ : stistically comparing the TGS-ANSA candidate method to the re'.r...c ricthod, the following definitions apply:

$\therefore$. piv refers to the average size of deviations of the candidate we:- $:$ iri.i. the reference method average. The average differences are ca....dic.s un a day-to-day basis and reported as bias (B) in the table te:

$1,1,1,111$ refers to the size of deviations from the candidate ma: Suerjuse obtained by repeated application of the sampling and in: : : 1, dl procedure. This is expressed as the standard deviation (S) of : c w llinin-day candidate samples.

\begin{tabular}{|c|c|c|c|c|}
\hline als & $\begin{array}{l}\text { TGS-ANSA } \\
\text { Avg; } \\
\text { (ppm) }\end{array}$ & $\begin{array}{l}\text { Reference Method } \\
\text { Avg; } \\
\text { (ppm) }\end{array}$ & $\stackrel{\mathrm{B}}{(\mathrm{ppm})}$ & $\stackrel{S}{(p p m)}$ \\
\hline$i / 1 \cdots:$ : & .0675 & .069 & -.0015 & .0041 \\
\hline il: • i & .3101 & .289 & .0211 & .0047 \\
\hline$/ 1: \ldots$ & .1275 & .120 & .0075 & .0036 \\
\hline$\mu \cdots:$ & .0571 & .063 & -.0059 & .0026 \\
\hline $126 . .: i_{i}$ & .2700 & 1.272 & -.0020 & .0085 \\
\hline $13:-\therefore$ & .1216 & .120 & .0016 & .0060 \\
\hline $12 \therefore: \therefore$ & .0585 & .052 & -.0035 & .0022 \\
\hline $12 \ldots .:$ & .1254 & .126 & -.0006 & .0044 \\
\hline
\end{tabular}

Avg: $\quad .0021$ Pooled: .0049 with $24 \mathrm{~d} . \mathrm{f}$.

- hi following probability statement incorporates both bias and 'eisiun in evaluating the candidate:

PñUGABILITY $[-.02 \mathrm{ppm}<$ CANDIDATE - REFERENCE $<.02 \mathrm{ppm}] \geq]-\frac{\left(B^{2}+s^{2}\right)}{(.02)^{2}}$

ere $10^{2}+S^{2}$ ) is the mean square error (MSE) of the candidate. 


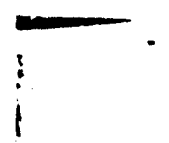

Based on the data, the following statement applies:

CS-ANSA. The probability of the candidate being within $\pm .02 \mathrm{ppm}$ of the eference is greater than .93. Another way of stating this is that if 00 analyses were made, 7 of these would be expected to differ by hance alone by more than $\pm .02 \mathrm{ppm}$ from the reference. 
Method No. EHS E-1

Title: Extraction Procedure Toxicity Test - Metals

Date 1ssued: Before 2-83 Approved by: MK Hamilton MKf

Written by: MK Hamilton

Supersedes Method No.

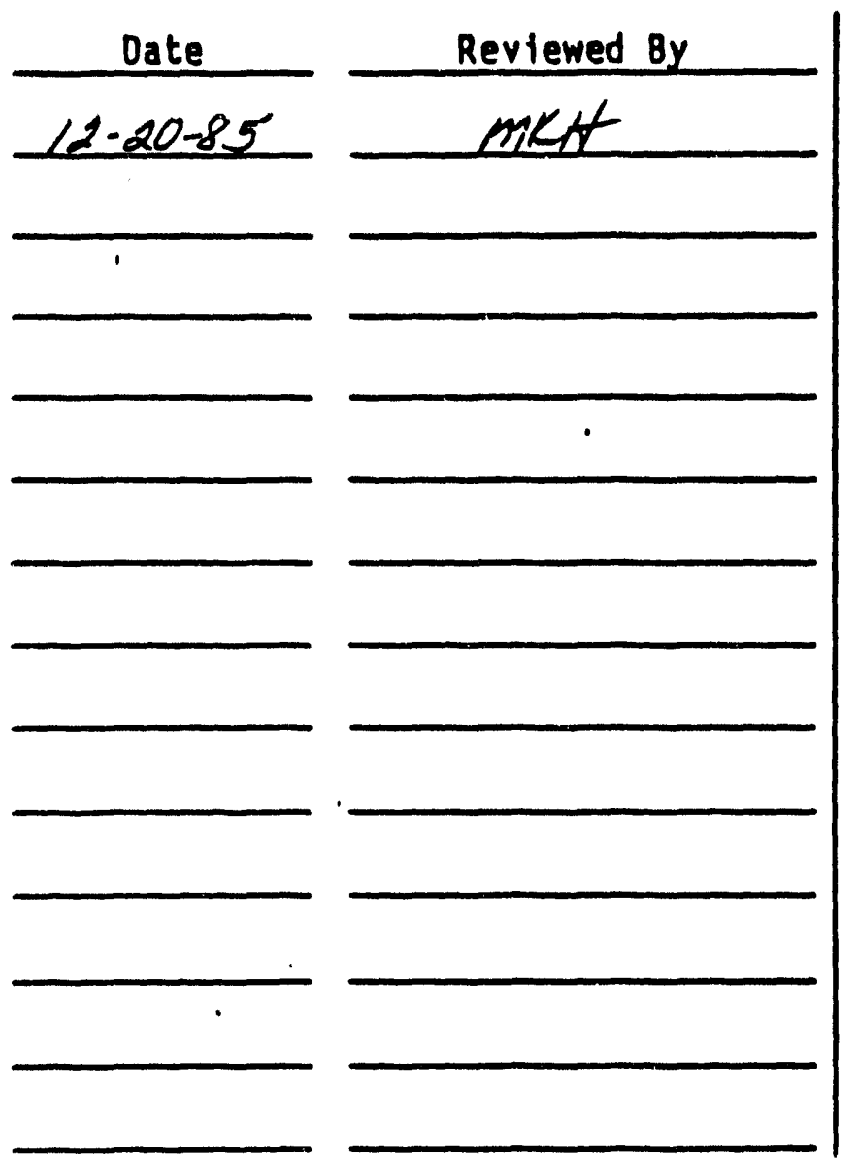

Replaced by Method No.

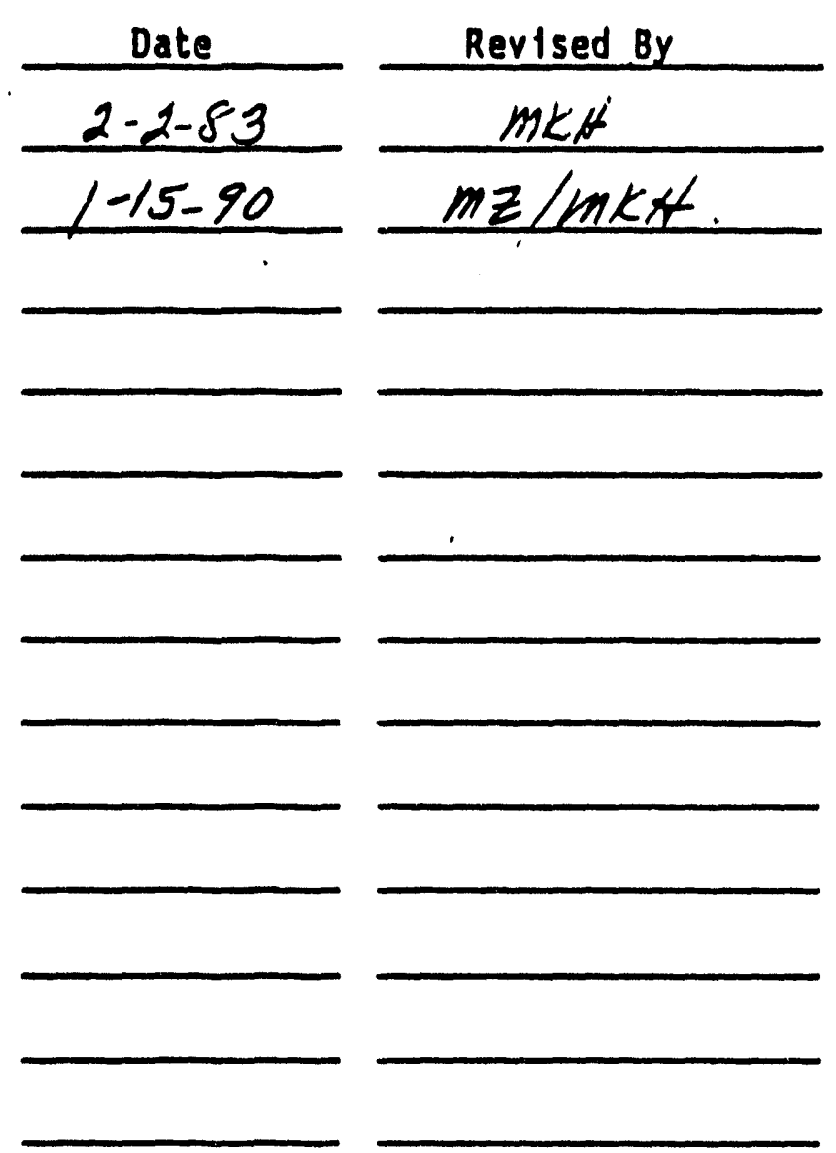

Date: 


\section{EP TOXICITY EXTRACTION PROCEDURE--METALS}

\section{REFERENCES}

1. Test Methods for Evaluating Sol id Waste: Physical and Chemical Methods., Method 1310 \& appropriate 7000 series methods, USEPA SW-846 3rd Edition, 1986.

2. Hazardous Waste Testing Manual, Millipore Corp., pp. 108+.

3. Apri1 21. 1982 Memorandum from J. Knudson, Washington State Department of Ecology, on the use of buffer for EP-Toxicity Test.

\section{PRINCIPLES}

Solid samples are extracted in a $\mathrm{pH} 5$ acetic acid buffer to determine the characteristic of EP toxicity due to the eight heavy metals arsenic, barium, cadmium, chromium, lead, mercury, selenium and silver.

\section{LIMITATIONS}

This procedure does not recover the analytes of interest quantitatively, it is a simulation of the leaching process that might occur in a landfill. All analyte recovery studies( i.e. spikes) should be performed after the extraction process.

\section{DEFINITIONS}

1. EP Toxic Metals: These metals are arsenic, barium, cadmium, chromium, lead, mercury, selenium and stlver. For liquid samples EP-TOX concentration equals total metals concentration; for solids it is the concentration of the extract resulting from the EP toxicity extraction procedure.

2. Total Metals: The metals concentration determined using a mineral acid digestion without filtration or centrifugation of the digestate.

3. Laboratory Control Sample (LCS): A sample containing known quantities of the analytes of interest (preferably certified) in the matrix of interest, prepared using the appropriate preparation method. The LCS is used to monitor the analyte recovery value of the sample preparation method employed.

4. Preparation Blank: An aliquot of the analytical solvent (DI water, acetic acid buffer, etc.) prepared by the appropriate sample preparation method. The preparation blank is used to monitor for contamination introduced by the sample preparation method.

5. Matrix Spike: A sample to which known quantities of analyte have been added before sample preparation. The matrix spike is used to monitor analyte recovery for a particular matrix/preparation method combination. 
6. Post Preparation Soike: A sample to which known quantities of analyte have been added after sample preparation. The post preparation spike is used to monitor analyte loss due to a particular matrix/interference independent of the sample preparation method.

7. Duplicate: A second identical preparation of a sample or spike. Duplicates are used to monitor method precision.

8. Method of Standard Additions (MSA): The use of multiple additions of analyte to equal portions of sample to create a calibration curve and determine concentration. MSA is used to compensate for altered sensitivity created by certain matrix effects, especially in the analysis of organic matrices.

\section{EOUIPMENT}

1. Nucleopore filtration chamber and stand

2. NBS rotating extractor

3. Polyethylene bottles compatible with extractor

4. Prefilters and filter membranes (Nucleopore P80, P100, and P300)

5. Wide mouth funnel

6. Graduated cylinders

7. $\mathrm{pH}$ meter

8. $50 \mathrm{ml}$ buret

9. Forceps, rubber policeman

10. Nitrogen tank, regulator, tubing, fittings

\section{REAGENTS \& STANDARDS .}

A. REAGENTS (STOCK)

1. Milli-Q Plus deionized water

2. Glacial acetic acid

3. Sodium acetate

4. Sodium hydroxide

5. Materials for metal standards as 1 isted in EHS $M-1, M-4 \& M-10$ 


\section{B. REAGENTS (PREPARED)}

1. $0.1 \mathrm{M}$ Sodium acetate buffer: Dissolve $13.6 \mathrm{~g}$ sodium acetate and $5.75 \mathrm{ml}$ glacial acetic acid in Milli-Q deionized water and dilute to 1 liter using Milli-Q water. This solution can be stored for up to six months.

2. $5.0 \mathrm{~N}$ Sodium hydroxide solution: Dissolve $200 \mathrm{~g}$ sodium hydroxide in deionized water. This solution can be stored for up to one year.

3. $0.5 \mathrm{~N}$ Acetic acid dilute $28.74 \mathrm{ml}$ of glacial acetic acid to 1 liter with deionized water. this solution can be stored for up to one year.

\section{Standards}

1. $1000 \mathrm{mg} / \mathrm{L}$ stock metal standards - See EHS M-1, M-4 \& M-10

\section{PROCEDURE}

A. Initial filtration is often required to separate solid phase from liquid phase portions of the sample. Initial filtration is performed as follows:

1. Place 3 filters onto the tefion support screen in increasing pore size using forceps (P80, P100, P300).

2. Assemble the filtration system. Place the chamber over the filter pad carefully and tighten the 3 bolts. Place a funnel in the opening at the top of the chamber and a suitable filtrate collector underneath the filtration assembly.

3. Transfer a portion of the sample via the funnel into the filtration assembly. Secure the lid on the chamber and attach the nitrogen supply. Close the gas supply and pressure release valves. Turn on the nitrogen regulator and adjust so that a small amount of pressure is indicated ( -10 psi). Slowly open the gas supply valve. liquid should begin to flow. Increase the pressure slowly (maximum pressure 75 psi) until all of the liquid has been expelled and gas breaks through.

4. Close the nitrogen tank valve and dial the pressure down to zero. Open the pressure release valve and vent the filtration assembly. Remove the three bolts and take the chamber off the filter pad.

5. Remove the filter pad from the filtration assembly. Remove solid from the filter pad and weigh an aliquot into an extraction vessel. Discard the filter pad.

6. Clean all apparatus immediately to prevent corrosion. 
EHS E-1-4

$1-15-90$

\section{B. Samole Extraction}

1. Transfer $12.5 \mathrm{~g}$ of solid to a $500 \mathrm{~mL}$ polyethylene bottle.

2. Add $200 \mathrm{~mL} 0.1 \mathrm{M}$ acetate/acetic acid buffer to the bottle.

3. Adjust the $\mathrm{pH}$ with $0.5 \mathrm{~N}$ acetic acid or $5.0 \mathrm{~N}$ sodium hydroxide to 5.0 0.2 units.

4. Start the extractor and repeat step B.3 every hour or until the pH change is less than 0.5 units.

5. Run the extractor overnight and check the $\mathrm{pH}$ in the morning. If the $\mathrm{pH}$ is $5.0 \pm 0.2$ units after 24 hours, stop the extraction. If the $\mathrm{pH}$ is not within this range adjust and extract for 4 more hours.

\section{Second Filtration}

1. Following the procedure for the first filtration, transfer all of the liquid from the extraction to the filtration apparatus.

2. Filter the extract, collecting it in a $250 \mathrm{~mL}$ volumetric flask.

3. Dilute to volume with acetate buffer solution.

4. Transfer the extract to a polyethylene bottle (optional).

\section{ANALYSIS}

1. Analyze the final extract for the eight matals using flame, graphite furnace or cold vapor atomic absorption spectroscopy (AAS).

a. Analyze for mercury by cold vapor AAS as described in EHS M-4, using $2.0 \mathrm{~mL}$ of sample.

b. Analyze for arsenic and selenium by graphite furnace AAS as described in EHS M-10, using the following standards:

$0.0 .005,0.01,0.03,0.05,0.10 \mathrm{mg} / \mathrm{L}$ As \& Se

c. Analyze for barium, cadmium, chromium, lead and silver by flame AAS as described in EHS $M-1$, using the following standards:

$0,0.04,0.10,0.20,0.60,1.0,2.0 \mathrm{mg} / \mathrm{L} \mathrm{Cd}, \mathrm{Cr} \& \mathrm{Ag}$

$0,0.2,0.5,1.0,3.0,5.0,10.0 \mathrm{mg} / \mathrm{L} \mathrm{Pb}$

$0,0.2,0.5,1.0,3.0,5.0,10.0 \mathrm{mg} / \mathrm{L} \mathrm{Ba}(1000 \mathrm{mg} / \mathrm{L} \mathrm{K}$ added to all Ba samples and standards) 
2. If the extract is cloudy or otherwise presents problems for direct analysis, digest the extract as described in EHS $M-11$ and then proceed with the AAS analysis as described above.

3. Report all EP-TOX concentrations as $\mathrm{mg} / \mathrm{L}$ metal in the final extract.

QUALITY CONTROL

The quality control measures required to assure that the sample preparation procedures presented here are adequate are discussed below. Other quality control measures associated with the atomic absorption spectroscopic analysis of samples are presented in those methods.

LABORATORY CONTROL SAMPLE: A Laboratory control sample should be prepared by spiking a volume of the extraction solution with known quantities of all analytes of interest in the concentration ranges of interest. The use of spiking solutions that are reference materials is preferred.

PREPARATION BLANK: A volume of extraction solution should be analyzed with each batch of samples as a preparation blank.

POST PREPARATION SPIKE AND POST PREPARATION DUPLICATE SPIKE: TWO identical post preparation spikes should be prepared with each batch of samples. 
Nethod Ho. EHS $\mathrm{M}-3$

Title: Mercury in Soil

Uate Issued: Before 11-82

Approved by: MK Hamilton

Hritten by: MR Hamilton

Supersedes Method to.

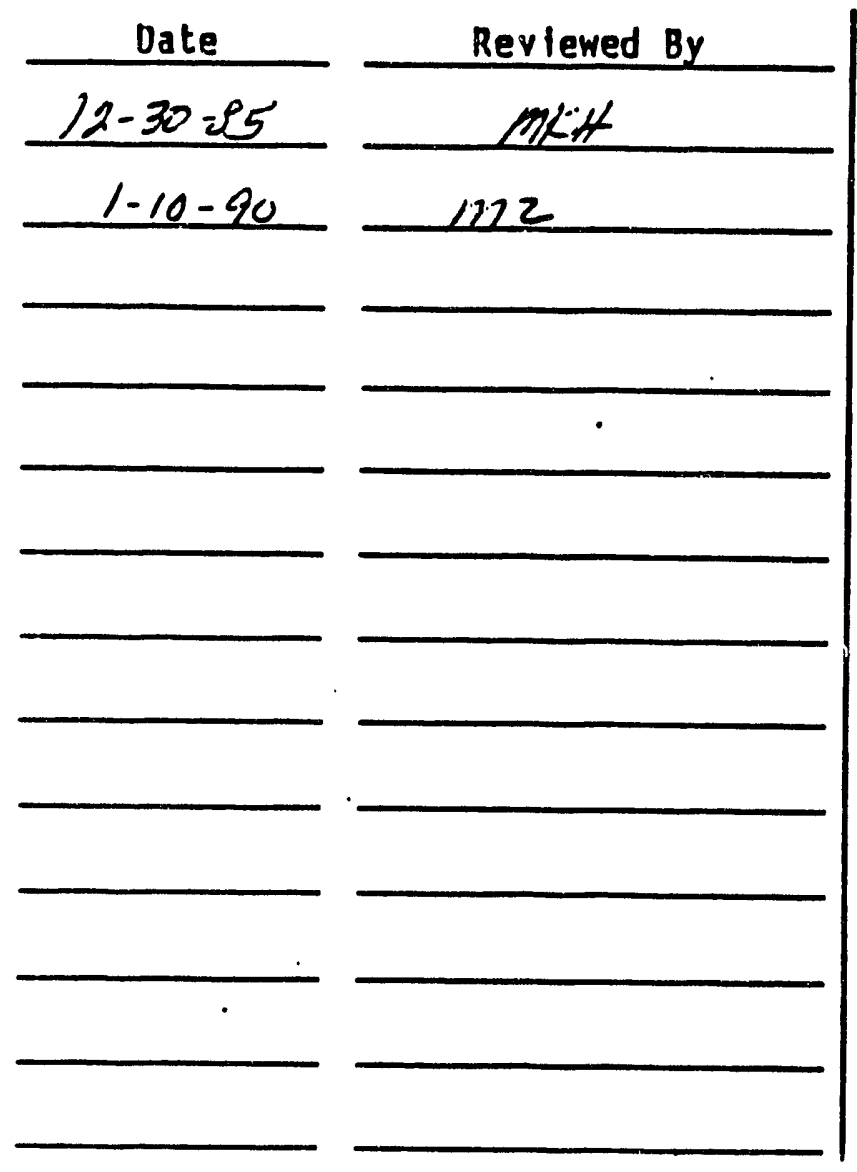

Replaced by Method No.

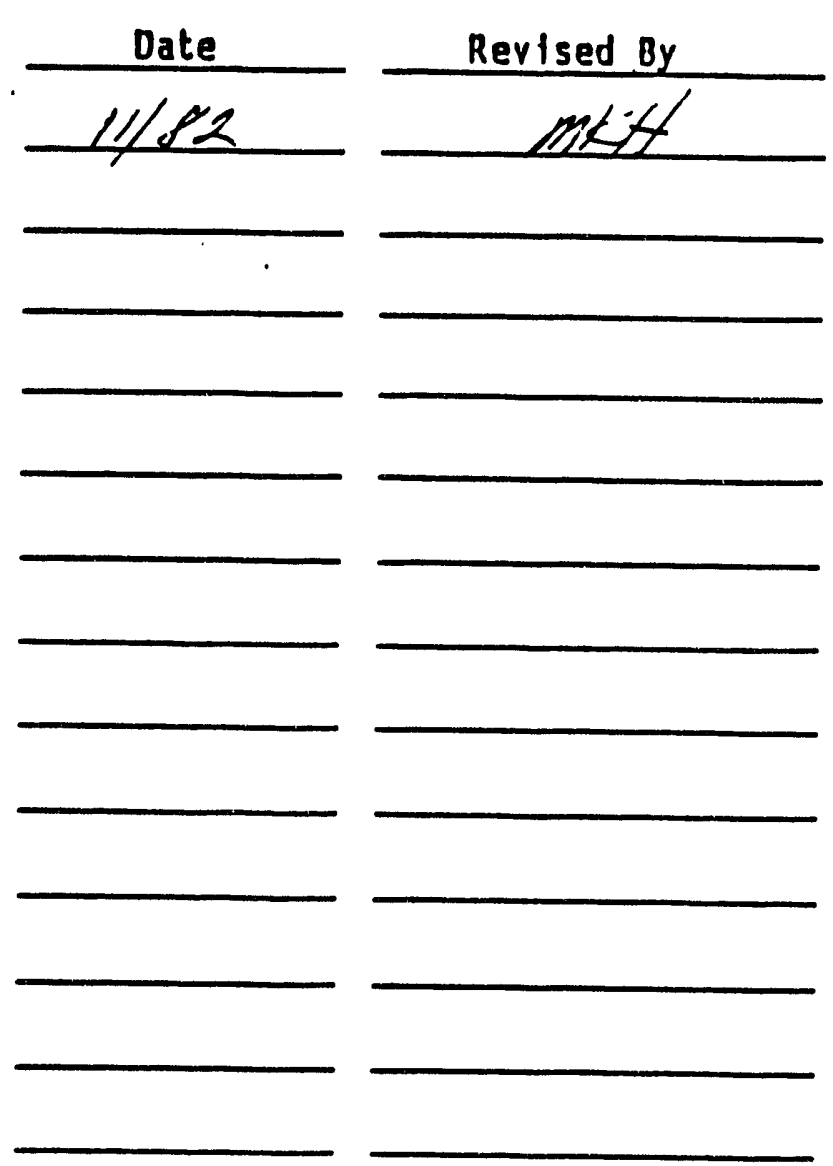

Date: 
MERCURY IN SOILS

\section{Reference}

Perkin-Elmer, Analytical Methods for Atomic Absorption Spectrophotometry, March 1971, Method GC-2 (Reference - Hatch and Ott, Anal. Chem, 40, 2085 (1968)).

\section{Principles}

Mercury is extracted from soil by the addition of nitric acid and hydrogen peroxide. The peroxide prevents the mercury from being reduced to the elemental state and lost by volatilization. The amount of mercury extracted is determined by the flameless atomic absorption technique described in EHS Procedure M-4.

\section{Limitations}

Oxidizing conditions must be maintained during the extraction to prevent loss of mercury. This method is suitable for the analysis of mercury pesticide residues in most soils. If the soil is a potentially hazardous waste, see EP Tüxicity Procedure (EHS E-1).

\section{Equipment}

1. $250 \mathrm{~mL}$ glass-stoppered er lenmyer flasks

2. $100 \mathrm{~mL}$ glass-stoppered graduated cylinders

3. Atomic absorption spectrophotometer and recorder

4. Absorption cell and reduction apparatus shown in EHS Procedure $M-4$

\section{Reagents (stock)}

1. Mercuric chloride $-\mathrm{HgCl}_{2}$

2. Stannous chloride $-\mathrm{SnCl}_{2} \cdot 2 \mathrm{H}_{2} \mathrm{O}$

3. Conc. nitric acid - $\mathrm{HNO}_{3}$

4. $30 \%$ hydrogen peroxide $-\mathrm{H}_{2} \mathrm{O}_{2}$

5. Potassium permanganate $-\mathrm{KMnO}_{4}$

6. Tributyl phosphate - TBP

7. Conc. hydrochloric acid - $\mathrm{HCl}$

8. Magnesium perchlorate $-\mathrm{Mg}\left(\mathrm{ClO}_{4}\right)_{2}$ 
Reagents (Prepared) - See EHS Procedure M-4.

Standards - See EHS Procedure M-4.

Procedure

1. Rinse all glassware with $1: 1 \mathrm{HNO}_{3}$, and defonized $\mathrm{H}_{2} \mathrm{O}$ before using.

2. Weigh out $5.0 \mathrm{~g}$ soil samples and place in $250 \mathrm{~mL}$ glass-stoppered erlenmeyers.

3. Prepare standards by adding $0.5,1.0,3.0$, and $5.0 \mathrm{~mL}$ of $0.1 \mu \mathrm{g} / \mathrm{mL} \mathrm{Hg}$ standard to $5.0 \mathrm{~g}$ portions of a representative soil sample.

4. Add $25 \mathrm{~mL}$ conc. $\mathrm{HNO}_{3}$ and one $\mathrm{mL} 30 \% \mathrm{H}_{2} \mathrm{O}_{2}$ to each sample and standard. Stopper the flasks and allow to stand overnight.

5. Add an additional one $\mathrm{mL} 30 \% \mathrm{H}_{2} \mathrm{O}_{2}$ to each solution.

6. Transfer samples (including soil) to $100 \mathrm{~mL}$ glass-stoppered cylinders and dilute to volume with deionized $\mathrm{H}_{2} \mathrm{O}$.

7. Allow the soil to settle and transfer a $50 \mathrm{~mL}$ aliquot (less if the soil is known to be contaminated) to a mercury reduction flask and add deionized $\mathrm{H}_{2} \mathrm{O}$ to give a total volume of $75 \mathrm{~mL}$.

8. Analyze according to EHS Procedure M-4 beginning with Procedure Step 7.

\section{Calculations}

1. Plot absorbance vs. $\mu \mathrm{gg}$ added to the spiked soil. Use the absorbance of the unspiked soil as $\mathrm{O} \mu \mathrm{g} \mathrm{Hg}$ added.

2. Back extrapolate the calibration curve to 0 absorbance to determine the amount of $\mathrm{Hg}$ present in the original soil.

3. Use this calibration curve to determine the amount of $\mathrm{Hg}$ present in the remaining soll samples.

4. Determine the soil $\mathrm{Hg}$ concentration as follows:

$$
\begin{aligned}
& \text { soil ppm } \mathrm{Hg}=\frac{A \times B}{C \times D} \\
& A=\mu \mathrm{Hg} \text { found } \\
& B=100 \mathrm{~mL} \text { initial volume } \\
& C=\text { aliquot used in determination (usually } 50 \mathrm{~mL} \text { ) } \\
& D=5.0 \mathrm{~g} \text { sample weight }
\end{aligned}
$$

(Note: Average $\mathrm{Hg}$ level in untreated $50 \mathrm{il}=0.07 \mathrm{ppm}$. Reference Elvaldo Kothny, Trace Elements in the Environment, ACS, 1973, p. 60.) 
Method No. EHS M-12

Title: Metals in Waste Organic Matrices by Atomic Absorption Spectroscopy

Date Issued:

$1-10-90$

Approved by: $\frac{\text { M.K. Hamilton }}{\sqrt{M}}$

Writton by:

M. L. Zabe 1

Supersedes Method No.

New

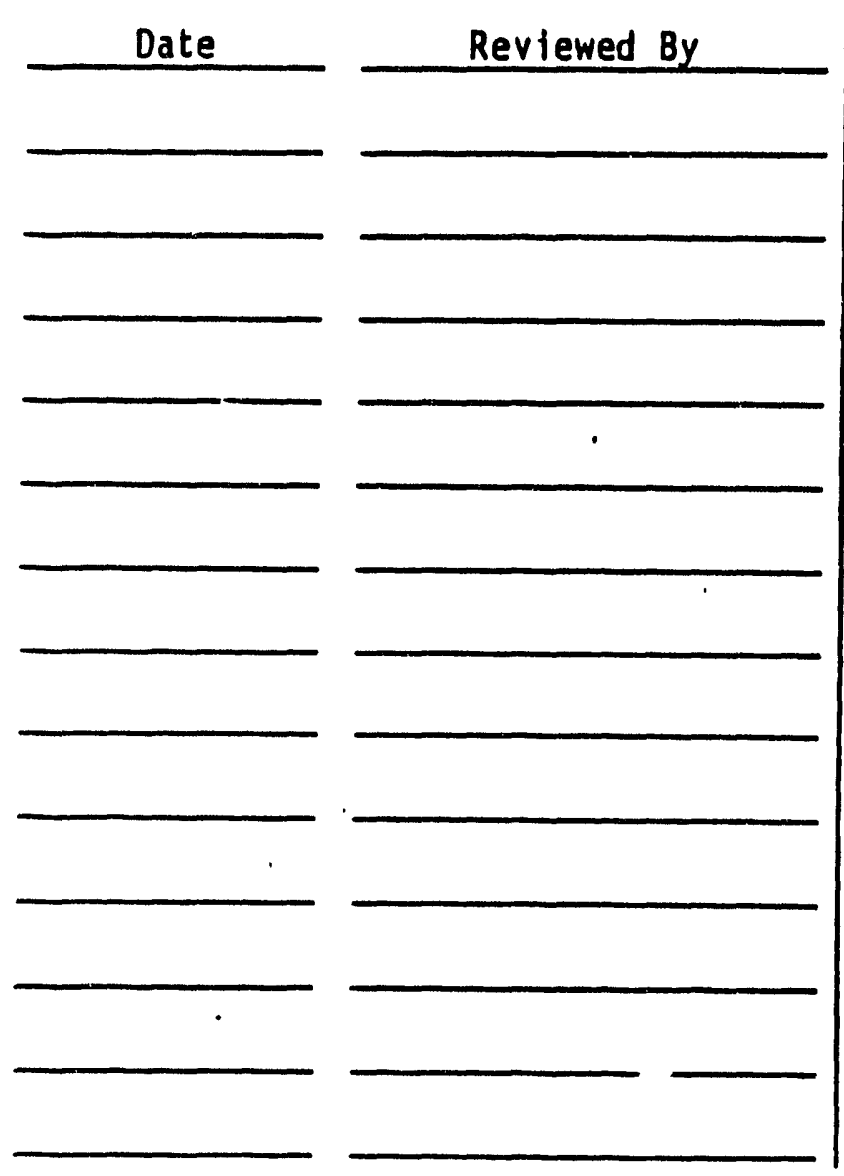

Replaced by Method No.

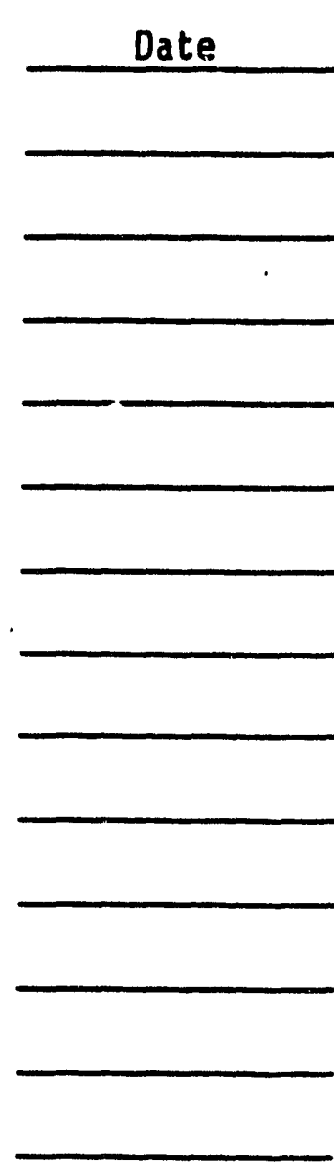

Revised By

Date: 
EHS $M-12$

$1-10-90$

METALS IN WASTE-ORGANIC MATRICES

BY ATOMIC ABSORPTION SPECTROSCOPY

\section{REFERENCES}

1. Test Methods for Evaluating Solid Waste: Physical and Chemical Methods, Methods 3040, 3050, and 7000, Section 8.7, and 7060, SW-846 3rd Edition, 1986, USEPA.

\section{PRINCIPLES}

The metals cadmium, chromium, and lead are determined in organic liquid matrices by dissolution in methyl isobutyl ketone (MIBK) or xylene followed by flame atomic absorption analysis. Matrix effects make the use of the method of standard additions mandatory. This method is also applicable to barium, silver, and other metal species.

Arsenic is determined in organic matrices using a sub-boiling nitric acid/hydrogen peroxide digestion for sample preparation, followed by analysis by graphite furnace atomic absorption spectroscopy. Digestion of samples is necessary to provide an aqueous matrix for graphite furnace atomic absorption analysis.

\section{LIMITATIONS}

This method does not apply to solid organic matrices or to organic materials which are water miscible. This method may not be adequate for organic liquids with high suspended solids content if determination of total metal content is desired. Due to the instability of diluted samples and organometallic standards, samples should be run as soon after dilution as possible.

The acid digestion method for arsenic may not completely destroy the organic matrix of many samples. A possible consequence of incomplete matrix destruction is incomplete recovery of analyte. The use of method control samples, preparation blanks, matrix spikes, duplicates, and post-preparation spikes is necessary to assure the applicability of this procedure to a given sample matrix.

\section{DEFINITIONS}

1. EP Toxic Metals: The heavy metals arsenic, barium, cadmium, chromium, lead, mercury, selenium, and silver. For liquid samples equal to total metals concentrations; for solids the concentration determined using the EP toxicity extraction procedure.

2. Laboratory Control Sample (LCS): A sample containing known quantities of the analytes of interest (preferabiy certified) in the matrix of interest, prepared using the appropriate preparation method. The LCS is used to monitor the analyte recovery value of the sample preparation method employed. 
3. Preparation Blank: An aliquot of the analytical solvent ( DI water, MIBK, Etc.) prepared by the appropriate sample preparation method. The preparation blank is used to monitor for contamination introduced by the sample preparation method.

4. Matrix Spike: A sample to which known quantities of analyte have been added before sample preparation. The matrix spike is used to monitor analyte recovery for a particular matrix/preparation method combination.

5. Post Preparation Soike: A sample to which known quantities of analyte have been added after sample preparation. The post preparation spike is used to monitor analyte loss due to a particular matrix/interference independent of the sample preparation method.

6. Duplicate: A second identical preparation of a sample or spike. Duplicates are used to monitor method precision.

7. Instrument calibration verification/continuing calibration verification samole (ICV/CCV): A sample, prepared from standard reference materials, used to verify the initial accuracy and the continuing accuracy of the calibration. The ICV/CCV should have a concentration near the center of the calibration range.

8. Instrument calfbration blank/continuing calibration blank (ICB/CCB): $A$ blank used to verify the initial and continuing accuracy of the calibration.

9. Method detection limit (MDL): The minimum concentration of analyte that can be measured and reported with $99 \%$ confidence that its concentration can be reported as greater than zero. The MDL is determined from analysis of a sample in a given matrix processed using the appropriate preparation procedure.

10. Instrument detection limit (IOL): The concentration equivalent to : signal, due to the analyte, which is equal to three times the standaid deviation of a series of at least seven replicates of the reagent blank signal at the analyte wavelength.

\section{EQUIPMENT}

A. Flame metals analys is

1. Atomic absorption spectrophotometer, equipped with deuterium arc background correction

2. Hollow cathode lamps (HCLS) for the elements of interest

3. Volumetric flasks and pipets

4. Disposable volumetric pipets 
5. $13 \times 125 \mathrm{~mm}$ test tubes with threaded tops and teflon lined caps

6. Test tube racks

7. Analytical balance with $0.1 \mathrm{mg}$ sensitivity

B. Graphite Furnace Analysis

1. Atomic absorption spectrophotometer, equipped with deuterium are background correction, graphite furnace and autosampler

2. Electrodless discharge lamp (EDL) for arsenic, and EDL power supply (other lamps as needed)

3. $100 \mathrm{~mL}$ Griffin beakers

4. Ribbed watch glasses

5. Hot plate

6. Centrifuge and centrifuge tubes

7. Volumetric flasks with stoppers, volumetric pipets

8. Analytical balance with $0.1 \mathrm{mg}$ sensitivity

\section{REAGENTS}

A. Flame Metals Analysis--Stock

1. Methyl isobutyl ketone (MIBK)

2. Xylene

3. Organometallic standards (see Standards for details)

B. Graphite Furnace Analys is -.-Stock

1. Concentrated, distilled nitric acid

2. Milli-Q finished deionized water

3. Hydrogen peroxide $30 \%$

4. Nickel metal--Class 2 Suspect Human Carcinogen

5. Arsenic Trioxide--Class 1 Human Carcinogen

C. Reagents (Prepared)--Graphite Furnace Analysis 
EHS $M-12-4$

$01-10-90$

1. $0.5 \%$ (V/V) nitric acid: Transfer approximately $1800 \mathrm{~mL}$ Milli-Q finished deionized water to a $2000 \mathrm{~mL}$ volumetric flask. Transfer $10.0 \mathrm{~mL}$ concentrated re-distilled nitric acid to the flask and fill to the mark with. Milli-Q finished delonized water. Transfer the solution to an acid rinsed polyethylene container.

2. $1000 \mathrm{mg} / \mathrm{L}$ nickel solution: Prepared as indicated in EHS M-10.

\section{STANDARDS}

\section{A. Flame Metals Analys is}

1. Organometallic standards, $5000 \mathrm{mg} / \mathrm{Kg}$ (avallable from the Conostan Division, Conoco Specialty Products Inc., Ponca City OK).

2. Organometallic Reference Materials (available from the National Institute of Standards and Technology).

3. Standard Addition Solution: Weigh approximately $0.100 \mathrm{~g}$ of 5000 $\mathrm{mg} / \mathrm{Kg}$ lead standard, $0.050 \mathrm{~g}$ of $5000 \mathrm{mg} / \mathrm{kg}$ chromium standard and $0.020 \mathrm{~g}$ of $5000 \mathrm{mg} / \mathrm{Kg}$ cadmium standard to a $100 \mathrm{~mL}$ volumetric flask. Record the weights added for each standard. Fill the flask to the mark with solvent (MIBK or $x y l e n e)$, stopper, and shake to dissolve the standards. Calculate and record the standard concentrations of each metal in the solution using the formula shown below:

$\mathrm{SW}(\mathrm{g}) \times 5000(\mu \mathrm{g} / \mathrm{g}) / 100(\mathrm{~mL})=$ Std. Conc. $(\mathrm{mg} / \mathrm{L})$ Where: SW = Standard Weight.

Approximate Conc. $=5 \mathrm{mg} / \mathrm{L} \mathrm{Pb}, 2.5 \mathrm{mg} / \mathrm{L} \mathrm{Cr}, 1 \mathrm{mg} / \mathrm{L} \mathrm{Cd}$

B. Graohite Furnace Analysis

1. Arsenic stock solution $1000 \mathrm{mg} / \mathrm{L}$ : Prepared as indicated in EHS M10.

2. NIST SRM 3103 Arsenic Solution $10 \mathrm{~g} / \mathrm{L}$

3. Arsenic intermediate solution $10.0 \mathrm{mg} / \mathrm{L}$ : Transfer $1.0 \mathrm{~mL} 1000 \mathrm{mg} / \mathrm{L}$ arsenic stock solution to a $100 \mathrm{~mL}$ volumetric flask and dilute to the mark with $0.5 \%(\mathrm{v} / \mathrm{v})$ nitric acid. Transfer to an acid rinsed polyethylene bottle. This solution should be replaced monthly.

4. Prepare standards by transferring the following amounts of arsenic intermediate solution to $100 \mathrm{~mL}$ volumetric flasks and diluting to the mark with $0.5 \%(\mathrm{v} / \mathrm{v})$ nitric acid. 
EHS $M-12-5$

$01-10-90$

Standard Concentration $\mathrm{mg} / \mathrm{L}$

uL As Intermediate Added

0.100

1000

0.050

500

0.030

300

0.010

100

0.005

50

Use the $0.5 \%(v / v)$ nitric acid as the callbration blank. Transfer the standard solutions to acid rinsed, labeled polyethylene bottles. Standards should be prepared daily.

5. ICV/CCV stock solution: Transfer $100 \mu \mathrm{L}$ NIST SRM 3103 (As $10 \mathrm{~g} / \mathrm{L}$ ). to a $100 \mathrm{~mL}$ volumetric and dilute to the mark with $0.5 \%(\mathrm{v} / \mathrm{v})$ nitric acid. Transfer this solution to an acid rinsed, labeled polyethylene bottle. This solution is $10.0 \mathrm{mg} / \mathrm{L}$. Prepare this solution monthly.

6. ICV/CCV solution: Transfer $100 \mu \mathrm{L} I \mathrm{CV} / \mathrm{CCV}$ stock solution to a $25 \mathrm{~mL}$ volumetric flask and dilute to the mark with $5 \%(v / v)$ nitric acid. This solution is $0.040 \mathrm{mg} / \mathrm{L}$ As. Prepare this solution daily.

\section{PROCEDURE}

A. Flame Metals Analysis--Pb, Cd, Cr

1. Weigh between 1.0 and 5.0 grams of sample into a $25 \mathrm{~mL}$ volumetric flask.

2. Dilute to the mark with MIBK. If the sample is insoluble in MIBK, use xylene. Samples insoluble in both MIBK or xylene are not amenable to analysis by this method.

3. Label 4 test tubes with the sample number and $+0,+1,+2$, and +3 .

4. Transfer a $5 \mathrm{~mL}$ aliquot from the sample flask to each of the 4 test tubes placed in the test tube rack. Transfer the remaining sample to a labeled test tube. Cap the test tube and save the sample.

5. Add $1.0 \mathrm{~mL}$ standard addition solution to the tube labeled $+1,2.0$ $\mathrm{mL}$ to the tube labeled +2 , and $3.0 \mathrm{~mL}$ to the tube labeled +3 .

6. Bring the total volume added to each tube to $10 \mathrm{~mL}$ with solvent $(5.0 \mathrm{~mL}$ for the to tube, $4.0 \mathrm{~mL}$ for the +1 tube, $3.0 \mathrm{~mL}$ for the +2 tube and $2.0 \mathrm{~mL}$ for the +3 tube). 
7. Cap the test tubes and shake vigorously. The samples are ready for analysis.

8. Set up the atomic absorption spectrophotometer according to the manufacturer's instructions for flame operation with organic solvents for the analyte of interest. The use of background correction is mandatory for wavelengths below $300 \mathrm{~nm}$.

9. Analyze the samples using the following steps:

a. Aspirate solvent and zero the instrument.

b. Take duplicate absorbance measurements of each sample and sample addition. Aspirate solvent continuously between sample readings.

c. Check the absorbances of the four sample solutions. If the concentration/ absorbance relationship deviates significantly from linear behavior or the absorbance of the +2 standard addition is not at least twice that of the to standard addition, repeat the standard addition analysis with a smaller initial sample aliquot or with a dilute sample.

10. Clean the sample introduction system of the AA spectrophotometer and remove and clean the sample drain trap. Discard the solvent portion of the waste generated and the sample solutions in the "Waste Solvent" container.

B. Graphite Furnace Analysis

1. Transfer a $5.00 \mathrm{~mL}$ aliquot of sample to a $100 \mathrm{~mL}$ Griffin beaker.

2. Slowly add $5 \mathrm{~mL}$ of $50 \%$ nitric acid to the sample and cover with a ribbed watch glass. Heat the sample so that it refluxes without boiling. Reflux for one hour or until the digestate volume is -5 $\mathrm{mL}$, whichever is shorter.

3. Very slowly add $5 \mathrm{~mL}$ concentrated, redistilled nitric acid to the sample. Continue heating the sample so that it refluxes without boiling until the digestate volume is $-5 \mathrm{~mL}$. Allow the sample to cool.

4. Repeat step 3 until oxidation is complete. For matrices containing organic compounds this may take many iterations. oxidation is considered complete when addition of acid ceases to generate brownish red fumes and the sample ceases to change in appearance. 
5. After step 4 has been completed and the sample has cooled, carefully add $2 \mathrm{~mL} 30 \%$ hydrogen peroxide. Return the covered sample to the hot plate. Watch the sample carefully as vigorous effervescence may cause it to overflow. Heat until the effervescence subsides and cool the sample.

6. Continue to add hydrogen peroxide in $2 \mathrm{~mL}$ allquots with warming until effervescence is minimal or until the general sample appearance does not change. Add a maximum of $10 \mathrm{~mL}$ of hydrogen peroxide.

7. Continue to reflux sample until the volume has been reduced to -5 $\mathrm{mL}$. Transfer the sample to a $25 \mathrm{~mL}$ volumetric flask and dilute to volume with Milli-Q/deionized water. The sample should be centrifuged if particulate residue is present and organic residue floating at the top of the sample should be withdrawn with a pasteur pipet. The sample is ready for analysis.

8. Set up the graphite furnace atomic absorption instrument for the analysis of arsenic according to the manufacturer's instructions. Conditions for a Perkin E1mer 2380/HGA-400 are 1isted below:

Wave lenghth: $193.7 \mathrm{~nm}$

slit width: $0.7 \mathrm{~nm}$

Peak height mode

Integration time: $5 \mathrm{sec}$

Background correction: on

Dry: Temp: 160 C Ramp: 5 sec Hold: $30 \mathrm{sec}$

Ash: Temp: 1050 C Ramp: 5 sec Hold: $25 \mathrm{sec}$

Atomize: Temp: 2500 C Ramp: 0 sec Hold: $5 \mathrm{sec}$

Clean: Temp: 2600 C Ramp: 1 sec Hold: 3 sec

Cool: Temp: 30 C Ramp: 1 sec Hold: $5 \mathrm{sec}$

Sample volume: $20 \mu \mathrm{L}$

Matrix modifier: Nickel Nitrate, $1000 \mathrm{mg} / \mathrm{L}, 20 \mu \mathrm{L}$

Tube type: Pyrolytically coated Lvov platform type with platforms.

9. Make replicate analyses of all standards and samples.

\section{CALCULATIONS}

\section{A. Flame Metals Analysis}

1. Calculate the $\mu g$ analyte added for each standard addition:

$\mu \mathrm{g}$ added $=$ CONC STD ADD $(\mu \mathrm{g} / \mathrm{mL}) \times A D D$ VOL $(\mathrm{mL})$

2. Prepare a calibration curve plotting standard addition concentration (in $\mu g$ ) in the horizontal $(x)$ axis versus absorbance (peak height) in the vertical (y) axis using curvilinear regression. 
3. Sample aliquot concentration (in $\mu g$ ) is the absolute value of $x$ at point where the calibration curve intercepts the horizontal $(x)$ axis. (See Appendix 1.)

4. Calculate the sample concentration in $\mathrm{mg} / \mathrm{Kg}$ :

$$
\begin{gathered}
\operatorname{CONC}(\mathrm{mg} / \mathrm{Kg})=A L I Q \cdot \operatorname{CONC}(\mu g) / A W(g) \\
\operatorname{AW}(g)=A 1 \text { iquot Weight }=\operatorname{SW}(g) \times \operatorname{AV}(\mathrm{mL}) / \operatorname{DV}(\mathrm{mL})
\end{gathered}
$$

SW - Sample Weight, AV - Aliquot Volume, DV - Dilution Volume

\section{B. Graphite Furnace Analysts}

1. Generate a callbration curve and regression equation by plotting standard concentration in the horizontal $(x)$ axis versus peak height in the vertical (y) axis and using curvilinear regression.

2. From the calibration curve determine sample analytical concentrations, $A C(\mu \mathrm{g} / \mathrm{mL})$ using the regression equation generated in Step 1.

3. Using dilution factors, sample weights, and dilution volumes, calculate the original sample concentrations $(\mathrm{mg} / \mathrm{Kg})$.

$$
C(\mathrm{mg} / \mathrm{Kg})=A C(\mu \mathrm{g} / \mathrm{mL}) \times D F \times D V(\mathrm{~mL}) / \mathrm{SW}(\mathrm{g})
$$

Where DF = Dilution factor, OV = Dilution volume $(\mathrm{mL})$, and $S W=$ Sample weight (g).

\section{QUALITY CONTROL}

\section{A. Flame Metals Analysis}

1. Solvents must be free from impurities. Solvents containing impurities may be suitable for use after distillation.

2. Standard reference materials should be analyzed with each batch of samples.

3. Duplicates should be analyzed in each batch of samples

4. NIST Standard reference materials diluted to the concentrations of analysis should be analyzed with each batch of samples to verify instrument performance and method accuracy. 
EHS $M=12-9$

$01-10-90$

B. Graphite Furnace Analysis

1. An ICV/CCV and a ICB/CCB must be analyzed after the initial calibration and after every fifth sample to verify the continuing accuracy of the calibration.

2. A method control sample and preparation blank must be prepared and analyzed with each sample batch.

3. For $10 \%$ of all samples, or at least once per batch of samples, a matrix spike and duplicate matrix spike shall be prepared and analyzed.

4. A post preparation spike and duplicate post preparation spike must be analyzed in cases where matrix spike recovery and/or matrix spike duplication error are not satisfactory.

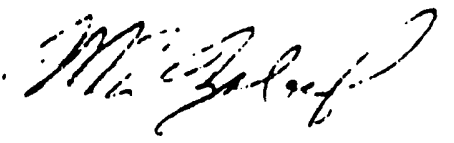


EHS $M-12-10$

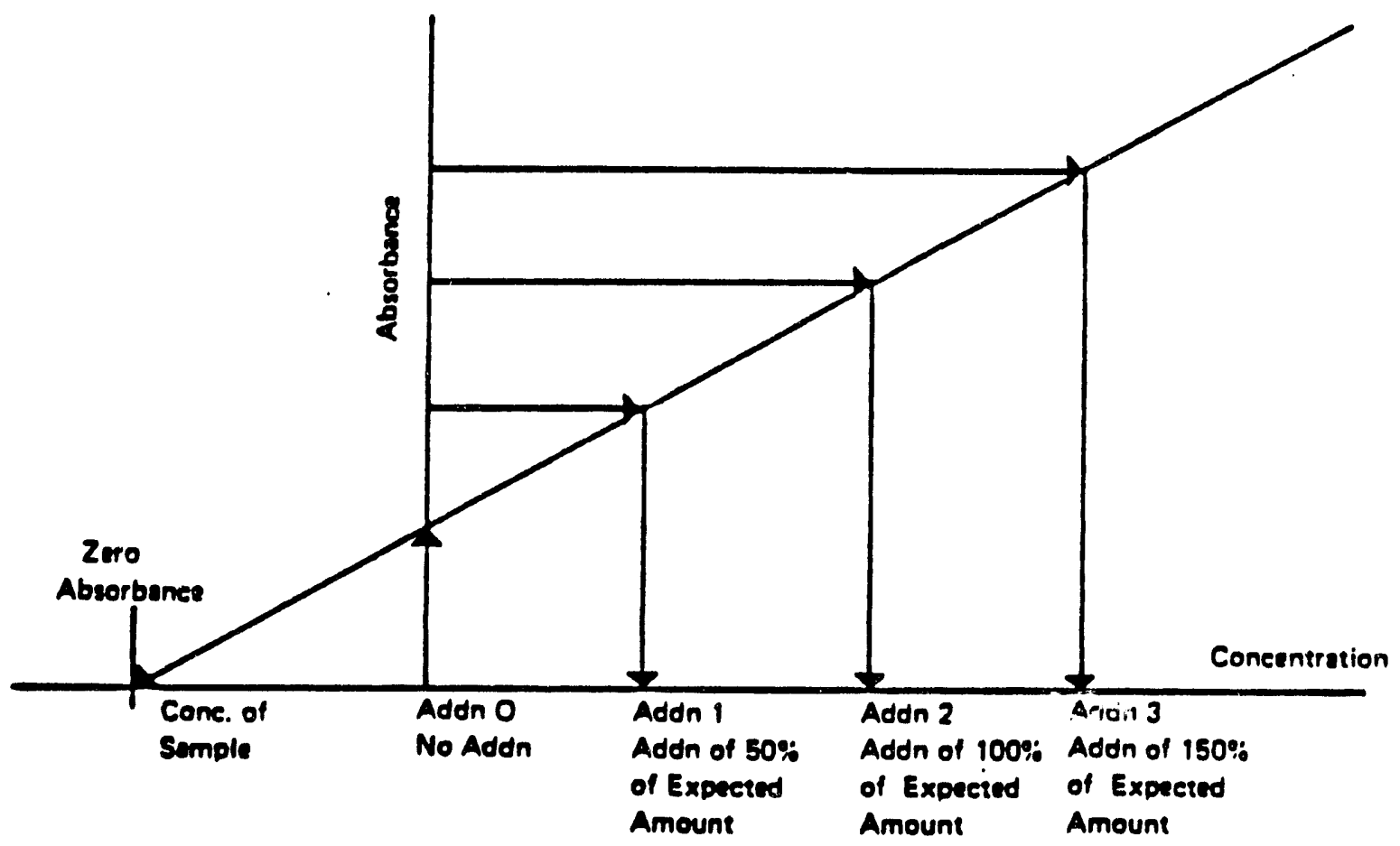

Figure 1. Standard Addition Plot.

$7000-13$ 
Method No. EHS $M-1$

Title:

Metais In $\mathrm{H}_{2} \mathrm{O}$ - Atomic Absorotion - Flame

$\mathrm{AG}, \mathrm{Ba}, \mathrm{Ca}, \mathrm{Cr}, \mathrm{CU}, \mathrm{Fe}, \mathrm{n}, \mathrm{n}, \mathrm{m}, \mathrm{Zn}$

Date Issued:

Refore 12-82

Approved by: MK Hamilton

Written by: MK Hamilton

Supersedes Method No.

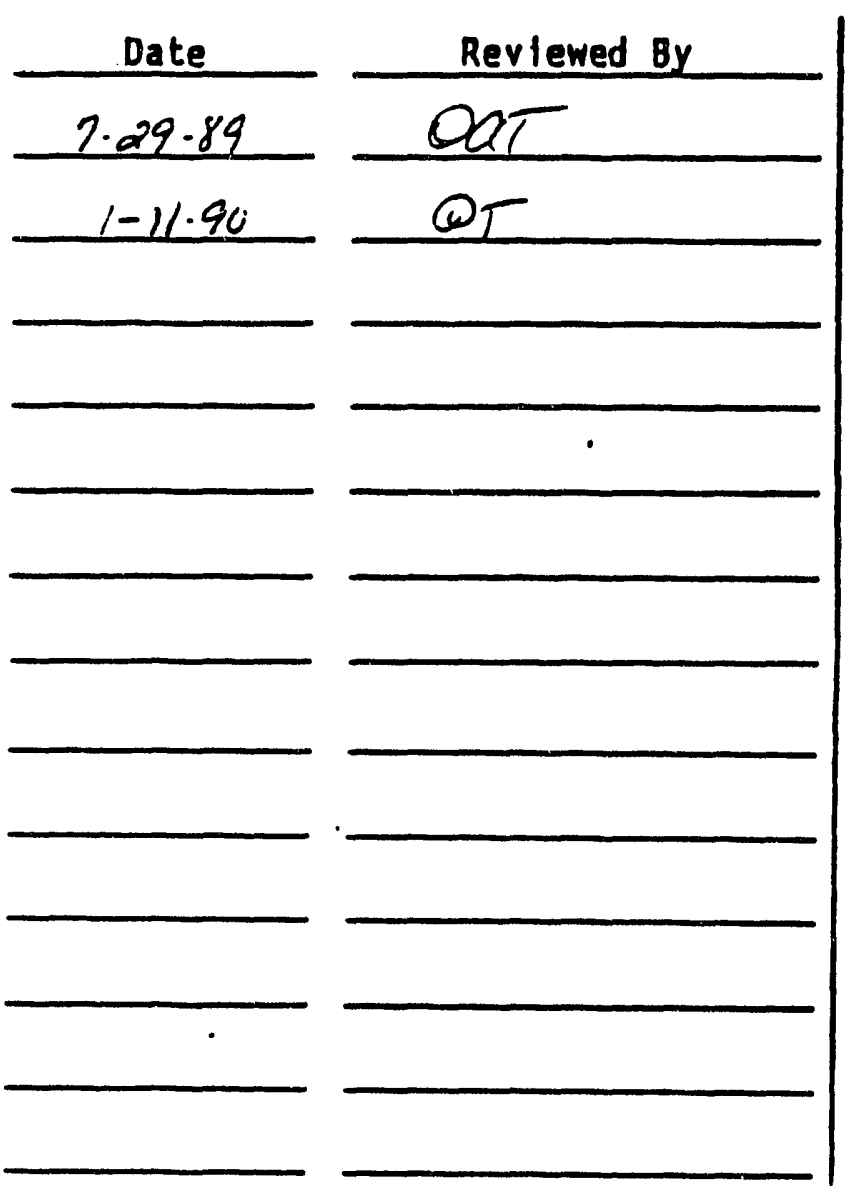

Replaced by Method No.

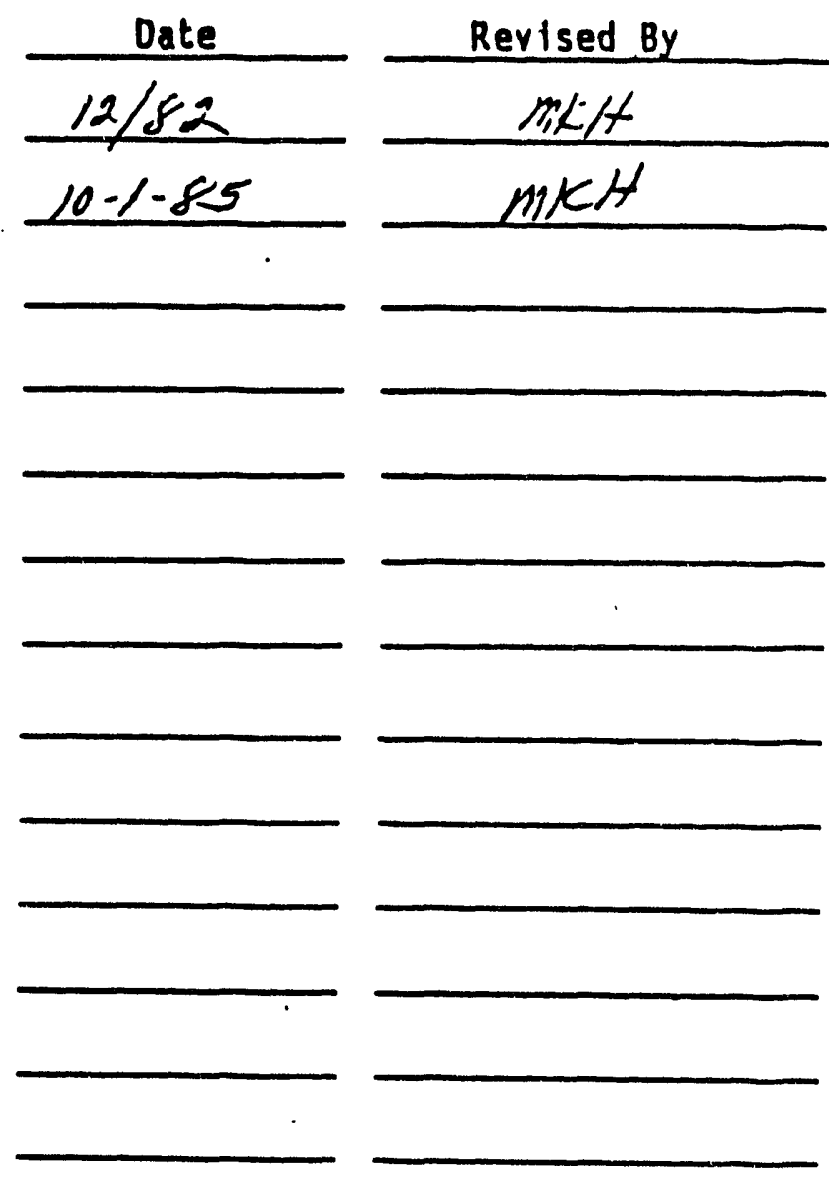

Date: 
METALS IN $\mathrm{H}_{2} \mathrm{O}$ - ATOMIC ABSORPTION - FLAME $\mathrm{Ag}, \mathrm{Ba}_{2} \mathrm{Ca}_{2} \mathrm{Cr}, \mathrm{Cu}, \mathrm{Fe}, \mathrm{Mg}, \mathrm{Mn}, \mathrm{Ln}$

\section{References}

1. Standard Methods for the Examination of Water and Wastewater, 16th Ed., 1985, pp. 151-160, 162-164.

2. Analytical Methods for Atomic Absorption Analyses, Perkin-Elmer, 1971.

Principles

When a solution containing metals is aspirated into a flame, some of the atoms will be dissociated from their chemical bonds and placed in an unexcited unionized ground state. If a beam of 1 ight from a source lamp whose cathode is composed of the element of interest is directed into the flame, the ground state atoms of that element will absorb light at a characteristic wavelength. The amount of light absorbed $c$ an be measured and is directly proportional to the concentration of the element in the sample.

\section{Limitations}

It is important to use the proper flame conditions to ensure maximum dissociation of the element of interest in order to obtain adequate sensitivity. In some cases, sensitivity will be decreased by the presence of interfering substances (phosphate interference of $\mathrm{Ca}$ and $\mathrm{Mg}$ ) or by an excess degree of ionization of the desired element. These interferences $c$ an often be overcome by the addition of a cation that undergoes the undesired reaction more readily than the element of interest ( $\mathrm{La}$ added in $\mathrm{Ca}$ and $\mathrm{Mg}$ determination). When extremely diluted solutions are encountered, it may be possible to increase the sensitivity of the analysis by using graphite furnace techniques (EHS $M-10$ ).

Equipment

1. Atomic absorption spectrophotometer and recorder

2. Hollow cathode lamps for metals of interest

3. $100 \mathrm{~mL}$ volumetric flasks

4. $250 \mathrm{~mL}$ volumetric flasks

5. 1-1iter beakers

Reagents (stock)

1. Nitric acid, conc. $70 \% \mathrm{HNO}_{3}$ - redistilled

2. Hydrochloric acid, conc. $37-38 \% \mathrm{HCl}$

3. Barium chloride, $\mathrm{BaCl}_{2}$ 
4. Potassium chloride, $\mathrm{KCl}$

5. Calcium carbonate, $\mathrm{CaCO}_{3}$

6. Copper.powder $99.99+\%$

7. Iron oxide, $99.99+\%-\mathrm{Fe}_{2} \mathrm{O}_{3}$

8. Zinc powder, $99.99+\%$

9. Manganese dioxide, $\mathrm{MnO}_{2}$

10. Silver nitrate, $\mathrm{AgNO}_{3}$

11. Potassium dichromate, primary standard $\mathrm{K}_{2} \mathrm{Cr}_{2} \mathrm{O}_{7}$

12. Magnesium metal

13. Lanthanum nitrate, $\mathrm{La}\left(\mathrm{NO}_{3}\right)_{3} \cdot 6 \mathrm{H}_{2} \mathrm{O}$

14. Hydrogen perioxide, $\mathrm{H}_{2} \mathrm{O}_{2}$

Reagents (Prepared)

1. Lanthanum solution $(20,000 \mu \mathrm{g} / \mathrm{mL} \mathrm{La})$ - dissolve $62.3 \mathrm{~g} \mathrm{La}\left(\mathrm{NO}_{3}\right)_{3}$ - $6 \mathrm{H}_{2} \mathrm{O}$ in dilute $\mathrm{HNO}_{3}$ and dilute to 1 liter with deionized water. Prepare annually.

2. Potassium solution $(20,000 \mu \mathrm{g} / \mathrm{mL} \mathrm{K})$ dissolve $38.13 \mathrm{~g} \mathrm{KCl}$ in deionized water and dilute to 1 Liter. Store in polyethylene. Prepare annually.

\section{Standards}

A. Stock Solutions (prepare every 6 months)

1. Barium stock solution - dissolve $1.516 \mathrm{~g}$ oven dried $\mathrm{BaCl}_{2}$ in deionized $\mathrm{H}_{2} \mathrm{O}$, add $10 \mathrm{~mL}$ conc. $\mathrm{HNO}_{3}$ and dilute to 1 Liter with deionized $\mathrm{H}_{2} \mathrm{O} .{ }^{2} \mathrm{I} \mathrm{mL}=1000 \mu \mathrm{g} \mathrm{Ba}$. Prepare every 6 months.

2. Calcium stock solution - dissolve 2.4972 oven dried $\mathrm{CaCO}_{3}$ in a minimum volume of $\mathrm{HCl}$ and dilute to 1 liter with deionized $\mathrm{H}_{2} \mathrm{O}$. $1 \mathrm{~mL}=1000 \mu \mathrm{g} \mathrm{Ca}$. Prepare every 6 months.

3. Cisromium stock solution - dissolve $2.828 \mathrm{~g}$ oven dried $\mathrm{K}_{2} \mathrm{Cr}_{2} \mathrm{O}_{7}$ in deionized water to give a final volume of 1 liter. $1 \mathrm{~mL}=1000 \mu \mathrm{g} \mathrm{Cr}$. .Prepare every 6 months.

4. Copper stock solution - dissolve $1.000 \mathrm{~g} \mathrm{Cu}$ powder in a minimum volume of $1: 1 \mathrm{HNO}_{3}$. Add an additional $10 \mathrm{~mL}$ of conc. $\mathrm{HNO}_{3}$ and dilute to 1 liter with deionized $\mathrm{H}_{2} \mathrm{O} .1 \mathrm{~mL}=1000 \mathrm{\mu g} \mathrm{Cu}$. Prepare every 6 months. 
5. Iron stock solution - dissolve $1.430 \mathrm{~g}$ oven dried $\mathrm{Fe}_{2} \mathrm{O}_{3}$ in $50 \mathrm{~mL}$ of $1: 1 \mathrm{HCl}$ and dilute to 1 liter with deionized $\mathrm{H}_{2} \mathrm{O} .1 \mathrm{~mL}=1000 \mu \mathrm{g}$ Fe. Prepare every 6 months.

6. Magnesfum stock solution - dissolve $1.000 \mathrm{~g} \mathrm{Mg}$ metal in $1: 1 \mathrm{HCl}$, add an additional $10 \mathrm{~mL}$ conc. $\mathrm{HCl}$ and dilute to 1 liter with delonized water. $1 \mathrm{~mL}=1000 \mu \mathrm{gg}$. Prepare every 6 months.

7. Manganese stock solution - dissolve $1.5823 \mathrm{~g} \mathrm{MnO}_{2}$ in a minimum volume of $1: 1 \mathrm{HCl}$. Add $\mathrm{H}_{2} \mathrm{O}_{2}$ as needed to complete dissolution. Add an additional $10 \mathrm{~mL}$ of conc. $\mathrm{HCl}$ and dilute to 1 liter with deionized water. $1 \mathrm{~mL}=1000 \mu \mathrm{g} \mathrm{Mn}$. Prepare every 6 months.

8. Silver stock solution - dissolve $1.575 \mathrm{~g}$ oven dried $\mathrm{AgNO}_{3}$ in deionized water, add $10 \mathrm{~mL}$ conc. $\mathrm{HNO}_{3}$ and dilute to 1 liter with deionized water. Store away from light in a brown glass bottle.

$1 \mathrm{~mL}=1000 \mu \mathrm{g} \mathrm{Ag}$. Prepare every 6 months.

9. Zinc stock solution - dissolve $1.000 \mathrm{~g} \mathrm{Zn}$ powder in a minimum volume of $1: 1 \mathrm{HCl}$. Add an additional $10 \mathrm{~mL}$ of conc. $\mathrm{HCl}$ and dilute to 1 liter with deionized $\mathrm{H}_{2} \mathrm{O} .1 \mathrm{~mL}=1000 \mathrm{ug} \mathrm{Zn}$. Prepare every 6 months.

\section{B. Working Standards}

1. Composite $\mathrm{Cu}, \mathrm{Fe}, \mathrm{Mn}, \mathrm{Zn}$ standards - pipet $1.0 \mathrm{~mL} \mathrm{Cu}$ stock, $0.5 \mathrm{~mL} \mathrm{Fe}$ stock, $0.1 \mathrm{~mL} M \mathrm{n}$ stock, and $3.0 \mathrm{~mL} 2 \mathrm{n}$ stock into a $100 \mathrm{~mL}$ volumetric flask, add $1 \mathrm{~mL}$ conc. $\mathrm{HNO}_{3}$ and and dilute to volume with deionized water.

$$
\begin{aligned}
& 1 \mathrm{~mL}=10 \mu \mathrm{g} \mathrm{Cu} \\
& 1 \mathrm{~mL}=5 \mu \mathrm{Fe} \\
& 1 \mathrm{~mL}=1 \mu \mathrm{Mn} \\
& 1 \mathrm{~mL}=30 \mu \mathrm{g} \mathrm{n}
\end{aligned}
$$

Prepare working standards by pipeting the following amounts of the composite standard into $100 \mathrm{~mL}$ volumetric flasks, adding $0.5 \mathrm{~mL}$ conc. $\mathrm{HNO}_{3}$, and diluting to volume with deionized water. Prepare fresh weekly.

\section{$\mathrm{mL}$ Composite Standard}

$$
0
$$

1.0

2.0

5.0

8.0

10.0
Conc. $\mu \mathrm{g} / \mathrm{mL}$

\begin{tabular}{llll}
\hline Cu & Fe & Mn & Zn \\
0 & 0 & 0 & 0 \\
0.1 & 0.05 & 0.01 & 0.3 \\
0.2 & 0.1 & 0.02 & 0.6 \\
0.5 & 0.25 & 0.05 & 1.5 \\
0.8 & 0.4 & 0.08 & 2.4 \\
1.0 & 0.5 & 0.10 & 3.0
\end{tabular}


2. Ba standards - Pipet $1.0 \mathrm{~mL} \mathrm{Ba} \mathrm{stock} \mathrm{into} \mathrm{a} 100 \mathrm{~mL}$ volumetric flask and dilute to volume with deionized water. $1 \mathrm{~mL}=10 \mu \mathrm{g} \mathrm{Ba}$. Prepare working standards by pipetting $0,1.0 ; 3.0,5.0,8.0$, and $10.0 \mathrm{~mL}$ of the above standard into $100 \mathrm{~mL}$ volumetic flasks. Add $5 \mathrm{~mL} 20,000$ $\mu \mathrm{g} / \mathrm{mL} \mathrm{K}$ solution to each and $1 \mathrm{~mL}$ conc. $\mathrm{HNO}_{3}$. Dilute to volume with delonized water. This gives standards containing $0,0.1,0.3$, $0.5,0.8$, and $1.0 \mu \mathrm{g} \mathrm{Ba} / \mathrm{mL}$. Prepare monthly.

3. Composite $\mathrm{Ag}$ and $\mathrm{Cr}$ standards - pipet $1.0 \mathrm{~mL} \mathrm{Ag}$ stock and $1.0 \mathrm{~mL} \mathrm{Cr}$ stock into a $100 \mathrm{~mL}$ volumetric flask, add $1 \mathrm{~mL}$ conc. $\mathrm{HNO}_{3}$, and dilute to volume with deionized water.

$$
\begin{aligned}
& 1 \mathrm{~mL}=10 \mu \mathrm{g} \mathrm{Ag} \\
& 1 \mathrm{~mL}=10 \mu \mathrm{g} \mathrm{Cr}
\end{aligned}
$$

Prepare working standards by pipeting the following amounts of the composite standard into $100 \mathrm{~mL}$ volumetric flasks, adding $0.5 \mathrm{~mL}$ conc. $\mathrm{HNO}_{3}$, and dfluting to volume with deionized water. Prepare fresh weekly.

$\mathrm{mL}$ Composite Standard

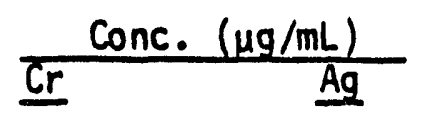

$\begin{array}{lll}0 & 0 & 0 \\ 0.1 & 0.01 & 0.01 \\ 0.3 & 0.03 & 0.03 \\ 0.5 & 0.05 & 0.05 \\ 1.0 & 0.1 & 0.1\end{array}$

4. Composite $\mathrm{Ca}$ and $\mathrm{Mg}$ standards - pipet $1.0 \mathrm{~mL} \mathrm{Mg} \mathrm{stock} \mathrm{and} 10.0 \mathrm{~mL} \mathrm{Ca}$ stock into a $100 \mathrm{~mL}$ volumetric flask, add $1 \mathrm{~mL}$ conc. $\mathrm{HMO}_{3}$, and dilute to volume with deionized water.

$$
\begin{aligned}
& 1 \mathrm{~mL}=10 \mu g \mathrm{Mg} \\
& 1 \mathrm{~mL}=100 \mu g \mathrm{Ca}
\end{aligned}
$$

Prepare working standards by pipeting the following amounts of the composite standard into $100 \mathrm{~mL}$ volumetric flasks, adding $5 \mathrm{~mL}$ of $20,000 \mu \mathrm{g} / \mathrm{mL} \mathrm{La}$ and $0.5 \mathrm{~mL}$ conc. $\mathrm{HNO}_{3}$, and diluting to volume with deionized water. Prepare fresh monthly.

\section{$\mathrm{mL}$ Composite Standard}

0
1.0
3.0
5.0
8.0
10.0

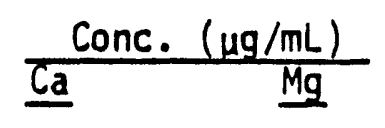

$\begin{array}{rl}0 & 0 \\ 1 & 0.1 \\ 3 & 0.3 \\ 5 & 0.5 \\ 8 & 0.8 \\ 10 & 1.0\end{array}$

Procedure

A. Sample Collection - collect in glass or polyethylene bottles that have been rinsed with $1: 1 \mathrm{HNO}_{3}$ and deionized $\mathrm{H}_{2} \mathrm{O}$. 
B. Analysis

1. Preliminary preservative treatment - as soon as the water sample is collected, add $5 \mathrm{~mL}$ redistilled conc. $\mathrm{HNO}_{3}$ per liter of sample. StabTe up to 6 months.

2. Direct determination of $\mathrm{Ag}, \mathrm{Cu}, \mathrm{Cr}, \mathrm{Fe}, \mathrm{Mn}, \mathrm{Zn}$ - directly aspirate the actdified sample along with the appropriate standards, using the followng instrument conditions:

Element Wavelength $(\mathrm{nm})$ slit $(\mathrm{nm})$ Fuel Mixture Flame

$\begin{array}{llll}\text { Ag } & 328.1 & 0.7 & \text { Air-acetylene Lean, blue* } \\ \mathrm{Cu} & 324.7 & 0.7 & \text { Air-acetylene Lean, blue } \\ \mathrm{Cr} & 357.9 & 0.7 & \text { Air-acetylene Rich, yellow* } \\ \mathrm{Fe} & 248.3 & 0.2 & \text { Air-acetylene+ Lean, blue } \\ \mathrm{Mn} & 279.5 & 0.2 & \text { Air-acetylene+ Lean, blue* } \\ \mathrm{Zn} & 213.8 & 0.7 & \text { Air-acetylene+ Lean, blue }\end{array}$

* Use $30 x$ scale expansion.

** Use 3-slot burner head and 30x scale expansion.

+ . Use deuterfum background correction.

3. Determination of $\mathrm{Ba}$

a. Pipet $2.5 \mathrm{~mL} 20,000 \mu \mathrm{g} / \mathrm{mL} \mathrm{K}$ solution into a dry $50 \mathrm{~mL}$ volumetric flask and dilute to volume with sample.

b. Aspirate the sample and standards using the following instrument conditions:

Element Wavelength $(\mathrm{nm})$ slit $(\mathrm{nm})$ Fuel Mixture Flame Ba $553.6,0.4 \quad \mathrm{~N}_{2} \mathrm{O}$-acetylene $10 \mathrm{~mm}$ red zone* (276.8 vis.)

\#Use 30x scale expansion

4. Determinaton of $\mathrm{Ca}$ and $\mathrm{Mg}$

a. Prepare a dilution of the sample by pipeting $1.0 \mathrm{~mL}$ of the acidif ied sample prepared in Procedure B.1 into a $25 \mathrm{~mL}$ volumetric flask. Add $1.25 \mathrm{~mL}$ of $20,000 \mu \mathrm{g} / \mathrm{mL}$ La solution, $0.25 \mathrm{~mL}$ conc. $\mathrm{HNO}_{3}$ and dilute to volume with deionized $\mathrm{H}_{2} \mathrm{O}$. (Low samples may require less than a 1:25 dllution.) Run every 5 th sample in duplicate. 
EHS M 1-6

b. Aspirate the samples and standards using the following instrument conditions:

\begin{tabular}{|c|c|c|c|c|}
\hline Element & Wavelength (nm) & sitt (nm) & Fuel Mixture & Flame \\
\hline $\mathrm{Ca}$ & 422.7 & 1.4 & Air-acetylene & Lean, blue \\
\hline Mg & 285.2 & 0.7 & air-acetylenet & Lean, blue \\
\hline
\end{tabular}

Fse deuterium background correction.

Calculations

1. $\mathrm{Ag}, \mathrm{Cu}, \mathrm{Cr}, \mathrm{Fe}, \mathrm{Mn}, \mathrm{Zn}$

Using the standard values, plot $\mu \mathrm{g} / \mathrm{mL}$ metal vs. absorbance. Determine the sample concentration from the caltbration curves. Report directly as $\mathrm{mg} / \mathrm{L}$ in the samples.

2. $B a$

Using the standard values, plot $\mu \mathrm{g} / \mathrm{mL}$ Ba versus absorbance. Determine the dllution concentration of each sample from the calibration curve. Determine the initial sample concentration as follows:

$$
\begin{aligned}
\mathrm{mg} / \mathrm{Ba} & =\mathrm{C} \times \mathrm{A} \\
C & =\mu \mathrm{g} / \mathrm{mL} \text { measured in dilution } \\
A & =50 / 47.5=\text { normal dilution factor }
\end{aligned}
$$

3. $\mathrm{Ca}$ and $\mathrm{Mg}$

Using the standard values, plot $\mu \mathrm{g} / \mathrm{mL}$ metal vs. absorbance. Determine the sample dilution concentration from the callbation curves. Deter-mine the initial sample concentration as follows:

$\mathrm{mg} / \mathrm{L} \mathrm{Ca}_{\mathrm{a}}$ or $\mathrm{Mg}=\mathrm{C} \times \mathrm{A}$

$C=\mu \mathrm{g} / \mathrm{mL}$ measured in dilution

$A=$ dilution factor (normally 25)

Quality control all samples - prepare new calibration curve every time values vary by more than 10\%. If precision data are out of control, rerun $20 \%$ of the samples. If still out of control, evaluate method to find source of error and rerun entire sample set if sample volume permits. 


\begin{tabular}{|c|c|c|c|}
\hline Metal & $\begin{array}{l}\text { Accuracy } x \\
\text { Recovery } \\
\end{array}$ & $\begin{array}{c}\text { Precision } \\
+\mathrm{mg} / L \\
\end{array}$ & Range (mg/L) \\
\hline $\mathrm{Ag}$ & 98.9 & 0.001 & $0.01-0.1$ \\
\hline $\mathrm{Fe}$ & 106.9 & 0.010 & $0.02-1.0$ \\
\hline$M n$ & 99.3 & .0 .002 & $0.01-0.5$ \\
\hline $\mathrm{Cu}$ & 109.3 & 0.037 & $0.01-0.45$ \\
\hline $2 n$ & 105.1 & 0.006 & $0.01-1.0$ \\
\hline $\mathrm{Ba}$ & 94.3 & 0.014 & $0.05-1.0$ \\
\hline $\mathrm{Cr}$ & 102.1 & 0.003 & $0.08-0.4$ \\
\hline $\mathrm{Ca}$ & 97.0 & 0.15 & $0.5-10$ \\
\hline $\mathrm{Mg}$ & 110.0 & 0.14 & $0.05-1.0$ \\
\hline
\end{tabular}


Method $110 . \quad$ EHS M-10

Title: Metals in Hater - Graphite Furnace A.A.

Ag, As, Ba, Cd, Cr, Co, Cu, Fe, Kti, Mo, Hi, Ph, Se, Sn, Ti, \& V

Vate Issued: Before 3-83

Approved by: MK Hamiltomk\#

Written by: MK Hamilton/D. Palke

Supersedes Method No.

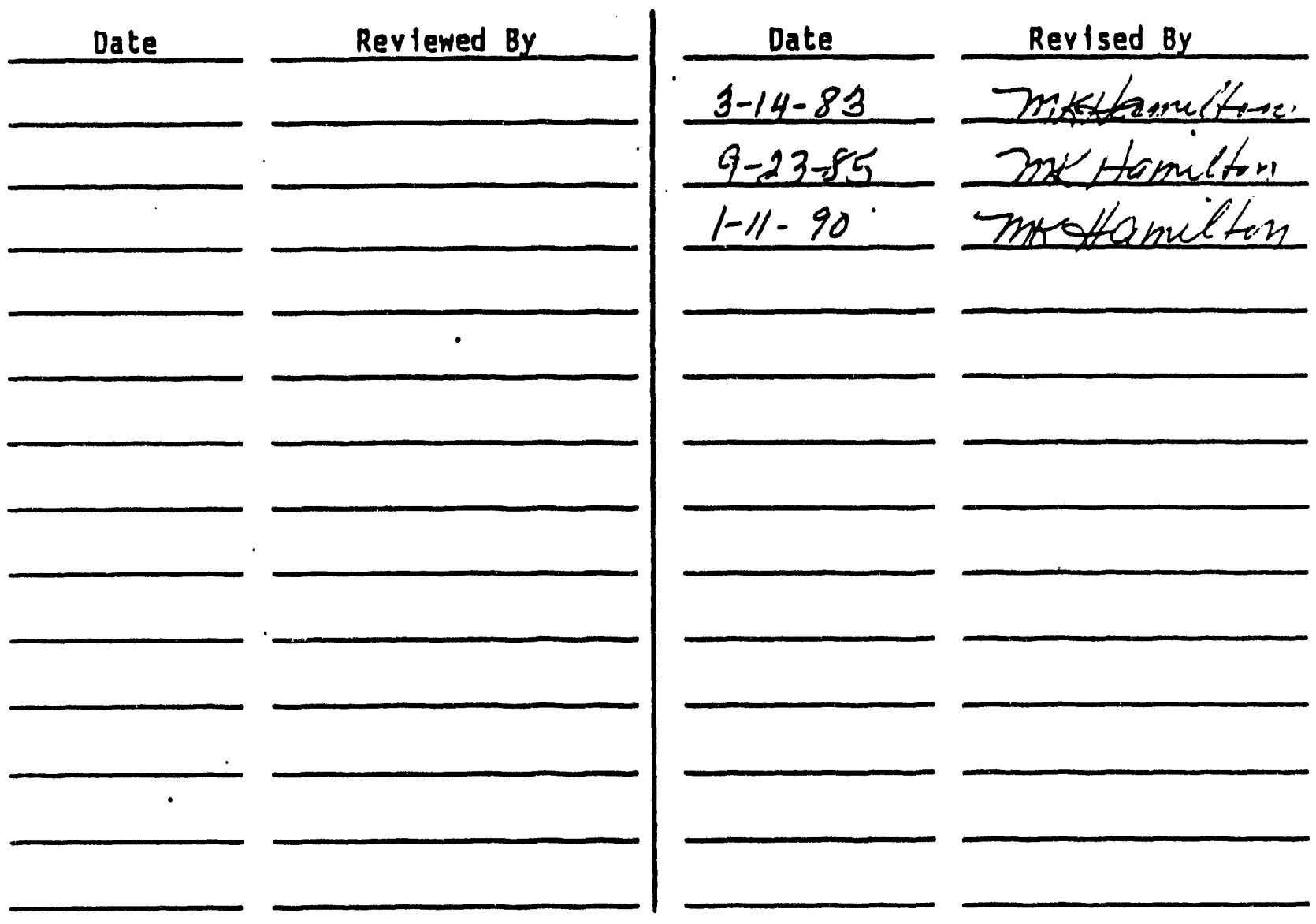

Replaced by Metliod No.

Date: 
EHS $M-10-1$

$01-11-90$

\author{
METALS IN WATER - GRAPHITE FURNACE A. A. \\ Ag. As, Be, Cd, $\mathrm{Cr}, \mathrm{Co}, \mathrm{Cu}, \mathrm{Fe}, \mathrm{Mn}, \mathrm{Mo}, \mathrm{Ni}, \mathrm{Pb}, \mathrm{Se}, \mathrm{Sn}, \mathrm{Ti}, \mathrm{V}$
}

\title{
References
}

1. Methods for Chemical Analys is of Water and Wastes, EPA-600/4-79-020, 1983, Section 200.

2. Analytical Methods for Furnace Atomic Absorotion Soectroscopy, Perkin Elmer, Corporation, 1980.

3. Standard Methods for the Evaluation of Water and Wastewater, 17th. Ed., 1989, Sections 3000 \& 3113 .

4. USEPA Test Methods for Evaluating Solid Waste, SW-846, 3rd. Ed., 1986, 7000 Series methods.

\section{Principles}

In furnace atomic absorption spectroscopy, a sample is thermally acomized into unionized, unexcited atoms in their ground states without the use of a flame. A light beam from a hollow cathode 1amp, which is composed of the element to be determined, is directed through the atomization area and onto a detector that measures the amount of light absorbed. Absorption depends upon the presence of free unexcited ground state atoms in the furnace. Since the wavelength of the light beam is characteristic of only the metal being determined, the light energy absorbed is a measure of the concentration of that metal in the sample.

\section{Limitations}

Background absorption of light from the source beam due to volatilized or atomized matrix material is the major source of interference in furnace atomic absorption. This problem can be alleviated in a number of ways. The addition of a matrix modifier to the sample which increases the volatility of the matrix or decreases the volatility of the analyte allows for separation of the components and achievement of more accurate results. Reduction of the sample size or use of a deuterium background corrector will also help to reduce background absorption. (For samples with complex matrices, the method of standard additions may be needed to completely overcome matrix problems.) The use of proper drying, ashing, and atomizing parameters is also necessary for good results.

\section{Equipment}

1. Atomic absorption spectrophotometer

2. Hollow cathode or electrodeless discharge lamps for metals of interest

3. Strip chart recorder \& printer

4. HGA 400 graphite furnace plus autosampler

5. Pyrolytically coated graphite tubes, with and without platform 
6. Deuterium background corrector

7. EDL power source

8. Various volumetric flasks and pipets

\section{Reagents (Stock)}

1. Hydrogen peroxide, $30 \% \mathrm{H}_{2} \mathrm{O}_{2}$

2. Nitric acid, conc. $\mathrm{HNO}_{3}$, redistilled

3. Ammonium phosphate, dibasic, $\left(\mathrm{NH}_{4}\right)_{2} \mathrm{HPO}_{4}$

4. Lanthanum nitrate, $\mathrm{LA}\left(\mathrm{NO}_{3}\right)_{3} \cdot 6 \mathrm{H}_{2} \mathrm{O}$

5. Nickel powder--CLASS? SUSPECT HUMAN CARCINOGEN

6. Cadmium meta1--CLASS? SUSPECT HUMAN CARCINOGEN

7. Potassium dichromate, $\mathrm{K}_{2} \mathrm{Cr}_{2} \mathrm{O}_{7}$

8. Copper powder

9. Lead nitrate, $\mathrm{Pb}\left(\mathrm{NO}_{3}\right)_{2}$

10. Silver nitrate, $\mathrm{AgNO}_{3}$

11. Arsenic trioxide, $\mathrm{As}_{2} \mathrm{O}_{3}$--CLASS 1 SUSPECT HUMAN CARCINOGEN

12. Sodium hydroxide, $\mathrm{NaOH}$

13. Selenium metal

14. Beryl1ium metal--CLASS 2 SUSPECT HUMAN CARCINOGEN

15. Manganese dioxide, $\mathrm{MnO}_{2}$

16. Iron oxide, $\mathrm{Fe}_{2} \mathrm{O}_{3}$

17. Hydrochloric acid, conc. $\mathrm{HCl}$

18. Cobalt metal

19. Ammonium molybdate-- $\left(\mathrm{NH}_{4}\right)_{6} \mathrm{Mo}_{7} \mathrm{O}_{24} \cdot 4 \mathrm{H}_{2} \mathrm{O}$

20. Titanium dioxide-- $\mathrm{TiO}_{2}$

21. Vanadyl sulfate-- $\mathrm{VOSO}_{4} \cdot 2 \mathrm{H}_{2} \mathrm{O}$

22. Potassium antimony tartrate--K(SbO) $\mathrm{C}_{4} \mathrm{H}_{4} \mathrm{O}_{6} \cdot 1 / 2 \mathrm{H}_{2} \mathrm{O}$

23. Tin metal 
EHS $M-10-3$

$01-11-90$

24. Ammonium hydroxide- $-\mathrm{NH}_{4} \mathrm{OH}$

25. Ammonium sulfate $\left(\mathrm{NH}_{4}\right)_{2} \mathrm{SO}_{4}$

26. Sulfuric acid, conc. $\mathrm{H}_{2} \mathrm{SO}_{4}$

\section{Reagents (Prepared)}

1. $40 \%\left(\mathrm{NH}_{4}\right)_{2} \mathrm{HPO}_{4}$ dissoive $40 \mathrm{~g}\left(\mathrm{NH}_{4}\right)_{2} \mathrm{HPO}_{4}$ in $100 \mathrm{~mL}$ volumetric flask and dilute to volume with deionized water. Prepare annually.

2. Lanthanum solution $(50,000 \mu \mathrm{g} / \mathrm{mL} \mathrm{La})--$ dissolve $77.9 \mathrm{~g} \mathrm{La}\left(\mathrm{NO}_{3}\right)_{3} \cdot 6 \mathrm{H}_{2} \mathrm{O}$ in dilute $\mathrm{HNO}_{3}$ and dilute to $500 \mathrm{~mL}$ with deionized water. Prepare annually.

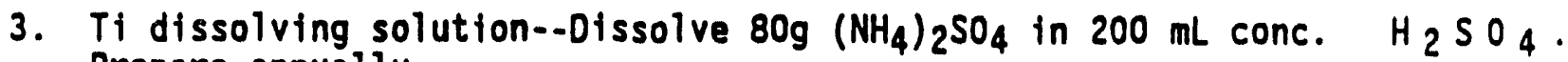
Prepare annually.

\section{Standards}

\section{A. Stock Solutions--Prepare every 6 months}

1. Antimony stock solution--Dissolve $0.6855 \mathrm{~g} \mathrm{~K}(\mathrm{SbO}) \mathrm{C}_{4} \mathrm{H}_{4} \mathrm{O}_{6} \cdot 1 / 2 \quad \mathrm{H}_{2} \mathrm{O}$ in defonized water and dilute to $250 \mathrm{~mL}$. DO NOT add acid. I mL $=1000$ $\mu \mathrm{g} / \mathrm{Sb}$.

2. Arsenic stock solution Dissolve $0.3302 \mathrm{~g}$ arsenic trioxide, $\mathrm{As}_{2} \mathrm{O}_{3}$, in $25 \mathrm{~mL}$ defonized water containing $1 \mathrm{~g} \mathrm{NaOH}$ and dilute to $250 \mathrm{~mL}$ with deionized water. $1 \mathrm{~mL}--1000 \mu \mathrm{g}$ As.

3. Beryllium stock solution--Dissolve $0.250 \mathrm{~g}$ Be metal in $15 \mathrm{~mL} 1: 1 \mathrm{HCl}$, add an additional $2.5 \mathrm{~mL}$ conc. $\mathrm{HCl}$ and dilute to $250 \mathrm{~mL}$ with deionized water. $1 \mathrm{~mL}=1000 \mu \mathrm{g} \mathrm{Be}$.

4. Cadmium stock solution--Dissolve $0.250 \mathrm{~g}$ cadmium metal in a minimum volume of $1: 1 \mathrm{HNO}_{3}$. Add an additional $2.5 \mathrm{~mL}$ conc. $\mathrm{HNO}_{3}$ and dilute to $250 \mathrm{~mL}$ with deionized water. $1 \mathrm{~mL}=1000 \mu \mathrm{g}$.

5. Chromium stock solution--Dissolve $0.707 \mathrm{~g}$ oven dried $\mathrm{K}_{2} \mathrm{Cr}_{2} \mathrm{O}_{7}$ in defonized water to give a final volume of $250 \mathrm{~mL}$. $1 \mathrm{~mL}$. $1000 \mu \mathrm{g} \mathrm{Cr}$.

6. Cobalt stock solution--Dissolve $0.250 \mathrm{~g}$ cobalt metal in a minimum volume of $1: 1 \mathrm{HNO}_{3}$. Add an additional $2.5 \mathrm{~mL}$ conc. $\mathrm{HNO}_{3}$ and dilute to $250 \mathrm{~mL}$ with deionized water. $1 \mathrm{~mL}=1000 \mu \mathrm{g} \mathrm{Co}$.

7. Copper stock solution--Dissolve $0.250 \mathrm{~g}$ copper powder in a minimum volume of $1: 1 \mathrm{HNO}_{3}$. Add an additional $2.5 \mathrm{~mL}$ conc. $\mathrm{HNO}_{3}$ and dilute to $250 \mathrm{~mL}$ with deionized water. $1 \mathrm{~mL}=1000 \mu \mathrm{g} \mathrm{Cu}$.

8. Iron stock solution--dissolve $0.3575 \mathrm{~g}$ oven dried $\mathrm{Fe}_{2} \mathrm{O}_{3}$ in $15 \mathrm{~mL}$ of $1: 1 \mathrm{HCl}$ and dilute to $250 \mathrm{~mL}$ with deionized water. $1 \mathrm{~mL}=1000 \mu \mathrm{g}$ $\mathrm{Fe}$.

9. Lead stock solution--Dissolve $0.3995 \mathrm{~g}$ oven dried $\mathrm{Pb}\left(\mathrm{NO}_{3}\right)_{2}$ in $1: 1$ $\mathrm{HNO}_{3}$ and dilute to $250 \mathrm{~mL}$ with deionized water. $1 \mathrm{~mL}=1000 \mu \mathrm{g} \mathrm{Pb}$. 
EHS $M-10-4$

$01-11-90$

10. Manganese stock solution--Dissolve $0.3956 \mathrm{~g} \mathrm{MnO}_{2}$ in a minimum volume of $1: 1 \mathrm{HCl}$. Add $\mathrm{H}_{2} \mathrm{O}_{2}$ as needed to complete dissolution. Add an additional $2.5 \mathrm{~mL}$ of conc. $\mathrm{HCl}$ and dilute to $250 \mathrm{~mL}$ with deionized water. $1 \mathrm{~mL}=1000 \mu \mathrm{g} \mathrm{Mn}$.

11. Molybdenum stock solution--Dissolve $0.433 \mathrm{~g}$ dried $\left(\mathrm{NH}_{4}\right)_{6} \mathrm{MO}_{7} \mathrm{O}_{24}$ in $1 \%$ $\mathrm{NH}_{4} \mathrm{OH}$ and dilute to $250 \mathrm{~mL}$ with deionized water. $1 \mathrm{~mL}=1000 \mu \mathrm{go}$.

12. Ni solution (1 $\mathrm{mL}=1000 \mu \mathrm{gi}$ )--Dissolve $0.250 \mathrm{~g} \mathrm{Ni}$ powder in a minimum volume of $1: 1 \mathrm{HNO}_{3}$. Add an additional $2.5 \mathrm{~mL}$ conc. $\mathrm{HNO}_{3}$ and dilute to $250 \mathrm{~mL}$ with deionized water.

13. Selenium stock solution--Dissolve $0.250 \mathrm{~g}$ selenium metal in $2 \mathrm{~mL}$ conc. $\mathrm{HNO}_{3}$. Warm until reaction is complete. Cautiously evaporate just to dryness and dilute to $250 \mathrm{~mL}$ with deionized water. $1 \mathrm{~mL}$ = $1000 \mu \mathrm{ge}$.

14. Silver stock solution--Dissolve $0.3938 \mathrm{~g}$ oven dried $\mathrm{AgNO}_{3}$ in deionized water. Add $2.5 \mathrm{~mL}$ conc. $\mathrm{HNO}_{3}$ and dilute to $250 \mathrm{~mL}$ with deionized water. Store away from light in a brown glass bottle. $1 \mathrm{~mL}=$ $1000 \mu \mathrm{gg}$.

15. Tin stock solution--Dissolve $0.250 \mathrm{~g}$ Sn metal in $-15 \mathrm{~mL}$ conc. $\mathrm{HCl}$ (not dilute). Dilute to $250 \mathrm{~mL}$ with deionized water, adding more HCl if necessary to keep $t$ in in solution. $1 \mathrm{~mL}=1000 \mu \mathrm{g} \mathrm{S}$.

16. Titanium stock solution--Dissolve $0.417 \mathrm{~g} \mathrm{TiO}_{2}$ in $25 \mathrm{~mL}$ of $\mathrm{H}_{2} \mathrm{SO}_{4} /\left(\mathrm{NH}_{4}\right)_{2} \mathrm{SO}_{4}$ dissolving solution and dilute to $250 \mathrm{~mL}$ with deionized water. $1 \mathrm{~mL}=1000 \mu \mathrm{g} \mathrm{Ti}$.

17. Vanadium stock solution--Dissolve $0.9768 \mathrm{~g} \mathrm{VOSO} 4 \cdot 2 \mathrm{H}_{2} \mathrm{O}$ in deionized water and dilute to $250 \mathrm{~mL}$. $1 \mathrm{~mL}=1000 \mu \mathrm{g} \mathrm{V}$.

\section{B. Working Standards}

Note: Prepare all intermediate and working standards using Milli-Q deionized water.

1. $\mathrm{Ag}, \mathrm{As}, \mathrm{Cd}, \mathrm{Cr}, \mathrm{Pb}, \mathrm{Sb}$, and Se working standards

a. Intermediate $\mathrm{Cd} \& \mathrm{Ag}$--pipet $1.0 \mathrm{~mL} \mathrm{Cd}$ stock and $2.0 \mathrm{~mL} \mathrm{Ag}$ stock into a $10 \mathrm{~mL}$ volumetric fiask and dilute to volume with deionized water. $1 \mathrm{~mL}=100 \mu \mathrm{g} \mathrm{Cd} \mathrm{\&} 200 \mu \mathrm{g} \mathrm{Ag}$. Prepare monthly.

b. Composite $\mathrm{Ag}, \mathrm{As}, \mathrm{Cd}, \mathrm{Cr}, \mathrm{Pb}, \mathrm{Sb}$ and Se standard

Pipet $0.5 \mathrm{~mL} \mathrm{Cr}$ stock, $1.0 \mathrm{~mL}$ each of the $\mathrm{As}, \mathrm{Pb}, \mathrm{Sb}$, and $\mathrm{Se}$ stock solutions and $1.0 \mathrm{~mL}$ of the $\mathrm{Cd} / \mathrm{Ag}$ intermediate solution into a $1000 \mathrm{~mL}$ volumetric flask, add $5 \mathrm{~mL}$ conc. $\mathrm{HNO}_{3}$, and dilute to volume with deionized water. Prepare weekly.

$1 \mathrm{~mL}=1 \mu \mathrm{g} \mathrm{As}, \mathrm{Pb}, \mathrm{Sb}, \mathrm{Se}$

$=0.5 \mu \mathrm{g} \mathrm{Cr}$

$=0.2 \mu \mathrm{g} \mathrm{Ag}$

$=0.1 \mu \mathrm{g} \mathrm{Cd}$ 
EHS $M-10-5$

$01-11-90$

c. Prepare working standards by pipetting the following amounts of the composite standard into $100 \mathrm{~mL}$ volumetric flasks adding 0.5 $\mathrm{mL}$ redistilled conc. $\mathrm{HNO}_{3}$ and diluting to volume with $\mathrm{Milli}-\mathrm{Q}$ detonized water. Prepare weekly.

\begin{tabular}{|c|c|c|c|c|}
\hline \multirow[b]{2}{*}{ mL Composite Standard } & \multicolumn{4}{|c|}{ Conc. $\mu \mathrm{g} / \mathrm{mL}$} \\
\hline & $\underline{\mathrm{Ag}}$ & $A s, P b, S e, S b$ & Cd & Cr \\
\hline $\begin{array}{r}0 \\
0.5 \\
1.0 \\
3.0 \\
5.0 \\
10.0\end{array}$ & $\begin{array}{l}0 \\
0.001 \\
0.002 \\
0.006 \\
0.010 \\
0.020\end{array}$ & $\begin{array}{l}0 \\
0.005 \\
0.01 \\
0.03 \\
0.05 \\
0.10\end{array}$ & $\begin{array}{l}0 \\
0.0005 \\
0.001 \\
0.003 \\
0.005 \\
0.010\end{array}$ & $\begin{array}{l}0 \\
0.0025 \\
0.005 \\
0.015 \\
0.025 \\
0.050\end{array}$ \\
\hline
\end{tabular}

2. Be, Co, Cu, Fe, Ni, Mn, Mo, and Sn Working Standards

a. Intermediate Be--pipet $1.0 \mathrm{~mL}$ Be stock into a $10 \mathrm{~mL}$ volumetric flask and dilute to volume with deionized water. $1 \mathrm{~mL}=100 \mu \mathrm{g}$ Be. Prepare monthly.

b. Composite Be, Co, Cu, Fe, $\mathrm{Ni}, \mathrm{Mn}$, Mo and $\mathrm{Sn}$ standard--Pipet $1.0 \mathrm{~mL}$ each $\mathrm{Cu}, \mathrm{Fe}$ and $\mathrm{Mn}$ stocks, $2.0 \mathrm{~mL}$ each Mo, Co and $\mathrm{Ni}$ stocks, $10.0 \mathrm{~mL}$ Sn stock and $1.0 \mathrm{~mL}$ Be intermediate into a $1000 \mathrm{~mL}$ volumetric flask, add $5 \mathrm{~mL}$ conc. $\mathrm{HNO}_{3}$ and dilute to volume with deionized water. Prepare weekly.

$$
\begin{aligned}
1 \mathrm{~mL} & =0.1 \mu \mathrm{g} \mathrm{Be} \\
& =1 \mu \mathrm{C} \mathrm{Cu}, \mathrm{Mn} \\
& =2 \mu \mathrm{g} \mathrm{Co}, \mathrm{Ni}, \mathrm{Mo} \\
& =3 \mu \mathrm{Fe} \\
& =10 \mu \mathrm{g} \mathrm{Sn}
\end{aligned}
$$

c. Prepare working standards by pipetting the following amounts of the

\begin{tabular}{|c|c|c|c|c|}
\hline $\begin{array}{c}\text { mL Composite Standard } \\
0 \\
0.5 \\
1.0 \\
3.0 \\
5.0 \\
10.0\end{array}$ & $\begin{array}{l}\quad \text { Be } \\
0.0005 \\
0.001 \\
0.001 \\
0.003 \\
0.005 \\
0.010\end{array}$ & $\begin{array}{c}\text { Cu. Fe, } \mathrm{Mn} \\
0 \\
0.005 \\
0.01 \\
0.03 \\
0.05 \\
0.10\end{array}$ & $\begin{array}{l}\text { Sn } \\
0 \\
0.05 \\
0.10 \\
0.30 \\
0.50 \\
1.00\end{array}$ & $\begin{array}{c}\mathrm{Co}, \mathrm{Mo}, \mathrm{Ni} \\
0 \\
0.01 \\
0.02 \\
0.06 \\
0.10 \\
0.20\end{array}$ \\
\hline
\end{tabular}
composite standard into $100 \mathrm{~mL}$ volumetric flasks, adding $0.5 \mathrm{~mL}$ redistilled conc. $\mathrm{HNO}_{3}$ and diluting to volume with deionized water. Prepare weekly.

Conc. ug/mL

3. Ti and $V$ Working Standards

a. Composite $T i$ and $V$ standard--pipet $2.0 \mathrm{~mL}$ stock $T i$ and $V$ into a 1000 $\mathrm{mL}$ volumetric flask, add $5 \mathrm{~mL}$ conc. $\mathrm{HNO}_{3}$ and dilute to volume with deionized water. Prepare weekly. $1 \mathrm{~mL}=2 \mu \mathrm{g} \mathrm{Ti}, V$ 
b. Prepare working standards by pipetting the following amounts of the composite standard into $100 \mathrm{~mL}$ volumetric flasks, adding 0.5 $\mathrm{mL}$ redistilled conc. $\mathrm{HNO}_{3}$ and diluting to volume with deionized water. Prepare weekly.

mL Comoosite Std.

0

0.5

2.0

5.0

10.0

15.0

25.0 $\mu \mathrm{g} / \mathrm{mL} \mathrm{Ti} \& \mathrm{~V}$

\section{0}

0.01

0.04

0.10

0.20

0.30

0.50

Procedures

A. Samole collection

1. Collect samples in glass or polyethylene bottles that have been rinsed with $1: 1 \mathrm{HNO}_{3}$ and deionized water.

2. As soon as the water sample is collected, add $5 \mathrm{~mL}$ redistilled conc. $\mathrm{HNO}_{3}$ per liter of sample as preservative. Stable up to 6 months.

B. Determination of $\mathrm{Ag}, \mathrm{Be}, \mathrm{Cd}, \mathrm{Cr}, \mathrm{CO}, \mathrm{Cu}, \mathrm{Fe}, \mathrm{Mn}, \mathrm{Mo}, \mathrm{Ni}, \mathrm{Pb}, \mathrm{Sb}, \mathrm{Sn}, \mathrm{Ti}, \mathrm{V}$

1. Preoaration

a. Ag, Co, $\mathrm{Cu}, \mathrm{Be}, \mathrm{Fe}, \mathrm{Mn}, \mathrm{Mo}, \mathrm{Ni}, \mathrm{Sb}, \mathrm{Ti}$, and $\mathrm{V}$--no treatment needed.

b. $\quad \mathrm{Cd}$--add $0.2 \mathrm{~mL}$ of $40 \%\left(\mathrm{NH}_{4}\right)_{2} \mathrm{HPO}_{4}$ solution to every $10.0 \mathrm{~mL}$ of sample and standard.

c. $\mathrm{Pb}--$ add $1.0 \mathrm{~mL}$ of La solution $(50,000 \mathrm{~g} / \mathrm{mL} \mathrm{La})$ to every $10.0 \mathrm{~mL}$ of sample and standard.

d. Cr--add $0.1 \mathrm{~mL} 30 \% \mathrm{H}_{2} \mathrm{O}_{2}$ to every $10.0 \mathrm{~mL}$ of sample and standard.

e. Sn--normally run without treatment. For improved sensitivity a matrix modifier of $10 \mu \mathrm{L}$ of $2 \%\left(\mathrm{NH}_{4}\right)_{3} \mathrm{PO}_{4}$ and $0.5 \% \mathrm{Mg}\left(\mathrm{NO}_{3}\right)_{2}$ is recommended but has not been tried by EHS.

2. Analysis

Set up the PE 2380 AA furnace and autosampler as per Lab Operating Procedure L-8.8. Program HGA 400 Graphite Furnace with the correct program for determination of the desired element as shown on the attached "Entry Sheets." 
EHS $M-10-7$

C. Determination of As and Se

1. Preparation

As and Se--add $0.2 \mathrm{~mL}$ of $30 \% \mathrm{H}_{2} \mathrm{O}_{2}$ to every $10.0 \mathrm{~mL}$ of sample and standard.

2. Analysis

Set up the PE 2380 AA, furnace and autosampler as per Lab Operating Procedure L-8.8. Include programming of the autosampler to inject into the graphite tube, before injecting the sample or standard, an aliquot of $\mathrm{Ni}$ solution $(1 \mathrm{~mL}=1000 \mu \mathrm{gi})$ equal in size to the sample aliquot $(20 \mu \mathrm{L})$.

Program HGA 400 Graphite Furnace with the correct program for determination of the desired element as shown on the attached "Entry Sheets".

\section{Calculations - All Metals}

Using the standard values, plot $\mu \mathrm{g} / \mathrm{mL}$ metal vs. absorbance. Determine the sample concentration from the calibration curves. Report directly as $\mathrm{mg} / \mathrm{L}$ in the sample.

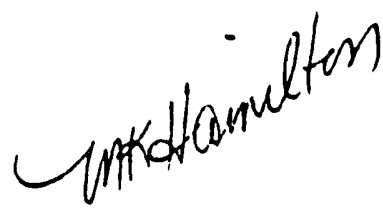


Element: Ao_ Matrix: Hater

Tube Type: Coated

Sample Aliquot: $20 \mu \mathrm{L}$

Keyboard Entries

\begin{tabular}{|l|r|r|r|r|r|r|r|l|}
\hline \multicolumn{1}{|l|}{ STEP } & 1 & 2 & 3 & 4 & 5 & 6 & 7 & 8 \\
\hline TEMP ( $\left.{ }^{\circ} \mathrm{C}\right)$ & 120 & 400 & 950 & 2700 & & & & \\
\hline RAMP TIME* (s) & 1 & 10 & 0 & 1 & & & & \\
\hline HOLD TIME (s) & 25 & 20 & 5 & 3 & & & & \\
\hline REC & & & & & & & & \\
\hline READ & & & & & & & & \\
\hline BASELINE & & & & & & & & \\
\hline MINI FLOW & & & ME & & & & & \\
\hline mI/min & & & 50 & & & & & \\
\hline STOP FLOW & & & & & & & & \\
\hline
\end{tabular}

* When RAMP TIME is zero (Max. Power Heating). Temperature Control requires caltibration.

NOTES:

Samples and standards $0.5 \% \mathrm{HNO}_{3}$ 
Element: As . Matrix:

Hater

Tube Type: Coated

Sample Aliquot: $20 \mu \mathrm{L}$

Keyboard Entries

\begin{tabular}{|l|c|c|c|c|c|c|c|c|}
\hline STEP & 1 & 2 & 3 & 4 & 5 & 6 & 7 & 8 \\
\hline TEMP ( $\left.{ }^{\circ} \mathrm{C}\right)$ & 120 & 1050 & $250 \mathrm{C}$ & & & & & \\
\hline RAMP TIME (s) & 1 & 5 & 0 & & & & & \\
\hline HOLD TIME (s) & 30 & 25 & 4 & & & & & \\
\hline REC & & & & & & & & \\
\hline READ & & & & & & & & \\
\hline BASELINE & & & & & & & & \\
\hline MINI FLOH & & & & & & & & \\
\hline $\mathrm{mI/min}$ & & & $\cdot$ & & & & & \\
\hline STOP FLOW & & & $\times$ & & & & & \\
\hline
\end{tabular}

* When RAMP TIME is zero (Max. Power Heating), Temperature Control requitres callbration.

NOTES:

Requires matrix modifier. Use equal aliauots of $100 \mathrm{n}$ ppm $\mathrm{Ni}$ standard along with $\mathrm{As}$ samples and standards. Inject $\mathrm{Ni}$ standard first, then As samples or standard. Sambles and standards are $0.5 \% \mathrm{HNO}_{3}$. Add $0.2 \mathrm{~mL} 30 \% \mathrm{H}_{2} \mathrm{O}_{2}$ to every $10 . \mathrm{n} \mathrm{mL}$ of .sample or -standard. Haste water and other such waters may require oreliminary sample digestion. 
Element: Be Matrix: Water

Tube Type: coated w/platform

Sample Aliquot: $20 \mu L$

Keyboard Entries

\begin{tabular}{|l|c|c|c|c|c|c|c|c|}
\hline STEP & 1 & 2 & 3 & 4 & 5 & 6 & 7 & 8 \\
\hline TEMP ( ${ }^{\circ} \mathrm{C}$ ) & 200 & 900 & 2500 & 2600 & 30 & & & \\
\hline RAMP TIME* (s) & 5 & 5 & 0 & 1 & 5 & & & \\
\hline HOLD TIME (s) & 25 & 20 & 4 & 3 & 5 & & & \\
\hline REC & & & $\times$ & & & & & \\
\hline READ & & & $\times$ & & & & & \\
\hline BASELINE & & & & & & & & \\
\hline MINI FLOW & & & & & & & & \\
\hline mI/min & & & & & & & & \\
\hline STOP FLOW & & & $\times$ & & & & & \\
\hline
\end{tabular}

* When RAMP TIME is zero (Max. Power Heating). Temperature Control requires calibration.

NOTES:

Not yet optimized 
Element: $C$ Cd Matrix: Hater

Tube Type: Coated

Sample Altquot: $20 \mathrm{iL}$

Keyboard Entries

\begin{tabular}{|l|r|r|r|r|r|r|r|l|}
\hline STEP & 1 & 2 & 3 & 4 & 5 & 6 & 7 & 8 \\
\hline TEMP (๑C) & 120 & 550 & 1050 & 2700 & & & & \\
\hline RAMP TIME (s) & 1 & 15 & 0 & 1 & & & & \\
\hline HOLD TIME (s) & 30 & 15 & 6 & 3 & & & & \\
\hline REC & & & & & & & & \\
\hline READ & & & & & & & & \\
\hline BASELINE & & & & & & & & \\
\hline MINI FLOW & & & NE & & & & & \\
\hline STOP FLOW & & & & & & & & \\
\hline
\end{tabular}

* When RAMP TIME is zero (Max. Power Heating), Temperature Control requites callbration.

NOTES: Prepare $.8 \%\left(\mathrm{NH}_{4}\right)_{2} \mathrm{HPO}_{4}$ samples and standard. Dissolve $40 \mathrm{~g}\left(\mathrm{NH}_{4}\right)_{2} \mathrm{HPO}_{4}$ in $100 \mathrm{~mL}$ volumetric flask. Add $0.2 \mathrm{~mL}$ of this to every $10.0 \mathrm{~mL}$ sample or standard. Samples and standards should be $0.5 \% \mathrm{HNO}_{3}$ before dilution with phosphate. 
Element: Cr Matrix: Hater

Tube Type: Coated

Sample Aliquot: 20 HL

Keyboard Entries

\begin{tabular}{|l|r|r|r|r|r|r|r|l|}
\hline \multicolumn{1}{|l|}{ STEP } & \multicolumn{1}{|c|}{1} & \multicolumn{1}{|c|}{2} & 3 & 4 & 5 & 6 & 7 & 8 \\
\hline TEMP (' $\mathrm{C}$ ) & 120 & 1050 & 2400 & 2700 & & & & \\
\hline RAMP TIME (s) & 1 & 10 & 0 & 1 & & & & \\
\hline HOLD TIME (s) & 25 & 25 & 5 & 3 & & & & \\
\hline REC & & & & & & & & \\
\hline READ & & & & & & & & \\
\hline BASELINE & & & & & & & & \\
\hline MINI FLOW & & & NE & & & & & \\
\hline mI/min & & & 50 & & & & & \\
\hline STOP FLOW & & & & & & & & \\
\hline
\end{tabular}

* When RAMP TIME is zero (Max. Power Heating), Temperature Control requitres caltbration.

NOTES: Samples and standards are $0.5 \% \mathrm{HNO}_{3}$. Add $0.1 \mathrm{~mL} 30 \% \mathrm{H}_{2} \mathrm{O}_{2}$ to every $10.0 \mathrm{~mL}$ sample or standard. 
Element: Co Matrix: Water

Tube Type: Coated

Sample Aliquot: $20 \mu L$

Keyboard Entries

\begin{tabular}{|l|c|c|c|c|c|c|c|c|}
\hline STEP & 1 & 2 & 3 & 4 & 5 & 6 & 7 & 8 \\
\hline TEMP ( $\left.{ }^{\circ} \mathrm{C}\right)$ & 120 & 900 & 2300 & 2700 & & & & \\
\hline RAMP TIME (s) & 1 & 5 & 0 & 1 & & & & \\
\hline HOLD TIME (s) & 25 & 25 & 6 & 3 & & & & \\
\hline REC & &. & & & & & & \\
\hline READ & & & & & & & & \\
\hline BASELINE & & & & & & & & \\
\hline MINI FLOW & & & $x$ & & & & & \\
\hline $\mathrm{mI/min}$ & & & 50 & & & & & \\
\hline STOP FLOW & & & & & & & & \\
\hline
\end{tabular}

* When RAMP tIME is zero (Max. Power Heating), Temperature Control requitres calibration.

NOTES: Not optimized 
Element: $\mathrm{Cu}$ . Matrix:

Hater

Tube Type: Coated

Sample Aliquot: $20 \mu$

Keyboard Entries

\begin{tabular}{|c|c|c|c|c|c|c|c|c|}
\hline STEP & 1 & 2 & 3 & 4 & 5 & 6 & 7 & 8 \\
\hline TEMP $\left({ }^{\circ} \mathrm{C}\right)$ & 120 & 1000 & 2450 & 2700 & & & & \\
\hline RAMP TIME* (s) & 1 & 1 & 0 & 1 & & & & \\
\hline HOLD TIME (s) & 20 & 10 & 10 & 3 & & & & \\
\hline \multicolumn{9}{|l|}{ REC } \\
\hline \multicolumn{9}{|l|}{ READ } \\
\hline \multicolumn{9}{|l|}{ BASELINE } \\
\hline MINI FLOW & & & NE & & & & & \\
\hline$m 1 / m i n$ & & & 50 & & & & & \\
\hline STOP FLOW & & & & & & & & \\
\hline
\end{tabular}

* When RAMP TIME is zero (Max. Power Heating), Temperature Control requitres caltbration.

NOTES: Samples and standards are $0.5 \% \mathrm{HNO}_{3}$. 


\section{HGA-400 KEYBOARD ENTRIES}

Element:

Fe Matrix:

Hater

Tube Type: Coated

Sample Allquot: $20 \mu L$

Keyboard Entries

\begin{tabular}{|l|c|c|c|c|c|c|c|c|}
\hline STEP & 1 & \multicolumn{1}{|c|}{2} & 3 & 4 & 5 & 6 & 7 & 8 \\
\hline TEMP (ㄷ) & 120 & 1050 & 2150 & 2700 & & & & \\
\hline RAMP TIME* (s) & 1 & 10 & 0 & 1 & & & & \\
\hline HOLD TIME (s) & 25 & 20 & 5 & 3 & & & & \\
\hline REC & & & & & & & & \\
\hline READ & & & & & & & & \\
\hline BASELINE & & & & & & & & \\
\hline MINI FLOW & & & NE & & & & & \\
\hline mI/min & & & 50 & & & & & \\
\hline STOP FLOW & & & & & & & & \\
\hline
\end{tabular}

* When RAMP TIME is zero (Max. Power Heating). Temperature Control requites caltbration.

NOTES: Samples and standards are $0.5 \% \mathrm{HNO}_{3}$. 
Element: An

Matrix:

Water

Tube Type: Coated

Sample Aliquot: $20 \mu L$

Keyboard Entries

\begin{tabular}{|c|c|c|c|c|c|c|c|c|}
\hline STEP & 1 & 2 & 3 & 4 & 5 & 6 & 7 & 8 \\
\hline TEMP $\left({ }^{\circ} \mathrm{C}\right)$. & 120 & 1000 & 2100 & 2700 & & & & \\
\hline RAMP TIME* (s) & 1 & 10 & 0 & 1 & & & & \\
\hline HOLD TIME (s) & 25 & 20 & 5 & 3 & & & & \\
\hline REC & & & & & & & & \\
\hline READ & & & & & & & & \\
\hline BASELINE & & & & & & & & \\
\hline MINI FLOW & & & ME & & & & & \\
\hline $\mathrm{m} 1 / \mathrm{min}$ & & & 50 & & & & & \\
\hline STOP FLOW & & & & & & & & \\
\hline
\end{tabular}

* When RAMP TIME is zero (Max. Power Heating), Temperature Control requires calibration.

NOTES: Samples and standards are $0.5 \% \mathrm{HNO}_{3}$. 
Element: . Matrix: Hater

Tube Type: Coated

Sample Aliquot: $20 \mathrm{uL}$

Keyboard Entries

\begin{tabular}{|l|c|c|c|c|c|c|c|c|}
\hline STEP & 1 & 2 & 3 & 4 & 5 & 6 & 7 & 8 \\
\hline TEMP $\left({ }^{\circ} \mathrm{C}\right)$ & 120 & 1400 & 2500 & $27 n 0$ & & & & \\
\hline RAMP TIME (s) & 1 & 5 & 0 & 1 & & & & \\
\hline HOLD TIME (s) & 25 & 25 & 10 & 3 & & & & \\
\hline REC & & & & & & & & \\
\hline READ & & & & & & & & \\
\hline BASELINE & & & & & & & & \\
\hline MINI FLOH & & & $\times$ & & & & & \\
\hline $\mathrm{mI} / \mathrm{min}$ & & & 50 & & & & & \\
\hline STOP FLOW & & & & & & & & \\
\hline
\end{tabular}

* When RAMP TIME is zero (Max. Power Heating), Temperature Control requires caltbration.

NOTES: Not totally optimized for char step 
Element: Ni . Matrix: Hater

Tube Type: Coated

Sample Aliquot: $2 n \mu L$

Keyboard Entries

\begin{tabular}{|l|c|c|c|c|c|c|c|c|}
\hline STEP & 1 & 2 & 3 & 4 & 5 & 6 & 7 & 8 \\
\hline TEMP ( $\left.{ }^{\circ} \mathrm{C}\right)$ & 120 & 1000 & 2400 & 2700 & & & & \\
\hline RAMP TIME (s) & 1 & 5 & 0 & 1 & & & &. \\
\hline HOLD TIME (s) & 25 & 20 & 6 & 3 & & & & \\
\hline REC & & & & & & & & \\
\hline READ & & & & & & & & \\
\hline BASELINE & & & & & & & & \\
\hline MINI FLOW & & & $\times$ & & & & & \\
\hline mI/min & & & 50 & & & & & \\
\hline STOP FLOW & & & & & & & & \\
\hline
\end{tabular}

* When RAMP TIME is zero (Max. Power Heating), Temperature Control requires callbration.

NOTES: 
Element: $\mathrm{Pb}$ Matrix: Water

Tube Type: Coated

Sample Aliquot:

20 ul

Keyboard Entries

\begin{tabular}{|l|r|r|r|r|r|r|r|l|}
\hline \multicolumn{1}{|l|}{ STEP } & \multicolumn{1}{|c|}{1} & \multicolumn{1}{|c|}{2} & \multicolumn{1}{|c|}{3} & 4 & 5 & 6 & 7 & 8 \\
\hline TEMP ( $\left.{ }^{\circ} \mathrm{C}\right)$ & 120 & 550 & 1400 & 2700 & & & & \\
\hline RAMP TIME* (s) & 1 & 10 & 0 & 1 & & & & \\
\hline HOLD TIME (s) & 20 & 20 & 5 & 3 & & & & \\
\hline REC & & & & & & & & \\
\hline READ & & & & & & & & \\
\hline BASELINE & & & & & & & & \\
\hline MINI FLOW & & & NE & & & & & \\
\hline $\mathrm{mI/min}$ & & & 50 & & & & & \\
\hline STOP FLOW & & & & & & & & \\
\hline
\end{tabular}

* When RAMP TIME is zero (Max. Power Heating), Temperature Control requitres callibration.

NOTES: Requires matrix modifter. Dissolve $77.9 \mathrm{~g} \mathrm{La}\left(\mathrm{NO}_{3}\right)_{3} \cdot 6 \mathrm{H}_{2} \mathrm{O}$ in $500 \mathrm{~mL}$ deionized $\mathrm{H}_{2} \mathrm{O}$. Add $1.0 \mathrm{~mL}$ of this solution to every $10.0 \mathrm{~mL}$ of sample and standard. Sample and standards should be $0.5 \% \mathrm{HNO}_{3}$ before dilution with La solution. 
Element: $S b$ . Matrix: Hater

Tube Type: Coated

Sample Aliquot: $20 \mathrm{\mu L}$

Keyboard Entries

\begin{tabular}{|l|c|c|c|c|c|c|c|c|}
\hline STEP & 1 & 2 & 3 & 4 & 5 & 6 & 7 & 8 \\
\hline TEMP ( $\left.{ }^{\circ} \mathrm{C}\right)$ & 120 & 900 & 2000 & 2700 & & & & \\
\hline RAMP TIME* (s) & 1 & 5 & 0 & 1 & & & & \\
\hline HOLD TIME (s) & 25 & 25 & 10 & 3 & & & & \\
\hline REC & & & & & & & & \\
\hline READ & & & & & & & & \\
\hline BASELINE & & & & & & & & \\
\hline MINI FLOW & & & $\times$ & & & & & \\
\hline mI/min & & & 50 & & & & & \\
\hline STOP FLOW & & & & & & & & \\
\hline
\end{tabular}

* When RAMP TIME is zero (Max. Power Heating), Temperature Control requites calibration.

NOTES: 
Element: Se Matrfx: Hater

Tube Type: Coated

Sample Aliquot: $20 \mathrm{LL}$

Keyboard Entries

\begin{tabular}{|l|r|r|r|r|r|r|r|l|}
\hline STEP & 1 & 2 & 3 & 4 & 5 & 6 & 7 & 8 \\
\hline TEMP (ㅇ) & 120 & 1000 & 2000 & 2700 & & & & \\
\hline RAMP TIME* (s) & 1 & 10 & 0 & 1 & & & & \\
\hline HOLD TIME (s) & 30 & 20 & 5 & 3 & & & & \\
\hline REC & & & & & & & & \\
\hline READ & & & & & & & & \\
\hline BASELINE & & & & & & & & \\
\hline MINI FLOW & & & & & & & & \\
\hline mI/min & & & $\cdot$ & & & & & \\
\hline STOP FLOW & & & NE & & & & & \\
\hline
\end{tabular}

* When RAMP TIME is zero (Max. Power Heating), Temperature Control requires caltbration.

NOTES: $\quad$ Requires matrix modifier. Use equal aliquots of $1000 \mathrm{ppm} N \mathrm{Ni}$ standard along with Se samples and standards. Inject $\mathrm{Ni}$ standard first, then Se samples and standards. Samples and standards are $0.5 \% \mathrm{HNO}_{3}$. Add $0.2 \mathrm{~mL} 30 \% \mathrm{H}_{2} \mathrm{O}_{2}$ to every $10.0 \mathrm{~mL}$. of sample and standard. Waste water and other such waters may require preliminary digestion. 
Element: Sn . Matrix: Nater $\left(1 \% \mathrm{HMO}_{3}\right)$

Tube Type: Uncoated

Sample Aliquot: $20 \mu L$

Keyboard Entries

\begin{tabular}{|l|r|c|c|c|c|c|c|c|}
\hline STEP & 1 & 2 & 3 & 4 & 5 & 6 & 7 & 8 \\
\hline TEMP $\left({ }^{\circ} \mathrm{C}\right)$ & 110 & 600 & 220 & 2500 & & & & \\
\hline RAMP TIME* (s) & 10 & 10 & 0 & 1 & & & & \\
\hline HOLO TIME (s) & 30 & 15 & 5 & 5 & & & & \\
\hline REC & & & $\times$ & & & & & \\
\hline READ & & & $x$ & & & & & \\
\hline BASELINE & & & & & & & & \\
\hline MINI FLOW & & & & & & & & \\
\hline mI/min & & & $\cdot$ & & & & & \\
\hline STOP FLOW & & & $\times$ & & & & & \\
\hline
\end{tabular}

* When RAMP TIME is zero (Max. Power Heating), Temperature Control requires caltbration.

NOTES:

Ahnve program not optimizen ${ }^{-}$for 10 mprover sensitivity may al so add not tried this). 
Element: $\quad$ TH

. Matrix:

$\mathrm{H}_{2} \mathrm{O}$

Tube Type:

Coater

Sample Aliquot: $2 \mathrm{C} \mathrm{LL}$

Keyboard Entries

\begin{tabular}{|l|c|c|c|c|c|c|c|c|}
\hline STEP & 1 & 2 & 3 & 4 & 5 & 6 & 7 & 8 \\
\hline TEMP ( ${ }^{\circ} \mathrm{C}$ ) & 120 & 1100 & 2700 & & & & & \\
\hline RAMP TIME (s) & 1 & 8 & 0 & & & & & \\
\hline HOLD TIME (s) & 25 & 25 & 10 & & & & & \\
\hline REC & & & & & & & & \\
\hline READ & & & & & & & & \\
\hline BASELINE & & & & & & & & \\
\hline MINI FLOW & & & $\times$ & & & & & \\
\hline m1/min & & & $5 n$ & & & & & \\
\hline STOP FLOW & & & & & & & & \\
\hline
\end{tabular}

* When RAMP TIME is zero (Max. Power Heating), Temperature Control requites caltbration.

NOTES: Not ontimizen 
Element: $\quad \underline{V}$ - Matrix: $\mathrm{H}_{2} \mathrm{O}$

Tube Type: Coated

Sample Aliquot: 2n UL

Keyboard Entries

\begin{tabular}{|l|c|c|c|c|c|c|c|c|}
\hline STEP & 1 & 2 & 3 & 4 & 5 & 6 & 7 & 8 \\
\hline TEMP (') & 120 & 1200 & 2600 & $27 n 0$ & & & & \\
\hline RAMP TIME (s) & 1 & 8 & 0 & 1 & & & & \\
\hline HOLO TIME (s) & 25 & 25 & 10 & 3 & & & & \\
\hline REC & - & & & & & & & \\
\hline REAO & & & & & & & & \\
\hline BASELINE & & & & & & & & \\
\hline MINI FLOW & & & $\times$ & & & & & \\
\hline $\mathrm{mI} / \mathrm{min}$ & & & 50 & & & & & \\
\hline STOP FLOW & & & & & & & & \\
\hline
\end{tabular}

* When RAMP TIME is zero (Max. Power Heating), Temperature Control requires calibration.

NOTES: 
Method No. EHS M-4

Title: TOTAL MERCURY (ORGANIC AND INORGANIC) IN WATER BY FLAMELESS AA

Date issued: ${ }_{\text {Written by: }}$ Before $3 / 83$ A K Hamiliton

Supersedes Method No. EHS M-2

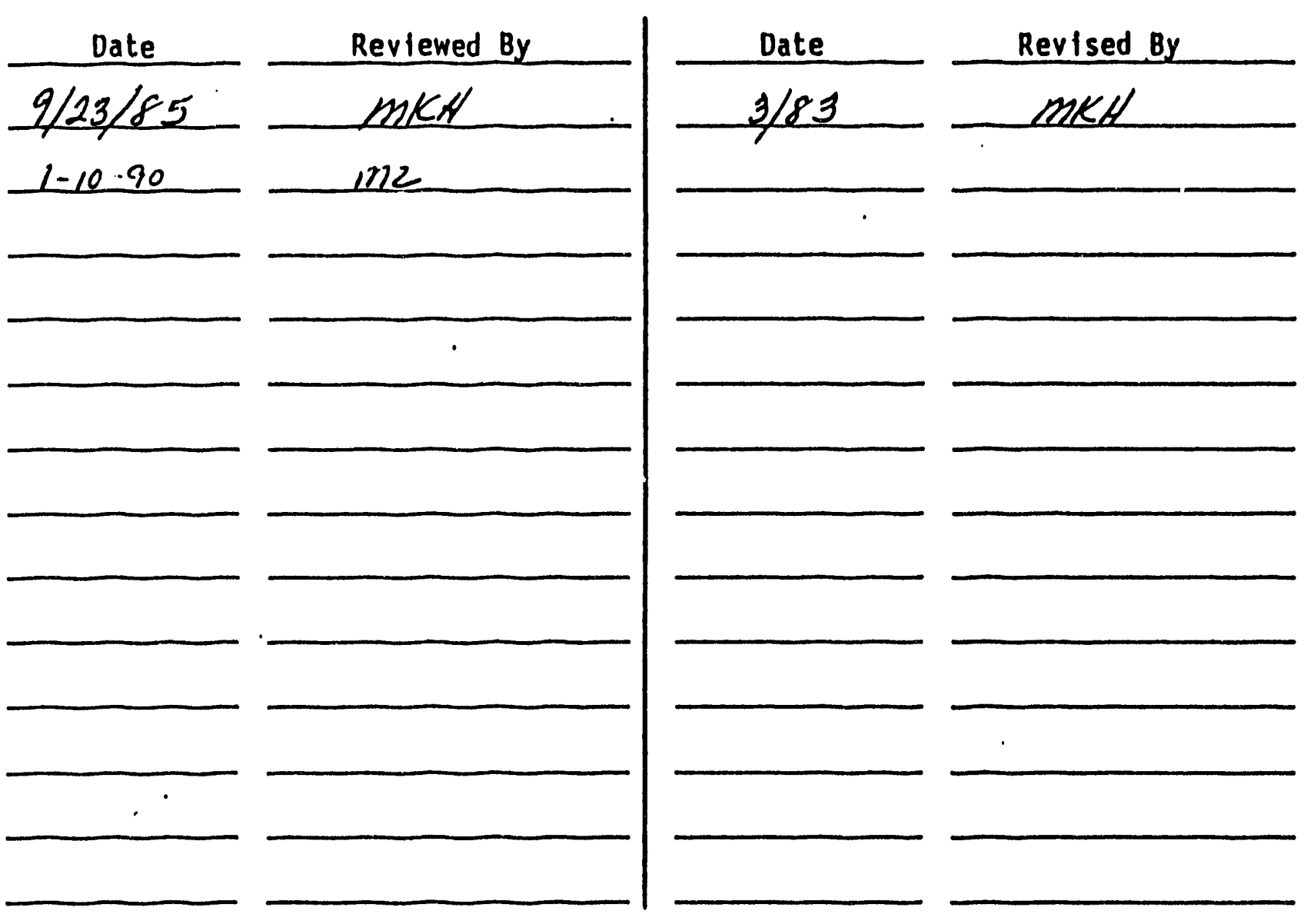

Replaced by Method No.

Date: 
References

1. Analysis for Mercury in Water, a Preliminary Study of Methods, John A. Winter and Harold A. Clements, Environmental Monitoring Series EPA-R4-72-003, September, 1972.

2. Standard Method for the Examination of Water and Wastewater, 16th Edition, 1985, pp. 171-173.

Principles

For organic mercurial compounds to respond to the flameless atomic absorption (AA) technique, they must first be broken down and converted to mercuric fons. Thts may be accomplished by oxidizing the compounds with potassium permanganate followed by potassium persulfate. Heating is also necessary to insure the oxidation of any methyl mercuric chloride that may be present. Once the oxidation is complete, the mercury may be determined by flameless $A A$. Mercury, in an acidic media, is reduced to the elemental state by the addition of stannous chloride. The mercury vapor is then passed through a cell positioned in the light path of the $A A$. The resulting absorbance is measured and used to determine the amount of mercury present.

\section{Limitations}

This method is applicable for surface waters, saline waters, waste-waters, effluents and domestic sewage. Copper and sulfide in concentrations above 20 $\mathrm{mg} / \mathrm{L}$ may interfere. High chloride concentrations (sea waters, brines, etc.) require the use of additional permanganate. Excess hydroxylamine hydrochloride and purging of the air space in the reagent flask are also required to remove the free chlorine formed as this will absorb at the $253.7 \mathrm{~nm}$ mercury wavelength. Some volatile organic materials may also absorb at the mercury wavelength. Such interferences may be eliminated by analyzing the sample as usual and again without the reducing reagents. The difference in the two values will be the true mercury value.

Equipment

1. Atomic absorption spectrophotometer with deuterium background corrector and mercury hollow cathode 1 amp.

2. Absorption cell, reduction flasks and apparatus as shown in Fig. 1.

3. Covered water bath capable of maintaining a temperature of $90-95^{\circ} \mathrm{C}$.

4. $300 \mathrm{~mL}$ stoppered BOD bottles. 


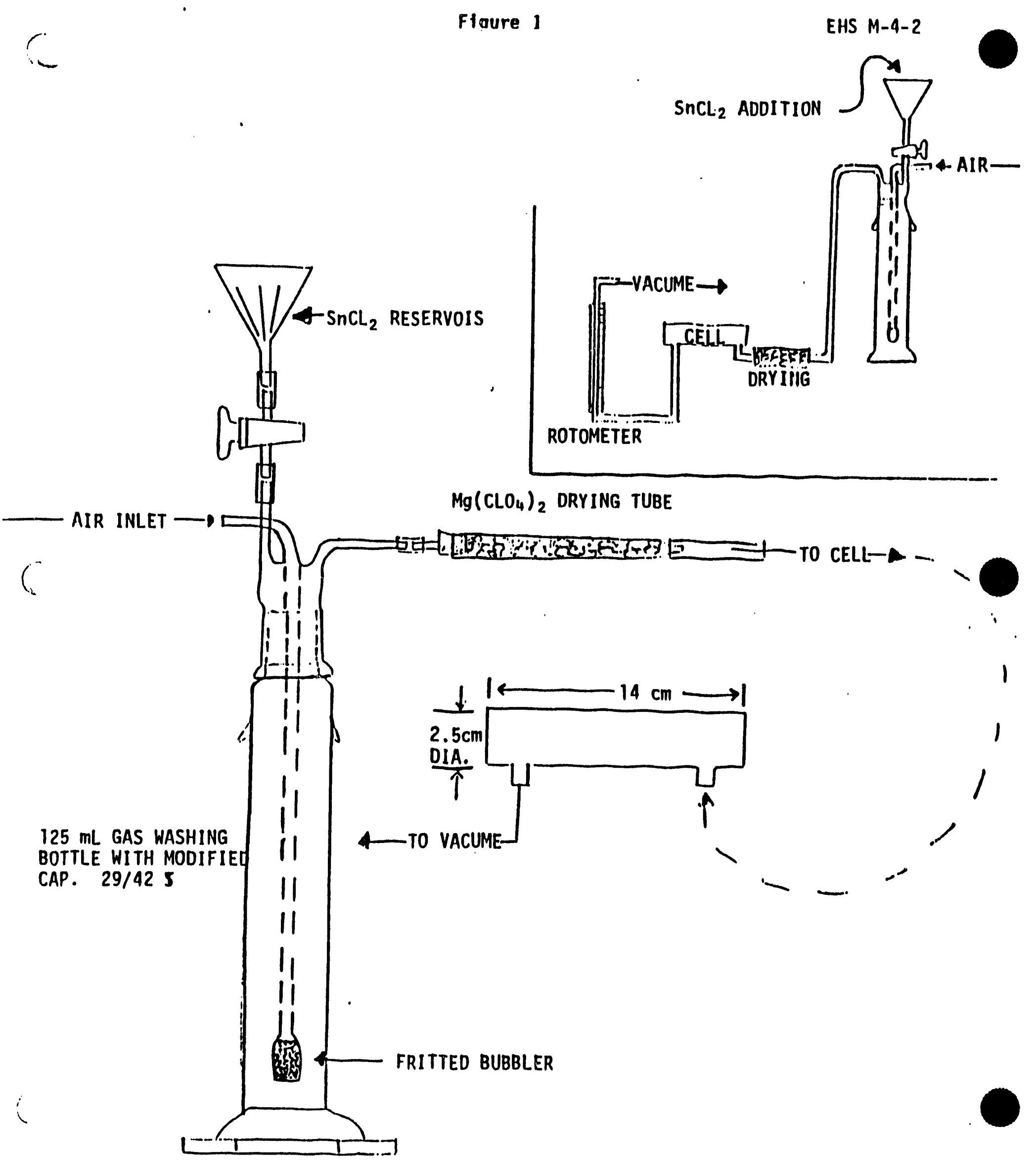


Reagents (stock)

1. Mercuric chloride $-\mathrm{HgCl}_{2}$

2. Sulfuric acid, conc. $\mathrm{H}_{2} \mathrm{SO}_{4}$

3. Nitric acid, conc. - $\mathrm{HNO}_{3}$

4. Potassium permanganate $-\mathrm{KMnO}_{4}$

5. Potassium persulfate $-\mathrm{K}_{2} \mathrm{~S}_{2} \mathrm{O}_{8}$

6. Stannous chloride $-\mathrm{SnCl}_{2} \cdot 2 \mathrm{H}_{2} \mathrm{O}$

7. Sodium chloride $-\mathrm{NaCl}$

8. Hydrochloric actd, conc. - $\mathrm{HCl}$

9. Hydroxylamine hydrochloride $-\mathrm{NH}_{2} \mathrm{OH}-\mathrm{HCl}$

10. Magnesium perchlorate $-\mathrm{Mg}\left(\mathrm{ClO}_{4}\right)_{2}$

Reagents (prepared)

1. $\mathrm{KMnO}_{4}-5 \% \mathrm{w} / \mathrm{v}$ solution - dissolve $25 \mathrm{~g} \mathrm{KMnO}_{4}$ in defonized water and dilute to $500 \mathrm{~mL}$. Prepare every 6 months.

2. $\mathrm{K}_{2} \mathrm{~S}_{2} \mathrm{O}_{8}-5 \% \mathrm{w} / \mathrm{v}$ solution - dissolve $12.5 \mathrm{~g} \mathrm{~K}_{2} \mathrm{~S}_{2} \mathrm{O}_{8}$ in detonized water and dilute to $250 \mathrm{~mL}$. Prepare every 6 months.

3. $\mathrm{NaCl}$ - hydroxylamine hydrochloride - dissolve $30 \mathrm{~g} \mathrm{NaCl}$ and $25 \mathrm{~g}$ hydroxylamine hydrochloride in defonized water and dilute to $250 \mathrm{~mL}$. Prepare every 6 months.

4. $\mathrm{SnCl}_{2}-20 \% \mathrm{w} / \mathrm{v}$ in $10 \% \mathrm{HCl}$ - add $25 \mathrm{~mL}$ conc. $\mathrm{HCl}$ to about $150 \mathrm{~mL}$ deionized water and $\mathrm{mix}$. Add $50 \mathrm{~g} \mathrm{SnCl}_{2} \cdot 2_{2} \mathrm{H}$, $\mathrm{mix}$ well and dilute to $250 \mathrm{~mL}$ with deionized water. (Solution will be milky). Prepare every 6 months.

Standards

1. Stock $\mathrm{Hg}$ solution - $1000 \mu \mathrm{g} / \mathrm{mL}$ - dissolve $1.3535 \mathrm{~g} \mathrm{HgCl}_{2}$ in deionized water, add $19 \mathrm{~K}_{2} \mathrm{~S}_{2} \mathrm{O}_{8}$ and dilute to one Liter with deionized water. Prepare every 6 months. Discard in inorganic heavy metal and carcinogen waste container.

2. Intermediate $\mathrm{Hg}$ standard - $10 \mu \mathrm{g} / \mathrm{mL}$ - pipet $1.0 \mathrm{~mL}$ stock $\mathrm{Hg}$ solution into a $100 \mathrm{~mL}$ volumetric flask, add $1 \mathrm{~mL}$ conc. $\mathrm{HNO}_{3}$ and dilute to volume with delonized water. Prepare monthly.

3. Working $\mathrm{Hg}$ standard - $0.1 \mu \mathrm{g} / \mathrm{mL}$ - pipet $1.0 \mathrm{~mL}$ intermediate $\mathrm{Hg}$ standard into a $100 \mathrm{~mL}$ volumetric flask, add $1 \mathrm{~mL}$ conc. $\mathrm{HNO}_{3}$ and dilute to volume with delonized water. Prepare dally. 
EHS $M-4-4$

\section{Procedure}

A. Sample Collection - colleat in glass bottles that have been rinsed with $1: 1 \mathrm{HNO}_{3}$ and delonized water.

B. Analysis

1. Preserve all samples by adding $19 \mathrm{~K}_{2} \mathrm{~S}_{2} \mathrm{O}_{8} / \mathrm{L}$ or by acidifying to $\mathrm{pH} 2$ or less with $\mathrm{HNO}_{3}$ immediately after collection. Samples stable for 2 weeks if refrigerated.

2. Rinse all glassware with 1:1 $\mathrm{HNO}_{3}$, and defonized water prior to use.

3. Check $\mathrm{Mg}\left(\mathrm{ClO}_{4}\right)_{2}$ drying tube and ref 111 if caked or wet.

4. Fill covered water bath and heat to $90-95^{\circ} \mathrm{C}$.

5. Prepare standards by pipetting $0,0.5,1.0,3.0$, and $5.0 \mathrm{~mL}$ of 0.1 $\mathrm{mg} / \mathrm{mL} \mathrm{Hg}$ standard into a series of BOD flasks. Add enough deionized water to each to give a total volume of $75 \mathrm{~mL}$. Prepare duplicates of all standards.

6. Transfer a $75 \mathrm{~mL}$ allquot of sample or a smaller amount dfluted to 75 $\mathrm{mL}$ :ifth defonized water to another BOD flask. Run every 10th sample in duplicate. Spike one sample with $1.0 \mathrm{~mL}$ of $0.1 \mu \mathrm{g} / \mathrm{mL} \mathrm{Hg}$ standard.

7. Add $5 \mathrm{~mL}$ conc. $\mathrm{H}_{2} \mathrm{SO}_{4}$ and $2.5 \mathrm{~mL}$ conc. $\mathrm{HNO}_{3}$ to each flask.

8. Add $15 \mathrm{~mL} \mathrm{KMnO}_{4}$ solution to each sample and standard and allow to stand until the purple color persists for at least 15 minutes. Add more $\mathrm{KMnO}_{4}$ if necessary.

9. Add $8 \mathrm{~mL}$ persulfate solution to each flask, stopper, and heat for two hours in the water bath at $90-95^{\circ} \mathrm{C}$. Record bath temperature on analyst worksheet.

10. Cool the flask and add $6 \mathrm{~mL}$ sodium chloride-hydroxylamine hydrochloride solution to each. Swirl unt1l the $\mathrm{KMnO}_{4}$ color is completely removed giving a colorless solution with no black precipitate.

11. Set up the spectrophotometer and measure the absorbance of each solution as follows:

a. Mount the absorption cell on top of the atomic absorption burner. Use the following instrument parameters (P.E. 306).

wavelength $-253.7 \mathrm{~nm}$

Silt $-4\left(7 A^{\circ}\right)$

mode - absorbance with background correction 
ENS $M-4-5$

b. Connect the reduction apparatus, minus reduction flask, to the cell. Adjust vacuum to give an air flow of $0.5 \mathrm{Lpm}(10 \mathrm{on}$ rotameter).

c.. Place $3 \mathrm{~mL} \mathrm{SnCL} 2$ reducing solution in funnel reservoir.

d. Transfer sample or standard to reduction flask under reservoir. Add $\mathrm{SnCl}_{2}$ and immediately connect flask to reduction apparahus, thus sweeping $\mathrm{Hg}$ into absorption cell.

e. Record absorbance at peak and disconnect flask.

12. Repeat steps $c$ - e for remaining samples and standards making all measurements in the same reduction flask. Run entire standard curve at the beginning and at the end of the analysis.

Calculations

Plot average absorbance vs $\mathrm{ug} \mathrm{Hg}$ present in standards. Use this calibreion curve to determine $\mu \mathrm{g} \mathrm{Hg}$ present in the sample aliquots.

$\mu \mathrm{g} / \mathrm{L} \mathrm{Hg}=\mu \mathrm{g}$ found $\times 1000$

mL sample

Accuracy: $93.4 \%$ recovery

Precision: $0.0006 \mathrm{mg} / \mathrm{L}$ 
Nethod No.

EHS C-2-1

Title:

Hexavalent Chromiun - Hater and Air

Date Issued: 2-73

Approved by: MK Hamilton y H

Written by: MK Hawilton

Supersedes Method No.

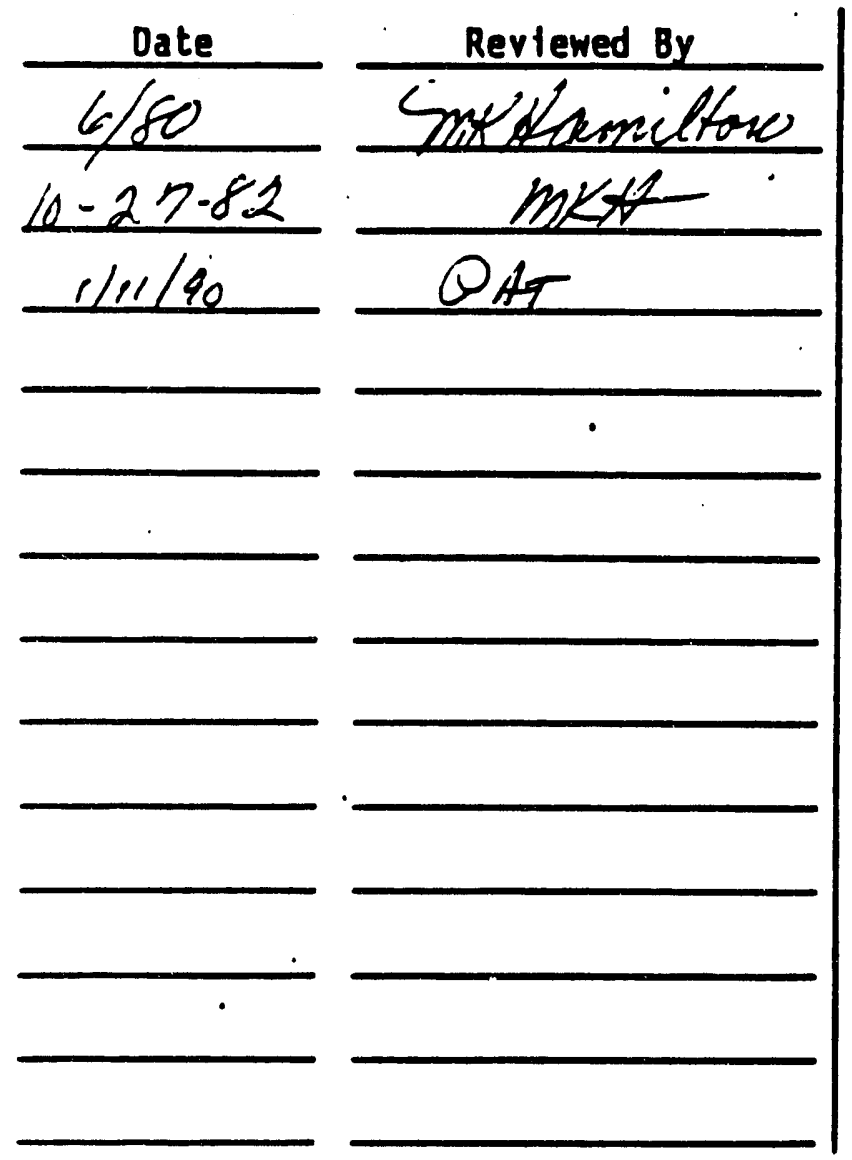

Replaced by Method No.

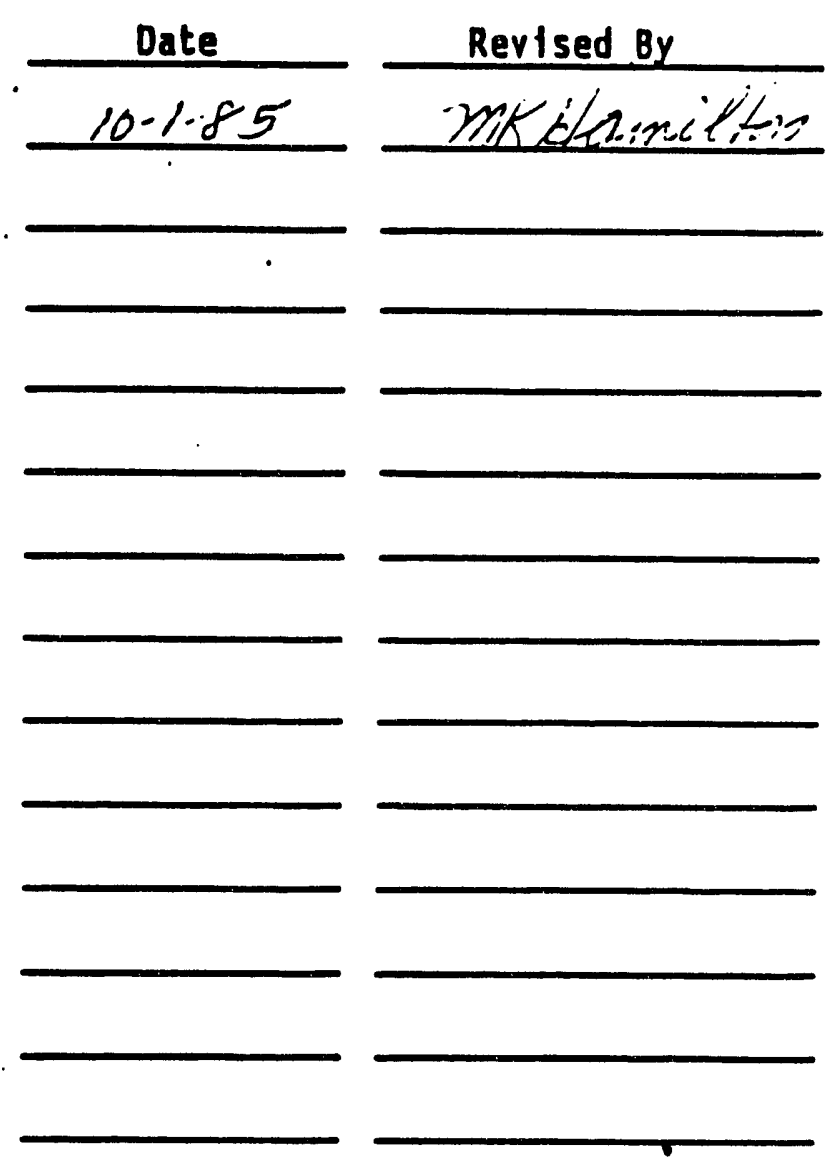

Date: 


\section{HEXAVALENT CHROMIUM - WATER AND AIR}

\section{References}

1. Standard Methods for the Examination of Water and Wastewater, 16th Ed., 1985, pp. 201-204.

2. NIOSH Manual of Analytical Methods, 3rd Ed., Method 7600, 1984.

Principle

Hexavalent chromium reacts with diphenylcarbazide in acidic solutions to produce a reddish-purple color with maximum absorbance at $540 \mathrm{~nm}$.

Limitations

This method is intended for use with potable water samples or personal air samples collected from an occupational environment. Mercury, iron, copper, molybdenum, nickel, and vanadium interfere with the color development but not. in the concentrations normally found in these types of samples. Water samples should be analyzed within 24 hours of collection. For waste samples or other water samples that may have high concentrations of interfering metals, refer to Reference 1 for pretreatment procedures.

Equipment

1. Spectrophotometer for use at $540 \mathrm{~nm}$ with $1.0 \mathrm{~cm}$ sipper cell.

2. $50 \mathrm{~mL}$ graduated cylinders with ground glass stoppers.

3. $50 \mathrm{~mL}$ side arm test tubes.

4. $37 \mathrm{~mm}$ Buchner funne 1 .

5. Personal sampling pumps.

6. Styrene cassettes.

7. PVC filters and cellulose backup pads.

8. Screw cap vials.

9. $\mathrm{pH}$ meter.

10. $100 \mathrm{~mL}$ beakers.

11. Hotplate

12. Water glasses

Reagents (stock)

1. Acetone.

2. 1,5-diphenylcarbazide 
3. Sulfurtc acid, conc. $\mathrm{H}_{2} \mathrm{SO}_{4}$.

4. Potassium dichromate, $\mathrm{K}_{2} \mathrm{Cr}_{2} \mathrm{O}_{7}$.

5. Sodium hydroxide, $\mathrm{NaOH}$

6. Sodium carbonate, $\mathrm{Na}_{2} \mathrm{CO}_{3}$

7. High purity nitrogen

Reagents (prepared):

A. Water Analysis

1. Dilute $\mathrm{H}_{2} \mathrm{SO}_{4}$ solution $(0.2 \mathrm{~N})-$ slowly add $2.8 \mathrm{~mL}$ conc. $\mathrm{H}_{2} \mathrm{SO}_{4}$ to defonized $\mathrm{H}_{2} \mathrm{O}$ and dilute to $500 \mathrm{~mL}$. Prepare annually.

2. Diphenylcarbohydrazide reagent - dissolve $250 \mathrm{mg}$ 1,5-diphenylcarbazide in $50 \mathrm{~mL}$ acetone. Reagent stable for one month if stored in brown bottle and refrigerated. (Discard if solution becomes discolored.)

B. Air Analysis

1. $0.25 \mathrm{M} \mathrm{H}_{2} \mathrm{SO}_{4}$.. add $14 \mathrm{~mL}$ conc. $\mathrm{H}_{2} \mathrm{SO}_{4}$ to about $500 \mathrm{~mL}$ deionized $\mathrm{H}_{2} \mathrm{O}$ and dilute to 1 liter with delonized $\mathrm{H}_{2} \mathrm{O}$. Prepare every 6 months.

2. $6 \mathrm{~N} \mathrm{H}_{2} \mathrm{SO}_{4}$ - slowly add 84 mL of conc. $\mathrm{H}_{2} \mathrm{SO}_{4}$ to deionized $\mathrm{H}_{2} \mathrm{O}$, coOl and dilute to $500 \mathrm{~mL}$. Prepare annually.

3. Diphenylcarbazide reagent - dissolve $0.25 \mathrm{~g} 1,5$-diphenylcarbazide in $50 \mathrm{~mL}$ acetone plus $50 \mathrm{~mL}$ deionized $\mathrm{H}_{2} \mathrm{O}$. Store in amber bottle in refrigerator. Prepare monthly.

4. Filter extract solution - Dissolve $5 \mathrm{~g} \mathrm{NaOH}$ plus $7.5 \mathrm{~g} \mathrm{Na}_{2} \mathrm{CO}_{3}$ in deionized $\mathrm{H}_{2} \mathrm{O}$ and dilute to $250 \mathrm{~mL}$. Prepare every 6 months.

Standards

1. Stock chromium solution - dissolve $2.828 \mathrm{~g}$ dried anhydrous $\mathrm{K}_{2} \mathrm{Cr}_{2} \mathrm{O}_{7}$ in deionized $\mathrm{H}_{2} \mathrm{O}$ and dilute to one liter. $1.0 \mathrm{~mL}=1000 \mu \mathrm{g} \mathrm{Cr}+6$. Prepare every 6 months.

2. Intermediate chromium solution - dilute $5.0 \mathrm{~mL}$ of stock chromium solution $(1000 \mathrm{\mu g} / \mathrm{mL})$ to $100 \mathrm{~mL}$ with deionized $\mathrm{H}_{2} \mathrm{O} .1 .0 \mathrm{~mL}=50 \mathrm{~kg} \mathrm{Cr}+6$. Prepare monthly.

3. Standard chromium solution - dilute $2.0 \mathrm{~mL}$ of intermediate chromium solution $(50 \mu \mathrm{g} / \mathrm{mL})$ to $100 \mathrm{~mL}$ with deionized $\mathrm{H}_{2} 0.1 .0 \mathrm{~mL}=1.0 \mu \mathrm{g}$ $\mathrm{Cr}+6$. Prepare daily. 


\section{Procedure}

A. Sample Collection

1. Water - collect the sample in a glass or plastic container that has been precleaned with $\mathrm{HNO}_{3}$, and deionized $\mathrm{H}_{2} \mathrm{O}$. Refrigerate and analyze within $24 \mathrm{hr}$.

2. Air - lising a personal sampling pump precalibrated at 1-2 Lpm, pull air through a $37 \mathrm{~mm}$ cassette containing a PVC $(5 \mu)$ filter with cellulose backup pad. Sample for at least 30 min. Within $1 \mathrm{hr}$ transfer the filter and backup pad to a clean screw cap vial. Analyze within 2 weeks.

\section{B. Water Analysis}

1. Using $50 \mathrm{~mL}$ graduated cyclinders with ground glass stoppers and the standard $\mathrm{Cr}+6$ solution $(1 \mu \mathrm{g} / \mathrm{mL})$, prepare standards containing 0 , $0.5,1.0,2.0,3.0,4.0$, and $5.0 \mu \mathrm{g} \mathrm{Cr}+6$ in $40 \mathrm{~mL}$ deionized $\mathrm{H}_{2} \mathrm{O}$.

2. Transfer a $40 \mathrm{~mL}$ aliquot of sample to a graduated cylinder. (Filter or centrifuge samples if necessary to remove turbidity.)

3. Use $0.2 \mathrm{~N} \mathrm{H}_{2} \mathrm{SO}_{4}$ to adjust the $\mathrm{pH}$ of each sample and standard to $1.0 \pm 0.3$. Dilute to $50 \mathrm{~mL}$ with deionized $\mathrm{H}_{2} \mathrm{O}$ and mix.

4. Add $1.0 \mathrm{~mL}$ water analysis diphenylcarbazide reagent to each sample and standard and mix.

5. Let stand five minutes but no more than 15 minutes.

6. Measure absorbance at $540 \mathrm{~nm}$ using a $1.0 \mathrm{~cm}$ sipper cell.

C. Air Analysis - Soluble Chromates and Chromic Acid

1. Calibrate the $50 \mathrm{~mL}$ side arm test tubes by pipetting $20.0 \mathrm{~mL}$ deionized $\mathrm{H}_{2} \mathrm{O}$ into each and marking the bottom of the miniscus. Empty and dry the tubes.

2. Remove the sample filter from the screw cap vial and place it in the Buchner funnel set up as shown. Cover the filter with $5 \mathrm{~mL} 0.25 \mathrm{M}$ $\mathrm{H}_{2} \mathrm{SO}_{4}$ and let stand for $5 \mathrm{~min}$.

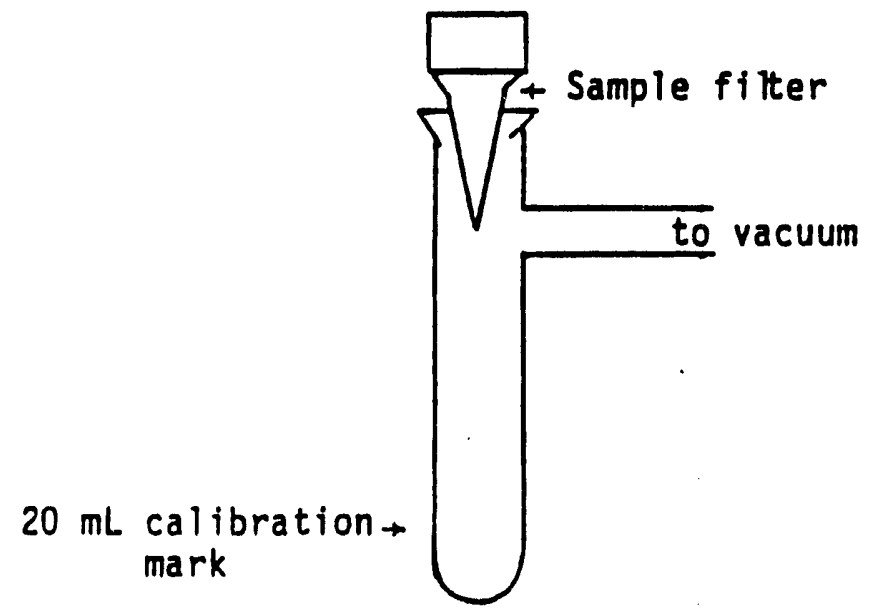


3. Using the vacuum, pull the $\mathrm{H}_{2} \mathrm{SO}_{4}$ through the filter into the tube. Rinse the filter and vial twice with small amounts of $0.25 \mathrm{M}$ $\mathrm{H}_{2} \mathrm{SO}_{4}$ and adjust the sample volume to the $20 \mathrm{~mL}$ mark with additional $\mathrm{H}_{2} \mathrm{SO}_{4}$ as needed.

4. Prepare a spike by pipetting $20 \mu \mathrm{L}$ of the $50 \mu \mathrm{g} / \mathrm{mL} \quad \mathrm{Cr}+6$ standard onto a PVC filter place in a Buchner funnel. Proceed as in Steps 2 and 3.

5. Prepare standards by pipetting 10, 20, 50, 100, and $200 \mu \mathrm{L}$ of the $50 \mathrm{\mu g} / \mathrm{mL} \mathrm{Cr}+6$ standard into calibrated tubes and diluting to the $20 \mathrm{~mL}$ mark with $0.25 \mathrm{M} \mathrm{H}_{2} \mathrm{SO}_{4}$. This gives standards containing $0.5,1.0,2.5,5$, and $10 \mathrm{ug} \mathrm{Cr}^{+6}$.

6. Add $0.5 \mathrm{~mL}$ air analysis diphenylcarbazide reagent to each sample and standard and $m 1 x$.

7. Within 5-15 min measure the absorbance at $540 \mathrm{~nm}$ using $1 \mathrm{~cm}$ sipper cell.

D. Air Analysis - insoluble chromates and all $\mathrm{Cr}_{\mathrm{r}}+6$ in the presence of iron or other reducing agents.

1. Calibrate the $50 \mathrm{~mL}$ side arm test tubes as for soluble chromate analysis (Section C.1).

2. Remove the sample filter from the screw cap vial and place it in a $100 \mathrm{~mL}$ beaker.

3. Rinse the vial with $5 \mathrm{~mL}$ of filter extract solution and add this to the beaker.

4. Prepare a spike by pipetting $20 \mu \mathrm{L}$ of the $50 \mu \mathrm{g} / \mathrm{mL} \mathrm{Cr}+6$ standard onto a PVC filter placed in a $100 \mathrm{~mL}$ beaker. Add $5 \mathrm{~mL}$ of filter extract solution and proceed as with the samples.

5. Purge the head space above the solutions with nitrogen and repeat the purge 2-3 times during the extraction.

6. Cover the beakers with watchglasses and heat to near boiling on a hot plate. Continue heating, with occasional swirling and purging, for 30-45 minutes. DO NOT, al low the solution to evaporate to dryness as $\mathrm{Cr}^{+6}$ may be iost. A brown colored PVC filter is an indication of such loss.

7. Cool the solutions and filter through a $5 \mu$ PVC filter using a Buchner funnel and precalibrated $50 \mathrm{~mL}$ side arm test tube. Rinse the filter and beaker with deionized $\mathrm{H}_{2} \mathrm{O}$, keeping the final volume below $18 \mathrm{~mL}$.

8. Add $1.9 \mathrm{~mL}$ of $6 \mathrm{~N} \mathrm{H}_{2} \mathrm{SO}_{4}$ to each sample and swirl carefully to mix. Let the samples sit for several minutes, unt 11 the vigorous gas evolution ceases. Occasional swirling will help speed up the gas removal. 
ENS $6-2-5$

9. When gas evolution ceases dilute the solution volumes to $20 \mathrm{~mL}$.

10. Prepare standards and proceed with color development as for soluble chromates (Section C, Steps 5-7).

Calculation

1. Plot $\mu g / \mathrm{Cr}+6$ vs absorbance.

2. Determine $\mu g / C_{r}+6$ in the sample from the calibration curve.

3. Calculate air or water concentrations as follows:

Air $\quad \mathrm{mg} / \mathrm{m}^{3} \mathrm{Cr}+{ }^{6}=\frac{\mu \mathrm{gr}+^{6}}{\mathrm{air} \text {. }}$

Water $\quad \mathrm{mg} / \mathrm{LCr}^{6}=\frac{\mathrm{gg} \mathrm{Cr}+{ }^{6}}{40 \mathrm{~mL}_{2} \mathrm{H}^{\mathrm{O}}}$ 
Hethod No. EHS C-3

Title: Cyanide - Colorimetric Nater \& Air

Date 1s sued: Before 2-17-83

Approved by: MK Hamilton pakt

Writiten by: MK Hamiliton

Supersedes Method No.

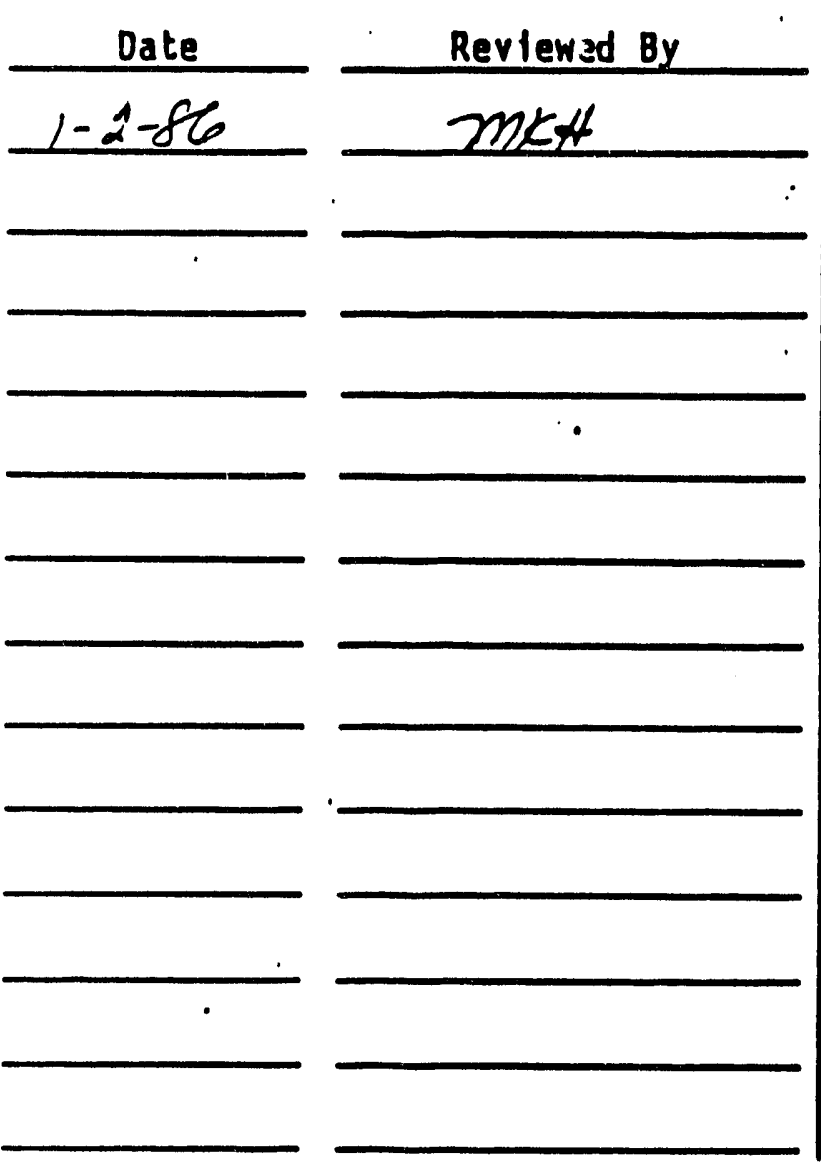

- Replaced by Method Ho.

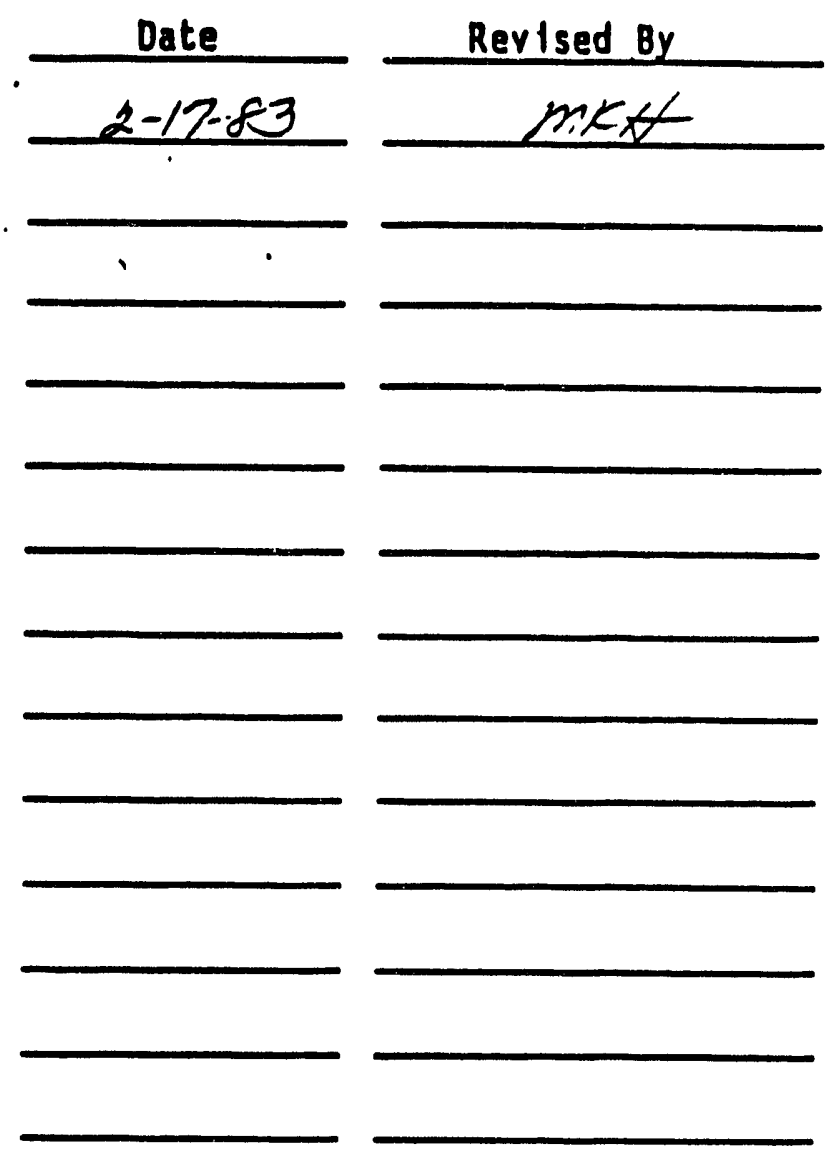

Date: 
EHS C-3-1

\section{CYANIDE - COLORIME TRIC - WATER \& AIR}

\section{Reference}

1. Manual of Methods for Chemical Analys is of Water \& Wastes, EPA-600-14-79-020 U.S. Environmental Protection Agency, 1979, Method 335.1 .

2. Analytical Chemistry, Vol. 44, No. 11, 1972, pp. 1845-46, "Determination of Nanogram Quantities of Simple \& Complex Cyanides in water," P. O. Goulden, et. al.

3. NIOSH Manual of Analytical Methods, 2nd Ed., Vol. 3, S250, 1977.

Principle

Cyanides in the aqueous solution are converted to hydrogen cyanide by distillation with acid and are absorbed in $\mathrm{NaOH}$ solution. Air samples are collected on membrane filters (particulate) plus $0.1 \mathrm{~N} \mathrm{NaOH}$ absorbing solution ( $\mathrm{HCN})$. The $\mathrm{CN}^{-}$in the distillate, absorbing solution or desorbed filter is converted to cyanogen chloride, CNCl, by reacting with chloramine-T at a $\mathrm{pH}$ less than eight. CNCl forms a colored dye on addition of pyridinebarbituric acid, the absorbance of which is measured at $578 \mathrm{~nm}$.

Limitations

Because most cyanides are highly reactive and unstable, water samples should be made alkaline immediately after collection by adding $4 \mathrm{~mL}$ of $6 \mathrm{~N}$ $\mathrm{NaOH}$ per Liter. The cyanide analys is should be performed within 24 hours of collection. Preliminary treatment may be necessary to remove interferences from sulfides and oxidizing agents. The distillation is important not only for removing interferences from varying salt concentrations, but also for converting any complex cyanides to simple $\mathrm{CN}^{-}$.

- Only the cobalticyanide complex is not converted by this procedure. Filters from air sampling should be desorbed as soon as possible after sampling. Samples should be analyzed within 2 hours of desorption.

\section{Equipment}

1. Distillation apparatus shown on next. page or equivalent (aqueous) 


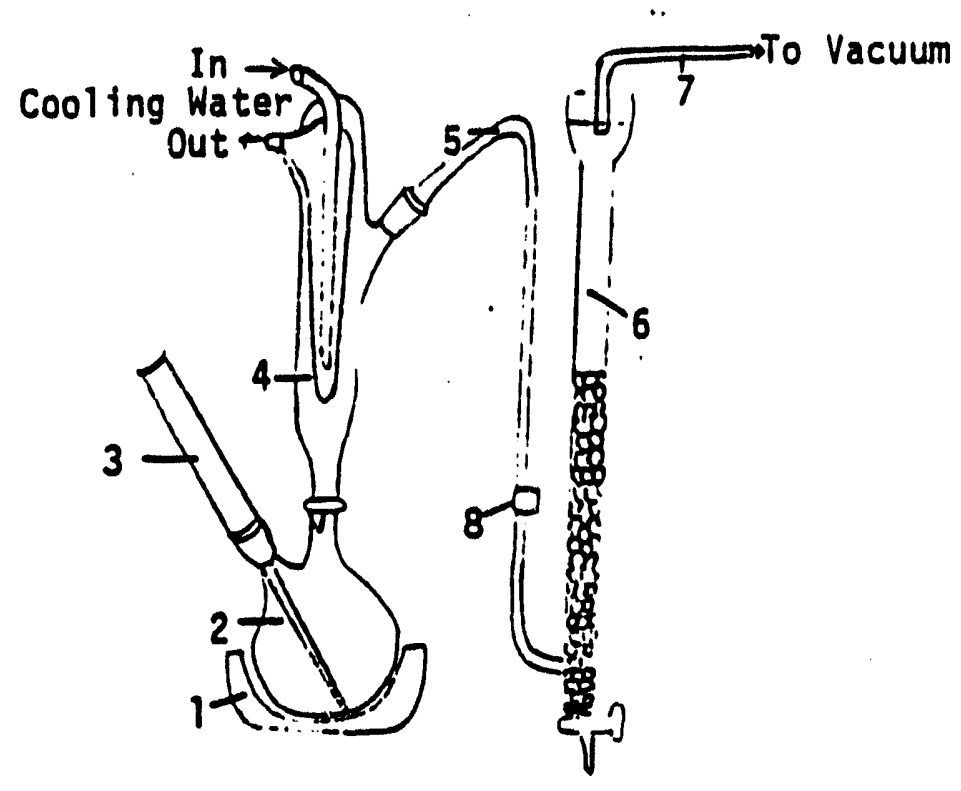

\section{Cyanide Dist 11 latian Apparatus}

1. Electric heating mantle

2. l-Liter, two neck distilling flask

3. Inlet tube tapered to $8 \mathrm{~mm} \mathrm{f.d.} \mathrm{at} \mathrm{lower} \mathrm{end}$

4. Friedrichs condensor

5. Glass connecting tube

6. Scrubber $-50 \mathrm{ml}$ buret with side arm at bottom and overflow bulb at top. Partially filled with glass beads.

7. Rubber stopper with glass tube for connecting system to hood vacuum.

8. Tygon tubing to attach connecting tube to buret side arm.

2. Spectrophotometer for use at $578 \mathrm{~nm}$ with $1.0 .0 \mathrm{r} 4.0 \mathrm{~cm}$ cell $\mathrm{s}$

3. $250 \mathrm{ml}$ volumetric flasks (aqueous) 
4. $100 \mathrm{~mL}$ volumetric flasks

5. Whatman $\$ 41$ filter paper (aqueous)

6. Long-stemmed funnels (aqueous)

7. GF/A glass fiber fllter paper (aqueous)

8. Personal sampling pumps (air)

9. Styrene cassettes (air)

10. Midget impingers (air)

11. $0.8 \mu$ cellulose acetate filters and cellulose backup pads (air)

12. Large test tubes (air)

\section{Reagents (Stock)}

1. Starch

2. Potassium lodide, KI

3. Lead acetate, $\mathrm{Pb}\left(\mathrm{C}_{2} \mathrm{H}_{3} \mathrm{O}_{2}\right)_{2} \cdot 3 \mathrm{H}_{2} \mathrm{O}$

4. Lead carbonate, $\mathrm{PbCO}_{3}$

5. Ascorbic acid

6. Sodium hydroxide, $\mathrm{NaOH}$

7. Cuprous chloride, $\mathrm{Cu}_{2} \mathrm{Cl}_{2}$

8. Sulfuric acid, con. $\mathrm{H}_{2} \mathrm{SO}_{4}$

9. Hydrochloric acid, conc., $\mathrm{HCl}$

10. Sodium dihydrogen phosphate, $\mathrm{NaH}_{2} \mathrm{PO}_{4} \cdot \mathrm{H}_{2} \mathrm{O}$

11. Potassium cyanide, KCN

12. Potassium hydroxide, $\mathrm{KOH}$

13. Chloramine-T

14. Pyridine 
15. Barbituric acid

16. Silver nitrate, $\mathrm{AgNO}_{3}$

17. Paradimethy 1 aminobenzalrhodanine $[5-(p-D$ imethy 1 amino benzylidene) rhodamine]

18. Acetone

\section{Reagents (Prepared)}

\section{A. Water Analysis}

1. Starch-iodide paper - Stir $5 \mathrm{~g}$ of starch into $100 \mathrm{~mL}$ of deion1zed $\mathrm{H}_{2} \mathrm{O}$, boll and add $0.5 \mathrm{~g} \mathrm{KI}$. Impregnate strips of Whatman $\$ 41$ filter paper with this solution, dry and store in glass bottle.

2. Lead acetate paper - Prepare a saturated solution of lead acetate in defonized $\mathrm{H}_{2} \mathrm{O}\left(-45 \mathrm{~g} \mathrm{~Pb}\left(\mathrm{C}_{2} \mathrm{H}_{3} \mathrm{O}_{2}\right)_{2}\right.$.

$\left.3 \mathrm{H}_{2} \mathrm{O} / 100 \mathrm{ml}\right)$. Impregnate strips of Whatman $\# 41$ filter paper with this solution, dry and store in glass bottle.

3. I $\mathrm{N} \mathrm{NaOH}$ - Oissolve $40.0 \mathrm{~g} \mathrm{NaOH}$ in defonized $\mathrm{H}_{2} \mathrm{O}$ and dilute to 1 Liter. Prepare annually.

4. Cuprous chloride reagent - Weight $20 \mathrm{~g} \mathrm{Cu}_{2} \mathrm{Cl}_{2}$ into an $800 \mathrm{~mL}$ beaker. Wash twice, by decantation, with $250 \mathrm{~mL}$ portions of dilute $(1+49) \mathrm{H}_{2} \mathrm{SO}_{4}$ and twice with deionized $\mathrm{H}_{2} \mathrm{O}$. Add about $250 \mathrm{~mL}$ deionized $\mathrm{H}_{2} \mathrm{O}$, followed by small additions of conc. $\mathrm{HCl}$ until the $\mathrm{Cu}_{2} \mathrm{Cl}_{2}$ dissolves. (At this point the solution should be clear and pale green. Brown or dark discoloration indicates presence of cupric salts and solution must be discarded.) Dilute to 1 Liter with deionized $\mathrm{H}_{2} \mathrm{O}$ adding conc. $\mathrm{HCl}$ as needed to keep the $\mathrm{Cu}_{2} \mathrm{Cl}_{2}$ in solution. Store in a tightly stoppered bottle containing a few lengths of pure copper wire extending from the bottom to the mouth of the bottle. Prepare fresh when solution darkens.

\section{B. Air or Water Analysis}

1. Sodium dihydrogen phosphate (IM) - Dissolve $13.8 \mathrm{~g} \mathrm{NaH}_{2} \mathrm{PO}_{4}$ - $\mathrm{H}_{2} \mathrm{O}$ in deionized water and dilute to $100 \mathrm{~mL}$. Store in refrigerator. Prepare every 6 months.

2. Chloramine-T solution - Dissolve $1.0 \mathrm{~g}$ chloramine-T in deionized $\mathrm{H}_{2} \mathrm{O}$ and dilute to $100 \mathrm{~mL}$. Store in refrigerator. Prepare weekly.

3. Pyridine-barbituric acid reagent - Place $15 \mathrm{~g}$ barbituric acid in a $250 \mathrm{~mL}$ volumetric $\mathrm{flask}$ and add just enough deionized $\mathrm{H}_{2} \mathrm{O}$ to wash down the sides of the flask and wet the barbituric acid. 
Add $75 \mathrm{~mL}$ pyridine, mix, add $15 \mathrm{~mL}$ conc. HC.7, mix until dissolved, cool and dilute to volume with deionized $\mathrm{H}_{2} \mathrm{O}$. (Dissolution complete only after adding $\mathrm{H}_{2} \mathrm{O}$ ). Store in dark. Prepare weekly.

4. $\mathrm{CN}$ - Rhodanine indicator - dissolve $0.02 \mathrm{~g}$ paradimethylaminobenzal-rhodanine in acetone and dilute to $100 \mathrm{~mL}$. Prepare annually.

C. Air Analysis

1. $0.1 \mathrm{~N} \mathrm{NaOH}$ - Dissolve $4.0 \mathrm{~g} \mathrm{NaOH}$ in defonized $\mathrm{H}_{2} \mathrm{O}$ and dilute to 1 Liter. Prepare annually.

Standards

1. Standard $\mathrm{AgNO}_{3}(0.0141 \mathrm{~N})$ - Dissolve $2.395 \mathrm{~g} \mathrm{AgNO}_{3}$ in deionized $\mathrm{H}_{2} \mathrm{O}$ and dilute to 1 Liter. Store in brown bottle. Standardize monthly against standard $\mathrm{NaCl}$ as in EHS C-5.

2. Stock cyanide solution - Dissolve $2.51 \mathrm{~g} \mathrm{KCN}$ and $2 \mathrm{~g} \mathrm{KOH}$ in deionized $\mathrm{H}_{2} \mathrm{O}$, dilute to $\mathrm{I}$ Liter and standardize as follows:

Pipet $10.0 \mathrm{~mL}$ of $\mathrm{KCN}$ solution into a $250 \mathrm{~mL}$ conical beaker. Add $100 \mathrm{~mL}$ deionized $\mathrm{H}_{2} \mathrm{O}$ and adjust $\mathrm{pH}$ to 11 or above with $1 \mathrm{~N}$ $\mathrm{NaOH}$. Add $0.5 \mathrm{~mL} \mathrm{CN}$ indicator and titrate with standarized $\mathrm{AgNO}_{3}$ solution to first color change from canary yellow to a salmon hue. Also titrate a reagent blank.

$$
\begin{aligned}
& \mathrm{Ag}^{+}+2 \mathrm{CN} \rightarrow \mathrm{Ag}(\mathrm{CN})_{2}^{-}
\end{aligned}
$$

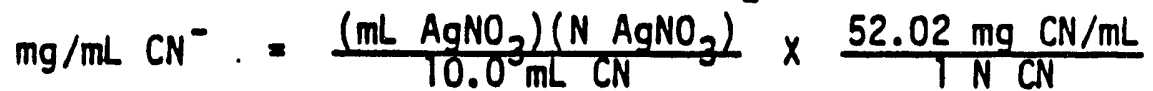

$$
\begin{aligned}
& =(\mathrm{mL} \mathrm{AgNO} 3)\left(\mathrm{N} \mathrm{AgNo}_{3}\right) \times 5.202
\end{aligned}
$$

Stock $\mathrm{CN}^{-}$solution must be restandardized weekly.

2. Intermediate cyanide solution - Dilute $5.0 \mathrm{~mL}$ of stock cyanide solution (or the amount necessary to contain $5000 \mathrm{\mu g} \mathrm{CN}-$ ) to $100 \mathrm{~mL}$ with deionized $\mathrm{H}_{2} \mathrm{O} .1 \mathrm{~mL}=50 \mathrm{\mu g} \mathrm{CN}-$. Prepare fresh daily.

3. Working cyanide solution - Dilute $2.0 \mathrm{~mL}$ of intermediate cyanide solution to $100 \mathrm{~mL}$ with defonized $\mathrm{H}_{2} \mathrm{O}$. $1 \mathrm{~mL}=1 \mu \mathrm{g} \mathrm{CN}-$.

Prepare fresh dafly. 
Procedure

A. Water Analysis

\section{Collection}

1. Collect the sample in glass or plastic containers.

2. Add $4 \mathrm{~mL}$ of $6 \mathrm{~N} \mathrm{NaOH}$ per Liter of sample and refrigerate. Analyze within 24 hours.

II. Pretreatment and Distillation

Carry an alkaline $\mathrm{CN}$ standard $(-0.02 \mathrm{mg} / \mathrm{L})$ through the entire procedure to determine recovery.

1. Sulfide removal - place a drop of sample on a strip of lead acetate test paper. If the test is negative (no darkening), skip to Step 2 for oxidizing agent renoval. If the test is positive (dark color), add small increments of $\mathrm{PbCO}_{3}$ to $502 \mathrm{~mL}$ of the alkaline sample. Repeat until no more blank $\mathrm{PbS}$ forms. Avoid excess $\mathrm{PbCO}_{3}$ or long period of contact. Filter through GF/A filter paper into a 1-Liter two neck distllling flask, rinse precipitate with $10 \mathrm{~mL}$ defonized $\mathrm{H}_{2} \mathrm{O}$ and add washings to the filtrate.

2. Oxidizing agent removal - check the filtrate from sulfide removal with starch-iodide paper. If test is positive (blue-black color), add ascorbic acid crystals until a negative test (no color) is obtained. Add an additional $0.3 \mathrm{~g}$ ascorbic acid to each sample.

3. Set up distillation apparatus in a well ventilated hood.

4. Add $30 \mathrm{~mL}$ of $1 \mathrm{~N} \mathrm{NaOH}$ to the $50 \mathrm{~mL}$ buret scrubber.

5. Connect the flask containing the sample $(502 \mathrm{~mL})$ to the distillation apparatus and adjut the vacuum so that air enters at a rate of about 2-3 bubbles per second. (This should be fast enough to prevent sample backup in the delivery tube.).

6. Slowly add $25 \mathrm{~mL}$ conc. $\mathrm{H}_{2} \mathrm{SO}_{4}$ through the air inlet tube, rinse the tube with deionized $\mathrm{H}_{2} \mathrm{O}$ and allow airflow to $\mathrm{mix}$ the flask contents for 3 minutes.

7. Add $10 \mathrm{~mL} \mathrm{Cu} \mathrm{Cl}_{2}$ reagent through the air inlet tube and again rinse with deionized $\mathrm{H}_{2} \mathrm{O}$.

8. Heat to rapid bolling but do not flood the condensor. Watch the air flow rate closely as the solution begins to boll and adjust it if necessary to prevent sample backup in the inlet tube. Reflux for one hour, then turn off heat but continue air flow for 15 minutes. 
9. Transfer the $1 \mathrm{~N} \mathrm{NaOH}$ scrubber solution to a $250 \mathrm{~mL}$ volumetric fiask. Rinse the buret and the connecting tube from condensor to buret and add the rinsings to the volumetric flask. Oilute to $250 \mathrm{~mL}$ with deionized $\mathrm{H}_{2} \mathrm{O}$.

If stable complex cyanides are present, repeat the distillation.

\section{Colorimetric Determination}

1. Prepare a series of standards by pipeting $0,0.5,1.0,3.0$, and $5.0 \mathrm{~mL}$ of the $1 \mathrm{\mu g} / \mathrm{mL} \mathrm{CN}$ - standard into $100 \mathrm{~mL}$ volumetric flasks. Add $6 \mathrm{~mL}$ of $1 \mathrm{~N} \mathrm{NaOH}$ to each flask plus enough deionized $\mathrm{H}_{2} \mathrm{O}$ to give $50 \mathrm{~mL}$ of solution. This gives standards containing $0.0 .5,1.0,3.0$, and $5.0 \mathrm{~g} \mathrm{CN}$.

2. Pipet a $50 \mathrm{~mL}$ aliquot of sample distillate into a $100 \mathrm{~mL}$ volumetric flask.

3. To each sample and standard add $15 \mathrm{~mL} \mathrm{NaH} \mathrm{PO}_{4}$ solution and $2.0 \mathrm{~mL}$ chloramine-T and $\mathrm{mix}$.

4. Immediately add $5.0 \mathrm{~mL}$ pyridine-barbituric acid reagent, mix, dilute to volume with deionized $\mathrm{H}_{2} \mathrm{O}$ and mix again.

5. After 8 minutes, but before 15 minutes, measure the absorbance of the solution at $578 \mathrm{~nm}$ using 1.0 or $4.0 \mathrm{~cm}$ cells and detonized $\mathrm{H}_{2} \mathrm{O}$ as reference.

\section{B. Air Analysis}

I. Collection

1. Using a personal sampling pump precalibrated at $0.5-1 \mathrm{Lpm}$ pull air through a sampling train consisting of a $37 \mathrm{~mm}$ cassette containing an 0.8 cellulose acetate filter followed by a midget impinger containing $15 \mathrm{~mL}$ of $0.1 \mathrm{~N}$ $\mathrm{NaOH}$. Sample for at least 30 minutes.

2. Place the membrane filter in a small jar or tube and desorb with $25 \mathrm{~mL}$ of $0.1 \mathrm{~N} \mathrm{NaOH}$. Stir occasionally for 30 minutes to complete the dissolution. Analyze the solution within 2 hours.

3. Prepare Blank and spiked filters and desorb in a similar manner.

11. Colorimetric determination.

1. Pipet $5.0 \mathrm{~mL}$ of absorbing solution from each desorbed filter and impinger into a large test tube. 
2. Prepare a series of standards by pipetting $0,50,100,300$ \& $500 \mu \mathrm{L}$ of the $1 \mu \mathrm{g} / \mathrm{mL} \mathrm{CN}$ standard into 1arge test tubes and diluting to $5.0 \mathrm{~mL}$ with $0.1 \mathrm{~N} \mathrm{NaOH}$. This gives standards containing $0,0.05,0.1,0.3$, and $0.5 \mathrm{~g} \mathrm{CN}$.

3. To each sample and standard add $1.5 \mathrm{~mL} \mathrm{NaH}_{2} \mathrm{PO}_{4}$ solution and $0.2 \mathrm{~mL}$ chloramine - $T$ and $\mathrm{mix}$.

4. Immediately add $0.5 \mathrm{~mL}$ pyridine-barbituric acid reagent and mix.

5. Add $2.8 \mathrm{~mL}$ deionized $\mathrm{H}_{2} \mathrm{O}$ and mix again.

6. After 8 minutes but before 15 minutes measure the absorbence of the samples and standards at $578 \mathrm{~nm}$ using 1.0 or $4.0 \mathrm{~cm}$ cells and deionized $\mathrm{H}_{2} \mathrm{O}$ as reference.

Calculation:

A. Water

1. Plot $\mu \mathrm{g} \mathrm{CN-}$ present in the $50 \mathrm{~mL}$ al iquot vs. absorbance.

2. Determine $\mu \mathrm{g} \mathrm{CN-}$ present in the sample aliquots from the above curve.

$\mathrm{mg} / \mathrm{CN}^{-}=\frac{\text { aliquot } \mu \mathrm{g} \mathrm{CN}-\frac{250 \mathrm{~mL}}{50 \mathrm{~mL}}}{500 \mathrm{~mL}}$

- al iquot $\mu \mathrm{g} \mathrm{CN} / 100$

Use the standard carried through the distillation to determine \% recovery and correct results for this if less than $100 \%$.

B. Air

1. Plot $\mu \mathrm{g} \mathrm{CN}$ present in the $5 \mathrm{~mL}$ aliquot versus absorbance

2. Determine $\mu \mathrm{g} C N$ present in each sample al iquot from the above curve.

Particulate $\mathrm{CN}$

$\mathrm{mg} / \mathrm{m}^{3} \mathrm{CN}=\frac{(\mathrm{a}) \mathrm{ig} \mu \mathrm{g} C \mathrm{CN})(\mathrm{A})}{\mathrm{B} \times \mathrm{V}}$ 


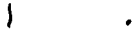

EHS C-3-9

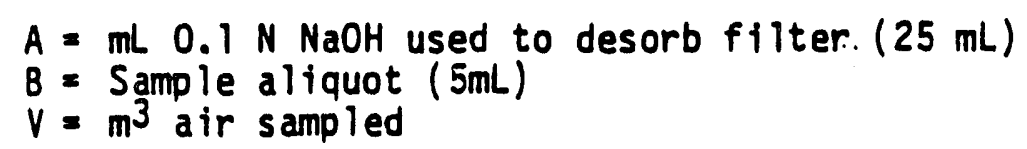

Gaseous HCN

$$
\mathrm{mg} / \mathrm{m}^{3} \mathrm{CN}=\frac{\text { (a) iq. } \mu \mathrm{gCN})(\mathrm{A})}{\mathrm{B} X V}
$$

$A=\mathrm{mL} 0.1 \mathrm{~N} \mathrm{NaOH}$ impinger absorbing soln. (15 mL)

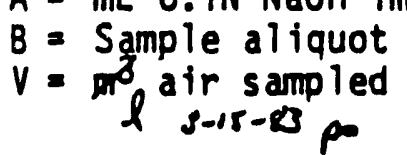

Revised 2/83 MK Hancitits 
Method No.

Title: Inorganic Anions in Water Using Ion Chromatography

Date Issued:

$1-9-90$

Approved by:

M.K. Hamil tory of.

,

Written by: P.A. Thurman

Supersedes Method No.

New
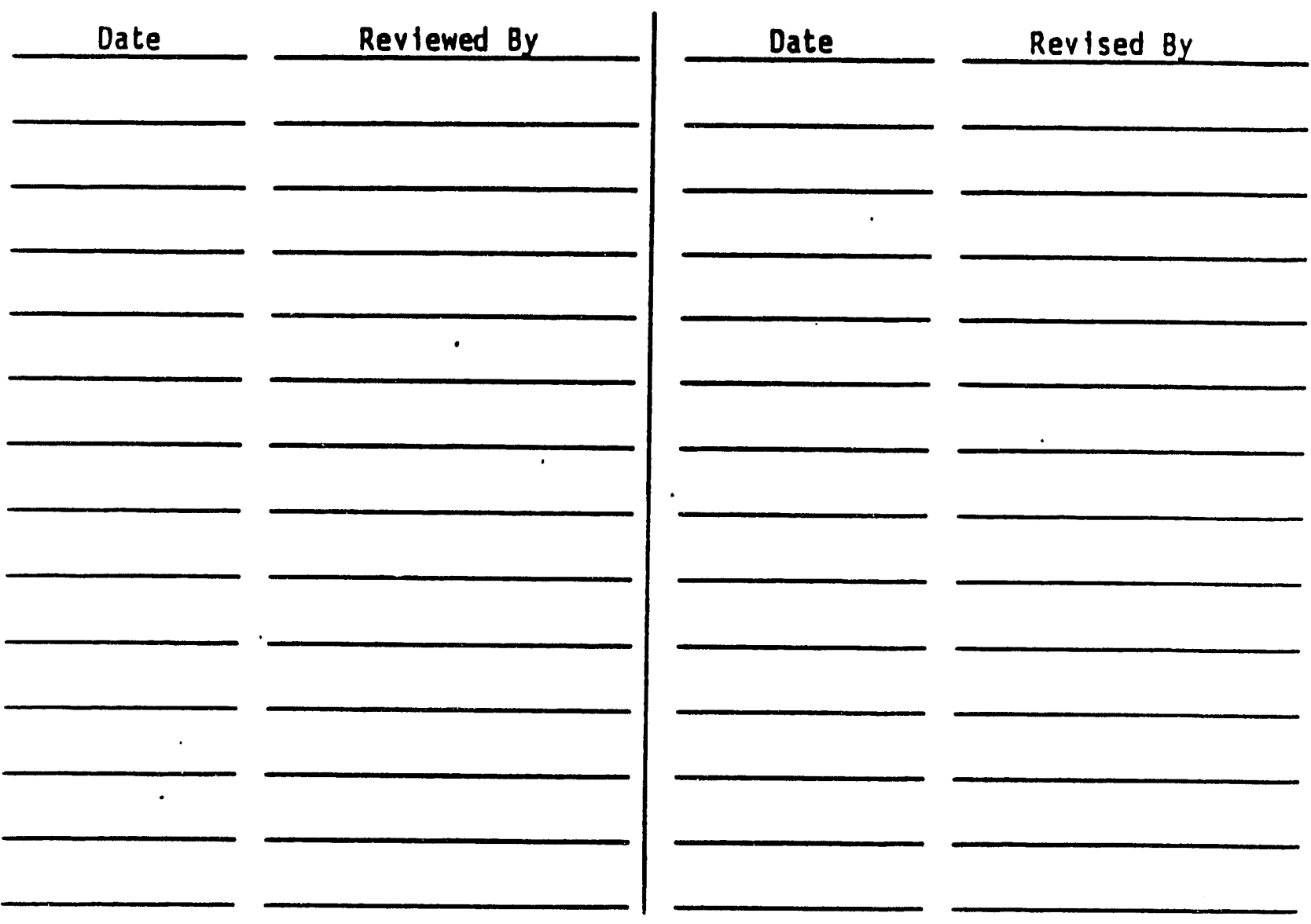

Replaced by Method No.

Date: 
EHS $A-7-1$

$01-09-90$

\section{INORGANIC ANIONS IN MATER USING IOON CHROMATOGRAPHY}

Reference

1. EPA Methods for Chemical Analysis of Water and Wastes, Method 300.0, EPA-600/4-84-017, March 1984.

2. Standard Methods for the Analysis of Water and Wastewater, 17th Ed., 1989, pp 4-2 through 4-6, Section 411C.

3. Nelson Analytical Model 4660X Operators Manual, 1986, pp 1-1 $\rightarrow$ 13-8.

4. Dionex System 2010i Operator's Manual.

\section{Princioles}

Use of ion chromatography provides a rapid simultaneous analyses of many common anions, with fluoride, chloride, nitrate, nitrite, phosphate, and sulfate being the most common. The method can also be used for other anions such as sulfite.

The sample is injected into a carbonate/bicarbonate eluent stream and passed through a series of ion exchangers. The anions are separated by a strongly basic anion exchanger (separator or guard column) and then converted to their highly conductive acidic form by an acidic cation exchanger (suppressor column). The separated acidified anions are measured by conductivity.

\section{Limitations}

This method is not approved for the analysis of fluoride in drinking water samples. That analysis must be done by specific ion electrode (EHS F-2).

Substances which have retention times coinciding with any of the anions of interest will interfere, such as, low molecular weight organic acids in high concentrations. Due to small sample volumes used, contamination from dirty and/or turbid samples must be avoided. All samples are filtered through a Millex-HV $0.45 \mu$ filter unit when injected to prevent column plugging.

Equipment

1. Ion Chromatograph (Dionex 2010i) connected via analog to digital converter to a data station (Hewlett Packard Model 300, Series 9000).

2. Anion separator column, with styrene divenylbenzene-based low-capacity pellicular anion exchange resin (HPIC-AS4A).

3. Guard column, same as separator column except $4 \times 50 \mathrm{~mm}$ HPIC-AG4A.

4. Micro Membrane Suppressor.

5. Auto regen accessory for suppressor column. 
6. High pressure in-line filter to protect guard column.

7. Deionized water finishing system--Millipore MilliQ-Plus.

8. Syringes, 10cc leur slip tip.

9. Sample filters (Millipore Millex HV $0.45 \mu \mathrm{m}$ ).

10. $100 \mathrm{~mL}$ volumetric flasks, misc pipets, etc.

\section{Reagents (stock)}

1. Sodium Bicarbonate $\left(\mathrm{NaHCO}_{3}\right)$

2. Sodium Carbonate $\left(\mathrm{Na}_{2} \mathrm{CO}_{3}\right)$

3. Sulfuric Acid, conc. $--\left(\mathrm{H}_{2} \mathrm{SO}_{4}\right)$

4. Sodium Sulfate $\left(\mathrm{Na}_{2} \mathrm{SO}_{4}\right)$

5. Potassium Nitrate $\left(\mathrm{KNO}_{3}\right), 99.99+\%$

6. Sodium Chloride $(\mathrm{NaCl}), 99.99+\%$

7. Sodium Fluoride (NaF), $99.99+\%$

8. Potassium Phosphate, Monobasic $\left(\mathrm{KH}_{2} \mathrm{PO}_{4}\right), 99.99+\%$

9. Potassium Sulfate $\left(\mathrm{K}_{2} \mathrm{SO}_{4}\right), 99.99+\%$

10. Sodium Nitrite $\left(\mathrm{NaNO}_{2}\right), 99.99+\%$

11. Nitrogen

\section{Reagents--Prepared}

1. Eluant solution: $1.7 \mathrm{mM} \mathrm{NaHCO} 3--1.8 \mathrm{mM} \mathrm{Na}_{2} \mathrm{CO}_{3}$ Dissolve $0.5712 \mathrm{~g} \mathrm{NaHCO}_{3}$ and $0.7632 \mathrm{~g} \mathrm{Na}_{2} \mathrm{CO}_{3}$ in deionized water and dilute to 4 liters with Millipore water.

2. Regenerant solution: $0.025 \mathrm{~N} \mathrm{H}_{2} \mathrm{SO}_{4}$

Dilute $0.7 \mathrm{~mL}$ conc. $\mathrm{H}_{2} \mathrm{SO}_{4}$ to 1 liters with deionized water.

3. Column Cleaning Solution-- $0.1 \mathrm{M} \mathrm{Na}_{2} \mathrm{CO}_{3}$

Dissolve $10.6 \mathrm{~g} \mathrm{Na}_{2} \mathrm{CO}_{3}$ in deionized water and dilute to 1 liter. Prepare fresh when needed. 
EHS $A-7-3$

$01-09-90$

4. Column cleaning solution--0.1M $\mathrm{Na}_{2} \mathrm{SO}_{4}--$ Dissolve $14.2 \mathrm{~g} \quad \mathrm{Na}_{2} \mathrm{SO}_{4}$ in deionized water and dilute to 1 liter. Prepare fresh when needed.

\section{Standards}

1. Stock standards (prepare all with Millipore finished deionized water)

a. Nitrate, $100 \mu \mathrm{g} / \mathrm{mL} \mathrm{NO}-\mathrm{N}$ or $445 \mu \mathrm{g} / \mathrm{mL} \mathrm{NO}$. Dissolve $0.361 \mathrm{~g}$ dried $\mathrm{KNO}_{3}$ in defonized water and dilute to $500 \mathrm{~mL}$. (Stable for six months).

b. Chloride, $500 \mu \mathrm{g} / \mathrm{mL}$. Dissolve $0.412 \mathrm{~g}$ dried $\mathrm{NaCl}$ in deionized water and dilute to $500 \mathrm{~mL}$. (Stable for 6 months)

c. Fluoride $-1000 \mu \mathrm{g} / \mathrm{mL}$. Dissolve $1.1106 \mathrm{~g} \mathrm{NaF}$ in deionized water and dilute to $500 \mathrm{~mL}$. Store in polyethylene. (Stable for six months.)

d. Phosphate--500 $\mu \mathrm{g} / \mathrm{mL}$. Dissolve $0.3582 \mathrm{~g} \mathrm{KH}_{2} \mathrm{PO}_{4}$ in deionized water and dilute to $500 \mathrm{~mL}$. Store in polyethylene. (Stable for three months.)

e. Sulfate-- $1000 \mu \mathrm{g} / \mathrm{mL}$. Dissolve $0.4517 \mathrm{~g}$ of 100.4 percent $\mathrm{K}_{2} \mathrm{SO}_{4}$ in deionized water and dilute to $250 \mathrm{~mL}$. Store in polyethylene. (Stable for six months.)

f. Nitrite- $-1000 \mu \mathrm{g} / \mathrm{mL} \mathrm{NO} 2$ or $305 \mu \mathrm{g} / \mathrm{mL} \mathrm{NO} 2-\mathrm{N}$. Dissolve $0.750 \mathrm{~g}$ dried $\mathrm{NaNO}_{2}$ in deionized water and dilute to $500 \mathrm{~mL}$. (Stable for three months.)

2. Intermediate Standards (Prepare with Millipore finished deionized water.)

a. To a $100 \mathrm{~mL}$ volumetric flask add:

$20.0 \mathrm{~mL}$ of $500 \mathrm{ppm} \mathrm{Cl}=100 \mu \mathrm{g} / \mathrm{mL}$

$9.0 \mathrm{~mL}$ of $445 \mathrm{ppm} \mathrm{NO}=40 \mu \mathrm{g} / \mathrm{mL}$

$20.0 \mathrm{~mL}$ of $1000 \mathrm{ppm} \mathrm{SO} 4=200 \mu \mathrm{g} / \mathrm{mL}$

$20 \mathrm{~mL}$ of $500 \mathrm{ppm} \mathrm{PO} 4=100 \mu \mathrm{g} / \mathrm{mL}$

$4.0 \mathrm{~mL}$ of $1000 \mathrm{ppm} \mathrm{NO}_{2}=40 \mu \mathrm{g} / \mathrm{mL}$

Dilute to volume with deionized water

b. In a separate $100 \mathrm{~mL}$ volumetric flask pipet, $2 \mathrm{~mL}$ of $1000 \mathrm{ppm} F$. Dilute to $100 \mathrm{~mL}$ with deionized water $(20 \mu \mathrm{g} / \mathrm{mL})$. Prepare intermediate standards monthly. 
EHS $A-7-4$

$01-09-90$

3. Working Standards

Pipet the following amounts of the appropriate intermediate standards into $100 \mathrm{~mL}$ volumetric flasks and dilute to $100 \mathrm{~mL}$ with Millipore finished deionized water. (Prepare weekly.)

$\mathrm{mL}$ Intermediate Standarc

0

0.5

1.0

2.0 (2.5 Fluoride)

5.0

20.0 (25 Fluoride)

$$
f \quad \mathrm{Cl} \mathrm{NO}_{3}
$$$$
0
$$$$
0
$$$$
0
$$

0.5

0.2

1.0

0.4

1.0

2.0

2.0

0.8

5.0

2.0

5.0

4.0

0.8

1.0

$5.0 \quad 20.0$

8.0

20.0

40.0

1.0

0.2

2.0

0.4

10.0

2.0

8.0

\section{Procedure}

1. Instrument start-up

See Laboratory Operating Guides L-8.4 for instrument start-up instructions.

2. Instrument Calibration

Run standards first to establish the initial calibration curve. See Appendix 1 to set-up calibration curve on the data station.

a. It is not always necessary to recalibrate the instrument each day it is run. Check the existing calibration by running 2 or 3 standards and calculating their values using the existing calibration curve-if the true values are within ten percent of the calculated values, the calibration curve is still valid and may be used. If calculated values are not within ten percent of the true values, rerun standards and make a new calibration curve.

3. Sample injections: All samples and standards are filtered through Millex HV $0.45 \mu$ filters. For data acquisition set-up see Laboratory Operating Guide L-8.4, Section C.

a. Turn auto offset-on.

b. Fill a $10 \mathrm{~mL}$ leur tip syringe with standard or sample.

c. Attach syringe to the sample port. 
EHS $A-7-5$

$01-09-90$

d. Inject 1-2 $\mathrm{mL}$ of the sample.

e. Press the load-inject button to inject. At the same time start the computer by pushing the start button on the $A / D$ box 707 .

4. Sample Protocol

a. Run every tenth sample in duplicate. (At least one sample must be run if there are less than ten samples.)

b. Spike at least one sample or one for every ten samples run.

c. Run a standard after every fifth sample to validate the calibration curves.

d. Dilute as necessary samples with concentrations outside the calibration range.

e. Run 2-3 standards at the end of the run to validate the calibration curves.

\section{Calculations}

Sample concentrations are normally calculated by the computer and printed out at the end of each sample run. Manually check the calculated sample values against the calibration curve. Verify that any dilution factors are calculated in the result. Also check validity of all QC and standard check data. 
Preparing a calibration curve using the "Metgen" program (method generatio program).

1. Run each standard in duplicate. Record" and average the heights for each component at each concentration level.

2. Proceed to the "Metgen" program by pressing the F1 key.

3. Enter the "Method File Name" (2010IC2 is currently being used).

4. Select the menu by pressing the key corresponding to "Metgen Menu" on the menu bar.

5. Select "Quant. Opts" by pressing the F5 key.

6. Select "Review Opts" by pressing the Fl key.

7. Select "Comp. Names" by pressing the F4 key.

8. Select "Cal. Ant. List" by pressing the F5 key.

9. Enter the averaged heights for each component at each concentration level as follows.

a. Position the cursor in the height column by pressing "Return."

b. Enter the averaged height for the component at the current level.

c. Move to the next level by pressing "Return" until the cursor is in the appropriate height column.

d. Press "Return" after the last height is entered.

e. Select "Cal. Amt. List" by pressing the F5 key.

f. Repeat Step 9 until all heights have been entered for all components.

10. Select the key corresponding to "Quant Menu" on the menu bar.

11. Select the key corresponding to "Metgen Menu" on the menu bar.

12. Select "Store Method" by pressing the F7 key.
a. Press "Return" when the name of the method (2010IC2) is displayed.
b. Press "Return" at the "Overwrite this File" prompt. (Method is now saved.)

13. Press the key corresponding to "New Program" on the menu bar.

14. Press "Return" at the next prompt. (XTRA CHROM II--Core program menu will appear.)

15. Precede to the "Acquire" program. 
Method No. EHS F-2-1

Title: Fluoride - Spectfic Ion Electrode

Date Issued: February 1973

Approved by: M. K. Hamiliton MEH

Written by: M. K. Hamilton

Supersedes Method No.

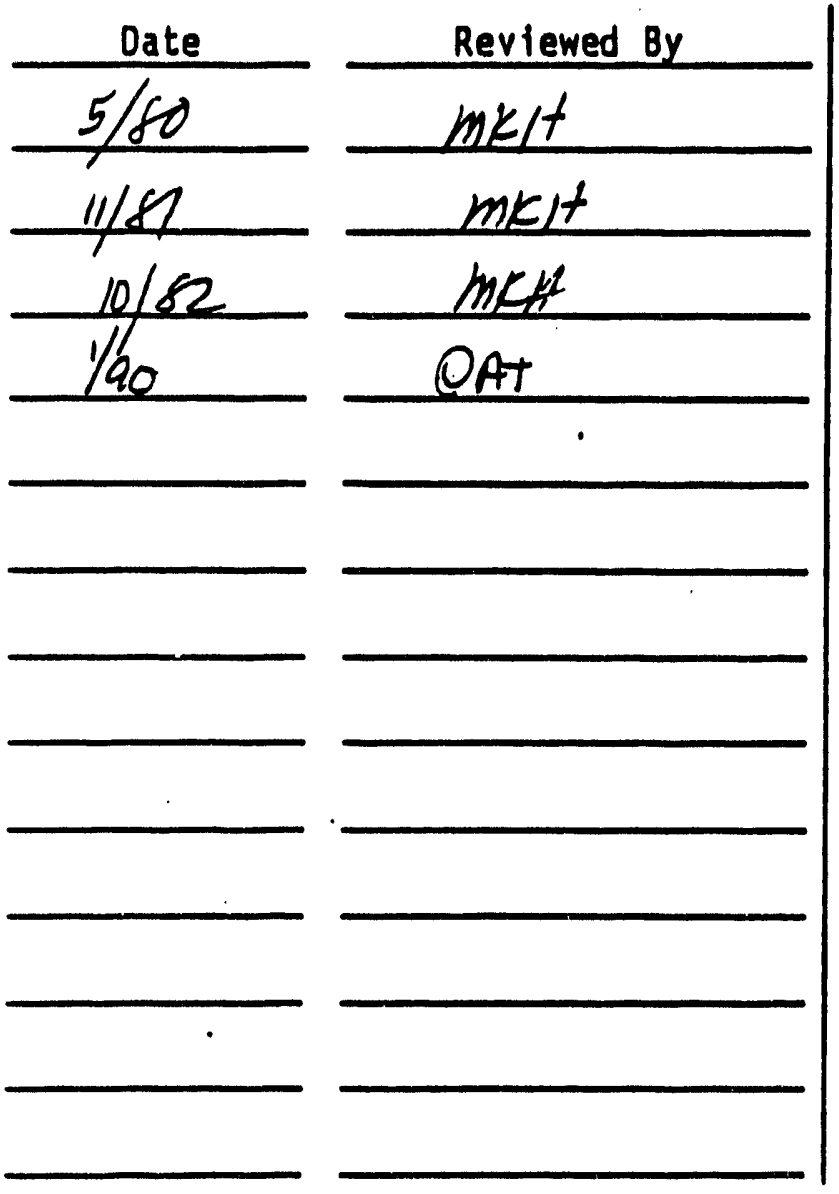

Replaced by Method No.

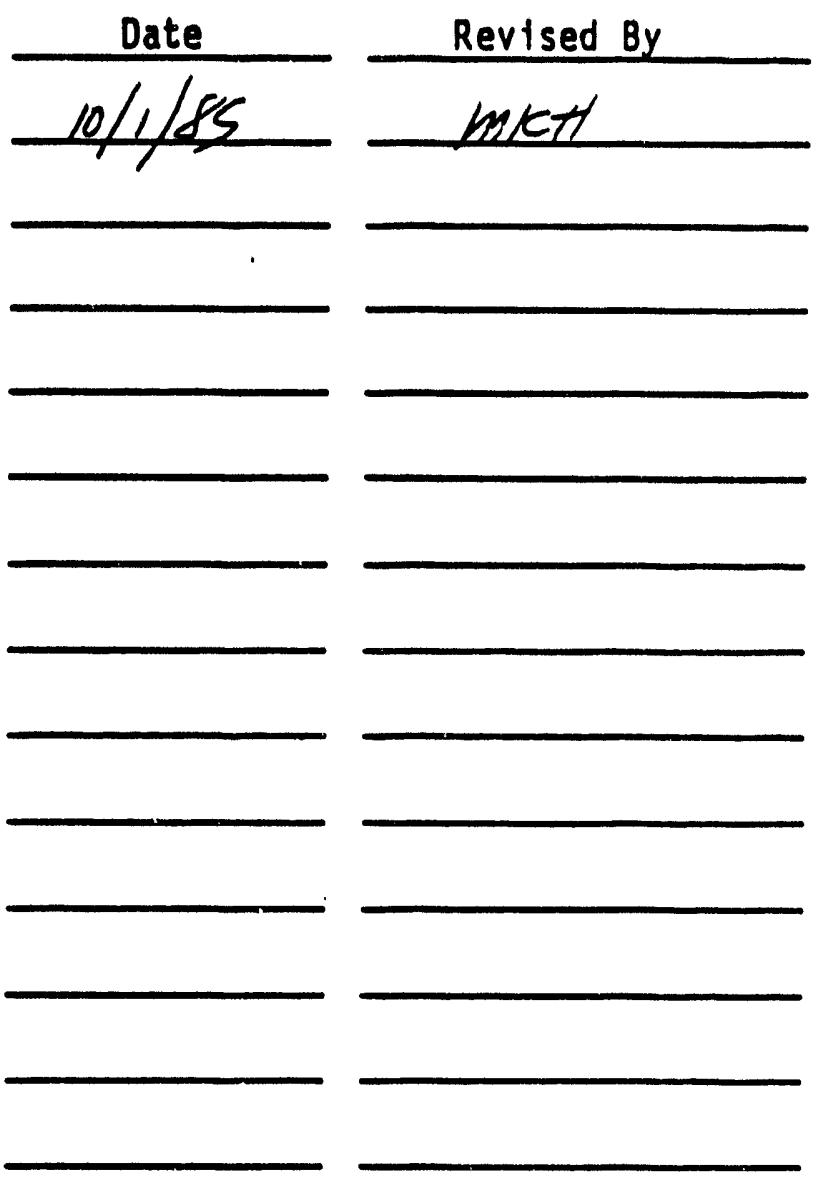

Date: 


\section{FLUORIDE - SPECIFIC ION ELECTROOE}

\section{References}

1. Standard Methods for the Examination of Water and Wastewater, 16th Edition, 1985, pp. 357-359.

2. Instruction Manual - pH/Ion Meter, 135 Corning, 1979.

3. Instruction Manual - Fluoride Electrode Model 94-09, Orion Research, Incorporated, 1970.

Principles

A fluoride ion activity electrode with a laser-type doped single lanthanum fluroide crystal is used with a saturated calomel reference electrode to measure fluoride concentration. This is done by measuring the potential established across the electrode crystal in the presence of fluoride ions.

\section{Limitations}

Polyvalent cations such as AI (III), Fe (III), and Si (IV) complex fluoride ions. In alkaline solutions, the hydroxyl fon also interferes with the electrode response to fluoride lons. Variations in the total ionic strength of the solutions being measured cause fluctuations in results. All of these problems can be overcome by diluting 1:1 with TISAB (Total lonic Strength Adjustment Buffer).

Equipment

1. $\mathrm{pH} /$ Specific ion meter - Corning 135 or equivalent.

2. Single junction sleeve-type reference electrode.

3. Fluoride specific ion electrode.

4. Magnetic stirrer and small stirring bars.

5. $100 \mathrm{~mL}$ plastic beakers.

Reagents (stock)

1. Anhydrous sodium fluoride, NaF.

2. Glactal acettc actd.

3. Sodium chloride, NaCl.

4. Sodium citrate dihydrate, $\mathrm{Na}_{3} \mathrm{C}_{6} \mathrm{H}_{5} \mathrm{O} \quad \cdot 2 \mathrm{H}_{2} \mathrm{O}$.

5. Sodium hydroxide, $\mathrm{NaOH}$.

6. Reference electrode filling solution. 
Reagents (prepared)

1. $6 \mathrm{~N} \mathrm{NaOH}$ - dissolve $120 \mathrm{~g} \mathrm{NaOH}$ in delonized $\mathrm{H}_{2} \mathrm{O}$ and dilute to $500 \mathrm{~mL}$. Prepare annually.

2. TISAB buffer solution - add the following to approximately $500 \mathrm{~mL}$ detonized $\mathrm{H}_{2} \mathrm{O}$ in a l-Liter beaker:

$57 \mathrm{~mL}$ glacial acetic acto

$58 \mathrm{~g} \mathrm{MaCl}$

$12 \mathrm{~g}$ sodium cttrate $\left(\mathrm{Na}_{3} \mathrm{C}_{6} \mathrm{H}_{5} \mathrm{O}+2 \mathrm{H}_{2} \mathrm{O}\right)$

Stir to dissolve. Use a $\mathrm{pH}$ meter $\mathrm{NaOH}$ pellets and $6 \mathrm{~N} \mathrm{NaOH}$ to adjust the $\mathrm{pH}$ to 5.0-5.5. Cool and dilute to one Liter. Prepare every 6 months.

Standards

1. Stock fluoride solution - dtssolve $1.105 \mathrm{~g}$ anhydrous $\mathrm{NaF}$ in deionized $\mathrm{H}_{2} \mathrm{O}$ and dilute to $500 \mathrm{~mL}$. $1 \mathrm{~mL}=1000 \mu \mathrm{g}$. Prepare every 6 months.

2. Intermediate fluoride dilution - dflute $1.0 \mathrm{~mL}$ of stock fluoride solution to $100 \mathrm{~mL}$ with deionized $\mathrm{H}_{2} \mathrm{O} .1 \mathrm{~mL}=10 \mathrm{\mu g}$. Prepare monthly.

3. Working fluoride standards - plpet $0.5,2.5,5.0,25.0$, and $50.0 \mathrm{~mL}$ of intermediate fluoride dilution into $100 \mathrm{~mL}$ volumetric fiasks. Add $50 \mathrm{~mL}$ TISAB solution and dflute to volume with delonized $\mathrm{H}_{2} \mathrm{O}$. Store in polyethylene bottles. These are equivalent to $0.1,0.5,1.0,5.0$, and $10.0 \mathrm{\mu g} / \mathrm{mL} F$ standards before addition of TISAB. Prepare monthly.

Procedure

A. Sample collection

Collect in polyethylene bottles which have been rinsed with deionized $\mathrm{H}_{2} \mathrm{O}$. Store at $4^{\circ} \mathrm{C}$ up to 7 days. No preservative.

B. Analysis

1. Set Corning 135 meter to "activity" mode and reset. Be sure the temperature probe is in place.

2. Rinse electrodes and blot dry with soft tissue, being careful not to scratch the LaF crystal.

3. Calibrate the meter as follows, using plastic beakers for all fluoride measurements:

a) Enter 5.0 for "Cal.1", 0.1 for "Blank" and 0.5 for "Cal. 2". Also enter the slope value of -60.000 .

b) Immerse the electrodes and temperature probe in the $5.0 \mathrm{\mu g} / \mathrm{mL} F$ standard. Stir for 3 minutes and then press "Cal.1" when stabilized. 
c) Rinse and dry the electrodes and get readings on the 0.1 and $0.5 \mu \mathrm{g} / \mathrm{mL} F$ standards after stirring each for 3 minutes. Press "Blank" after the $0.1 \mu \mathrm{g} / \mathrm{mL}$ standard stabllizes and "Cal. 2 " after the $0.5 \mu \mathrm{g} / \mathrm{mL}$ standard.

d. Read and record the new slope which should be near - $60 \mathrm{ml}$.

e. Take readings on all five standards $(0.1$ to $10.0 \mu \mathrm{g} / \mathrm{mL} F)$.

4. Prepare samples by pipetting $10.0 \mathrm{~mL}$ of sample plus $10.0 \mathrm{~mL}$ TISAB solution into a plastic beaker. Run every loth sample in duplicate.

5. Measure the fluoride concentration by immersing the electrodes in the buffered solution, stirring three minutes and recording the meter reading. Check instrument calibration by running a standard after every 5th sample. Rerun the entire callbration curve at the end of the analysis.

\section{Calculation}

1. Prepare a calibration curve by plotting $\mu \mathrm{g} / \mathrm{mL} F$ vs meter reading on 2 cycle log paper.

2. Determine the sample concentration in $\mu \mathrm{g} / \mathrm{mL}(\mathrm{mg} / \mathrm{L})$ from the calibration curve.

Preciston

In the EHS laboratory using drinking water samples at concentrations of 0.2 to $9.0 \mu \mathrm{g} / \mathrm{mL} F$, the standard deviation was $2 \%$ of the average $( \pm 0.04$ to \pm 0.15$)$. Precision of a single determination at $95 \%$ confidence-level is $\pm 5 \%$ at concentrations of 0.2 to $9.0 \mu \mathrm{g} / \mathrm{mL} F$.

Accuracy

In the EHS laboratory using drinking water samples at concentrations of 0.822 and $8.50 \mu \mathrm{g} / \mathrm{mL} F$, recoveries were $99.3( \pm 1.2 \%)$ and $100.1 \%( \pm 1 \%)$ respectively. 
Method No. EHS F-8

Title: Flashpoint Determination

Date Issued: $8-81$

Approved by: MR Hamilton fff

Written by: Susan Kinsey

Supersedes' Method No.

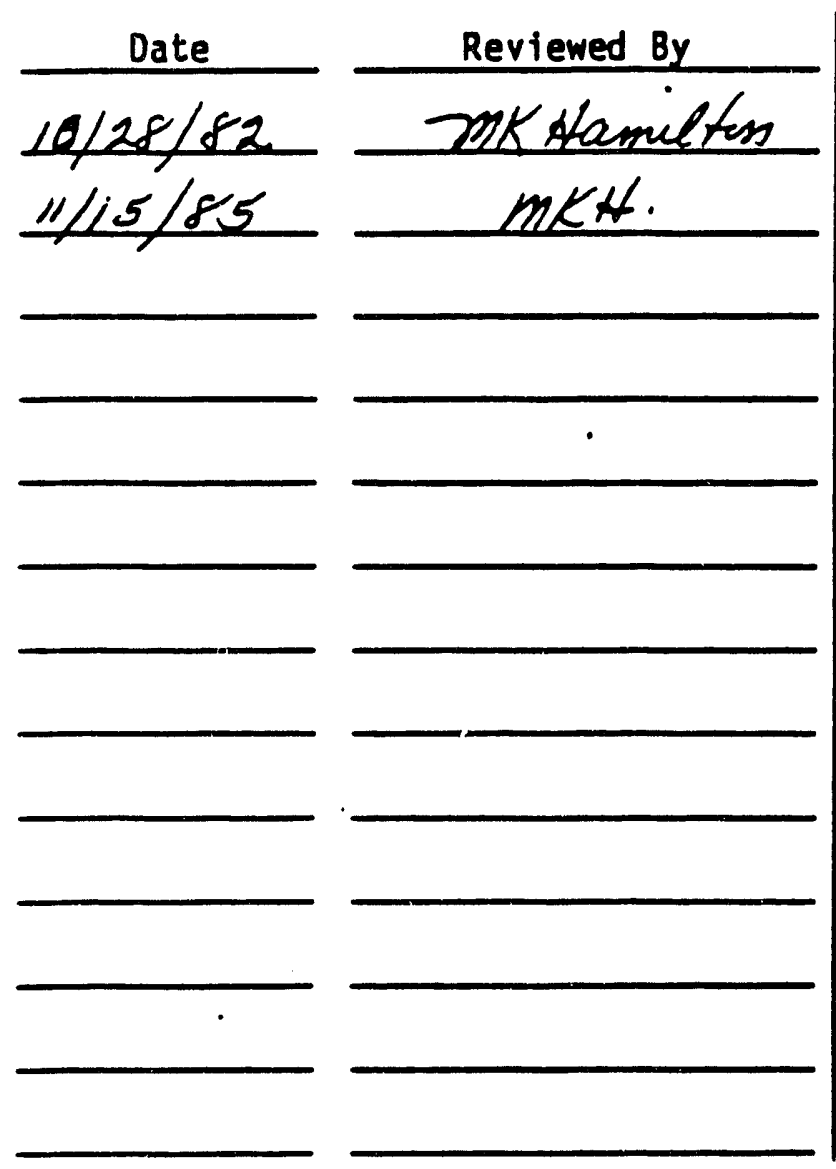

Replaced by Method No.

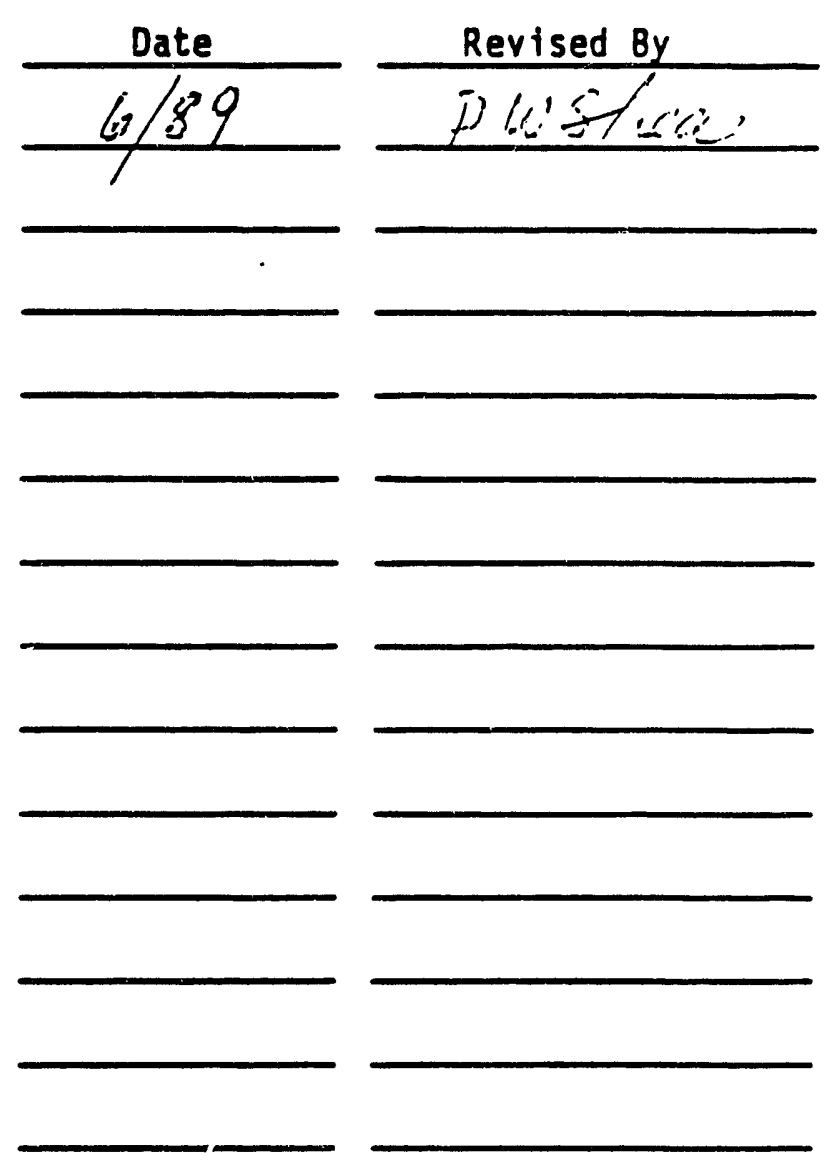

Date: 
EHS $F-8-1$

\section{ELASH POINT DETERMINATION}

\section{Reference}

1. Hazardous Waste Testing Manual, Millipore, PD. 63-86 (includes ASTM D9379 Method on Pp. 74+).

2. Test Methods for Evaluating Solid Wastes: Physical and Chemical Methods SW-846 3rd Ed, USEPA, 1986, volume IC, chapter 8, Methods 1010 (ASTM D93-85) and 1020 (ASTM D3278-82).

\section{Princioles}

These methods, prepared by the American Society for Testing and Materials (ASTM), are designed for the determination of flash point, using either the Pensky-Martens Closed Cup Tester or the Setaflash Closed Cup Tester. The flash point of an organic material is defined as the temperature, (under controlled conditions), at which the concentration of the material in the vapor phase has reached the lower explosive limit. In such a flammable atmosphere the introduction of a spark will ignite the vapor. This ignition results in a flame that instantaneously propagates itself across the surface of the sample. Vapor pressure is a fundamental physical property of any chemical, determined largely by intermolecular attractions. Vapor pressure is also affected by the equilibrium state of the system. Consequently, in this analysis volume, temperature, and time are important variables.

For the purposes of Department of Transportation (DOT) compliance, liquids with a flash point below $100^{\circ} \mathrm{F}\left(37^{\circ} 8^{\circ} \mathrm{C}\right)$ are regulated as flammable. Under RCRA regulations for ignitability, substances are considered hazardous when the flash point is below $60^{\circ} \mathrm{C}$. When testing samples with unknown flash points, the test flame must be applied at regular intervals, from the initial temperature to $100^{\circ} \mathrm{C}$ or until the flash point is reached.

\section{Limitations}

These procedures are specifically designed for fuel oils, lube oils, solvents, greases, some solids, suspensions of solids, and liquids that tend to form a surface film under test conditions.

Exact reproducibility of the flash point testers, and their comparability has not been proven at this point. 


\section{Setaflash Closed Cup Tester}

This method requires $2 \mathrm{~mL}$ of sample material. It is best used when there is. little sample material, a rapid analysis time is desired, trace cross contamination must be avoided, and an accuracy of $5^{\circ} \mathrm{C}$ intervals is acceptable. Accuracy comparable to that of the Pensky-Martens method requires iterative analysis (see section on finite testing). This is the procedure routinely used by the EHS laboratory.

\section{Equipment}

1. Setaflash Closed Cup Tester

2. $2 \mathrm{~mL}$ glass syringe

3. tissue wipes, acetone

4. cooling block (kept in freezer)

\section{Procedure-finite flash ooint (Primary Method)}

1. This procedure is used to determine the exact flash point of a test material. The ASTM method calls for an iterative approach where the flash point is first approximated and then the analysis is repeated with the temperature adjusted to just below that of the first observed flash. In our laboratory we have modified this approach more closely to that of the Pensky-Martens method described above. This is a valid approximation if the sample chamber is heated at such a rate so that there is time for vapor and liquid phases to reach equilibrium. For samples of low volitility and low volume $(<70 \mathrm{~mL})$, use the iterative approach.

2. Begin the test with the sample chamber at, or, by using the cooling block, below ambient temperature. Sample material is introduced into the sample chamber via the $2 \mathrm{~mL}$ glass syringe. For viscous or solid samples the $2 \mathrm{~mL}$ volume may have to be estimated using other means.

3. The temperature dial is set to some value that produces a $5^{\circ} \mathrm{C} /$ minute increase. Additional adjustments may be necessary as the tester reaches the set value and begins to cycle on and off. The pilot and ignition flames are set as described above but are not shut down after adjustment. The temperature of the sample cup is monitored and the sample tested for flashpoint at every $5^{\circ} \mathrm{C}$ increase. After the flash has been observed, the temperature dial is reset to the beginning value, the 1 id of the sample chamber opened, and excess material wiped from the testercup. Use acetone as necessary to remove remaining residues, if any. To cool the sample cup down to ambient temperatures, the aluminum block is removed from the freezer and fitted into the sample cup. When the sample cup has returned to ambient temperature, the next sample can be tested. 
EHS - F $-8-3$

\section{Procedure-flash/no flash (Alternative Procedure)}

1. This method is for testing a material at a predetermined temperature.

2. Basic procedure--the power switch of the tester is turned on and the temperature dial set to the value corresponding to the desired temperature. The coarse and fine knobs allow adjustment to within $1^{\circ} \mathrm{C}$. The temperature of the tester cup is indicated on the built-in thermometer. While the tester cup is heating, light and adjust the pilot and ignition flames. Use the pinch ciamp to shut off gas without changing flow rates. When the temperature has stabilized at the desired setting the indicator light will cycle on and off. Fill the syringe with $2 \mathrm{~mL}$ of sample material and dispense through injection port in lid of tester chamber. Start the 1 minute timer. Release the pinch clamp and light the gas streams. When the timer tones, trip the release lever and observe for the flash/no-flash condition. Shut off gas flow, turn temperature dial back to its original setting, and clean the sample cup as described above.

3. Multiple analyses--the temperature dial is not reset after an analysis, rather the tester cup is cleaned, the lid shut and the cup allowed to again reach thermal equilibrium. The steps outlined under the basic procedure are repeated. If a temperature other than that currently in equilibrium is desired the temperature dial is set accordingly. For temperatures less than the current setting, the cooling block can be used.

\section{Pensky-Martens Closed Cup Tester}

This method is employed when low volatile samples are encountered (i.e. tar, heavy oils), where greater accuracy (flash point to within $2^{\circ} \mathrm{C}$ ) is desired and trace cross contamination is not a problem. This method requires $70 \mathrm{~mL}$ of organic material.

\section{Equioment}

1. Pensky-Martens Closed Cup Tester

2. Motorized stirrer with flexible belt

3. Thermometers

4. 2 beakers, 1 large enough to hold brass sample cup

5. Materials to clean brass sample cup: tissue wipes, detergent solution, small nylon bottle brush, acetone.

\section{Procedure}

1. Fill clean, dry brass cup to mark with sample; place cup in well and secure cover apparatus by tightening attachment screws; adjust thermometer in provided port so that stirring mechanism does not strike it; check all gas connections and adjust larger needle valve for gas 
EHS $F-8-4$

$6-89$

flow; connect belt; turn gas on, light pllot flame, and adjust smaller needle valve for test flame; turn stirrer on. (Stop stirring when apply test flame.)

2. Basic procedure--adjust the Ful-Kontrol dial for a temperature increase of $5-6^{\circ} \mathrm{C} / \mathrm{min}$. (approximately 70 increasing to 90 by the end of test); set the belt on the smaller pulley to achive a stirring rate of approximately $115 \mathrm{rpm}$. Test the sample at $2^{\circ} \mathrm{C}$ intervals beginning 17$28^{\circ} \mathrm{C}$ below expected flash point (lower test flame in $0.5 \mathrm{sec}$, hold 1 sec., raise quickly); if flash point is unknown, test in similar manner, except start at ambient temperature. Record the flash point as the temperature at which there is a distinct flash in the cup (there may be a bluish halo present in the reading preceding the flash).

3. Multiple analyses--after the flash has been observed perform the following: shut off gas, shut off stirrer, disconnect belt, remove cover, remove sample cup from well and place in water bath (water filled beaker), turn Ful-Kontrol knob back to start position. For routine samples the test cup should be placed in the water bath immediately after the end of the test. The sample cup is cleaned as follows: return remaining sample to original container, use nylon brush to scrub cup with detergent solution, rinse first with water then with acetone, use tissue to dry sample cup. The sample cup is then refilled with the next sample and placed in the tester. The Ful-Kontrol is reset to 70 and the sample tested in thew manner already described.

4. Notes--samples with low flash points can be tested by cooling the sample cup in a freezer prior to analysis. A second sample cup is useful in this situation; one can be kept in the freezer while the other is in use.

An important consideration in disassembling the tester: Place the test cup in the water immediately after the test is completed. If this is not done, the sample will continue to receive heat from the cup and sample well, consequently, the sample may superheat once the stirrer has been disconnected. In this situation, sample material can be violently ejected from the cup. This is especially the case with aqueous/organic mixed samples. Such samples should be analyzed only in the Setaflash tester.

Quality control

Quality control records for the flash point analysis are maintained in the "Waste" volume of quality control data. There are separate sections for the Pensky-Martens and for the Setaflash methods. Compounds of known purity and flashpoint are used to check the accuracy of the tester and analyst. Currently undecane, with a flash point of $65^{\circ} \mathrm{C}$ is used as our reference standard. The observed flashpoint of the standard, the date of the test, the analyst's initials, and the customer order number of the associated sample set are recorded.

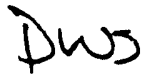




\section{UL I MI LMUI I \\ Closed-Cup Tester}

r

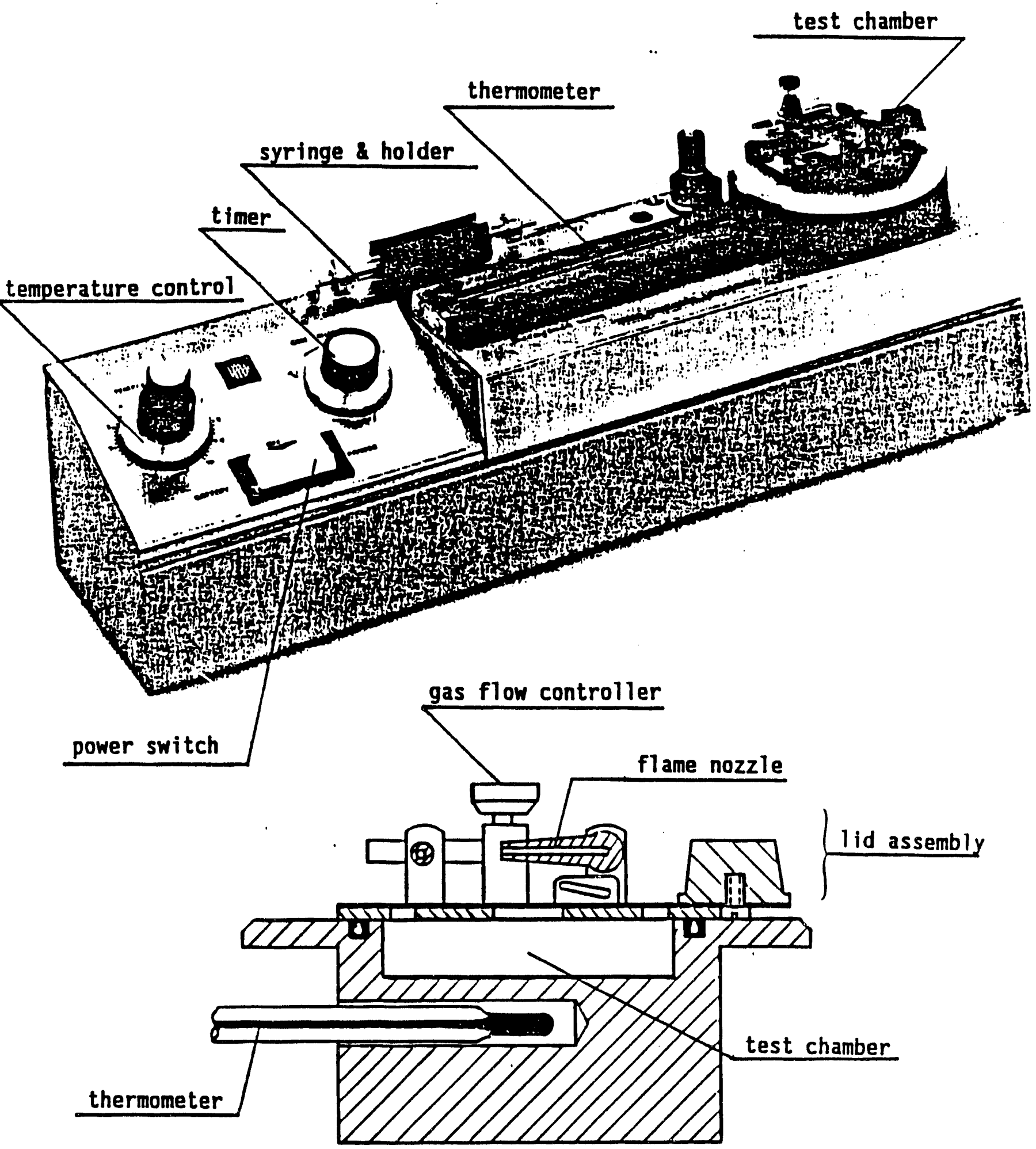




\section{PENSKY-MARTENS Closed-Cup Tester}
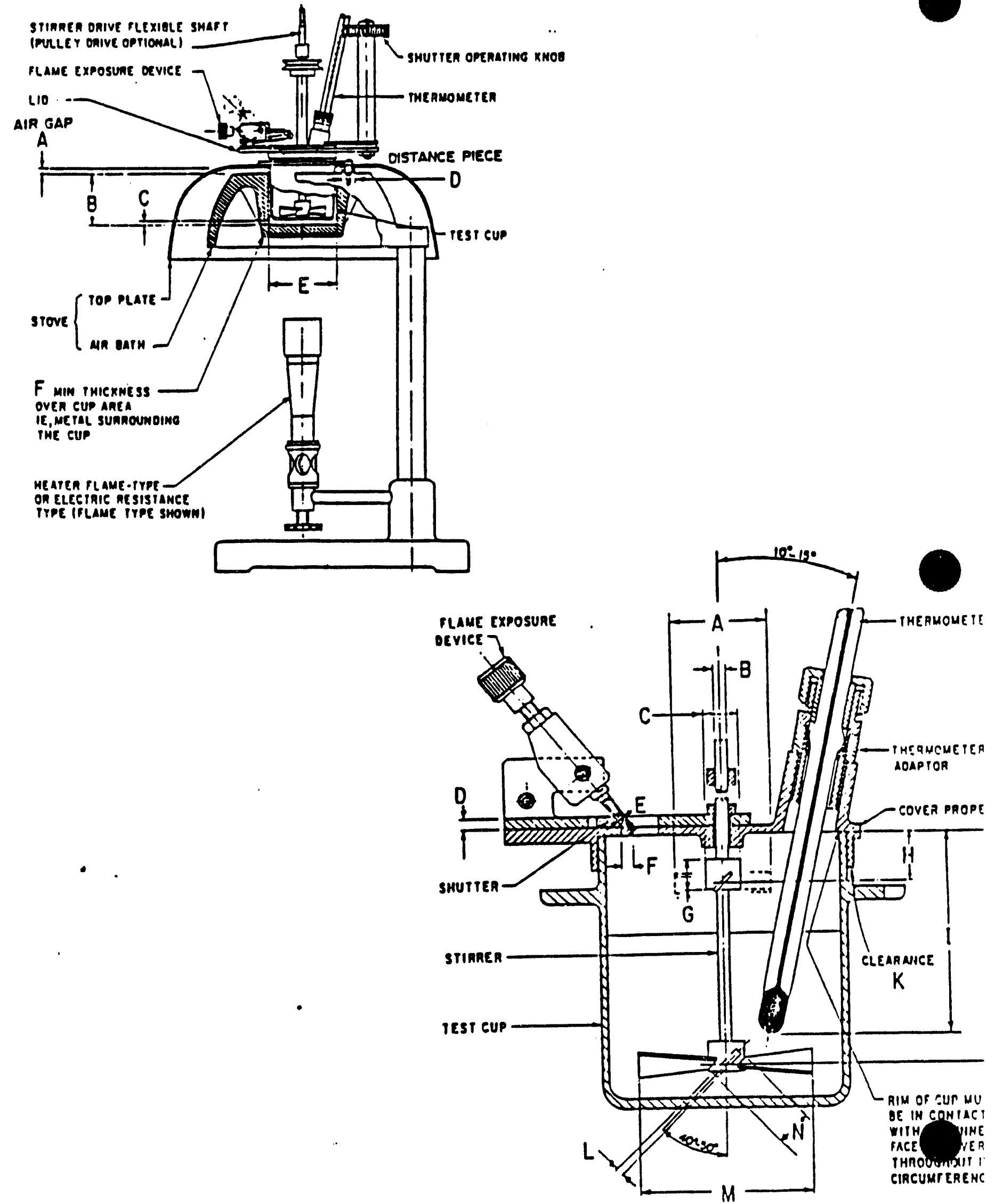
Metliod 110. EHS $\mathrm{H}-7$

Title: TGS ANSA Pethod for the Determination of Mitrogen Dioxide in the Atmosphere

Uate Issued: $2-79$

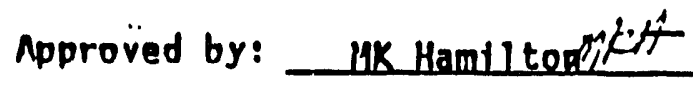

Written by: K. Norton

Supersedes Method No.

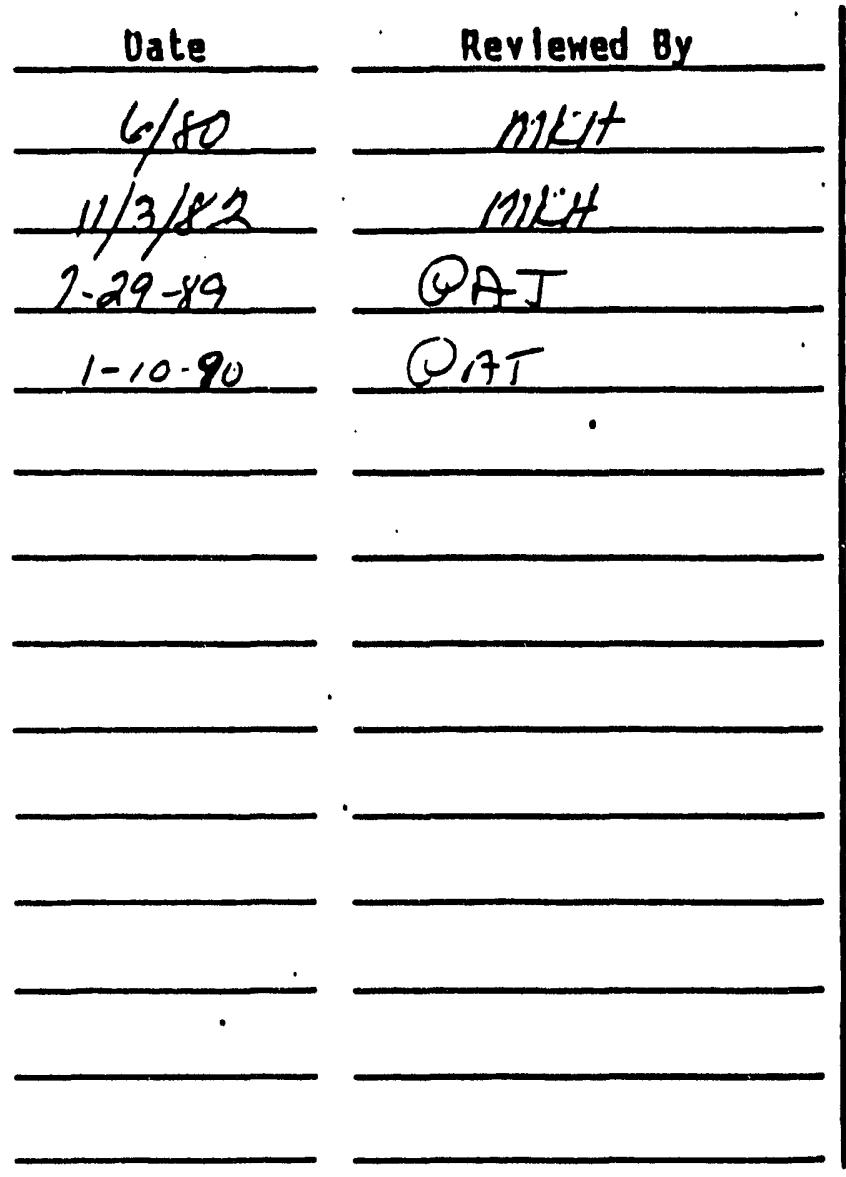

Replaced by Metliod Ho.

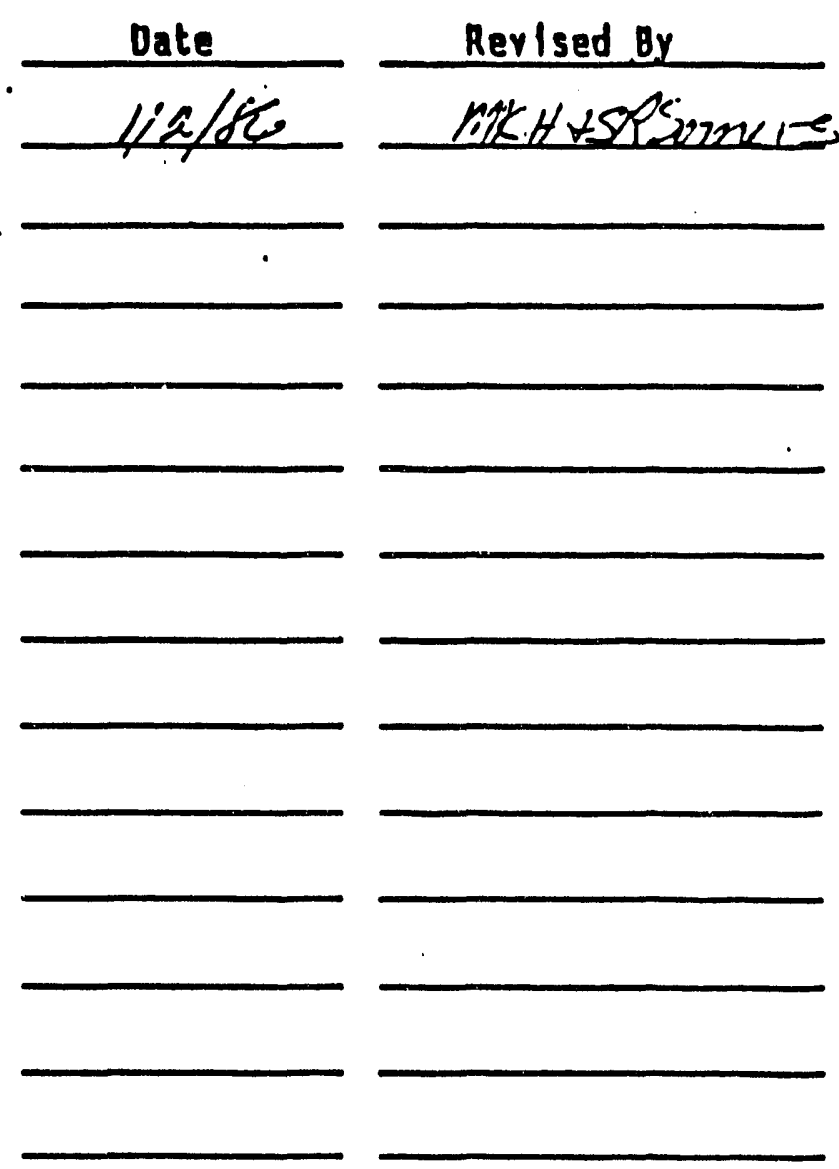

Date: 
EHS $N-7-1$

8-19-89

\section{TGS ANSA METHOD FOR THE DETERMINATION OF NITROGEN}

\section{References}

1. IGS ANSA Method for the Determination of Nitrogen Dioxide in the Atmosohere, EPA Designated Equivalent Method No. EQN-1277-028.

\section{Princioles}

Ambient nitrogen dioxide $\left(\mathrm{NO}_{2}\right)$ is collected by bubbling air through a $50 \mathrm{~mL}$ solution of triethanolamine, o-methoxyphenol (Guaiacol), and sodium metabisulfite in a two port polypropylene tube. The inlet port is fitted with an $8 \mathrm{~mm}$ 0.D., $6 \mathrm{~mm}$ 1.D. glass tube with the end drawn out to form an orifice with an 1.0. of $0.3-0.6 \mathrm{~mm}$.

The concentration of nitrite ion $\left(\mathrm{NO}_{2}\right)$ produced during sampling is determined colorimetrically by reacting the nitrite ion with sulfanilamide and 8-anilino1 -napthalenesulfonic actd ammonium salt and measuring the absorbance of the highly colored AZO dye at $550 \mathrm{~nm}$.

The method is applicable to 24 -hour integrated sampling of $\mathrm{NO}_{2}$ in ambient air with a sampling rate of $200 \mathrm{~cm}^{3} / \mathrm{min}$.

\section{Limitations}

At an $\mathrm{NO}_{2}$ concentration of $100 \mu \mathrm{g} / \mathrm{m}^{3}(0.05 \mathrm{ppm})$ the follqwing pollutants, at the level's indicated, do not interfere: ammonia, $205 \mu \mathrm{g} / \mathrm{m}^{3}(0.29 \mathrm{ppm})$; carbon monoxide, $154,000 \mu \mathrm{g} / \mathrm{m}^{3}$ (134 ppm); formaldehyde, $750 \mu \mathrm{g} / \mathrm{m}^{3}(0.61 \mathrm{ppm}) ; \mathrm{nitric}$ oxide, $734 \mu \mathrm{g} / \mathrm{m}^{3}(0.60 \mathrm{ppm})$; phenol, $150 \mu \mathrm{g} / \mathrm{m}^{3}(0.04 \mathrm{ppm}) ;$ ozone, $400 \mu \mathrm{g} / \mathrm{m}^{3}$ $(.020 \mathrm{ppm})$; and sulfur dioxide, $439 \mu \mathrm{g} / \mathrm{m}^{3}(0.17 \mathrm{ppm})$.

\section{Equipment}

1. Two port polypropylene tubes (164 mmx.32 mm).

2. Approximately $152 \mathrm{~mm}$ long bubbler tubes $(8 \mathrm{~mm}$ 0.D., $6 \mathrm{~mm}$ I.D. with an orifice of I.D. $0.3-0.6 \mathrm{~mm}$ ).

3. Test tubes (150 mm long $\times 20 \mathrm{~mm}$ diameter).

4. RAC 24-hour sequential samplers.

5. Spectrophotometer capable for measuring absorbance at $550 \mathrm{~nm}$ using $1 \mathrm{~cm}$. optical path length cells or sipper cell and/or autosampler.

6. Autosampler tubes.

\section{Reagents (Stock)}

1. Triethanolamine

2. O-methoxyphenol (guaiacol) - reagant grade

3. Sodium Metabisulfite 
4. Sulfantlamide

EHS $N-7-2$

5. 8-anilino-1-napthalenesulfonic acid ammonium salt (ANSA)

6. Hydrogen peroxide, $30 \%$

7. Absolute Methanol

8. Hydrochloric Acid, concentrated ( $\mathrm{HCl}$ )

9. Sodium Nitrite - $\mathrm{NaNO}_{2}$

Reagents (Prepared) Reagents should be prepared in amounts which will be used within the holding times. This is in keeping with waste reduction efforts.

1. Absorbing Solution - Dissolve $90 \mathrm{~mL}$ of triethanolamine, $2.25 \mathrm{~mL}$ of o-methoxyphenol (gualacol) and $1.25 \mathrm{~g}$ of sodium metabisulfite consecutively in $3 \mathrm{~L}$ of delonized water. Ollute to $5 \mathrm{~L}$ with defonized water. Stable for 3 weeks if protected from 1 ight.

2. Sulfantlamide Solution. Add $20 \mathrm{~g}$ of sulfanilamide to $1,000 \mathrm{~mL}$ volumetric

flask containing approximately $500 \mathrm{~mL}$ of deionized water. Slowly add 330 $\mathrm{mL}$ of concentrated $\mathrm{HCl}$ and dilute to $1,000 \mathrm{~mL}$ with deionized water. Stable for 4 weeks under normal laboratory conditions.

3. ANSA Solution. Dissolve $1.0 \mathrm{~g}$ of ANSA in $500 \mathrm{~mL}$ of absolute methanol.

Dilute to $1,000 \mathrm{~mL}$ with absolute methanol in a volumetric flask. Mix thoroughly. Stable for 3 weeks when stoppered and stored under normal laboratory conditions. Should not be exposed to temperatures of $30^{\circ} \mathrm{C}$ or higher for 8 hours or more.

4. Hydrogen Peroxide Solution - Dilute $0.2 \mathrm{~mL}$ of $30 \%$ hydrogen peroxide to 250 $\mathrm{mL}$ with defonized water. Stable for 1 month if refrigerated and protected from 1 ight.

\section{Standards}

1. Sodium Nitrite Stock Solution - $(500 \mu \mathrm{g} \mathrm{NO} / \mathrm{mL})$ - Dissolve $0.7732 \mathrm{~g}$ of oven dried $\mathrm{NaNO}_{2}$ in defonized water and dilute to $1 \mathrm{~L}$ with deionized water. Can be stored for 6 weeks, if refrigerated.

2. Sodium Nitrite Working Solution - $(10 \mu \mathrm{g} \mathrm{NO} / \mathrm{mL})$ Pipet $5.0 \mathrm{~mL}$ of the stock solution into a $250 \mathrm{~mL}$ volumetric flask and dilute to volume with absorbing solution. Prepare fresh daily.

3. Working Standards - Transfer $0,1.0,3.0,5.0,8.0$, and $10.0 \mathrm{~mL}$ of the sodium nitrite working solution to $100 \mathrm{~mL}$ volumetric flasks and dilute to volume with absorbing solution. This yields standards of $0,0.1,0.3$, $0.5,0.8$, and $1.0 \mu \mathrm{g} \mathrm{NO} 2 / \mathrm{mL}$. 


\section{Procedure}

A. Samole collection

1. Place $50 \mathrm{~mL}$ absorbing solution into a polypropylene tube, $164 \mathrm{~mm}$ long $x 32 \mathrm{~mm}$ diameter. The tube is fitted with a polypropylene two-port closure equipped with an $8 \mathrm{~mm} 0.0 ., 6 \mathrm{~mm}$ I.D. glass tube having an end drawn out to form the specified orifice.

2. Draw air through the bubbler using a conventent flow control device, such as a critical orifice and RAC sequential sampler. The device must be capable of maintaining a constant flow through the sampling solution between 180 and $220 \mathrm{~cm}^{3} / \mathrm{min}$. Sample for 24 hours and record the volume of air samples based on the actual calibration sampling rate.

B. Analysis

1. Replace any water lost by evaporation during sampling by adding delonized water up to $50 \mathrm{~mL}$ calibration mark.

2. Plpet $5 \mathrm{~mL}$ of each standard and collected sample into a test tube.

3. Add $0.5 \mathrm{~mL}$ of hydrogen peroxide solution and mix for approximately 15 seconds.

4. Add $2.7 \mathrm{~mL}$ of sulfanilamide solution and mix vigorousiy for about 30 seconds.

5. Add $3.0 \mathrm{~mL}$ of ANSA solution and $\mathrm{mix}$ vigorously for about 30 seconds (the ANSA must be added within 6 minutes after adding the sulfanilamide solution. Longer time intervals will result in lower absorbance values.)

6. Transfer aliquots of the samples and standards to autosampler tubes. If not using autosampler, use sipper cell.

7. Measure and record the absorbance of the blank and each standard and sample at $550 \mathrm{~nm}$, using the autosampler (see Lab Operating Procedure L-8.2 for set up instructions). The absorbance measurement can be made anytime from 1 to 40 minutes after the addition of the ANSA.

\section{Calculations}

1. Use the standard values to plot absorbance vs. $\mu \mathrm{g} / \mathrm{NO}_{2} / \mathrm{mL}$ absorbing solution.

2. Use the calibration curve to determine $\mu \mathrm{NO}_{2}$ present in the sample aliquot.

3. Calculate $\mathrm{NO}_{2}$ in air as follows:

$$
\mu g \mathrm{NO}_{2} / \mathrm{m}^{3}=\frac{\mu \mathrm{g} \mathrm{NO}-/ \mathrm{mL} \times 50 \mathrm{~mL} \times \mathrm{D}}{V\left(M^{3}\right) \times 0.93}
$$


EHS $N-7-4$

- Where:

$\mu \mathrm{g} \mathrm{NO} / \mathrm{mL}$ - $\mathrm{NO}_{2}$ concentration in añalyzed sample

$$
\begin{aligned}
50 & \text { - volume of absorbing reagent used in sampling } \\
V & \text { - volume of air sample }\left(\mathrm{m}^{3}\right) \\
0.93 & \text { - Sampling efficiency } \\
0 . & \text { Dilution factor - for no dilution } \\
& -2 \text { for } 1: 1 \text { dilution }
\end{aligned}
$$

4. The $\mathrm{NO}_{2}$ concentration may be calculated as ppm using:

$$
\text { ppm NO} 2-\left(\mu \mathrm{gNO}_{2} / \mathrm{m}^{3}\right) \times 5.32 \times 10-4
$$

NOTE: Calculations may also be performed with an IBM-PC using Lotus 1-2-3 and the program written by S. R. Somers (Appendix 1). 


\section{COMPUTER INSTRUCTIONS FOR LOTUS $\mathrm{NO}_{2}$ PROGRAM}

\section{INTRODUCTION}

The following instructions allow the user to manipulate data generated from the weekly $\mathrm{NO}_{2}$ atr survelllance program on the IBM PC using the LOTUS 1-2-3 software. All calculations are programmed so all the user has to do is enter the appropriate measurements in the designated location and the program will convert absorption to $\mathrm{ppm} \mathrm{NO}_{2}$.

\section{START UP}

Turn the computer on using the multiple outlet switch.

Insert the LOTUS 1-2-3 diskette into the left drive, which will be referred to as drive $A$. Close the $A$ drive door. Wait a few moments while the computer loads (boots) LoTUS. When the red light is on, this indicates the computer is obtaining information from the diskette or manipulating information. DO NOT REMOVE THE DISKETTE WHEN THIS LIGHT IS ON.

Insert the data diskette labeled ( $\mathrm{NO}_{2}$ CALCULATIONS) into the right drive or drive 8 . Close the door.

If the computer is already on, and not in use, there will be an A prompt (A) in the upper left corner of the screen. When the $A>$ appears it is ready to accept commands. Simply type: LOTUS, return ( $h$ and the software will automatically boot.

When LOTUS is activated, follow the instructions for date and time, striking the return $(ل)$ key after each entry. Make sure that the date is entered correctly because it will be used later in the program, i.e., mn-day-yr $(5-01-85)$.

LOTUS will now list a menu. This menu shows the user different options within the LOTUS network. Use the 1-2-3--LOTUS spreadsheet program. Strike return when the highlighted command cursor is centered on 1-2-3.

Next a copyright will appear, strike any key to continue.

If the appropriate diskette is placed in drive B, the program will automatically load the $\mathrm{NO}_{2}$ spreadsheet and generate a list of commands needed to utflize the program.

The spreadsheet program is now loaded; letters should appear in the vertical direction (rows) and numbers in horizontal (columns). Notice that the letters and numbers make up a matrix so the user can identify each cell.

The beginning of the program appears and is ready to be manipulated. Notice the greenish and white areas. Data can only be entered to the cells that appear greenish or those that have been designated for data inpui; all other cells are internally protected and will not accept entries. 
IMPORTANT: Striking the AIt M keys simultaneously causes a menu directly relating to the $\mathrm{NO}_{2}$ spreadsheet to appear. This menu lists most of the commands needed to manipulate the spreadsheet. . The commands are set up so the user can move from one end to another (down the line) to complete the objective. The menu should appear as follows:

\section{EXIT DATE INPUT LAB NO PRINT FILE SAVE QUIT}

DATING THE WORKSHEET

By striking $A \mid t, M$ keys and selecting DATE, the cursor will automatically move to cell $\mathrm{B22}$ and wait unt 11 the user enters the weekly date. The date should be entered as shown here: 1/28 - 2/05; followed by a return (-l). The easiest way to change the date is by striking the F-2 key (edit), making the necessary changes and erasing with the delete key.

DATA ENTRY

To start the input mode, go to menu Alt $M$ ), select INPUT, (notice another menu appears). Select INPUT again and the curser automaticaliy moves to enter the standard absorption curve for Run 1 and Run 2; manipulate the cursor using the keys located to the right of the key board (primarily , down). This in essence will give you the fundamental rudiments of latter calculations derivirig ppm from absorption.

To enter the data for each respected site, locate the site and its information cells as shown below.

ABS. CONC. $\angle A B N O$ $(550 \mathrm{~nm}) \quad(\mathrm{ppm} / \mathrm{NO})$ E85-01-

SITE:

DATE :

PUMP NO:

OR IF ICE NO:

FLOW $(\mathrm{cc} / \mathrm{m})$ :

AIR VOLUME:

CAL. DATE:

DUP:

AVG:

Check all pertinent information in the first column to make sure all pump characteristics are correct and current (especially flow and air volume). All ABS enteries will then be placed under the ABS column. Continue to enter the absorption for each site using the cursor movement keys to advance the spreadsheet. After all absorption entries are entered, to break the program loop strike Ctrl Break simultaneously. 
CALCULATING

After all data has been entered and the pump characteristics checked, the entries need to be calculated. Simply recall the menu, select INPUT, followed by CALCULATE.

\section{LABORATORY NUMBER SYSTEM}

The lab number identifies each sample and is responsible for the integrity of quality assurance. To add the laboratory numbers in chronological order, retrieve the menu ( $A L T[M]$ ) and enter command $L A B$ NO.

To operate, the program will ask the user to enter the address (site) to go to. Type in the appropriate site (Ale, 200W, 100B, 100D,615C, AB, Wye, FFTF, or $S B$ ). Enter the starting lab no., strike return $(-d)$, and the program will supply the log numbers for the rest of the cell. Again, the program will ask the cell address. Type the next site on which data was collected (ل) and the lab no. $(-)$ ). Repeat until all sites are accounted for. NOTE: If only five samples were collected, then your worksheet should represent this; hence, the ABS columns and the laboratory number must coincide. To break the program strike [Ctr] Break simultaneously. IMPORTANT: A cross check against the log book will determine if the process was done correctly.

\section{PRINTING WEEKLY REPORT}

When all data entries are finished a weekly printout is essential, and must be done before the FILE and SAVE commands. This printout will be placed in the $\mathrm{NO}_{2}$ notebook for future reference. Before printing make sure the printer is on, paper loaded, and ready to accept information. The ON-LINE light must be

1it. The printer settings should be the following:

MARGINS

$\begin{array}{lll}\text { Left: } 7 & \text { Top: } 0 & \text { Page Length: } 64 \\ \text { Right: } 136 & \text { Bottom: } 2 & \text { Footer:"i Date: }\end{array}$

IMPORTANT: Before sending information to the printer, the paper must first be aligned so that the top perforation "lines-up" with the printer head. This will allow for a weekly report that is bondable, legible, and neat.

To print the data sheet, recall the menu and select PRINT. After this is complete, remove the printout from the printer and store in the notebook. Record data in the $\log$ and QC books.

FILE

After the absorbance numbers have been converted to parts per million $\mathrm{NO}_{2}$, the data needs to be stored in a calendar matrix for future manipulations.

Recall the menu (A]t (M]) and select FILE, the cursor will automatically move to R5 and ask the user to "align cursor at appropriate date". Strike return $(-)$ to continue. Using the cursor movement keys or page down, move the cursor accordingly. Once the starting date is located, position the cursor in column $R$ (ALE) and strike return $(J)$. The data will be automatically placed in the matrix for the remaining sites, and a range is set for later use. 
After all data has been entered, printed, and filed the last operation is to store the results in a calendar matrix for yearly summations. To do this, go to the meni (AIt M) and select SAVE $W$ ). The computer will then perform this command and presents another menu:

\section{EXIT FILE SAVE QUIT}

Select FILE $(\mathrm{f})$, notice the same calendar appears as in the previous spreadsheet. The comment "Align cursor at approprlate Date" appears. Strike return $(-)$ and move the cursor accordingly. When the cursor is properly aligned in the ' $C$ ' (ALE) column, strike return $(-)$ ) and the weekly results are combined, but not saved. After the data is combined, select SAVE (ل) to protect and complete the process. Selecting Quit will exit the user from the spread sheet.

\section{RETURN TO FILE}

The computer will then present the beginning menu. Strike EXIT, followed by a self check $(Y / N)$. Strike Yes if you want to leave the LOTUS Access System. The final result will be an $A$. Retrieve the diskettes from drives $A$ and $B$, place in protective wrappers, and store in respective location. Turn the computer off using the multiple outlet switch.

\section{PROTECTION SYSTEM}

The protection status minimizes the chance that unintentional harm will be done to the spreadsheet. Basically, those areas which appear greenish are unprotected and the rest (white) are internally protected. To break the internal protection, which would be needed to change pump characteristics, simply strike Slash (/), Worksheet (W), Global (G), Protection (P), Disable $(D)$, and make corrections. It is wise to turn the protection back on after the necessary corrections are entered to protect the integrity of the spreadsheet. To turn the protection system back on, strike /WGPE.

\section{E.RASING}

This operation will be used to delete characters that change within the weeks time. To do this, strike slash (/), Range (R), Erase (E), color in range to be erased, return $(J)$, and continue. The deleted material is not losted until the spreadsheet is saved.

OTHER IMPORTANT KEYS AND INDICATORS IN LOTUS

Keys

Control break: Allows the user to escape from an internal program ("Loop").

F-1: Help key

ESC: Escape, allows the user to back-out and exit the command.

Indicators

Upper left corner of screen identifies the current location within the spread sheet, 1.e., E31.

Upper right corner of the screen indicates the command mode (ready, wait, command, error, etc.). 
Method No. EHS 5-6

Title: $\quad \mathrm{SO}_{2}$ In Air and Stack Samples Using Barium Perchlorate Titration

Date Issued: $\quad 4-78$

Approved by: MK Hamil ton

Written by: MK Hamilton

Supersẹdes Method No.

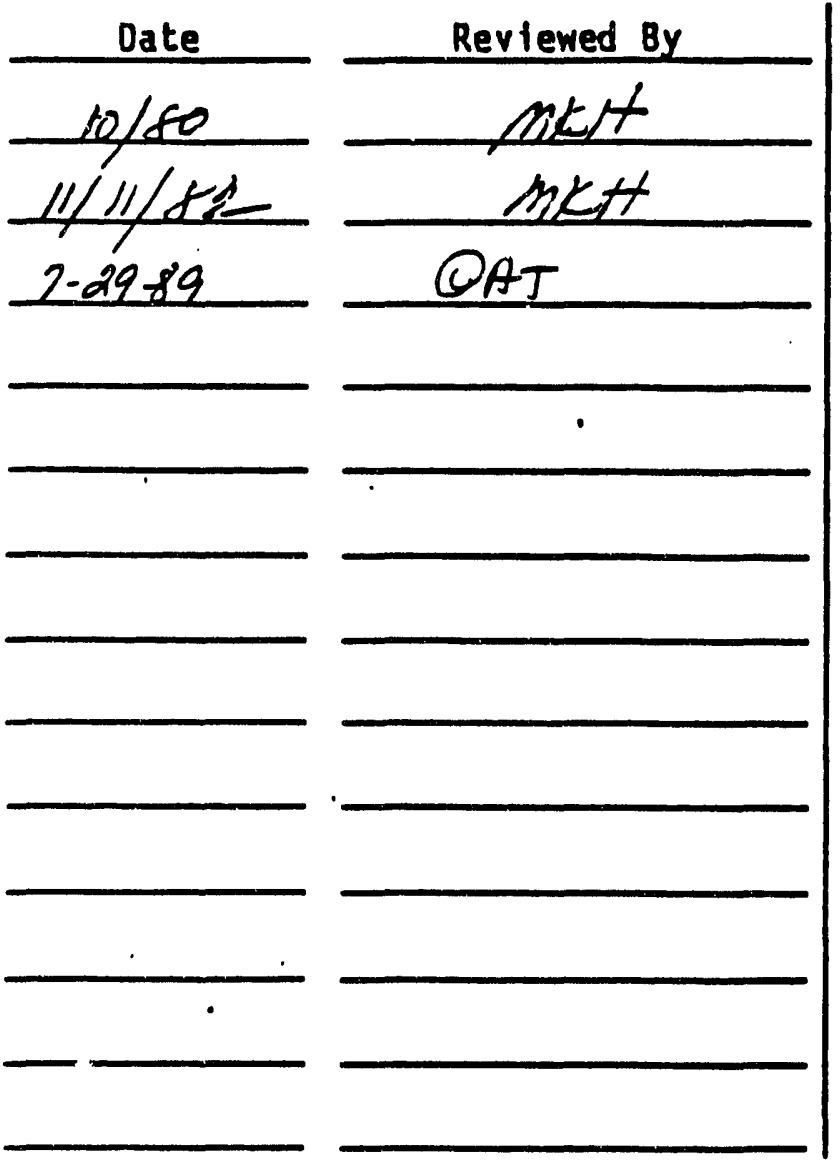

Replaced by Method No.

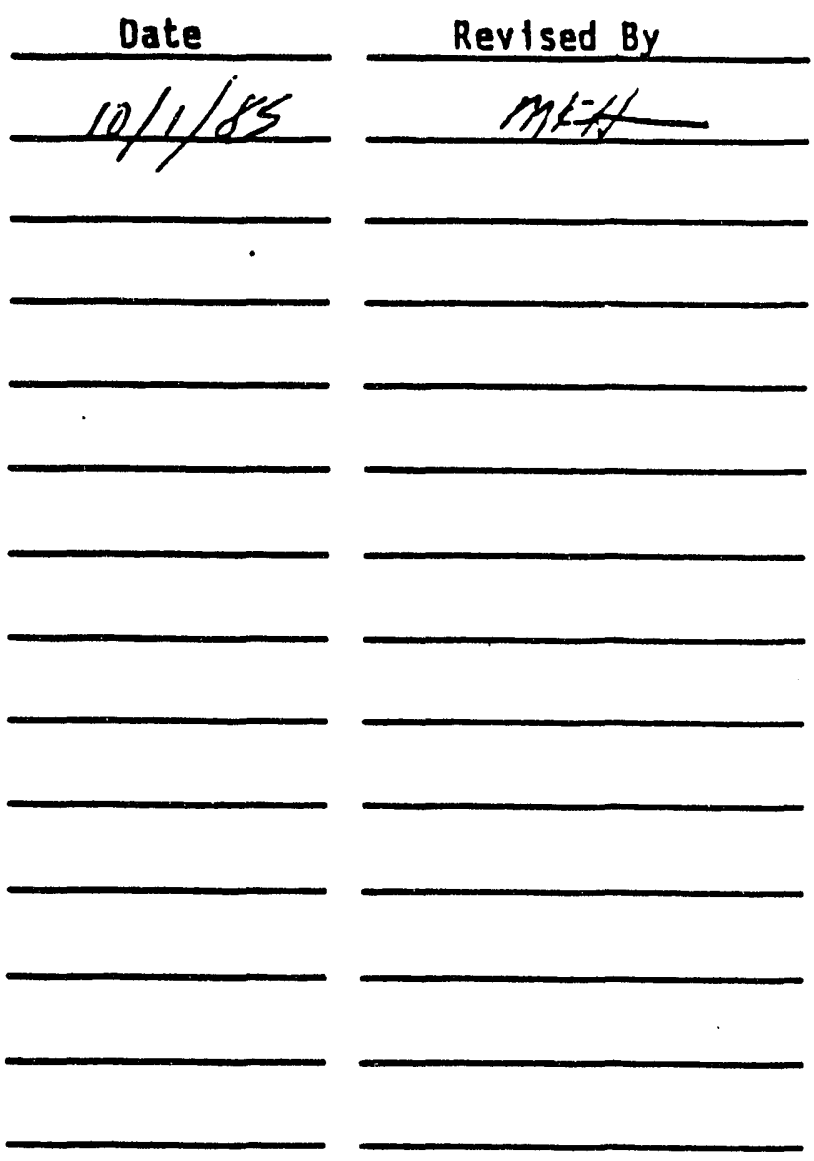

Date: 
$\mathrm{SO}_{2}$ IN AIR AND STACK SAMPLES USING BARIUM PERCHLORATE IITRATION

\section{References}

1. Sulfur Dioxide in Air, NIOSH Analytical Method P\&CAM 163.

2. Tentative Test Method for Sulfur Dioxide in Workplace Atmospheres (Barium Perchlorate Method), ASTM Designation D3449-75T.

3. EPA Method 6: Determination of Sulfur Dioxide Emissions from Stationary Sources, 40 CFR Part 60 .

\section{Princioles}

Sulfur dioxide in the air is absorbed in $0.3 \mathrm{~N} \mathrm{H}_{2} \mathrm{O}_{2}$ (3 percent $\mathrm{H}_{2} \mathrm{O}_{2}$ if stack) and oxidized to sulfate. After the $\mathrm{pH}$ of the solution has been adjusted with perchloric acid, the resulting sulfate is titrated with bartum perchlorate using thorin as the indicator.

\section{Limitations}

Particulate sulfates, sulfuric acid and $\mathrm{SO}_{3}$ will all cause erroneously high $\mathrm{SO}_{2}$ values. This problem can be eliminated by placing a $0.8 \mu$ membrane prefilter ahead of the Impinger for ambient sampling or by using an initial scrub of 80 percent 1sopropanol, as is the case when stack sampling. Metal ion and phosphate ion interferences are also eliminated by using a prefilter. oxidizing material trapped on the prefilter could cause erroneously $10 \mathrm{~W} \mathrm{SO}_{2}$ results but is not often a problem.

Equipment

1. $125 \mathrm{~mL}$ erlenmeyer flasks

2. 10 and $50 \mathrm{~mL}$ graduated burettes

3. Stack sampling train as described in EPA Method 6, or

4. Midget impingers, $0.8 \mu$ membrane filters and cassettes, and personal sampling pump

5. $\mathrm{pH}$ meter

- Reagents (Stock)

1. Barium perchlorate - $\mathrm{Ba}\left(\mathrm{ClO}_{4}\right)_{2} \cdot 3 \mathrm{H}_{2} \mathrm{O}$

2. Isopropyl alcohol (isopropanol)

3. Perchloric Acid, conc. $-\mathrm{HClO}_{4}$

4. Sulfuric Acid, conc. $-\mathrm{H}_{2} \mathrm{SO}_{4}$ 
5. Thorin indicator

6. Hydrogen peroxide, 30 percent $-\mathrm{H}_{2} \mathrm{O}_{2}$

7. Sodium hydroxide - $\mathrm{NaOH}$

8. Potassium acid phthalate (KHP), primary standard

9. Phenolphthalein indicator

10. Ethyl alcohol (ethanol)

\section{Reagent (Prepared)}

1. Hydrogen peroxide absorbing solution $(0.3 \mathrm{~N})$ - dilute $17 \mathrm{~mL}$ of 30 percent $\mathrm{H}_{2} \mathrm{O}_{2}$ to 1 liter using defonized $\mathrm{H}_{2} \mathrm{O}$. Prepare dafly.

2. 80 percent isopropanol (stack sampling only) - dilute $800 \mathrm{~mL}$ isopropanol to 1 liter with deionized $\mathrm{H}_{2} \mathrm{O}$. Prepare annually.

3. Perchloric acid (1.8\%) - dilute $25 . \mathrm{mL}$ conc. $\mathrm{HClO}_{4}$ to 1 liter with deionized $\mathrm{H}_{2} \mathrm{O}$. Prepare annually.

4. Thorin indicator solution - dissolve 0.1-0.2g thorin in $100 \mathrm{~mL}$ defonized $\mathrm{H}_{2} \mathrm{O}$. Prepare annually.

5. Phenolphthalein indicator - dissolve $0.01 \mathrm{~g}$ phenolphthale in in $50 \mathrm{~mL}$ ethanol + $50 \mathrm{~mL}$ deionized water. Prepare annually.

6. Hydrogen peroxide absorbing solution (3\%) - dilute $100 \mathrm{~mL}$ of 30 percent $\mathrm{H}_{2} \mathrm{O}_{2}$ to 1 liter with delonized $\mathrm{H}_{2} \mathrm{O}$. Prepare daily. (Stack sampling only)

\section{$\underline{\text { Standards }}$}

1. $0.0100 \mathrm{~N}$ KHP - Dissolve $0.2042 \mathrm{~g}$ oven dried potassium hydrogen phthalate in defonized $\mathrm{H}_{2} \mathrm{O}$ and dilute to $100 \mathrm{~mL}$. Prepare monthly.

2. $-0.01 \mathrm{~N} \mathrm{NaOH}$ - dissolve $0.4 \mathrm{~g} \mathrm{NaOH}$ in defonized $\mathrm{H}_{2} \mathrm{O}$ and dilute to 1

liter. Standardize every three months as follows: Pipet two $25.0 \mathrm{~mL}$ aliquots of $0.0100 \mathrm{~N}$ KHP into $125 \mathrm{~mL}$ erlenmeyer flasks. Prepare a blank from $25 \mathrm{~mL}$ deionized $\mathrm{H}_{2} \mathrm{O}$. Add 2-4 drops phenolphthalein to each and titrate with the $\mathrm{NaOH}$ to a pink end point.

$$
\begin{aligned}
\mathrm{N}_{\mathrm{NaOH}} & =\frac{m L_{K H P} \times{ }_{K H P}}{m L} \\
\mathrm{NaOH} & \\
\mathrm{NaOH}_{\mathrm{NaO}} & =(\mathrm{mL} \text { to titrate KHP) - (mL to titrate BIK) }
\end{aligned}
$$


3. $-0.01 \mathrm{~N} \mathrm{H}_{2} \mathrm{SO}_{4}$ - Add $0.3 \mathrm{~mL}$ conc. $\mathrm{H}_{2} \mathrm{SO}_{4}$ to deiontzed $\mathrm{H}_{2} \mathrm{O}$ and dilute to 1 1iter. Standardize every three months against the standardized $\mathrm{NaOH}$ as follows: Pipet two $25.0 \mathrm{~mL}$ aliquots ..of $-0.01 \mathrm{~N} \mathrm{H}_{2} \mathrm{SO}_{4}$ into $125 \mathrm{~mL}$ erlenmeyer flasks. Prepare a blank from $25 \mathrm{~mL}$ deionized $\mathrm{H}_{2} \mathrm{O}$. Add 2-4 drops phenolphthalein to each flask and titrate with the standardized $\mathrm{NaOH}$ to a pink end point.

N

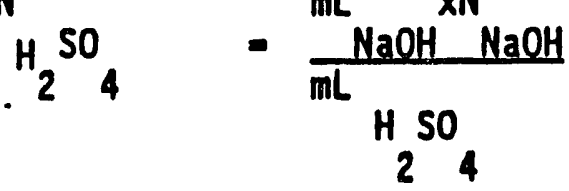

$m L_{\mathrm{NaOH}}=\left(\mathrm{mL}\right.$ to titrate $\left.\mathrm{H}_{2} \mathrm{SO}_{4}\right)$ - (mL to titrate blank)

4. $\left.-0.01 \mathrm{~N} \mathrm{Ba}^{2} \mathrm{ClO}_{4}\right)_{2}$ - Dissolve $1.95 \mathrm{~g} \mathrm{Ba}\left(\mathrm{ClO}_{4}\right)_{2}$. $3 \mathrm{H}_{2} \mathrm{O}$ in $200 \mathrm{~mL}$ deionized $\mathrm{H}_{2} \mathrm{C}$ :. Add $800 \mathrm{~mL}$ tsopropanol, $\mathrm{mix}$ well and adjust the $\mathrm{pH}$ to -3.5 with dilute $\mathrm{HClO}_{4}$. Standardize every three months as follows: Pipet two $10.0 \mathrm{~mL}$ al qquots of standardized $\mathrm{H}_{2} \mathrm{SO}_{4}$ into $125 \mathrm{~mL}$ erlenmeyer flasks and add $40 \mathrm{~mL}$ isopropanol. Prepare a blank from $10.0 \mathrm{~mL}$ detonized $\mathrm{H}_{2} \mathrm{O}+40$ $\mathrm{mL}$ isopropanol. Adjust the $\mathrm{pH}$ of the solutions to -3.5 using dilute $\mathrm{HClO}_{4}$ and add 4-6 drops thorin to each. Titrate with the $\mathrm{Ba}\left(\mathrm{ClO}_{4}\right)_{2}$ to an end point color change from yellow to pink.

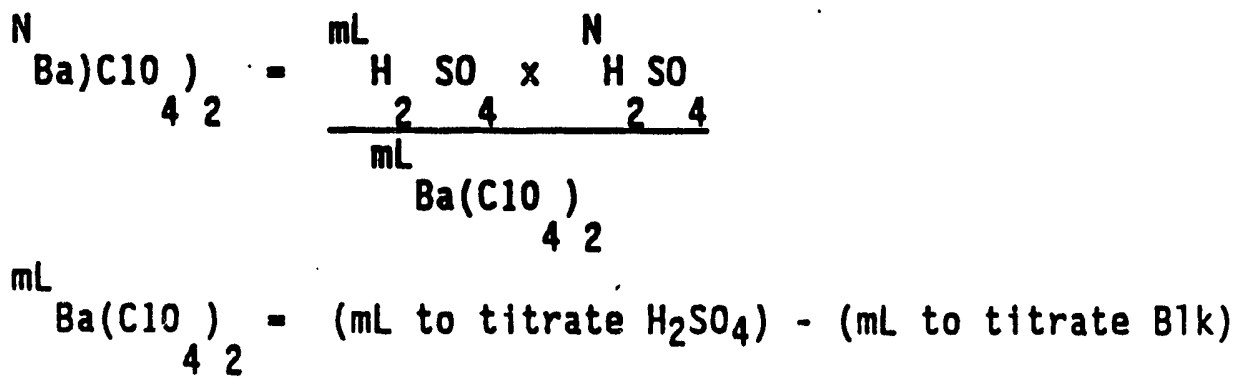

\section{Procedure}

1. Sampling

A. Stacks - see EPA Method 6

B. Ambient - Plac $15 \mathrm{~mL} 0.3 \mathrm{~N}$ peroxide absorbing solution in a midget impinger and sample at $1.0 \mathrm{Lpm}$ for a minimum of $100 \mathrm{~min}$. Use a $0.8 \mu$ membrane prefilter when necessary.

2. Analys is

A. Transfer the samples to volumetric flasks $(25 \mathrm{~mL}$ for ambient samples, $500 \mathrm{~mL}$ for stack samples) and dilute to volume with deionized $\mathrm{H}_{2} \mathrm{O}$. 
EHS-S-6-4

B. Pipet a $10.0 \mathrm{~mL}$ alfquot to a $125 \mathrm{~mL}$ erlenmeyer flask and add $40 \mathrm{~mL}$ isopropanol plus 4-6 drops thorin. Prepare a blank using $10.0 \mathrm{~mL}$ of approprlate absorbing solution in place of the sample allquot. Adjust $\mathrm{pH}$ to -3.5 using dilute $\mathrm{HClO}_{4}$.

C. Titrate to pink end point using standardized $\mathrm{Ba}\left(\mathrm{ClO}_{4}\right)_{2}$.

\section{Calculations}

1. Stack samples - see EPA Method 6 or computer program written by B. K. Grogan.

2. Ambient Samples

$$
\frac{m g / m^{3} S_{2}={ }_{B} \times H_{B} \times{ }_{S O} \times F}{V}
$$

$m L_{B}=m L B a\left(C_{4}\right)_{2}$ to titrate sple minus amount to titrate $B 1 k$

MB - Molarity $\mathrm{Ba}\left(\mathrm{ClO}_{4}\right)_{2}-1 / 2$ normality

$\mathrm{SW}_{2}-$ molecular wt $\mathrm{SO}_{2}=64.06$

$F=$ dilution factor $=\frac{\text { total sol, vol. }}{\text { aliquot vol. }}$

$V=m^{3}$ air sampled

$\mathrm{ppm} \mathrm{SO} \mathrm{S}_{2}=\mathrm{mg} / \mathrm{m}^{3} \mathrm{SO}_{2} \times 0.382$

$0.382=\frac{24.45 \mathrm{~mL} / \mathrm{mmole}}{64.06 \mathrm{mg} / \mathrm{m} \mathrm{mole}}$ 
Method No.

EHS $N-1$

Title:

Determination of $\mathrm{NO}$ In Stack Gas

Daie 1ssued: 6-25-74

Approved by: HK Hamilton

Written by: MK Hamilton

Supersedes Method No.
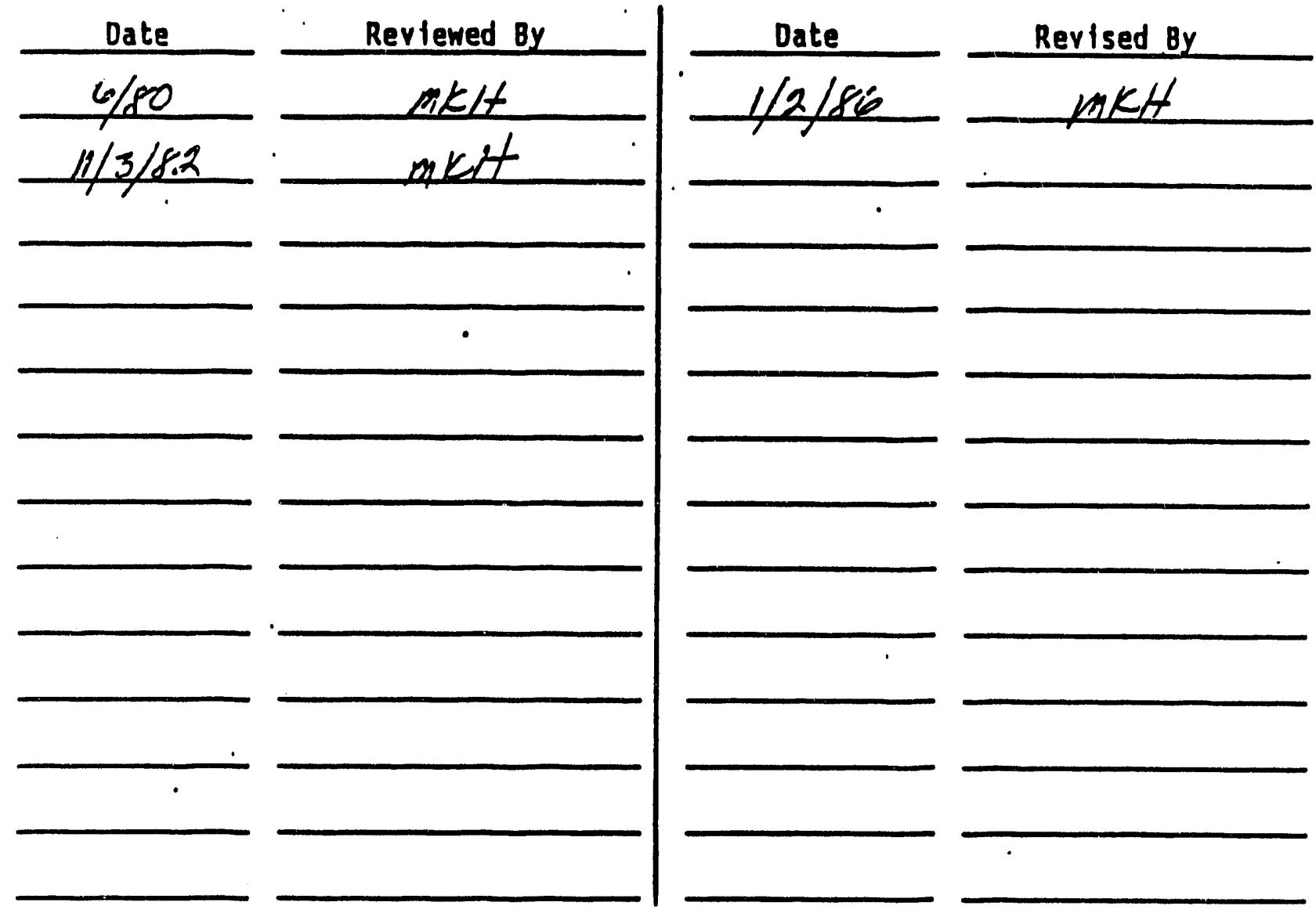

Replaced by Method No.

Date: 


\section{DETERMINATION OF NOX IN STACK GAS}

\section{References}

1. Federal Register, Vo1. 42, No. 160, August 18, 1977, pp. 41784-41786.

2. EPA Method 7, Determination of Nitrogen Oxide Emissions from Stationary Sources, October 4, 1982.

3. Environmental Sctences \& Technology 9 (10), 979-981, October 1975.

Principles

A grab sample of air is collected in an evacuated flask containing a dilute $\mathrm{H}_{2} \mathrm{SO}_{4}-\mathrm{H}_{2} \mathrm{O}_{2}$ absorbing solution. Nitrogen oxides, except nitrous oxide, are collected in this solution which is treated with phenoldisulfonic acid and neutralized with $\mathrm{NH}_{4} \mathrm{OH}$ to give a yellow color, the absorbance of which is measured at $405 \mathrm{~nm}$. Results are reported as $\mathrm{ppm} \mathrm{NO}_{2}$.

Limitations

This method is applicable for the determination of nitrogen oxides, except nitrous oxide, from stationary sources at concentrations greater than $10 \mathrm{ppm}$ $\mathrm{NO}_{2}$.

Equipment

1. 1 liter evacuable round bottom flasks $(500 \mathrm{~mL}$ and $2000 \mathrm{~mL}$ flasks may also be used).

2. Pyrex glass sampling probe

3. Vacuum pump and manometer

4. Steam bath

5. $100 \mathrm{~mL}$ beakers

6. Red or neutral litmus paper

7. $100 \mathrm{~mL}$ volumetric flasks

8. Spectrophotometer for use at $405 \mathrm{~nm}$ with $1.0 \mathrm{~cm}$ cells or sipper cell Reagents (stock)

1. Sulfuric acid, conc. $-\mathrm{H}_{2} \mathrm{SO}_{4}$

2. Hydrogen peroxide, $30 \%-\mathrm{H}_{2} \mathrm{O}_{2}$

3. Sodium hydroxide - $\mathrm{NaOH}$

4. Phenoldisulfonic acid

5. Ammonium hydroxide, conc. - $\mathrm{NH}_{4} \mathrm{OH}$ 
EHS $N-1-2$

6. Potassium nitrate, analyzed reagent - $\mathrm{KNO}_{3}$

Reagents (prepared)

1. Absorbing solution - add $2.8 \mathrm{~mL}$ conc. $\mathrm{H}_{2} \mathrm{SO}_{4}$ to 1 liter deionized $\mathrm{H}_{2} \mathrm{O}$ and $\mathrm{mix}$ well. Add $0.6 \mathrm{~mL} 30 \% \mathrm{H}_{2} \mathrm{O}_{2}$ to $5.4 \mathrm{~mL}$ detonized $\mathrm{H}_{2} \mathrm{O}$ and $\mathrm{mix}$. Add the $\mathrm{H}_{2} \mathrm{O}_{2}$ solution to the $\mathrm{H}_{2} \mathrm{SO}_{4}$ solution and mix. Store away from extreme heat or direct sunlight. Prepare weekly.

2. $1 \mathrm{~N} \mathrm{NaOH}$ - dissolve $40 \mathrm{~g} \mathrm{NaOH}$ in defonized $\mathrm{H}_{2} \mathrm{O}$ and dilute to 1 liter.

Standards

1. Stock $\mathrm{NO}_{2}$ solution ( $\left.1 \mathrm{~mL}=250 \mu \mathrm{g} \mathrm{NO}\right)$ - dissolve $0.2748 \mathrm{~g}$ oven dried $\mathrm{KNO}_{3}$ in deionized $\mathrm{H}_{2} \mathrm{O}$ and dilute to $500 \mathrm{mk}$. Prepare monthly.

2. Intermediate $\mathrm{NO}_{2}$ dilution $(1 \mathrm{~mL}-25 \mu \mathrm{g} \mathrm{NO} 2)$ - tranfer $10.0 \mathrm{~mL}$ stock $\mathrm{NO}_{2}$ solution to a $100 \mathrm{~mL}$ volumetric flask and dilute to volume with deionized $\mathrm{H}_{2} \mathrm{O}$. Prepare weekly.

Procedure

A. Sample collection

1. Fill the collection flask completely with $\mathrm{H}_{2} \mathrm{O}$ and measure the volume of water used. This gives the volume of the flask at room temp.

2. Place $25 \mathrm{~mL}$ absorbing solution in the flask and evacuate to at least 3 inches of $\mathrm{Hg}$. Measure the negative pressure (vacuum) just before using the $f$ lask and record $\left(P_{I}\right)$.

3. Purge the sample probe, then open the flask for about 15 seconds to collect a sample.

4. Close the flask and shake for 5 minutes. Allow to stand at least 16 hours.

5. Shake the flask for 2 minutes and measure the flask pressure $\left(P_{F}\right)$ at room temperature.

B. Analysis

1. Transfer the $25 \mathrm{~mL}$ absorbing solution from the sampling filask to a $100 \mathrm{~mL}$ beaker. Rinse the flask twice with $10 \mathrm{~mL}$ aliquots of deiontzed $\mathrm{H}_{2} \mathrm{O}$ and add rinsings to beaker.

2. Prepare standards by pipetting $0,1.0,3.0,6.0,10.0,15.0$ and 20.0 $\mathrm{mL}$ intermediate $\mathrm{NO}_{2}$ standard $(25 \mu \mathrm{g} / \mathrm{mL})$ into $100 \mathrm{~mL}$ beakers. Add $25 \mathrm{~mL}$ absorbing solution and enough deionized $\mathrm{H}_{2} \mathrm{O}$ to give a volume of about $45 \mathrm{~mL}$. NOTE: If analyst is new to the procedure, standards should be carried through the entire procedure before starting samples to be sure techniques are mastered and procedure is working. 
3. Neutralize samples and standards to litmus using $\mathrm{I} N \mathrm{NaOH}$. Be careful not to add excess $\mathrm{NaOH}$ as it will cause low results:

4. Evaporate all solutions to dryness on steam bath. (Avoid over-baking the samples once dryness is reached).

5. Add $2 \mathrm{~mL}$ phenoldisulfonic acid and use a plastic rod to crush and wet the residue thoroughly.

6. Add $1 \mathrm{mb}$ defonized $\mathrm{H}_{2} \mathrm{O}$ (use to rinse plastic rod) and 4 drops conc. $\mathrm{H}_{2} \mathrm{SO}_{4}$.

7. Heat on steam bath for 3 minutes with occasional stirring and cool.

8. Add $20 \mathrm{~mL}$ detonized $\mathrm{H}_{2} \mathrm{O}, \mathrm{mix}$, and add $15 \mathrm{~mL}$ conc. $\mathrm{NH}_{4} \mathrm{OH}$. (A yellow color should develop in the presence of $\mathrm{NO}_{2}$ ).

9. Transfer the solutions to $100 \mathrm{~m}$ volumetric flasks and dilute to volume with deionized $\mathrm{H}_{2} \mathrm{O}$. If the sample color is darker than the highest standard, dilute as needed.

10. Measure absorbance of samples and standards at $405 \mathrm{~nm}$ using $1.0 \mathrm{~cm}$ cells and detonized $\mathrm{H}_{2} \mathrm{O}$ reference. Sipper cell may also be used. (Color is stable for several hours.)

\section{Calculations}

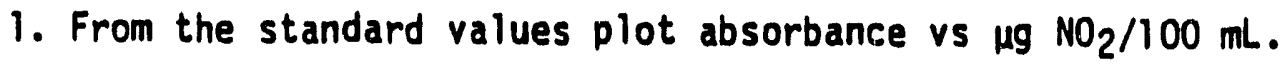

2. Using this calibration curve determine the ${ }_{10} \mathrm{NO}_{2}$ present in the samples.

3. Determine $\mathrm{ppm} \mathrm{NO} 2$ in the air samples as follows:

$$
\mathrm{ppm} \mathrm{NO} \mathrm{O}_{2}=\frac{\mathrm{A}\left(\mu \mathrm{g} \mathrm{NO} \mathrm{N}_{2} / 100 \mathrm{~mL}\right)}{\mathrm{v}_{1}} \times 0.532
$$

$A=$ dilution factor

$V_{1}=$ liter air sampled

$$
=\frac{P_{2} V_{2}}{P_{1}}
$$

$P_{1}=760 \mathrm{~mm}$ standard pressure $=29.9 \mathrm{in} . \mathrm{Hg}$

$P_{2}=$ measured flask pressure $\left(P_{\text {initial }}{ }^{-P}\right.$ final $)$ as in. $\mathrm{Hg}$

$V_{2}=(\mathrm{mL}$ flask volume $-25 \mathrm{~mL}$ absorbing solution)/1000 $=L$ air sampled

$0.532=$ factor to convert $\mu \mathrm{g} / \mathrm{L}$ to $\mu \mathrm{L} / \mathrm{L}(\mathrm{ppm})$ at $25^{\circ} \mathrm{C}$

$$
=\frac{24.45 \mu \mathrm{L}}{46.01 \mu g}
$$


$24.45 \mu$ volume of 1 umole at $25^{\circ} \mathrm{C}$

$=\frac{v_{1} T_{2}}{T_{1}}$

$V_{1}=22.4 \mu \mathrm{L} / \mathrm{umole}$ at $0^{\circ} \mathrm{C}$

$T_{1}=273^{\circ} \mathrm{K}=0^{\circ} \mathrm{C}$

$T_{2}=298^{\circ} \mathrm{K}=25^{\circ} \mathrm{C}$.

$46.01 \mathrm{\mu g}=$ weight of $1 \mu \mathrm{molec} \mathrm{NO}_{2}$

NOX SAMPLING BULB VOLUMES (BULB + CAP)

Bulb No. $\quad$ Vol, mL

101

102

103

105

108

109

110

112

113

115

117

118

123

124

125

128

130
550

552

548

535

550

535

535

545

531

530

557

559

535

530

575

552

540
Bulb No. $\quad$ Vol, m

131

132

134

135

137

139

140

141

142

143

144

147

148

149

152

153

154

548

532

535

548

526

555

535

547

538

549

532

540

541

548

535

535
Bulb No. $\quad$ Vol, mL

199 535
1035

1041

1033

1037

1028

2220

2095

2100

2310

2120 
NO SAMPLING BULB VOLUMES (BULB + CAP)

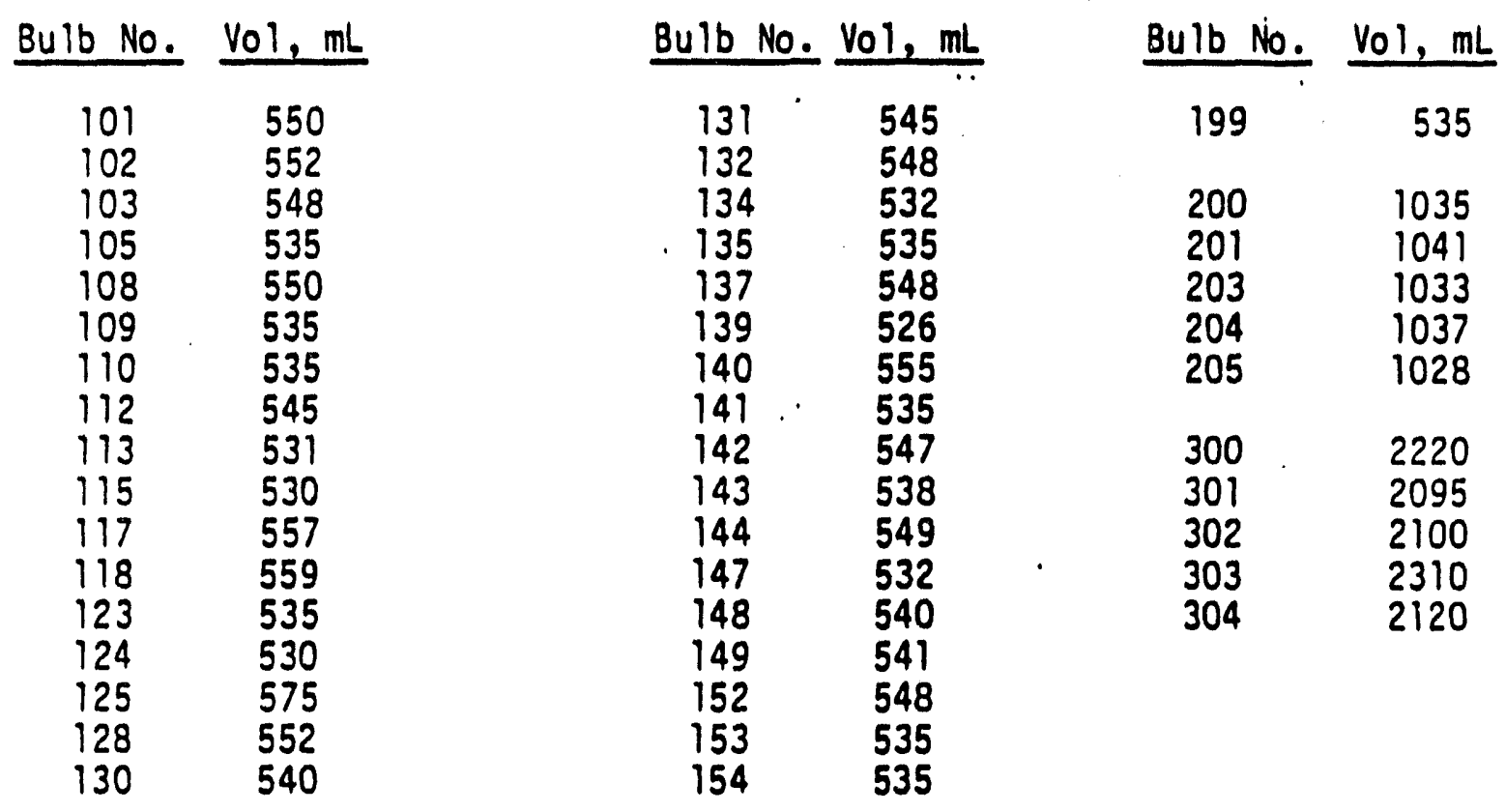


Method No. EHS H-1-1

Title:

Hardness (EDTA)

Date Issued:

Before 1983

Approved by: H. K. Hamilton /"Lí

Written by:

11. K. Hamilton

Supersedes Method No.
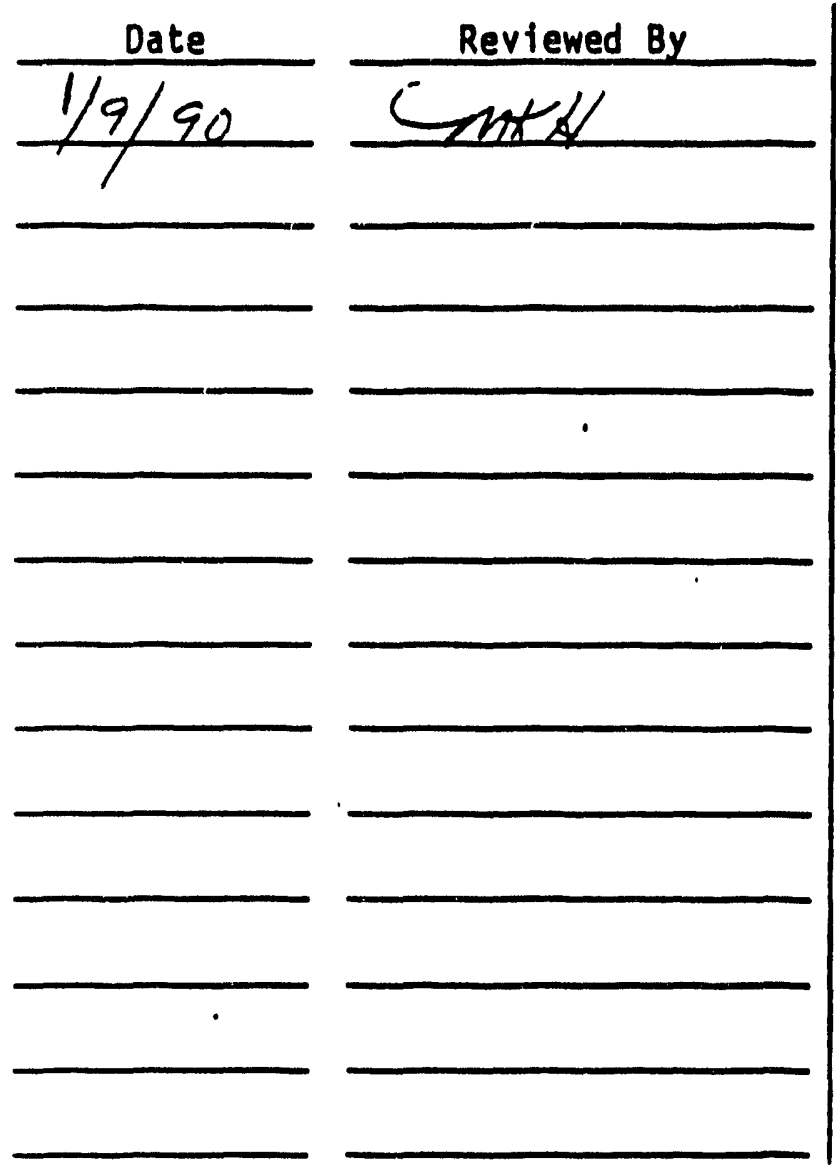

Replaced by Method No.

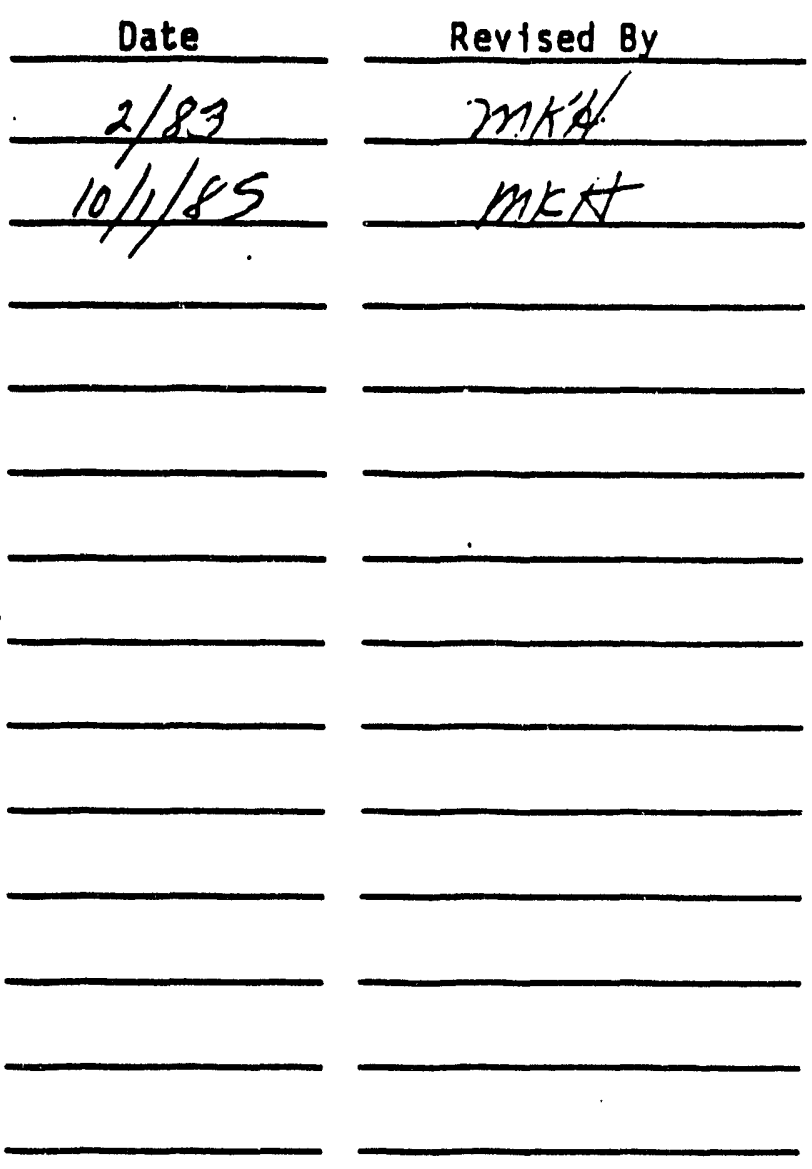

Date: 
EHS $\mathrm{H}-1-1$

$01-09-90$

HARDNESS (EDTA)..

\section{Reference}

1. Standard Methods for the Examination of Water and Wastewater, 17 th Edition, 1989, Pp. 2-52 $\rightarrow$ 2-57.

\section{Principles}

Calcium and magnesium, when present in an aqueous solution at $\mathrm{pH} 10$, will produce a wine-red color in the presence of the dye Eriochrome Black $T$. The addition of ethylenediamine tetraacetic acid (EDTA) will complex the calcium and magnesium. When the complexation is complete, the solution will change from wine-red to blue. If the EDTA has been standardized with a known concentration of calcium carbonate, the results of the EDTA hardness titration will be reported as $\mathrm{mg} / \mathrm{L} \mathrm{CaCO}_{3}$.

\section{Limitations}

Magnesium ions must be present to yield a satisfactory endpoint in the titration. To meet this requirement, a small amount of complexometrically neutral magnesium salt of EDTA is added to the buffer. An indistinct or fading endpoint may result from the presence of metal ions such as $\mathrm{Fe}, \mathrm{Cu}, \mathrm{Co}, \mathrm{Al}, \mathrm{Ni}$, etc. This problem may be overcome by the addition of an inhibitor such as hydroxylamine hydrochloride. Barium, and strontium, if present, will also titrate as EDTA hardness. Suspended or colloidal organic matter may also interfere with the endpoint. This can be overcome by evaporating the sample to dryness, heating at $550^{\circ} \mathrm{C}$, dissolving the residue in $\mathrm{IN} \mathrm{HCl}$ and neutralizing with iN NaOH.

\section{Equipment}

1. $10 \mathrm{~mL}$ buret

2. $250 \mathrm{~mL}$ erlenmeyer flasks

3. Magnetic stirrer and stirring bars

\section{Reagents (stock)}

1. Disodium ethylenediamine tetraacetate dihydrate (EDTA)--also called disodium (Ethylenedinitrilo) tetraacetate--analyzed reagent grade.

2. Ammonium chloride-- $\mathrm{NH}_{4} \mathrm{Cl}$

3. Ammonium hydroxide, conc.- $-\mathrm{NH}_{4} \mathrm{OH}$

4. (Ethylenedinitrilo) tetraacetic acid, magnesium salt 
EHS $H-1-2$

$01-09-90$

5. Eriochrome Black $T$ dye (sodium salt of 1-(1-hydroxy-2-naphthylazo)-5nitro-2-naphtriol-4-suifonic acid).

6. Triethanolamine

7. Anhydrous calcium carbonate-- $\mathrm{CaCO}_{3}-$-primary standard or ACS reagent grade.

8. Hydrochloric acid, conc.--HCl

9. Methyl orange

\section{Reagents (Prepared)}

1. Buffer--dissolve $6.75 \mathrm{~g} \mathrm{NH} \mathrm{NCl}_{4}$ in $57.2 \mathrm{~mL}$ conc. $\mathrm{NH}_{4} \mathrm{OH}$, add $0.5 \mathrm{~g}$ magnesium salt of EDTA and dilute to $100 \mathrm{~mL}$ with deionized water. Store in a polyethylene bottle, kept tightly closed when not in use. Prepare monthly.

2. Indicator--dissolve $0.5 \mathrm{~g}$ Erfochrome Black $T$ in $100 \mathrm{~g}$ triethanolamine. Prepare annually.

3. EDTA titrant--dissolve $3.723 \mathrm{~g}$ disodium EDIA in deionized water and dilute to one liter. Standardize monthly against a standard calcium solution, following the sample procedure below. Store in a polyethylene bottle. Prepare annually.

4. $3 \mathrm{~N} \mathrm{NH}_{4} \mathrm{OH}$--dilute $50 \mathrm{~mL}$ conc. $\mathrm{NH}_{4} \mathrm{OH}$ to $250 \mathrm{~mL}$ with deionized water. Prepare annually.

\section{Standards}

1. Standard calcium solution--1.0 mL $=1.0 \mathrm{mg} \mathrm{CaCO}_{3}$-weigh $1.000 \mathrm{~g}$ anhydrous $\mathrm{CaCO}_{3}$ into a $500 \mathrm{~mL}$ erlenmeyer and add $1: 1 \mathrm{HCl}$ gradual iy untif the $\mathrm{CaCO}_{3}$ dissolves. Add $200 \mathrm{~mL}$ deionized water and boil a few minutes. Cool, add a few drops methyl orange and adjust to the intermediate orange endpoint with $3 \mathrm{~N} \mathrm{NH}_{4} \mathrm{OH}$ or 1:1 HCl. Transfer quantitatively to a 1-Liter volumetric flask and dilute to volume with deionized water. Prepare every six months.

\section{Procedure}

1. Transfer a sample aliquot, requiring less than $10 \mathrm{~mL}$ EDTA titrant, to a $250 \mathrm{~mL}$ erlenmeyer flask and dilute to $100 \mathrm{~mL}$, if necessary, with deionized water.

2. Add two $\mathrm{mL}$ buffer and 4-5 drops of indicator solution. 
3. Begin stirring and titrate immediately wi.th EDTA until the last reddish tinge disappears from the solution. (If the endpoint color change is not sharp, the indicator may have deteriorated, or a different inhibitor may be needed. See standard Methods, for a list of additional indicators.)

4. Titrate a blank, using $100 \mathrm{~mL}$ deionized water instead of sample.

\section{Calculation}

1. Standardization of EDTA solution:

$$
A=\frac{B \times C}{D}
$$

$A=m g \mathrm{CaCO}_{3}$ equivalent to $1.0 \mathrm{~mL}$ EDTA

$B=\mathrm{mL}$ standard $\mathrm{CaCO}_{3}$ solution titrated

$\mathrm{C}=1.0 \mathrm{mg} / \mathrm{mL}$ concentration of $\mathrm{CaCO}_{3}$ solution

$D=m L$ EDTA needed in titration ( $m L_{s t d}-m L_{b 1 k}$ )

2. Calculation of EDTA hardness:

A. Hardness as $\mathrm{mg} / \mathrm{L} \mathrm{CaCO}_{3}=\frac{A \times B \times 1000}{C}$

$A=m g \mathrm{CaCO}_{3}$ equivalent to $1.0 \mathrm{~mL}$ EDTA

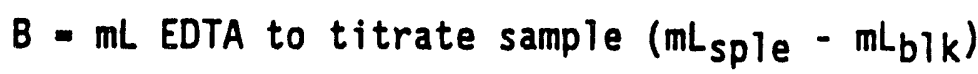

$1000=\mathrm{mL} / \mathrm{L}$

C $\quad=m L$ sample titrated

B. Hardness as grains/gal $=\frac{m g / L \mathrm{CaCO}}{17.1}$

EPA Quality criteria for water hardness:

$$
\begin{array}{ll}
0-75 \mathrm{mg} / \mathrm{L} & =\text { soft } \\
75-150 \mathrm{gm} / \mathrm{L} & =\text { mod. hard } \\
150-300 \mathrm{mg} / \mathrm{L} & =\text { hard } \\
300 \mathrm{mg} / \mathrm{L} & =\text { very hard }
\end{array}
$$


Method No.

F-1-1

Title:

Filtrable Residue (Total Dissolved Solids)

Date Issued: Fehruary 1973

Approved by: II. K. Hamilton MKHt

Written by:

M. K. Hamilton

Supersedes Method No.

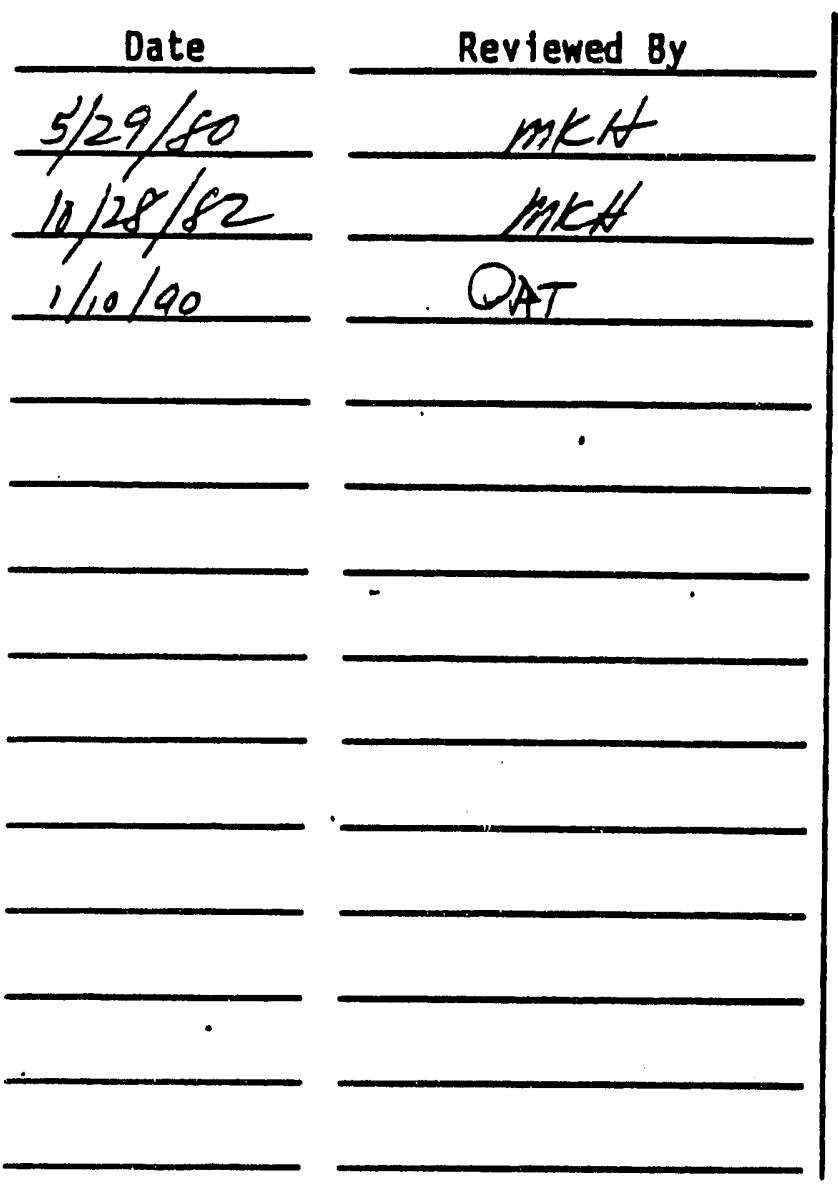

Replaced by Method No.

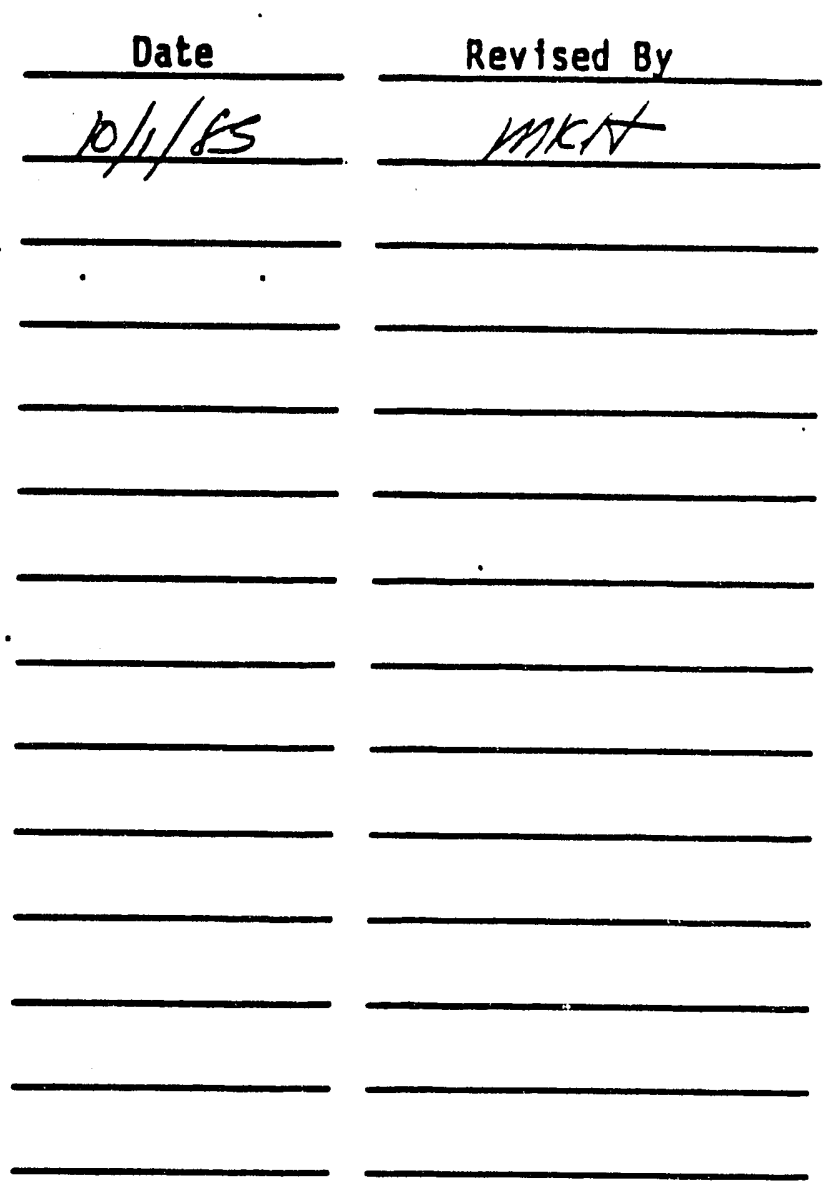

Date: 
FILTRABLE RESIDUE

(TOTAL DISSOLVED SOLIOS)

\section{Reference}

1. Standard Methods for the Examination of Water and Wastewater, 16th Edition, 1985, pp 95-96.

\section{Principle}

The sample is filtered and the filtrate is evaporated on a steam bath. The residue remaining after evaporation, drfed to a constant weight, is equal to the filtrable residue.

\section{Limitations}

Because of the many variables due to the chemical and physical nature of the sample which affect filtration, the filtrable residue value obtained is not subject to the usual criteria for accuracy. The drying temperature also affects the results. At $180^{\circ} \mathrm{C}$, some water of crystallization may remain, and the organic matter may be reduced by volatilization; however, the results agree more closely with those obtained by suming the individually determined mineral salts than residue values obtained by drying at a lower temperature.

\section{Equipment}

1. Oven for drying samples at $179-181^{\circ} \mathrm{C}$.

2. $9 \mathrm{~cm}$ Porcelain filtering funnel

3. $9 \mathrm{~cm}$ Whatman $\mathrm{GF} / \mathrm{C}$ or equivalent glass fiber filters.

4. $150-\mathrm{mL}$ porcelain evaporating dishes

5. 250 or $500 \mathrm{~mL}$ suction flasks

6. Hot plate or steam bath

\section{Procedure}

1. Diny the evaporating dishes in an oven at $180^{\circ} \mathrm{C}, \mathrm{co0l}$ in a desiccator, and weigh.

2. Assembie filtering apparatus. Rinse a glass fiber filter with about $50 \mathrm{~mL}$ of the water sample and discard the rinse.

3. Filter about $150 \mathrm{~mL}$ of the water sample t... ough the glass fiber filter.

4. Place a $100 \mathrm{~mL}$ aliquot of the filtered sample in a dried and weighed evaporating dish. Evaporate to dryness on a steam bath or ?ow temperature hot plate, being careful to avoid splattering. 
EHS $F-1-2$

5. After the water is completely evaporated, place the dish in an oven at $180^{\circ} \mathrm{C}$ for at least one hour. $\mathrm{CoO} l$ in desiccator and weigh. Repeat drying step until a constant weight is obtained. Record the temperature at which the dishes were dried on the analyst worksheet.

\section{Calculation}

For $100 \mathrm{~mL}$ aliquot:

$\mathrm{mg} / \mathrm{L}$ filtrable residue $=\mathrm{mg}$ residue $\times 10$

Report results as:

$\mathrm{mg} / \mathrm{L}$ filtrable residue on drying at $180^{\circ} \mathrm{C}$ 
Method No. EHS C-11

Title:

CHEMICAL OXYGEN DEMAND (COD)--HACH CLOSED-TUBE METHOD

Date 1ssued: $\quad 1-11-90$

Appröved by: MK Hamilton, CIH.t.

Written by: P.A. Thurman

Supersedes Method No.

EHS $C-8$

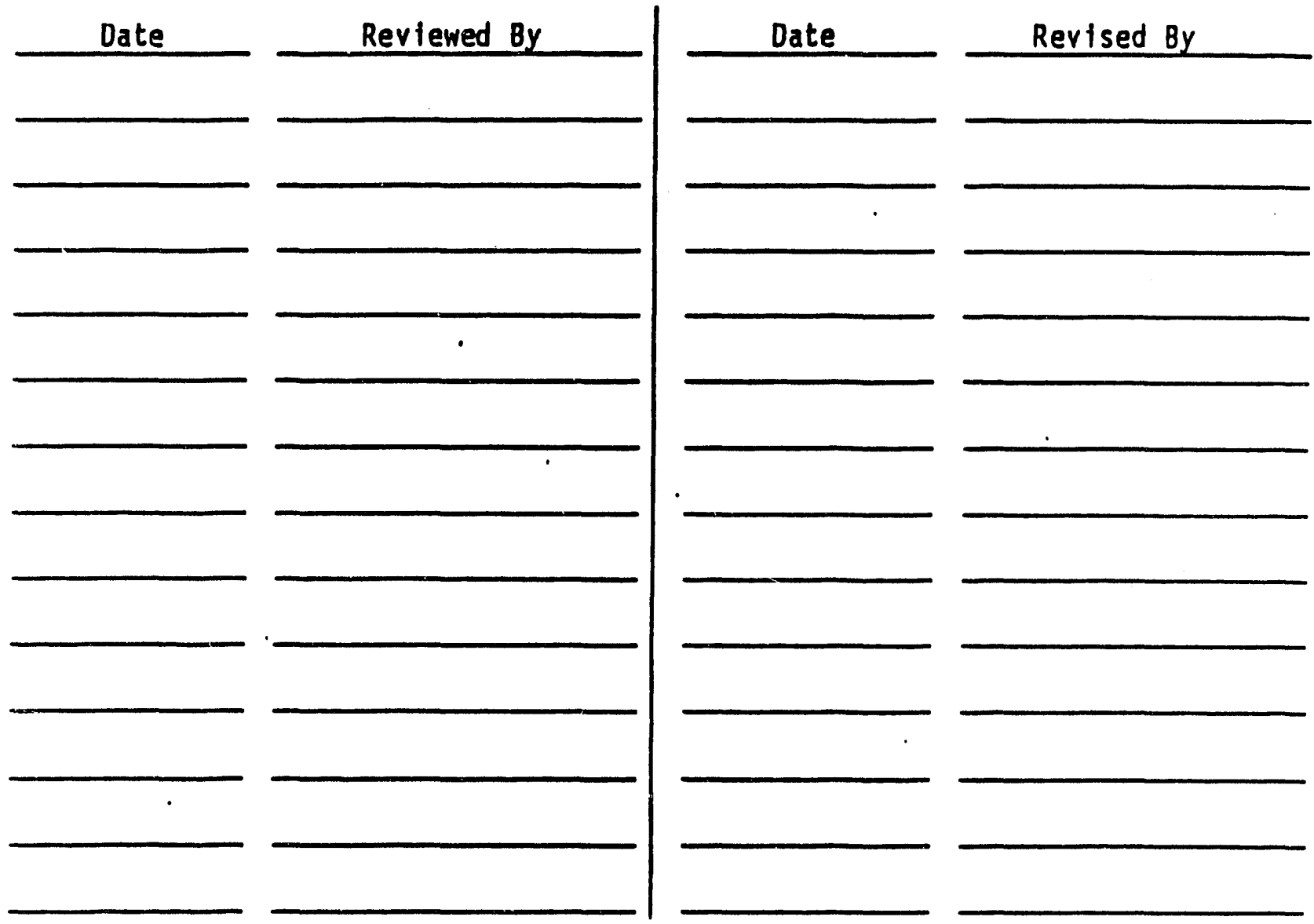

Replaced by Method No.

Date: 
EHS $C-11-1$

$01-09-90$

\section{CHEMICAL OXYGEN DEMAND (COD)--HACH CLOSED TUBE METHOD}

\section{References}

1. Hach COD Reactor Mode1 16500 Instruction Manual.

2. Standard Methods for the Examination of Water and Wastewater, 17th Edition, 1989, Section 5220C, PP 5-14 \& 15 .

\section{Principles}

Chemical Oxygen Demand (COD) is a measure of the oxygen equivalent of the material present in the sample subject to oxidation by a strong chemical oxidant, namely dichromate. The sample is refluxed in a closed tube with a known amount of potassium dichromate and sulfuric acid to oxidize most organic matter present. The excess dichromate is titrated with standard ferrous ammonium sulfate. The amount of oxidizable organic matter present is proportional to the amount of dichromate consumed.

\section{Limitations}

Volatile straight chain aliphatic hydrocarbons and pyridine and related materials may not be significantly oxidized by this procedure. Samples containing more than $2000 \mathrm{mg} / \mathrm{L}$ chloride cannot be analyzed by this procedure. The presence of significant amounts of reduced inorganic species such as ferroils iron and sulfide may produce high results as they will also be oxidized by the dichromate. This method uses reagent vials for 2 concentration ranges approved by EPA:

$0-150 \mathrm{mg} / \mathrm{L}$ COD (Hach Catalog \#21258) $0-1500 \mathrm{mg} / \mathrm{L}$ COD (Hach catalog \#21259)

\section{Equipment}

1. Hach COD reactor, Model 16500

2. Buret $--10 \mathrm{~mL}$

3. stirring bars, teflon-coated (10 $\mathrm{mm} \times 3 \mathrm{~mm})$

4. magnetic stirrer

5. small test tube rack

6. Water purification system Millipore--Milli-Q-Plus

\section{Reagents (stock)}

1. Potassium dichromate, primary standard grade-- $\mathrm{K}_{2} \mathrm{Cr}_{2} \mathrm{O}_{7}$

2. Sulfamic acid 
3. Ferrous ammonium sulfate-hexahydrate-- $\mathrm{Fe}\left(\mathrm{NH}_{4}\right)_{2}\left(\mathrm{SO}_{4}\right)_{2} \cdot 6 \mathrm{H}_{2} \mathrm{O}$

4. 1,10-phenanthroline monohydrate

5. Ferrous sulfate heptahydrate-- $-\mathrm{FeSO}_{4} \cdot 7 \mathrm{H}_{2} \mathrm{O}$

6. Potassium acid phthalate, primary standard grade

7. Sulfuric acid conc. $--\mathrm{H}_{2} \mathrm{SO}_{4}$

Reagents (Prepared)

1. Ferroin indicator solution

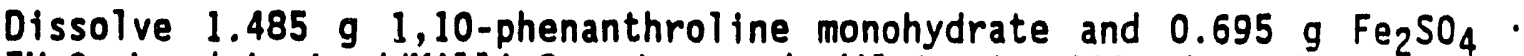
$7 \mathrm{H}_{2} \mathrm{O}$ in deionized/Milli-Q water and dilute to $100 \mathrm{~mL}$. Use a $1: 10$ difution of this for $0-150 \mathrm{mg} / \mathrm{L}$ range.

2. Ferrous Ammonium Su1fate $0.125 \mathrm{~N}$

Dissolve $12.25 \mathrm{~g} \mathrm{Fe}\left(\mathrm{NH}_{4}\right)_{2}\left(\mathrm{SO}_{4}\right)_{2} \cdot 6 \mathrm{H}_{2} \mathrm{O}$ in deionized/Milli-Q water. Add 1 $\mathrm{mL}$ conc. $\mathrm{H}_{2} \mathrm{SO}_{4}$ and dilute to $250 \mathrm{~mL}$ with deionized/Milli-Q water. Standardize with each use.

3. Ferrous Ammonium Sulfate--0.0125N

Dissolve $1.225 \mathrm{~g}$ Ferrous Ammonium sulfate in deionized/Milli-Q water. Add $1 \mathrm{~mL}$ concentrated sulfuric acid and dilute to $250 \mathrm{~mL}$ with deionized/Milli-Q water. Must be standardized with each use.

4. Potassium Dichromate--0.25 N

Dissolve $1.226 \mathrm{~g}$ primary standard $\mathrm{K}_{2} \mathrm{Cr}_{2} \mathrm{O}_{7}$, previously dried for 2 hours at $100-105^{\circ} \mathrm{C}$ in deionized/Milli-Q water. Add $12 \mathrm{mg}$ sulfamic acid and dilute to $100 \mathrm{~mL}$ with deionized Milli-Q water. Prepare every 6 months.'

5. Potassium Dichromate--0.025 N

Dissolve $0.1226 \mathrm{~g}$ dried primary standard $\mathrm{K}_{2} \mathrm{Cr}_{2} \mathrm{O}_{7}$ in deionized/Milli-Q water. Add $12 \mathrm{mg}$ sulfamic acid and dilute to $100 \mathrm{~mL}$ with deionized/Milli-Q water. Prepare every 6 months.

6. Potassium acid phthalate (KHP) standard, $500 \mathrm{mg} / \mathrm{L}$ COD equivalent

Dissolve $0.4251 \mathrm{~g}$ oven dried primary standard KHP in deionized/Milli-Q water and dilute to 1 liter. Prepare fresh when needed.

7. Hach vials with COD digestion solution for $0-150 \mathrm{mg} / \mathrm{L}(\# 21258)$ and 0 . $1500 \mathrm{mg} / \mathrm{L}$ (\#21259). 
EHS $C-11-3$

$01-09-90$

\section{Procedure}

A. Sample collection and preservation

1. Collect samples in glass containers that have been rinsed with sulfuric acid and Milli-Q deionized water.

2. If samples cannot be run immediately, acidify to $\mathrm{pH}<2$ using conc. $\mathrm{H}_{2} \mathrm{SO}_{4}\left(-2 \mathrm{~mL} / \mathrm{L}\right.$ sample) and refrigerate at $4^{\circ} \mathrm{C}$. Cooled, acidified samples are stable for 7-28 days.

3. Homogenize samples containing solid material just prior to analysis.

B. Digestion

1. Turn on Hach $\mathrm{COD}$ reactor and preheat to reach a temperature of $150^{\circ} \mathrm{C}$ for 30 minutes.

2. Slowly pipet $2.0 \mathrm{~mL}$ of sample into a Hach digestion vial containing reagents for the desired COD range. Do not use any vials which have had reagents spilled from them. Caution: Vials contain concentrated sulfuric acid, dichromate, and mercuric sulfate-. handle carefully.

3. Replace vial cap tightly and holding vial by the cap, gently severe the vial until contents are well mixed. These vials become hot--do not grab the vial itself!

4. Prepare a reagent blank using $2.0 \mathrm{~mL}$ of Milli-Q water instead of sample. Also prepare a standard in the proper range using the KHP $500 \mathrm{mg} / \mathrm{L}$ COD equivalent standard.

5. Place vials in the preheated reactor.

6. Heat vials for 2 hours at $150^{\circ} \mathrm{C}$. Turn off reactor and allow vials to cool in place to $120^{\circ}$ or less. This takes approximately 20 minutes.

7. While still warm, invert each vial several times. Place in a test tube rack and allow to cool completely. If a pure green color is obtained in the reactor sample, the sample concentration is too high for the range of the vials $(150 \mathrm{mg} / \mathrm{L}$ [low range] or $1500 \mathrm{mg} / \mathrm{L}$ [high range]). If the low range is exceeded, rerun a diluted sample or use the high range vials. If the high range is exceeded, rerun using a diluted sample. (Do not directly pipet less than i $\mathrm{mL}$ of sample of a greater dilution is needed, make dilution in another flask and pipet $2 \mathrm{~mL}$ cf the dilution into the reaction vial.) 
C. Titration Procedure $0-150 \mathrm{mg} / \mathrm{L}$ COD range *

1. Remove cap and rinse the inside walls of the digestion vial with less than $1 \mathrm{~mL}$ of Milli-Q deionized water.

2. Add a small stirring bar and one drop of the diluted Ferroin indicator to the vial. If the color changes to brown at this point, the $C O D$ is greater than $150 \mathrm{mg} / \mathrm{L}$. Rerun with $2 \mathrm{~mL}$ of a diluted sample.

3. Place vial on the magnetic stirrer and begin stirring.

4. Titrate with $0.0125 \mathrm{~N}$ ferrous ammonium sulfate to the color change from greenish-blue to orange-brown.

5. Record the volume in $\mathrm{mL}$ of the ferrous ammonium sulfate used.

6. Standardize the ferrous ammonium sulfate $(0.0125)$ as follows:

a. Pipet $2.0 \mathrm{~mL}$ of $0.025 \mathrm{~N}$ Standard Potassium Dichromate into a clean via.

b. Add $3 \mathrm{~mL}$ conc. sulfuric acid and swirl to mix. Allow to cool until comfortable to touch.

c. Add a stirring bar and one drop of the diluted Ferroin indicator.

d. Place on a magnetic stirrer and titrate with $0.0125 \mathrm{~N}$ ferrous ammonium sulfate to the color change greenish-blue to orangebrown.

e. Record the volume in $\mathrm{mL}$ of ferrous ammonium sulfate used for standardization.

7. Dispose of waste in the inorganic waste container.

D. Titration Procedure $0-1500 \mathrm{mg} / \mathrm{L}$ range

1. Remove cap and rinse the inside walls of the digestion vial with less than $1 \mathrm{~mL}$ of Milli-Q deionized water.

2. Add a stirring bar and one drop of ferroin indicator. If the color of the sample changes to brown at this point, the $\mathrm{COD}$ is greater than $1500 \mathrm{mg} / \mathrm{L}$. Rerun using a diluted sample. (Use $2 \mathrm{~mL}$ of a dilution of the sample rather than using less than $1 \mathrm{~mL}$ of the original sample.)

3. Place vial on the magnetic stirrer and begin stimsing 
4. Titrate with $0.125 \mathrm{~N}$ ferrous ammonium sulfate until color changes from greenish-blue to orange-brown.

5. Record the volume in $\mathrm{mL}$ of the ferrous ammonium sulfate used.

6. If the volume of ferrous ammonium sulfate used by the sample is within $0.2 \mathrm{~mL}$ of the volume used for the blank, the sample is too low for accurate analys is using high range reagents. Rerun sample using the low range vials.

7. Standardize the $0.0125 \mathrm{~N}$ ferrous ammonium sulfate as follows:

a. Pipet $2.0 \mathrm{~mL}$ of $0.25 \mathrm{~N}$ standard potassium dichromate into a clean vial.

b. Add $3 \mathrm{~mL}$ conc. sulfuric acid and swirl to mix. Allow to cool until comfortable to touch.

c. Add a stirring bar and one drop ferroin indicator.

d. Place on a magnetic stirrer and titrate with $0.125 \mathrm{~N}$ ferrous ammonium sulfate to a color change of greenish-blue to orangebrown.

e. Record the volume in $\mathrm{mL}$ of the ferrous ammonium sulfate used for standardization.

8. Discard waste in the inorganic waste container.

Calculation

A. $\quad 0-150 \mathrm{mg} / \mathrm{L}$ range:

$$
\begin{aligned}
(A-B) \times \frac{200}{C}=\mathrm{mg} / \mathrm{L} C O D \\
A=\mathrm{mL} \text { titrant used for blank } \\
B=\mathrm{mL} \text { titrant used for sample } \\
C=\mathrm{mL} \text { titrant used to standardize the } 0.0125 \mathrm{~N} \text { ferrous } \\
\text { ammonium sulfate }
\end{aligned}
$$

$0-1500 \mathrm{mg} / \mathrm{L}$ range:

$(A-B) \times \frac{2000}{C}=\mathrm{mg} / \mathrm{L}$ COD

$A=m L$ titrant used for blank

$B=m L$ titrant used for sample

$C=\mathrm{mL}$ titrant used to standardize the $0.125 \mathrm{~N}$ ferrous amnonium sulfate 
Method No. EHS B-4

Title: BIOCHEMICAL OXYGEN DEMAND (BOD) - DO PROBE

Date Issued: Before $5 / 80$

Approved by: MK Hamilto phet

Written by: PA Swoboda

Supersedes Method No.

EHS B-1

\begin{tabular}{c}
$\frac{\text { Date }}{5 / 29 / 80}$ \\
\hline $10 / 27 / 82$ \\
\hline $9 / 22 / 85$ \\
$1-15-88$ \\
\hline
\end{tabular}

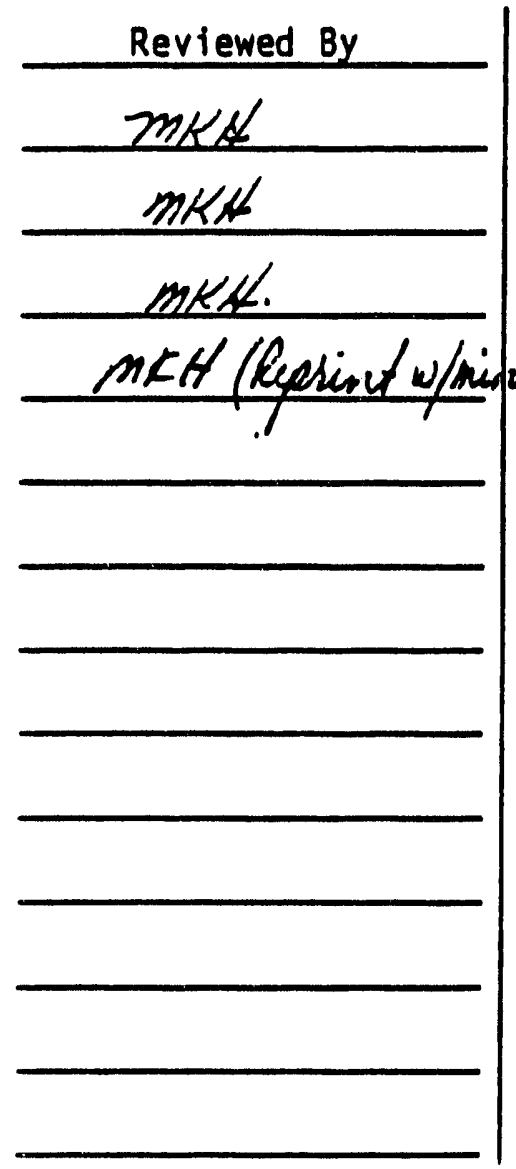

Replaced by Method No.

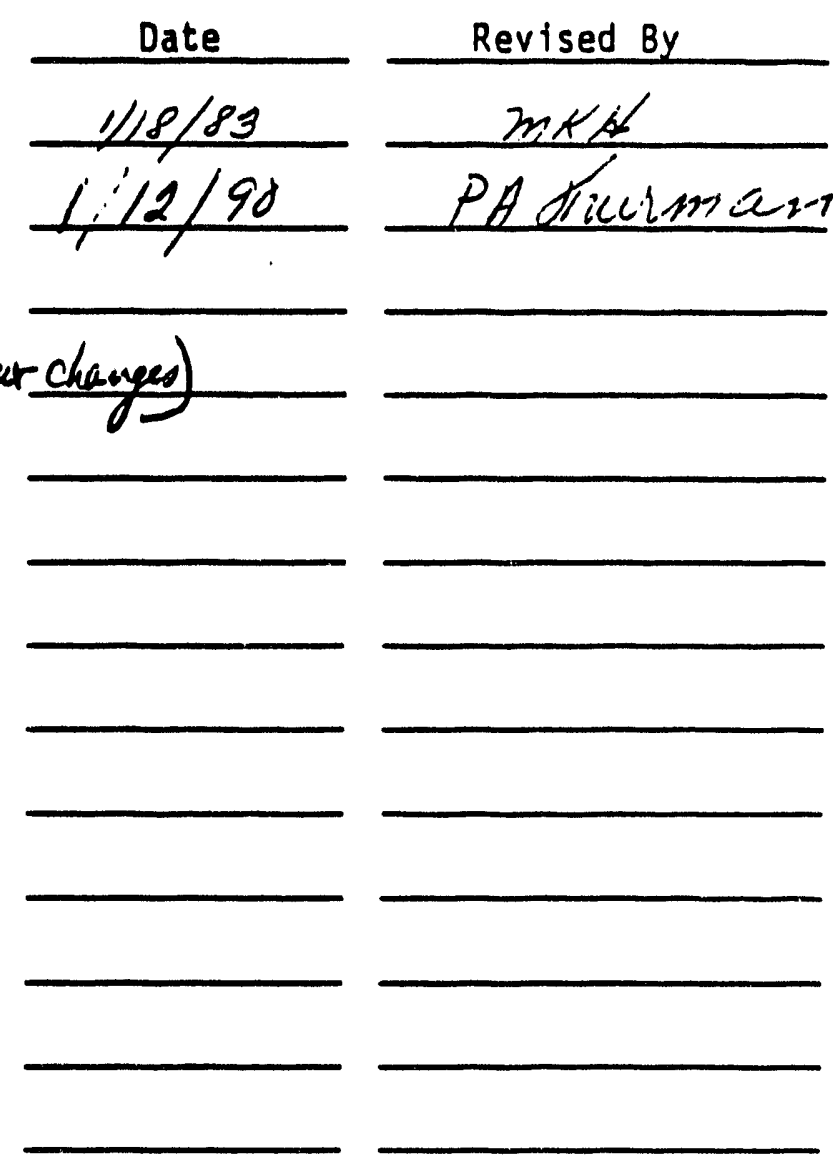

Date: 
EHS B-4-1

$01-12-90$

\section{BIOCHEMICAL OXYGEN DEMAND (BOD) - -DO PROBE}

1. Standard Methods for the Examination of Water and Wastewater, 17 th Edition, 1989, Section 5210, pp. 5-2 through 5-10.

2. YSI Dissolved Oxygen Meter--Instruction Manual.

3. Introduction to Biological Oxygen Demand, Technical Information Series.Booklet No. 7, Hach, 1989.

\section{Principles}

The biochemical oxygen demand is an empirical test to determine the relative oxygen requirements of waste waters, effluents, and polluted waters. This is done by determining the dissolved oxygen (DO) present initially and after a five-day incubation at $20^{\circ} \mathrm{C}$. The difference in these two values equals the BOD. The amount of dissolved oxygen present is determined using the YSI Model 58 Dissolved Oxygen Meter. Dissolved oxygen measurements are taken using the membrane covered probe. This membrane allows oxygen and certain other gases to pass through so that when a polarizing voltage is applied across the sensor, oxygen that has passed through reacts at the cathode causing a current. This is read on the scale as ppm dissolved oxygen.

\section{Limitations}

The $B O D$ values obtained cannot be compared with other BOD results unless they were obtained under identical test conditions. Any oxidizing or reducing materials which are present could cause interferences in the DO analysis. Residual chlorine, which may be present, is destroyed by adding an equivalent amount of sodium sulfite. If the samples are supersaturated with DO, they should be reduced to saturation by aerating with compressed air to prevent loss of oxygen during incubation.

\section{Equipment}

1. YSI Model 58 dissolved oxygen meter

2. YSI Model $5720 \mathrm{~A}$ BOD bottle probe

3. Air incubator thermostatically controlled at $20^{\circ} \mathrm{C} \pm 1^{\circ} \mathrm{C}$

4. Flared mouth BOD bottles, $300 \mathrm{~mL}$

5. Various size graduated cylinders

6. 11-liter glass container

7. Tubing for siphons

8. Deionized water finishing system--Millipore Milli-Q Plus

\section{Reagents (Stock)}

1. Sodium hydroxide $(\mathrm{NaOH})$ 
2. Sodium sulfite $\left(\mathrm{Na}_{2} \mathrm{SO}_{3}\right)$

3. DPD free chlorine reagent

4. Sulfuric Acid, Cond. $\left(\mathrm{H}_{2} \mathrm{SO}_{4}\right)$

5. Glucose

6. Glutamic acid

7. Nutrient buffer pillows (Hach \#14861-98)

\section{Reagents (Prepared)}

1. IN $\mathrm{NaOH}--$ dissolve $40.0 \mathrm{~g} \mathrm{NaOH}$ in deionized water and dilute to one liter. Prepare annually:

2. IN $\mathrm{H}_{2} \mathrm{SO}_{4}$--add $28 \mathrm{~mL}$ conc. $\mathrm{H}_{2} \mathrm{SO}_{4}$ to deionized water and dilute to one liter. Prepare annually.

3. BOD dilution water--place the necessary amount of Milli-Q deionized water into a large glass container. For every 3 liters of water, add one Hach 3-1iter nutrient buffer pillow. Mix well to assure complete dissolution of the reagents (some residue may remain with some pillows). Saturate with DO by aerating with compressed air. The temperature should be $20^{\circ} \mathrm{C} \pm 1^{\circ} \mathrm{C}$. Prepare dilution water the day of use.

4. Glucose-Glutamic acid control solution--dissolve $0.150 \mathrm{~g}$ dried glucose and $0.150 \mathrm{~g}$ dried glutamic acid in deionized water and dilute to 1 liter with Milli-Q deionized water. Prepare as needed.

\section{Procedure}

A. Dilution Preparation

1. Check the $\mathrm{pH}$ of the samples and adjust to $\mathrm{pH} 6.5-7.5$, using $\mathrm{IN}$ $\mathrm{H}_{2} \mathrm{SO}_{4}$ or $1 \mathrm{~N} \mathrm{NaOH}$.

2. Add a DPD free chlorine reagent pillow to $5 \mathrm{~mL}$ of sample to check for residual chlorine. If the test is positive (pink color), add a small amount of $\mathrm{Na}_{2} \mathrm{SO}_{3}$ to the original sample. Mix (DO NOT SHAKE). Allow to sit a few minutes, then repeat procedure until the test shows no pink color change upon addition of DPD reagent. 
3. Make several dilutions of the sample. (See Standard Methods if seeding is necessary.) Suggested dilution ranges for samples are:

$$
\begin{array}{ll}
0.1-1.0 \% & \text { strong trade waste } \\
1-5 \% & \text { raw and settled sewage } \\
5-25 \% & \text { oxidized effluents } \\
25-100 \% & \text { polluted river water }
\end{array}
$$

Make the dilutions as follows:

Siphon BOD dilution water into a $1000 \mathrm{~mL}$ graduated cylinder until the cylinder is about half full. Siphon the desired amount of mixed sample into an appropriate graduated cylinder and carefully add it to the cylinder of dilution water. Adjust volume to $1000 \mathrm{~mL}$ with dilution water and mix well with a glass rod. IMPORTANT: DURING THE ENTIRE DILUTION PROCESS, BE CAREFUL TO AVOID TRAPPING AIR IN THE SOLUTIONS.

4. Siphon each of the mixed dilutions into one BOD bottle and stopper tightly, covering the seal with solution. Read the initial DO, then incubate sample bottle for five days at $20^{\circ} \mathrm{C}$. Replace any lost solution with dilution water as needed to maintain the water seal.

5. Fill a BOD bottle with dilution water for a blank and treat as a sample.

6. Prepare a control by carefully pipetting $20.0 \mathrm{~mL}$ of the glucoseglutamic acid solution into a $1000 \mathrm{~mL}$ volumetric flask and diluting to volume with Milli-Q deionized water. Fill a BOD bottle and proceeding as with a sample.

7. After five days, determine the final DO of the incubated samples.

B. Determination of $D 0$

1. Preparation of probe and meter:

a) See Appendix 1 for filling probe with electrolyte and membrane placement. Membrane should be replaced every month or sooner if bubbles and discoloration appear under the membrane or if the meter cannot be calibrated.

b) Allow 15 minutes for instrument warm up and probe stabilization before calibrating. This is done with the meter turned to the $0.01 \mathrm{mg} / \mathrm{L}$ range. Steps $b$ and $c$ must be performed whenever the instrument has been off or the probe has been disconnected. 
EHS $8-4-4$

$01-12-90$

c) Switch the meter to the zero position and adjust the $\mathrm{O}_{2}$ zero control knob to give a meter reading of 00.0 .

2. Calibration--Air Calibration--Fresh Water

a) The probe is kept stored in a partially filled BOD bottle. This provides moist air necessary for the calibration and prevents dehydration of the electrolyte.

b) Switch the meter to the temperature position and note the temperature. Refer to Table 1 and determine the dissolved oxygen calibration value.

c) Determine the atmospheric correction factor using Table 2.

d) Multiply the calibration value from Table 1 by the correction factor from Table 2 (correction factor for Tri-Cities area = $0.98)$.

Example: At a temperature of $22^{\circ} \mathrm{C}$ (from Table 1) the calibration value is $8.8 \mathrm{ppm}$. $8.8 \times 0.98$ (correction factor) $=8.62$.

e) Switch to the $0.01 \mathrm{mg} / \mathrm{L}$ range and adjust the calibrate knob so that the meter reads the corrected calibration value from Step d. Wait 2 minutes to verify stability. Readjust, if necessary.

3. Dissolved oxygen measurement

a) Place the probe in the sample BOD bottle, being careful not to trap air bubbles, and turn on probe stirrer.

b) Allow sufficient time for probe to stabilize to sample temperature and dissolved oxygen (approximately 2-3 min.).

c) Read dissolved oxygen in $\mathrm{mg} / \mathrm{L}$ from the meter.

Calculations

$$
\begin{aligned}
& m g / L B O D=\frac{\left[\left(D_{1}-D_{2}\right)-B 1 k\right]}{P} \\
& D_{1}=D O \text { of initial diluted sample } \\
& D_{2}=D 0 \text { of diluted sample after incubation } \\
& P=\text { dilution factor }=\frac{\mathrm{mL} \text { sample used }}{1000 \mathrm{~mL}} \\
& B 1 k=\left(D O_{B} 1 k_{1}-D O_{B} 1 k_{2}\right)-P\left(D O_{B} 1 k_{1}-D O_{B} 1 k_{2}\right)
\end{aligned}
$$


EHS B-4-5

$01-12-90$

Example:

$20 \mathrm{~mL}$ of sample diluted to $1000 \mathrm{~mL}$

$D_{1}=8.15 \quad z_{2}=4.25 \quad P=0.02(20 / 1000)$

$\mathrm{DOB}_{\mathrm{B}} \mathrm{k}_{1}=8.20 \quad \mathrm{DOB}_{\mathrm{B} 1 \mathrm{k}_{2}}=8.05$

$m g / L=\frac{(8.15-4.25)-[(8.20-8.05)-0.02(8.20-8.05)]}{0.02}$

$\frac{-3.90-(0.15-0.003)}{0.02}=188$

Qual ity Control

Routine quality control for this procedure includes monitoring results obtained for the blank and glucose-glutamic acid control solution. Uptake of unseeded blanks should not exceed $0.2 \mathrm{mg} / \mathrm{L} \mathrm{DO}$. The control solution should give a BOD equivalent of $198 \mathrm{mg} / \mathrm{L} \pm 30$. If these conditions are not met, evaluate the procedure for possible interference or contamination problems. 


\section{Calibration Tables}

Table 1 shows the amount of oxygen in PPM-that is dissolved in air saturated fresh water at sea level (760 $\mathrm{mm} \mathrm{Hg}$ atmospheric pressure), as temperature varies from $0^{\circ}$ to $45^{\circ} \mathrm{C}$.

\section{Table 1}

Solubility

\begin{tabular}{cccc}
\hline $\begin{array}{c}\text { Temperature } \\
\text { C }\end{array}$ & $\begin{array}{c}\text { PPM Dissolved } \\
\text { Oxygen }\end{array}$ & $\begin{array}{c}\text { Temperature } \\
\text { C }\end{array}$ & $\begin{array}{c}\text { PPM Dissolved } \\
\text { Oxygen }\end{array}$ \\
\hline 0 & 14.6 & 23 & 8.7 \\
1 & 14.2 & 24 & 8.5 \\
2 & 13.9 & 25 & 8.4 \\
3 & 13.5 & 26 & 8.2 \\
4 & 13.2 & 27 & 8.1 \\
5 & 12.8 & 28 & 7.9 \\
6 & 12.5 & 29 & 7.8 \\
7 & 12.2 & 30 & 7.7 \\
8 & 11.9 & 31 & 7.5 \\
9 & 11.6 & 32 & 7.4 \\
10 & 11.3 & 33 & 7.3 \\
11 & 11.1 & 34 & 7.2 \\
12 & 10.8 & 35 & 7.1 \\
13 & 10.6 & 36 & 7.0 \\
14 & 10.4 & 37 & 6.8 \\
15 & 10.2 & 38 & 6.7 \\
16 & 9.9 & 39 & 6.6 \\
17 & 9.7 & 40 & 6.5 \\
18 & 9.5 & 41 & 6.4 \\
19 & 9.3 & 42 & 6.3 \\
20 & 9.2 & 43 & 6.2 \\
21 & 9.1 & 44 & 6.1 \\
22 & 8.8 & 45 & 6.0 \\
\hline
\end{tabular}

Source: Derived from Standard Methods for the Examination of Water and Wastewater. 
EHS B-4-7

$01-12-90$

Table II shows the correction factor that should be used to correct the calibration value for the effects of atmospheric pressure or altitude. Find true atmospheric pressure in the left hand column and read across to the right hand column to determine the correction factor. (Note that "true" atmospheric pressure is as read on a barometer. Weather Bureau reporting of atmospheric pressure is corrected to sea level.) If atmospheric pressure is unknown, the local altitude may be substituted. Select the altitude in the center column and read across to the right hand column for the correction factor.

\section{Table LI}

Correction for Atmospheric Pressure

\begin{tabular}{crc}
\hline $\begin{array}{c}\text { Atmospheric Pressure } \\
\mathrm{mm} \mathrm{Hg}\end{array}$ & or & $\begin{array}{c}\text { Equivalent } \\
\mathrm{Ft} .\end{array}$ \\
\hline 775 & 540 & $\begin{array}{c}\text { Correction } \\
\text { Factor }\end{array}$ \\
760 & 0 & 1.02 \\
745 & 542 & 1.00 \\
730 & 1094 & .98 \\
714 & 1688 & .96 \\
699 & 2274 & .94 \\
684 & 2864 & .92 \\
669 & 3466 & .90 \\
654 & 4082 & .88 \\
638 & 4756 & .86 \\
623 & 5403 & .84 \\
608 & 6065 & .82 \\
593 & 6744 & .80 \\
578 & 7440 & .78 \\
562 & 8204 & .76 \\
547 & 8939 & .74 \\
532 & 9694 & .72 \\
517 & 10472 & .70 \\
502 & 11273 & .68 \\
& & .66 \\
\hline
\end{tabular}

Source: Derived from Standard Methods for the Examination of Water and Wastewater. 


\section{APPENDIX 1}

\section{Operating Procedures}

PREPARING THE PROBE

All YSI 5700 Series Probes have similar sensors and should be cared for in the same manner. They are precision devices relying on good treatment if high accuracy measurements are to be made. Prepare the probes as follows (see Figure 1):

\section{ALL PROBES ARE SHIPPED DRY--YOU MUST FOLLOW THESE INSTRUCTIONS}

1. Prepare the electrolyte by dissolving the $\mathrm{KCl}$ crystals in the dropper bottle with deionized water. Fill the bottle to the top.

2. Unscrew the sensor guard from the probe (YSI 5739 only) and then remove the "O" ring and membrane. Thoroughly rinse the sensor with $\mathrm{KCl}$ solution.

3. Fill the probe with electrolyte as follows:

A. Grasp the probe in your left hand. When preparing the YSI 5739 probe, the pressure compensating vent should be to the right. Successively fill the sensor body with electrolyte while pumping the diaphragm with the eraser end of a pencil or similar soft, blunt tool. Continue filling and pumping until no more air bubbles appear. (With practice, you can hold the probe and pump with one hand while filling with the other.) When preparing the YSI 5720A and 5750 probes, simply fill the sensor body until no more air bubbles appear.

B. Secure a membrane under your left thumb. Add more electrolyte to the probe until a large meniscus completely covers the gold cathode.

NOTE: Handle membrane material with care, keeping it clean and dust free, and touching it only at the ends.

C. With the thumb and forefinger of your other hand, grasp the free end of the membrane.

D. Using a continuous motion, stretch the membrane UP, OVER, and DOWN the other side of the sensor. Stretching forms the membrane to the contour of the probe. The membrane can be stretched to approximately $1-1 / 2$ times its normal length.

E. Secure the end of the membrane under the forefinger of the hand holding the probe.

F. Roll the "O" ring over the end of the probe. There should be no wrinkles (or trapped air bubbles) in the membrane. Some wrinkles may be removed by lightly tugging on the edges of the membrane beyond the "o" ring. 
G. Trim off excess membrane with scissors or sharp knife. Check that the stainless steel temperature sensor is not covered by excess membrane.

4. Shake off excess $K C l$ and reinstall the sensor guard.

5. The YSI 5720A and 5750 probes can be stored in a B.0.D. bottle containing about 1 inch of water.

6. Membranes will last indefinitely, depending on usage. Average replacement is 2-4 weeks. However, should the electrolyte be allowed to evaporate and an excessive amount of bubbles form under the membrane, or the membrane become damaged, thoroughly flush the reservoir with $\mathrm{KCl}$ and install a new membrane.

7. Also, replace the membrane if erratic readings are observed or calibration is not stable.

8. "Home brew" electrolyte can be prepared by making a saturated solution of reagent grade $\mathrm{KCl}$ and deionized water, and then diluting the solution to half strength with deionized water. Adding 2 drops of Kodak Photo Flo per $100 \mathrm{~mL}$ of solution assures good wetting of the sensor, but is not absolutely essential.

9. The gold cathode should always be bright and untarnished. To clean, wipe with a clean lint-free cloth or hard paper. NEVER USE ANY FORM OF ABRASIVE OR CHEMICAL. Rinse the sensor several times with $K C I$, refill, and install a new membrane.

10. Some gasses contaminate the sensor, evidenced by discoloration of the gold. If the tarnish cannot be removed by vigorous wiping with a soft cloth, lab wipe, or hard paper, return the probe to the factory for service.

11. Oxides of nitrogen and sulphur, halides, and $\mathrm{H}_{2} \mathrm{~S}$ are known interfering gases. Helium and Neon are reported to interfere with the oxygen reaction at the cathode. If you suspect erroneous readings, it may be necessary to determine if these are the cause.

12. If the probe has been operated for extended periods with a loose or wrinkled membrane, the gold cathode may become plated with silver. In this event, return the probe to the factory for refinishing. 


\section{APPENDIX 2 \\ ALTERNATE DILUTION WATER PREPARATION}

As an alternative to using the Hach nutrient buffer pillows to prepare the dilution water, the following method may be used:

\section{Reagents (Stock)}

1. Potassium dihydrogen phosphate $\left(\mathrm{KH}_{2} \mathrm{PO}_{4}\right)$.

2. Dipotassium hydrogen phosphate $\left(\mathrm{K}_{2} \mathrm{HPO}_{4}\right)$

3. Disodium hydrogen phosphate $\left(\mathrm{Na}_{2} \mathrm{HPO}_{4} \cdot 7 \mathrm{H}_{2} \mathrm{O}\right)$

4. Anmonium chioride $\left(\mathrm{NH}_{4} \mathrm{Cl}\right)$

5. Magnesium sulfate $\left(\mathrm{MgSO}_{4} \cdot 7 \mathrm{H}_{2} \mathrm{O}\right.$ or $\left.\mathrm{MgSO}_{4}\right)$

6. Calcium chloride $\left(\mathrm{CaCl}_{2}\right)$

7. Ferric chloride $\left(\mathrm{FeCl}_{3} \cdot \mathrm{TH}_{2} \mathrm{O}\right)$

\section{Reagents (Prepared)}

1. Phosphate buffer--pH 7.2--dissolve $4.25 \mathrm{~g} \mathrm{KH}_{2} \mathrm{PO}_{4}, 10.9 \mathrm{~g} \mathrm{~K}_{2} \mathrm{HPO}_{4} \cdot 16.7 \mathrm{~g}$ $\mathrm{Na}_{2} \mathrm{HPO}_{4} \cdot \mathrm{TH}_{2} \mathrm{O}$, and $0.85 \mathrm{~g} \mathrm{NH}_{4} \mathrm{Cl}$ in $\mathrm{Milli}-\mathrm{Q}$ deionized water and dilute to $500 \mathrm{~mL}$. Prepare annualiy or when Blank values exceed $0.2 \mathrm{mg} / \mathrm{L}$.

2. Magnesium sulfate solution--dissolve $11.2 \mathrm{~g} \mathrm{MgSO}_{4} \cdot 7_{2} \mathrm{O}(5.3 \mathrm{~g} \mathrm{MgSO}$ ) in Milli-Q defonized water and dilute to $500 \mathrm{~mL}$. Prepare annually or when Blank values exceed $0.2 \mathrm{mg} / \mathrm{L}$.

3. Calcium chloride solution--dissolve $13.75 \mathrm{~g} \mathrm{CaCl}_{2}$ in Milli-Q deionized water and dilute to $500 \mathrm{~mL}$. Prepare annually or when Blank values exceed $0.2 \mathrm{mg} / \mathrm{L}$.

4. Ferric chloride solution--dissolve $0.125 \mathrm{~g} \mathrm{FeCl}_{3} \cdot 6 \mathrm{H}_{2} \mathrm{O}$ in Milli-n deionized water and dilute to $500 \mathrm{~mL}$. Prepare annually or when Blank values exceed $0.2 \mathrm{mg} / \mathrm{L}$.

\section{Dilution Water Preparation}

Place the necessary amount of Milli-Q deionized water in a large glass container. Saturate the water with $D O$ by aerating with compressed air. The temperature of the water should be $20^{\circ} \pm 1^{\circ} \mathrm{C}$. For each liter of water, add $1 \mathrm{~mL}$ each of the phosphate buffer, magnesium sulfate solution, calcium chloride solution and ferric chloride solution. Prepare the dilution water the day of use. 
Method No. EHS L-1

Title: Linear Alkybenzene Sulfonate - Nethylene Blue Active Substances - (MBAS)

Date 1ssued: Before 3-83

Approved by: MK Hamilton'Mk't

Written by: MK Hamilton

Supersedes Method No.

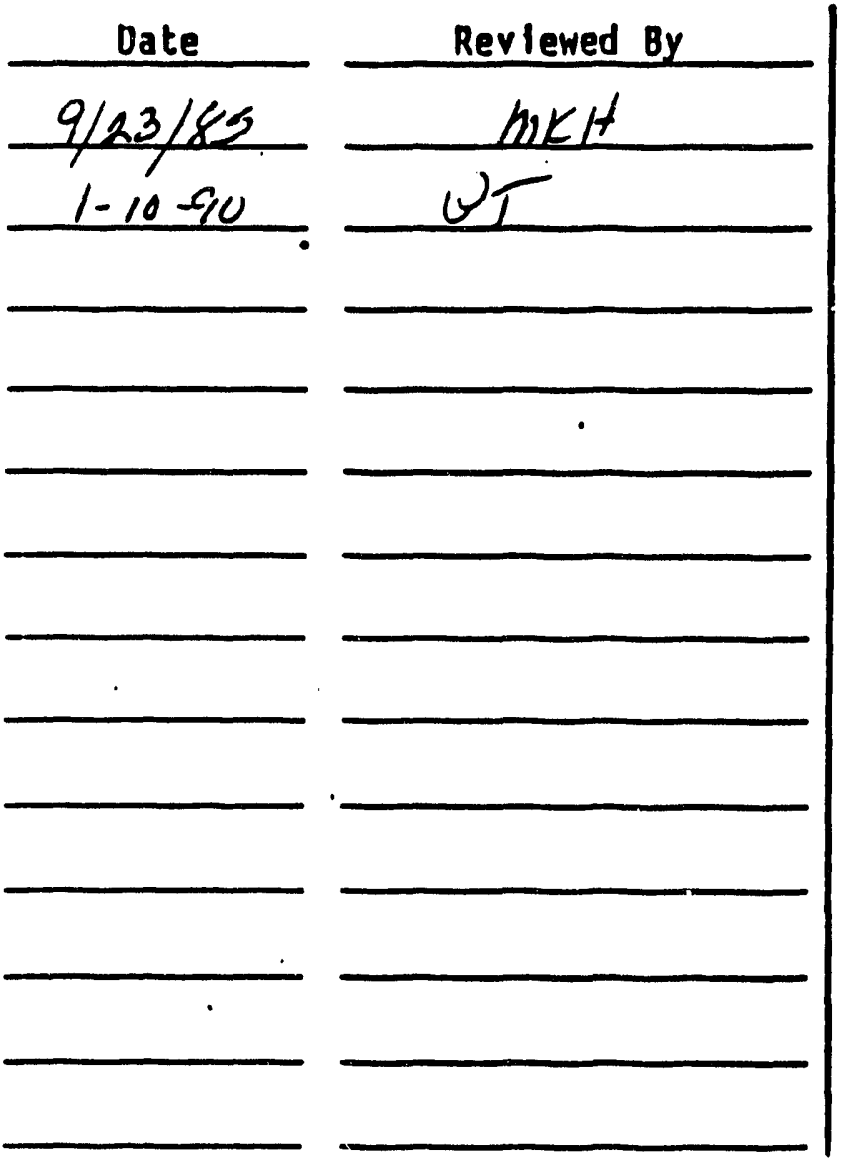

Replaced by Hethod Ho.

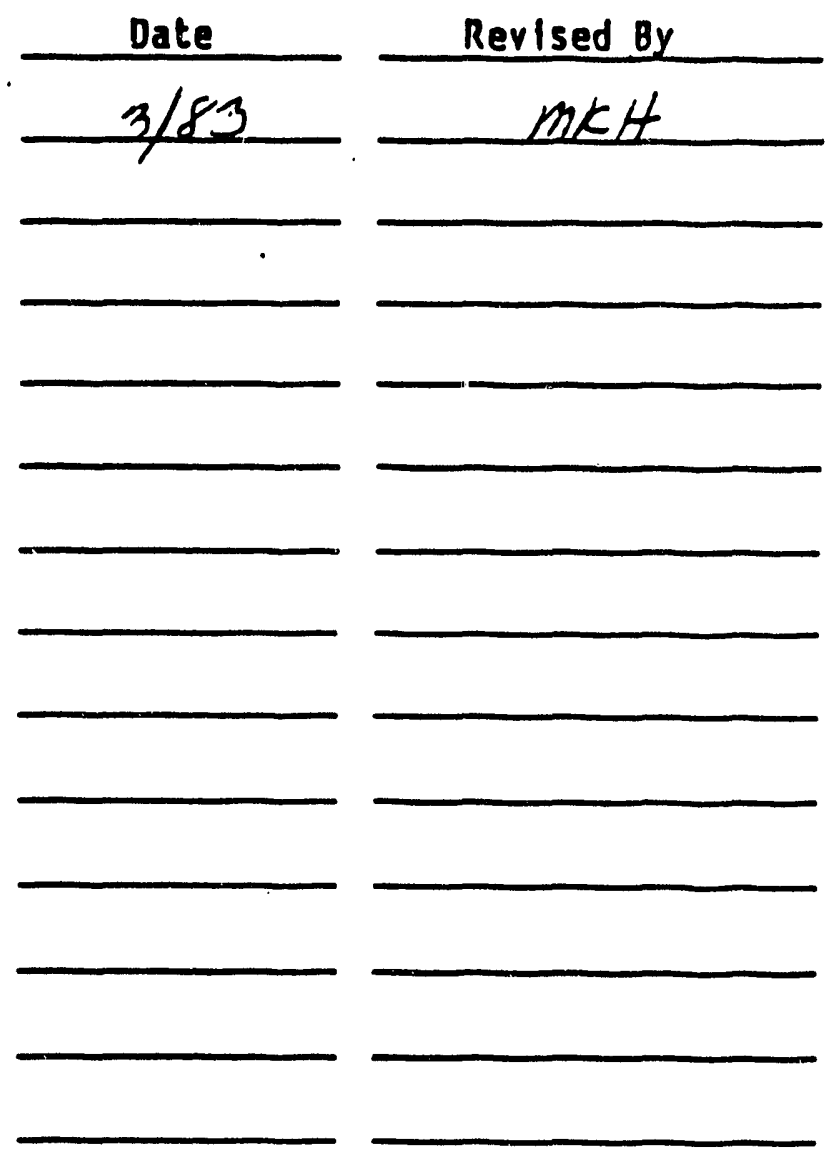

Daté: 


\section{LINEAR ALKYBENZENE SULFONATE}

- METHYLENE BLUE ACTIVE SUBSTANCES - (MBAS)

\section{Reference}

1. Standard Methods for the Examination of Water and Wastewater, 16th Edition, 1985, pages 581-585.

Principles

Anionic surfactants such as LAS react with methylene blue to form a colored salt. This salt is extractable into chloroform where the absorbance at $652 \mathrm{~nm}$ can be measured.

NOTE: CHLOROFORM IS LISTED AS A CLASS 2 SUSPECT HUMAN CARCINOGEN. REFER TO LABORATORY POLICY GUIDE - USE OF CARCINOGENS (L-H.10) FOR PROPER HANDLING OF THIS MATERIAL.

\section{Limitations}

The method is limited to water of "drinking quality" and not wastes or sewages. The method is subject to positive interferences from the following compounds: organic sulfates, sulfonates, carboxylates, phosphates, phenols, inorganic cyanates, chlorides, nitrates, and thiocyanates. Negative interferences can be caused by amines. (With the exception of chlorides, interferences from the above compounds can be generally ignored unless the compound is present in "unusually high" quantities.)

Minimum detectable amount: $10 \mu \mathrm{g}$ LAS

\section{Equipment}

1. $250 \mathrm{~mL}$ separatory funnels with Tefion stopcorks.

2. $100 \mathrm{~mL}$ Volumetric flasks.

3. Spectrophotometer for use at $652 \mathrm{~nm}$ providing a light path of one $\mathrm{cm}$ or longer.

\section{Reagents (Stock)}

1. Linear Alkybenzene Sulfonate, LAS

2. Phenolphthalein indicator solution.

3. Sodium Hydroxide, Reagent grade, $\mathrm{NaOH}$.

4. Sulfuric Acid, conc., $\mathrm{H}_{2} \mathrm{SO}_{4}$ 
5. Chloroform, $\mathrm{CHCl}_{3}$ - CLASS 2 - SUSPECT HUMAN CARCINOGEN

6. Methylene Blue (Eastman No. P573 or equivalent)

7. Monosodium dihydrogen phosphate monohydrate $\mathrm{NaH}_{2} \mathrm{PO}_{4} \cdot \mathrm{H}_{2} \mathrm{O}$

Reagents (Prepared)

1. Methylene Blue Reagent - Dissolve $100 \mathrm{mg}$ of methylene blue in $100 \mathrm{~mL}$ deionized water. Transfer $30 \mathrm{~mL}$ to a one liter flask, add $500 \mathrm{~mL}$ of deionized water, $6.8 \mathrm{~mL}$ of conc. sulfuric acid, and 50 grams of $\mathrm{NaH}_{2} \mathrm{PO}_{4}$. $\mathrm{H}_{2} \mathrm{O}$. Shake until dissolved and dilute to one liter. Prepare annually.

2. Wash solution - Add $6.8 \mathrm{~mL}$ of conc. sulfuric acid to $500 \mathrm{~mL}$ of deionized water in one liter flask. Add 50.0 grams of $\mathrm{NaH}_{2} \mathrm{PO}_{4} \cdot \mathrm{H}_{2} \mathrm{O}$, shake until dissolved and dilute to one liter. Prepare annualiy.

3. Sodium Hydroxide, IN - Dissolve 40 grams $\mathrm{NaOH}$ in one liter of water. Prepare annually.

4. Sulfuric Acid, IN - Dilute $28 \mathrm{~mL}$ of conc. $\mathrm{H}_{2} \mathrm{SO}_{4}$ to one liter. Prepare annually.

\section{$\underline{\text { Standards }}$}

1. Stock LAS - Weigh an amount of the reference materfal equal to 1.000 grams LAS on a $100 \%$ active basis. Dissolve in deionized water and dilute to one liter. $1.00 \mathrm{~mL}=1.00 \mathrm{mg}$ LAS. Store in a refrigerator. Prepare week ly.

2. Working standard LAS - Dilute $10.00 \mathrm{~mL}$ stock LAS to one liter with deionized water. $1.00 \mathrm{~mL}=10.0 \mu \mathrm{g}$ LAS. Prepare daily.

\section{Procedures}

Standard Curve: Pipet 1.00, 3.00, 5.00, 7.00, and $10.00 \mathrm{~mL}$ of the LAS working standard into separatory funnels and dilute each to $100 \mathrm{~mL}$. This gives standards equalling 10, 30 50, 70 and $100 \mathrm{~kg}$ LAS. Treat as per the following procedure.

1. Add $100 \mathrm{~mL}$ of the sample to a separatory funnel. (This may vary depending on the concentration of LAS.)

2. Add one or two drops of phenolphthalein.

3. Add $1 \mathrm{~N} \mathrm{NaOH}$ dropwise until alkaline and then add $\mathrm{NN}_{2} \mathrm{SO}_{4}$ until pink color disappears.

4. Add $10 \mathrm{~mL}$ of chloroform and $25 \mathrm{~mL}$ of methylene blue reagent and rock vigorously for 30 seconds. (NO NOT agitate vigorously because emulsion may form.) Allow the phase to separate. 
NOTE: ALL CHLOROFORM WORK SHALL BE DONE IN A HOOD WHILE WEARING GLOVES.

5. Swirl the sample gently, let settle and draw off lower phase into a secondary funnel. If sample $\mathrm{CHCl}_{3}$ layer is lighter than low standard, stop here and report less than value of $0.1 \mathrm{mg} / \mathrm{l}$. See end of procedure for disposal of chloroform solutions.

6. Repeat the extraction three times, using $10 \mathrm{~mL}$ of chloroform.

Note: If the blue color in the water phase becomes faint and disappears, discard the sample and start over, using a smaller sample size.

7. Combine all extracts in the second separatory funnel. Add $50 \mathrm{~mL}$ of wash solution, shake vigorously for 30 seconds and allow to settle. (No emulsions should form.)

8. Oraw off the chloroform layer through IPS phase separating paper into a $100 \mathrm{~mL}$ volumetrick flask.

9. Wash the aqueous solution from step seven twice with $10 \mathrm{~mL}$ of chloroform, collecting the chloroform in the $100 \mathrm{~mL}$ flask.

10. Rinse the phase separating paper with chloroform, collecting the rinse in the flask. Dilute to $100 \mathrm{~mL}$ mark with chloroform.

11. Measure the absorbance at $652 \mathrm{~nm}$ with one $\mathrm{cm}$ cells against a chloroform blank.

Disposal All chloroform solutions shall be disposed of in the organic solvent and carcinogen waste container.

Calculation

Plot a curve of standard concentration in ug LAS extracted versus absorbance.

Read the value of LAS from the curve and calculate as follows:

$\frac{\mu g \text { LAS }}{\text { Titers of sample extracted }}=m g / 1$ iter LAS

Report as "Methylene Blue Active Substances". 

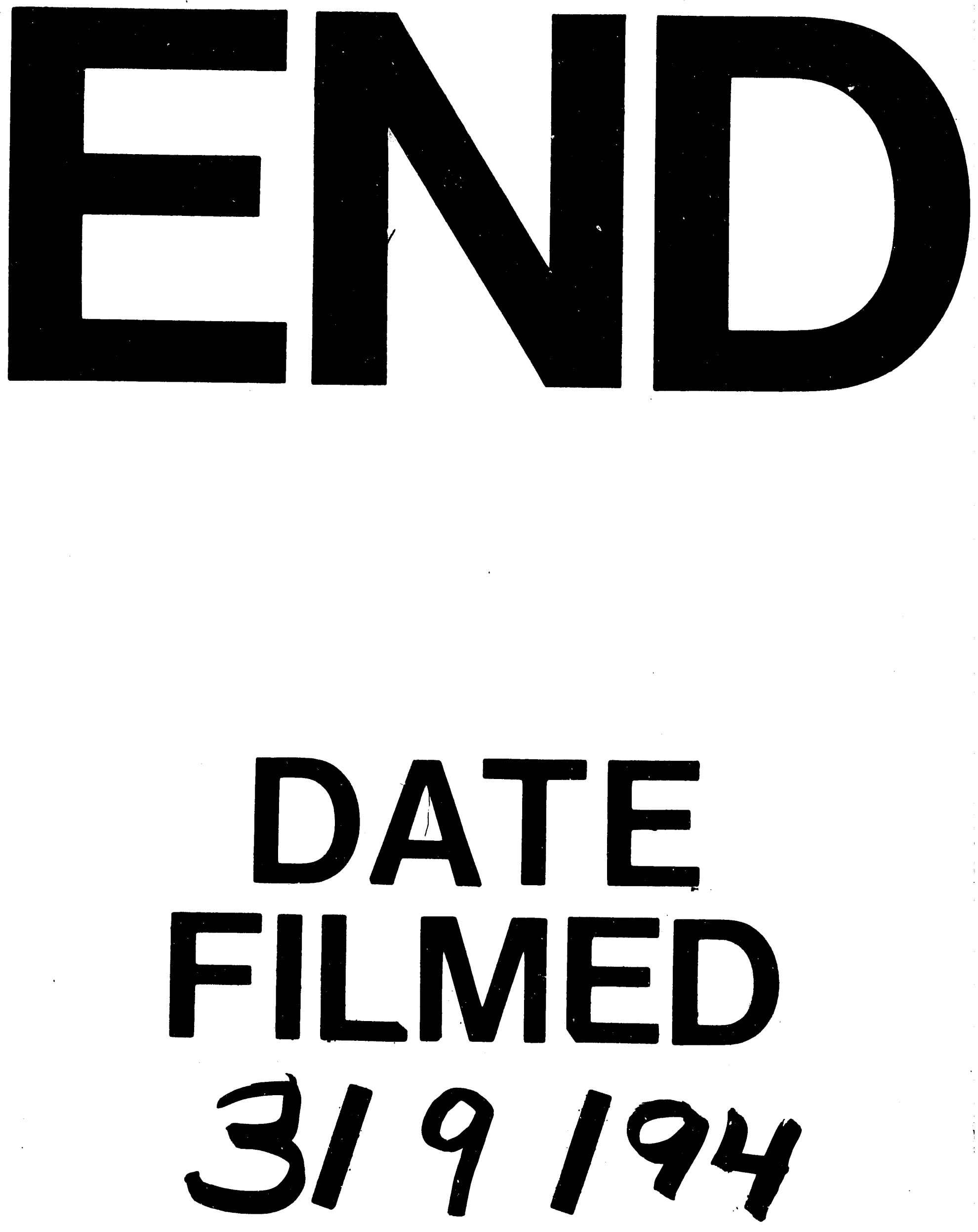
- 